\title{
Barrier properties of polymer nanocomposites during cyclic sorption-desorption and stress-coupled sorption experiments
}

\author{
Suneetha Burla \\ West Virginia University
}

Follow this and additional works at: https://researchrepository.wvu.edu/etd

\section{Recommended Citation}

Burla, Suneetha, "Barrier properties of polymer nanocomposites during cyclic sorption-desorption and stress-coupled sorption experiments" (2006). Graduate Theses, Dissertations, and Problem Reports. 1696.

https://researchrepository.wvu.edu/etd/1696

This Thesis is protected by copyright and/or related rights. It has been brought to you by the The Research Repository @ WVU with permission from the rights-holder(s). You are free to use this Thesis in any way that is permitted by the copyright and related rights legislation that applies to your use. For other uses you must obtain permission from the rights-holder(s) directly, unless additional rights are indicated by a Creative Commons license in the record and/ or on the work itself. This Thesis has been accepted for inclusion in WVU Graduate Theses, Dissertations, and Problem Reports collection by an authorized administrator of The Research Repository @ WVU. For more information, please contact researchrepository@mail.wvu.edu. 


\title{
Barrier Properties of Polymer Nanocomposites during Cyclic Sorption-Desorption and Stress-Coupled Sorption Experiments
}

\author{
Suneetha Burla \\ Thesis Submitted to the \\ College of Engineering and Mineral Resources \\ at West Virginia University \\ in partial fulfillment of the requirements \\ for the degree of \\ Master of Science \\ in \\ Chemical Engineering \\ Dr. Rakesh K Gupta, Ph.D., Chair \\ Dr. Dady Dadyburjor, Ph.D. \\ Dr. Eung H Cho, Ph.D. \\ Department of Chemical Engineering \\ Morgantown, West Virginia \\ 2006
}

Keywords: Cyclic Sorption-Desorption, Stress-coupled Diffusion, Barrier Properties,

Nanocomposites, Nanoclay, SEM, TEM

Copyright 2006 Suneetha Burla 


\section{ABSTRACT \\ Barrier Properties of Polymer Nanocomposites during Cyclic Sorption and Stress Coupled Sorption Experiments}

\section{Suneetha Burla}

It is well known that layered silicate nanoparticles, when distributed within the matrix of a polymer, can retard the diffusion of small molecules and improve barrier properties. This has been demonstrated in both sorption and permeation experiments in the past. In order to assess the long-term retention of barrier properties of polymerlayered silicate nanocomposites, it becomes important to study their response to various environmental effects.

The main theme of this investigation is to study the effect of several water exposure cycles and exposure coupled with external tensile stress on the barrier properties of various polymers like vinyl ester, polyester and epoxy and their polymer-based nanocomposites. As expected, Montmorillonite clay decreased the diffusivity of moisture in the above polymers and retained its effect during the repeated cycles of sorption and desorption. However, in the presence of clay ( $5 \mathrm{wt} \%)$, diffusivities measured during absorption under external stress were larger than those without stress. SEM analysis on the $5 \mathrm{wt} \%$ clay loaded vinyl ester samples subjected to stress-coupled sorption revealed the presence of micro cracks which caused increase in diffusivities. 


\section{ACKNOWLEDGEMENTS}

I am highly indebted to my research advisor Dr. Rakesh K. Gupta for providing me an opportunity to work under him and for all his guidance, advice and encouragement during this research. It was a wonderful experience and honor to work with a great researcher and a wonderful person like him. I am also grateful to my committee members Dr. Dady Dadyburjor and Dr. Eung H. Cho for their valuable suggestions and comments which helped me towards shaping my research. I would also like to thank Dr. Hota Ganga Rao for his valuable suggestions and help with the resins during my research. I would like to thank Dr.Vinod Berry for conducting TEM analysis and, Liviu Magean and Stephen Carpenter for carrying out SEM and XRD analysis on my samples.

Special thanks to Dr. Sushant Agarwal and all my labmates of Polymers group for all their valuable suggestions and inputs throughout the project. I would like to express my sincere thanks to Jim Hall for promptly preparing the molds inspite of other commitments and providing valuable suggestions for the design of experiments.

I would also like to thank Linda Rogers and Bonita Helmick for doing my paper work and being good friends. I would like to thank Bhyrav Mutnuri and Sandilya Hota for their help during the last stages of my research and for all the little things they have done for me.

I would like to thank my friends Satya Manoj Bantupalli, Sreedhar Chitullapally and Madhavi Nallani Chakravartula for their special love and care, and for making my stay in Morgantown a fun-filled and memorable experience. Thanks for always being there for me. I love you all!

I would like to thank my parents Mr. Damodar Burla and Mrs. Shobha Burla for their constant support, blessings, and trust in me, and my brothers Sravan and Sukumar for their special love and affection for me. I would also like to thank V. Narsimha Rao sir, Vinay Kumar sir, Martin Luther sir and Peddamma for all their moral and financial support and without whom this dream would not have come true.

I would like to thank West Virginia Research Challenge Grant for funding this research project. Thank you all! 


\section{DEDICATION}

To my beloved parents....... 


\section{TABLE OF CONTENTS}

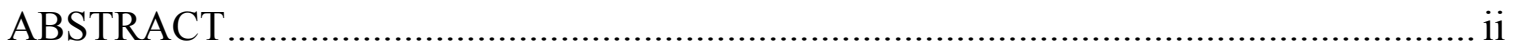

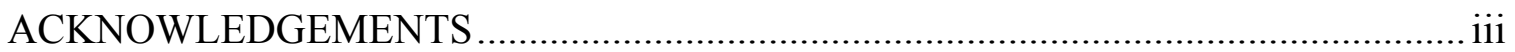

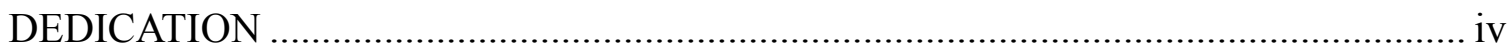

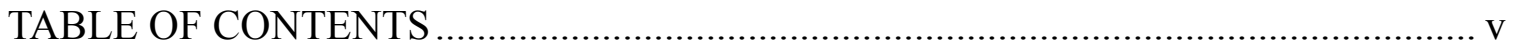

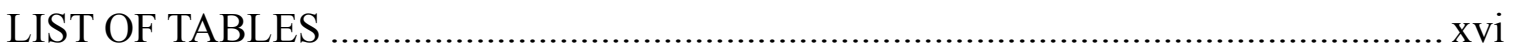

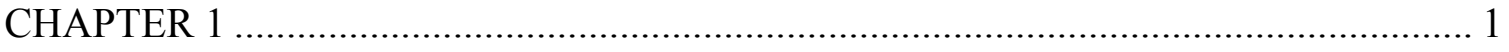

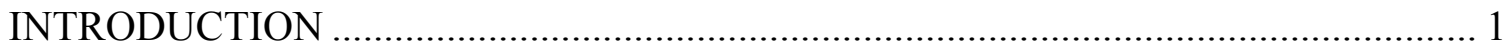

1.1 Introduction to Polymer Layered Silicate Nanocomposites ......................................... 2

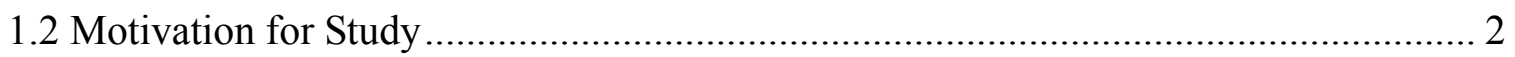

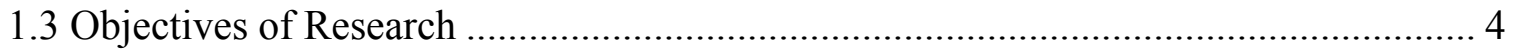

1.4 Industrial Applications of Polymeric Membranes ……………………………......... 5

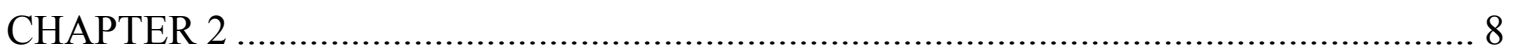

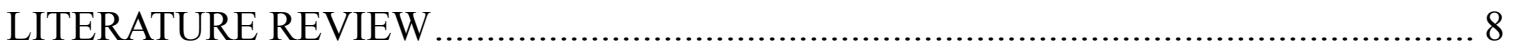

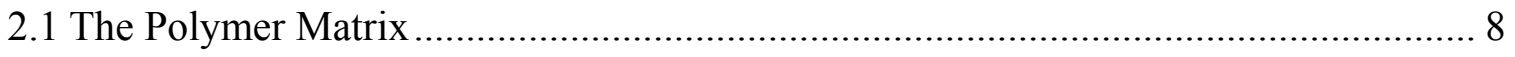

2.2 Mechanism of Diffusion of Water through Polymers and Polymer Nanocomposites 12

2.3 Stress Assisted Moisture Diffusion through Neat Resins, Composites and Polymer

Layered Silicate Nanocomposites........................................................................... 14

2.4 Factors Affecting the Mass Transport Process........................................................... 15

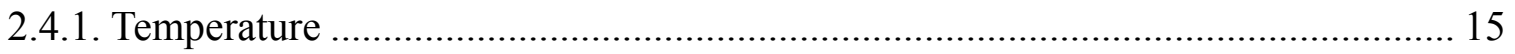

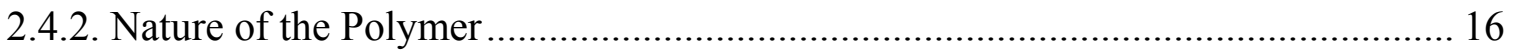

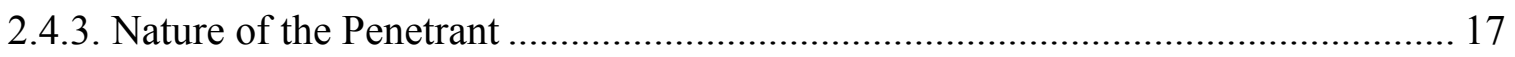

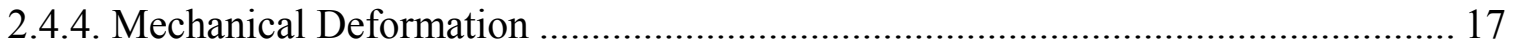

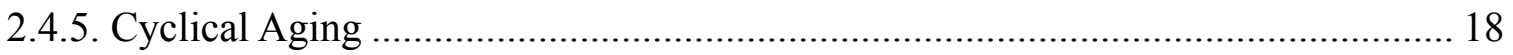

2.5 Models Describing the Phenomenon of Diffusion in Composites.............................. 19

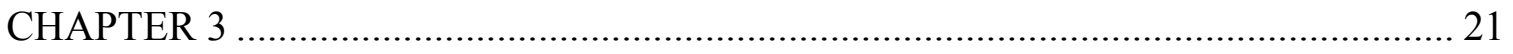

EXPERIMENTAL PROCEDURE AND METHODS OF CALCULATION................... 21

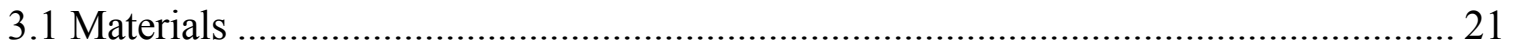

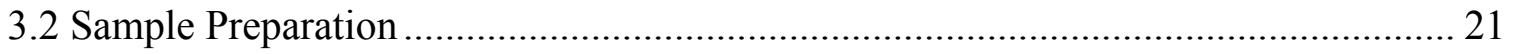

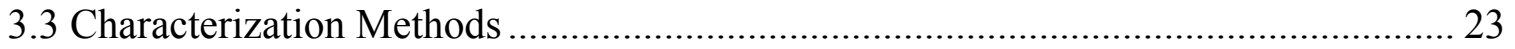

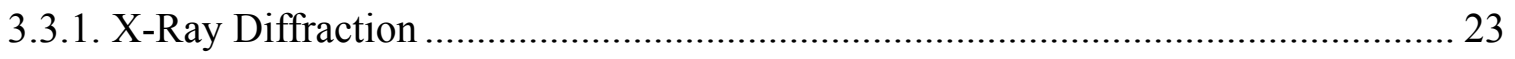


3.3.2. Transmission Electron Microscopy …………………........................................... 24

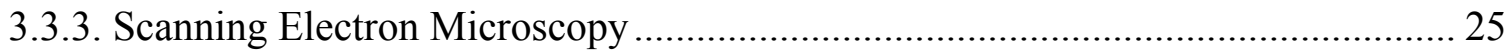

3.3.4. Cyclic Sorption-Desorption Experiments …………............................................ 26

3.3.5. Equilibrium Moisture Content .......................................................................... 27

3.3.6. Stress Coupled Sorption Experiments ............................................................ 27

3.4 Method of Calculation of Diffusion Coefficient in Samples During Sorption ........... 28

3.5 Method of Calculation of Diffusion Coefficient in Samples During Desorption ....... 29

3.6 Method of Calculation of Equilibrium Moisture Content........................................... 29

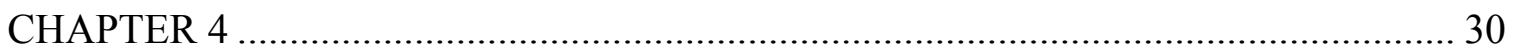

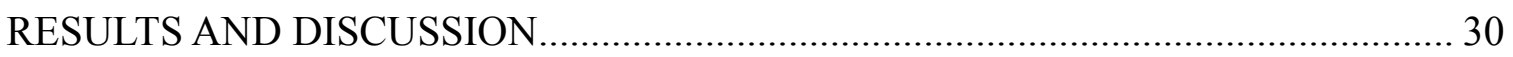

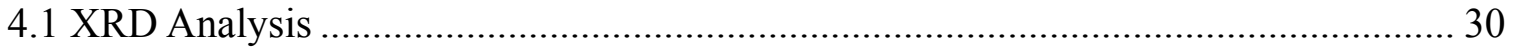

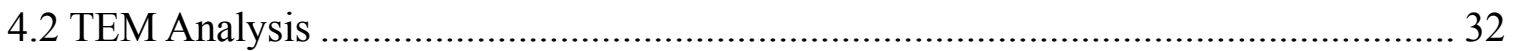

4.3 Cyclic Sorption-Desorption Experiments with Distilled Water at Room Temperature

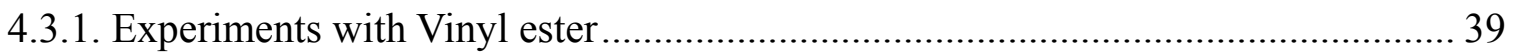

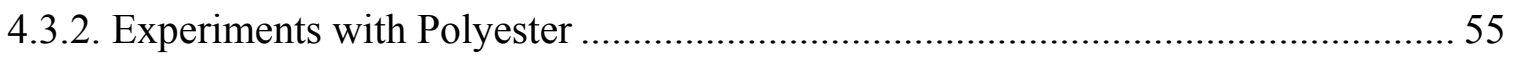

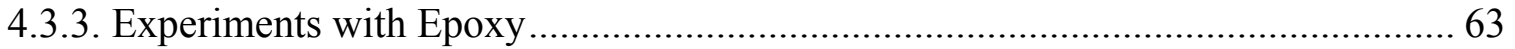

4.3.4. Interaction of Water with Polymers During Cyclic Sorption-Desorption............... 72

4.4 Sorption Experiments with Neat and Clay loaded Vinyl ester Samples at Different

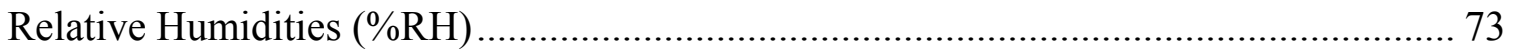

4.4.1. EMC at 40\% Relative Humidity ……………………..................................... 73

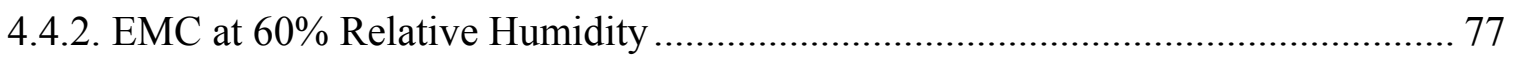

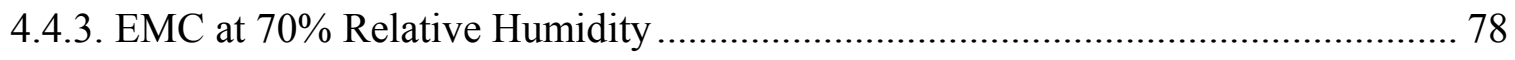

4.4.4. EMC at $80 \%$ Relative Humidity ………………................................................ 78

4.5 Sorption Experiments with Vinyl ester under Stress ............................................ 81

4.5.1. Sorption Experiments under Stress in Water ....................................................... 83

4.5.2. Sorption Experiments under Stress at 60\% RH ................................................... 90

4.5.3. Mechanism of Diffusion through Polymer Nanocomposites under Stress ............. 95

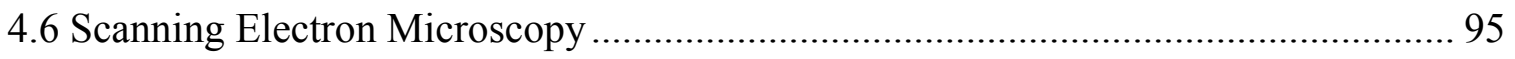

4.6.1. Mechanism of Crack Initiation and Propagation .................................................. 106

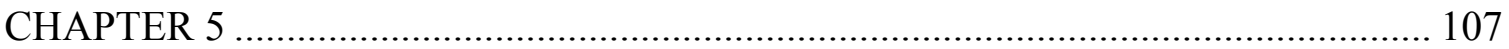


CONCLUSIONS...

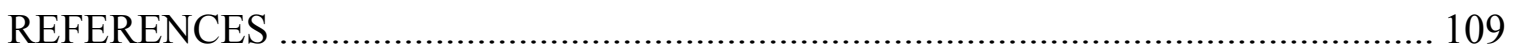

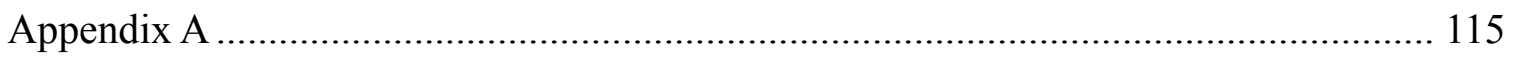

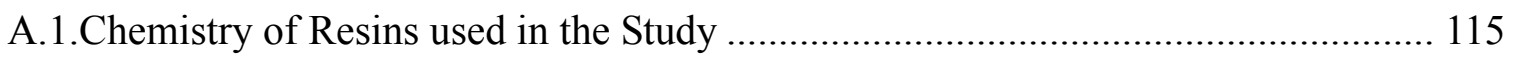

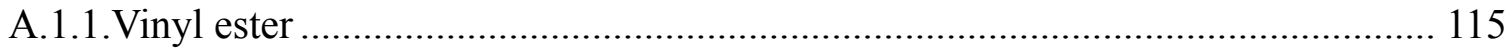

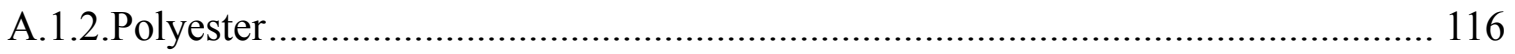

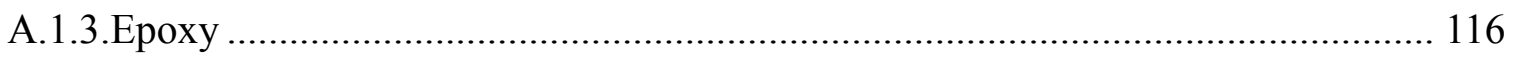

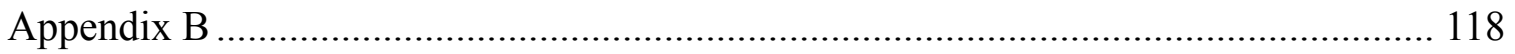

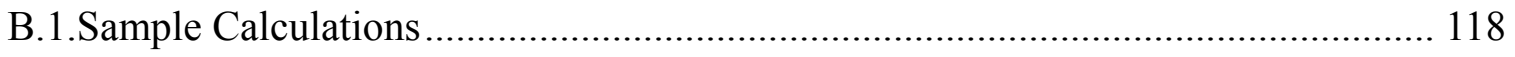

B.1.1.Sample Calculation for Absorption Diffusion Coefficient $\left(D_{a}\right) \ldots \ldots \ldots \ldots \ldots \ldots \ldots \ldots \ldots . . . . .118$

B.1.2.Sample Calculation for Desortpion Diffusion Coefficient $\left(D_{d}\right) \ldots \ldots \ldots \ldots \ldots \ldots \ldots \ldots \ldots . . . . .119$

B.1.3.Sample Calculation for Sorption Experiments under Stress ................................. 121

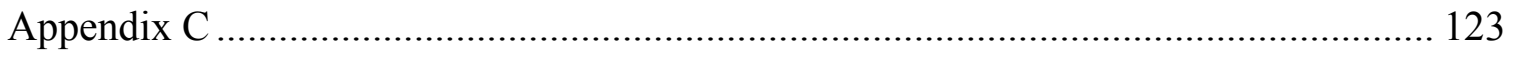

C.1.Results of Cyclic Sorption-Desorption Experiments with Distilled Water at Room

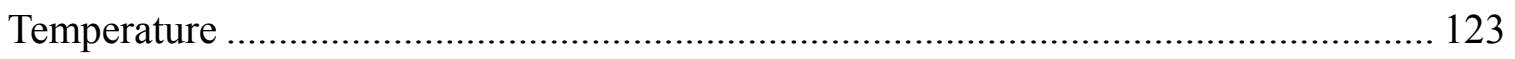

C.1.1.Experiments with Vinyl ester ..................................................................... 123

C.1.2.Experiments with Polyester............................................................................. 125

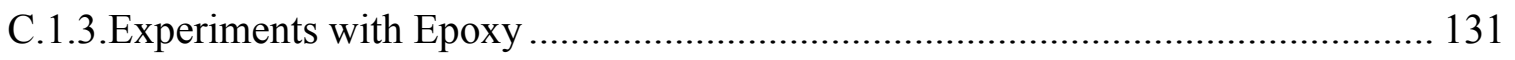

C.2.Results of Sorption Experiments with Neat and Clay loaded Vinyl ester Samples at

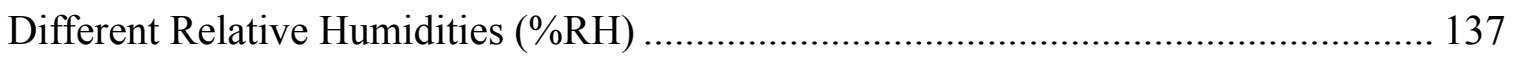

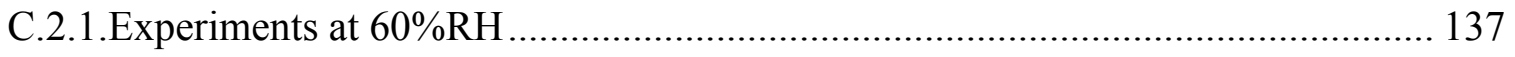

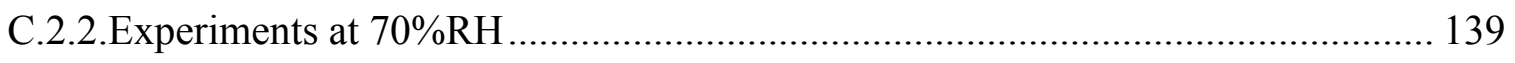

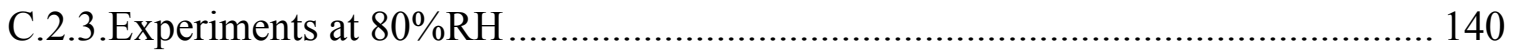

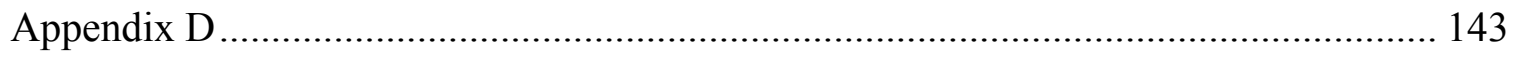

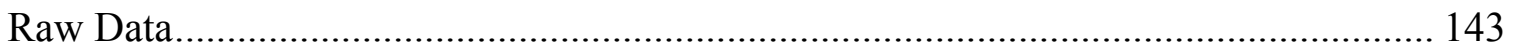




\section{LIST OF FIGURES}

Figure 1 Primary types of barrier structures

Figure 2 Schematic of the flow of a penetrant through a nanocomposite (Yano et al., 1993)

Figure 3 Teflon mold used to cast the samples ……

Figure 4 Cured neat vinyl ester samples ....................................................................... 22

Figure 5 (a) Molds and Samples used for TEM analysis (b) Carbon coated $\mathrm{Cu}$ grids used

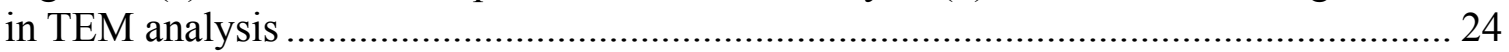

Figure 6 Schematic representation of sample microtoming for TEM analysis. Direction of

electron beam incidence is the direction of view......................................................... 25

Figure 7 (a) Gold sputter coater (b) Gold coated sample grounded with copper tape..... 26

Figure 8 Assembly of the load frame loaded with samples for sorption under stress ...... 28

Figure 9 Experimental set up for sorption under stress at $60 \%$ RH................................ 28

Figure 10 XRD scans on Cloisite $10 \mathrm{~A}^{\circledR}$ and vinyl ester nanocomposites ......................... 31

Figure 11 XRD scans on neat vinyl ester resin and vinyl ester nanocomposites............... 31

Figure 12 TEM image of $5 \mathrm{wt} \%$ clay loaded vinyl ester $(14,400 \mathrm{x})$................................. 32

Figure 13 TEM image of $2 \mathrm{wt} \%$ clay loaded vinyl ester $(30,000 \mathrm{x})$................................ 33

Figure 14 TEM image of $5 \mathrm{wt} \%$ clay loaded vinyl ester $(30,000 \mathrm{x})$................................... 33

Figure 15 TEM image of $2 \mathrm{wt} \%$ clay loaded vinyl ester $(108,000 \mathrm{x})$............................... 34

Figure 16 TEM image of $5 \mathrm{wt} \%$ clay loaded vinyl ester $(108,000 \mathrm{x})$................................ 34

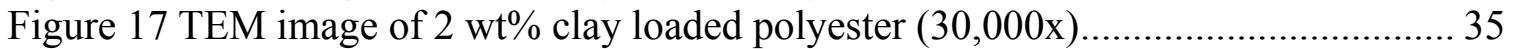

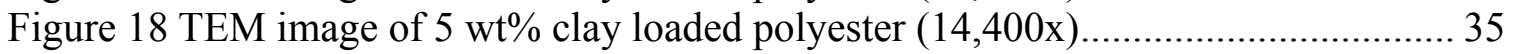

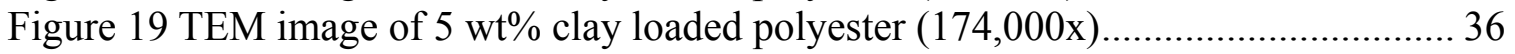

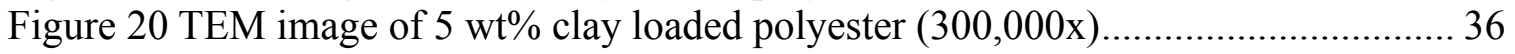

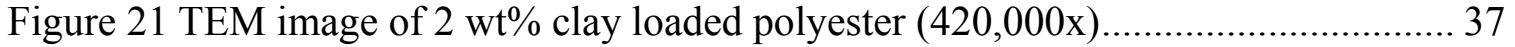

Figure 22 TEM image of $2 \mathrm{wt} \%$ clay loaded epoxy $(30,000 \mathrm{x})$...................................... 37

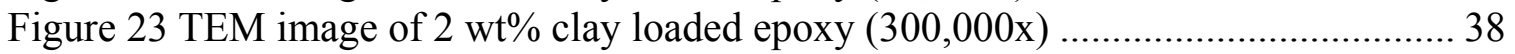

Figure 24 TEM image of $5 \mathrm{wt} \%$ clay loaded epoxy $(300,000 \mathrm{x})$..................................... 38

Figure 25 Moisture uptake $(\mathrm{mg})$ versus $\mathrm{t}(\mathrm{h})$ for neat vinyl ester samples during cyclic absorption (water) - desorption (20\%RH) at $25^{\circ} \mathrm{C} \mathrm{......................................................} 40$

Figure 26 Moisture uptake $(\mathrm{mg}$ ) versus $\mathrm{t}(\mathrm{h})$ for vinyl ester samples containing $2 \mathrm{wt} \%$

Cloisite $10 \mathrm{~A}^{\circledR}$ during cyclic absorption (water) - desorption $(20 \% \mathrm{RH})$ at $25^{\circ} \mathrm{C} \ldots \ldots \ldots \ldots . . . .40$

Figure 27 Moisture uptake $(\mathrm{mg})$ versus $\mathrm{t}(\mathrm{h})$ for vinyl ester samples containing $5 \mathrm{wt} \%$

Cloisite $10 \mathrm{~A}^{\circledR}$ during cyclic absorption (water) - desorption $(20 \% \mathrm{RH})$ at $25^{\circ} \mathrm{C} . \ldots \ldots \ldots . . . . .41$

Figure 28 Average moisture uptake $(\mathrm{mg})$ versus $\mathrm{t}(\mathrm{h})$ for vinyl ester samples containing different clay loadings during cyclic absorption (water) - desorption $(20 \% \mathrm{RH})$ at $25^{\circ} \mathrm{C} 41$ Figure 29 Moisture content versus $t$ for neat vinyl ester samples during absorption

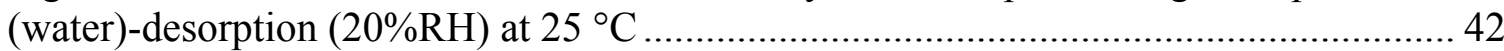

Figure 30 Moisture content versus $\mathrm{t}$ for vinyl ester samples containing $2 \mathrm{wt} \%$ Cloisite $10 \mathrm{~A}^{\circledR}$ during absorption (water)-desorption $(20 \% \mathrm{RH})$ at $25^{\circ} \mathrm{C}$..................................... 42

Figure 31 Moisture content versus $\mathrm{t}$ for vinyl ester samples containing $5 \mathrm{wt} \%$ Cloisite $10 \mathrm{~A}^{\circledR}$ during absorption (water)-desorption $(20 \% \mathrm{RH})$ at $25^{\circ} \mathrm{C}$...................................... 43

Figure 32 Average moisture content versus time for vinyl ester samples containing

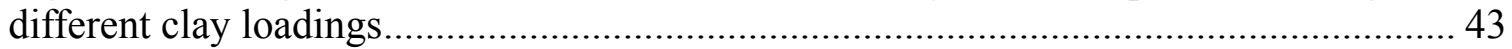


Figure 33 Comparison of equilibrium moisture content for vinyl ester samples containing different clay loadings obtained during cyclic sorption-desorption ............................. 44 Figure 34 Moisture content versus t for Cloisite $10 \mathrm{~A}^{\circledR}$ during exposure at $60 \% \mathrm{RH}$ at 25 ${ }^{\circ} \mathrm{C}$.....

Figure $35 \mathrm{M}_{\mathrm{t}} / \mathrm{M}_{\infty}$ versus $\mathrm{t}^{1 / 2}$ for vinyl ester samples containing $0 \mathrm{wt} \%$ Cloisite $10 \mathrm{~A}^{\circledR}$ at 25

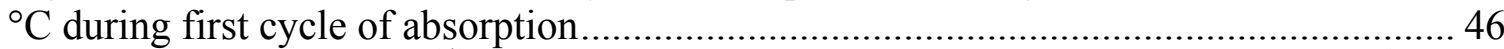

Figure $36 \mathrm{M}_{\mathrm{t}} / \mathrm{M}_{\infty}$ versus $\mathrm{t}^{1 / 2}$ for vinyl ester samples containing $0 \mathrm{wt} \%$ Cloisite $10 \mathrm{~A}^{\circledR}$ at 25

${ }^{\circ} \mathrm{C}$ during second cycle of absorption ....................................................................... 46

Figure $37 \mathrm{M}_{\mathrm{t}} / \mathrm{M}_{\infty}$ versus $\mathrm{t}^{1 / 2}$ for vinyl ester samples containing $0 \mathrm{wt} \%$ Cloisite $10 \mathrm{~A}^{\circledR}$ at 25

${ }^{\circ} \mathrm{C}$ during third cycle of absorption........................................................................ 47

Figure $38 \mathrm{M}_{\mathrm{t}} / \mathrm{M}_{\infty}$ versus $\mathrm{t}^{1 / 2}$ for vinyl ester samples containing $2 \mathrm{wt} \%$ Cloisite $10 \mathrm{~A}^{\circledR}$ at 25

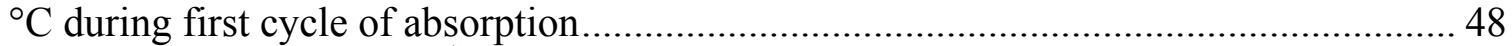

Figure $39 \mathrm{M}_{\mathrm{t}} / \mathrm{M}_{\infty}$ versus $\mathrm{t}^{1 / 2}$ for vinyl ester samples containing $2 \mathrm{wt} \%$ Cloisite $10 \mathrm{~A} \AA$ at 25

${ }^{\circ} \mathrm{C}$ during second cycle of absorption ..................................................................... 48

Figure $40 \mathrm{M}_{\mathrm{t}} / \mathrm{M}_{\infty}$ versus $\mathrm{t}^{1 / 2}$ for vinyl ester samples containing $2 \mathrm{wt} \%$ Cloisite $10 \mathrm{~A}^{\circledR}$ at 25

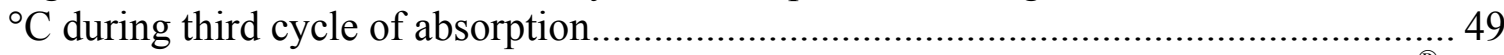

Figure $41 \ln \left(\mathrm{M}_{\mathrm{t}}-\mathrm{M}_{\infty}\right)$ versus $\mathrm{t}$ for vinyl ester samples containing $0 \mathrm{wt} \%$ Cloisite $10 \mathrm{~A}^{\circledR}$ at

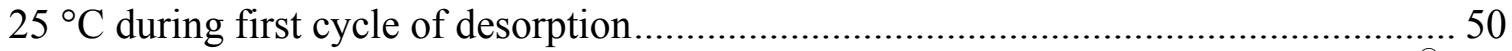

Figure $42 \ln \left(\mathrm{M}_{\mathrm{t}}-\mathrm{M}_{\infty}\right)$ versus $\mathrm{t}$ for vinyl ester samples containing $0 \mathrm{wt} \%$ Cloisite $10 \mathrm{~A}^{\circledR}$ at

$25^{\circ} \mathrm{C}$ during second cycle of desorption .............................................................. 50

Figure $43 \ln \left(\mathrm{M}_{\mathrm{t}}-\mathrm{M}_{\infty}\right)$ versus $\mathrm{t}$ for vinyl ester samples containing $0 \mathrm{wt} \%$ Cloisite $10 \mathrm{~A}^{\circledR}$ at

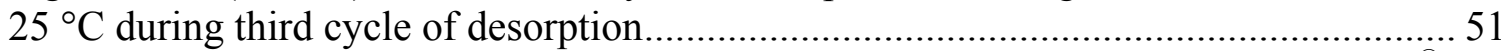

Figure $44 \ln \left(\mathrm{M}_{\mathrm{t}}-\mathrm{M}_{\infty}\right)$ versus $\mathrm{t}$ for vinyl ester samples containing $2 \mathrm{wt} \%$ Cloisite $10 \mathrm{~A}^{\circledR}$ at

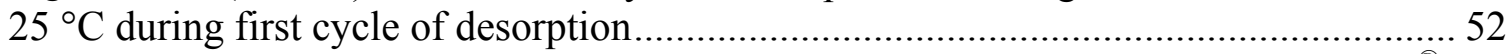

Figure $45 \ln \left(\mathrm{M}_{\mathrm{t}}-\mathrm{M}_{\infty}\right)$ versus $\mathrm{t}$ for vinyl ester samples containing $2 \mathrm{wt} \%$ Cloisite $10 \mathrm{~A}^{\circledR}$ at

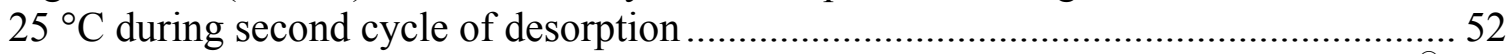

Figure $46 \ln \left(\mathrm{M}_{\mathrm{t}}-\mathrm{M}_{\infty}\right)$ versus $\mathrm{t}$ for vinyl ester samples containing $2 \mathrm{wt} \%$ Cloisite $10 \mathrm{~A}^{\circledR}$ at

$25^{\circ} \mathrm{C}$ during third cycle of desorption.

Figure 47 Variation of average diffusivity with number of cycles for vinyl ester samples containing different wt percentages of Cloisite $10 \mathrm{~A}^{\circledR}$ at $25^{\circ} \mathrm{C}$ during three cycles of

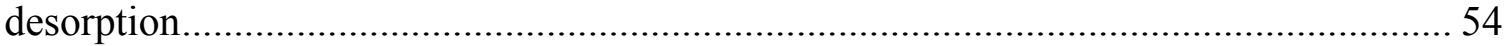

Figure 48 Moisture uptake (mg) versus $\mathrm{t}(\mathrm{h})$ for neat polyester samples during cyclic

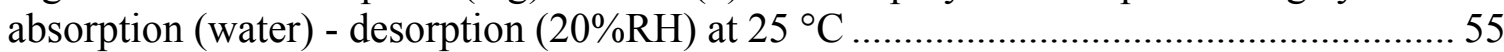

Figure 49 Moisture uptake (mg) versus $\mathrm{t}(\mathrm{h})$ for polyester samples containing $2 \mathrm{wt} \%$ Cloisite $10 \mathrm{~A}^{\circledR}$ during cyclic absorption (water) - desorption $(20 \% \mathrm{RH})$ at $25^{\circ} \mathrm{C} \ldots \ldots \ldots . . . .56$ Figure 50 Moisture uptake $(\mathrm{mg})$ versus $\mathrm{t}(\mathrm{h})$ for polyester samples containing $5 \mathrm{wt} \%$ Cloisite $10 \mathrm{~A}^{\circledR}$ during cyclic absorption (water) - desorption $(20 \% \mathrm{RH})$ at $25^{\circ} \mathrm{C} \ldots \ldots \ldots . . . .56$ Figure 51 Average moisture uptake $(\mathrm{mg})$ versus $\mathrm{t}(\mathrm{h})$ for polyester samples containing different clay loadings during cyclic absorption (water) - desorption $(20 \% \mathrm{RH})$ at $25^{\circ} \mathrm{C} 57$ Figure 52 Moisture content versus t for neat polyester samples during absorption (water)desorption $(20 \% \mathrm{RH})$ at $25{ }^{\circ} \mathrm{C}$ 58

Figure 53 Moisture content versus t for polyester samples containing $2 \mathrm{wt} \%$ Cloisite

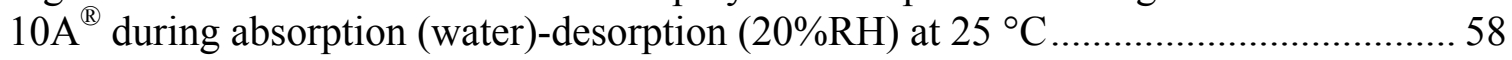

Figure 54 Moisture content versus t for polyester samples containing $5 \mathrm{wt} \%$ Cloisite $10 \mathrm{~A}^{\circledR}$ during absorption (water)-desorption $(20 \% \mathrm{RH})$ at $25^{\circ} \mathrm{C}$. 
Figure 55 Average moisture content versus time for polyester samples containing different clay loadings.

Figure 56 Equilibrium moisture content for polyester samples containing different clay loadings obtained during cyclic sorption-desorption. 60 Figure 57 Variation of diffusivity with number of cycles for polyester samples containing different wt percentages of Cloisite $10 \mathrm{~A}^{\circledR}$ at $25^{\circ} \mathrm{C}$ during three cycles of desorption .... 62 Figure 58 Moisture uptake $(\mathrm{mg})$ versus $\mathrm{t}(\mathrm{h})$ for neat epoxy samples during cyclic absorption (water) - desorption $(20 \% \mathrm{RH})$ at $25^{\circ} \mathrm{C}$ 64 Figure 59 Moisture uptake (mg) versus $\mathrm{t}(\mathrm{h})$ for epoxy samples containing $2 \mathrm{wt} \%$ Cloisite $10 \mathrm{~A}^{\circledR}$ during cyclic absorption (water) - desorption $(20 \% \mathrm{RH})$ at $25{ }^{\circ} \mathrm{C}$. 64 Figure 60 Moisture uptake $(\mathrm{mg})$ versus $\mathrm{t}(\mathrm{h})$ for epoxy samples containing $5 \mathrm{wt} \%$ Cloisite $10 \mathrm{~A}^{\circledR}$ during cyclic absorption (water) - desorption $(20 \% \mathrm{RH})$ at $25{ }^{\circ} \mathrm{C}$. 65 Figure 61 Average moisture uptake (mg) versus $\mathrm{t}(\mathrm{h})$ for epoxy samples containing different clay loadings during cyclic absorption (water) - desorption $(20 \% \mathrm{RH})$ at $25{ }^{\circ} \mathrm{C} 65$ Figure 62 Moisture content versus $t$ for neat epoxy samples during absorption (water)desorption $(20 \% \mathrm{RH})$ at $25^{\circ} \mathrm{C}$.

Figure 63 Moisture content versus t for epoxy samples containing $2 \mathrm{wt} \%$ Cloisite $10 \mathrm{~A}^{\circledR}$ during absorption (water)-desorption $(20 \% \mathrm{RH})$ at $25{ }^{\circ} \mathrm{C}$.

Figure 64 Moisture content versus t for epoxy samples containing $5 \mathrm{wt} \%$ Cloisite $10 \mathrm{~A}^{\circledR}$

during absorption (water)-desorption $(20 \% \mathrm{RH})$ at $25^{\circ} \mathrm{C}$.

Figure 65 Average moisture content versus time for epoxy samples containing different clay loadings ....

Figure 66 Equilibrium moisture content for epoxy samples containing different clay

loadings obtained during cyclic sorption-desorption

Figure 67 Variation of diffusivity with number of cycles for epoxy samples containing different wt percentages of Cloisite $10 \mathrm{~A}^{\circledR}$ at $25^{\circ} \mathrm{C}$ during three cycles of desorption .... 70 Figure 68 Idealized chemical structure of a typical epoxy based vinyl ester .................. 72 Figure 69 Idealized chemical structure of a typical epoxy based polyester ................... 72 Figure 70 Idealized chemical structure of a typical epoxy (diglycidyl ether of bisphenol-A)

Figure 71 Moisture content versus t for neat vinyl ester samples exposed to $40 \% \mathrm{RH}$ at 25 ${ }^{\circ} \mathrm{C}$......

Figure 72 Moisture content versus t for $2 \mathrm{wt} \%$ clay loaded vinyl ester samples exposed to $40 \% \mathrm{RH}$ at $25^{\circ} \mathrm{C}$ 74

Figure 73 Moisture content versus $\mathrm{t}$ for $5 \mathrm{wt} \%$ clay loaded vinyl ester samples exposed to $40 \%$ RH at $25^{\circ} \mathrm{C}$ 75

Figure $74 \mathrm{M}_{\mathrm{t}} / \mathrm{M}_{\infty}$ versus $\mathrm{t}^{1 / 2}$ for vinyl ester samples containing $0 \mathrm{wt} \%$ Cloisite $10 \mathrm{~A}^{\circledR}$ exposed to $40 \%$ RH ........................................................................................ 76 Figure $75 \mathrm{M}_{\mathrm{t}} / \mathrm{M}_{\infty}$ versus $\mathrm{t}^{1 / 2}$ for vinyl ester samples containing $2 \mathrm{wt} \%$ Cloisite $10 \mathrm{~A}^{\circledR}$

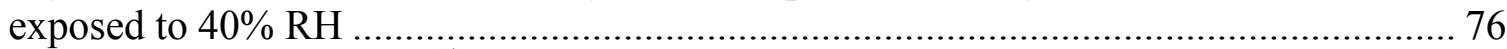
Figure $76 \mathrm{M}_{\mathrm{t}} / \mathrm{M}_{\infty}$ versus $\mathrm{t}^{1 / 2}$ for vinyl ester samples containing $5 \mathrm{wt} \%$ Cloisite $10 \mathrm{~A}^{\circledR}$ exposed to $40 \% \mathrm{RH}$ 77

Figure 77 Variation of equilibrium moisture content with variation in relative humidity (\%) for vinyl ester samples containing different wt percentages of Cloisite $10 \mathrm{~A}^{\circledR}$ at $25^{\circ} \mathrm{C}$ 
Figure 78 Variation of Diffusivity with variation in relative humidity (\%) for vinyl ester samples containing different wt percentages of Cloisite $10 \mathrm{~A}^{\circledR}$ at $25^{\circ} \mathrm{C}$......................... 81 Figure 79 Typical stress strain curve in a polymer ................................................... 81 Figure 80 Stress Strain Curve for a Representative Neat Vinyl ester (Rana, 2003) ........ 82 Figure 81 Moisture uptake $(\mathrm{mg})$ versus $\mathrm{t}(\mathrm{h})$ for neat vinyl ester samples immersed in water and subjected to $17 \%$ UTS at $25^{\circ} \mathrm{C}$....

Figure 82 Moisture content versus $t$ for neat vinyl ester samples immersed in water and subjected to $17 \%$ UTS at $25^{\circ} \mathrm{C}$

Figure $83 \mathrm{M}_{\mathrm{t}} / \mathrm{M}_{\infty}$ versus $\mathrm{t}^{1 / 2}$ for neat vinyl ester samples immersed in water and subjected to $17 \%$ UTS at $25^{\circ} \mathrm{C}$ 84

Figure 84 Moisture uptake (mg) versus $\mathrm{t}(\mathrm{h})$ for neat vinyl ester samples immersed in water and subjected to $30 \% \mathrm{UTS}$ at $25^{\circ} \mathrm{C}$

Figure 85 Moisture content versus t for neat vinyl ester samples immersed in water and subjected to $30 \% \mathrm{UTS}$ at $25^{\circ} \mathrm{C}$......

Figure $86 \mathrm{M}_{\mathrm{t}} / \mathrm{M}_{\infty}$ versus $\mathrm{t}^{1 / 2}$ for neat vinyl ester samples immersed in water and subjected to $30 \%$ UTS at $25^{\circ} \mathrm{C}$ 86

Figure 87 Moisture uptake (mg) versus $\mathrm{t}(\mathrm{h})$ for vinyl ester samples containing $5 \mathrm{wt} \%$ clay immersed in water and subjected to $17 \%$ UTS at $25^{\circ} \mathrm{C}$.

Figure 88 Moisture content versus t for vinyl ester samples containing $5 \mathrm{wt} \%$ clay immersed in water and subjected to $17 \%$ UTS at $25^{\circ} \mathrm{C}$. 87 Figure $89 \mathrm{M}_{\mathrm{t}} / \mathrm{M}_{\infty}$ versus $\mathrm{t}^{1 / 2}$ for vinyl ester samples containing $5 \mathrm{wt} \%$ clay immersed in water and subjected to $17 \%$ UTS at $25^{\circ} \mathrm{C}$.

Figure 90 Moisture uptake (mg) versus $\mathrm{t}(\mathrm{h})$ for vinyl ester samples containing $5 \mathrm{wt} \%$ clay immersed in water and subjected to $30 \%$ UTS at $25^{\circ} \mathrm{C}$ 88

Figure 91 Moisture content versus t for vinyl ester samples containing $5 \mathrm{wt} \%$ clay immersed in water and subjected to $30 \%$ UTS at $25^{\circ} \mathrm{C}$

Figure $92 \mathrm{M}_{t} / \mathrm{M}_{\infty}$ versus $\mathrm{t}^{1 / 2}$ for vinyl ester samples containing $5 \mathrm{wt} \%$ clay immersed in water and subjected to $30 \%$ UTS at $25^{\circ} \mathrm{C}$.

Figure 93 Moisture uptake $(\mathrm{mg}$ ) versus $\mathrm{t}(\mathrm{h})$ for neat vinyl ester samples at $60 \% \mathrm{RH}$ and subjected to $30 \%$ UTS at $25^{\circ} \mathrm{C}$

Figure 94 Moisture content versus t for neat vinyl ester samples at $60 \%$ RH and subjected

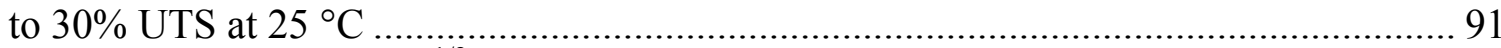
Figure $95 \mathrm{M}_{\mathrm{t}} / \mathrm{M}_{\infty}$ versus $\mathrm{t}^{1 / 2}$ for neat vinyl ester samples at $60 \% \mathrm{RH}$ and subjected to $30 \%$ UTS at $25^{\circ} \mathrm{C}$. 91

Figure 96 Moisture uptake (mg) versus $\mathrm{t}(\mathrm{h})$ for vinyl ester samples containing $5 \mathrm{wt} \%$ clay at $60 \% \mathrm{RH}$ and subjected to $30 \%$ UTS at $25^{\circ} \mathrm{C}$.

Figure 97 Moisture content versus $\mathrm{t}(\mathrm{h})$ for vinyl ester samples containing $5 \mathrm{wt} \%$ clay at $60 \% \mathrm{RH}$ and subjected to $30 \%$ UTS at $25{ }^{\circ} \mathrm{C}$ 93 Figure $98 \mathrm{M}_{\mathrm{t}} / \mathrm{M}_{\infty}$ versus $\mathrm{t}^{1 / 2}$ for vinyl ester samples containing $5 \mathrm{wt} \%$ clay at $60 \% \mathrm{RH}$ and

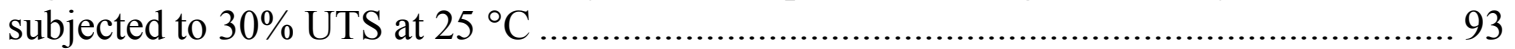
Figure 99 SEM image of freshly prepared neat vinyl ester sample (no cracks) ............... 96 Figure 100 SEM image of freshly prepared $5 \mathrm{wt} \%$ clay loaded vinyl ester sample (no

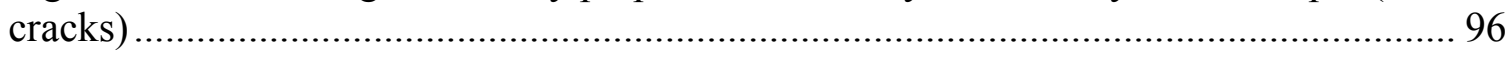
Figure 101 SEM image of freshly prepared $2 \mathrm{wt} \%$ clay loaded epoxy sample (no cracks) 
Figure 102 SEM image of freshly prepared $5 \mathrm{wt} \%$ clay loaded epoxy sample (no cracks)

Figure 103 SEM image of $2 \mathrm{wt} \%$ clay loaded epoxy subjected to cyclic sorption-

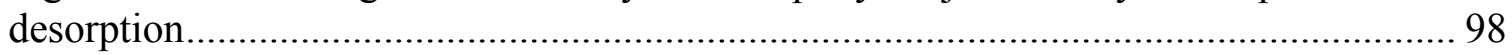

Figure 104 SEM image of $2 \mathrm{wt} \%$ clay loaded epoxy subjected to cyclic sorption-

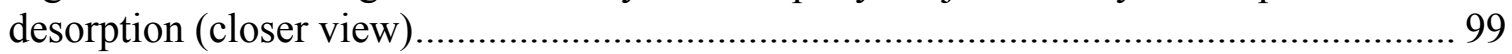

Figure 105 SEM image of $5 \mathrm{wt} \%$ clay loaded epoxy subjected to cyclic sorptiondesorption.

Figure 106 SEM image of $5 \mathrm{wt} \%$ clay loaded epoxy subjected to cyclic sorptiondesorption (closer view)

Figure $107 \mathrm{SEM}$ image of $5 \mathrm{wt} \%$ clay loaded vinyl ester sample immersed in water and subjected to $17 \%$ UTS

Figure 108 SEM image of $5 \mathrm{wt} \%$ clay loaded vinyl ester sample immersed in water and subjected to $17 \%$ UTS (closer view) ......

Figure 109 SEM image of $5 \mathrm{wt} \%$ clay loaded vinyl ester sample immersed in water and subjected to $30 \% \mathrm{UTS}$ 102

Figure 110 SEM image of $5 \mathrm{wt} \%$ clay loaded vinyl ester sample immersed in water and subjected to $30 \%$ UTS (closer view) 103

Figure 111 SEM image of $5 \mathrm{wt} \%$ clay loaded vinyl ester sample immersed in water and subjected to $30 \%$ UTS (closer view) 103 Figure 112 SEM image of $5 \mathrm{wt} \%$ clay loaded vinyl ester sample immersed in water and subjected to 30\%UTS (closer view, showing the size of crack $(0.2 \mu \mathrm{m})$..................... 104 Figure 113 SEM image of $5 \mathrm{wt} \%$ clay loaded vinyl ester sample exposed to $60 \% \mathrm{RH}$ and subjected to $30 \% \mathrm{UTS}$ 104 Figure 114 SEM image of $5 \mathrm{wt} \%$ clay loaded vinyl ester sample exposed to $60 \% \mathrm{RH}$ and subjected to $30 \%$ UTS (Closer view) ..................................................................... 105 Figure 115 Idealized chemical structure of a typical epoxy based vinyl ester ............... 115 Figure 116 Schematic of a cross linked vinyl ester resin (Mallick, 1993).................... 116 Figure 117 Idealized chemical structure of a typical epoxy based polyester................. 116 Figure 118 Idealized chemical structure of a typical epoxy (diglycidyl ether of bisphenol-

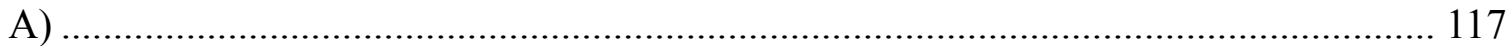

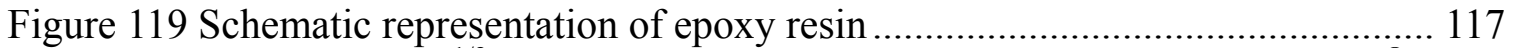
Figure $120 \mathrm{M}_{\mathrm{t}} / \mathrm{M}_{\infty}$ versus $\mathrm{t}^{1 / 2}$ for vinyl ester sample containing $0 \mathrm{wt} \%$ Cloisite $10 \mathrm{~A}^{\circledR}$ at 25 ${ }^{\circ} \mathrm{C}$ during first cycle of absorption.......................................................................... 119 Figure $121 \ln \left(\mathrm{M}_{\mathrm{t}}-\mathrm{M}_{\infty}\right)$ versus t for vinyl ester sample containing $0 \mathrm{wt} \%$ Cloisite $10 \mathrm{~A}^{\circledR}$ at $25{ }^{\circ} \mathrm{C}$ during first cycle of desorption...

Figure $122 \mathrm{M}_{\mathrm{t}} / \mathrm{M}_{\infty}$ versus $\mathrm{t} 1 / 2$ for vinyl ester sample containing $0 \mathrm{wt} \%$ Cloisite $10 \mathrm{~A}^{\circledR}$ immersed in distilled water and subjected to $17 \%$ UTS at $25{ }^{\circ} \mathrm{C}$. Figure $123 \mathrm{M}_{\mathrm{t}} / \mathrm{M}_{\infty}$ versus $\mathrm{t}^{1 / 2}$ for vinyl ester samples containing $5 \mathrm{wt} \%$ Cloisite $10 \mathrm{~A}^{\circledR}$ at $25{ }^{\circ} \mathrm{C}$ during first cycle of absorption. Figure $124 \mathrm{M}_{\mathrm{t}} / \mathrm{M}_{\infty}$ versus $\mathrm{t}^{1 / 2}$ for vinyl ester samples containing $5 \mathrm{wt} \%$ Cloisite $10 \mathrm{~A}^{\circledR}$ at $25^{\circ} \mathrm{C}$ during second cycle of absorption.... 123 Figure $125 \mathrm{M}_{\mathrm{t}} / \mathrm{M}_{\infty}$ versus $\mathrm{t}^{1 / 2}$ for vinyl ester samples containing $5 \mathrm{wt} \%$ Cloisite $10 \mathrm{~A} \AA$ at $25^{\circ} \mathrm{C}$ during third cycle of absorption. 124 Figure $126 \ln \left(\mathrm{M}_{\mathrm{t}}-\mathrm{M}_{\infty}\right)$ versus $\mathrm{t}$ for vinyl ester samples containing $5 \mathrm{wt} \%$ Cloisite $10 \mathrm{~A} \AA$ at $25^{\circ} \mathrm{C}$ during first cycle of desorption. 
Figure $127 \ln \left(\mathrm{M}_{\mathrm{t}}-\mathrm{M}_{\infty}\right)$ versus $\mathrm{t}$ for vinyl ester samples containing $5 \mathrm{wt} \%$ Cloisite $10 \mathrm{~A} \AA$ at $25{ }^{\circ} \mathrm{C}$ during second cycle of desorption

Figure $128 \ln \left(\mathrm{M}_{\mathrm{t}}-\mathrm{M}_{\infty}\right)$ versus t for vinyl ester samples containing $5 \mathrm{wt} \%$ Cloisite $10 \mathrm{~A}^{\circledR}$ at $25^{\circ} \mathrm{C}$ during third cycle of desorption.

Figure $129 \mathrm{M}_{\mathrm{t}} / \mathrm{M}_{\infty}$ versus $\mathrm{t}^{1 / 2}$ for polyester samples containing $0 \mathrm{wt} \%$ Cloisite $10 \mathrm{~A} \AA$ at 25

${ }^{\circ} \mathrm{C}$ during first cycle of absorption 125 Figure $130 \mathrm{M}_{\mathrm{t}} / \mathrm{M}_{\infty}$ versus $\mathrm{t}^{1 / 2}$ for polyester samples containing $0 \mathrm{wt} \%$ Cloisite $10 \mathrm{~A}^{\circledR}$ at 25 ${ }^{\circ} \mathrm{C}$ during second cycle of absorption

Figure $131 \mathrm{M}_{\mathrm{t}} / \mathrm{M}_{\infty}$ versus $\mathrm{t}^{1 / 2}$ for polyester samples containing $0 \mathrm{wt} \%$ Cloisite $10 \mathrm{~A}^{\circledR}$ at 25

${ }^{\circ} \mathrm{C}$ during third cycle of absorption.

Figure $132 \ln \left(\mathrm{M}_{\mathrm{t}}-\mathrm{M}_{\infty}\right)$ versus $\mathrm{t}$ for polyester samples containing $0 \mathrm{wt} \%$ Cloisite $10 \mathrm{~A}^{\circledR}$ at

$25^{\circ} \mathrm{C}$ during first cycle of desorption.

Figure $133 \ln \left(\mathrm{M}_{\mathrm{t}}-\mathrm{M}_{\infty}\right)$ versus $\mathrm{t}$ for polyester samples containing $0 \mathrm{wt} \%$ Cloisite $10 \mathrm{~A}^{\circledR}$ at

$25^{\circ} \mathrm{C}$ during second cycle of desorption

Figure $134 \ln (\mathrm{Mt}-\mathrm{M} \infty)$ versus $\mathrm{t}$ for samples containing $0 \mathrm{wt} \%$ Cloisite $10 \mathrm{~A} \AA$ at $25^{\circ} \mathrm{C}$

during third cycle of desorption.

Figure $135 \mathrm{M}_{\mathrm{t}} / \mathrm{M}_{\infty}$ versus $\mathrm{t}^{1 / 2}$ for polyester samples containing $2 \mathrm{wt} \%$ Cloisite $10 \mathrm{~A}^{\circledR}$ at 25

${ }^{\circ} \mathrm{C}$ during first cycle of absorption.

Figure $136 \mathrm{M}_{\mathrm{t}} / \mathrm{M}_{\infty}$ versus $\mathrm{t}^{1 / 2}$ for polyester samples containing $2 \mathrm{wt} \%$ Cloisite $10 \mathrm{~A}^{\circledR}$ at 25

${ }^{\circ} \mathrm{C}$ during second cycle of absorption

Figure $137 \mathrm{M}_{\mathrm{t}} / \mathrm{M}_{\infty}$ versus $\mathrm{t}^{1 / 2}$ for polyester samples containing $2 \mathrm{wt} \%$ Cloisite $10 \mathrm{~A}^{\circledR}$ at 25

${ }^{\circ} \mathrm{C}$ during third cycle of absorption.

Figure $138 \ln \left(\mathrm{M}_{\mathrm{t}}-\mathrm{M}_{\infty}\right)$ versus $\mathrm{t}$ for polyester samples containing $2 \mathrm{wt} \%$ Cloisite $10 \mathrm{~A}^{\circledR}$ at

$25{ }^{\circ} \mathrm{C}$ during first cycle of desorption................................................................... 128

Figure $139 \ln \left(\mathrm{M}_{\mathrm{t}}-\mathrm{M}_{\infty}\right)$ versus $\mathrm{t}$ for polyester samples containing $2 \mathrm{wt} \%$ Cloisite $10 \mathrm{~A}^{\circledR}$ at

$25^{\circ} \mathrm{C}$ during second cycle of desorption.

Figure $140 \ln \left(\mathrm{M}_{\mathrm{t}}-\mathrm{M}_{\infty}\right)$ versus $\mathrm{t}$ for polyester samples containing $2 \mathrm{wt} \%$ Cloisite $10 \mathrm{~A}^{\circledR}$ at

$25^{\circ} \mathrm{C}$ during third cycle of desorption.

Figure $141 \mathrm{M}_{\mathrm{t}} / \mathrm{M}_{\infty}$ versus $\mathrm{t}^{1 / 2}$ for polyester samples containing $5 \mathrm{wt} \%$ Cloisite $10 \mathrm{~A}^{\circledR}$ at 25

${ }^{\circ} \mathrm{C}$ during first cycle of absorption.

Figure $142 \mathrm{M}_{\mathrm{t}} / \mathrm{M}_{\infty}$ versus $\mathrm{t}^{1 / 2}$ for polyester samples containing $5 \mathrm{wt} \%$ Cloisite $10 \mathrm{~A}^{\circledR}$ at 25

${ }^{\circ} \mathrm{C}$ during second cycle of absorption

Figure $143 \mathrm{M}_{\mathrm{t}} / \mathrm{M}_{\infty}$ versus $\mathrm{t}^{1 / 2}$ for polyester samples containing $5 \mathrm{wt} \%$ Cloisite $10 \mathrm{~A}^{\circledR}$ at 25

${ }^{\circ} \mathrm{C}$ during third cycle of absorption.

Figure $144 \ln \left(\mathrm{M}_{\mathrm{t}}-\mathrm{M}_{\infty}\right)$ versus $\mathrm{t}$ for polyester samples containing $5 \mathrm{wt} \%$ Cloisite $10 \mathrm{~A}^{\circledR}$ at

$25{ }^{\circ} \mathrm{C}$ during first cycle of desorption

Figure $145 \ln \left(\mathrm{M}_{\mathrm{t}}-\mathrm{M}_{\infty}\right)$ versus t for polyester samples containing $5 \mathrm{wt} \%$ Cloisite $10 \mathrm{~A}^{\circledR}$ at

$25^{\circ} \mathrm{C}$ during second cycle of desorption.....

Figure $146 \ln \left(\mathrm{M}_{\mathrm{t}}-\mathrm{M}_{\infty}\right)$ versus $\mathrm{t}$ for polyester samples containing $5 \mathrm{wt} \%$ Cloisite $10 \mathrm{~A}^{\circledR}$ at

$25^{\circ} \mathrm{C}$ during third cycle of desorption....

Figure $147 \mathrm{M}_{\mathrm{t}} / \mathrm{M}_{\infty}$ versus $\mathrm{t}^{1 / 2}$ for epoxy samples containing $0 \mathrm{wt} \%$ Cloisite $10 \mathrm{~A}^{\circledR}$ at $25^{\circ} \mathrm{C}$ during first cycle of absorption

Figure $148 \mathrm{M}_{\mathrm{t}} / \mathrm{M}_{\infty}$ versus $\mathrm{t}^{1 / 2}$ for epoxy samples containing $0 \mathrm{wt} \%$ Cloisite $10 \mathrm{~A}^{\circledR}$ at $25^{\circ} \mathrm{C}$ during second cycle of absorption

Figure $149 \mathrm{M}_{\mathrm{t}} / \mathrm{M}_{\infty}$ versus $\mathrm{t}^{1 / 2}$ for epoxy samples containing $0 \mathrm{wt} \% \mathrm{Cloisite} 10 \mathrm{~A}^{\circledR}$ at $25^{\circ} \mathrm{C}$ during third cycle of absorption 
Figure $150 \ln \left(\mathrm{M}_{\mathrm{t}}-\mathrm{M}_{\infty}\right)$ versus $\mathrm{t}$ for epoxy samples containing $0 \mathrm{wt} \%$ Cloisite $10 \mathrm{~A}^{\circledR}$ at 25 ${ }^{\circ} \mathrm{C}$ during first cycle of desorption.

Figure $151 \ln \left(\mathrm{M}_{\mathrm{t}}-\mathrm{M}_{\infty}\right)$ versus $\mathrm{t}$ for epoxy samples containing $0 \mathrm{wt} \%$ Cloisite $10 \mathrm{~A}^{\circledR}$ at 25

${ }^{\circ} \mathrm{C}$ during second cycle of desorption

Figure $152 \ln \left(\mathrm{M}_{\mathrm{t}}-\mathrm{M}_{\infty}\right)$ versus $\mathrm{t}$ for epoxy samples containing $0 \mathrm{wt} \%$ Cloisite $10 \mathrm{~A}^{\circledR}$ at 25

${ }^{\circ} \mathrm{C}$ during third cycle of desorption.

Figure $153 \mathrm{M}_{\mathrm{t}} / \mathrm{M}_{\infty}$ versus $\mathrm{t}^{1 / 2}$ for epoxy samples containing $2 \mathrm{wt} \%$ Cloisite $10 \mathrm{~A}^{\circledR}$ at $25^{\circ} \mathrm{C}$

during first cycle of absorption .

Figure $154 \mathrm{M}_{\mathrm{t}} / \mathrm{M}_{\infty}$ versus $\mathrm{t}^{1 / 2}$ for epoxy samples containing $2 \mathrm{wt} \%$ Cloisite $10 \mathrm{~A}^{\circledR}$ at $25^{\circ} \mathrm{C}$

during second cycle of absorption

Figure $155 \mathrm{M}_{\mathrm{t}} / \mathrm{M}_{\infty}$ versus $\mathrm{t}^{1 / 2}$ for epoxy samples containing $2 \mathrm{wt} \%$ Cloisite $10 \mathrm{~A}^{\circledR}$ at $25^{\circ} \mathrm{C}$

during third cycle of absorption

Figure $156 \ln \left(\mathrm{M}_{\mathrm{t}}-\mathrm{M}_{\infty}\right)$ versus $\mathrm{t}$ for epoxy samples containing $2 \mathrm{wt} \%$ Cloisite $10 \mathrm{~A}^{\circledR}$ at 25

${ }^{\circ} \mathrm{C}$ during first cycle of desorption...

Figure $157 \ln \left(\mathrm{M}_{\mathrm{t}}-\mathrm{M}_{\infty}\right)$ versus $\mathrm{t}$ for epoxy samples containing $2 \mathrm{wt} \%$ Cloisite $10 \mathrm{~A}^{\circledR}$ at 25

${ }^{\circ} \mathrm{C}$ during second cycle of desorption

Figure $158 \ln \left(\mathrm{M}_{\mathrm{t}}-\mathrm{M}_{\infty}\right)$ versus $\mathrm{t}$ for epoxy samples containing $2 \mathrm{wt} \%$ Cloisite $10 \mathrm{~A}^{\circledR}$ at 25

${ }^{\circ} \mathrm{C}$ during third cycle of desorption.

Figure $159 \mathrm{M}_{\mathrm{t}} / \mathrm{M}_{\infty}$ versus $\mathrm{t}^{1 / 2}$ for epoxy samples containing $5 \mathrm{wt} \%$ Cloisite $10 \mathrm{~A}^{\circledR}$ at $25^{\circ} \mathrm{C}$

during first cycle of absorption

135

Figure $160 \mathrm{M}_{\mathrm{t}} / \mathrm{M}_{\infty}$ versus $\mathrm{t}^{1 / 2}$ for epoxy samples containing $5 \mathrm{wt} \%$ Cloisite $10 \mathrm{~A}^{\circledR}$ at $25^{\circ} \mathrm{C}$

during second cycle of absorption

Figure $161 \mathrm{M}_{\mathrm{t}} / \mathrm{M}_{\infty}$ versus $\mathrm{t}^{1 / 2}$ for epoxy samples containing $5 \mathrm{wt} \%$ Cloisite $10 \mathrm{~A}^{\circledR}$ at $25^{\circ} \mathrm{C}$

during third cycle of absorption.

135

Figure $162 \ln \left(\mathrm{M}_{\mathrm{t}}-\mathrm{M}_{\infty}\right)$ versus $\mathrm{t}$ for epoxy samples containing $5 \mathrm{wt} \%$ Cloisite $10 \mathrm{~A}^{\circledR}$ at 25

${ }^{\circ} \mathrm{C}$ during first cycle of desorption.

Figure $163 \ln \left(\mathrm{M}_{\mathrm{t}}-\mathrm{M}_{\infty}\right)$ versus $\mathrm{t}$ for epoxy samples containing $5 \mathrm{wt} \%$ Cloisite $10 \mathrm{~A}^{\circledR}$ at 25

${ }^{\circ} \mathrm{C}$ during second cycle of desorption

Figure 164 Moisture content versus t for neat vinyl ester samples exposed to $60 \% \mathrm{RH}$ at

$25{ }^{\circ} \mathrm{C}$

Figure 165 Moisture content versus t for $2 \mathrm{wt} \%$ clay loaded vinyl ester samples exposed to $60 \% \mathrm{RH}$ at $25^{\circ} \mathrm{C}$

Figure 166 Moisture content versus $\mathrm{t}$ for $5 \mathrm{wt} \%$ clay loaded vinyl ester samples exposed

to $60 \% \mathrm{RH}$ at $25^{\circ} \mathrm{C}$

Figure $167 \mathrm{M}_{\mathrm{t}} / \mathrm{M}_{\infty}$ versus $\mathrm{t}^{1 / 2}$ for vinyl ester samples containing $0 \mathrm{wt} \%$ Cloisite $10 \mathrm{~A}^{\circledR}$

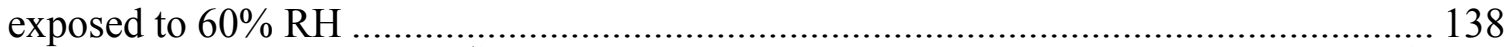

Figure $168 \mathrm{M}_{\mathrm{t}} / \mathrm{M}_{\infty}$ versus $\mathrm{t}^{1 / 2}$ for vinyl ester samples containing $2 \mathrm{wt} \%$ Cloisite $10 \mathrm{~A}^{\circledR}$

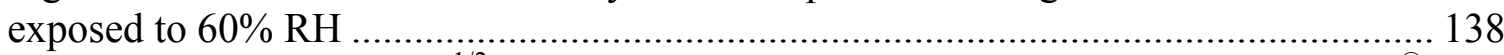

Figure $169 \mathrm{M}_{\mathrm{t}} / \mathrm{M}_{\infty}$ versus $\mathrm{t}^{1 / 2}$ for vinyl ester samples containing $5 \mathrm{wt} \%$ Cloisite $10 \mathrm{~A}^{\circledR}$

exposed to $60 \% \mathrm{RH}$

Figure 170 Moisture content versus t for neat vinyl ester samples exposed to $70 \% \mathrm{RH}$ at

$25^{\circ} \mathrm{C}$

Figure 171 Moisture content versus t for $2 \mathrm{wt} \%$ clay loaded vinyl ester samples exposed to $70 \% \mathrm{RH}$ at $25^{\circ} \mathrm{C}$.

Figure 172 Moisture content versus t for $5 \mathrm{wt} \%$ clay loaded vinyl ester samples exposed to $70 \% \mathrm{RH}$ at $25^{\circ} \mathrm{C}$. 
Figure $173 \mathrm{M}_{\mathrm{t}} / \mathrm{M}_{\infty}$ versus $\mathrm{t}^{1 / 2}$ for vinyl ester samples containing $0 \mathrm{wt} \%$ Cloisite $10 \mathrm{~A}^{\circledR}$ exposed to $70 \% \mathrm{RH}$

Figure $174 \mathrm{M}_{\mathrm{t}} / \mathrm{M}_{\infty}$ versus $\mathrm{t}^{1 / 2}$ for vinyl ester samples containing $2 \mathrm{wt} \%$ Cloisite $10 \mathrm{~A}^{\circledR}$ exposed to $70 \% \mathrm{RH}$

Figure $175 \mathrm{M}_{\mathrm{t}} / \mathrm{M}_{\infty}$ versus $\mathrm{t}^{1 / 2}$ for vinyl ester samples containing $5 \mathrm{wt} \%$ Cloisite $10 \mathrm{~A}^{\circledR}$ exposed to $70 \% \mathrm{RH}$ 140

Figure 176 Moisture content versus $t$ for neat vinyl ester samples exposed to $80 \% \mathrm{RH}$ at $25{ }^{\circ} \mathrm{C}$

Figure 177 Moisture content versus t for $2 \mathrm{wt} \%$ clay loaded vinyl ester samples exposed to $80 \% \mathrm{RH}$ at $25^{\circ} \mathrm{C}$

Figure 178 Moisture content versus t for $5 \mathrm{wt} \%$ clay loaded vinyl ester samples exposed to $80 \% \mathrm{RH}$ at $25{ }^{\circ} \mathrm{C}$

Figure $179 \mathrm{M}_{\mathrm{t}} / \mathrm{M}_{\infty}$ versus $\mathrm{t}^{1 / 2}$ for vinyl ester samples containing $0 \mathrm{wt} \%$ Cloisite $10 \mathrm{~A}^{\circledR}$ exposed to $80 \% \mathrm{RH}$

Figure $180 \mathrm{M}_{\mathrm{t}} / \mathrm{M}_{\infty}$ versus $\mathrm{t}^{1 / 2}$ for vinyl ester samples containing $2 \mathrm{wt} \%$ Cloisite $10 \mathrm{~A}^{\circledR}$

exposed to $80 \% \mathrm{RH}$

Figure $181 \mathrm{M}_{\mathrm{t}} / \mathrm{M}_{\infty}$ versus $\mathrm{t}^{1 / 2}$ for vinyl ester samples containing $5 \mathrm{wt} \%$ Cloisite $10 \mathrm{~A}^{\circledR}$ exposed to $80 \% \mathrm{RH}$ 


\section{LIST OF TABLES}

Table 1. Table showing catalyst, promoter, inhibitor quantities, curing temperature and post curing temperature used for different resins used in the study....

Table 2. Results of Cyclic Sorption-Desorption Experiments for Vinyl ester Samples at 25 ${ }^{\circ} \mathrm{C}$

Table 3. Results of Cyclic Sorption-Desorption Experiments for Polyester Samples at 25 ${ }^{\circ} \mathrm{C}$.

Table 4. Results of Cyclic Sorption-Desorption Experiments for Epoxy Samples at $25{ }^{\circ} \mathrm{C}$

Table 5. Summarized Results of Cyclic Sorption-Desorption Experiments for Polyester,

Vinyl ester and Epoxy..... 71

Table 6. Variation of Equilibrium Moisture Content and Diffusivity with Relative Humidity if Exposed Environment. 80

Table 7. Variation of equilibrium moisture content and diffusivity with various stress levels and percentage clay loadings for samples immersed in water.

Table 8 . Variation of equilibrium moisture content and diffusivity with various stress levels and percentage clay loadings for samples exposed at $60 \% \mathrm{RH}$

Table 9. Sorption Data of Vinyl ester Samples containing $0 \mathrm{wt} \%$ Cloisite $10 \mathrm{~A}$ at $25^{\circ} \mathrm{C}$

During First Cycle of Absorption

Table 10. Desorption Data of Vinyl ester Samples containing $0 \mathrm{wt} \%$ Cloisite $10 \mathrm{~A}$ at $25^{\circ} \mathrm{C}$

During First Cycle of Absorption

Table 11. Sorption data of vinyl ester samples containing $0 \mathrm{wt} \%$ Cloisite $10 \mathrm{~A}$ immersed

in distilled water subjected to $17 \%$ UTS at $25^{\circ} \mathrm{C}$

Table 12. Sorption Data of Vinyl ester Samples containing $0 \mathrm{wt} \%$ Cloisite $10 \mathrm{~A}$ at $25^{\circ} \mathrm{C}$

During Three Cycles of Absorption ....................................................................... 143

Table 13. Desorption Data of Vinyl ester Samples containing $0 \mathrm{wt} \%$ Cloisite $10 \mathrm{~A}$ at $25^{\circ} \mathrm{C}$

During Three Cycles of Absorption......................................................................... 146

Table 14. Sorption Data of Vinyl ester Samples containing $2 \mathrm{wt} \%$ Cloisite $10 \mathrm{~A}$ at $25^{\circ} \mathrm{C}$

During Three Cycles of Absorption ....................................................................... 149

Table 15. Desorption Data of Vinyl ester Samples containing $2 \mathrm{wt} \%$ Cloisite $10 \mathrm{~A}$ at $25^{\circ} \mathrm{C}$

During Three Cycles of Absorption...................................................................... 152

Table 16. Sorption Data of Vinyl ester Samples containing $5 \mathrm{wt} \%$ Cloisite $10 \mathrm{~A}$ at $25^{\circ} \mathrm{C}$

During Three Cycles of Absorption ........................................................................ 155

Table 17. Desorption Data of Vinyl ester Samples containing $5 \mathrm{wt} \%$ Cloisite $10 \mathrm{~A}$ at $25^{\circ} \mathrm{C}$

During Three Cycles of Absorption ....................................................................... 158

Table 18. Sorption Data of Polyester Samples containing $0 \mathrm{wt} \%$ Cloisite $10 \mathrm{~A}$ at $25^{\circ} \mathrm{C}$

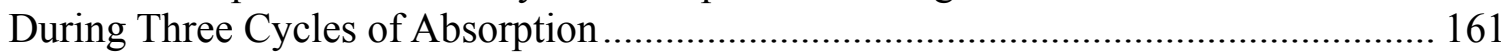

Table 19. Desorption Data of Polyester Samples containing $0 \mathrm{wt} \%$ Cloisite $10 \mathrm{~A}$ at $25^{\circ} \mathrm{C}$

During Three Cycles of Absorption .......................................................................... 164

Table 20. Sorption Data of Polyester Samples containing $2 \mathrm{wt} \%$ Cloisite $10 \mathrm{~A}$ at $25^{\circ} \mathrm{C}$

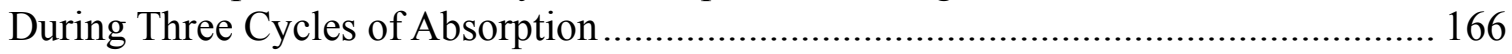

Table 21. Desorption Data of Polyester Samples containing $2 \mathrm{wt} \%$ Cloisite $10 \mathrm{~A}$ at $25^{\circ} \mathrm{C}$

During Three Cycles of Absorption .......................................................................... 169

Table 22. Sorption Data of Polyester Samples containing $5 \mathrm{wt} \%$ Cloisite $10 \mathrm{~A}$ at $25^{\circ} \mathrm{C}$

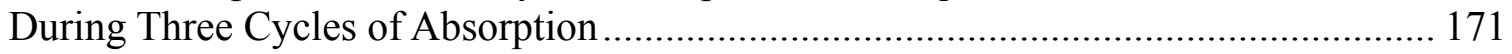


Table 23. Desorption Data of Polyester Samples containing $5 \mathrm{wt} \%$ Cloisite $10 \mathrm{~A}$ at $25^{\circ} \mathrm{C}$

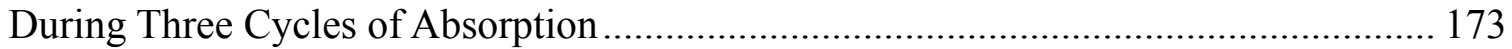

Table 24. Sorption Data of Epoxy Samples containing $0 \mathrm{wt} \%$ Cloisite $10 \mathrm{~A}$ at $25^{\circ} \mathrm{C}$ During

Three Cycles of Absorption ..................................................................................... 176

Table 25. Desorption Data of Epoxy Samples containing $0 \mathrm{wt} \%$ Cloisite $10 \mathrm{~A}$ at $25^{\circ} \mathrm{C}$

During Three Cycles of Absorption ...................................................................... 179

Table 26. Sorption Data of Epoxy Samples containing $2 \mathrm{wt} \%$ Cloisite $10 \mathrm{~A}$ at $25^{\circ} \mathrm{C}$ During

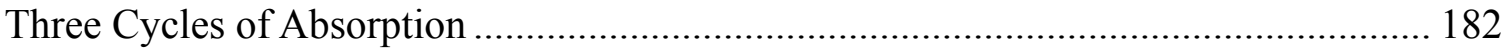

Table 27. Desorption Data of Epoxy Samples containing $2 \mathrm{wt} \%$ Cloisite $10 \mathrm{~A}$ at $25^{\circ} \mathrm{C}$

During Three Cycles of Absorption ....................................................................... 185

Table 28. Sorption Data of Epoxy Samples containing $5 \mathrm{wt} \%$ Cloisite $10 \mathrm{~A}$ at $25^{\circ} \mathrm{C}$ During

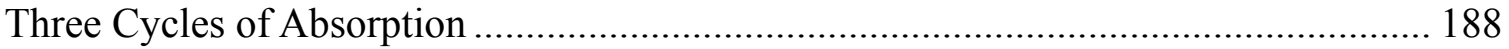

Table 29. Desorption Data of Epoxy Samples containing $5 \mathrm{wt} \%$ Cloisite $10 \mathrm{~A}$ at $25^{\circ} \mathrm{C}$

During Three Cycles of Absorption ....................................................................... 191

Table 30. Sorption Data of neat vinyl ester Samples exposed to $40 \% \mathrm{RH}$ at $25^{\circ} \mathrm{C} \ldots \ldots . .194$

Table 31. Sorption Data of vinyl ester samples containing $2 \mathrm{wt} \%$ Cloisite $10 \mathrm{~A}^{\circledR}$ exposed to $40 \% \mathrm{RH}$ at $25^{\circ} \mathrm{C}$

Table 32. Sorption Data of vinyl ester samples containing $5 \mathrm{wt} \%$ Cloisite $10 \mathrm{~A}^{\circledR}$ exposed

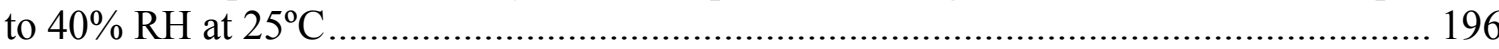

Table 33. Sorption Data of neat vinyl ester Samples exposed to $60 \% \mathrm{RH}$ at $25^{\circ} \mathrm{C} \ldots \ldots . .197$

Table 34. Sorption Data of vinyl ester samples containing $2 \mathrm{wt} \%$ Cloisite $10 \mathrm{~A}^{\circledR}$ exposed

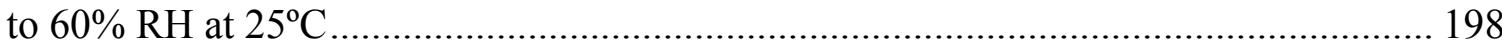

Table 35. Sorption Data of vinyl ester samples containing $5 \mathrm{wt} \%$ Cloisite $10 \mathrm{~A}^{\circledR}$ exposed

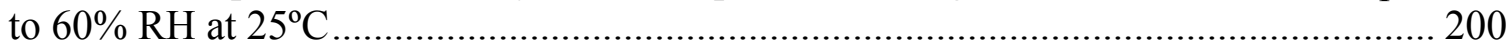

Table 36. Sorption Data of neat vinyl ester Samples exposed to $70 \% \mathrm{RH}$ at $25^{\circ} \mathrm{C} \ldots \ldots . .201$

Table 37. Sorption Data of vinyl ester samples containing $2 \mathrm{wt} \%$ Cloisite $10 \mathrm{~A}^{\circledR}$ exposed

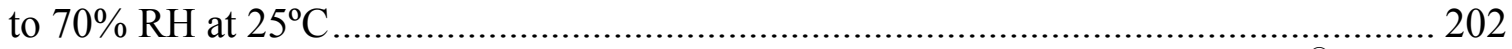

Table 38. Sorption Data of vinyl ester samples containing $5 \mathrm{wt} \%$ Cloisite $10 \mathrm{~A}^{\circledR}$ exposed

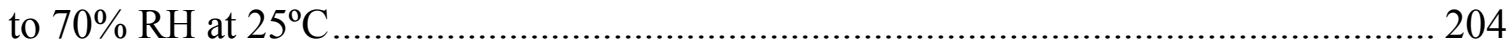

Table 39. Sorption Data of neat vinyl ester Samples exposed to $80 \% \mathrm{RH}$ at $25^{\circ} \mathrm{C} \ldots \ldots . .205$

Table 40. Sorption Data of vinyl ester samples containing $2 \mathrm{wt} \%$ Cloisite $10 \mathrm{~A}^{\circledR}$ exposed

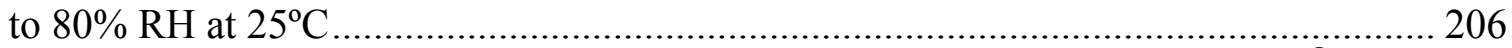

Table 41. Sorption Data of vinyl ester samples containing $5 \mathrm{wt} \%$ Cloisite $10 \mathrm{~A}^{\circledR}$ exposed

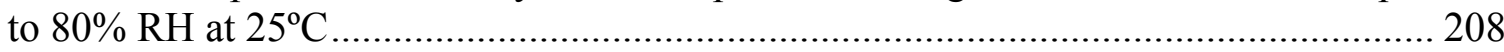

Table 42. Sorption data of vinyl ester samples containing $0 \mathrm{wt} \%$ Cloisite $10 \mathrm{~A}$ immersed

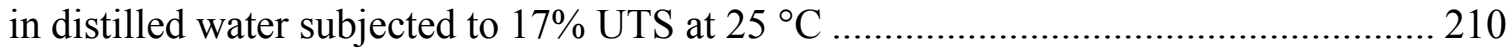
Table 43. Sorption data of vinyl ester samples containing $5 \mathrm{wt} \%$ Cloisite $10 \mathrm{~A}$ immersed

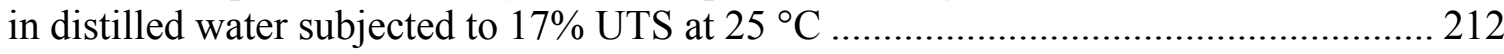
Table 44. Sorption data of vinyl ester samples containing $0 \mathrm{wt} \%$ Cloisite $10 \mathrm{~A}$ immersed

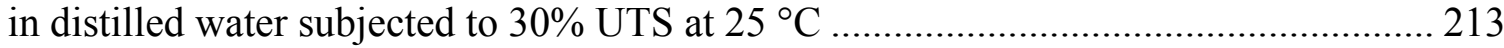
Table 45. Sorption data of vinyl ester samples containing $5 \mathrm{wt} \%$ Cloisite $10 \mathrm{~A}$ immersed in distilled water subjected to $30 \%$ UTS at $25{ }^{\circ} \mathrm{C}$................................................. 215 Table 46. Sorption data of vinyl ester samples containing $0 \mathrm{wt} \%$ Cloisite $10 \mathrm{~A}$ exposed to $60 \% \mathrm{RH}$ at $25^{\circ} \mathrm{C}$ subjected to $30 \%$ UTS .......................................................... 216 Table 47. Sorption data of vinyl ester samples containing $5 \mathrm{wt} \%$ Cloisite $10 \mathrm{~A}$ exposed to

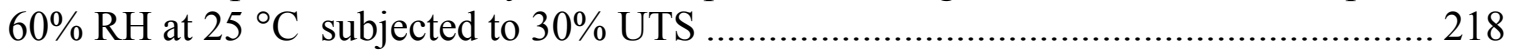




\section{CHAPTER 1}

\section{INTRODUCTION}

This chapter gives a short introduction to polymer layered silicate (PLS) nanocomposites and the effects of addition of nanoparticles to polymers on the barrier, mechanical and thermal properties of the polymers. It mentions the motivation for the study of polymers selected and lists the main objectives of this research project. Finally, it discusses several industrial applications of polymeric membranes, based on their barrier properties.

In addition to aerospace, marine and automotive applications, polymer composites are being increasingly used for structural applications such as construction of roads and bridges because of the durability of composites under harsh environmental conditions. Conventional structural materials are susceptible to corrosion and deteriorate when they come in contact with moisture or other deicing salt solutions. The growing concern over the deterioration of the infrastructure has prompted engineers to consider alternatives to conventional structural materials. Polymer composites offer superior resistance to corrosion, fatigue and other environmental effects when compared to metals and have other advantages such as lower density, high strength-to-weight ratio, high stiffness-toweight ratio and ease of installation. Though the polymer composites may not corrode via the same mechanisms as metals, they undergo plasticization and degradation when exposed to moisture, caustic solutions, UV radiation etc. This results in deterioration of mechanical properties and reduction in the life of the composite structures. Polymer layered silicate nanocomposites, made by dispersing nano-sized particles, seem to provide a solution to this problem by reducing the diffusivity of moisture and other molecules in polymer composites. Nano materials, such as nanoclay, when distributed within the polymer matrix, act as physical barriers to the diffusing moisture by increasing the path of diffusion. Consequently, the nanocomposite would take a longer time before it is completely saturated with water. In addition, due to its hydrophilic nature, clay can help to sequester water molecules. 


\subsection{Introduction to Polymer Layered Silicate Nanocomposites}

Nanotechnology is a new word which defines the creation of materials, devices and systems through the control of matter at the nanoscale $\left(1 \mathrm{~nm}=10^{-9} \mathrm{~m}\right)$ and has become one of the most powerful driving forces in technologies of the 21st century. PLS nanocomposites exhibit significant improvements in the properties such as modulus, strength, diffusivity and thermal stability by addition of only small amounts of organically modified layered silicates, when compared to their "neat" polymer constituents or their macrocomposite counterparts (Shah, 2001; Rana, 2003 and Ravindran, 2005). Such property enhancements are induced not only by the physical presence of the filler but also by the interaction of the polymer with the filler via altering the local properties of the polymer material. In this regard, PLS nanocomposites have been effective in modifying polymer properties due to the high surface area of contact and high aspect ratio (Cussler et al., 1988 and Alamgir et al., 2002). This large aspect ratio creates a tortuous path for a penetrant molecule resulting in improvement in barrier properties. More recent results indicate that chemical interactions may further improve the barrier properties of these systems (Ajit, 2004). The ever-growing industrial interest has stimulated the development of theoretical models to describe the transport process, but these may lack a correct microscopic description of the diffusion process.

\subsection{Motivation for Study}

Polymer-clay composites have been produced using a broad range of polymers, such as polystyrene, polypropylene, polyamide and epoxy. Some polymers are used in protective clothing application, electronic devices, cable materials and biomedical devices. A variety of major applications of polymers are in the fields of textiles, automobiles, food packaging, and consumer products etc, in which transport of small molecules across polymeric membranes plays an important role. This has drawn researchers' attention in the field of PLS nanocomposites and in the applications which demand stringent performance specifications and tolerances in properties and dimensions. The orientation and dispersion of layered silicate particles greatly influences the performance of the nanocomposites (Cussler, 2004 and Malwitz, 2003). Mechanical deformation is an important factor affecting the transport process through polymer nanocomposites as it can lead to changes in orientation and delamination of PLS in the 
polymer matrix.

Any application of polymer composites in an outdoor environment involves the interaction with moisture either in the form of atmospheric water vapor or rain. Also, the composites may have to come in contact with the chemicals and the solvents depending on the applications. Some examples include aviation turbine fuel, deicing liquids and paint strippers in aircraft applications; gasoline or motor fuel in automotive applications; and salt water in waterfront or seashore applications. This interaction can be continuous or periodic; periodicity can be either due to daily or seasonal changes in the atmospheric humidity, which can be regarded as harmonic or step wise changes caused by specific storage, operational or application conditions. Such environments may have a significant effect on the properties of the matrix resin and the composite. The effects of moisture on polymer composites have been investigated, but the focus of most experiments has been on the effects of a single cyclic absorption process (Chin et al., 1999 and Shah, 2002). The present study involves multiple sorption-desorption cycles to determine if cyclical aging introduces additional damage into the composite system.

However, in order to project the service life of composites, the knowledge of their performance and long time durability under conditions such as moisture, mechanical stress and stress coupled moisture becomes essential. A topic of practical interest is the effect of stress on moisture diffusion in polymers and composites. Most of the previous publications have dealt with the transport of moisture in polymers and polymer nanocomposites without stress. However, in many applications composite structures are subjected to internal and external stresses during much or all of their life. Some researchers have tried to understand the effect of stress on the water transport, but their investigation was restricted to polymers and polymer composites without any nano-sized particles (Fahmy, 1980; Marom, 1981; Weitsman, 1986 and Chipalkatti, 1986). The improvement of the barrier properties of the polymer-clay nanocomposites under zerostress has been widely studied (Shah, 2001; Chen, 2002 and Rana, 2005). The number of studies addressing the effect of mechanical stress on the barrier properties of nanocomposites has been rather small (Liu, 2004). This is partly because the effects were considered inconsequential and also because of the limitations of the experimental techniques employed. 
A more comprehensive understanding of stress effects may be gained by studying the diffusion behavior exhibited by both neat resins and their respective nanocomposites under conditions of zero tensile stress and uniaxial tensile stress. This research project aims at developing a new experimental technique designed to study stress-coupled diffusion in polymer nanocomposites. In addition, the investigation also involves study of diffusion during cyclic sorption-desorption of moisture in both neat resins and nanoclay composites.

\subsection{Objectives of Research}

- Structural characterization of polymer nanocomposites containing nanoclay using various techniques like SEM, TEM and XRD

- Measuring equilibrium moisture content and diffusivity of water in resins like vinyl ester, polyester, epoxy and their nanocomposites and establishing the mechanism of water diffusion through the polymers.

- Reducing the diffusion coefficient through polymers by dispersing nanoclay in the matrix and studying the effect of clay loading on the diffusion properties by varying the amount of clay.

- Conducting cyclic moisture sorption-desorption experiments to assess the effect of clay dispersion on the long term barrier properties.

- Conducting stress coupled moisture sorption experiments to study the effect of clay loading and stress on the transport properties.

To summarize, the transport of water through vinyl ester, polyester and epoxy resins and the effect of clay loading on transport properties will be studied gravimetrically, by performing transient water uptake experiments. Cyclic absorptiondesorption experiments will be conducted to study the effect of cyclic changes in the concentration driving force on the diffusivity values. Stress-coupled diffusion experiments will be conducted to determine the effect of stress on moisture diffusion. Diffusion coefficient and equilibrium moisture content will be calculated from the data 
obtained which will provide insight into the rate and amount of water ingress into the sample.

\subsection{Industrial Applications of Polymeric Membranes}

In industry, polymeric membranes have been mainly used as barrier plastics, where resistance to diffusion of molecules plays an important role and as separation membranes, where selectivity and permeability are important factors. One particular industry where barrier properties of polymers play a significant role is the packaging industry. For example, for the packaging of carbonated soft drinks the package should not allow the permeation of carbon dioxide, oxygen or water. In the packaging of products containing fats and oils like fried snacks and meat, protection against the effects of oxygen and light is required.

An interesting exception to the simple barrier demands is the storage of blood platelets (Koros, 1990). Blood platelets are living cells that consume oxygen to live and generate carbon dioxide as a metabolic byproduct. The carbon dioxide generated presents a large problem as it tends to cause undesirable changes in the $\mathrm{pH}$ unless the carbon dioxide can escape. At the same time aqueous solution containing the platelets should not lose significant amounts of water by permeation. This case, therefore, illustrates the need for an advanced controlled atmosphere package which would allow relatively free exchange of oxygen and carbon dioxide while essentially preventing outward permeation losses of water.

Not only can the type of polymer be adjusted to the needs, but the macroscopic structure of the membrane can also be altered. As shown in Figure 1, one can use a variety of barrier structures besides that of a simple film to control the exchange of mass between the internal and external environment.

For example, in an application where there is a need for a barrier to oxygen an often used polymer is ethylene-vinyl alcohol $(\mathrm{EvOH})$. EvOH has a very low permeability to oxygen in the dry state. The problem however is that it loses its barrier properties at high relative humidities, so in such cases an interface layer is placed on the EvOH membrane such that it is shielded from the humid environment. 


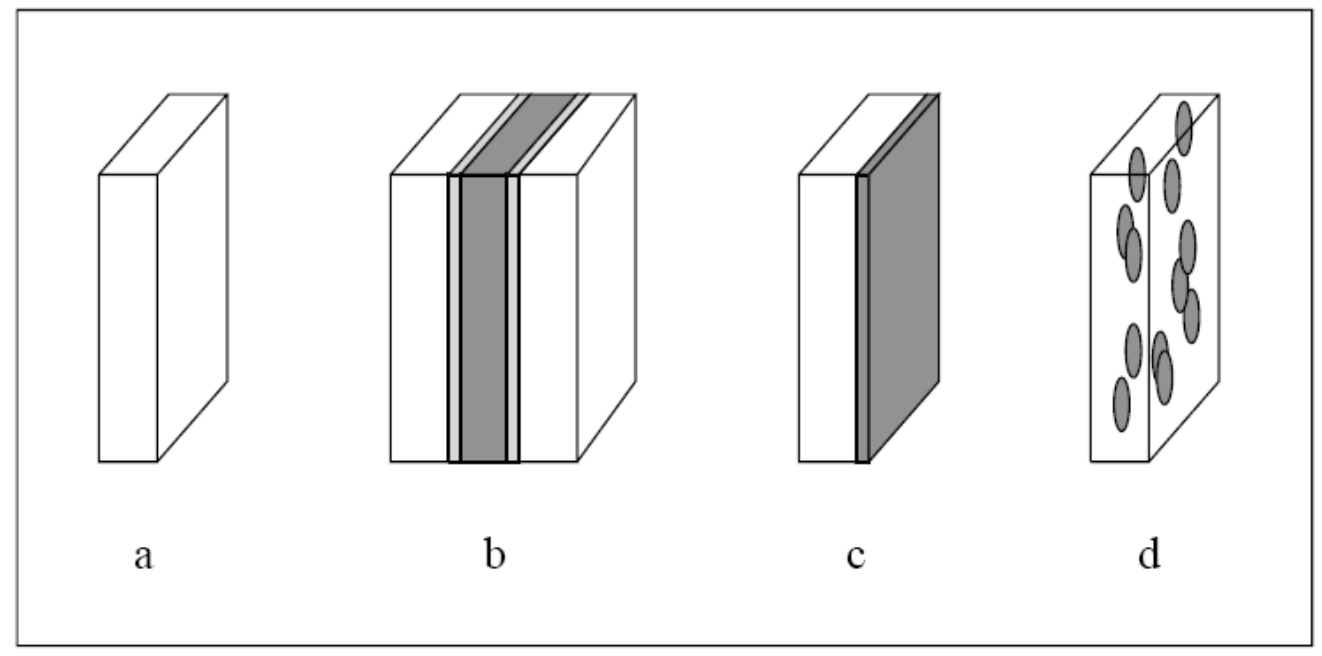

Figure 1 Primary types of barrier structures a) Monolithic, single polymer b) Laminate of two or more polymers, middle high barrier layer e.g. EvOH, covered with surface layers. These interact with the environment which could damage the middle layer. c) Reactively formed or coated laminate

d) Polymer filled with inorganic platelets or higher barrier polymer lamellae to enhance the tortuosity of the path of the penetrants (Sok, 1994).

Another application which has large industrial interest is the selective separation of gases by use of membranes. In these cases there is a need for both high selectivity and high permeability. Silicone polymers have been used as selective membranes mainly because of the latter requirement. The enhancement of the selectivity usually has a negative influence on the rate of permeation, so for every application a new tradeoff has to be made. An interesting example of the enhancement of the selectivity is the use of polymer films containing metal complexes. The incorporation of cobalt-porphyrin complexes in a copolymer of poly (alkylmethacrylate) produces an increase in the selectivity $\left(\mathrm{O}_{2} / \mathrm{CO}_{2}\right)$ from 3.4 to 12.8 . The complex selectively absorbs (according to a Langmuir isotherm) and transports oxygen in the membrane (Nishide et.al., 1986 and Tsuchida, 1988).

Another class of applications is biomedical applications, for example the usage of polymers as contact lenses. Contact lenses are classified based on their mechanical strength and physical behavior as "hard", to denote glassy polymers, or "soft" for rubbery polymers. For polymers used as contact lenses, surface wettability and flexure and high oxygen permeability are the important properties. Silicone films have been used as a material for contact lenses for the past three decades. Presently the polymer used in hard lenses is usually PMMA (polymethylmethacrylate) and most of the present soft contact 
lenses are prepared from poly (2-hydroxyethyl methacrylate) (PHEMA).

Controlled drug release is another biomedical application. Delivering the drugs at a controlled rate enhances their therapeutic efficacy and reduces their toxicities. Controlled release drug administration not only means prolongation in the duration of drug delivery, but also implies predictability and reproducibility. A number of therapeutic transdermal (through-skin) products employing silicone rubbers (including PDMS) are commercially available, for example for the controlled release of anesthetic vapors or steroids (Folkman, 1966 and Roseman, 1972).

The resins used in the present study are epoxy, polyester and vinyl ester and these have been widely used in automotive, marine, chemical, electrical and construction applications, mainly due to the ease of processing and composite manufacture, higher thermal stability, and chemical resistance. The construction applications involve construction of roads and bridges. Unsaturated polyester resins with styrene crosslinking agents are widely used, with applications in sanitation and in naval industries as composite matrix materials. The resistance of vinyl ester resins to degradation by corrosive and hostile environments has led to their use in many applications, such as in swimming pools, sewer pipes and solvent storage tanks. Epoxy resins, due to their excellent mechanical properties, are widely used as adhesives for bonding applications, including many in the construction, electronic packaging, aerospace, aircraft and automotive applications.

In all these and other applications modeling of the moisture transport can be of crucial importance to both a better understanding of the process or even the design of new polymer-based barrier films. 


\section{CHAPTER 2}

\section{LITERATURE REVIEW}

This chapter gives a brief review of the polymers used as matrix materials in composites, the mechanism of mass transport in polymeric membranes, classification of the diffusion process and features of various diffusion processes. It also presents highlights of work done by various researchers on moisture diffusion through neat resins, composites and polymer layered silicate nanocomposites both with and without stress. It gives details of theoretical models describing the processes of diffusion and various factors affecting the mass transport process.

The knowledge of the performance of polymer layered silicate nanocomposites under different environmental conditions such as moisture, elevated temperatures and external stress has been of intense interest to scientists and engineers due to applications such as construction of roads and bridges, aerospace and other high performance applications. The mass transport process, however, is complex and so far no single theoretical framework or mathematical model has been able to explain the correct microscopic description of the phenomenon. In order to be transported through bulk polymers, small molecules must first be absorbed on the surface of the polymeric material. The dissolved molecules then diffuse through the polymer. Finally, the small molecules desorb on the other surface of the polymer.

\subsection{The Polymer Matrix}

Before looking at the mechanism of mass transport through membranes it is necessary to consider some features of the two principal microstructural conditions of polymeric materials, the glassy and rubbery state. It has been known for a long time that the mechanism of diffusion is very different in rubbery and glassy polymers. This is mainly due to the fact that glassy polymers are not in a true state of equilibrium. The difference in mechanism is reflected in the significant differences observed in the dependence of the diffusion coefficient, as well as the permeability and solubility coefficients, on the penetrant gas pressure or concentration in polymers and on the 
temperature (Stastna and De Kee, 1995). For example, the diffusion coefficients for light gases in rubbery polymers are often independent of concentration. By contrast, in glassy polymers the diffusion coefficients can be highly nonlinear functions of penetrant concentration and reach a constant value only at sufficiently high concentration. At temperatures below the glass transition temperature the polymer is in its glassy state and is hard and may be brittle, which is directly related to the restricted chain mobility. The intermolecular forces between the chains do not allow movements other than vibrations. Depending on the conditions during the formation of the glassy state (for example, the temperature gradient) the polymer is more or less trapped in a non-equilibrium state. In glassy polymers the penetrant diffusion is low but size selectivity is very good. Above the glass transition temperature the polymer is in its rubbery state. In this state the polymers are generally tough and flexible; this is associated with freer chain motion. Rubbery polymers have very short relaxation times (compared to glassy polymers) and respond very rapidly to external stresses. Thus a change in temperature causes an "immediate" adjustment to the new equilibrium state. A similar immediate adjustment occurs when small penetrants are absorbed in a rubbery polymer. Larger segments of the polymer are thought to participate in the penetrant diffusion process due to internal chain motions such as chain rotations, translations and stronger vibrational motions. The penetrant diffusion is much faster in a rubbery polymer than in a glassy polymer but size selectivity is lower. In both the glassy and rubbery states the polymer properties can be further modified by the presence of crystalline phases, by stress induced orientations or as a function of cross-link density. They tend to place additional constraints on the mobility of the amorphous phase through which diffusion takes place (It is partly because of these possible variations in polymer properties that there is such a wide range in experimental values of mass transport coefficients).

The basic equations governing the mass transport of one component through another component are described by Fick's laws. Fick's first law describes the flux to be linear with the concentration gradient and the proportionality constant is known as the diffusion coefficient. Fick's second law relates the concentration gradient with the change in the flux. The mass transport process that satisfies Fick's laws is called Fickian diffusion process (Case I). This kind of diffusion process has been modeled and solved 
systematically (Crank and Park, 1968 and Crank, 1975).

Diffusion in polymers occurs by the transport of a penetrant via random molecular motion. In glassy polymers the diffusion process can be classified as follows (Alfrey et al., 1966 and Crank, 1968):

I. Case I- Fickian diffusion: the rate of diffusion of the penetrant is much smaller than the rate of the relaxation processes (polymer segment mobility).

II. Case II- the diffusion is much greater than the rate of the relaxation processes (polymer segment mobility).

III. Non-Fickian (anomalous) diffusion: the rates of diffusion and relaxation are comparable.

These different cases are usually differentiated by the shape of the sorption curves $\left(\mathrm{M}_{\mathrm{t}} / \mathrm{M}_{\infty}=\mathrm{Kt}^{\alpha}\right)$ [Frisch et al., 1980]. $\mathrm{M}_{\mathrm{t}}$ represents the mass of diffusant sorbed at time $\mathrm{t}$, and $\mathrm{M}_{\infty}$ refers to the mass sorbed by the polymer at equilibrium. For Fickian diffusion, $\alpha$ $=1 / 2$, for non-Fickian systems, $\alpha=1$ and the diffusion process is considered to be anomalous for $\alpha \in(1 / 2,1)$.

When Fick's first law is used in a mass balance, one obtains Fick's second law, whose

one-dimensional form is

$$
\frac{\partial c}{\partial t}=D \frac{\partial^{2} c}{\partial x^{2}}
$$

in which, $\mathrm{c}$ is the concentration of the diffusing species (in this case water), $\mathrm{t}$ is time, $\mathrm{x}$ is the position in the diffusing direction and D is the diffusion coefficient. Here D is taken to be a constant, but its value can depend on temperature and concentration of the diffusing species; it usually increases with increasing temperature.

When a dry sheet of polymer of uniform thickness $(2 l)$ is exposed to moisture, the sample mass increases due to water uptake and using appropriate boundary conditions for diffusion into a semi-infinite film exposed to an infinite bath of penetrant, Equation [2.1] can be solved to obtain moisture uptake (or mass gain) $M_{t}$ to be

$$
\frac{\mathrm{M}_{t}}{\mathrm{M}_{\infty}}=\left[1-\sum \frac{8}{(2 n+1)^{2} \pi^{2}} \exp \left[\frac{-D(2 n+1)^{2} \pi^{2} t}{4 l^{2}}\right]\right]
$$

where $M_{\infty}$ is the equilibrium increase in sample mass and $2 l$ is the sample thickness. 
The corresponding solution of Fick's Law at short times is

$$
\frac{\mathrm{M}_{t}}{\mathrm{M}_{\infty}}=2\left(\frac{D t}{l^{2}}\right)^{1 / 2}\left\{\pi^{-1 / 2}+2 \sum_{0}^{\infty}(-1)^{n} \operatorname{ierfc} \frac{n l}{\sqrt{(D t)}}\right\}
$$

The diffusion coefficient can be calculated by simplifying the above equation (Crank, 1975). For Dt $/ 2 l^{2}<0.05$, the above equation can be approximated to (Singh et al., 1991 for example)

$$
\frac{\mathrm{M}_{t}}{\mathrm{M}_{\infty}}=4\left(\frac{D t}{\pi(2 l)^{2}}\right)^{1 / 2}
$$

The diffusion coefficient can now be calculated from the initial slope of $\mathrm{M}_{t} / \mathrm{M}_{\infty}$ $\mathrm{Vs} \mathrm{t}^{1 / 2} / 2 l$ plot. Alternately, the diffusion coefficient can be determined from (Crank, 1975) $D=\frac{0.049}{\left(t / 4 l^{2}\right)_{1 / 2}}$

where $\left(\mathrm{t} / 4 l^{2}\right)_{1 / 2}$ is the value at $\mathrm{M}_{\mathrm{t}} / \mathrm{M}_{\infty}=0.5$.

In the case of desorption (during the final stages), the equivalent form of Equation [2.3] is given by the following (Crank, 1975)

$$
\frac{d}{d t}\left\{\ln \left[\mathrm{M}_{t}-\mathrm{M}_{\infty}\right]\right\}=-\frac{\pi^{2} D}{(2 l)^{2}}
$$

and a plot of $\ln \left[\mathrm{M}_{t}-\mathrm{M}_{\infty}\right]$ versus time should approach a straight line, whose slope is given by the right hand side of Equation [2.6].

Gravimetric sorption involves exposing the specimen to a penetrant and monitoring the change in specimen mass with time. For liquid uptake experiments, a "blot-and-weigh" technique is often used. Mass uptake is referenced to the original mass of the specimen and is calculated by

$$
\mathrm{M}=\frac{\mathrm{M}_{t}}{\mathrm{M}_{0}} \times 100
$$

$$
\begin{aligned}
& \text { Where } M=\text { Moisture Content }(\%) \\
& M_{t}=\text { Mass uptake of water at time } t \\
& M_{0}=\text { Dry weight of the sample }
\end{aligned}
$$




\subsection{Mechanism of Diffusion of Water through Polymers and Polymer Nanocomposites}

Diffusion of water through polymers may take place due to absorption and adsorption (Chin et al., 1999). Absorption is a capillary uptake of water by existing pores in the material and this process does not plasticize the matrix and generates little heat or swelling. Adsorption, on the other hand, is the process by which a solution is formed and generates heat (in the form of heat of solution) and results in swelling, as observed when a polymer is immersed in an organic solvent. In such a case, the term uptake or sorption should be used. Adsorption of water molecules takes place on the surface of the polymer, followed by the penetration of water into the polymer due to random molecular motion. For a polymer free of pores or voids, the process of water uptake is mainly due to adsorption. However in reality, no polymer is free of voids or pores, hence both adsorption and absorption take place simultaneously. Thus the entire process of water uptake is termed as a sorption process.

Moisture transport in polymers is related to molecular-sized holes (nanovoids) within the polymer matrix and to the polymer matrix-water affinity. There are two states of water in the water-absorbed epoxy system. The unbounded free water, filling the nanovoids, doesn't cause swelling. Hydrogen-bonded water, on the other hand, causes swelling of the polymer. Another study of moisture diffusion in plastic packaging by Cai et al. (2002) revealed that the water molecules inside the plastic materials were chemically bonded with polymers by hydrogen bonds in the microholes formed by the polymer-molecule chain. The amount of volume change due to moisture-induced swelling is significantly less than the volume of moisture absorbed, indicating that a large portion of absorbed water resides in the nanovoids. It is well accepted that the polarity of polymers affects the diffusion of water. However, it has not been established to what extent the topology has a significant effect on the moisture diffusion. The traditional theory suggests that the free volume affects the moisture absorption. However, studies have found no correlation between the topology (nanovoids size and total volume of nanovoids) and the moisture transport. Polar sites act as the bottleneck for transport through nanopores; the rate of formation and breakage of internal hydrogen bonds dictates the rate of the moisture transport. Furthermore, water in the nanopores may form 
hydrogen bonds with polymer chains and water transport is reduced. So far, the mobility of water in a polymer matrix and how absorbed water affects the mobility of polymer chains at temperature below and above $\mathrm{T}_{\mathrm{g}}$ are not well known. The solvent absorption in any appreciable amount into polymeric films gives rise to a certain degree of swelling in the structure, which strongly influences the proportion between the amorphous and crystal phases of films (Junya, 2001). The presence of crystallites in a polymer reduces the effective cross-sectional area for diffusion and increase the effective path length. This may also result in restraints being imposed on the amorphous phase (Crank and Park, 1968).

Shah (2002) and Rana (2003) conducted moisture sorption experiments on vinyl ester nanocomposites and found significant improvement in the mechanical properties and reduction in diffusivities with increasing clay loading. The exfoliated clay particles improve barrier properties by physically impeding the movement of the penetrant molecules through the matrix. This mechanism is termed as "Tortuous Path" impedance. The clay platelets orient themselves in layers as shown in the schematic representation in Figure 2. Since the nanoparticles are dispersed through out the resin, the effective path of the diffusing molecule is longer, leading to a decrease in the diffusion coefficient and permeability. The addition of clay also showed an effect opposite to the above explained diffusion behavior as far as diffusivity through nanocomposites is concerned. Becker et al. (2004) have investigated the effect of nanoclay on the water uptake properties and thermal stability of high performance epoxy nanocomposites. Water sorption measurements showed an increase in diffusivity values with clay addition. The results also showed that the equilibrium water uptake of all nanocomposites was reduced when compared to neat epoxy system. 


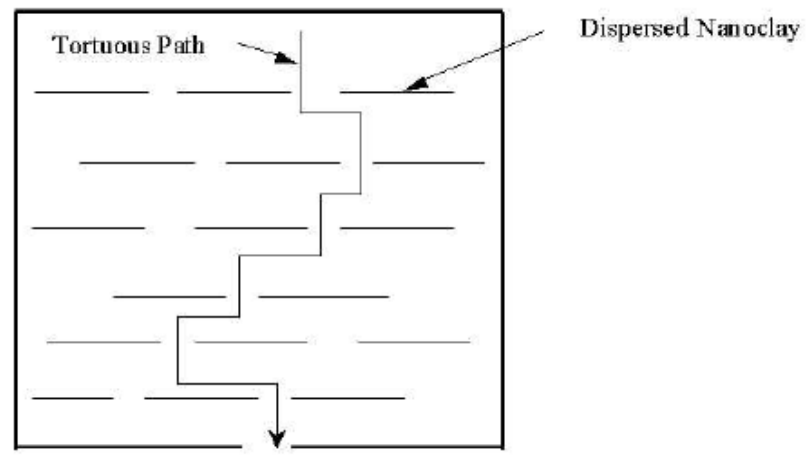

Figure 2 Schematic of the flow of a penetrant through a nanocomposite (Yano et al., 1993) 2.3 Stress Assisted Moisture Diffusion through Neat Resins, Composites and Polymer Layered Silicate Nanocomposites

Marom and Broutman (1981) studied the moisture penetration into composites under external stress. It was concluded that external stressing of composites results in increasing their rate of moisture absorption, their maximum moisture content and the diffusion coefficients. The results also indicate that the exposure of the composites to water produces a typical damage mechanism which enhances moisture take-up. Similar phenomenon was observed by Henson (1986) and Chipalkatti (1989).

Henson (1986) conducted moisture sorption and desorption experiments on neat epoxy and graphite epoxy under stress and concluded that both initial rate of diffusion and maximum moisture content increased in the presence of external stress. It was also proved that elastic strain, viscoelastic creep, and hygrothermal swelling generated during absorption in stressed coupons contributed significantly to the total deformation. Inspection of coupons under load revealed that an external stress increased both the crack density and the crack size, which might have accounted for the increased levels of moisture content found in the stressed coupons.

Chipalkatti (1989) investigated the stress and deformation coupled moisture transport in polymers. His results revealed that equilibrium moisture content and diffusion coefficient increased with applied stress. 


\subsection{Factors Affecting the Mass Transport Process}

\subsubsection{Temperature}

Temperature plays a very important role in the diffusion of penetrant molecules through polymeric membranes. Diffusion, like reaction rates, may be thought of as an activated process following an expression of the Arrhenius form

$\mathrm{D}=\mathrm{D}_{\mathrm{O}} \exp \left(-\mathrm{E}_{\mathrm{D}} / \mathrm{RT}\right)$

where the activation energy E depends on the polymer and size of the penetrant.

The break through time, time required for the penetrant to be detected on the opposite side of the membrane, is also dependent on the temperature according to Arrhenius form of relationship:

$\mathrm{t}_{\mathrm{b}}=\mathrm{t}_{\mathrm{O}} \exp \left(\mathrm{E}_{\mathrm{B}} / \mathrm{RT}\right)$

where $t_{b}$ and $E_{B}$ are the breakthrough time and activation energy of breakthrough time respectively. The breakthrough time is the time taken in standard tests for permeation of a chemical through a protective barrier (such as a rubber glove) to be detected.

Sorption curves for the majority of the liquids show a systematic variation with temperature; i.e., sorption generally increases with increasing temperature. The sorption, diffusion, and permeation results increase with increasing temperature, and so, Arrhenius activation parameters for diffusion $\left(E_{D}\right)$ and permeation $\left(E_{P}\right)$ have been calculated with a general equation of the following type:

$\mathrm{X}=\mathrm{X}_{\mathrm{O}} \exp \left(-\mathrm{E}_{\mathrm{X}} / \mathrm{RT}\right)$

where $\mathrm{X}$ represents $\mathrm{D}$ or $\mathrm{P}$ and $\mathrm{E}_{\mathrm{x}}$ represents $\mathrm{E}_{\mathrm{D}}$ or $\mathrm{E}_{\mathrm{P}}$; RT is the usual energy term. The energy of activation is a function of the nature and size of the permeating liquid within the polymer matrix. With increasing temperature, the segmental motion of the polymer chain also increases; this creates additional free volume and, therefore, increases liquid transport (Aminabhavi et al., 1999).

The temperature dependence of the permeation and solubility can also be expressed by the following Arrhenius types of relationships:

$\mathrm{J}=\mathrm{J}_{\mathrm{O}} \exp \left(\frac{-\mathrm{E}_{\mathrm{J}}}{\mathrm{RT}}\right)$ 
$\mathrm{S}=\mathrm{S}_{\mathrm{O}} \exp \left(\frac{-\mathrm{H}_{\mathrm{S}}}{\mathrm{RT}}\right)$

where $\mathrm{J}$ is the flux and $\mathrm{E}_{\mathrm{J}}$ is the apparent activation energy of permeation, and $\mathrm{S}$ is the solubility and $\mathrm{H}_{\mathrm{S}}$ is the heat of sorption. $\mathrm{H}_{\mathrm{S}}$ can be either positive or negative. The positive value of the heat of sorption suggests that the sorption process is endothermic, and sorption increases with increasing temperature, suggesting segmental movements of the polymer chain segments and thereby accommodating more solvent molecules at higher temperatures (Aminabhavi et al., 1999). When the sorption process is exothermic (heat of sorption is negative), the sorption decreases with increasing temperature (Chung et al., 2003). Such behavior can be explained in terms of thermodynamics by considering that the sorption of solvent molecules occurs at the liquid-polymer interface and it is generally assumed that there is a thermodynamic equilibrium at this interface. The process of sorption is a result of the equilibrium between the chemical tendency of mixing and the elasticity of the polymer network, which tends to limit the swelling. Therefore, depending upon the chemical nature of the solvent and the polymer, the sorption process could be endothermic or exothermic (Khinnavar and Aminabhavi, 1992).

\subsubsection{Nature of the Polymer}

According to the hole theory of diffusion, the rate of diffusion depends on the number and size distribution of pre-existing holes, and the ease of hole formation. The former depends on the ease and degree of packing of the chains and is related to the free volume and to the density (Hedenqvist et al., 1996). The ease of hole formation depends on the segmental chain mobility, i.e. the chain stiffness, and on the cohesive energy of the polymer. In addition, the degree of crystallinity and of crosslinking as well as additives such as fillers and plasticizers will affect the diffusion process. The dual type sorption behavior is typical of glassy polymers, appearing in polymers analyzed well below the glass-transition temperature, and it is due to localized adsorption on specific sites. Sorption is visualized as a process in which there are dual modes: either the penetrant molecules are normally dissolved and free to diffuse, or they are immobilized on particular sites of the polymeric matrix. In the case of organo layered silicates, in the absence of the polymeric matrix, we must assume that the dual behavior is due to adsorption on specific sites (Giuliana et al., 2003). It has been shown that the sorption 
and diffusion coefficients in the crystalline phase are substantially smaller than in the glassy or rubbery phases. As a result, it is generally assumed that the crystalline phase doesn't sorb, and hence, doesn't allow any penetrant to diffuse through it. In this case D depends on the volume fraction of the amorphous phase, $\alpha$, the tortuosity of penetrant path, $\tau$ and the "blocking factor", $\mathrm{B}_{1}$ :

$\mathrm{D}=\mathrm{D}_{\mathrm{a}} \alpha \mathrm{n} / \mathrm{B}_{1} \tau$

where $\mathrm{D}_{\mathrm{a}}$ is the diffusion coefficient in a hypothetical, completely amorphous polymer, and n, approximately equal to 1 , is an empirical parameter, dependent on the nature of the penetrant molecule (Chung et al., 2003). Hedenqvist et al. (2000) have studied the transport properties of hyperbranched and dendrimer-like star polymers and the results obtained confirmed that the transport properties were primarily controlled by the hydroxyl group concentration.

\subsubsection{Nature of the Penetrant}

Permeation through polymer membranes can occur from both the gas and the liquid phase. In gas permeation diffusion coefficients are independent of penetrant concentration in the membrane in contrast to vapor or liquid permeation. In latter case, membrane may be highly swollen by a penetrating liquid. This opens up the structures with the result that the absolute flux rates through the membrane can be 2 or 3 orders of magnitude larger than for a (noncondensible) gas. Thus in vapor or liquid permeation the diffusion coefficients are strong (typically exponential) functions of concentration.

If the available free volume spaces between polymer segments are bigger than the solvent molecule, then the liquid entering into these spaces may not cause significant change in volume. On the other hand, when the solvent molecules do not enter into the already available free volume, then the polymer segments tend to relax and thereby contribute toward swelling. In the absence of any such interactions between the polymer segments and solvent molecules at any time $t$, the mass uptake by the geomembrane may not be equivalent to the corresponding volume gain (Aminabhavi et al., 1999).

\subsubsection{Mechanical Deformation}

The effect of elongation depends on the nature and size of the penetrants, the barrier material, and, in addition, the magnitude and direction of the extension. Barrie and Platt (1961) investigated the diffusion of hydrocarbons into rubber cross linked with 
dicumyl peroxide and found that for an extension of up to $70 \%$, no significant change in solubility and diffusivity was observed. At higher extensions, the permeability decreased with increasing extension. Several authors have observed that if the extension is less than a critical value, the effect of the extension on permeability is negligible. A decrease in permeability followed by an increase as the extension increases has also been reported (Liu et al., 2004). Wolf and Fu (1996) observed an increase in diffusion when the applied stress was above a critical value. Henson (1986) studied the stress effects on moisture transport in an epoxy resin and its composite. His results show that the maximum moisture content increases roughly with stress for the composite coupons, but grows nonlinearly for the epoxy samples. Also, the diffusivity values increase with increasing stress level for both epoxy and composite coupons. The interaction between stress and moisture in epoxy can be attributed to the time dependent response of the resin and that in composite are apparently due mainly to damage.

\subsubsection{Cyclical Aging}

The issue of moisture ingress into polymer nanocomposites is of utmost concern. The time-scale of moisture diffusion is much slower than heat transfer, but the effects can be more dramatic. Absorbed moisture causes plasticization of the polymer matrix and reduces the glass transition temperature of the resin. This results in changes in modulus, strength, and strain to failure and fracture toughness. These effects may be reversible, but the swelling stresses induced by moisture uptake can cause permanent damage such as matrix cracking, hydrolysis etc. The effect of moisture on polymer nanocomposites has been extensively studied, but the focus has been on the effect of a single cyclic absorption process. The cyclical aging might introduce an additional damage into the composite system.

Garcia et al. (1998) have studied the effects of cyclic moisture aging on a glass/vinyl ester composite system and found that the material properties are reduced significantly after the first conditioning cycle, but damage does not continue to accumulate with exposure time. The initial damage is not recovered when the material is allowed to return to its initial moisture content, suggesting that there is permanent damage to the matrix or fiber and plasticization of the matrix material. Lee and Rockett (1992) found that in unsaturated polyester, vinyl ester and acrylic resins, the diffusion 
coefficient, D, calculated for absorption was much higher than that for desorption and reabsorption. Grinsted et al. (1992) performed experiments on poly-(methyl methacrylate) exposed to methanol and reported that the diffusivity increased with the number of cycles. Martin and Garcia (2000) studied the effect of water exposure cycles on particle-filled epoxy-based adhesives. Their results showed a marked increase in saturation level between absorption and reabsorption. This could be attributed to the re-development of hydrogen bonds, created between filler and resin, during reabsorption. The results of their work showed a depression in glass transition temperature with the number of cycles which is dependent on the moisture contained in the apparent free volume. Mauri et al. (1978) have determined moisture sorption and desorption in a number of graphitereinforced epoxy and high temperature resistant polymer composites at different conditions of humidity and temperature. They observed that the sorption and desorption rates were roughly equivalent and the diffusion coefficients were independent of the relative humidity. They also found an increase of diffusivities with subsequent resorption cycles and this was thought to be due to microstructural damage. Chipalkatti (1989) studied the stress and deformation coupled cyclic moisture sorption-desorption in polymers (Nylon 6, 6 and Polycarbonate). His results revealed that equilibrium moisture content increased with applied stress and rose over repeated cycles of sorption-desorption. The diffusion coefficient was observed to increase with applied stress but decreased with time through repeated cycles. It was established that the effect of hysteresis and the effect of repeated cycles was largely thermo-reversible in the materials studied.

\subsection{Models Describing the Phenomenon of Diffusion in Composites}

A common model (Maxwell, 1881) describes the diffusion coefficient D of a small solute through a continuum partly filled with a suspension of impermeable spheres

$$
\mathrm{D} / \mathrm{D}_{\mathrm{O}}=\frac{1-\varphi}{1+\frac{\varphi}{2}}
$$

where $D_{o}$ is the diffusion coefficient in the absence of the spheres and $\varphi$ is the "loading," that is, the volume fraction of the spheres. This is a small effect: if $\varphi$ equals 0.1 , the diffusion drops about $15 \%$.

According to Cussler et al. (1988), diffusion through polymers is described as the 
diffusion of small solute molecules through a continuum partly filled with a periodic suspension of impermeable flakes. They used Monte Carlo calculations of diffusion across membranes containing impermeable flakes to show the effects of tortuous paths around the flakes, of diffusion through slits between flakes, and of constricted transport from entering these slits. The flakes are so arranged that the diffusion is essentially twodimensional. This diffusion depends strongly on the orientation of the flakes. If the flakes are all oriented parallel to the direction of the diffusion, the result is approximately

$\frac{\mathrm{D}}{\mathrm{D}_{\mathrm{O}}}=\frac{1-\varphi}{1+\varphi}$

For a membrane containing impermeable flakes oriented perpendicular to the diffusion, the simplest limit is

$$
\frac{\mathrm{D}}{\mathrm{D}_{\mathrm{O}}}=1+\left(\frac{\alpha^{2} \varphi^{2}}{1-\varphi}\right)
$$

Here $\varphi$ is the volume fraction of the flakes and $\alpha$ is the aspect ratio, half the second longest dimension of the flakes divided by the shortest dimension (Eitzman, 1996; Carter and Kibler, 1978). 


\title{
CHAPTER 3
}

\section{EXPERIMENTAL PROCEDURE AND METHODS OF CALCULATION}

\begin{abstract}
The purpose of the experimental phase of this investigation was to study the effect of clay addition on repeated cycles of sorption and desorption in the absence of stress and on stress coupled moisture sorption in polymers. Specimens were monitored for moisture absorption and desorption, mechanical deformation, material property changes and damage accumulation. This chapter includes materials used in this study, chemistry of resins used, sample preparation, characterization methods, experimental set up for each type of experiment and methods of data analysis.
\end{abstract}

\subsection{Materials}

Commercial vinyl ester, polyester and epoxy were used in this study. All three matrices are thermosets suitable for fabricating FRP composites through pultrusion and resin transfer molding processes. Hetron 922 vinyl ester and AROPOL 2036 C polyester were obtained from Ashland Chemicals. Both the vinyl ester and polyester resins were dissolved in styrene. The epoxy used was Tyfo S Saturant Epoxy consisting of two components A and B obtained from FYFE Company LLC. Part A was epoxy resin, which is a modified bisphenol-A polyglycidyl ether and Part B was hardener, which is a modified polyamine. Nanocomposites were made using Cloisite $10 \mathrm{~A}^{\circledR}$ clay obtained from Southern Clay Products.

Methyl ethyl ketone peroxide (9\% active oxygen) was used as an initiator and 6\% cobalt naphthenate was used as promoter in the preparation of vinyl ester and polyester samples. In case of polyester sample preparation, the reaction between initiator and promoter is very fast and hence an inhibitor was added to increase the gel time and to inhibit the resin from curing very quickly. 10\% Hydroquinone in methanol was used as an inhibitor. All the chemicals were obtained from Sigma Aldrich Company.

\subsection{Sample Preparation}

Samples of neat vinyl ester were prepared by mixing together resin, catalyst and promoter in the quantities mentioned in Table 1, and then pouring the mixture into a 
Teflon mold. The Teflon molds used are as shown in Figure 3. A similar procedure was followed for polyester except that inhibitor was added in addition to catalyst and promoter in case of polyester samples. To prevent oxygen inhibition of the free radical cross linking reaction and also to minimize styrene evaporation, the Teflon mold was sealed using another Teflon sheet. Typical dimensions of the samples used for sorption experiments were $5 \mathrm{~cm} \times 1.25 \mathrm{~cm}$ and thicknesses varied between $0.07 \mathrm{~cm}$ and $0.1 \mathrm{~cm}$. The cured samples are as shown in Figure 4. The resin was allowed to cure at room temperature for 24 hours and the samples were post cured for 3 hours in an oven maintained at $95{ }^{\circ} \mathrm{C}$. Samples of neat epoxy were prepared by mixing 100 parts of component A by weight with 34.5 parts of component B by weight for about an hour to assure complete homogeneity of the mixture. The mixture was then poured into Teflon molds, cured for 24 hours at room temperature and post cured for 24 hours at $60^{\circ} \mathrm{C}$.

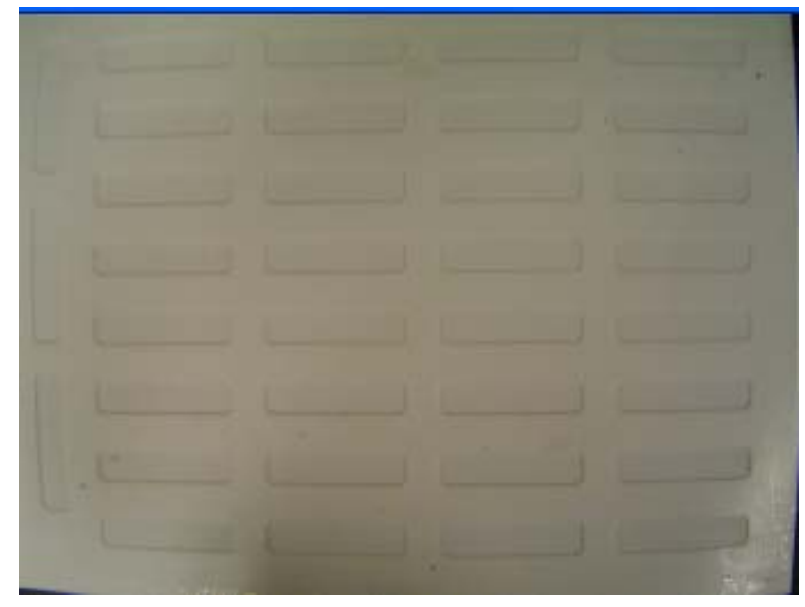

Figure 3 Teflon mold used to cast the samples

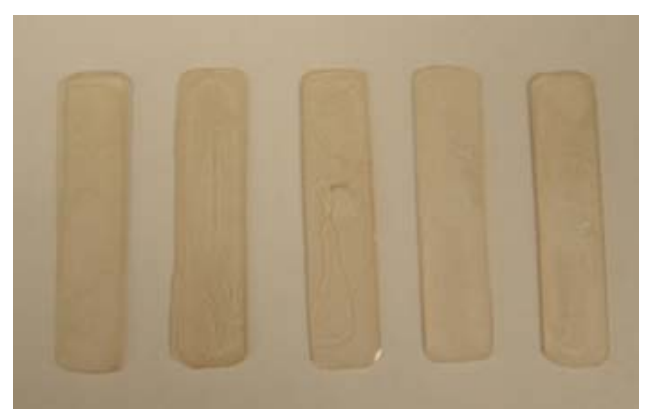

Figure 4 Cured neat vinyl ester samples 
Table 1. Table showing catalyst, promoter, inhibitor quantities, curing temperature and post curing temperature used for different resins used in the study

\begin{tabular}{|c|c|c|c|c|c|c|c|}
\hline \multirow[t]{2}{*}{ Resin } & \multirow{2}{*}{$\begin{array}{c}\text { Catalyst } \\
\text { (wt \%) }\end{array}$} & \multirow{2}{*}{$\begin{array}{c}\text { Promoter } \\
(\mathrm{wt} \%)\end{array}$} & \multirow{2}{*}{$\begin{array}{c}\text { Inhibitor } \\
\text { (wt \%) }\end{array}$} & \multicolumn{2}{|c|}{ Curing } & \multicolumn{2}{|c|}{ Post curing } \\
\hline & & & & Time(hrs) & $\operatorname{Temp}\left({ }^{\circ} \mathrm{C}\right)$ & Time(hrs) & $\operatorname{Temp}\left({ }^{\circ} \mathrm{C}\right)$ \\
\hline $\begin{array}{l}\text { Vinyl } \\
\text { ester }\end{array}$ & 1.25 & 0.3 & - & 24 & 25 & 3 & 95 \\
\hline Polyester & 1.25 & 0.15 & 0.3 & 24 & 25 & 3 & 75 \\
\hline Epoxy & - & - & - & 24 & 25 & 24 & 60 \\
\hline
\end{tabular}

Nanocomposite samples for the diffusion experiments were prepared by mixing different weight percentages of Cloisite $10 \mathrm{~A}^{\circledR}$ with resin in a sonicator (for about 20-30 minutes) until the mixture was completely homogenized. The mixture was then degased in a vacuum chamber to make sure that all the gas bubbles were completely removed and then promoter, initiator and inhibitor were added to the mixture in quantities mentioned in Table 1 and stirred for about 10 minutes. The mixture was then poured into Teflon molds, cured for 24 hours at room temperature and then post cured.

Vinyl ester samples for diffusion experiments under stress were prepared in a similar manner as mentioned above and holes of $0.7 \mathrm{~mm}$ diameter were drilled at the two ends of the samples.

\subsection{Characterization Methods}

\subsubsection{X-Ray Diffraction}

X-ray diffraction was used to determine the basal spacing of the montmorillonite clay. These tests were performed on both clay and clay-polymer nanocomposites. The samples were prepared in a manner similar to those prepared for sorption experiments 
and were molded to disc shape with $40 \mathrm{~mm}$ diameter and $3-5 \mathrm{~mm}$ thickness. The tests were conducted using PANalytical X'pert Pro PW3040-Pro X-Ray Diffractometer. The samples were scanned from $2 \theta$ of $0^{\circ}$ to $12^{\circ}$. The slit settings on the tube side were $1 / 4^{\circ}$ for scatter and $1 / 8^{\circ}$ for divergence. Intercalation of the clay by the polymer chains would lead to an increase in the basal spacing, while exfoliation would cause the peak in the XRD graph to disappear.

\subsubsection{Transmission Electron Microscopy}

Samples used for TEM analysis were prepared in a manner similar to the preparation of samples for diffusion experiments. The pictures of samples and the molds used for the preparation of samples are shown in Figure 5(a). Characterization was done using JEOL 100CX Transmission Electron Microscope with an accelerating voltage of 80 $\mathrm{kV}$. Ultra thin sections of the polymer/clay nanocomposite with a thickness of approximately $65 \mathrm{~nm}$ were cut parallel to the face of the sample using an ultra microtome equipped with a diamond knife.
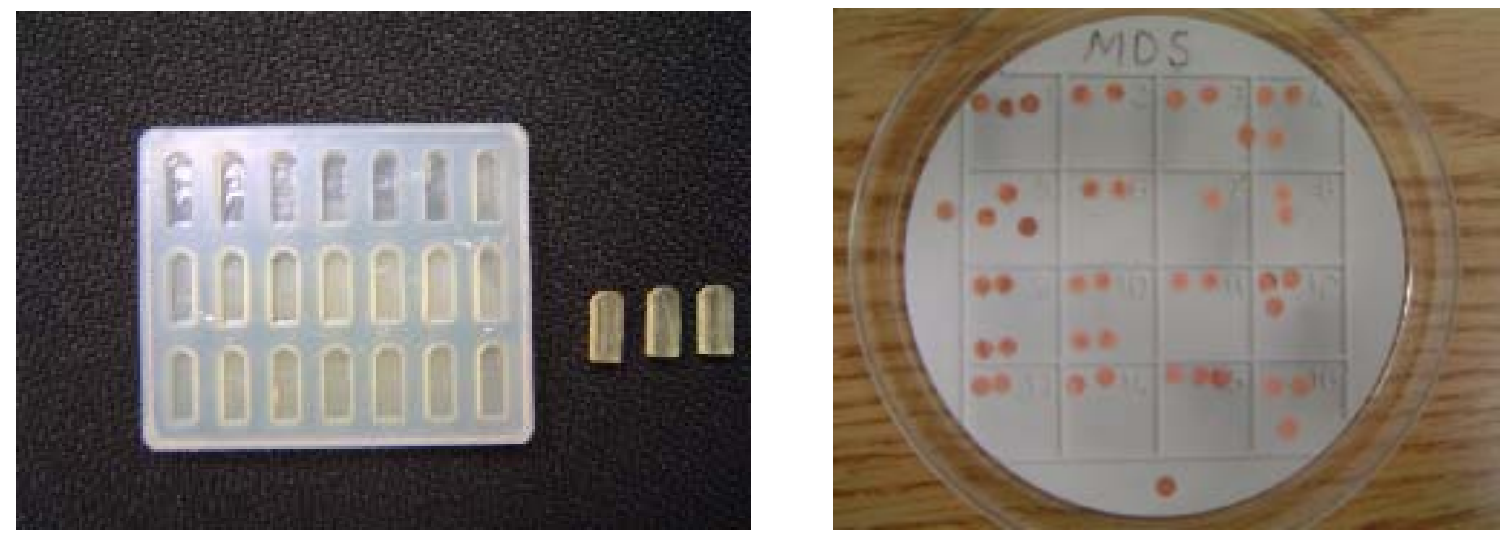

Figure 5 (a) Molds and Samples used for TEM analysis (b) Carbon coated Cu grids used in TEM analysis

A representative diagram of the sectioning is shown in Figure 6. The sections were transferred dry to carbon-coated $\mathrm{Cu}$ grids of 200 mesh shown in Figure 5(b). The contrast between the layered silicates and the polymer phase was sufficient for imaging, so heavy metal staining of sections prior to imaging was not required. The pictures obtained show the dispersion of nanoclay within the polymer. 


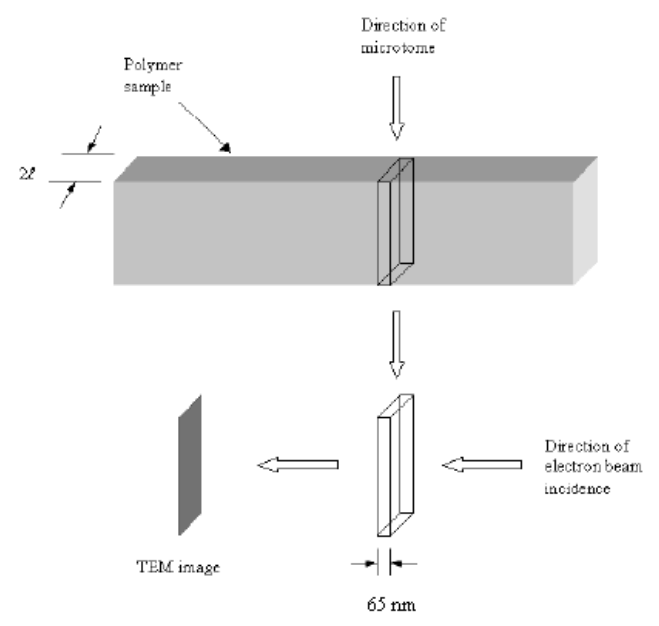

Figure 6 Schematic representation of sample microtoming for TEM analysis. Direction of electron beam incidence is the direction of view.

\subsubsection{Scanning Electron Microscopy}

Cyclical Aging could cause microcracking of the matrix and degradation of tensile stiffness and strength and changes in mode of failure. Also, it is highly likely that external stresses will enhance the accumulation of such damage and further affect stressassisted diffusion. The presence and extent of such damage was monitored using scanning electron microscopy.

Scanning electron micrographs of freshly prepared samples $(5 \mathrm{~cm} \times 1.25 \mathrm{~cm}$, thickness-(0.07-0.1) $\mathrm{cm})$ with various clay loadings were taken and recognized as "Reference" samples. Samples were examined for the presence of microcracks after each cycle of sorption-desorption and also after the stress coupled diffusion experiments. A sample to be examined was fixed to an aluminum stub using double sided graphite tape. Then the sample was kept in $400 \mathrm{~mm} \mathrm{Hg}$ vacuum for 15 minutes to ensure that there was no water inside the sample. The sample was then coated with a 30-40 nm gold layer in a sputter coater shown in Figure 7(a) to make the surface conductive. Then the sample was grounded to the aluminum tab using a copper tape shown in Figure 7(b). 

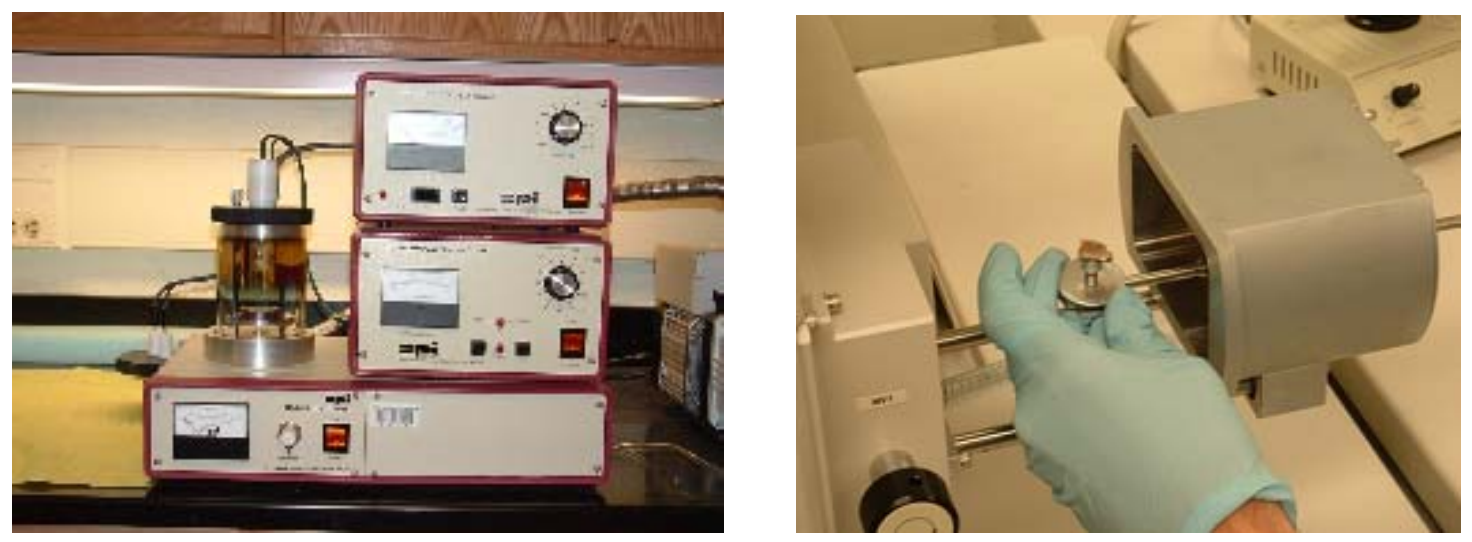

Figure 7 (a) Gold sputter coater (b) Gold coated sample grounded with copper tape

The scanning electron microscope used was Hitachi S4700 cold fielding machine

and the sputter coater was Gold-Pd SPI-MODULETM sputterer. Scanning electron micrographs of the samples obtained were compared with the micrographs of the "Reference" samples.

\subsubsection{Cyclic Sorption-Desorption Experiments}

Post-cured samples were immersed in a beaker containing distilled water at room temperature. Samples were periodically removed, blotted dry with Kimberly Clarke lintfree tissue, weighed and re-immersed in water. A Mettler electronic balance with an accuracy of $1 \mu \mathrm{g}$ was used to measure the weight of the samples. Samples were weighed after every 30 minutes for the first 3 hours after immersion, every hour for the next 12 hours, every 12 hours for the next 2 days and every day until samples are completely saturated. Each experiment was continued until there was no mass gain reported over a period of 5 days. Data obtained for at least 4 - 5 samples were used to calculate the average diffusion coefficient of the material. The diffusion coefficients and equilibrium moisture contents were calculated from the sorption curve.

The completely saturated samples were, then, kept inside a controlled humidity chamber maintained at a humidity of $20 \% \mathrm{RH}$. Temperature of the humidity chamber was found to be $25^{\circ} \mathrm{C}$ throughout the experiments. All the samples were weighed periodically to understand the desorption behavior of these samples. Here, the equilibrium was considered to have been attained when no weight loss was recorded over a period of 5 days. The above procedure was repeated for three repeated sorption-desorption cycles. Diffusion coefficients for desorption were calculated from the slope of the normalized weight- loss curves during later stages of desorption. 


\subsubsection{Equilibrium Moisture Content}

The dependence of maximum moisture content of vinyl ester samples, both neat and clay loaded, on the relative humidity of the environment was determined experimentally. The samples were allowed to reach equilibrium moisture content in an air-sealed constant humidity chamber during exposure to four different relative humidities: $40 \%, 60 \%, 70 \%$ and $80 \%$. The humidity of the chamber is varied by placing hot water in the chamber until required humidity is attained. Five samples each for all clay loadings were used for monitoring weight gain during exposures at all relative humidities. All the samples were weighed periodically until equilibrium was attained. The temperature of the chamber was at $27^{\circ} \mathrm{C}$ during these four exposures.

\subsubsection{Stress Coupled Sorption Experiments}

A stainless steel cylindrical load frame was used to apply a constant load for up to 36 specimens at a time as shown in the Figure 8. The frame consisted of twelve holes on its circumference. Twelve specimens parallel to each other were loaded and each specimen contained three samples in series linked using momentless steel wire in order to produce pure uniform uniaxial tension in all the samples. Each specimen containing three samples swiveled in series was latched to the frame using a die spring of known spring constant, nut and bolt. The load was applied on the specimens by tightening the spring. The ultimate tensile stress (UTS) of the fresh samples was determined (Rana, 2003) prior to the experiment and specimens were monitored for two different load levels of $8 \mathrm{lb}_{\mathrm{f}}$ $(17 \%$ UTS $)$ and $14 \mathrm{lb}_{\mathrm{f}}(30 \% \mathrm{UTS})$. Both neat and clay loaded samples were subjected to the same load levels. The entire load frame with samples mounted on it was then immersed in water for experiments in water and placed in a humidity chamber maintained at $60 \% \mathrm{RH}$ for experiments at $60 \% \mathrm{RH}$ shown in Figure 9. The moisture weight-gain measurements were performed by periodically removing three samples in series as explained in the previous section. Since initial weight measurements were more frequent than the later ones and to avoid periodic stress relaxations in the samples, all the samples for the initial period of 48 hours were not reloaded but kept for future characterization after weight gain measurement. Weight gain during the later stages of absorption was monitored by periodically weighing the samples and reloading them onto 
the load frame until equilibrium weight gain was attained.

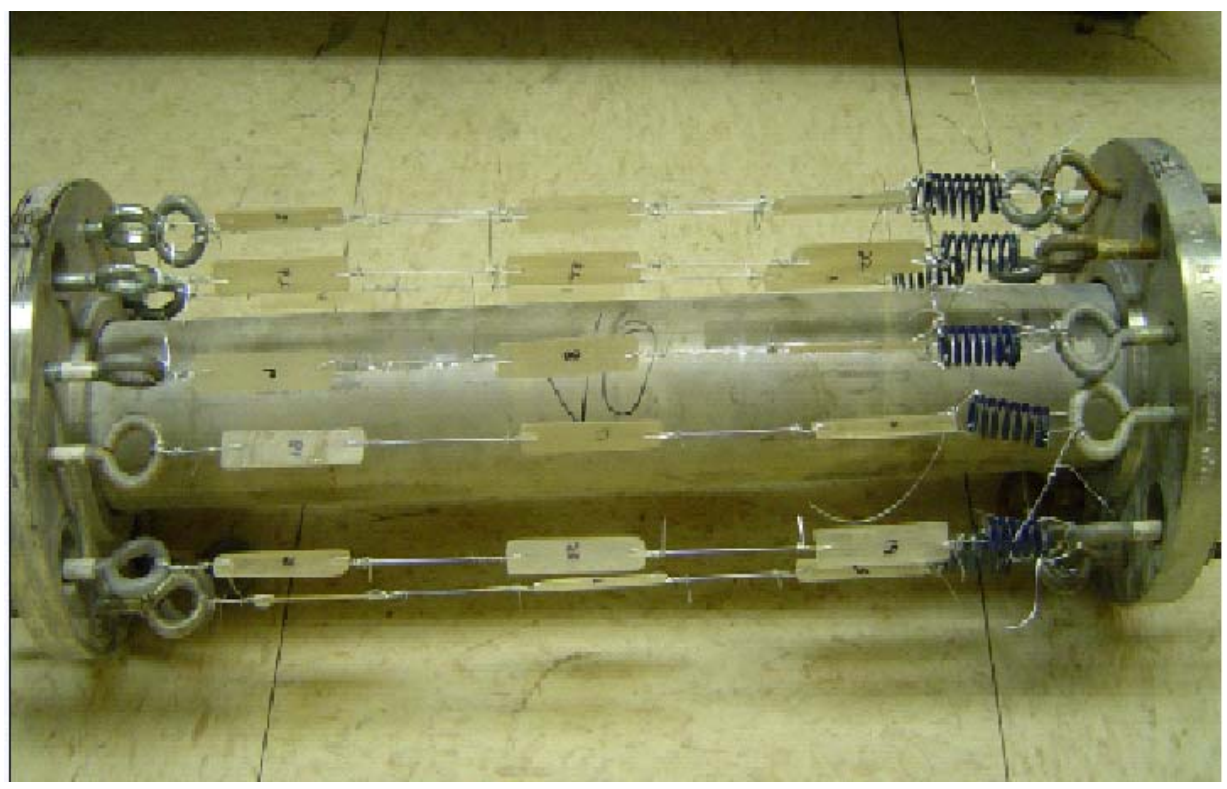

Figure 8 Assembly of the load frame loaded with samples for sorption under stress

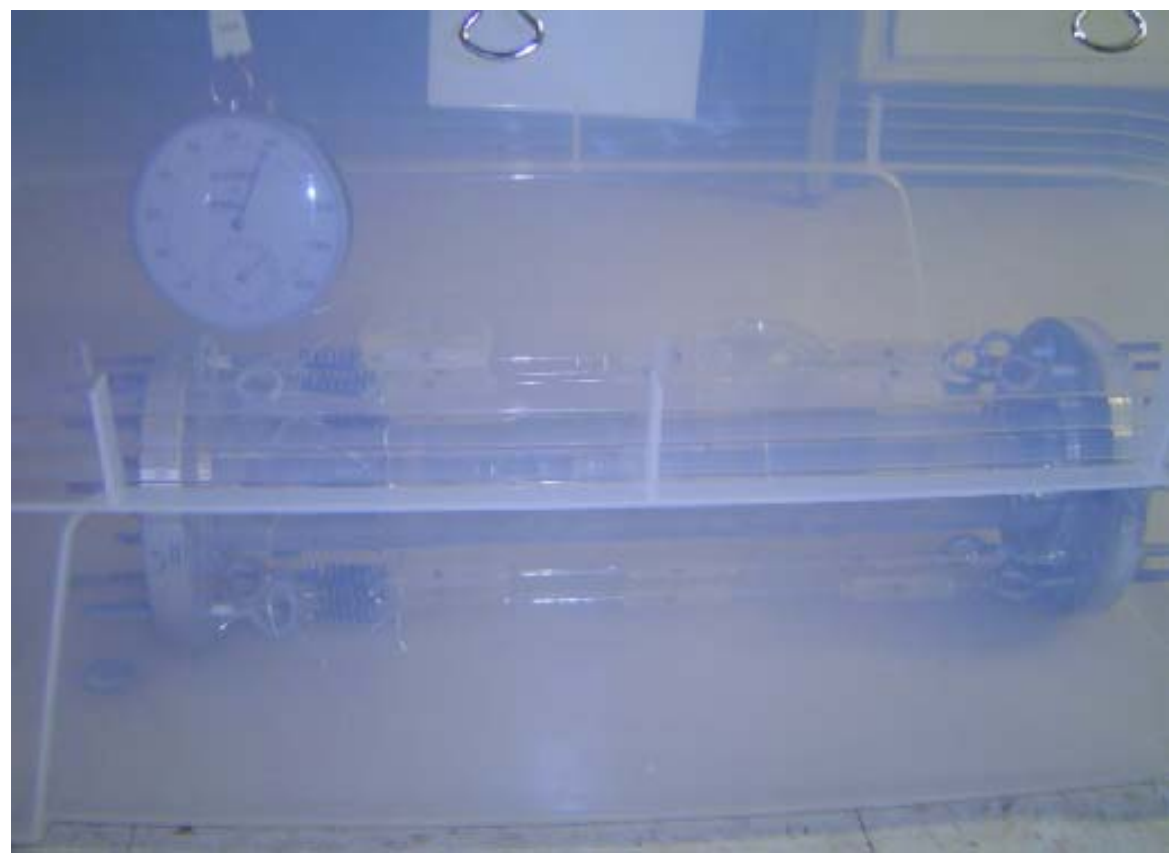

Figure 9 Experimental set up for sorption under stress at $60 \% \mathrm{RH}$ 3.4 Method of Calculation of Diffusion Coefficient in Samples During Sorption

The diffusivity for the samples was calculated using Fick's law as described in the previous chapter.

Thickness of the sample $=2 l \mathrm{~cm}$ 
Weight gain of the sample at time $\mathrm{t}=\mathrm{M}_{\mathrm{t}} \mathrm{gm}$

Weight gain of the sample at equilibrium $=\mathrm{M}_{\infty} \mathrm{gm}$

The diffusion coefficient, D can be calculated by rearranging the following Equation

$$
\frac{\mathrm{M}_{t}}{\mathrm{M}_{\infty}}=4\left(\frac{D t}{\pi(2 l)^{2}}\right)^{1 / 2}
$$

into the following equation

$$
D=\frac{\pi \times(2 l)^{2}}{16}\left(\frac{\mathrm{M}_{t} / \mathrm{M}_{\infty}}{\sqrt{t}}\right)^{2}
$$

Where $\frac{M_{t} / M_{\infty}}{\sqrt{t}}$ is the slope of the straight line from the plot of $M_{t} / M_{\infty}$ versus $V_{t}$ drawn up to $\mathrm{M}_{\mathrm{t}} / \mathrm{M}_{\infty}<0.5$ and the units of $\mathrm{D}$ are $\mathrm{cm}^{2} / \mathrm{sec}$.

\subsection{Method of Calculation of Diffusion Coefficient in Samples During Desorption}

The diffusion coefficient during desorption can be calculated by rearranging the following equation:

$$
\frac{d}{d t}\left\{\ln \left[\mathrm{M}_{t}-\mathrm{M}_{\infty}\right]\right\}=-\frac{\pi^{2} D}{(2 l)^{2}}
$$

into the following equation

$$
D=-\left(\frac{\ln \left[\mathrm{M}_{t}-\mathrm{M}_{\infty}\right]}{t}\right) \frac{(2 l)^{2}}{\pi^{2}}
$$

Where $\left(\frac{\ln \left[\mathrm{M}_{t}-\mathrm{M}_{\infty}\right]}{t}\right)$ is the slope of the straight line from the plot of $\ln \left[\mathrm{M}_{t}-\mathrm{M}_{\infty}\right]$ versus $t$ drawn during the last stages of desorption and the units of $D$ are $\mathrm{cm}^{2} / \mathrm{sec}$.

\subsection{Method of Calculation of Equilibrium Moisture Content}

The moisture content within the samples was calculated using the following equation

$$
\mathrm{M}=\frac{\mathrm{M}_{t}}{\mathrm{M}_{0}} \times 100
$$

Where $\mathrm{M}=$ Moisture Content (\%)

$\mathrm{M}_{\mathrm{t}}=$ Mass uptake of water at time $\mathrm{t}$

$\mathrm{M}_{0}=$ Dry weight of the sample 


\section{CHAPTER 4}

\section{RESULTS AND DISCUSSION}

\subsection{XRD Analysis}

Figure 10 shows XRD scan on Cloisite $10 \mathrm{~A}^{\circledR}$ and also on vinyl ester nanocomposite samples containing $0 \mathrm{wt} \%, 2 \mathrm{wt} \%$ and $5 \mathrm{wt} \%$ clay. The $\mathrm{d}$ spacing for clay can be calculated using the Bragg equation [4.1]

$2 d \sin \theta=\lambda$

where $d$ is the $\lambda$ average distance between the individual clay platelets, $\theta$ is half the diffraction angle and is the wavelength of the incident X-ray. The XRD pattern of the Cloisite $10 \mathrm{~A}^{\circledR}$ montmorillonite clay contained a strong peak at $2 \theta=4.5^{\circ}$. The interlayer distance (d-space) of clay was found to be $3.9 \mathrm{~nm}$. This value matches with the interlayer distance of the nanoclay platelets determined using TEM. Similar results were reported by Shah (2001). No strong characteristic basal reflections (peaks) were observed for nanocomposites samples. The absence of such a peak indicates either exfoliation or breakdown of ordered structure of the clay. However, when the scans were observed on different scale on separate graph shown in Figure 11, very small peaks were seen for 2 $\mathrm{wt} \%$ and $5 \mathrm{wt} \%$ Cloisite $10 \mathrm{~A}^{\circledR}$ nanocomposites too, which become insignificant when seen on a combined XRD scan shown in Figure 10. 


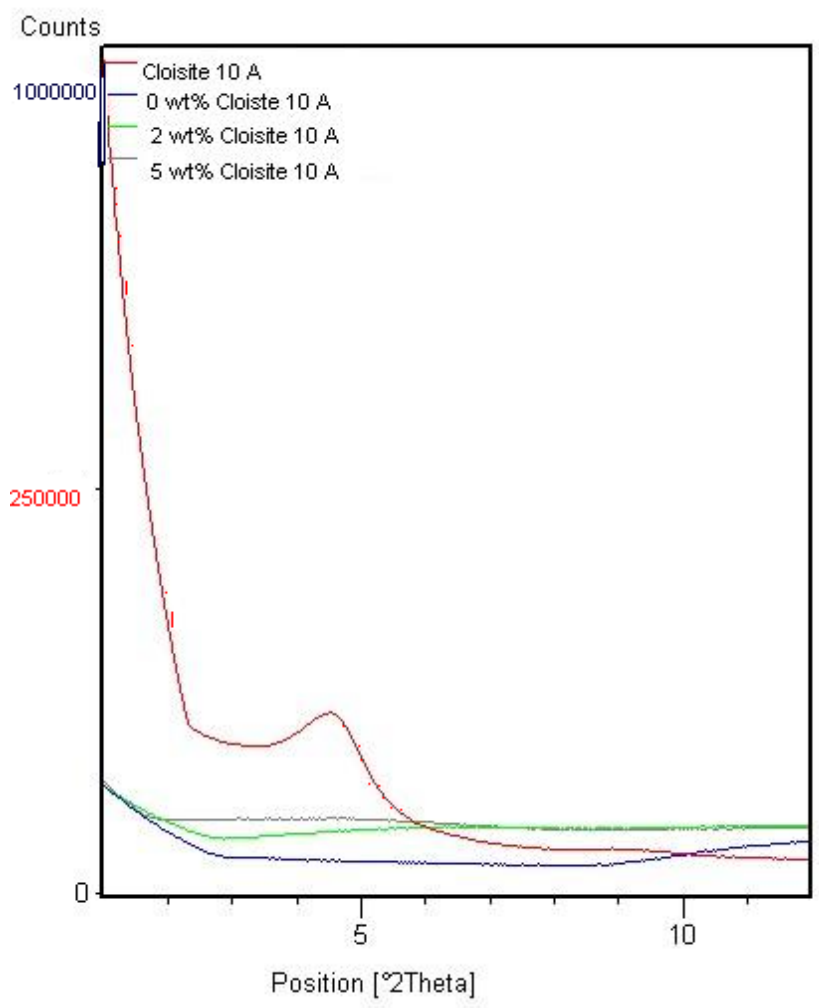

Figure 10 XRD scans on Cloisite $10 A^{\circledR}$ and vinyl ester nanocomposites

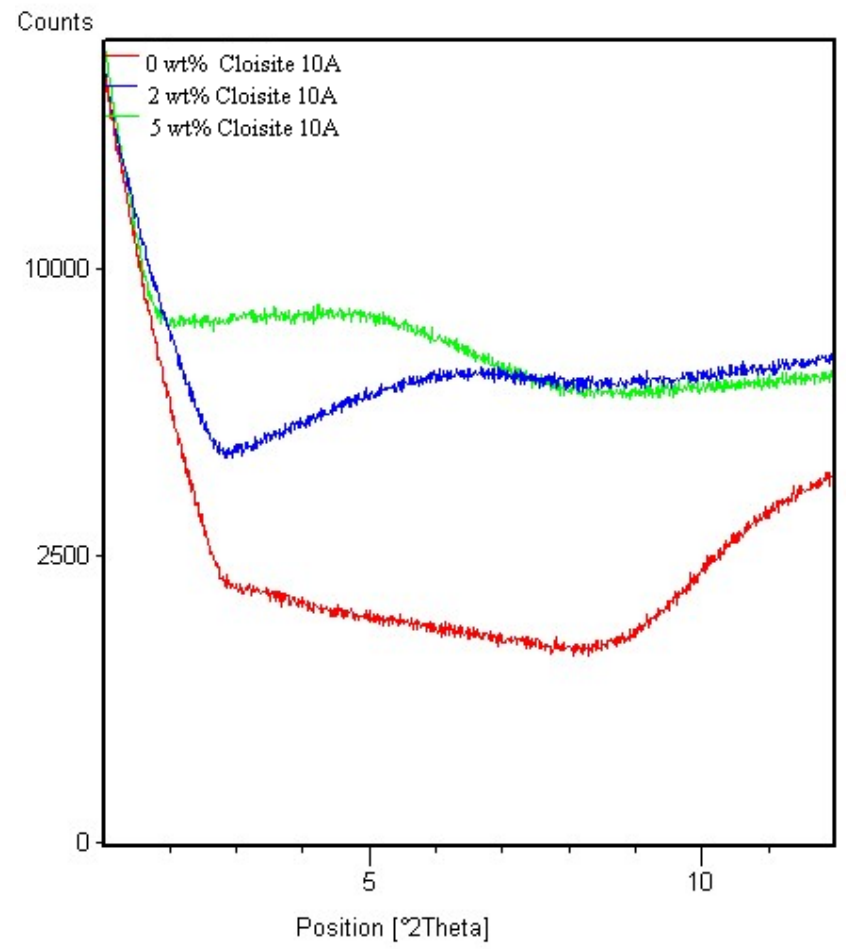

Figure 11 XRD scans on neat vinyl ester resin and vinyl ester nanocomposites 


\subsection{TEM Analysis}

Analysis of TEM images of nanocomposite samples explains morphology of the various clay loaded polymer samples. Figure 12 to Figure 16 show TEM micrographs of vinyl ester nanocomposites, Figure 17 to Figure 20 show micrographs of polyester nanocomposites and Figure 22 to Figure 24 show micrographs of epoxy nanocomposites. TEM pictures at low magnification show that the clay particles are reasonably dispersed, uniformly distributed and randomly oriented. This is shown in representative pictures of $2 \mathrm{wt} \%$ and $5 \mathrm{wt} \%$ clay loaded vinyl ester, polyester and epoxy nanocomposites in Figure 12, Figure 13, Figure 14, Figure 17, Figure 18 and Figure 22. At higher magnifications of $>100,000 x$, it was found that the clay particles existed both as clusters or aggregates and as individual platelets in the form of dark lines, as shown in Figure 15, Figure 16, Figure 19, Figure 20, Figure 21, Figure 23 and Figure 24. The aggregates consisted of about 2 to 20 expanded silicate sheets and the distance between the individual platelets in these aggregates was found to be in the range of $3-4 \mathrm{~nm}$.

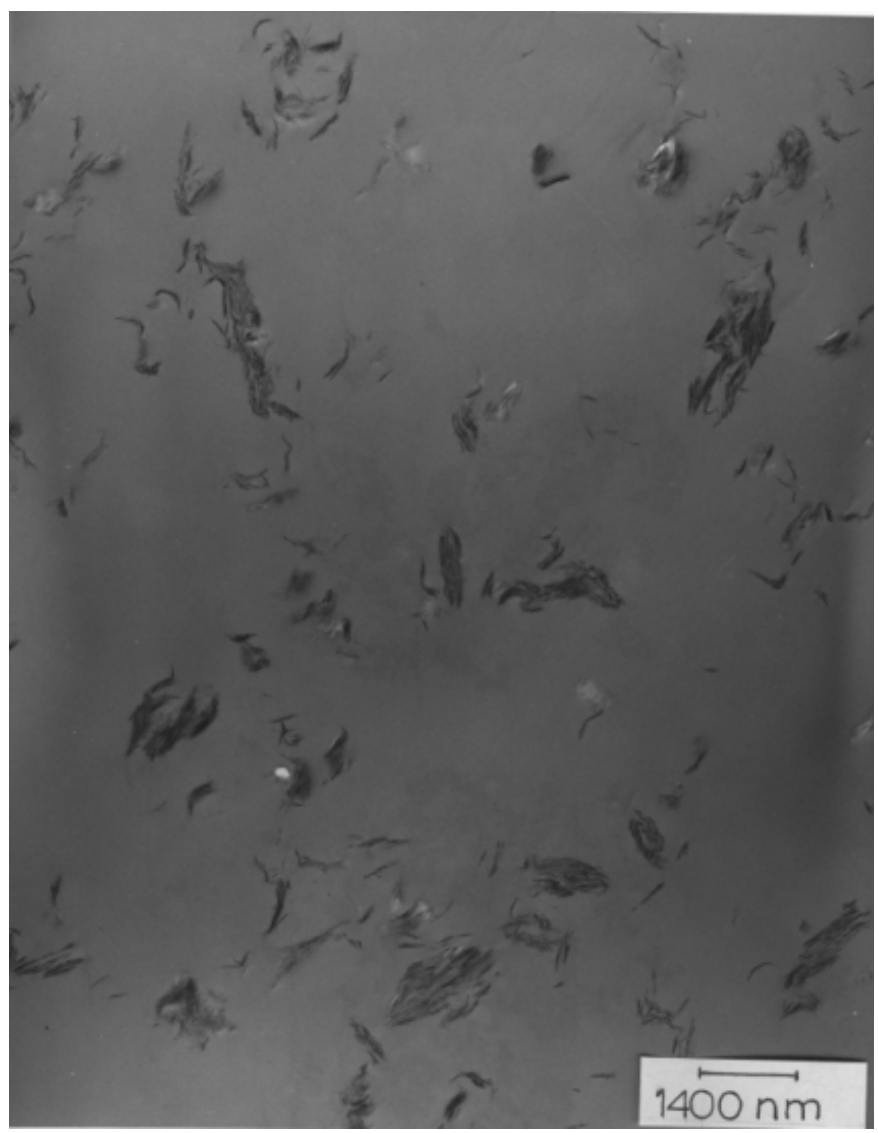

Figure 12 TEM image of 5 wt\% clay loaded vinyl ester $(14,400 x)$ 


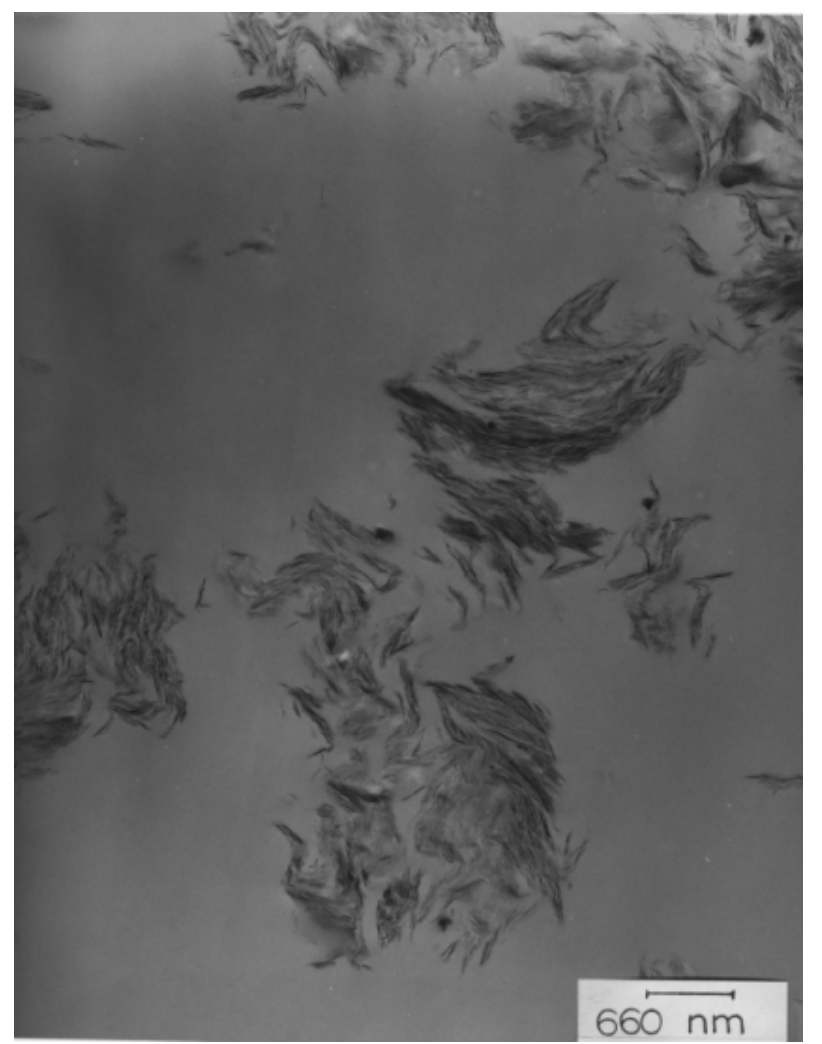

Figure 13 TEM image of 2 wt $\%$ clay loaded vinyl ester $(30,000 x)$

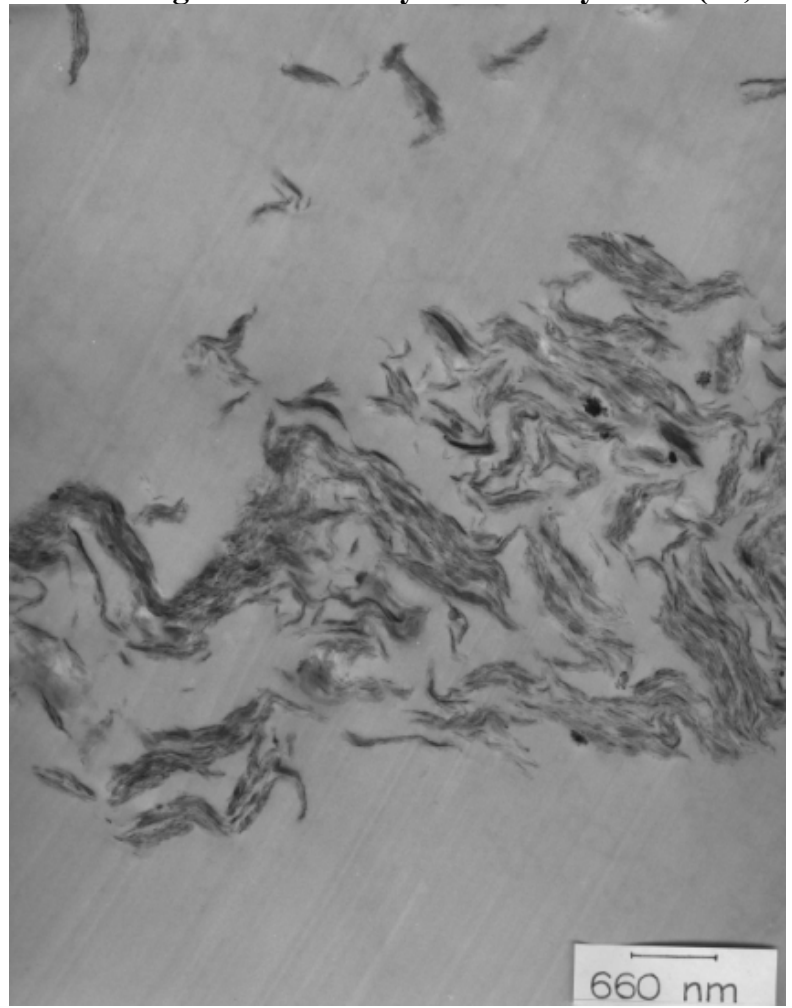

Figure 14 TEM image of 5 wt\% clay loaded vinyl ester $(30,000 x)$ 


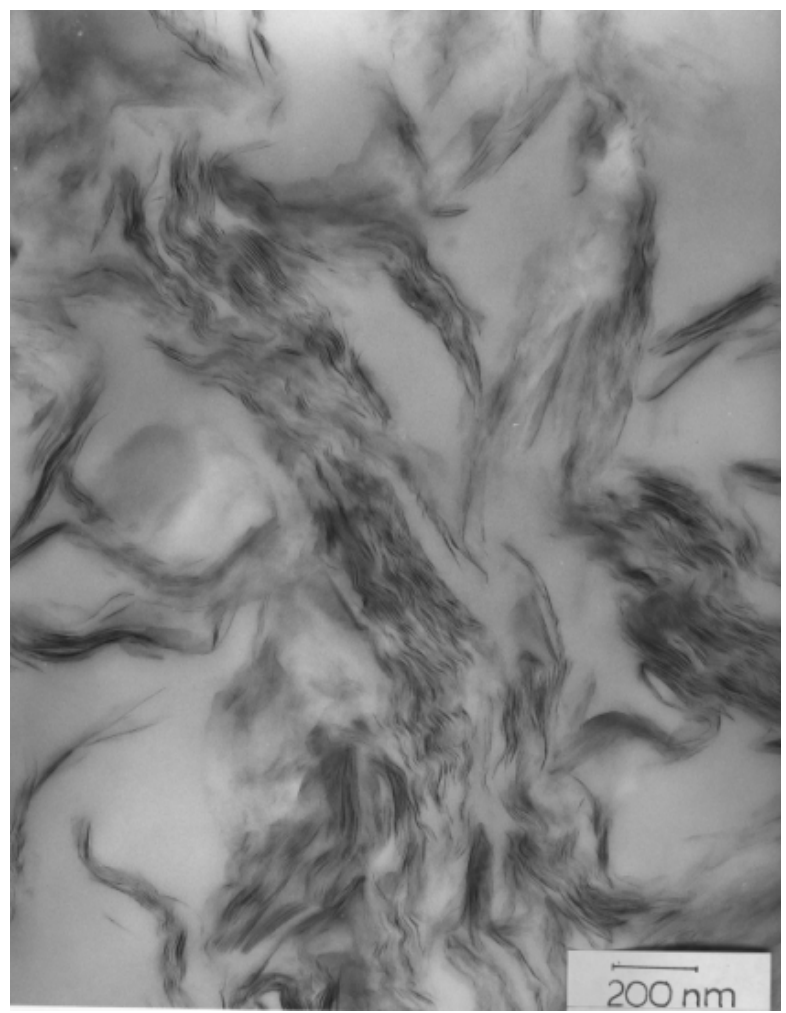

Figure 15 TEM image of 2 wt\% clay loaded vinyl ester $(108,000 x)$

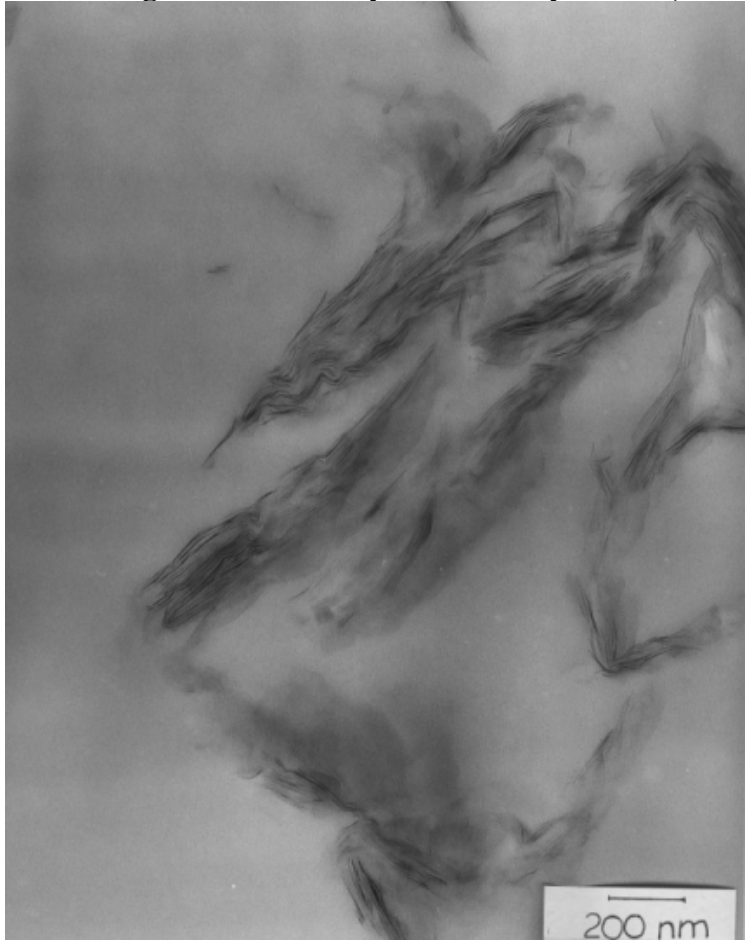

Figure 16 TEM image of $5 \mathrm{wt} \%$ clay loaded vinyl ester $(108,000 x)$ 


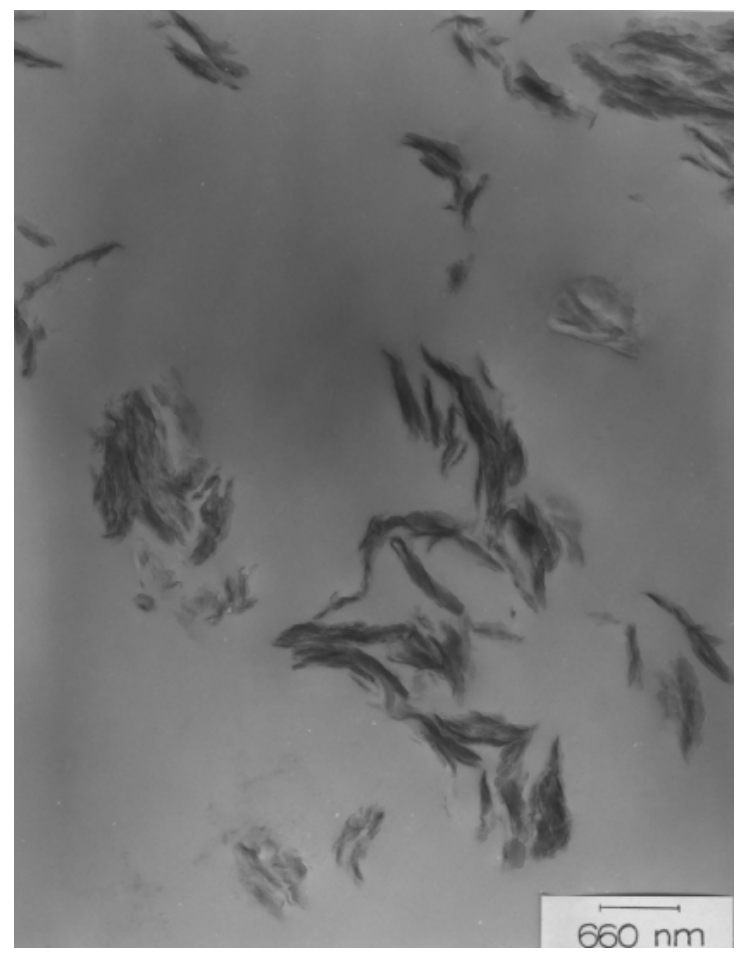

Figure 17 TEM image of $2 \mathrm{wt} \%$ clay loaded polyester (30,000x)

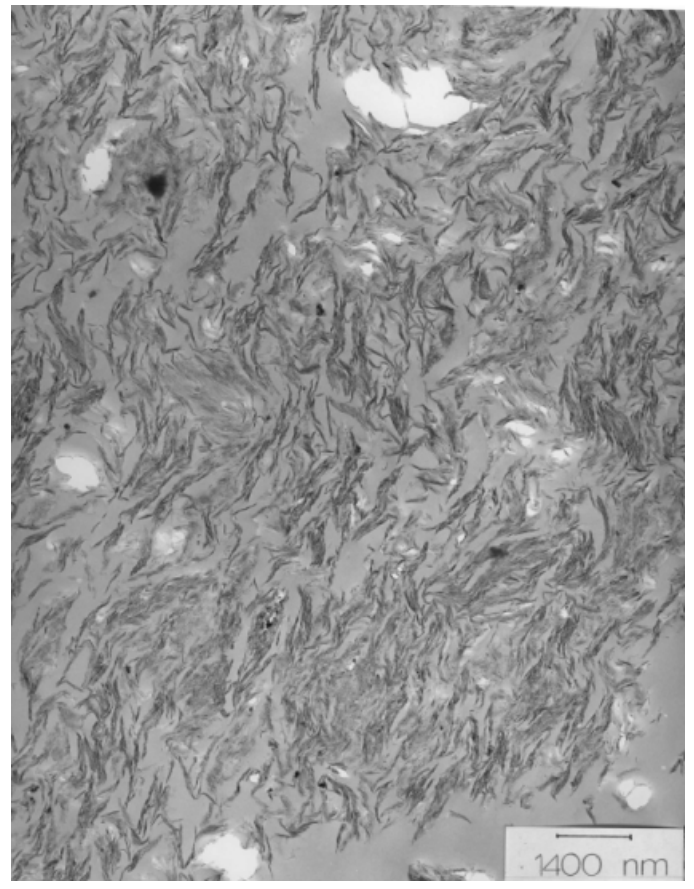

Figure 18 TEM image of $5 \mathrm{wt} \%$ clay loaded polyester $(14,400 x)$ 


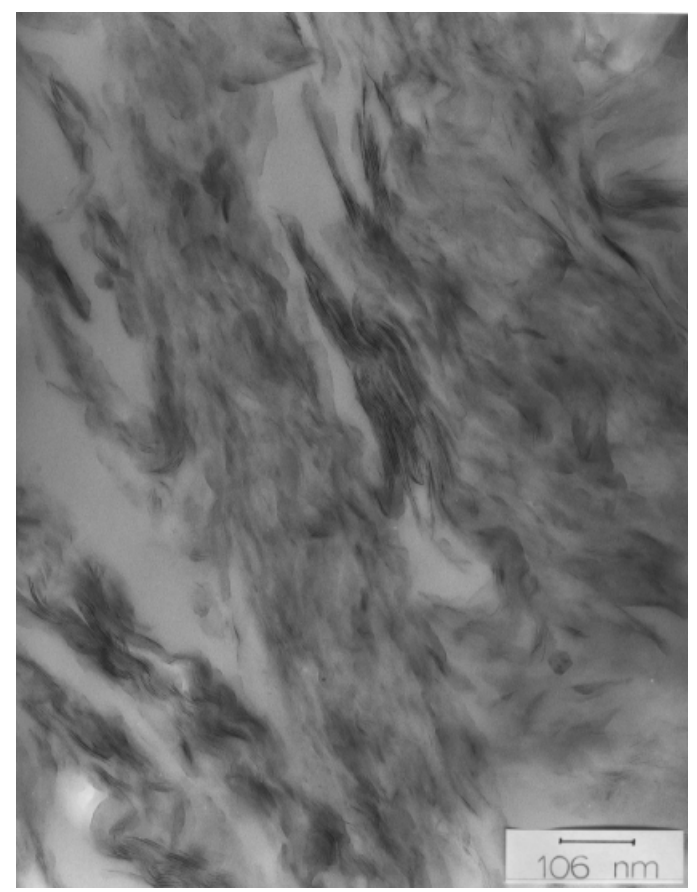

Figure 19 TEM image of 5 wt\% clay loaded polyester $(174,000 x)$

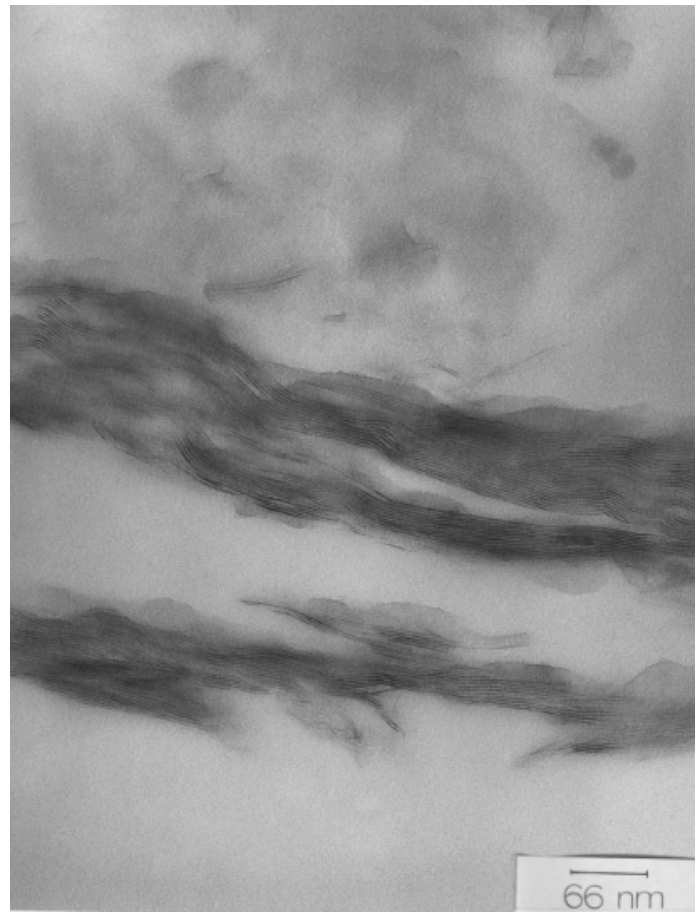

Figure 20 TEM image of $5 \mathrm{wt} \%$ clay loaded polyester $(300,000 x)$ 


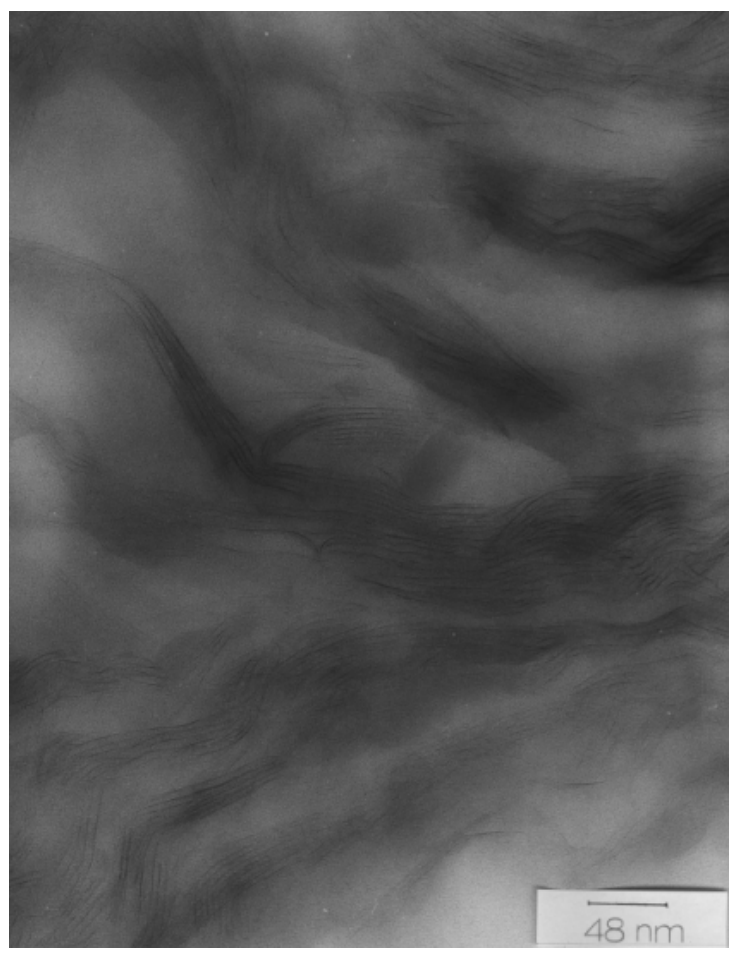

Figure 21 TEM image of $2 \mathrm{wt} \%$ clay loaded polyester $(420,000 x)$

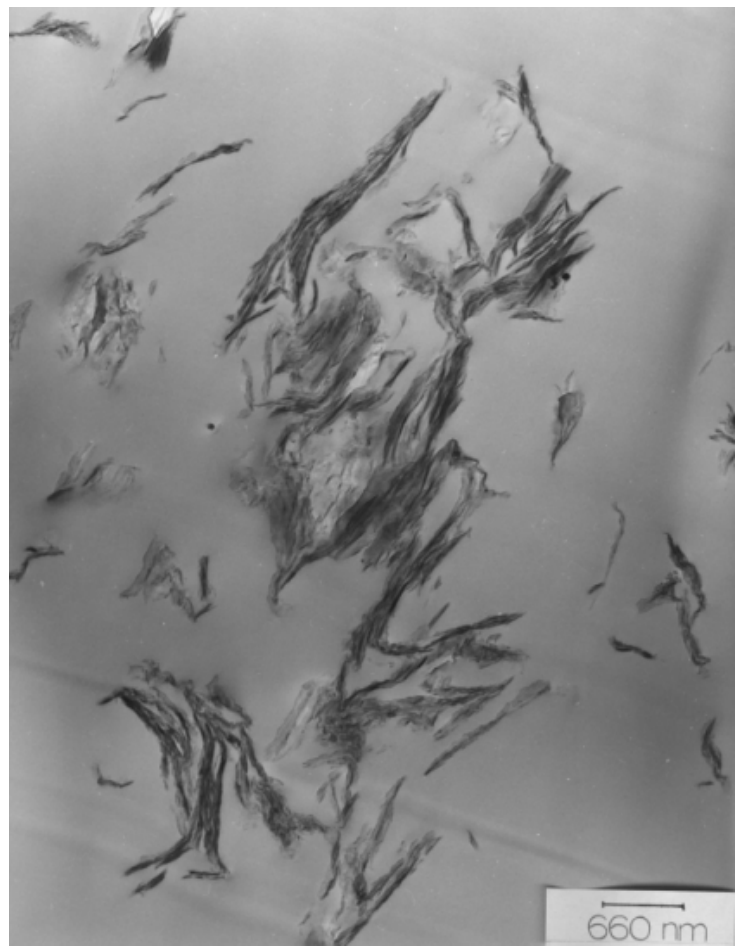

Figure 22 TEM image of 2 wt $\%$ clay loaded epoxy $(30,000 x)$ 


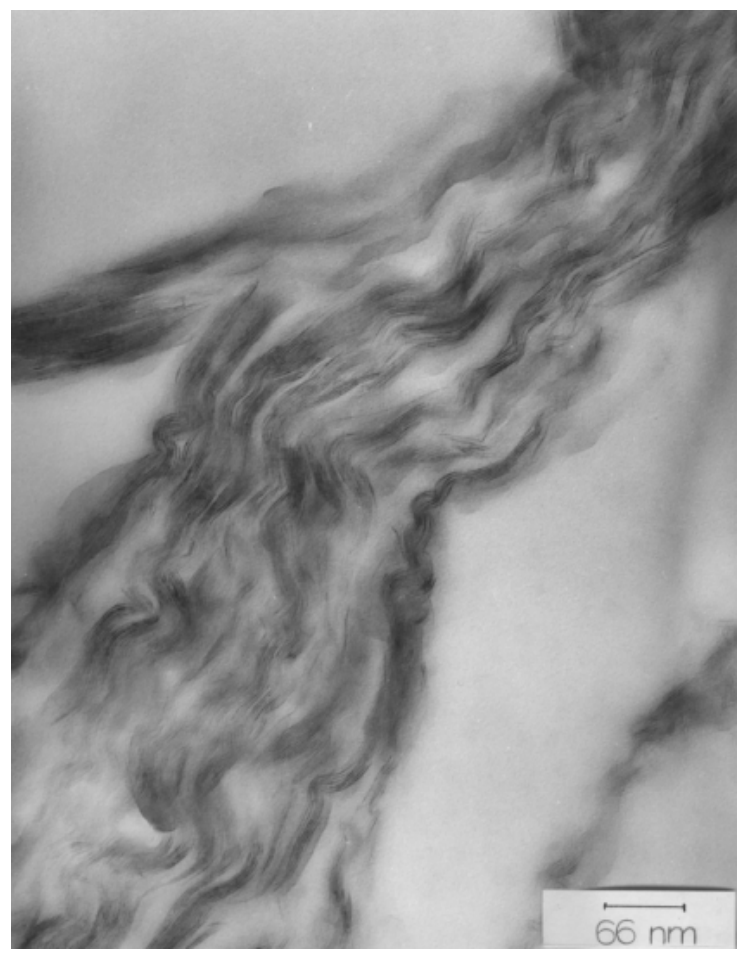

Figure 23 TEM image of 2 wt \% clay loaded epoxy $(300,000 x)$

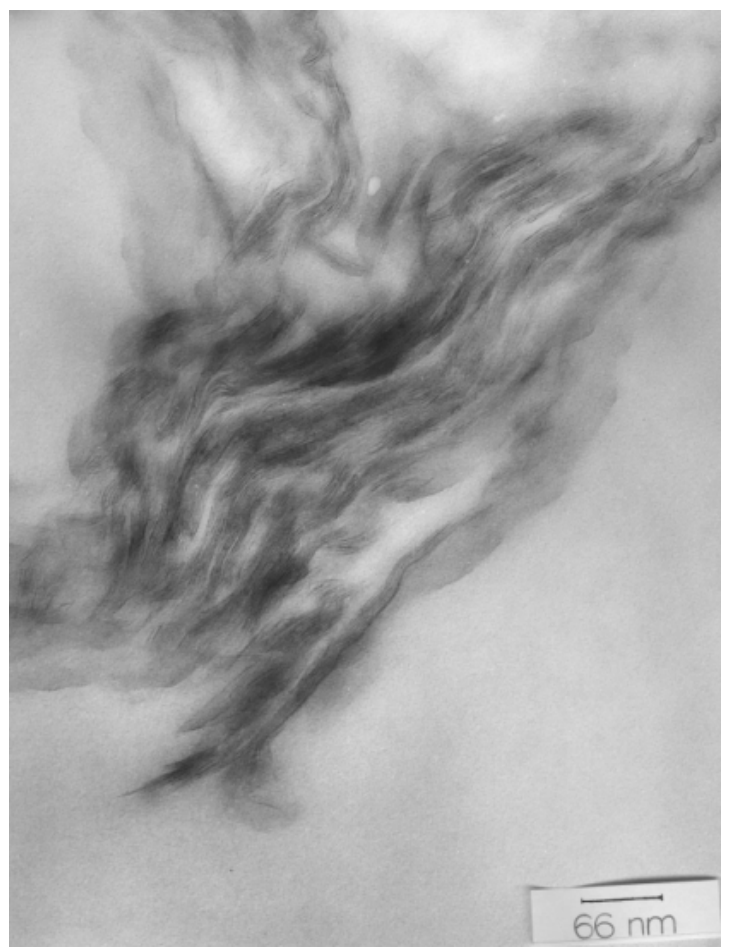

Figure 24 TEM image of $5 \mathrm{wt} \%$ clay loaded epoxy $(300,000 x)$

The presence of clay in the form of both aggregates and individual platelets 
suggests that the samples are not completely exfoliated, and a better dispersion of clay can be obtained through improved mixing techniques. A possible explanation for the observed morphology may be the method of mixing/dispersing the clay used. The clay was ultrasonically mixed with resin using a sonicator at room temperature. It is possible that in regions where the clay platelets started to expand and peel away, the local viscosity greatly increased. There was no possibility of lowering the viscosity as the mixing was done at room temperature, and there might be loss of styrene at higher temperatures. The shear produced by the ultrasonic waves was not enough to break these regions of high concentrations of clay. Also, there might be chances of these ultrasonic waves not being able to penetrate into the regions of high viscosity. The clay in the low concentration regions was completely exfoliated and that in the high concentration regions remained as aggregates or clusters and was not effectively dispersed to the lower concentration zones. Thus the problem could possibly be solved by increasing the shear, which could improve the dispersion of the clay particles. Other suggestion would be ultrasonic mixing coupled with manual/mechanical stirring to prevent the excess build up of local clay concentration.

The TEM pictures explain the morphology of the corresponding nanocomposites of the polymers used in the study as a combination of exfoliated, intercalated and stacked structure.

\subsection{Cyclic Sorption-Desorption Experiments with Distilled Water at Room Temperature}

\subsubsection{Experiments with Vinyl ester}

Graphs of moisture uptake versus time and moisture content (\%) versus time were plotted for all the vinyl ester samples containing different percentages of clay to show the trends at each of the three cycles of absorption (in water) and desorption (at 20\% Relative Humidity). It was seen that the samples never quite reached the initial dry weight and retained some of the moisture. This is because desorption was done at $20 \% \mathrm{RH}$. The sample was in equilibrium with air at $20 \% \mathrm{RH}$ at the beginning of the next cycle of sorption-desorption. The data from each cycle of absorption-desorption for different weight percentages of clay were plotted to demonstrate the effect of cyclical aging and clay addition on the equilibrium moisture content. The raw data for cyclic sorption- 
desorption experiments with neat vinyl ester samples is given in Appendix D in Table 12 and Table 13.

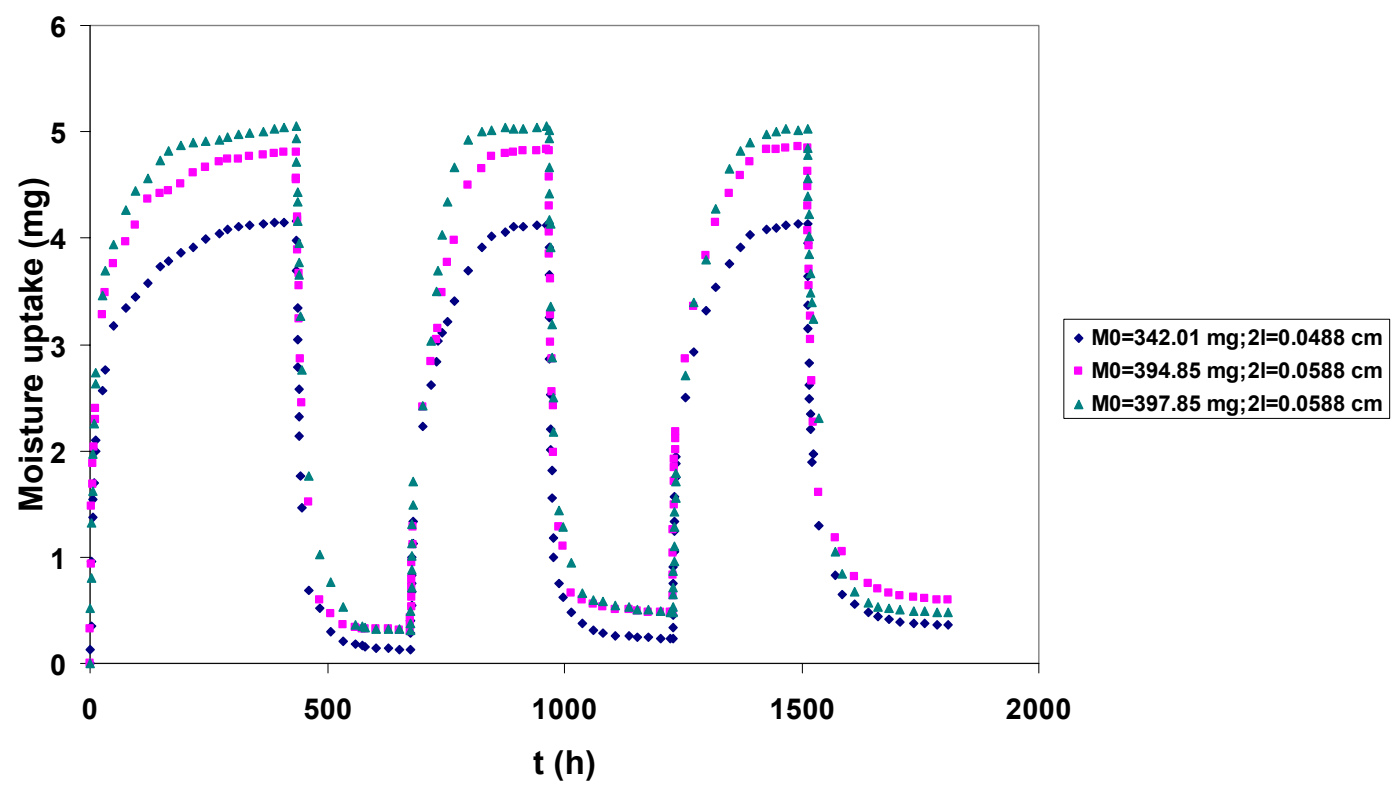

Figure 25 Moisture uptake (mg) versus $\mathrm{t}(\mathrm{h})$ for neat vinyl ester samples during cyclic absorption (water) - desorption $(20 \% \mathrm{RH})$ at $25^{\circ} \mathrm{C}$

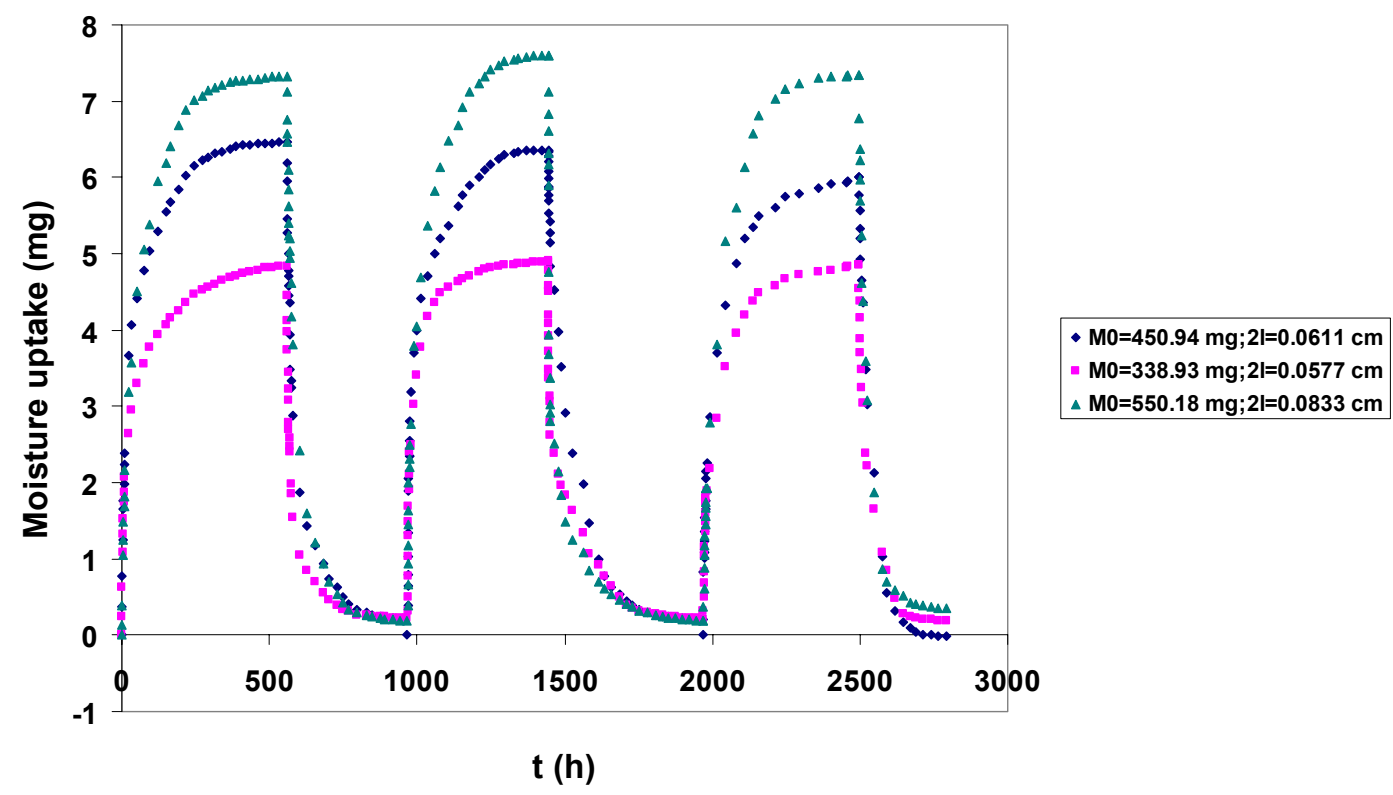

Figure 26 Moisture uptake (mg) versus t (h) for vinyl ester samples containing $2 \mathrm{wt}^{\mathrm{m}}$ Cloisite $10 \mathrm{~A}^{\circledR}$ during cyclic absorption (water) - desorption (20\%RH) at $25^{\circ} \mathrm{C}$ 


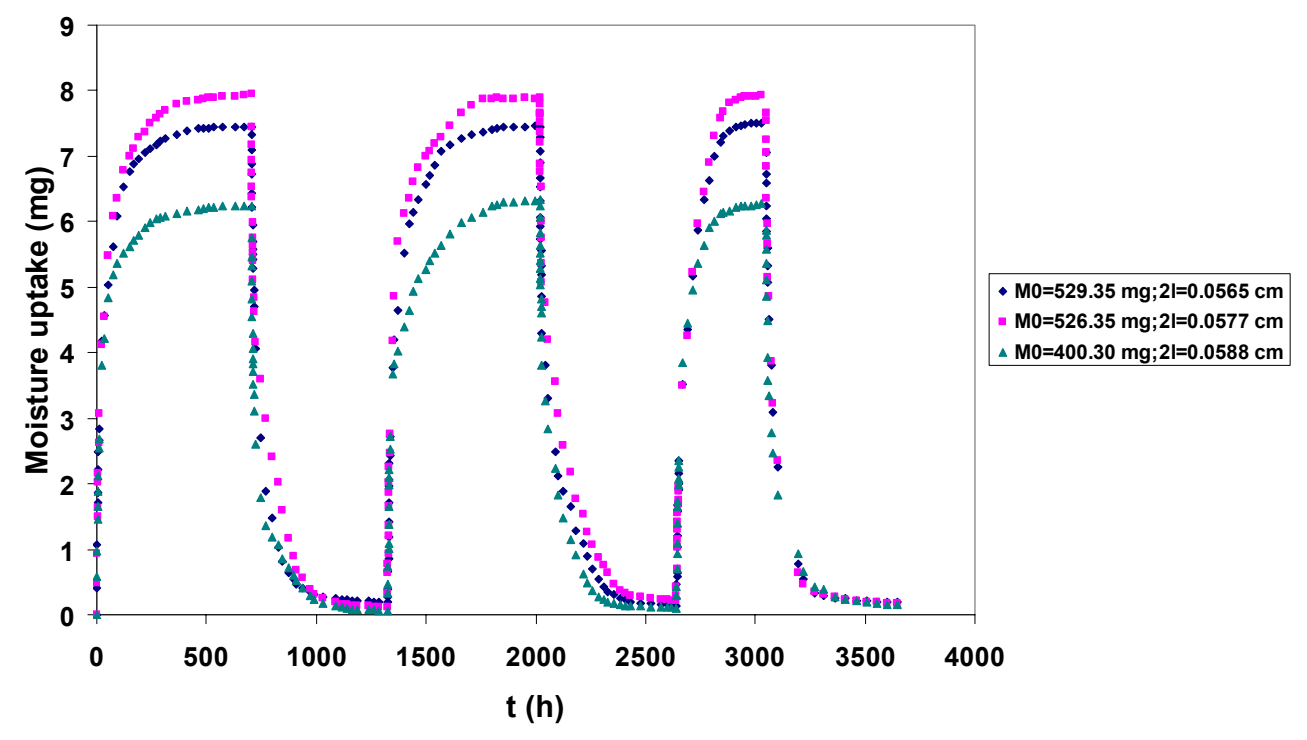

Figure 27 Moisture uptake (mg) versus t (h) for vinyl ester samples containing 5 wt\% Cloisite $10 A^{\circledR}$ during cyclic absorption (water) - desorption (20\%RH) at $25{ }^{\circ} \mathrm{C}$

Figure 25, Figure 26 and Figure 27 show moisture uptake versus time for neat vinyl ester samples and vinyl ester samples containing $2 \mathrm{wt} \%$ and $5 \mathrm{wt} \%$ clay respectively, during three cycles of sorption-desorption at $25{ }^{\circ} \mathrm{C}$. For a given cycle of sorptiondesorption, the time taken by the samples to reach equilibrium during absorption and desorption for clay loaded samples was more than that for the neat vinyl ester samples.

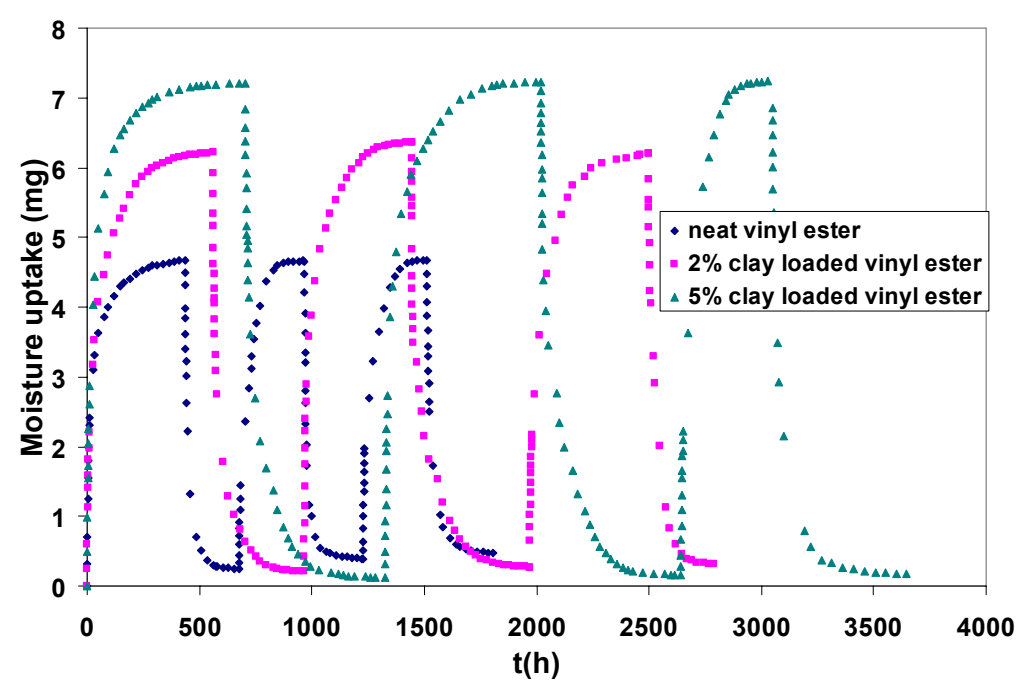

Figure 28 Average moisture uptake (mg) versus $t(h)$ for vinyl ester samples containing different clay loadings during cyclic absorption (water) - desorption (20\%RH) at $25^{\circ} \mathrm{C}$

Figure 28 shows average moisture uptake data for neat vinyl ester resin samples and those containing clay during cyclic sorption-desorption. It can be seen from the figure that the equilibrium moisture uptake for clay loaded samples was more than that for the 
neat vinyl ester samples. It was also observed that the cycling did not alter the equilibrium moisture content of the samples for given clay loading.

Using the mass uptake data of the samples, moisture content (\%) for all the samples was determined and the graphs are shown in the following figures. Figure 29, Figure 30 and Figure 31 show moisture content versus time for neat vinyl ester samples, $2 \mathrm{wt} \%$ clay loaded and $5 \mathrm{wt} \%$ clay loaded vinyl ester samples respectively.

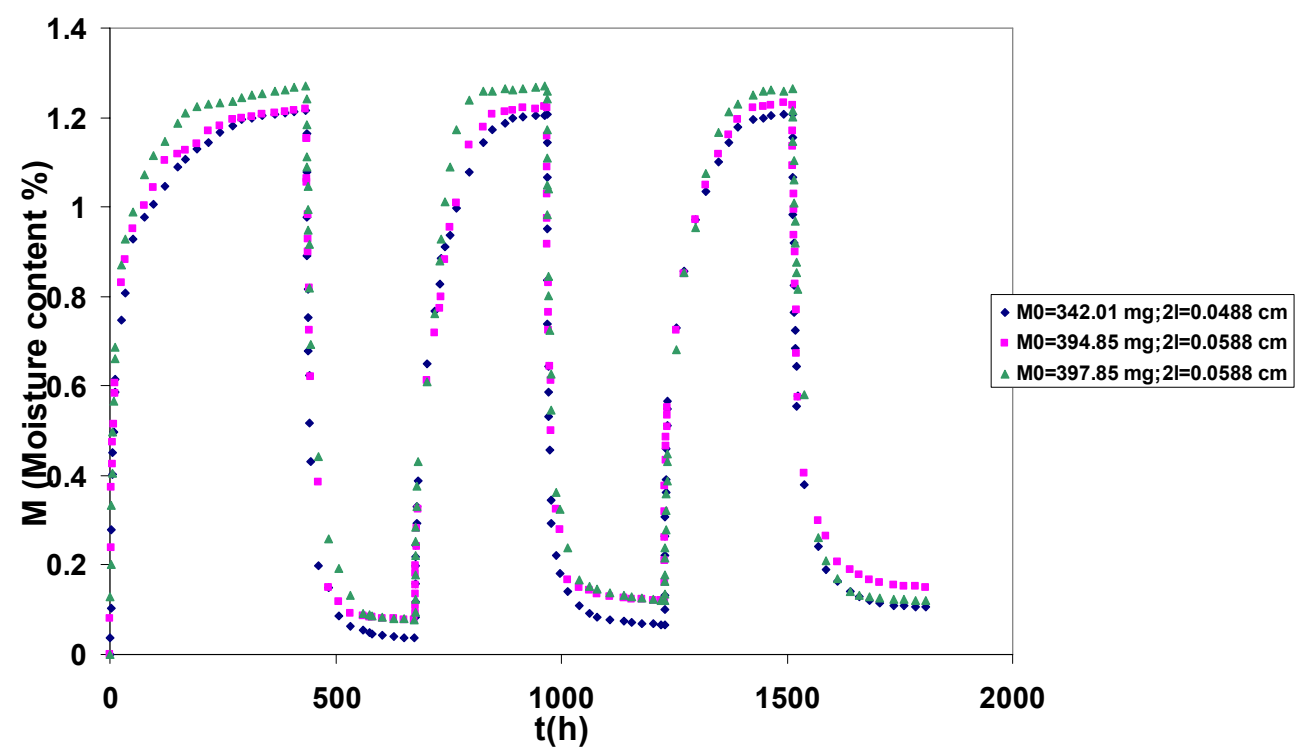

Figure 29 Moisture content versus $t$ for neat vinyl ester samples during absorption (water)desorption $(20 \% \mathrm{RH})$ at $25^{\circ} \mathrm{C}$

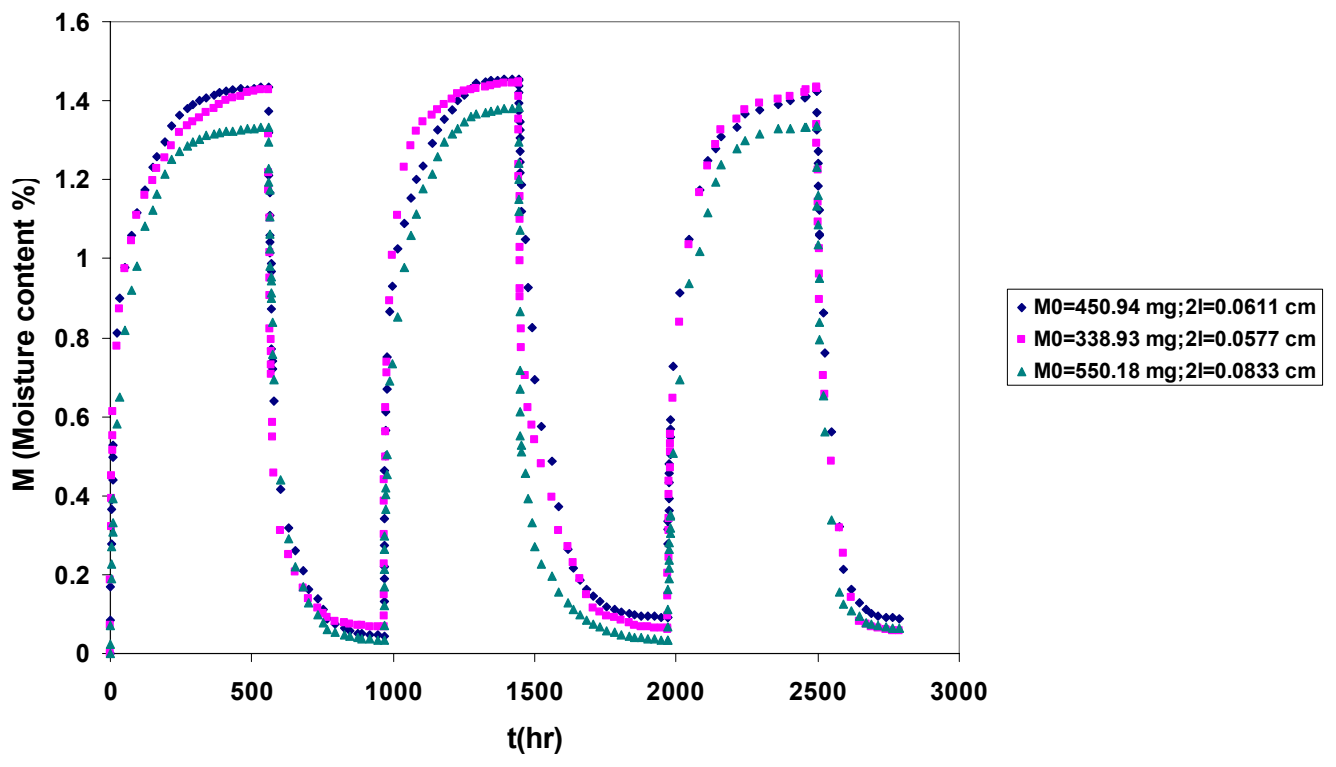

Figure 30 Moisture content versus t for vinyl ester samples containing 2 wt $\%$ Cloisite $10 A^{\circledR}$ during absorption (water)-desorption (20\% RH) at $25^{\circ} \mathrm{C}$ 


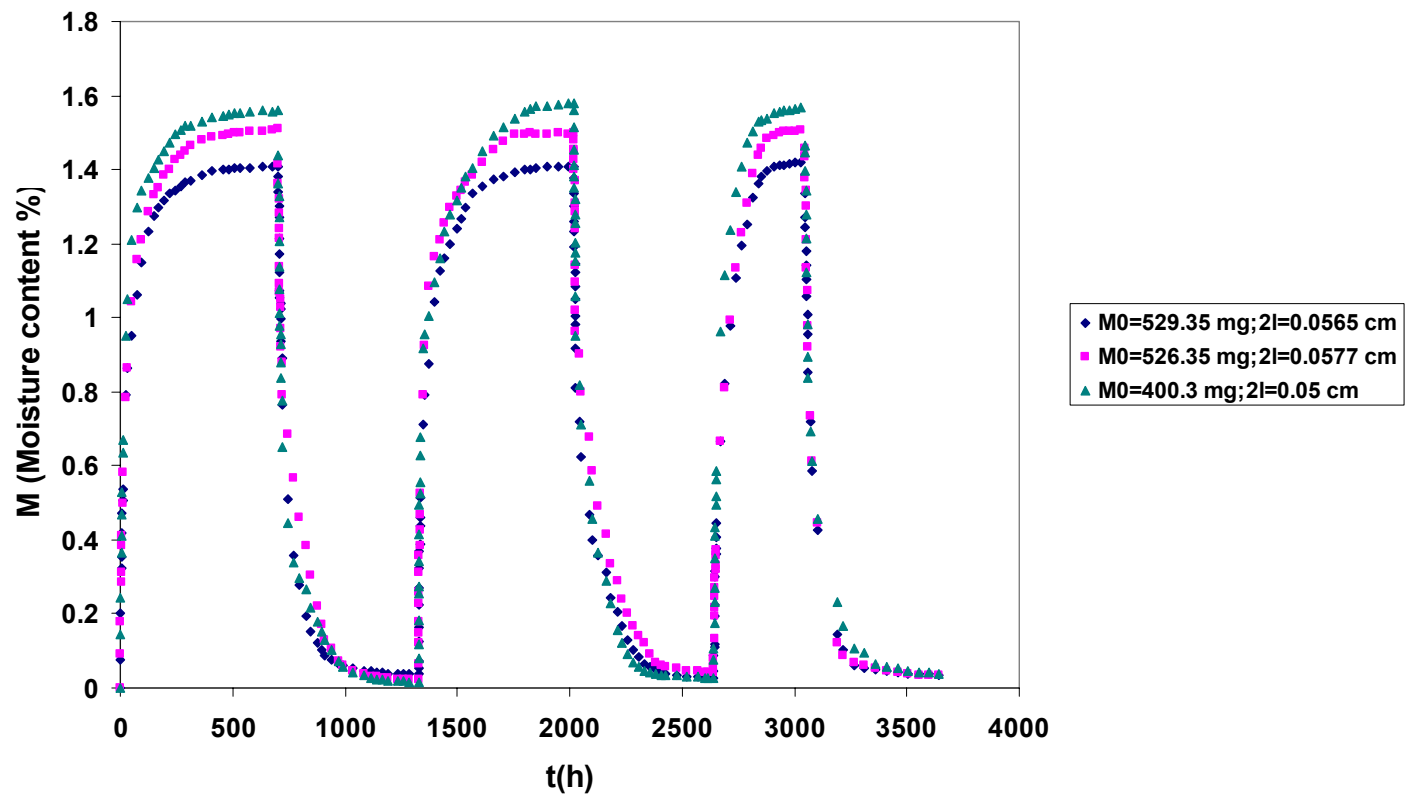

Figure 31 Moisture content versus t for vinyl ester samples containing $5 \mathrm{wt} \%$ Cloisite $10 \mathrm{~A}^{\circledR}$ during absorption (water)-desorption (20\%RH) at $25^{\circ} \mathrm{C}$

It can be clearly seen from the figures that for given clay loading, the samples reached same equilibrium moisture content during three cycles of sorption-desorption. Figure 32 shows average moisture content versus time plotted for vinyl ester samples containing different weight percentages of clay.

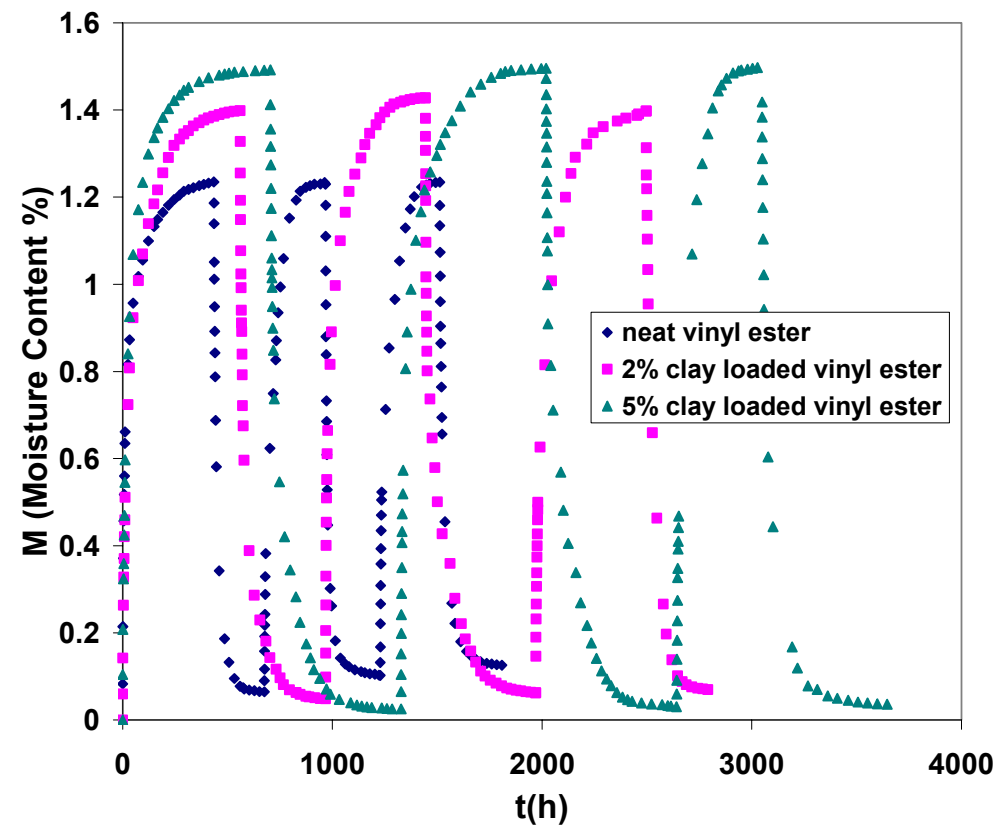

Figure 32 Average moisture content versus time for vinyl ester samples containing different clay loadings 


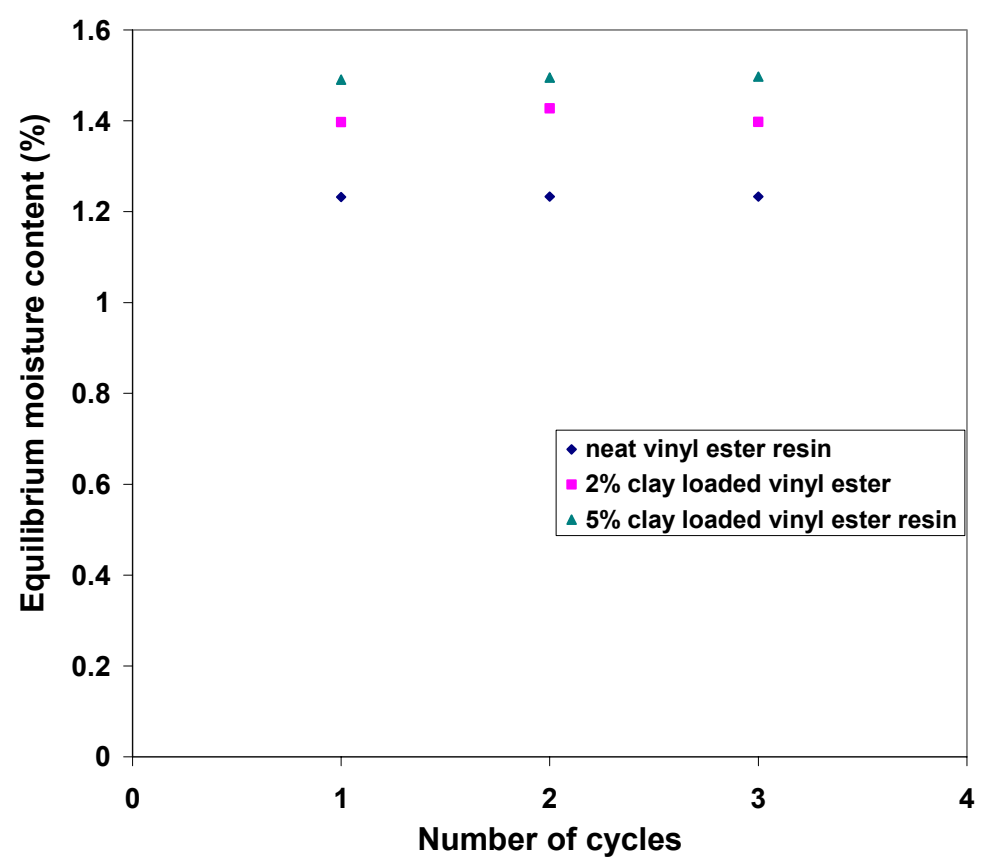

Figure 33 Comparison of equilibrium moisture content for vinyl ester samples containing different clay loadings obtained during cyclic sorption-desorption

Figure 33 shows comparison of equilibrium moisture content for vinyl ester samples containing different weight percentages of clay during three cycles of sorptiondesorption. The equilibrium moisture content was found to be $1.23 \%$ for neat vinyl ester resin samples, $1.4 \%$ for $2 \mathrm{wt} \%$ clay loaded vinyl ester samples and $1.5 \%$ for $5 \mathrm{wt} \%$ clay loaded vinyl ester samples. It was observed that cycling did not affect the equilibrium moisture content for a given clay percentage i.e., the samples reached the same equilibrium moisture content at the end of the second and third cycles as that in the first cycle. But, for a given cycle, the equilibrium moisture content and the time taken to reach equilibrium increased with the increasing amount of clay. Similar results have been reported by Shah (2001) and Rana (2003). They observed non-linear increase in equilibrium moisture content with increased clay loading.

The reason for increasing equilibrium moisture content with increasing clay loading is due to the natural tendency of clay to adsorb water. The clay platelets preferentially absorbed the water molecules until they were saturated and hindered further ingress of water molecules by effectively increasing the diffusion path and tortuosity. Once the platelets were completely saturated, the water molecules would then follow a tortuous 
path to diffuse. Also, the presence of nanoparticles in an intercalated nanocomposite decreases the segmental mobility of polymer chains confined to regions between clay platelets. As a result, the water diffusion slows down (decrease in the diffusivity values), and the penetrating water molecules form aggregates or clusters in the nanocomposite. These clusters are mainly formed in neighborhoods of clay particles. According to free volume theory, clustering of water molecules implies an increase in the total mass uptake by the polymer matrix. This is shown by the water uptake by Cloisite $10 \mathrm{~A}^{\circledR}$ in a humid environment of $60 \%$ RH at $25{ }^{\circ} \mathrm{C}$ in the Figure 34 . Measured quantity of Closite $10 \mathrm{~A}^{\circledR}$ is placed inside the humidity chamber and is periodically removed to measure the weight gain until equilibrium. The weight gain data is then used to calculate change in moisture content of the clay with time. Figure 34 clearly shows that the Cloisite $10 \mathrm{~A}^{\circledR}$ absorbs moisture with time.

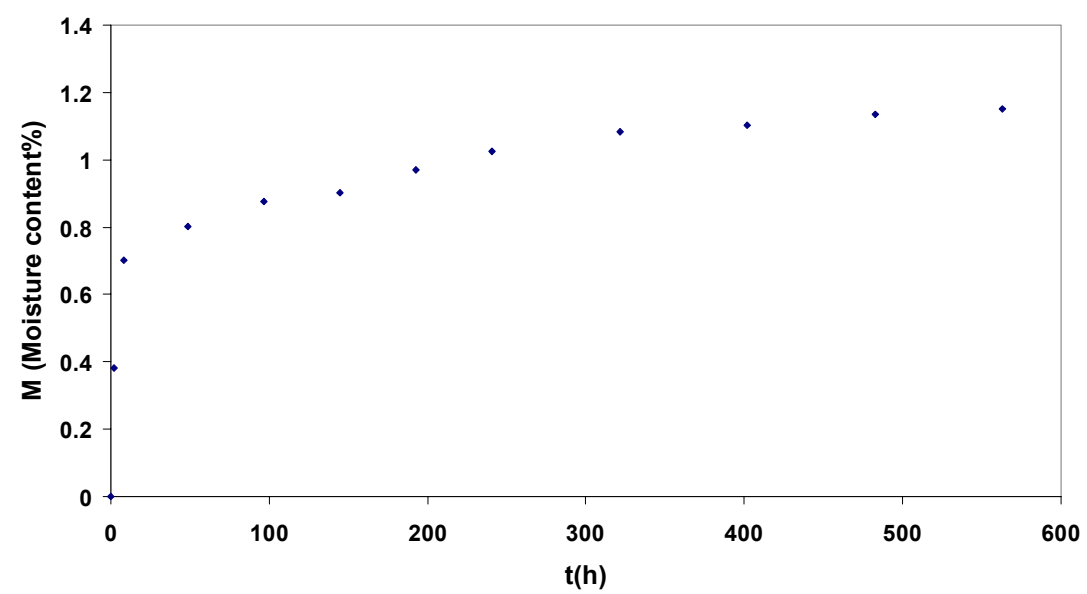

Figure 34 Moisture content versus t for Cloisite $10 \mathrm{~A}^{\circledR}$ during exposure at $60 \% \mathrm{RH}$ at $25^{\circ} \mathrm{C}$ A graph of $\mathrm{M}_{\mathrm{t}} / \mathrm{M}_{\infty}$ versus $\mathrm{t}^{1 / 2}$ for absorption experiment was plotted for all the vinyl ester samples during three cycles of sorption-desorption where $\mathrm{M}_{t}$ and $\mathrm{M}_{\infty}$ were masses uptake of water at time $t$ and at equilibrium respectively. 


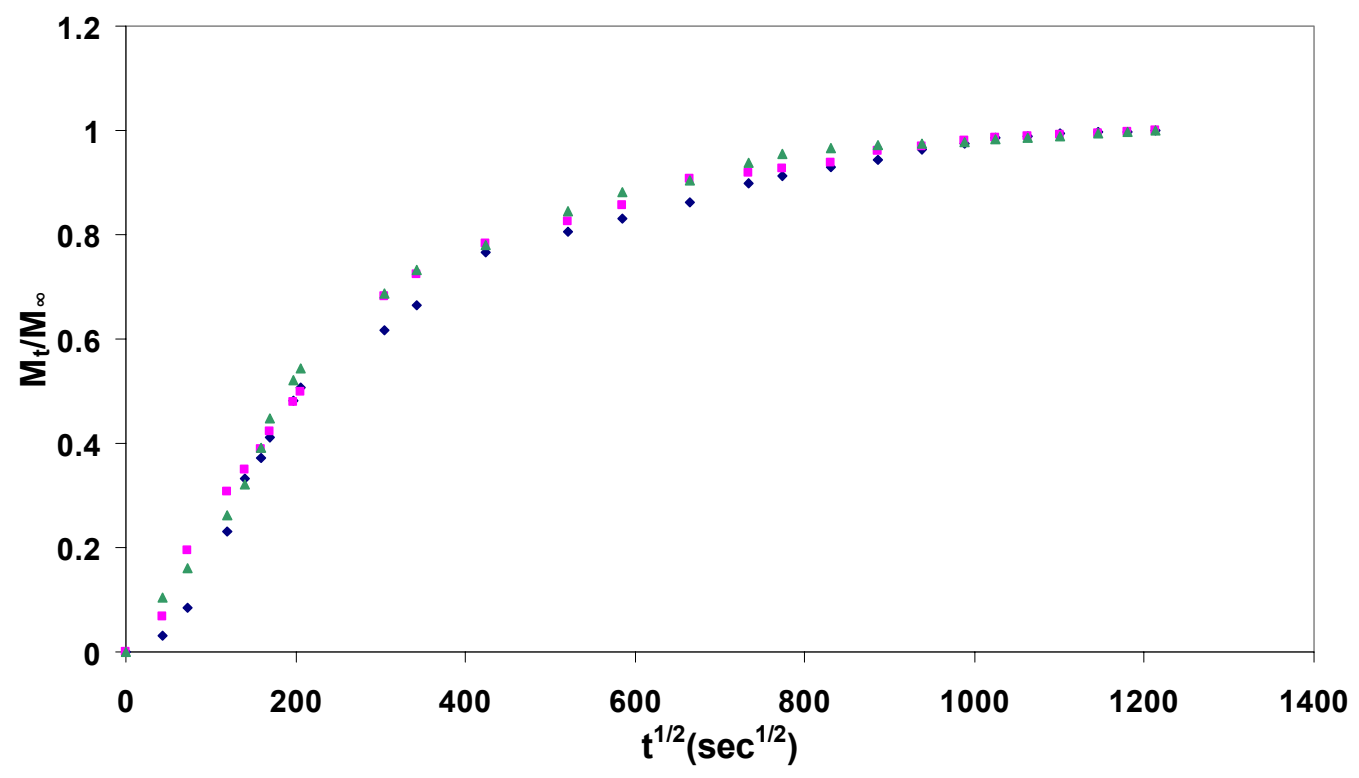

Figure $35 M_{t} / M_{\infty}$ versus $t^{1 / 2}$ for vinyl ester samples containing 0 wt $\%$ Cloisite $10 A^{\circledR}$ at $25{ }^{\circ} \mathrm{C}$ during first cycle of absorption

Figure 35, Figure 36 and Figure 37 show graphs of $\mathrm{M}_{t} / \mathrm{M}_{\infty}$ versus $\mathrm{t}^{1 / 2}$ for neat vinyl ester samples during first, second and third cycles of absorption. The plots show a linear initial uptake for the samples indicating that diffusion followed a Fickian process. From the initial slopes of these curves, absorption diffusion coefficients for all the cycles were calculated according to the method explained in Section 3.4.

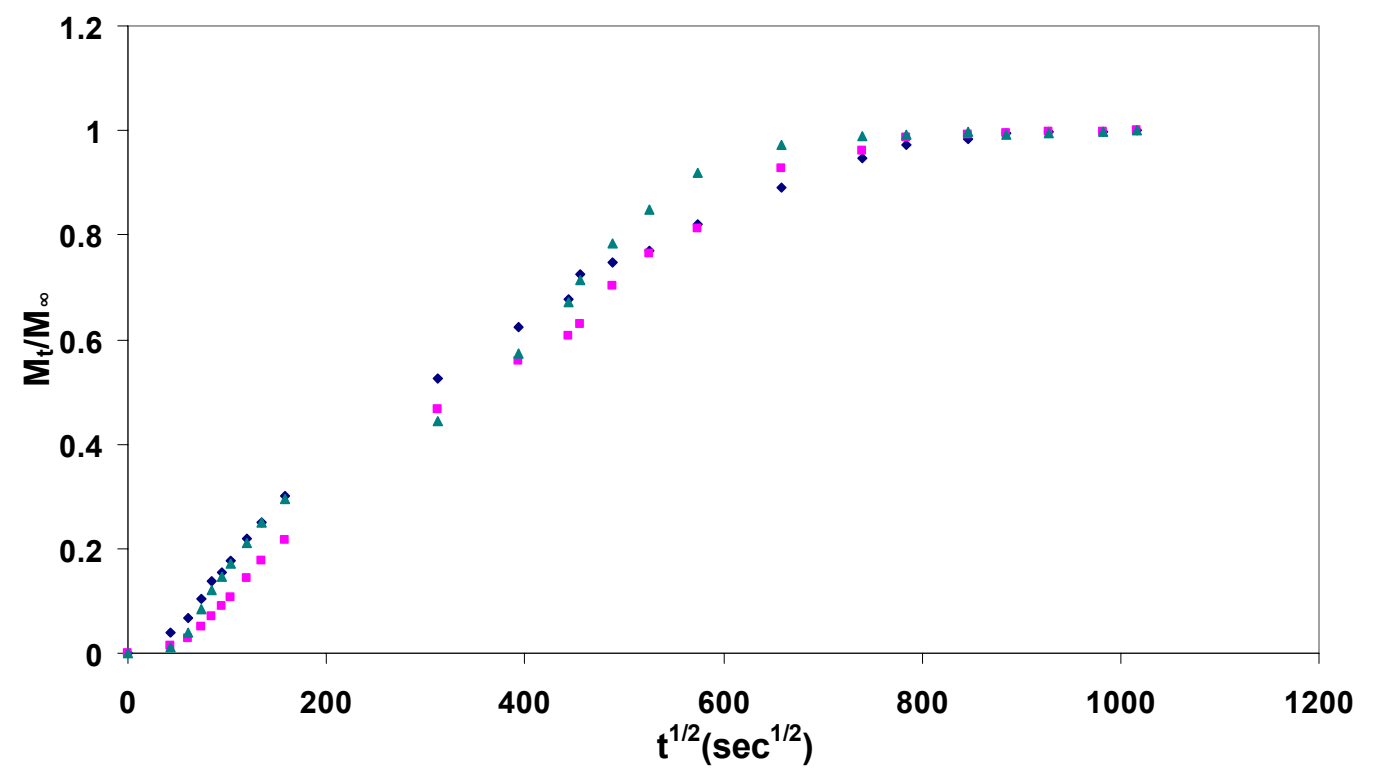

Figure $36 M_{t} / M_{\infty}$ versus $t^{1 / 2}$ for vinyl ester samples containing 0 wt $\%$ Cloisite $10 A^{\circledR}$ at $25{ }^{\circ} \mathrm{C}$ during second cycle of absorption 


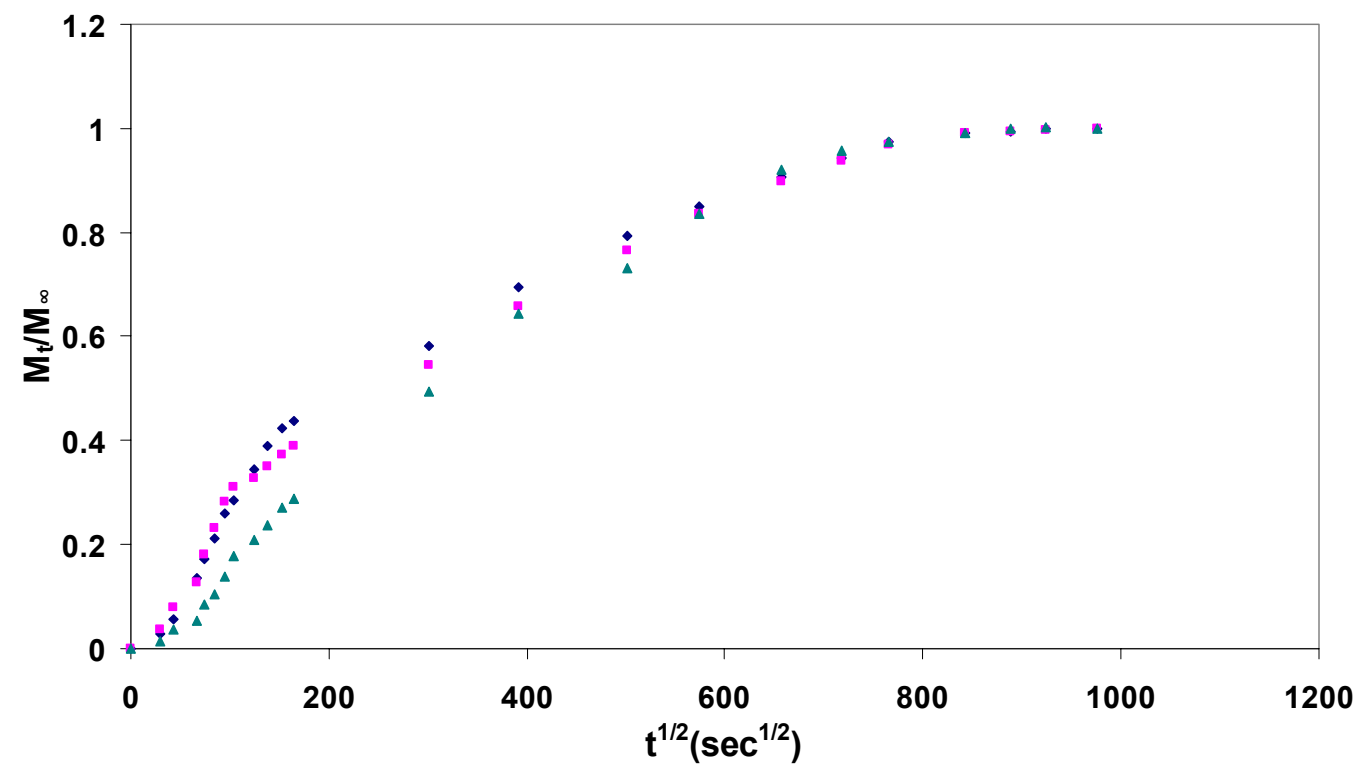

Figure $37 M_{t} / M_{\infty}$ versus $t^{1 / 2}$ for vinyl ester samples containing 0 wt $^{\%}$ Cloisite $10 \mathrm{~A}^{\circledR}$ at $25{ }^{\circ} \mathrm{C}$ during third cycle of absorption

The diffusivity of water in neat vinyl ester resin during first cycle of absorption was found to be $4.15 \times 10^{-9} \mathrm{~cm}^{2} / \mathrm{s}$ and this is comparable to the value reported by others (Chin et al., 1999; Verghese et al., 1999; Rana, 2003 and Ravindran, 2005). The absorption diffusivities decreased slightly with subsequent cycles. The absorption diffusivities were found to be $1.53 \times 10^{-9} \mathrm{~cm}^{2} / \mathrm{s}$ for second cycle and $2.37 \times 10^{-9} \mathrm{~cm}^{2} / \mathrm{s}$ during third cycle. This could possibly be due to improved curing and greater crosslinking between the polymer chains with time and subsequent reabsorption. This improved curing and crosslinking with moisture absorption was also reported by other researchers in the past (Startsev, 1985 and Ravindran, 2005). Water was found to activate postcure of the epoxy materials for a whole class of epoxy compounds. In epoxy polymers, the residue of the groups that are capable for reaction but have not reacted is preserved. When polymers absorb water, the polar physical bonds become weak and the intensity of molecular motion increases. This in turn increases the probability of a contact between the groups that have not reacted, and therefore, of creating chemical bonds. 


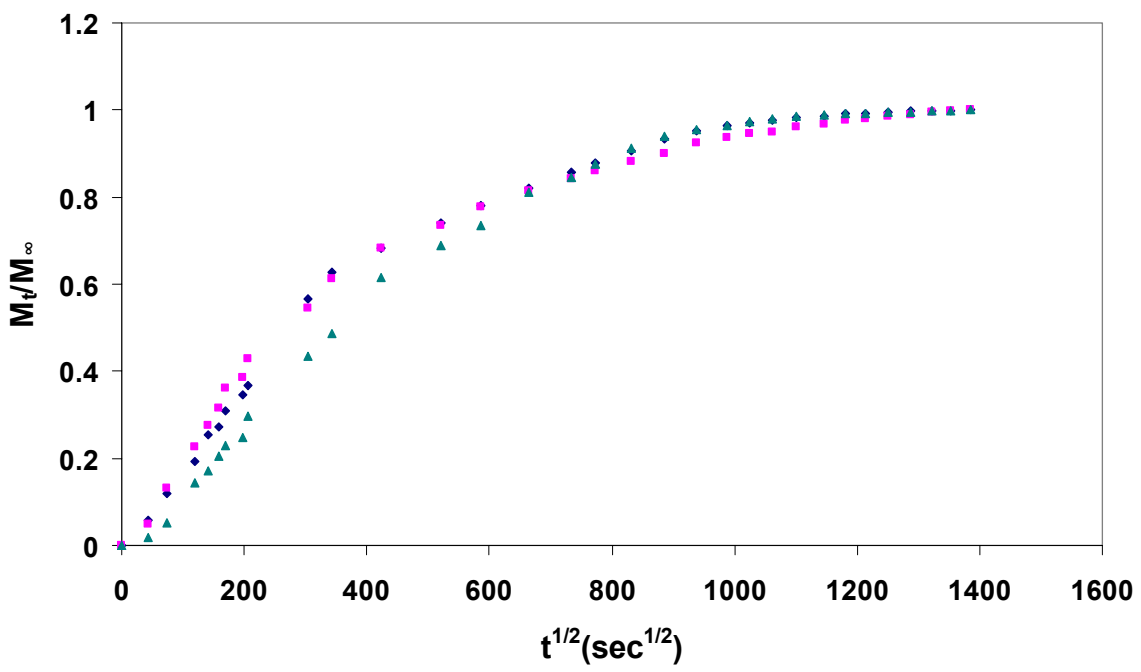

Figure $38 M_{t} / M_{\infty}$ versus $t^{1 / 2}$ for vinyl ester samples containing $2 w^{\circ} \%$ Cloisite $10 A^{\circledR}$ at $25{ }^{\circ} \mathrm{C}$ during first cycle of absorption

Figure 38, Figure 39 and Figure 40 show graphs of $\mathrm{M}_{\mathrm{t}} / \mathrm{M}_{\infty}$ versus $\mathrm{t}^{1 / 2}$ during first, second and third cycles of absorption respectively for vinyl ester samples containing 2 wt $\%$ Cloisite $10 \mathrm{~A}^{\circledR}$. The graphs show linear initial uptake indicating Fickian diffusion during three cycles of absorption. From the initial slopes of these curves, diffusion coefficients were calculated as explained in Section 3.4. The raw data for cyclic sorptiondesorption experiments with vinyl ester samples containing $2 \mathrm{wt} \%$ Cloisite $10 \mathrm{~A}^{\circledR}$ is given in Appendix D in Table 14 and Table 15.

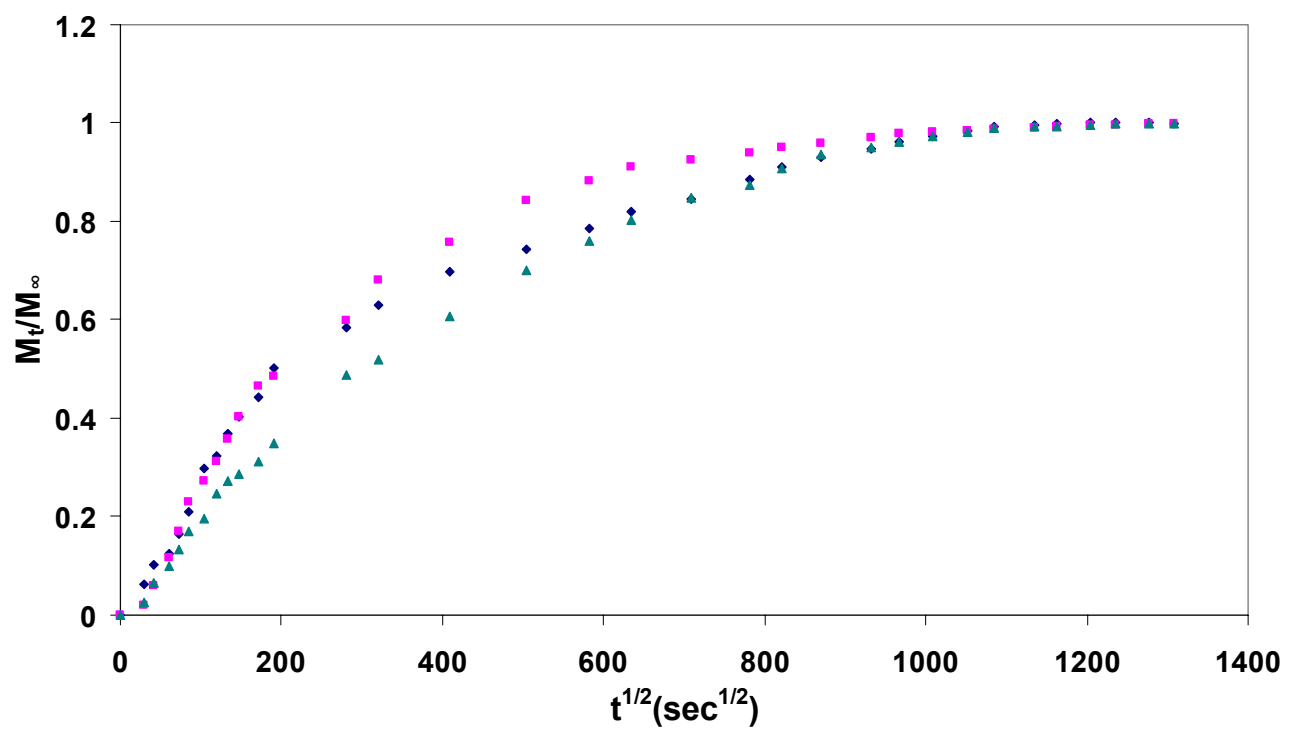

Figure $39 M_{t} / M_{\infty}$ versus $t^{1 / 2}$ for vinyl ester samples containing $2 w^{t} \%$ Cloisite $10 A ®$ at $25{ }^{\circ} \mathrm{C}$ during second cycle of absorption 


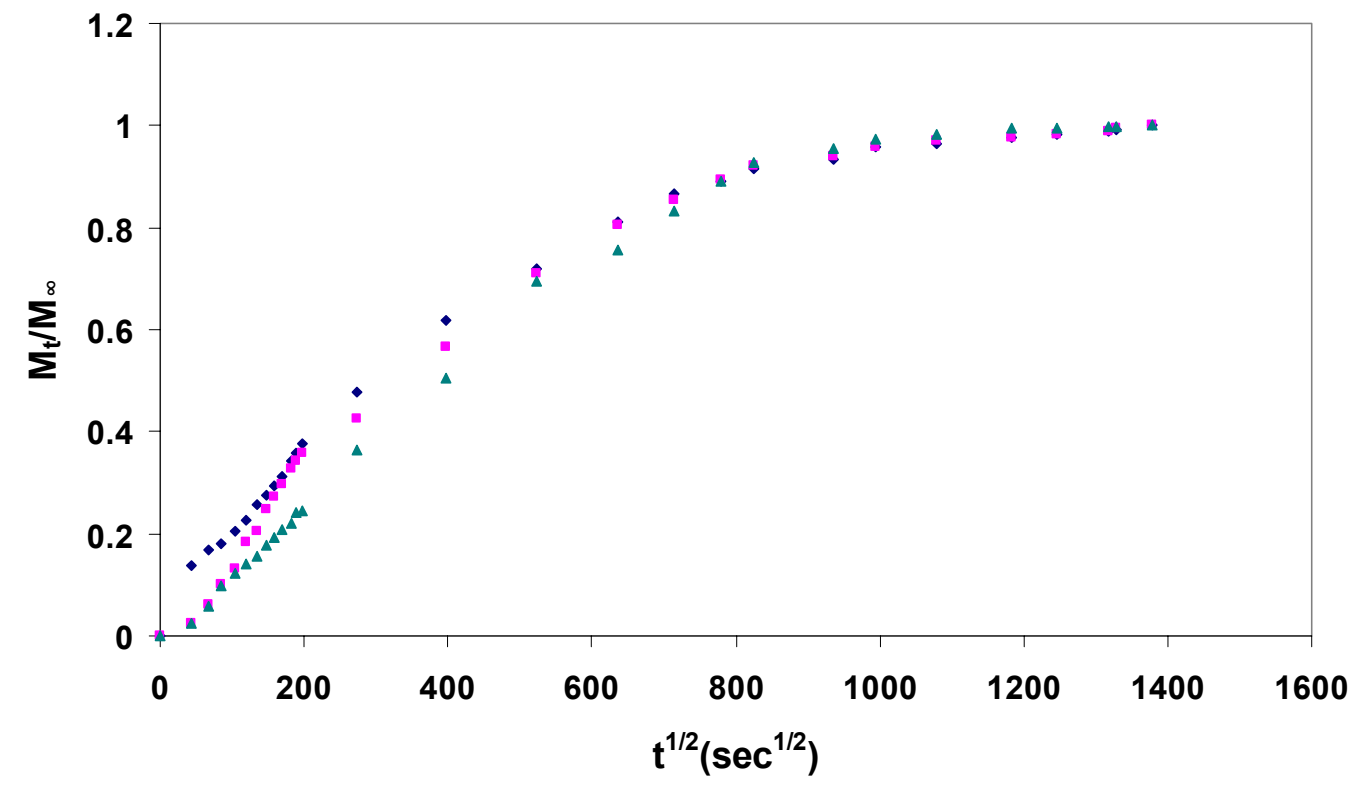

Figure $40 M_{t} / M_{\infty}$ versus $t^{1 / 2}$ for vinyl ester samples containing $2 w_{t} \%$ Cloisite $10 A^{\circledR}$ at $25{ }^{\circ} \mathrm{C}$ during third cycle of absorption

The average diffusivities were found to be $2.63 \times 10^{-9} \mathrm{~cm}^{2} / \mathrm{s}$ for first cycle, $2.54 \mathrm{x}$ $10^{-9} \mathrm{~cm}^{2} / \mathrm{s}$ for second cycle and $2.23 \times 10^{-9} \mathrm{~cm}^{2} / \mathrm{s}$ for third cycle of absorption.

Similar graphs of $\mathrm{M}_{\mathrm{t}} / \mathrm{M}_{\infty}$ versus $\mathrm{t}^{1 / 2}$ for samples containing $5 \mathrm{wt} \%$ Cloisite $10 \mathrm{~A}^{\circledR}$ during first, second and third cycles of absorption were drawn and are given in Appendix $\mathrm{C}$ in Figure 123, Figure 124 and Figure 125 respectively. The graphs showed linear initial uptake indicating Fickian diffusion during three cycles of absorption. From the initial slopes of these curves, diffusion coefficients were calculated as explained in Section 3.4. The average diffusivities were found to be $2.04 \times 10^{-9} \mathrm{~cm}^{2} / \mathrm{s}$ for first cycle, $2.12 \times 10^{-9}$ $\mathrm{cm}^{2} / \mathrm{s}$ for second cycle and $1.53 \times 10^{-9} \mathrm{~cm}^{2} / \mathrm{s}$ for third cycle of absorption.

Also, graphs of $\ln \left(\mathrm{M}_{\mathrm{t}}-\mathrm{M}_{\infty}\right)$ versus $\mathrm{t}$ for desorption experiment were plotted for all the samples during three cycles of sorption-desorption. From the slopes drawn during the final stages of desorption curves, desorption coefficients were calculated according to the method explained in Section 3.5. 


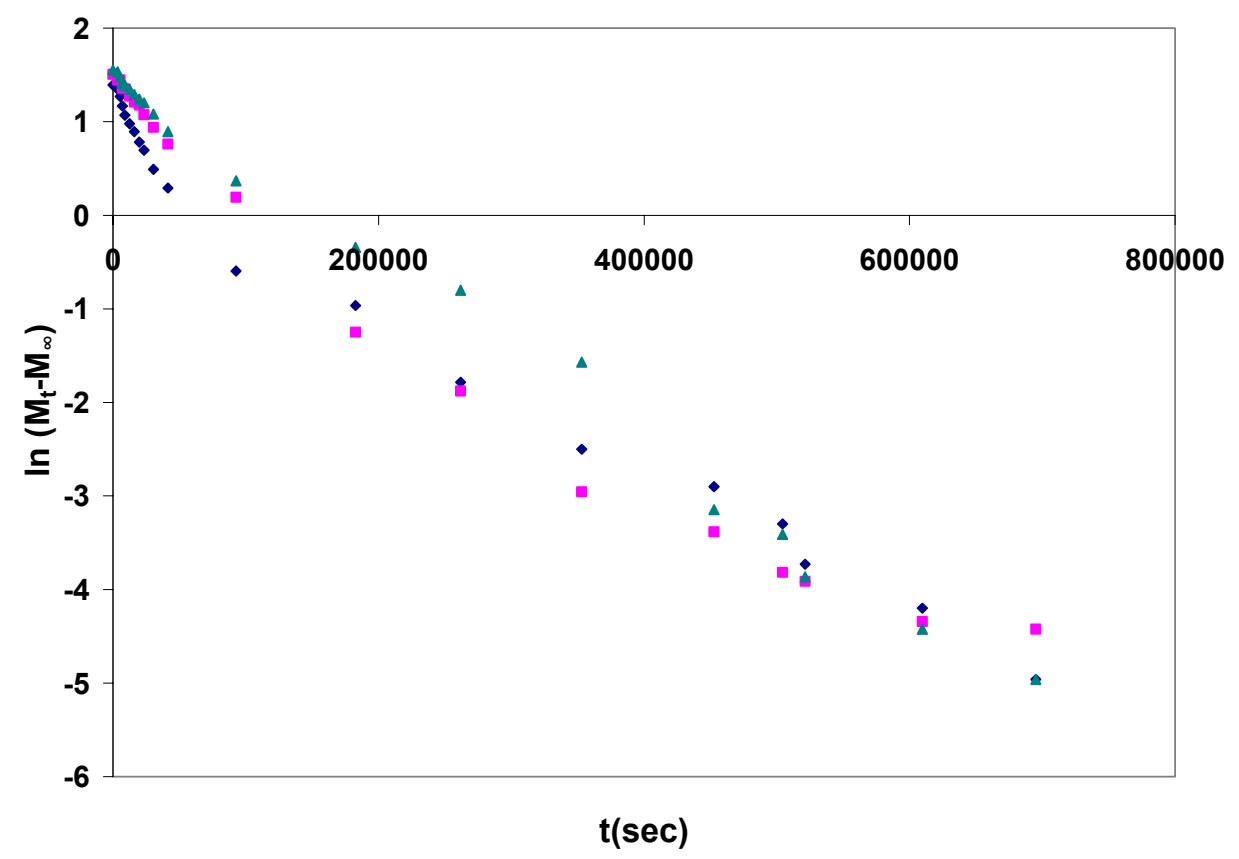

Figure 41 In $\left(M_{t}-M_{\infty}\right)$ versus $t$ for vinyl ester samples containing $0 \mathrm{wt} \%$ Cloisite $10 A^{\circledR}$ at $25^{\circ} \mathrm{C}$ during first cycle of desorption

Figure 41, Figure 42 and Figure 43 show $\ln \left(\mathrm{M}_{\mathrm{t}}-\mathrm{M}_{\infty}\right)$ versus time for neat vinyl ester samples during first, second and third cycles of desorption respectively. The plots show linear curves during the final or later stages of desorption indicating that the diffusion followed Fickian process during desorption.

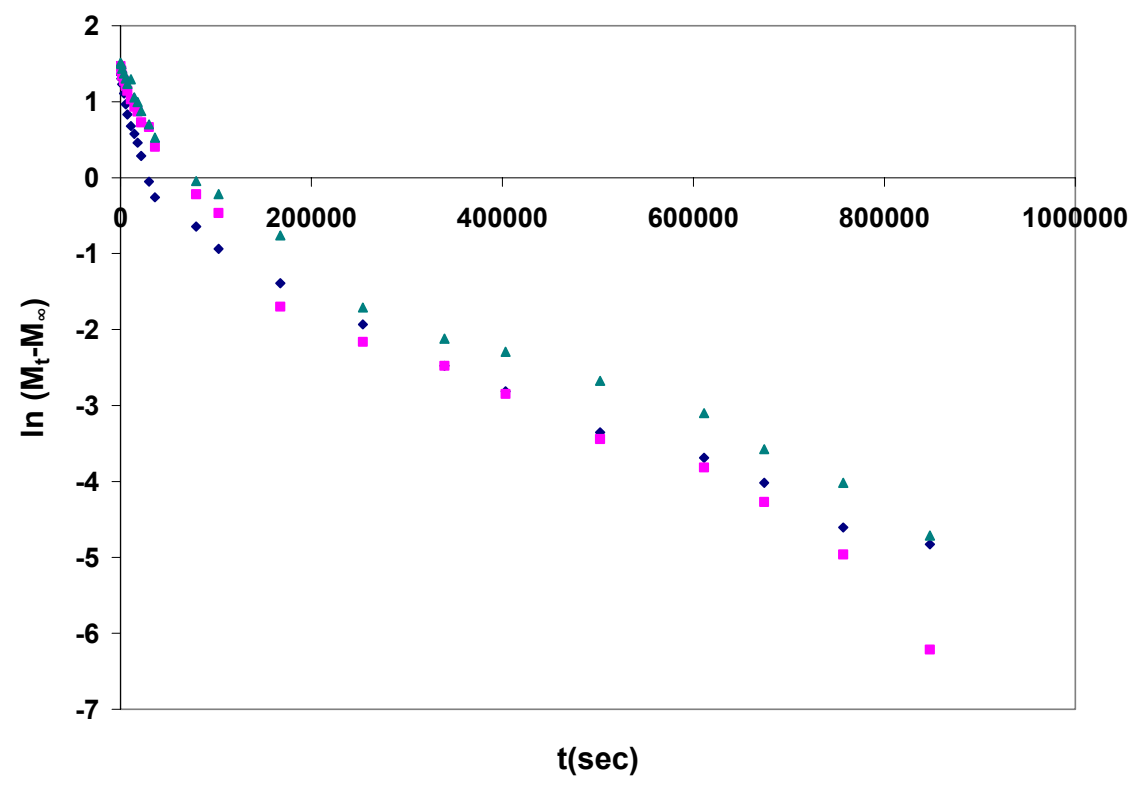

Figure $42 \ln \left(\mathrm{M}_{\mathrm{t}}-\mathrm{M}_{\infty}\right)$ versus t for vinyl ester samples containing $0 \mathrm{wt} \%$ Cloisite $10 \mathrm{~A}^{\circledR}$ at $25{ }^{\circ} \mathrm{C}$ during second cycle of desorption 


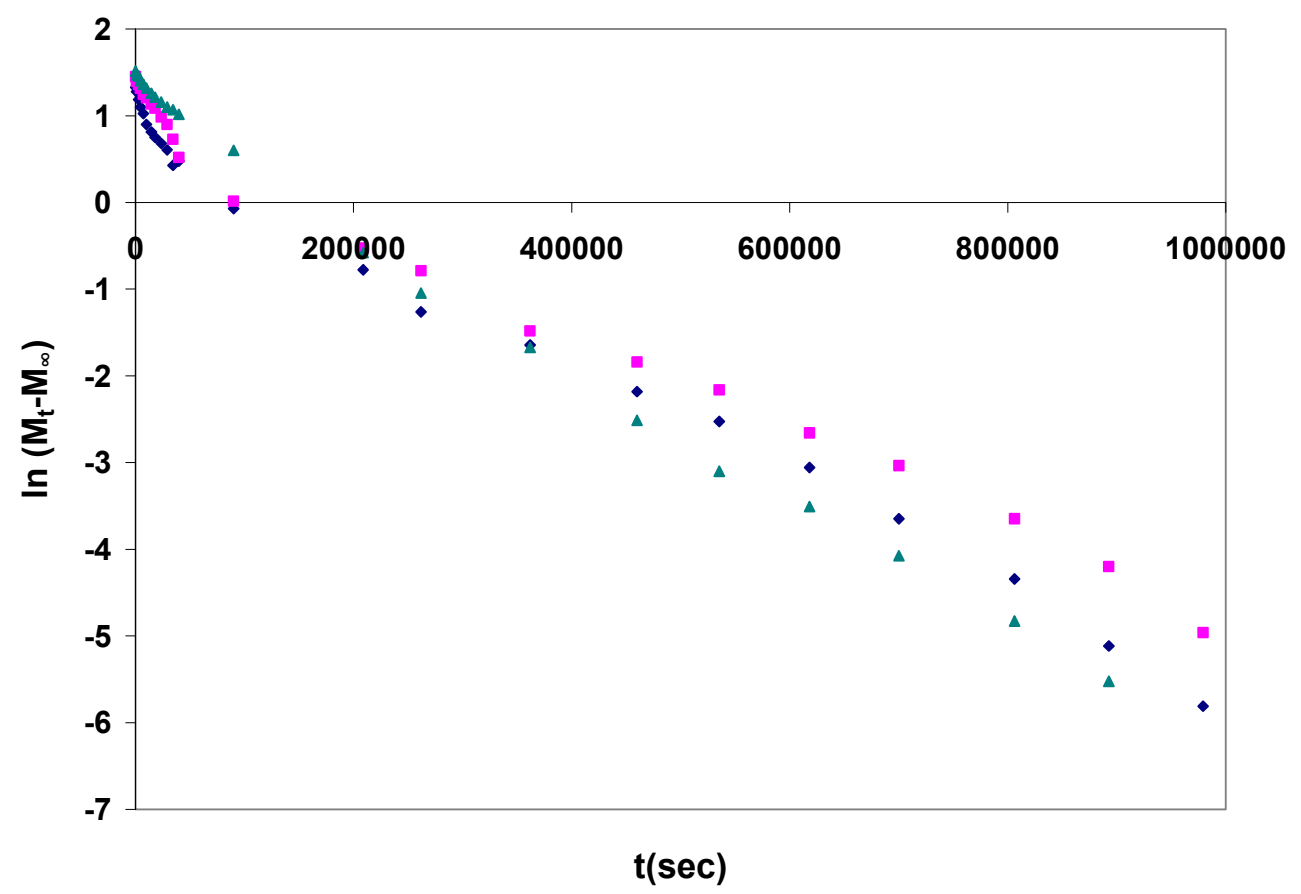

Figure 43 ln $\left(M_{t}-M_{\infty}\right)$ versus t for vinyl ester samples containing 0 wt\% Cloisite $10 A^{\circledR}$ at $25{ }^{\circ} \mathrm{C}$ during third cycle of desorption

The diffusivities can be calculated from these curves as explained in the Section 3.5. The diffusivities of water in neat vinyl ester resin during desorption were found to be $2.15 \times 10^{-9} \mathrm{~cm}^{2} / \mathrm{s}$ for first cycle, $1.8 \times 10^{-9} \mathrm{~cm}^{2} / \mathrm{s}$ for second cycle and $2.02 \times 10^{-9} \mathrm{~cm}^{2} / \mathrm{s}$ for third cycle. This indicates constant desorption diffusivity of water through neat vinyl ester during cyclic sorption-desorption. 


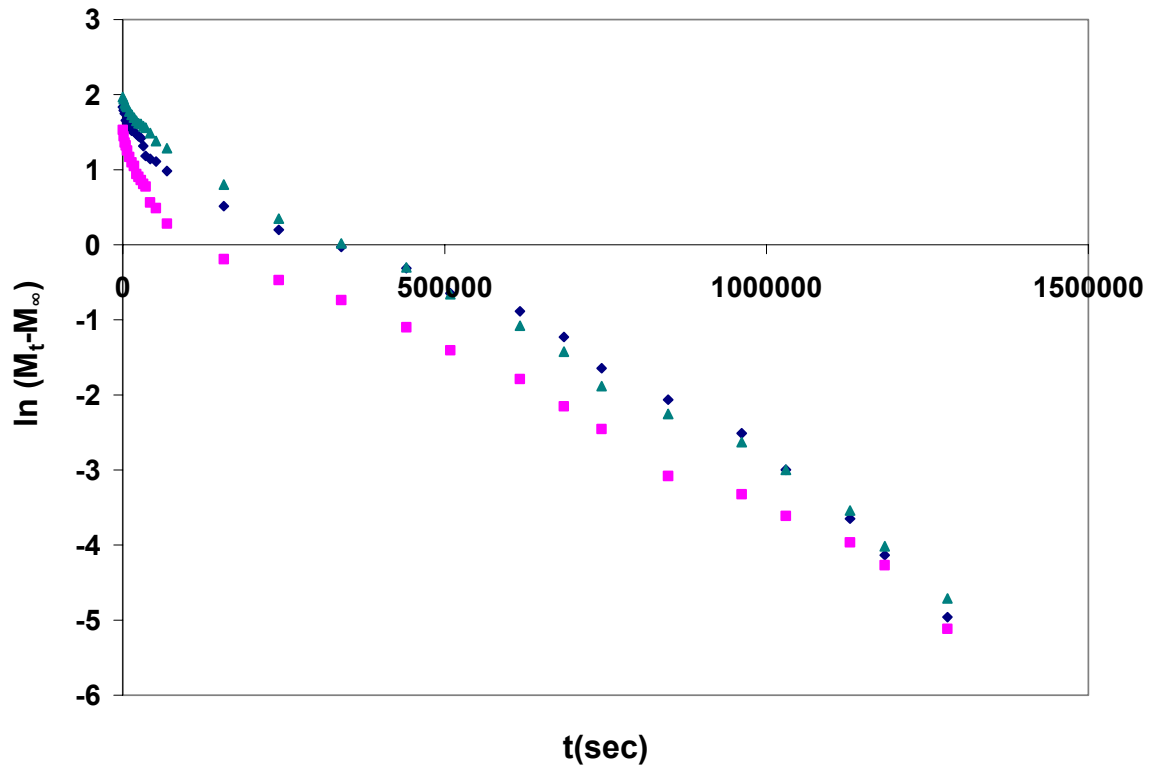

Figure $44 \ln \left(M_{t}-M_{\infty}\right)$ versus t for vinyl ester samples containing 2 wt\% Cloisite $10 A^{\circledR}$ at $25{ }^{\circ} \mathrm{C}$ during first cycle of desorption

Figure 44, Figure 45 and Figure 46 show $\ln \left(\mathrm{M}_{\mathrm{t}}-\mathrm{M}_{\infty}\right)$ versus time for samples containing $2 \mathrm{wt} \%$ Cloisite $10 \mathrm{~A}^{\circledR}$ during three cycles of desorption. The graphs show linear curves during later stages of desorption for all the samples indicating Fickian diffusion during desorption.

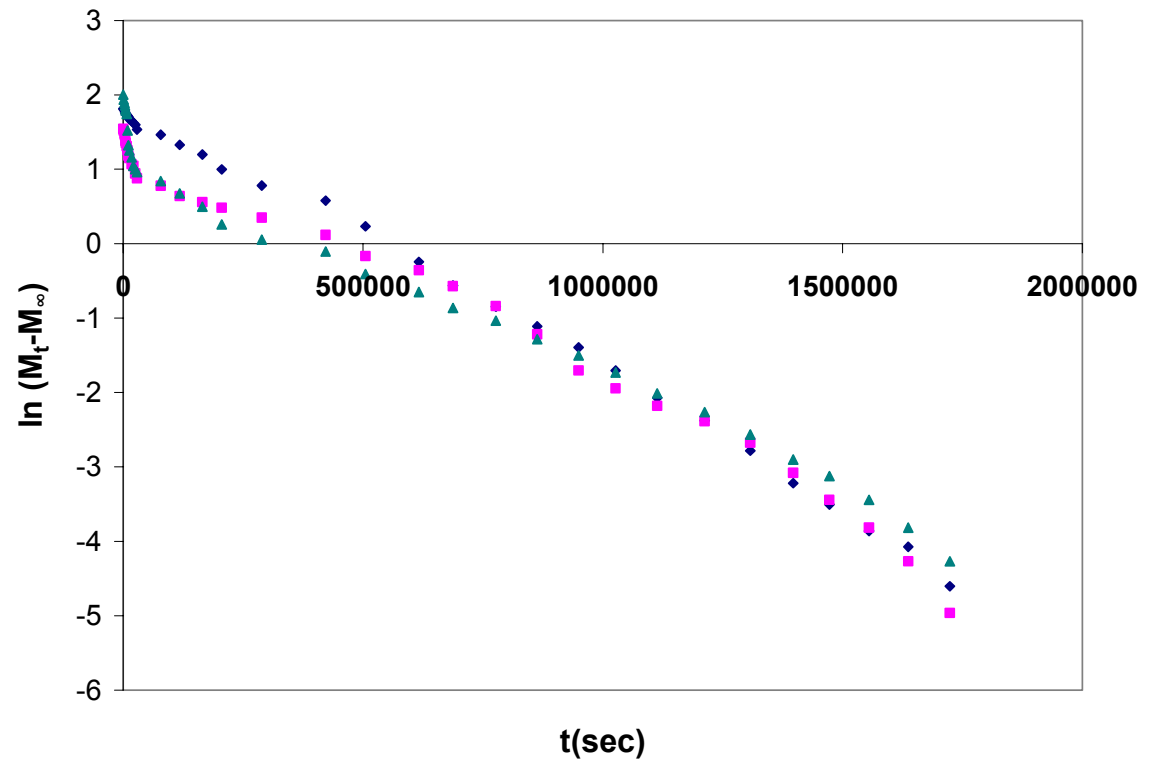

Figure $45 \ln \left(\mathrm{M}_{\mathrm{t}}-\mathrm{M}_{\infty}\right)$ versus t for vinyl ester samples containing $2 \mathrm{wt} \%$ Cloisite $10 \mathrm{~A}^{\circledR}$ at $25{ }^{\circ} \mathrm{C}$ during second cycle of desorption 


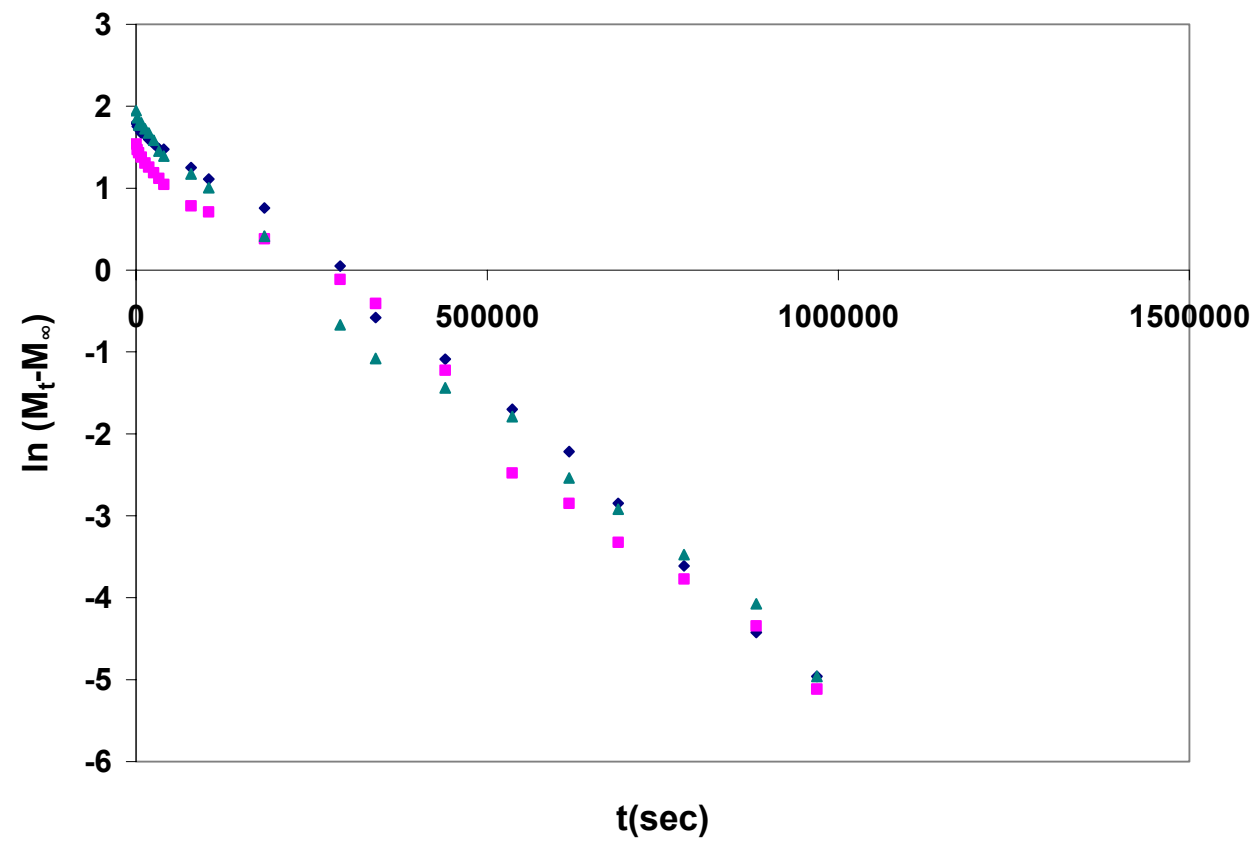

Figure 46 In $\left(M_{t}-M_{\infty}\right)$ versus $t$ for vinyl ester samples containing $2 \mathrm{wt}^{\circ}$ Cloisite $10 A^{\circledR}$ at $25^{\circ} \mathrm{C}$ during third cycle of desorption

The average diffusivities were found to be $2.02 \times 10^{-9} \mathrm{~cm}^{2} / \mathrm{s}$ for first cycle, $1.77 \mathrm{x}$ $10^{-9} \mathrm{~cm}^{2} / \mathrm{s}$ for second cycle and $2.53 \times 10^{-9} \mathrm{~cm}^{2} / \mathrm{s}$ for third cycle of desorption.

Similar graphs of $\ln \left(\mathrm{M}_{\mathrm{t}}-\mathrm{M}_{\infty}\right)$ versus time for samples containing $5 \mathrm{wt} \%$ Cloisite $10 \mathrm{~A}^{\circledR}$ during first, second and third cycles of desorption were drawn and are given in Appendix C in Figure 126, Figure 127 and Figure 128 respectively. The raw data for cyclic sorption-desorption experiments with vinyl ester samples containing $5 \mathrm{wt} \%$ Cloisite $10 \mathrm{~A}^{\circledR}$ is given in Appendix D in Table 16 and Table 17. The graphs show linear curves during later stages of desorption for all the cycles indicating Fickian diffusion during desorption. The diffusivities can be calculated from these curves as explained in the Section 3.5. The average diffusivities were found to be $1.18 \times 10^{-9} \mathrm{~cm}^{2} / \mathrm{s}$ for first cycle, $1.08 \times 10^{-9} \mathrm{~cm}^{2} / \mathrm{s}$ for second cycle and $0.92 \times 10^{-9} \mathrm{~cm}^{2} / \mathrm{s}$ for third cycle of desorption.

The clay loaded samples exhibited similar trend to the neat resin samples in that the diffusivity values during second and third absorption cycle decreased when compared to diffusivity during first cycle. 


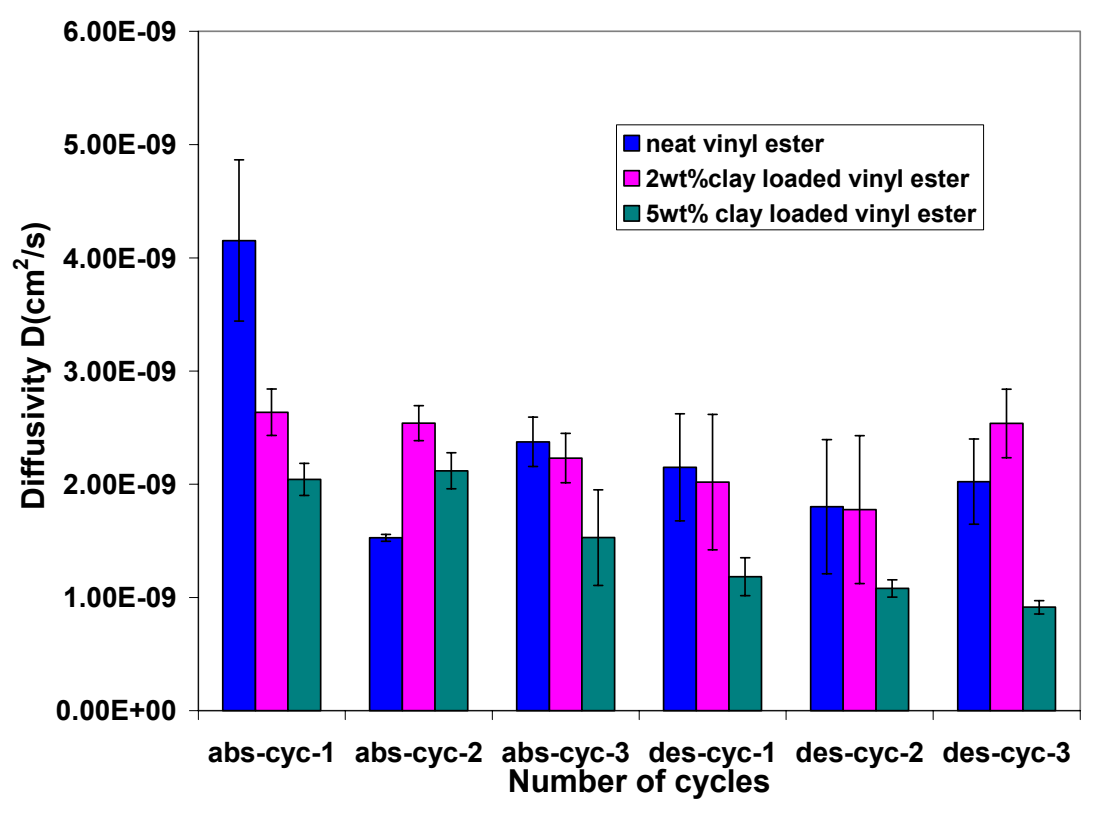

Figure 47 Variation of average diffusivity with number of cycles for vinyl ester samples containing different wt percentages of Cloisite $10 \mathrm{~A}^{\circledR}$ at $25^{\circ} \mathrm{C}$ during three cycles of desorption

It can be clearly seen from the plot of Diffusivity versus Number of cycles in

Figure 47 that the diffusivity decreased with increasing amount of clay for a given cycle of sorption-desorption. Also, after the first absorption cycle, the diffusivity seemed to level off and remained constant during second and third cycles of sorption-desorption. The clay platelets preferentially absorbed the water molecules until they were saturated and hindered further ingress of water molecules by effectively increasing the diffusion path and tortuosity. Once the platelets were completely saturated, the water molecules would then follow a tortuous path to diffuse, thus reducing the diffusion coefficient. Also, the presence of nanoparticles in an intercalated nanocomposite decreases the segmental mobility of polymer chains confined to regions between clay platelets. As a result, the water diffusion slows down (decrease in the diffusivity values), and the penetrating water molecules form aggregates or clusters in the nanocomposite. The decrease in diffusivity with addition of nanoparticles has been widely reported in literature (Petrovicova et al., 2000; Bharadwaj, 2001; Shah, 2001 and Rana, 2003). Addition of $2 \mathrm{wt} \%$ clay reduces the diffusion coefficient by approximately $36 \%$ and a decrease in diffusivity by about $50 \%$ can be observed by addition of $5 \mathrm{wt} \%$ clay. The results for diffusion coefficients, absorption diffusivity $\left(\mathrm{D}_{\mathrm{a}}\right)$, desorption diffusivity $\left(\mathrm{D}_{\mathrm{d}}\right)$ and equilibrium moisture content (EMC) are tabulated in Table 2. 
Table 2. Results of Cyclic Sorption-Desorption Experiments for Vinyl ester Samples at $25^{\circ} \mathrm{C}$

\begin{tabular}{|c|c|c|c|c|c|c|c|c|c|}
\hline $\mathrm{Wt} \%$ & \multicolumn{3}{|c|}{ Cycle-1 } & \multicolumn{3}{|c|}{ Cycle-2 } & \multicolumn{3}{|c|}{ Cycle-3 } \\
\hline $\begin{array}{l}\text { Cloisite } \\
10 A^{\circledR}\end{array}$ & $\begin{array}{l}\mathrm{D}_{\mathrm{a}} \times 10^{9} \\
\left(\mathrm{~cm}^{2} / \mathrm{s}\right)\end{array}$ & EMC (\%) & $\begin{array}{l}\mathrm{D}_{\mathrm{d}} \times 10^{9} \\
\left(\mathrm{~cm}^{2} / \mathrm{s}\right)\end{array}$ & $\begin{array}{l}\mathrm{D}_{\mathrm{a}} \times 10^{9} \\
\left(\mathrm{~cm}^{2} / \mathrm{s}\right)\end{array}$ & EMC (\%) & $\begin{array}{l}D_{d} \times 10^{9} \\
\left(\mathrm{~cm}^{2} / \mathrm{s}\right)\end{array}$ & $\begin{array}{l}\mathrm{D}_{\mathrm{a}} \times 10^{9} \\
\left(\mathrm{~cm}^{2} / \mathrm{s}\right)\end{array}$ & EMC (\%) & $\begin{array}{l}\mathrm{D}_{\mathrm{d}} \times 10^{9} \\
\left(\mathrm{~cm}^{2} / \mathrm{s}\right)\end{array}$ \\
\hline 0 & $4.15 \pm 0.7$ & $1.23 \pm 0.03$ & $2.15 \pm 0.47$ & $1.53 \pm 0.03$ & $1.23 \pm 0.03$ & $1.8 \pm 0.59$ & $2.37 \pm 0.21$ & $1.23 \pm 0.02$ & $2.02 \pm 0.37$ \\
\hline 2 & $2.63 \pm 0.2$ & $1.39 \pm 0.05$ & $2.02 \pm 0.59$ & $2.54 \pm 0.15$ & $1.43 \pm 0.04$ & $1.77 \pm 0.65$ & $2.23 \pm 0.21$ & $1.39 \pm 0.05$ & $2.53 \pm 0.30$ \\
\hline 5 & $2.04 \pm 0.14$ & $1.49 \pm 0.07$ & $1.18 \pm 0.16$ & $2.12 \pm 0.16$ & $1.49 \pm 0.08$ & $1.08 \pm 0.07$ & $1.53 \pm 0.42$ & $1.49 \pm 0.07$ & $0.92 \pm 0.58$ \\
\hline
\end{tabular}

\subsubsection{Experiments with Polyester}

Similar sets of experiments were done with neat polyester samples and polyester samples loaded with $2 \mathrm{wt} \%$ and $5 \mathrm{wt} \%$ clay. Graphs of moisture uptake versus time and moisture content (\%) versus time were plotted for all polyester samples containing different percentages of clay to show the scatter at each of the three cycles of absorption and desorption. As seen in the vinyl ester samples, polyester samples also never quite reached the initial dry weight and retained some of the moisture. The data from each cycle of absorption-desorption for different weight percentages of clay are plotted to demonstrate the effect of cyclical aging and clay addition on the equilibrium moisture content. The raw data for cyclic sorption-desorption experiments with neat polyester samples is given in Appendix D in Table 18 and Table 19.

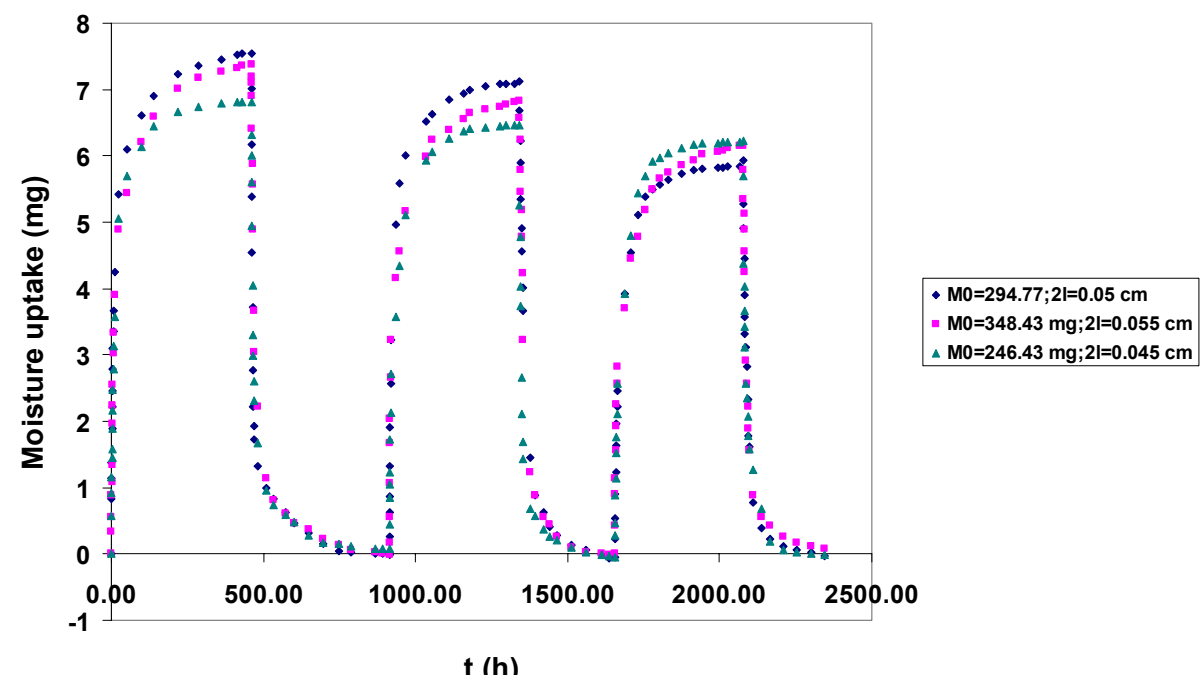

Figure 48 Moisture uptake (mg) versus t (h) for neat polyester samples during cyclic absorption (water) - desorption $(20 \% \mathrm{RH})$ at $25^{\circ} \mathrm{C}$

Figure 48, Figure 49 and Figure 50 show moisture uptake versus time for neat polyester samples and polyester samples containing $2 \mathrm{wt} \%$ and $5 \mathrm{wt} \%$ clay respectively, 
during three cycles of sorption-desorption at $25{ }^{\circ} \mathrm{C}$. For a given cycle of sorptiondesorption, the time taken by the samples to reach equilibrium during absorption and desorption for clay loaded samples was more than that for the neat polyester samples, maximum being for $5 \mathrm{wt} \%$ clay loaded samples.

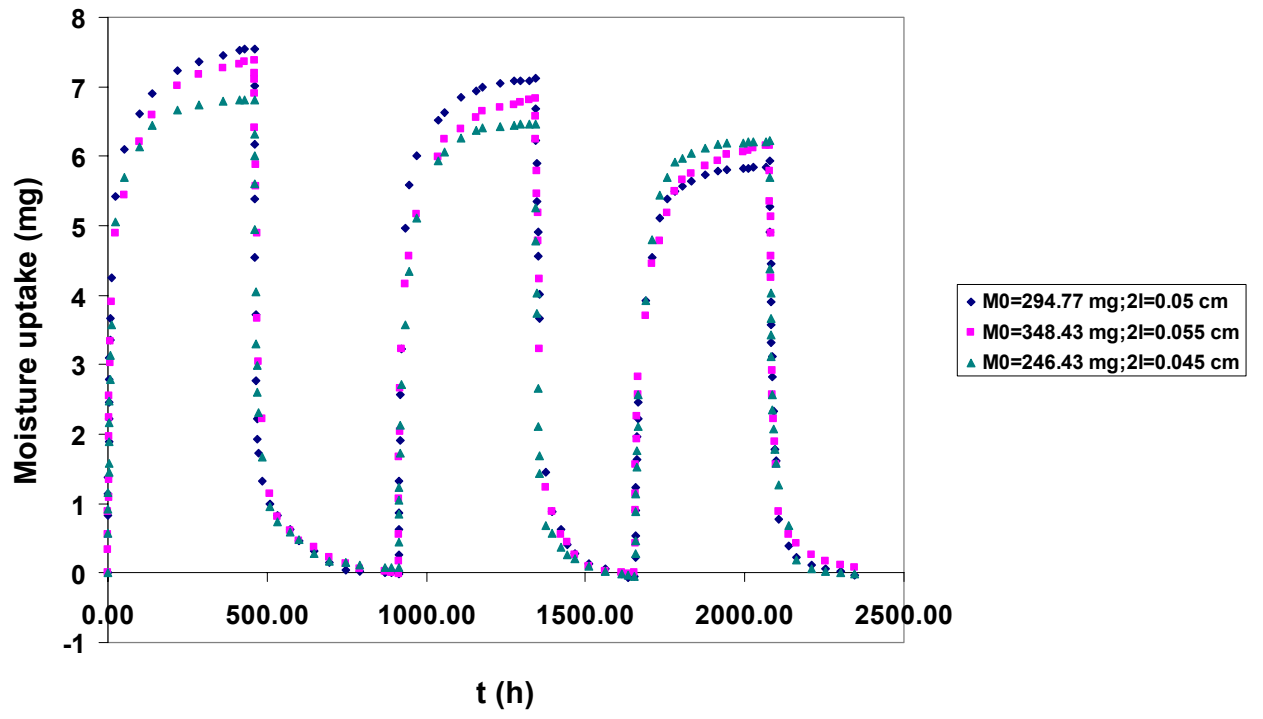

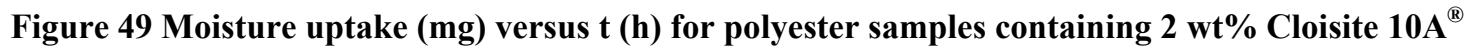
during cyclic absorption (water) - desorption (20\%RH) at $25{ }^{\circ} \mathrm{C}$

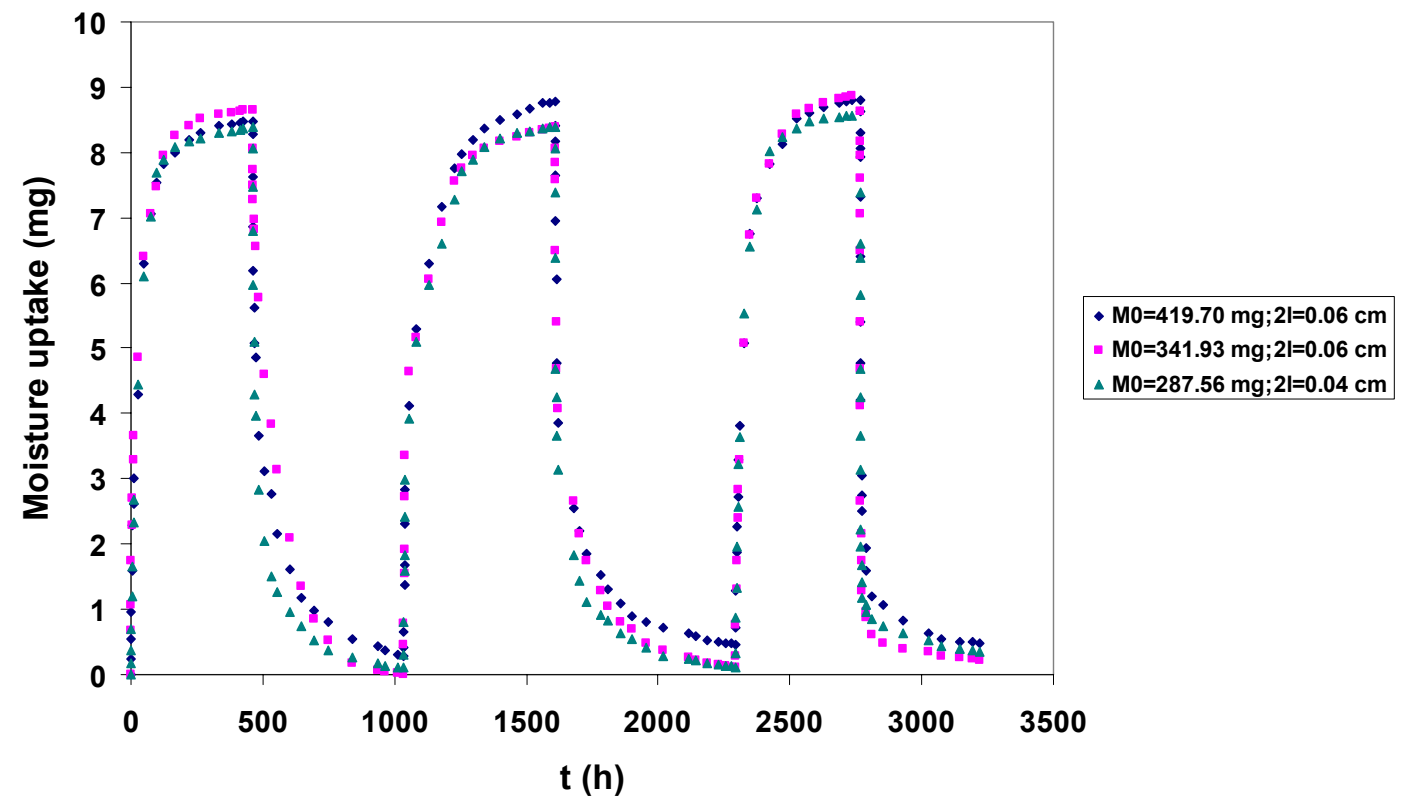

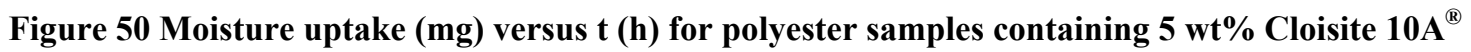
during cyclic absorption (water) - desorption $(20 \% \mathrm{RH})$ at $25{ }^{\circ} \mathrm{C}$ 


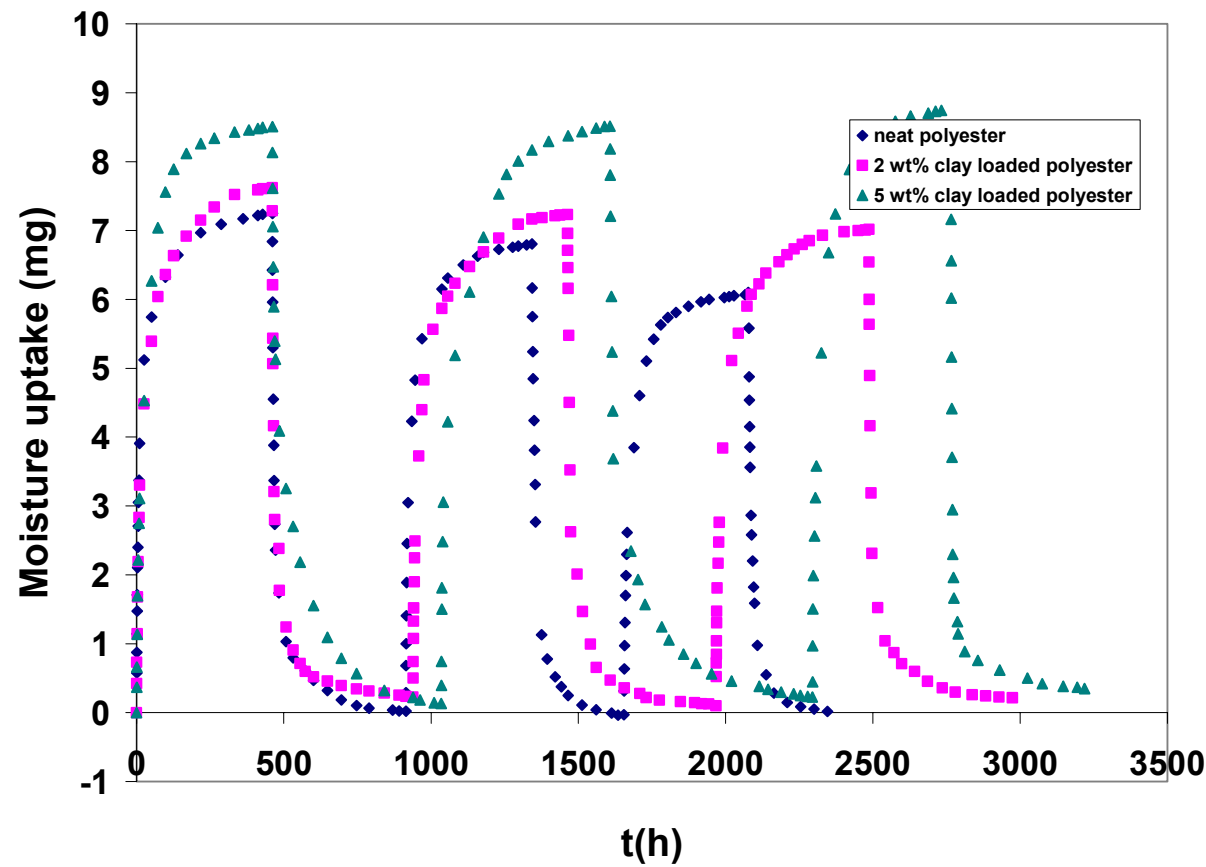

Figure 51 Average moisture uptake (mg) versus t (h) for polyester samples containing different clay loadings during cyclic absorption (water) - desorption (20\%RH) at $25^{\circ} \mathrm{C}$

Figure 51 shows average moisture uptake data for neat polyester resin samples and those containing clay during cyclic sorption-desorption. It can be seen that the equilibrium moisture uptake for clay loaded samples was more than that for the neat polyester samples. It was also observed that the cycling did not alter the equilibrium moisture content of the samples for given clay loading.

The moisture uptake data for neat polyester resin samples and those containing clay depicted that the equilibrium moisture uptake increased with increase in clay loading. The moisture uptake of the neat polyester samples decreased slightly with subsequent cycling. This could have happened because of the polymer degradation due to hydrolysis. This was practically observed during the experiments as the polymer samples became soft and weak.

Using the mass uptake data of the samples, moisture content (\%) for all the samples was determined and the graphs are shown in the following figures. Figure 52, Figure 53 and Figure 54 show moisture content versus time for neat polyester samples, $2 \mathrm{wt} \%$ clay loaded and $5 \mathrm{wt} \%$ clay loaded polyester samples respectively. 


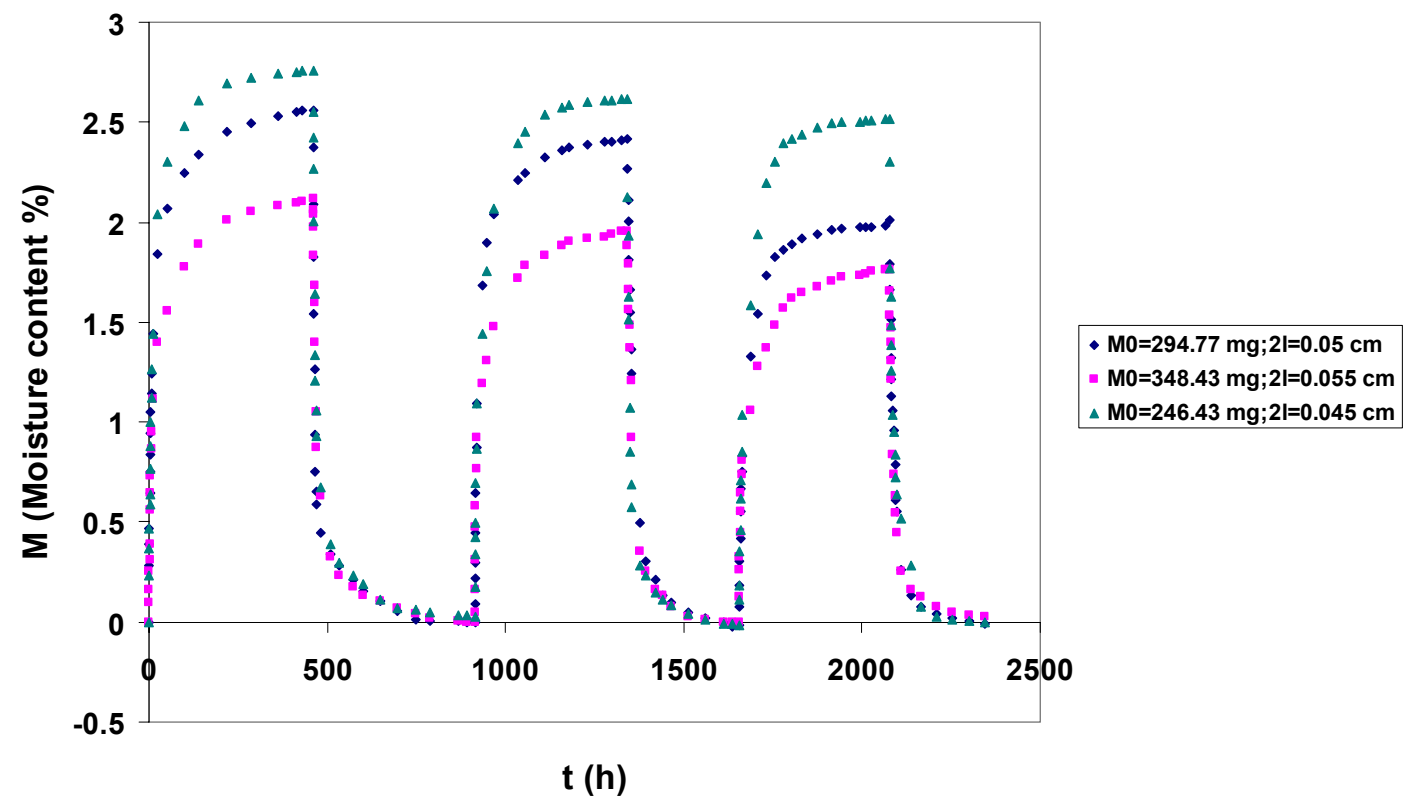

Figure 52 Moisture content versus $t$ for neat polyester samples during absorption (water)-desorption $\left(20 \%\right.$ RH) at $25{ }^{\circ} \mathrm{C}$

Figure 52 shows that moisture content of neat polyester samples decreased with the number of cylces. This again could have happened due to the polymer degradation.

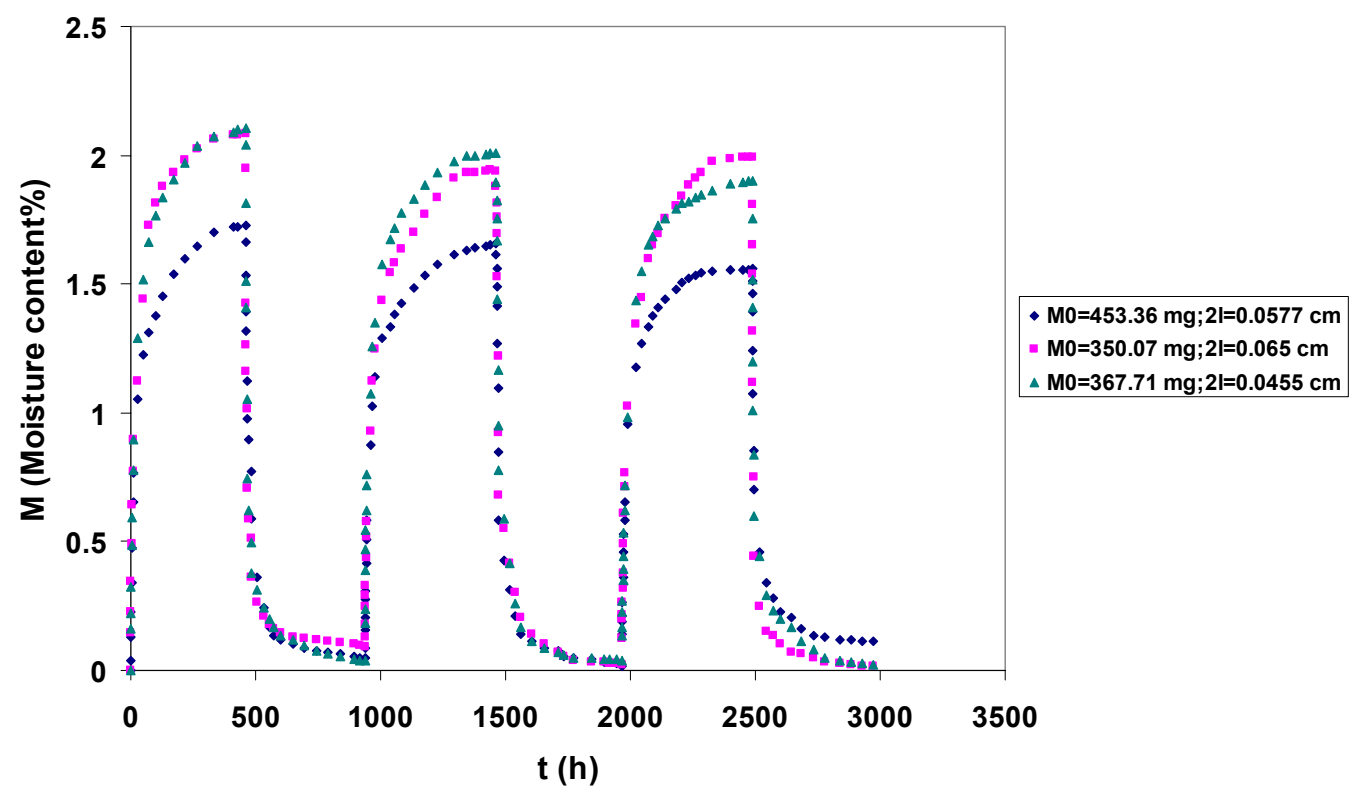

Figure 53 Moisture content versus t for polyester samples containing 2 wt $\%$ Cloisite $10 \mathrm{~A}^{\circledR}$ during absorption (water)-desorption $(20 \% \mathrm{RH})$ at $25{ }^{\circ} \mathrm{C}$ 


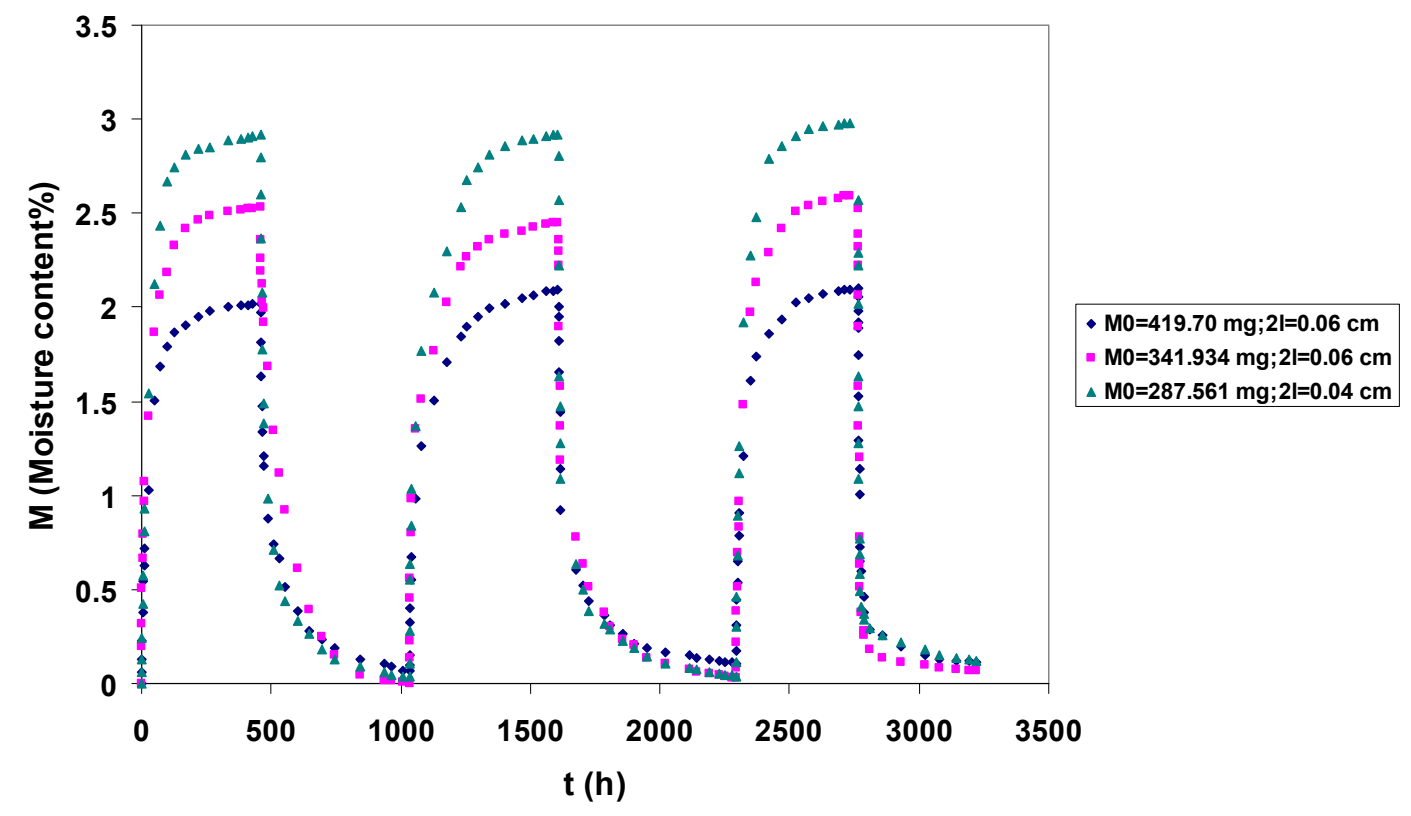

Figure 54 Moisture content versus t for polyester samples containing 5 wt $\%$ Cloisite $10 A^{\circledR}$ during absorption (water)-desorption (20\% RH) at $25^{\circ} \mathrm{C}$

It can be clearly seen from the Figure 53 and Figure 54 that for given clay loading, the samples reached same equilibrium moisture content during three cycles of sorptiondesorption.

Figure 55 shows average moisture content versus time plotted for polyester samples containing different weight percentages of clay.

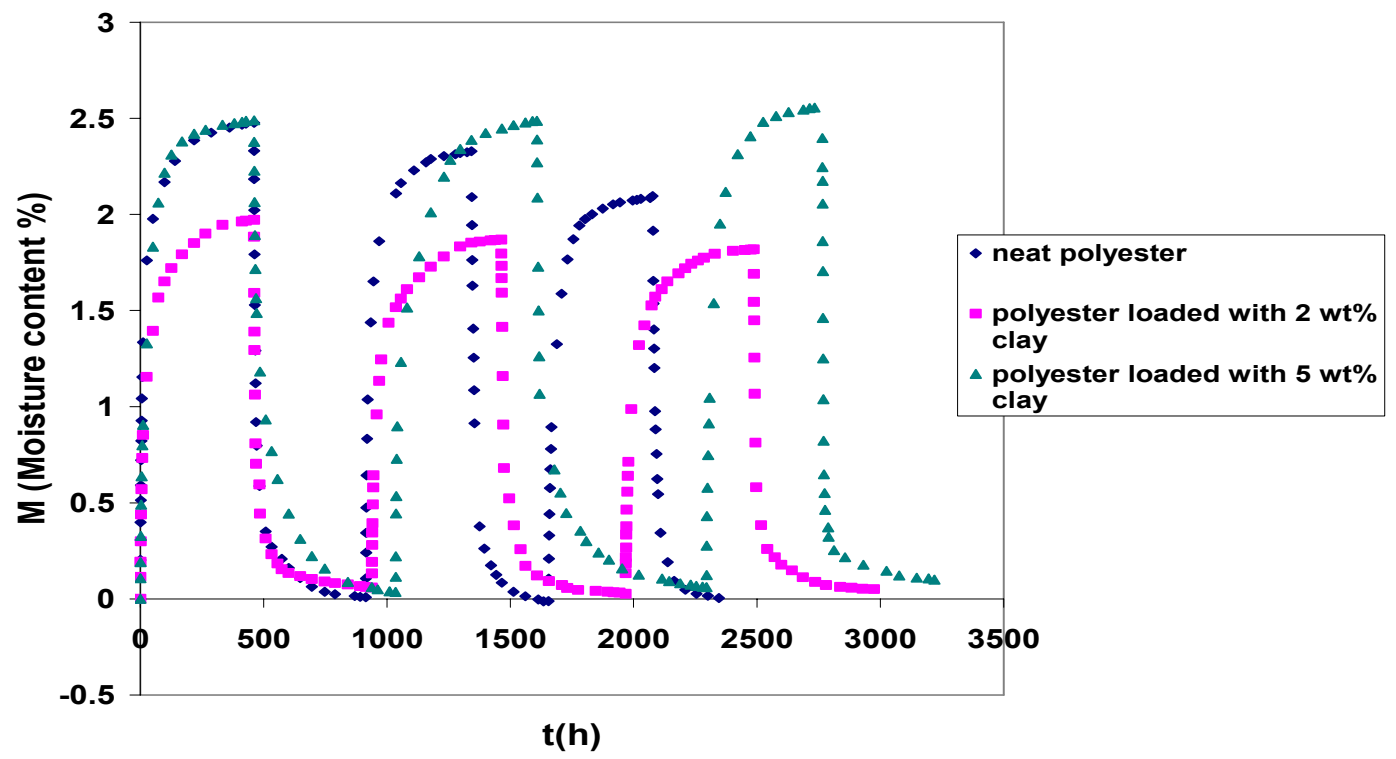

Figure 55 Average moisture content versus time for polyester samples containing different clay loadings 


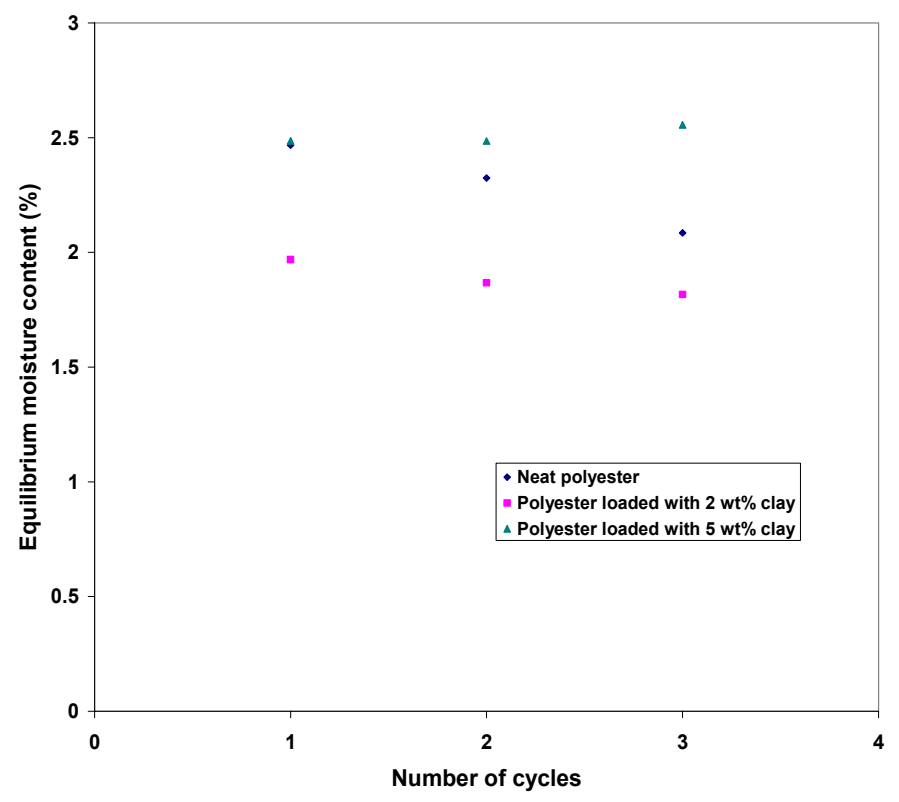

Figure 56 Equilibrium moisture content for polyester samples containing different clay loadings obtained during cyclic sorption-desorption

Figure 56 shows equilibrium moisture content for polyester samples containing different weight percentages of clay during three cycles of sorption-desorption. The average equilibrium moisture content was found to be $2.46 \%$ for neat polyester resin samples, decreased to $2.32 \%$ during second cycle and $2.08 \%$ during third cycle. It was found to be approximately $1.9 \%$ for $2 \mathrm{wt} \%$ clay loaded polyester samples and $2.4 \%$ for 5 $\mathrm{wt} \%$ clay loaded polyester samples during three cycles. The equilibrium moisture content of the neat polyester resin samples during the first absorption cycle was found to be about $2.46 \%$, which is comparable to the findings of other researchers (Gopalan, 1989, 2.4\%). The equilibrium moisture content of the neat polyester samples seemed to decrease with cycling and cycling had no effect on the equilibrium moisture content of polyester samples loaded with clay. The equilibrium moisture content of $2 \mathrm{wt} \%$ clay loaded samples decreased and that of $5 \mathrm{wt} \%$ clay loaded samples remained same as compared to neat polyester resin.

Graphs of $\mathrm{M}_{\mathrm{t}} / \mathrm{M}_{\infty}$ versus $\mathrm{t}^{1 / 2}$ for neat polyester samples, $2 \mathrm{wt} \%$ and $5 \mathrm{wt} \%$ clay loaded polyester samples, during first, second and third cycles of absorption were drawn and are given in Appendix C in Figure 129, Figure 130, Figure 131, Figure 135, Figure 136 and Figure 137 respectively. The graphs show linear initial uptake indicating Fickian 
diffusion during three cycles of absorption. From the initial slopes of these curves, diffusion coefficients were calculated as explained in Section 3.4. The raw data for cyclic sorption-desorption experiments with polyester samples containing $2 \mathrm{wt} \%$ and $5 \mathrm{wt} \%$ Cloisite $10 \mathrm{~A}^{\circledR}$ is given in Appendix D in Table 20, Table 21, Table 22 and Table 23 respectively.

The diffusivity of water in neat polyester resin during first absorption cycle was found to be $4.26 \times 10^{-9} \mathrm{~cm}^{2} / \mathrm{s}$ and this is comparable to the value reported by others (Chin et al., 1999, Marais et.al., 1999 and Verghese et al., 1999). It was found that the corresponding diffusivities of water in neat polyester resin decreased slightly with subsequent cycles. This could be possible due to improved curing and greater crosslinking between the polymer chains with time and subsequent reabsorption. This improved curing and crosslinking with moisture absorption was also previously reported in the past. Similar results were reported by Lee and Rockett (1992) and Grinsted et al. (1992) where, diffusion coefficient, D, calculated for absorption was much higher than that for desorption and reabsorption. It was also observed that the cycling did not alter the equilibrium moisture content of the samples containing clay. The average diffusivities for neat polyester were found to be $4.26 \times 10^{-9} \mathrm{~cm}^{2} / \mathrm{s}$ for first cycle, $4.76 \times 10^{-9} \mathrm{~cm}^{2} / \mathrm{s}$ for second cycle and $2.71 \times 10^{-9} \mathrm{~cm}^{2} / \mathrm{s}$ for third cycle of absorption. The average absorption diffusivities for $2 \mathrm{wt} \%$ clay loaded polyester samples were found to be $3.05 \times 10^{-9} \mathrm{~cm}^{2} / \mathrm{s}$ for first cycle, $2.74 \times 10^{-9} \mathrm{~cm}^{2} / \mathrm{s}$ for second cycle and $2.77 \times 10^{-9} \mathrm{~cm}^{2} / \mathrm{s}$ for third cycle of absorption. The average absorption diffusivities for $5 \mathrm{wt} \%$ clay loaded polyester samples were found to be $2.45 \times 10^{-9} \mathrm{~cm}^{2} / \mathrm{s}$ for first cycle, $1.68 \times 10^{-9} \mathrm{~cm}^{2} / \mathrm{s}$ for second cycle and $2.42 \times 10^{-9} \mathrm{~cm}^{2} / \mathrm{s}$ for third cycle of absorption.

Graphs of $\ln \left(\mathrm{M}_{\mathrm{t}}-\mathrm{M}_{\infty}\right)$ versus time for neat polyester samples, $2 \mathrm{wt} \%$ and $5 \mathrm{wt} \%$ clay loaded polyester samples, during first, second and third cycles of desorption were drawn and are given in Appendix C in Figure 132, Figure 133, Figure 134, Figure 138, Figure 139 and Figure 140 respectively. The graphs show linear curves during later stages of desorption for all the cycles indicating Fickian diffusion during desorption. The diffusivities can be calculated from these curves as explained in the Section 3.5. The average desorption diffusivities were found to be $1.13 \times 10^{-9} \mathrm{~cm}^{2} / \mathrm{s}$ for first cycle, $1.25 \mathrm{x}$ $10^{-9} \mathrm{~cm}^{2} / \mathrm{s}$ for second cycle and $1.61 \times 10^{-9} \mathrm{~cm}^{2} / \mathrm{s}$ for third cycle of desorption. The 
average desorption diffusivities for $2 \mathrm{wt} \%$ clay loaded polyester were found to be $1.08 \mathrm{x}$ $10^{-9} \mathrm{~cm}^{2} / \mathrm{s}$ for first cycle, $1.08 \times 10^{-9} \mathrm{~cm}^{2} / \mathrm{s}$ for second cycle and $1.6 \times 10^{-9} \mathrm{~cm}^{2} / \mathrm{s}$ for third cycle of desorption. And, the average desorption diffusivities for $5 \mathrm{wt} \%$ clay loaded polyester were found to be $1.06 \times 10^{-9} \mathrm{~cm}^{2} / \mathrm{s}$ for first cycle, $1.57 \times 10^{-9} \mathrm{~cm}^{2} / \mathrm{s}$ for second cycle and $1.08 \times 10^{-9} \mathrm{~cm}^{2} / \mathrm{s}$ for third cycle of desorption.

A decrease in absorption diffusivity for all the samples during second and third absorption cycle was observed when compared to diffusivity during first cycle. The reduced diffusivity signifies improved curing and greater crosslinking between the polymer chain molecules during cyclic sorption-desorption. After the first absorption cycle, the diffusivity seemed to level off and remained constant during second and third cycles of sorption-desorption.

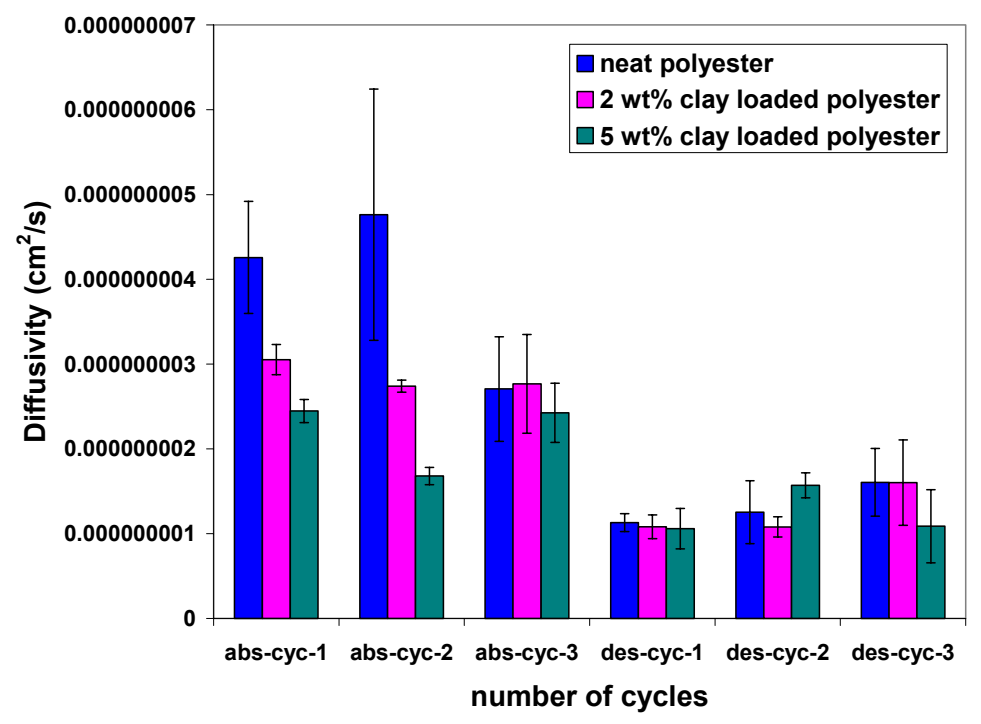

Figure 57 Variation of diffusivity with number of cycles for polyester samples containing different wt percentages of Cloisite $10 \mathrm{~A}^{\circledR}$ at $25^{\circ} \mathrm{C}$ during three cycles of desorption

Figure 57 shows the variation of diffusivity values for samples containing different weight percentages of clay with number of cycles of sorption-desorption. The clay loaded samples exhibited similar trend to the neat resin samples in that the diffusivity values during second and third absorption cycle decreased when compared to diffusivity during first cycle.

The equilibrium moisture content values obtained were consistent with the findings in the literature (Gopalan, 1989) and the decrease in the equilibrium moisture content with increased clay loading was also reported (Ole Becker, 2004). Addition of $2 \mathrm{wt} \%$ clay 
reduces the diffusion coefficient by approximately $28 \%$ and a decrease in diffusivity by about $42 \%$ can be observed by addition of $5 \mathrm{wt} \%$ clay. The results for diffusion coefficients, absorption diffusivity $\left(D_{a}\right)$ and desorption diffusivity $\left(D_{d}\right)$ and equilibrium moisture content (EMC) are tabulated in Table 3.

Table 3. Results of Cyclic Sorption-Desorption Experiments for Polyester Samples at $25^{\circ} \mathrm{C}$

\begin{tabular}{|l|l|l|l|l|l|l|l|l|l|}
\hline \multirow{2}{*}{$\begin{array}{l}\text { Wt\% } \\
\begin{array}{l}\text { Cloisite10A } \\
\circledast\end{array}\end{array}$} & \multicolumn{3}{|c|}{ Cycle-1 } & \multicolumn{3}{|c|}{ Cycle-2 } & \multicolumn{3}{c|}{ Cycle-3 } \\
\cline { 2 - 9 } & $\begin{array}{l}\mathrm{D}_{\mathrm{a}} \mathrm{x} 10^{9} \\
\left(\mathrm{~cm}^{2} / \mathrm{s}\right)\end{array}$ & EMC $(\%)$ & $\begin{array}{l}\mathrm{D}_{\mathrm{d}} \mathrm{x} 10^{9} \\
\left(\mathrm{~cm}^{2} / \mathrm{s}\right)\end{array}$ & $\begin{array}{l}\mathrm{D}_{\mathrm{a}} \mathrm{x} 10^{9} \\
\left(\mathrm{~cm}^{2} / \mathrm{s}\right)\end{array}$ & EMC $(\%)$ & $\begin{array}{l}\mathrm{D}_{\mathrm{d}} \mathrm{x} 10^{9} \\
\left(\mathrm{~cm}^{2} / \mathrm{s}\right)\end{array}$ & $\begin{array}{l}\mathrm{D}_{\mathrm{a}} \mathrm{x} 10^{9} \\
\left(\mathrm{~cm}^{2} / \mathrm{s}\right)\end{array}$ & $\begin{array}{l}\text { EMC }(\%) \\
\left(\mathrm{cm}^{2} / \mathrm{s}\right)\end{array}$ \\
\hline 0 & $4.26 \pm 0.6$ & $2.46 \pm 0.33$ & $1.13 \pm 0.1$ & $4.76 \pm 0.14$ & $2.32 \pm 0.33$ & $1.25 \pm 0.37$ & $2.71 \pm 0.61$ & $2.08 \pm 0.38$ & $1.61 \pm 0.39$ \\
\hline 2 & $3.05 \pm 0.17$ & $1.96 \pm 0.21$ & $1.08 \pm 0.14$ & $2.74 \pm 0.07$ & $1.86 \pm 0.18$ & $1.08 \pm 0.12$ & $2.77 \pm 0.58$ & $1.81 \pm 0.22$ & $1.6 \pm 0.5$ \\
\hline 5 & $2.45 \pm 0.13$ & $2.48 \pm 0.44$ & $1.06 \pm 0.23$ & $1.68 \pm 0.1$ & $2.48 \pm 0.41$ & $1.57 \pm 0.14$ & $2.42 \pm 0.35$ & $2.55 \pm 0.44$ & $1.08 \pm 0.43$ \\
\hline
\end{tabular}

\subsubsection{Experiments with Epoxy}

Similar set of experiments were done with neat epoxy samples and epoxy samples loaded containing $2 \mathrm{wt} \%$ and $5 \mathrm{wt} \%$ clay. Graphs of moisture uptake versus time and moisture content (\%) versus time were plotted for all epoxy samples containing different percentages of clay to show the scatter at each of the three cycles of absorption and desorption. As seen in the vinyl ester and polyester samples, epoxy samples also never quite reached the initial dry weight and retained some of the moisture. The data from each cycle of absorption-desorption for different weight percentages of clay are plotted to demonstrate the effect of cyclical aging and clay addition on the equilibrium moisture content. The raw data for cyclic sorption-desorption experiments with neat epoxy samples is given in Appendix D in Table 24 and Table 25. 


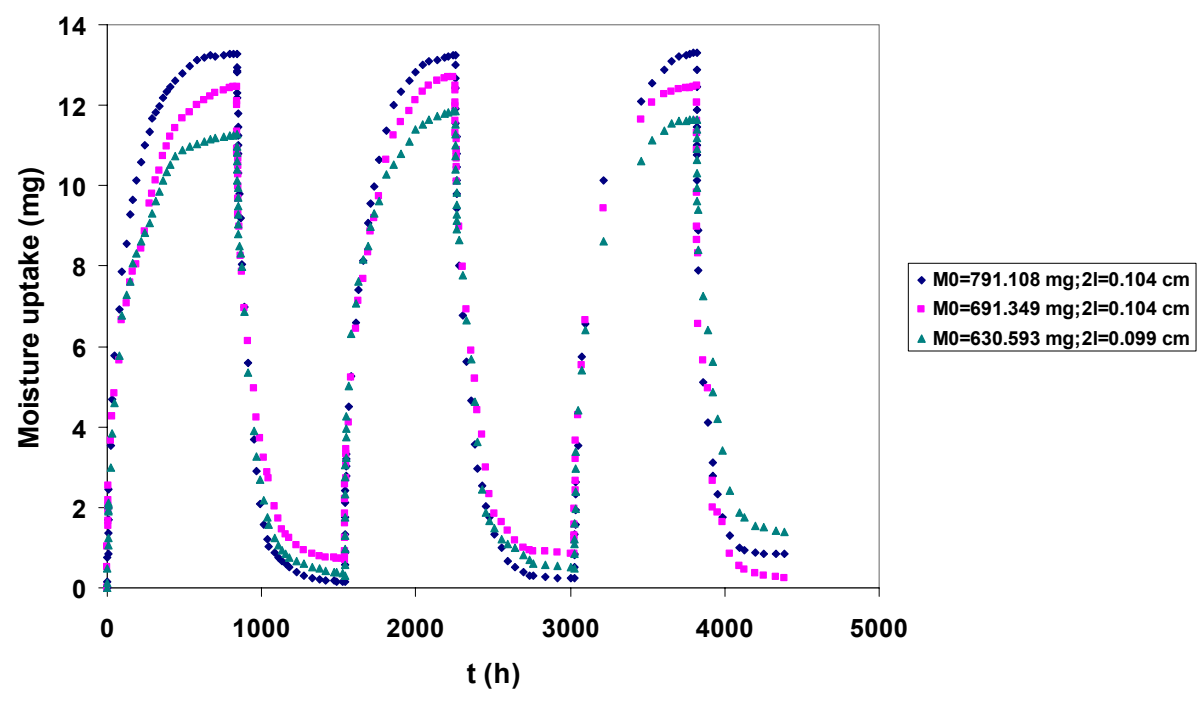

Figure 58 Moisture uptake (mg) versus $\mathrm{t}(\mathrm{h})$ for neat epoxy samples during cyclic absorption (water) - desorption (20\%RH) at $25^{\circ} \mathrm{C}$

Figure 58, Figure 59 and Figure 60 show moisture uptake versus time for neat epoxy samples and epoxy samples containing $2 \mathrm{wt} \%$ and $5 \mathrm{wt} \%$ clay respectively, during three cycles of sorption-desorption at $25{ }^{\circ} \mathrm{C}$. For a given cycle of sorption-desorption, the time taken by the samples to reach equilibrium during absorption and desorption for clay loaded samples was more than that for the neat epoxy samples, maximum being for 5 $\mathrm{wt} \%$ clay loaded samples.

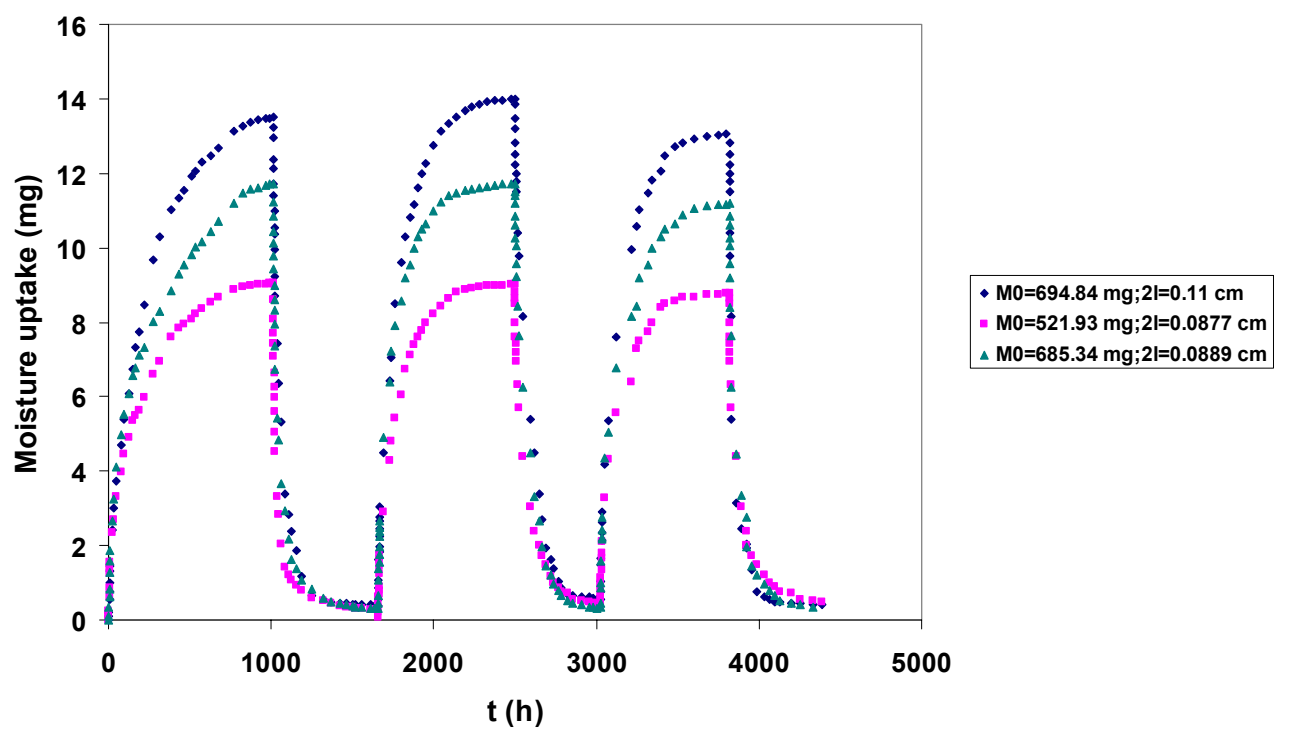

Figure 59 Moisture uptake (mg) versus $t$ (h) for epoxy samples containing $2 w^{\circ} \%{\text { Cloisite } 10 A^{\circledR}}^{\circledR}$ during cyclic absorption (water) - desorption (20\%RH) at $25^{\circ} \mathrm{C}$ 


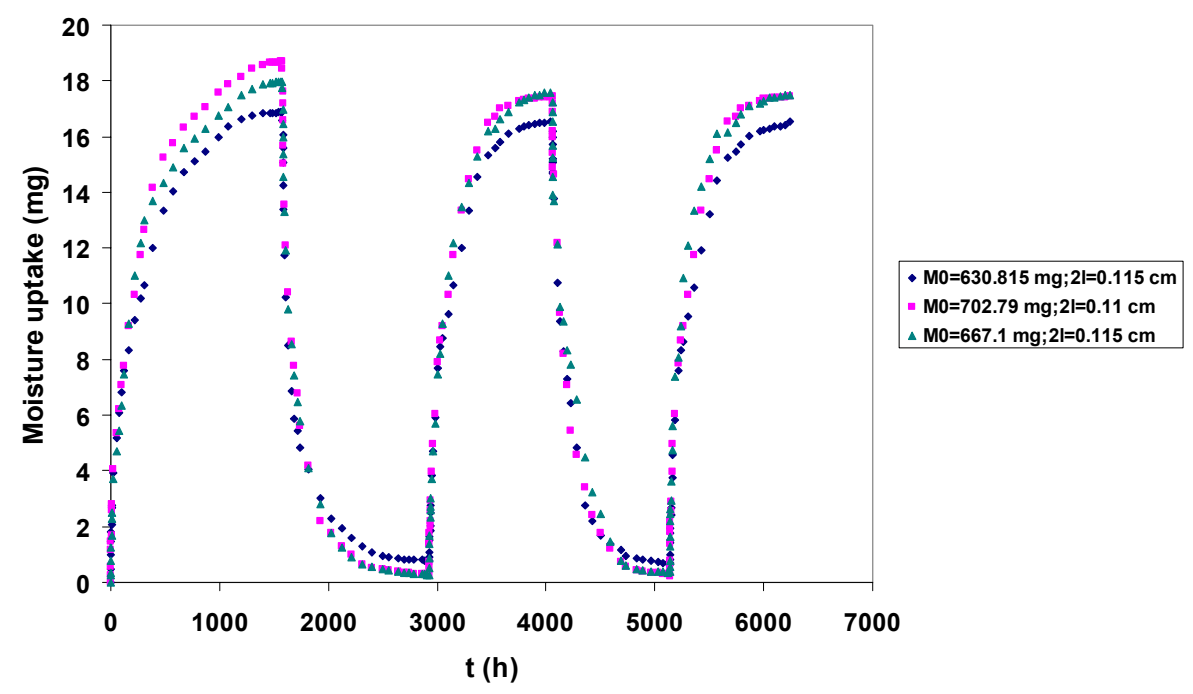

Figure 60 Moisture uptake (mg) versus t (h) for epoxy samples containing 5 wt $\%$ Cloisite $10 \mathrm{~A}^{\circledR}$ during cyclic absorption (water) - desorption (20\%RH) at $25^{\circ} \mathrm{C}$

Figure 61 shows average moisture uptake data for neat polyester resin samples and those containing clay during cyclic sorption-desorption. It can be seen from the figure that the equilibrium moisture uptake for $2 \mathrm{wt} \%$ clay loaded samples was less and $5 \mathrm{wt} \%$ clay loaded samples was more than that for the neat epoxy samples. It was also observed that the cycling did not alter the equilibrium moisture content of the samples for given clay loading.

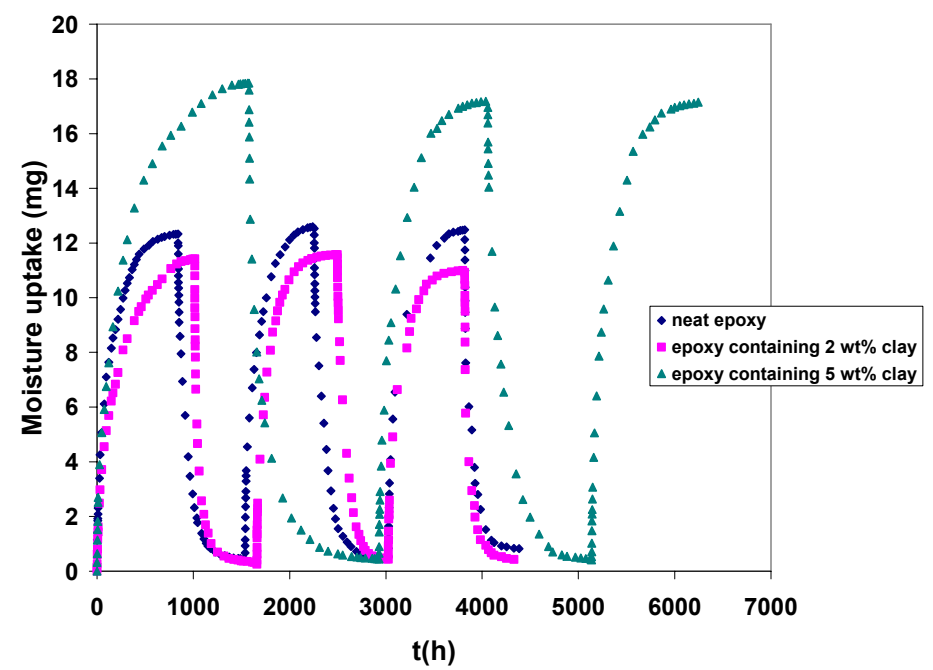

Figure 61 Average moisture uptake (mg) versus $t(h)$ for epoxy samples containing different clay loadings during cyclic absorption (water) - desorption $(20 \% \mathrm{RH})$ at $25^{\circ} \mathrm{C}$

Using the mass uptake data of the samples, moisture content (\%) for all the samples was determined and the graphs are shown in the following figures. Figure 62, Figure 63 
and Figure 64 show moisture content versus time for neat epoxy samples, $2 \mathrm{wt} \%$ clay loaded and $5 \mathrm{wt} \%$ clay loaded polyester samples respectively.

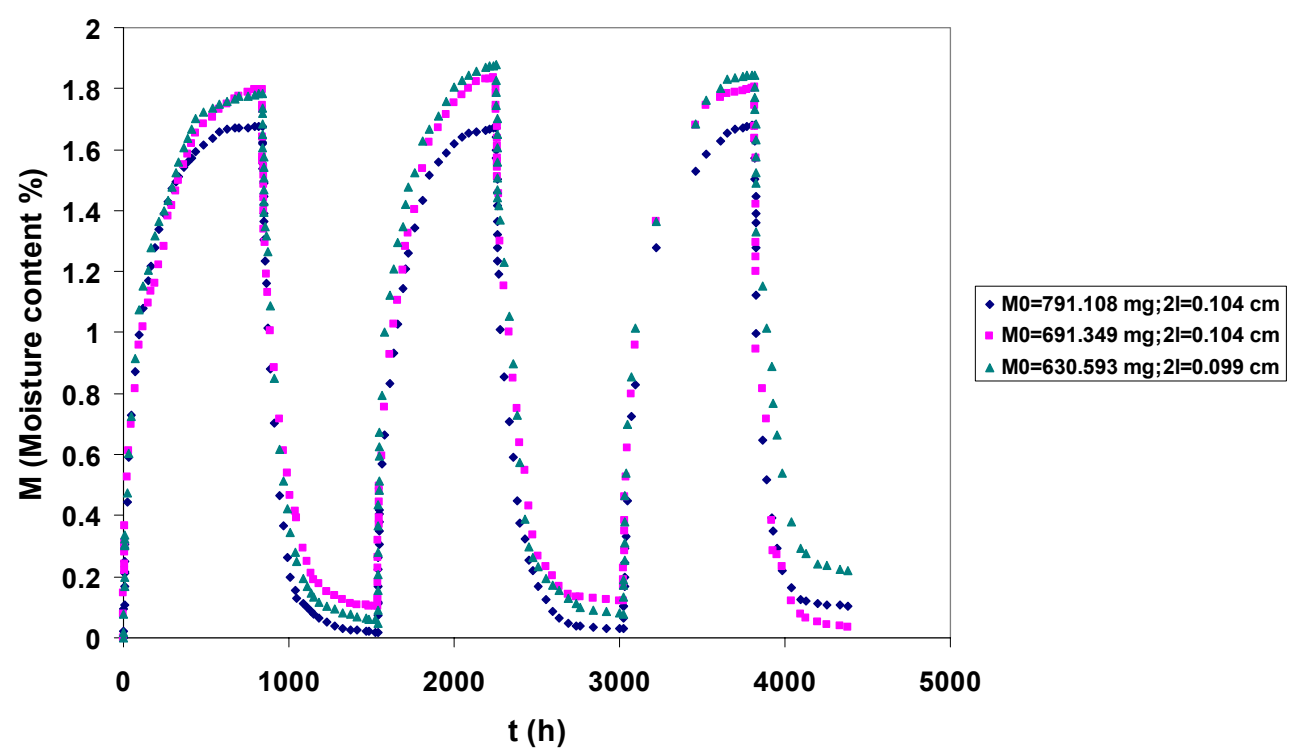

Figure 62 Moisture content versus $t$ for neat epoxy samples during absorption (water)-desorption $(20 \% \mathrm{RH})$ at $25^{\circ} \mathrm{C}$

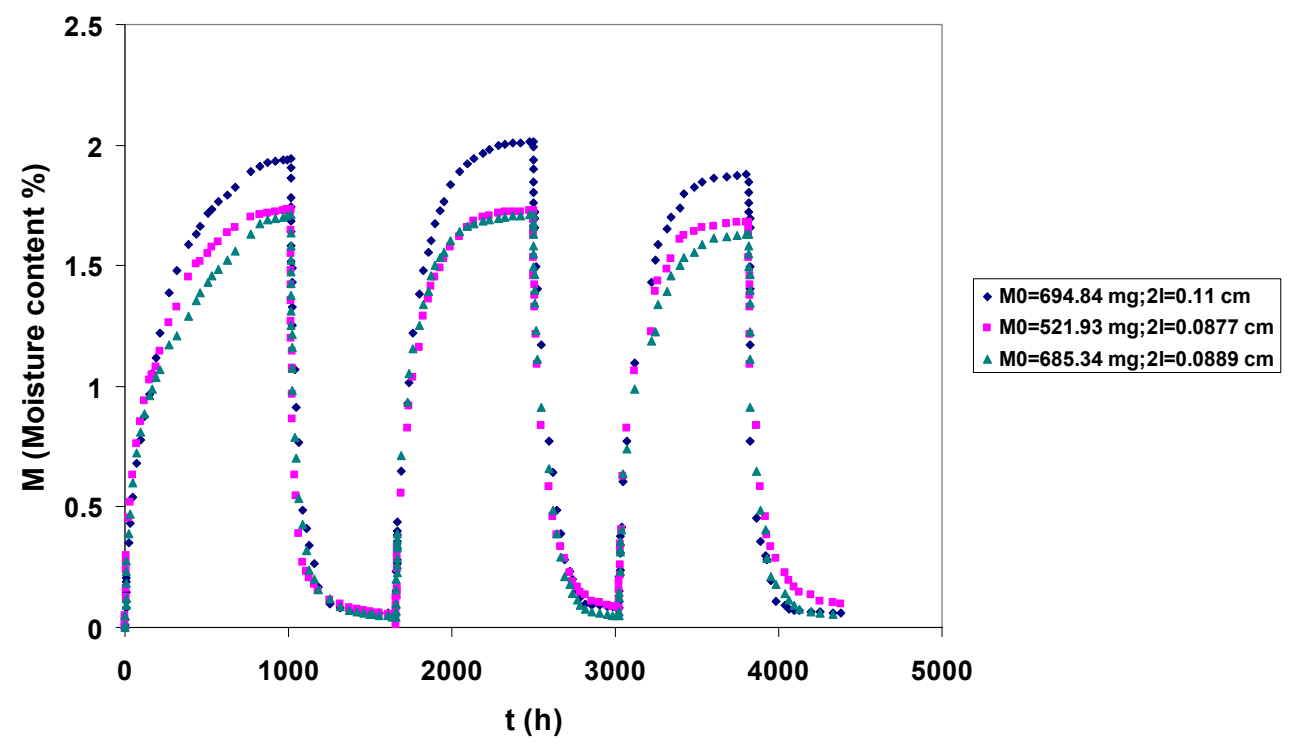

Figure 63 Moisture content versus t for epoxy samples containing $2 \mathrm{wt} \%$ Cloisite $10 \mathrm{~A}^{\circledR}$ during absorption (water)-desorption (20\% RH) at $25{ }^{\circ} \mathrm{C}$ 


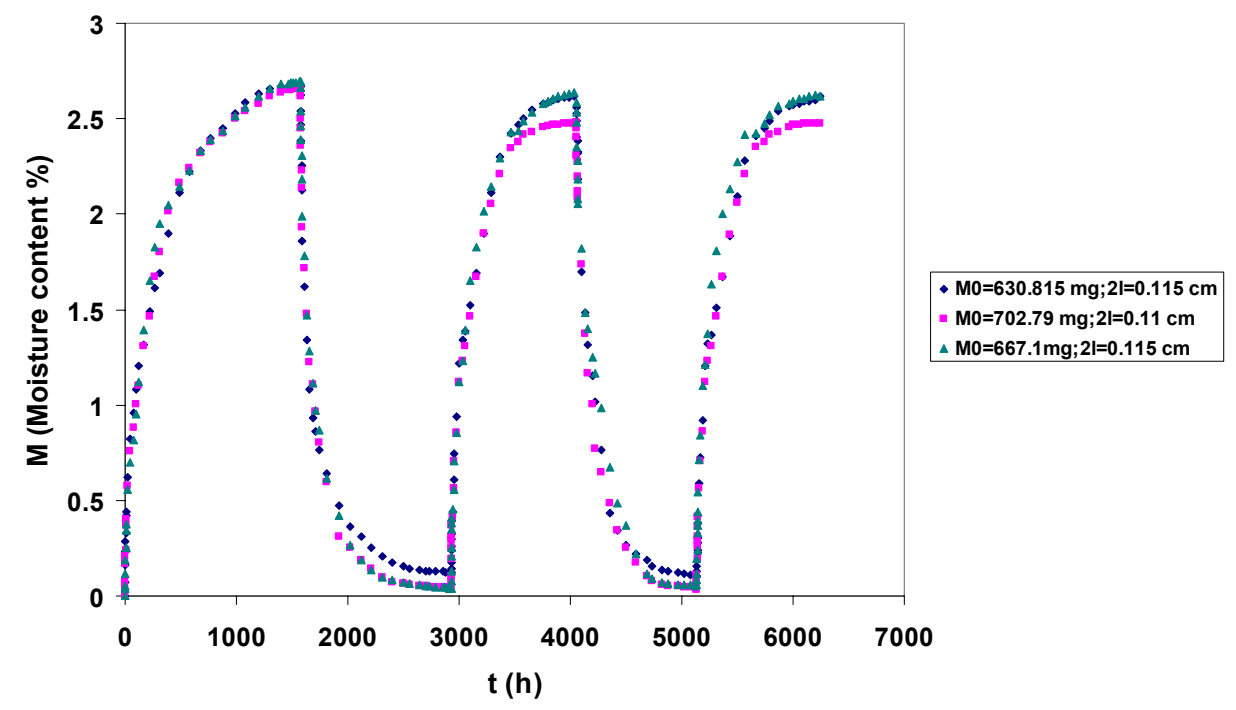

Figure 64 Moisture content versus t for epoxy samples containing $5 \mathrm{wt} \%$ Cloisite $10 \mathrm{~A}^{\circledR}$ during absorption (water)-desorption (20\%RH) at $25^{\circ} \mathrm{C}$

It can be clearly seen from the above figures that for given clay loading, the samples reached same equilibrium moisture content during three cycles of sorptiondesorption.

Figure 65 shows average moisture content versus time plotted for epoxy samples containing different weight percentages of clay.

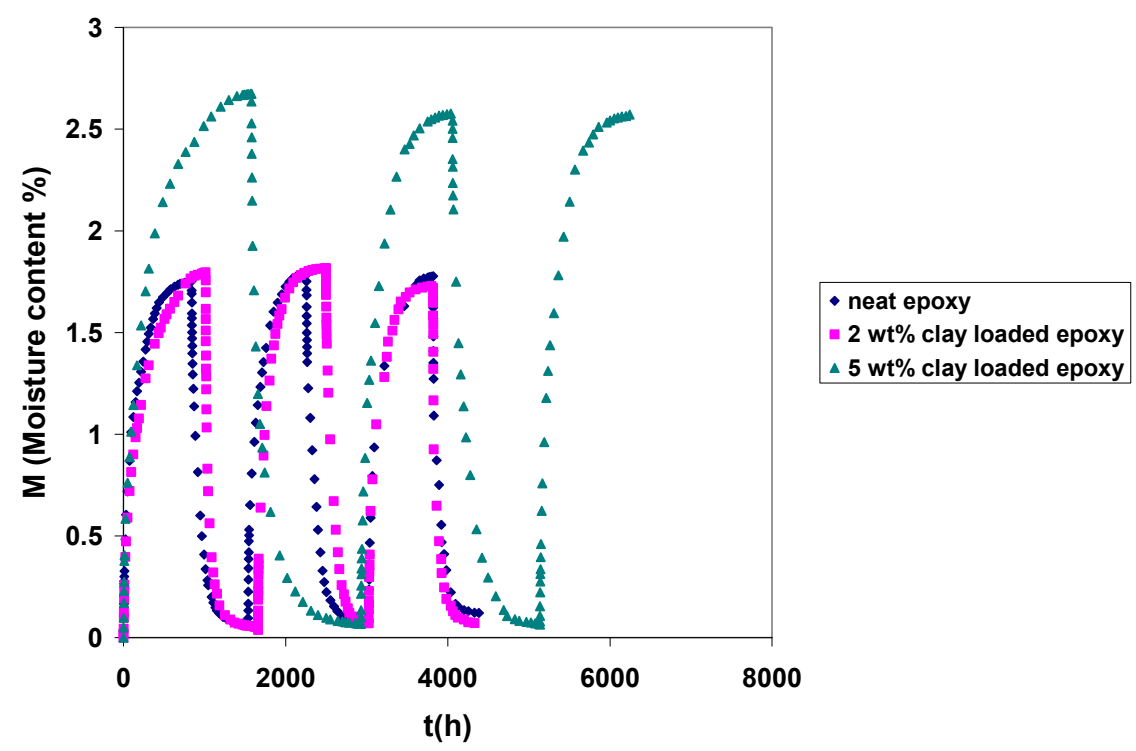

Figure 65 Average moisture content versus time for epoxy samples containing different clay loadings 


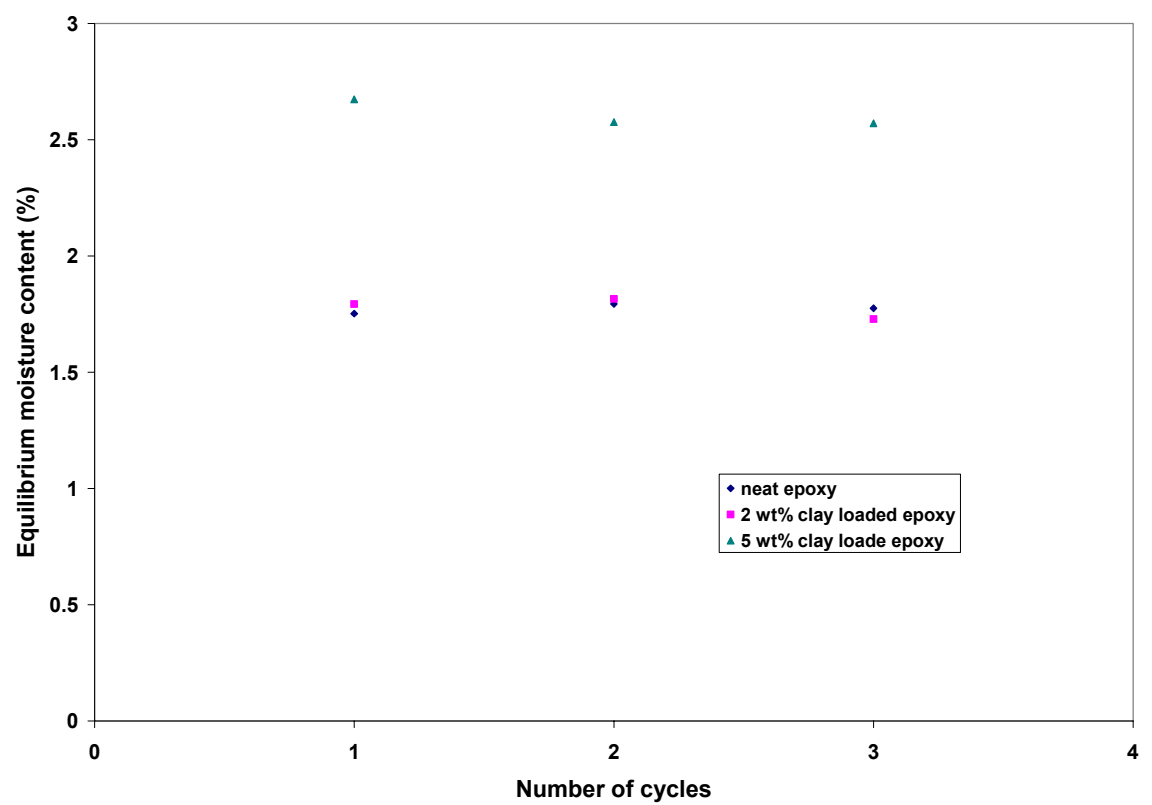

Figure 66 Equilibrium moisture content for epoxy samples containing different clay loadings obtained during cyclic sorption-desorption

Figure 66 shows equilibrium moisture content for epoxy samples containing different weight percentages of clay during three cycles of sorption-desorption. The equilibrium moisture content was found to be $1.75 \%$ for neat epoxy samples, $1.79 \%$ for 2 wt $\%$ clay loaded epoxy samples and $2.67 \%$ for $5 \mathrm{wt} \%$ clay loaded epoxy samples during three cycles. The equilibrium moisture content of the neat epoxy samples seemed to remain constant with cycling. The equilibrium moisture content of $2 \mathrm{wt} \%$ clay loaded samples remained same and that of $5 \mathrm{wt} \%$ clay loaded samples increased as compared to neat epoxy resin.

Graphs of $\mathrm{M}_{\mathrm{t}} / \mathrm{M}_{\infty}$ versus $\mathrm{t}^{1 / 2}$ for neat epoxy, $2 \mathrm{wt} \%$ and $5 \mathrm{wt} \%$ clay loaded epoxy samples during first, second and third cycles of absorption were drawn and are given in Appendix C in Figure 147, Figure 148, Figure 149, Figure 153, Figure 154 and Figure 155. The graphs show linear initial uptake indicating Fickian diffusion during three cycles of absorption. From the initial slopes of these curves, diffusion coefficients were calculated as explained in Section 3.4. The raw data for cyclic sorption-desorption experiments with epoxy samples containing $2 \mathrm{wt} \%$ and $5 \mathrm{wt} \%$ Cloisite $10 \mathrm{~A}^{\circledR}$ is given in Appendix D in Table 26, Table 27, Table 28 and Table 29 respectively.

The diffusivity of water in neat epoxy resin during first absorption cycle was found to be $2.03 \times 10^{-9} \mathrm{~cm}^{2} / \mathrm{s}$ and this is comparable to the value reported by others (Chin et al., 
1999, $0.5 \times 10^{-9} \mathrm{~cm}^{2} / \mathrm{s}$ and Becker et.al., 2004, $4.3 \times 10^{-9} \mathrm{~cm}^{2} / \mathrm{s}$ ). The average diffusivities for neat epoxy were found to be $2.03 \times 10^{-9} \mathrm{~cm}^{2} / \mathrm{s}$ for first cycle, $2.33 \times 10^{-9} \mathrm{~cm}^{2} / \mathrm{s}$ for second cycle and $2.28 \times 10^{-9} \mathrm{~cm}^{2} / \mathrm{s}$ for third cycle of absorption. The average absorption diffusivities for $2 \mathrm{wt} \%$ clay loaded epoxy samples were found to be $1.15 \times 10^{-9} \mathrm{~cm}^{2} / \mathrm{s}$ for first cycle, $1.79 \times 10^{-9} \mathrm{~cm}^{2} / \mathrm{s}$ for second cycle and $2.02 \times 10^{-9} \mathrm{~cm}^{2} / \mathrm{s}$ for third cycle of absorption. The average absorption diffusivities for $5 \mathrm{wt} \%$ clay loaded epoxy samples were found to be $1.1 \times 10^{-9} \mathrm{~cm}^{2} / \mathrm{s}$ for first cycle, $1.71 \times 10^{-9} \mathrm{~cm}^{2} / \mathrm{s}$ for second cycle and $1.99 \times 10^{-9} \mathrm{~cm}^{2} / \mathrm{s}$ for third cycle of absorption.

Graphs of $\ln \left(\mathrm{M}_{\mathrm{t}}-\mathrm{M}_{\infty}\right)$ versus time for neat epoxy , $2 \mathrm{wt} \%$ and $5 \mathrm{wt} \%$ clay loaded epoxy samples during first, second and third cycles of desorption were drawn and are given in Appendix C in Figure 156, Figure 157, Figure 158, Figure 162 and Figure 163 respectively. The graphs show linear curves during later stages of desorption for all the cycles indicating Fickian diffusion during desorption. The diffusivities can be calculated from these curves as explained in the Section 3.5. The average desorption diffusivities for neat epoxy were found to be $3.9 \times 10^{-9} \mathrm{~cm}^{2} / \mathrm{s}$ for first cycle, $2.27 \times 10^{-9} \mathrm{~cm}^{2} / \mathrm{s}$ for second cycle and $3.81 \times 10-9 \mathrm{~cm}^{2} / \mathrm{s}$ for third cycle of desorption. The average desorption diffusivities for $2 \mathrm{wt} \%$ clay loaded epoxy were found to be $3.16 \times 10-9 \mathrm{~cm}^{2} / \mathrm{s}$ for first cycle, $3.19 \times 10^{-9} \mathrm{~cm}^{2} / \mathrm{s}$ for second cycle and $2.48 \times 10^{-9} \mathrm{~cm}^{2} / \mathrm{s}$ for third cycle of desorption. The average desorption diffusivities for $5 \mathrm{wt} \%$ clay loaded epoxy were found to be $2.54 \times 10^{-9} \mathrm{~cm}^{2} / \mathrm{s}$ for first cycle and $3.68 \times 10^{-9} \mathrm{~cm}^{2} / \mathrm{s}$ for second cycle of desorption.

The diffusivity seemed to remain constant for neat epoxy samples during three cycles of sorption-desorption. For clay loaded samples, an increase in absorption diffusivity during second and third absorption cycle was observed when compared to diffusivity during first cycle. The increased diffusivity signifies damage occurred to the samples during cyclic sorption-desorption. 


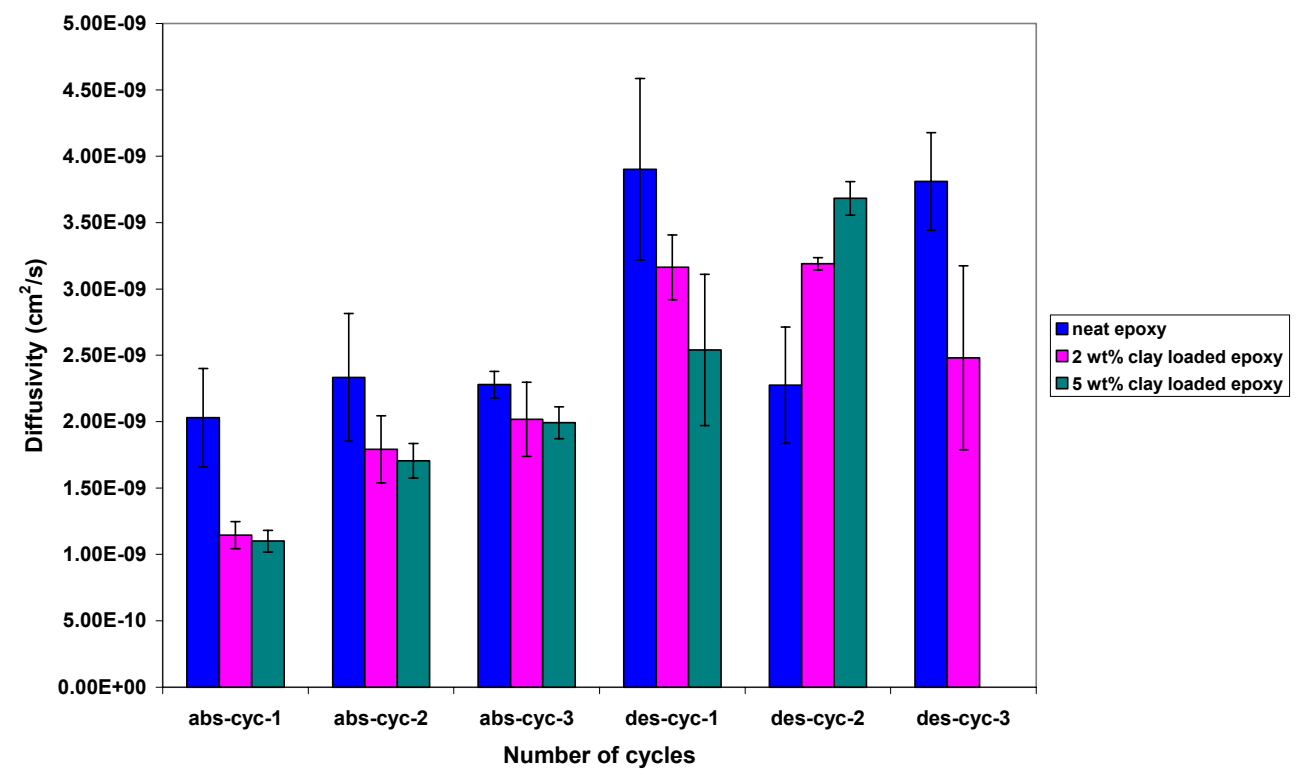

Figure 67 Variation of diffusivity with number of cycles for epoxy samples containing different wt percentages of Cloisite $10 \mathrm{~A}^{\circledR}$ at $25^{\circ} \mathrm{C}$ during three cycles of desorption

Figure 67 shows the variation of diffusivity values for samples containing clay with number of cycles of sorption-desorption. For a given cycle, diffusivity decreased with the addition of clay but increased with increase in the number of cycles.

Table 4. Results of Cyclic Sorption-Desorption Experiments for Epoxy Samples at $25^{\circ} \mathrm{C}$

\begin{tabular}{|c|c|c|c|c|c|c|c|c|c|}
\hline \multirow{2}{*}{$\begin{array}{c}\text { Wt\% } \\
\text { Cloisite } \\
10 A^{\circledR}\end{array}$} & \multicolumn{3}{|c|}{ Cycle-1 } & \multicolumn{3}{c|}{ Cycle-2 } & \multicolumn{3}{c|}{ Cycle-3 } \\
\cline { 2 - 9 } & $\left.\mathrm{D}_{\mathrm{a}} \times 10^{9} / \mathrm{s}\right)$ & EMC $(\%)$ & $\begin{array}{c}\mathrm{D}_{\mathrm{d}} \times 10^{9} \\
\left(\mathrm{~cm}^{2} / \mathrm{s}\right)\end{array}$ & $\begin{array}{c}\mathrm{D}_{\mathrm{a}} \times 10^{9} \\
\left(\mathrm{~cm}^{2} / \mathrm{s}\right)\end{array}$ & EMC $(\%)$ & $\begin{array}{c}\mathrm{D}_{\mathrm{d}} \mathrm{x} 10^{9} \\
\left(\mathrm{~cm}^{2} / \mathrm{s}\right)\end{array}$ & $\begin{array}{c}\mathrm{D}_{\mathrm{a}} \times 10^{9} \\
\left(\mathrm{~cm}^{2} / \mathrm{s}\right)\end{array}$ & $\begin{array}{c}\text { EMC }(\%) \\
\mathrm{D}_{\mathrm{d}} \times 10^{9} \\
\left(\mathrm{~cm}^{2} / \mathrm{s}\right)\end{array}$ \\
\hline 0 & $2.03 \pm 0.37$ & $1.75 \pm 0.06$ & $3.9 \pm 0.68$ & $2.33 \pm 0.48$ & $1.79 \pm 0.1$ & $2.27 \pm 0.43$ & $2.28 \pm 0.09$ & $1.77 \pm 0.08$ & $3.81 \pm 0.37$ \\
\hline 2 & $1.15 \pm 0.10$ & $1.79 \pm 0.12$ & $3.16 \pm 0.24$ & $1.79 \pm 0.25$ & $1.81 \pm 0.17$ & $3.19 \pm 0.47$ & $2.02 \pm 0.28$ & $1.73 \pm 0.13$ & $2.48 \pm 0.69$ \\
\hline 5 & $1.1 \pm 0.08$ & $2.67 \pm 0.01$ & $2.54 \pm 0.57$ & $1.71 \pm 0.13$ & $2.57 \pm 0.08$ & $3.68 \pm 1.26$ & $1.99 \pm 0.12$ & $2.57 \pm 0.08$ & - \\
\hline
\end{tabular}

The results of cyclic sorption-desorption experiments with neat epoxy and clay loaded epoxy samples at $25^{\circ} \mathrm{C}$ are summarized in Table 4 . It can be seen that absorption rate and corresponding diffusion coefficient significantly increase with subsequent resorption cycles in epoxy nanocomposites loaded with $2 \mathrm{wt} \%$ clay and $5 \mathrm{wt} \%$ clay where as increase is not very significant in case of neat epoxy samples. This increase was thought to be due to microstructural damage such as microcracking. This was confirmed with the help of SEM images (Figure 103, Figure 104, Figure 105 and Figure 106) taken on the samples subjected to cyclic sorption and desorption. Equilibrium moisture content 
also increased with the increasing clay content, increase being more significant in $5 \mathrm{wt} \%$ clay loaded samples.

When moisture is being absorbed into a dry laminate, the outer regions tend to swell isotropically, but, the inner moisture-free core will restrain swelling. This non-uniform swelling through the thickness of the laminate would yield high stresses at the surface of the laminate that can result in crack formation (Shirrell, 1978). Martin et al. (2000) studied the effect of water exposure cycles on diffusion properties of a particle-filled epoxy-based adhesive. They have observed an increased saturation level between absorption and reabsorption. They have also reported an increased diffusion coefficient during desorption and subsequent absorption. They attributed the difference to the hydrogen bond formation during the previous hygrothermal aging history. Hydrogen bonds are created between the filler and the resin during the initial hygrothermal aging process within specimens. The bonding strength between the filler and the resin is disrupted even when the water has been extracted during desorption. Thus, during reabsorption, the hydrogen bond formations are in a sense, re-developed to a greater extent at the interface between the fillers and the resin.

Table 5 gives a summary of results of cyclic sorption-desorption experiments for polyester, vinyl ester and epoxy resins. It can be observed that for a given percentage clay, equilibrium moisture content for polyester was greater than that of either vinyl ester or epoxy. The chemical structure and morphology of a polymer are known to affect moisture uptake.

\section{Table 5. Summarized Results of Cyclic Sorption-Desorption Experiments for Polyester, Vinyl ester and Epoxy}

\begin{tabular}{|l|l|l|l|l|l|l|l|l|l|}
\hline \multirow{2}{*}{$\begin{array}{l}\text { Wt } \% \\
\begin{array}{l}\text { Cloisite } \\
10 A^{\circledR}\end{array}\end{array}$} & \multicolumn{3}{|c|}{ Polyester } & \multicolumn{3}{c|}{ Vinyl ester } & \multicolumn{3}{c|}{ Epoxy } \\
\cline { 2 - 10 } & $\begin{array}{l}\mathrm{D}_{\mathrm{a}} \mathrm{x} 10^{9} \\
\left(\mathrm{~cm}^{2} / \mathrm{s}\right)\end{array}$ & $\begin{array}{l}\text { EMC } \\
(\%)\end{array}$ & $\begin{array}{l}\mathrm{D}_{\mathrm{d}} \mathrm{x} 10^{9} \\
\left(\mathrm{~cm}^{2} / \mathrm{s}\right)\end{array}$ & $\begin{array}{l}\mathrm{D}_{\mathrm{a}} \mathrm{x} 10^{9} \\
\left(\mathrm{~cm}^{2} / \mathrm{s}\right)\end{array}$ & $\begin{array}{l}\text { EMC } \\
(\%)\end{array}$ & $\begin{array}{l}\mathrm{D}_{\mathrm{d}} \mathrm{x} 10^{9} \\
\left(\mathrm{~cm}^{2} / \mathrm{s}\right)\end{array}$ & $\begin{array}{l}\mathrm{D}_{\mathrm{a}} \mathrm{x} 10^{9} \\
\left(\mathrm{~cm}^{2} / \mathrm{s}\right)\end{array}$ & $\begin{array}{l}\text { EMC } \\
(\%)\end{array}$ & $\begin{array}{l}\mathrm{D}_{\mathrm{d}} \mathrm{x} 10^{9} \\
\left(\mathrm{~cm}^{2} / \mathrm{s}\right)\end{array}$ \\
\hline 0 & $4.26 \pm 0.6$ & $2.46 \pm 0.33$ & $1.13 \pm 0.1$ & $4.15 \pm 0.7$ & $1.23 \pm 0.03$ & $2.15 \pm 0.47$ & $2.03 \pm 0.37$ & $1.75 \pm 0.06$ & $3.9 \pm 0.68$ \\
\hline 2 & $3.05 \pm 0.17$ & $1.96 \pm 0.21$ & $1.08 \pm 0.14$ & $2.63 \pm 0.2$ & $1.4 \pm 0.05$ & $2.02 \pm 0.59$ & $1.15 \pm 0.1$ & $1.79 \pm 0.12$ & $3.16 \pm 0.24$ \\
\hline 5 & $2.45 \pm 0.13$ & $2.48 \pm 0.44$ & $1.06 \pm 0.23$ & $2.04 \pm 0.14$ & $1.5 \pm 0.16$ & $1.18 \pm 0.16$ & $1.1 \pm 0.08$ & $2.67 \pm 0.01$ & $2.54 \pm 0.57$ \\
\hline
\end{tabular}




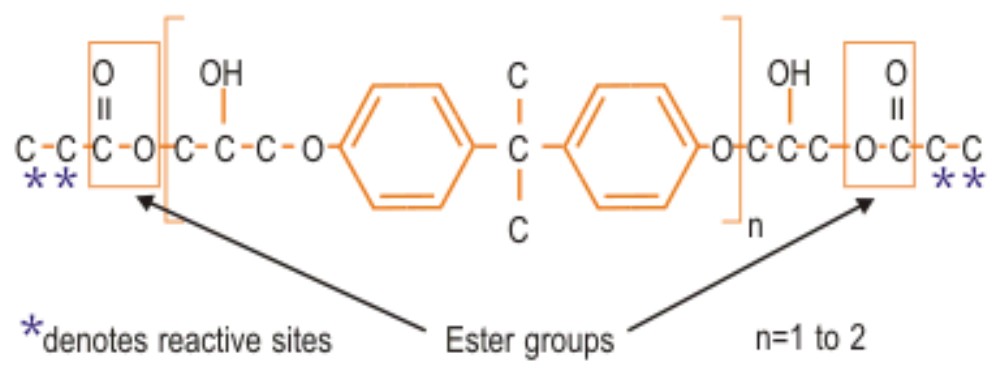

Figure 68 Idealized chemical structure of a typical epoxy based vinyl ester

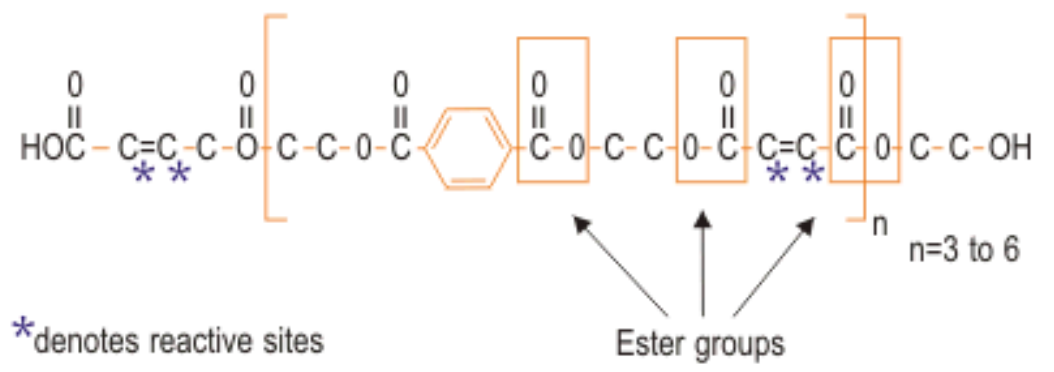

Figure 69 Idealized chemical structure of a typical epoxy based polyester

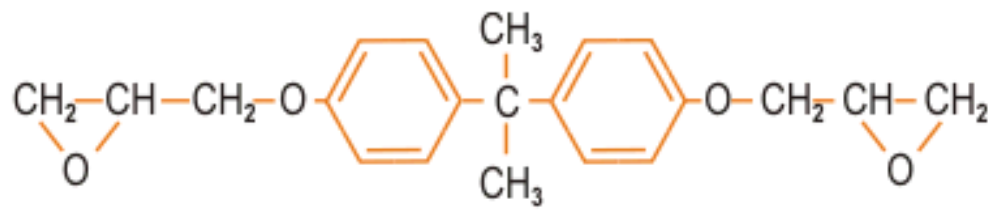

Figure 70 Idealized chemical structure of a typical epoxy (diglycidyl ether of bisphenol-A)

Vinyl ester resins are similar in their molecular structure to polyesters, but differ primarily in the location of their reactive sites and ester groups. Figure 68, Figure 69 and Figure 70 show idealized chemical structures of typical vinyl ester, polyester and epoxy respectively. In case of vinyl ester, the reactive sites and ester groups are present only at the end of the molecular chains whereas in polyester these are present not only at the end of the molecular chain but also within the molecular chain. Also, vinyl ester molecule contains fewer ester groups, which are susceptible to water degradation and less prone to damage by hydrolysis. Epoxy has a long chain molecular structure similar to vinyl ester with reactive sites at both ends. However, in epoxy, epoxy groups instead of ester groups form these reactive sites. The absence of ester groups means that the epoxy resin has particularly good water resistance.

\subsubsection{Interaction of Water with Polymers During Cyclic Sorption-Desorption}

Startsev et al. (1995) conducted a wide range of investigation on the influence of 
water on the properties of various classes of polymers and polymeric composite materials. Polymeric materials when exposed to a humid environment undergo plasticization due to water ingress, and this results in a reduction in strength, modulus and glass transition temperature. At low temperature (30-50 K below $273 \mathrm{~K})$, water crystallizes and acts as a hard dispersed filler instead of a plasticizer. Interaction of water with polymers causes irreversible effects due to structural relaxation and activation by a chemical reaction. Under the influence of water, the mobility of polymeric chains increases creating a more perfect polymer structure as a result of exfoliation of the system. Also, water is a peculiar catalyst of the post curing chemical reaction. Water, while plasticizing a polymer in a humid climate, can speed up chemical reactions of destruction. With the development of structural reconstructions, chemical reactions, and formation of defects, the rate of moisture ingress and the maximum rates of water sorption alter.

\subsection{Sorption Experiments with Neat and Clay loaded Vinyl ester Samples at Different Relative Humidities (\%RH)}

To determine the dependence of equilibrium moisture content (EMC) and diffusivity on relative humidity $(\mathrm{RH})$ of exposed environment, neat vinyl ester samples and those containing $2 \mathrm{wt} \%$ and $5 \mathrm{wt} \%$ clay were exposed to four different relative humidities $40 \% \mathrm{RH}, 60 \% \mathrm{RH}, 70 \% \mathrm{RH}$ and $80 \% \mathrm{RH}$. Graphs of moisture content versus time were plotted for all the samples and equilibrium moisture content was determined from the maximum or equilibrium value attained by the samples for a given relative humidity.

\subsubsection{EMC at $40 \%$ Relative Humidity}

Figure 71, Figure 72 and Figure 73 show respective graphs of moisture content (\%) versus time for neat vinyl ester samples and those containing $2 \mathrm{wt} \%$ and $5 \mathrm{wt} \%$ Cloisite $10 \mathrm{~A}^{\circledR}$ exposed to $40 \% \mathrm{RH}$ at $25^{\circ} \mathrm{C}$. 


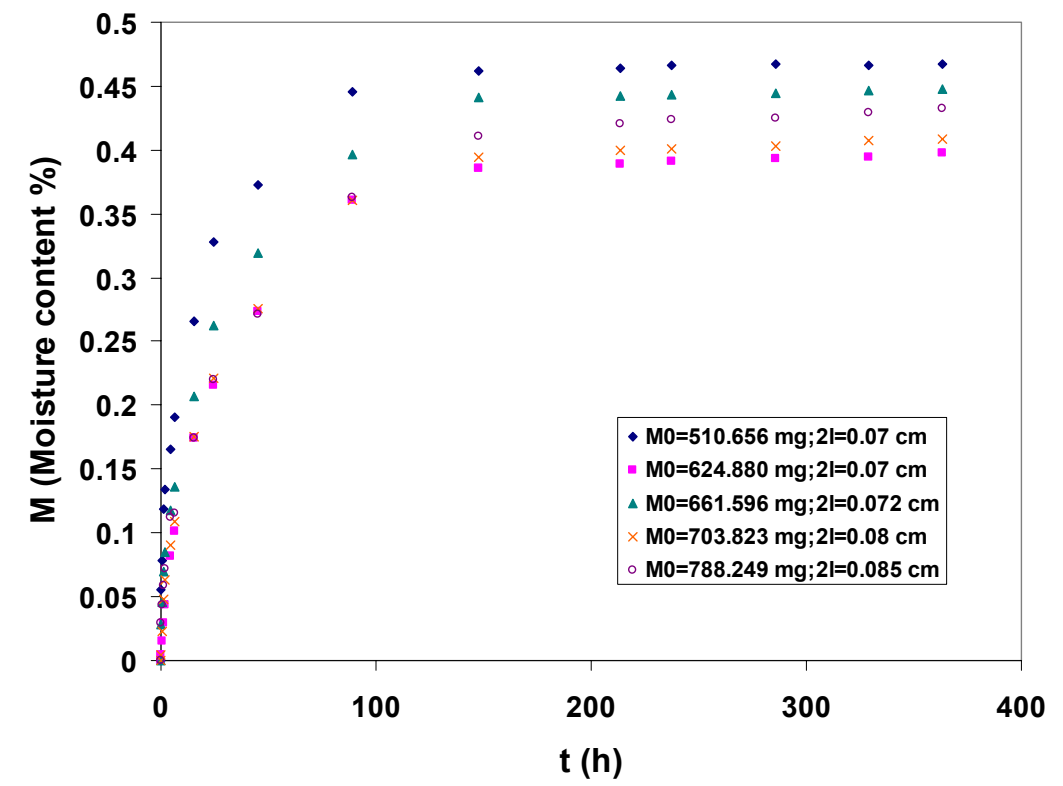

Figure 71 Moisture content versus t for neat vinyl ester samples exposed to $40 \% \mathrm{RH}$ at $25^{\circ} \mathrm{C}$

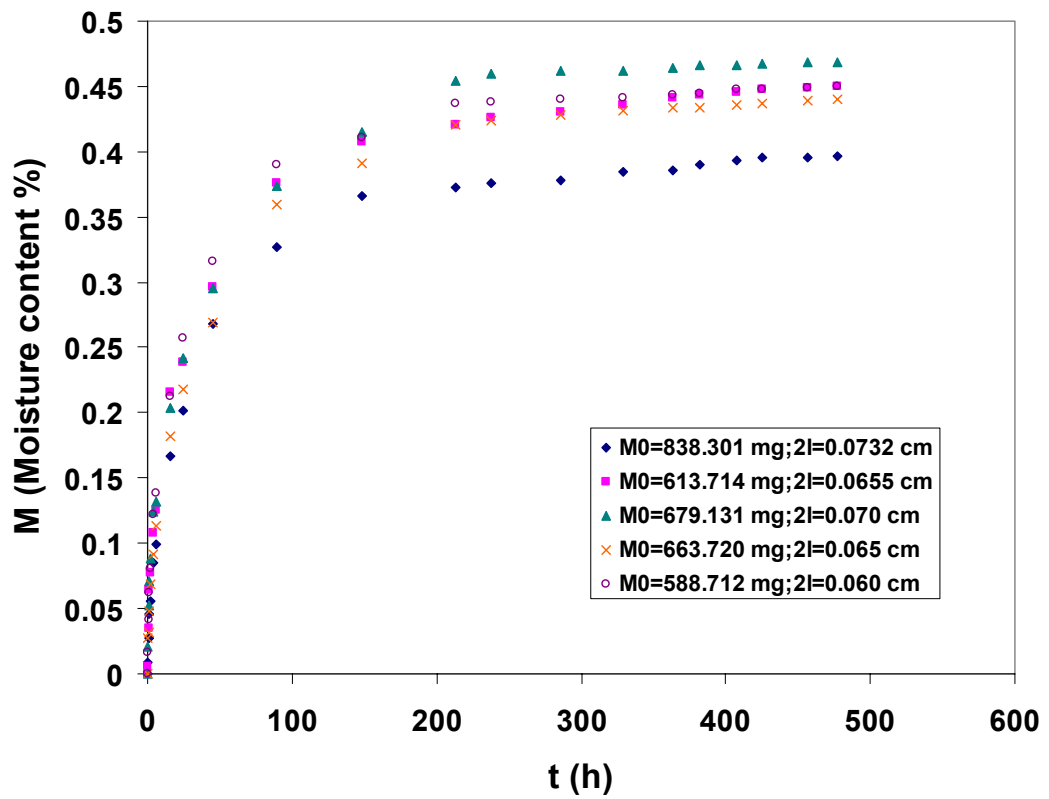

Figure 72 Moisture content versus t for $2 \mathrm{wt} \%$ clay loaded vinyl ester samples exposed to $40 \% \mathrm{RH}$ at $25^{\circ} \mathrm{C}$ 


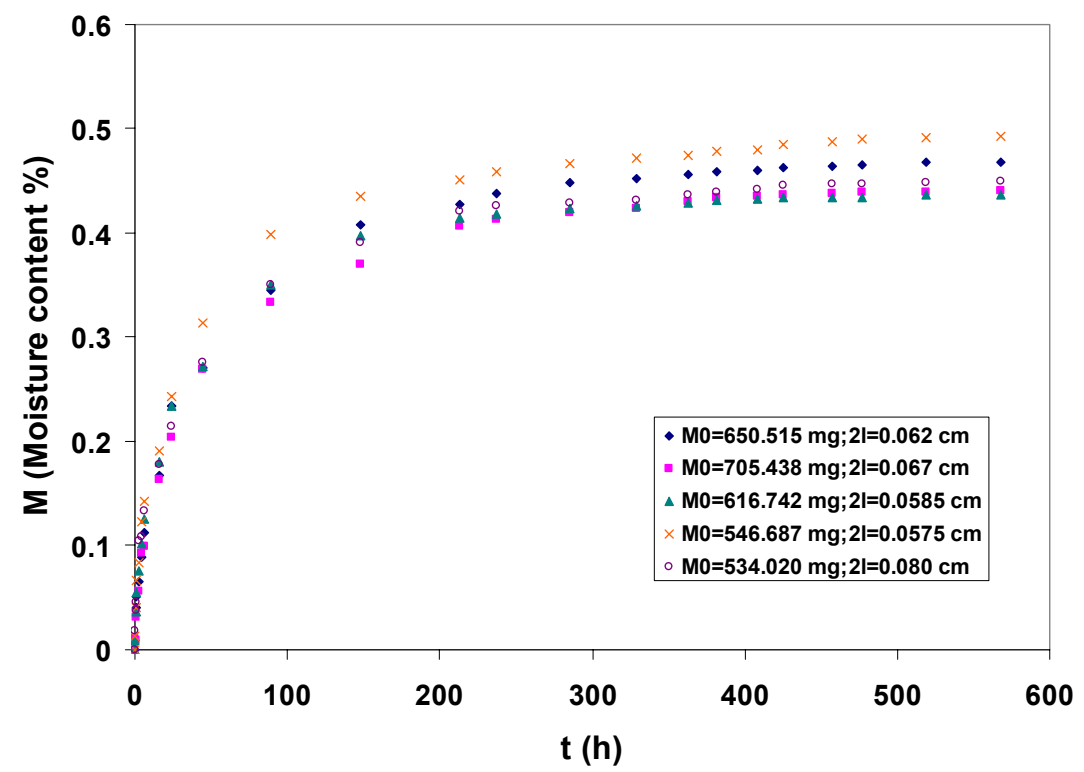

Figure 73 Moisture content versus t for 5 wt \% clay loaded vinyl ester samples exposed to $40 \%$ RH at $25^{\circ} \mathrm{C}$

Figure 74, Figure 75 and Figure 76 show $\mathrm{M}_{\mathrm{t}} / \mathrm{M}_{\infty}$ versus $\mathrm{t}^{1 / 2}$ for neat vinyl ester samples and those containing $2 \mathrm{wt} \%$ and $5 \mathrm{wt} \%$ clay exposed to $40 \% \mathrm{RH}$ at $25{ }^{\circ} \mathrm{C}$ respectively. The figures show initial linear uptake indicating Fickian diffusion. The average diffusion coefficients calculated from the slopes of the curves are found to be $4.17 \times 10^{-9} \mathrm{~cm}^{2} / \mathrm{s}$ for neat vinyl ester samples, $2.73 \times 10^{-9} \mathrm{~cm}^{2} / \mathrm{s}$ for $2 \mathrm{wt} \%$ clay loaded samples and $2.52 \times 10^{-9} \mathrm{~cm}^{2} / \mathrm{s}$ for $5 \mathrm{wt} \%$ clay loaded samples. The vinyl ester samples exposed at $40 \% \mathrm{RH}$ at $25{ }^{\circ} \mathrm{C}$ exhibited trend of decrease in diffusivity of moisture in vinyl ester with addition of clay. The raw data for sorption experiments with neat vinyl ester samples and those containing $2 \mathrm{wt} \%$ and $5 \mathrm{wt} \%$ Cloisite $10 \mathrm{~A}^{\circledR}$ exposed to $40 \% \mathrm{RH}$ at $25^{\circ} \mathrm{C}$ is given in Appendix D in Table 30, Table 31 and Table 32 respectively. 


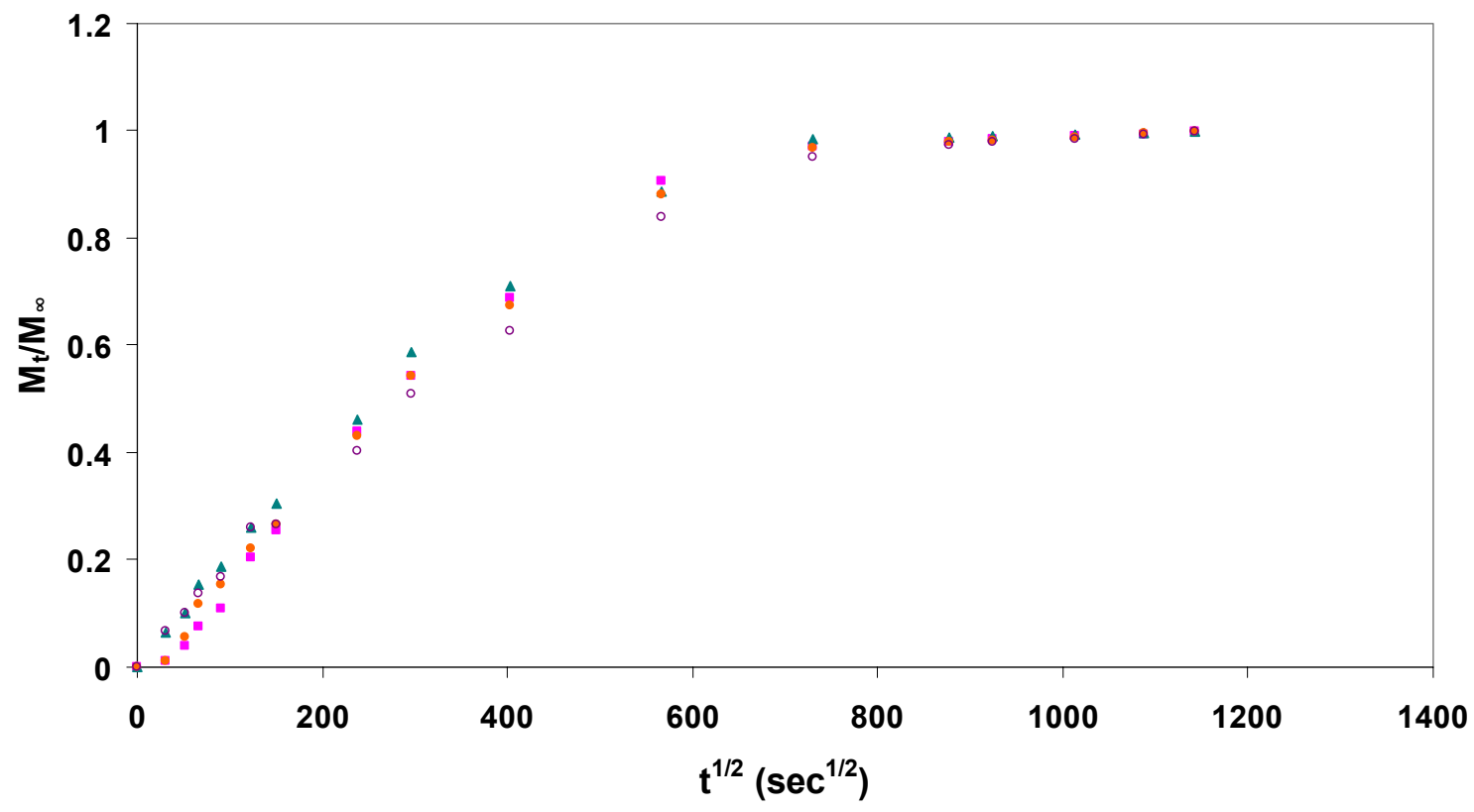

Figure $74 M_{t} / M_{\infty}$ versus $t^{1 / 2}$ for vinyl ester samples containing 0 wt $\%$ Cloisite $10 A^{\circledR}$ exposed to $40 \%$ RH

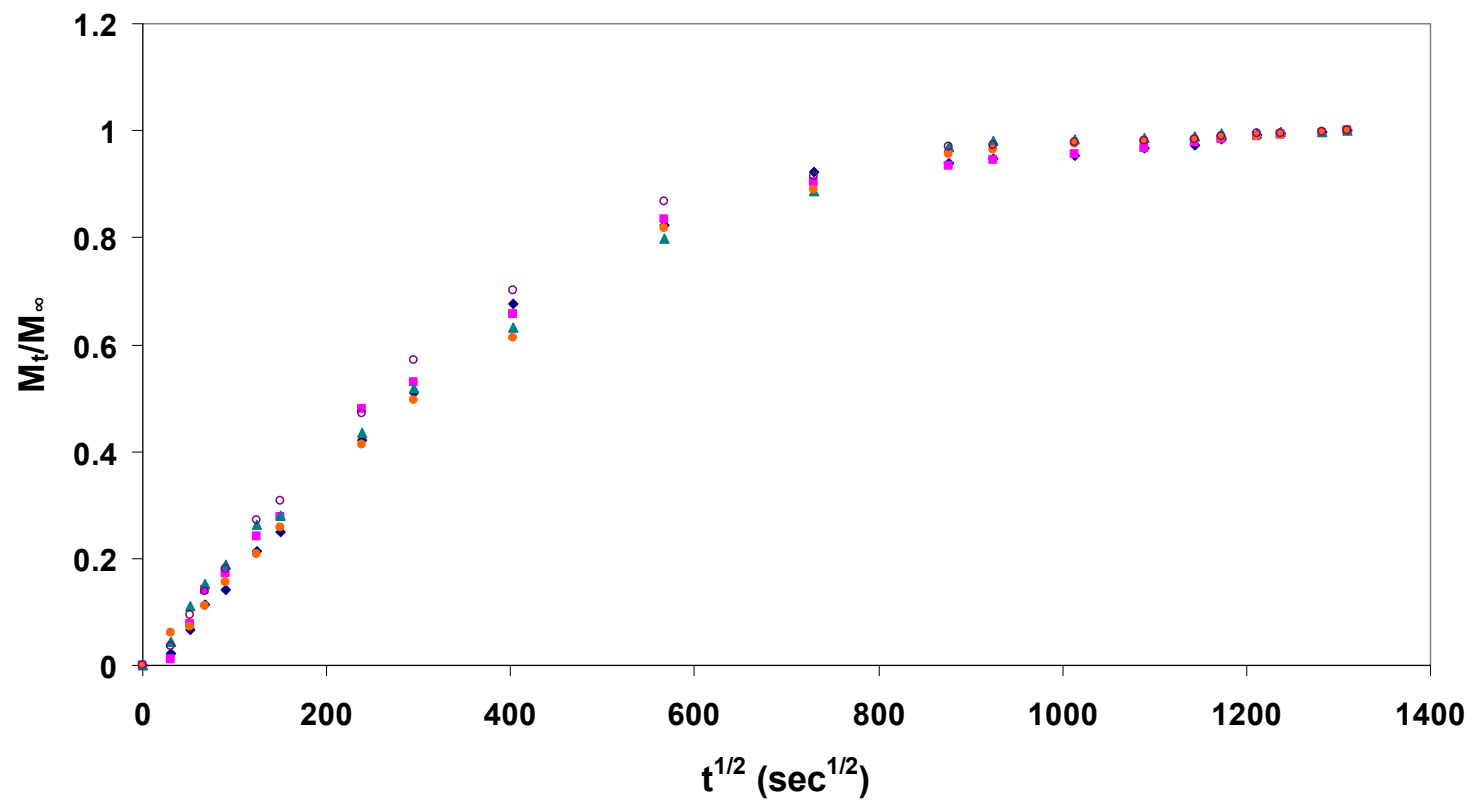

Figure $75 M_{t} / M_{\infty}$ versus $t^{1 / 2}$ for vinyl ester samples containing $2 w^{\circ} \%$ Cloisite $10 A^{\circledR}$ exposed to $40 \%$ RH 


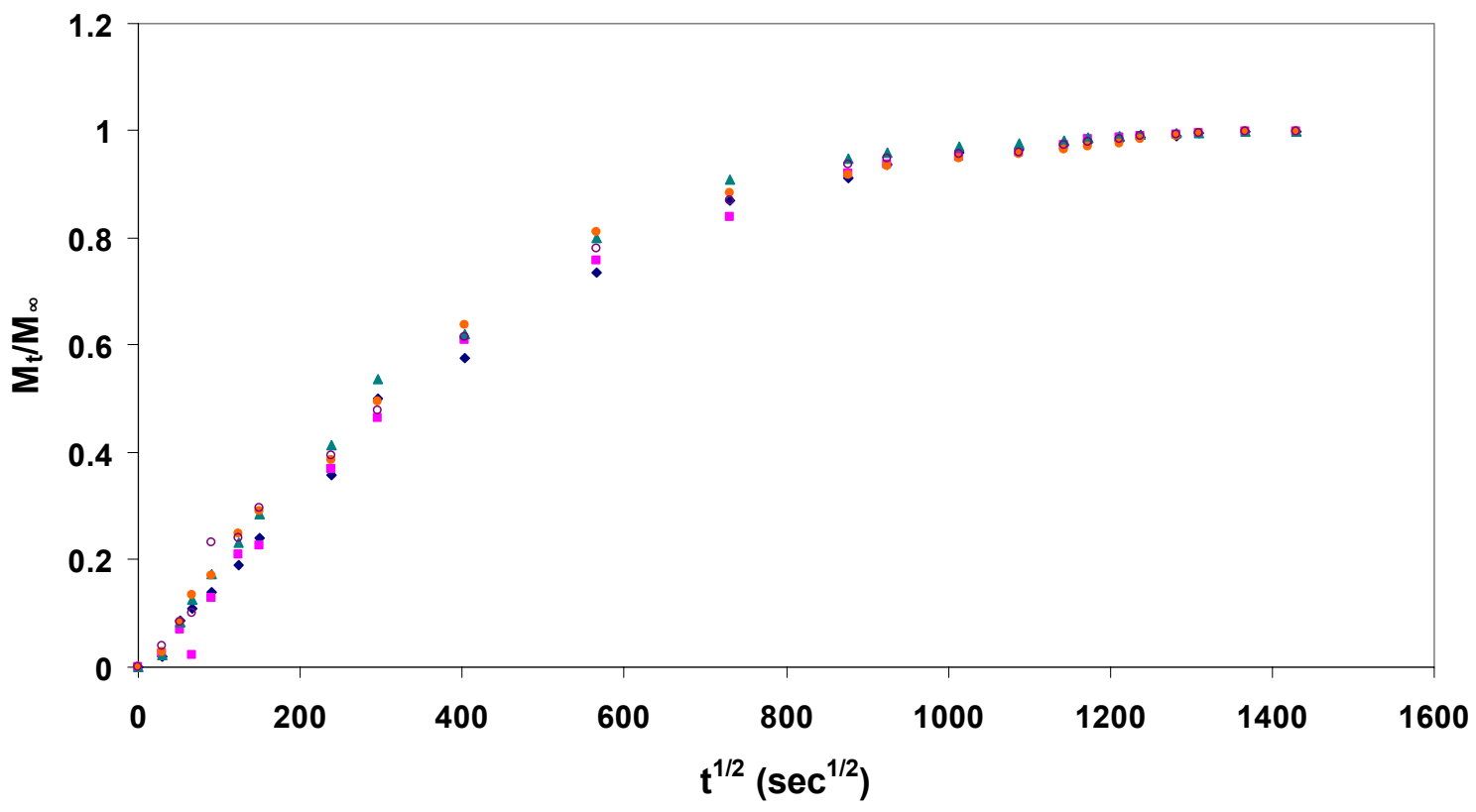

Figure $76 M_{t} / M_{\infty}$ versus $t^{1 / 2}$ for vinyl ester samples containing 5 wt $\%$ Cloisite $10 A^{\circledR}$ exposed to $40 \%$ RH

\subsubsection{EMC at $60 \%$ Relative Humidity}

Similar graphs of moisture content versus time were drawn for neat vinyl ester samples and clay loaded vinyl ester samples at $60 \% \mathrm{RH}$ and are given in Appendix $\mathrm{C}$ in Figure 164, Figure 165 and Figure 166 respectively. The graphs showed that the average moisture content for neat, $2 \mathrm{wt} \%$ and $5 \mathrm{wt} \%$ clay loaded samples was $0.59 \%$ at $60 \% \mathrm{RH}$.

Graphs of $\mathrm{M}_{\mathrm{t}} / \mathrm{M}_{\infty}$ versus $\mathrm{t}^{1 / 2}$ for neat vinyl ester samples and those containing 2 wt $\%$ and $5 \mathrm{wt} \%$ Cloisite $10 \mathrm{~A}^{\circledR}$ were plotted and are given in Appendix C in Figure 167, Figure 168 and Figure 169 respectively. The graphs showed a linear initial uptake indicating Fickian diffusion and the diffusion coefficients were found to be $3.98 \times 10^{-9}$ $\mathrm{cm}^{2} / \mathrm{s}$ for neat vinyl ester samples, $2.66 \times 10^{-9} \mathrm{~cm}^{2} / \mathrm{s}$ for $2 \mathrm{wt} \%$ clay loaded samples and $2.31 \times 10^{-9} \mathrm{~cm}^{2} / \mathrm{s}$ for $5 \mathrm{wt} \%$ clay loaded samples. The raw data for sorption experiments with neat vinyl ester samples and those containing $2 \mathrm{wt} \%$ and $5 \mathrm{wt} \%$ Cloisite $10 \mathrm{~A}^{\circledR}$ exposed to $60 \% \mathrm{RH}$ at $25^{\circ} \mathrm{C}$ is given in Appendix D in Table 33, Table 34 and Table 35 respectively. 


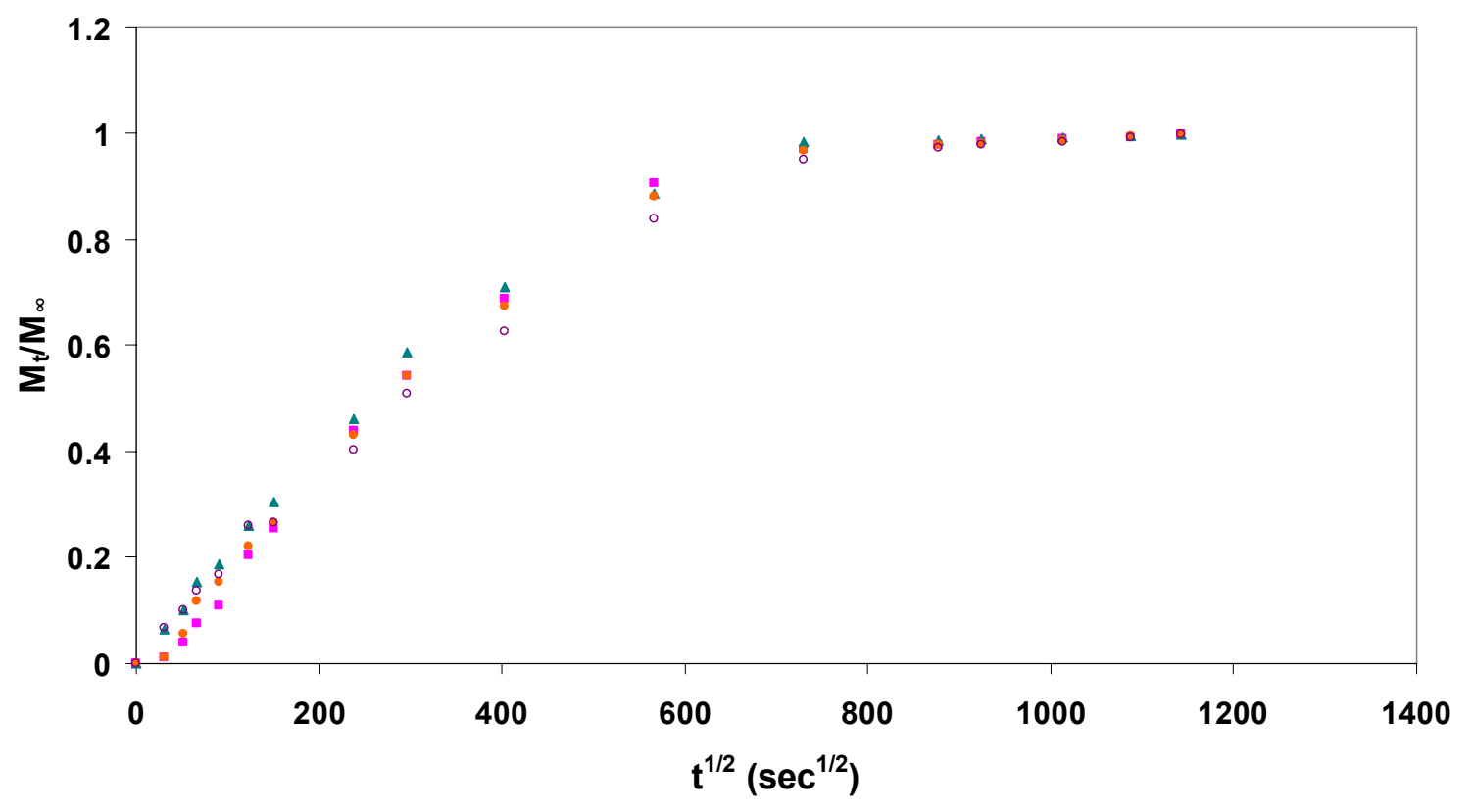

\subsubsection{EMC at $70 \%$ Relative Humidity}

Similar graphs of moisture content versus time were drawn for neat vinyl ester samples and clay loaded vinyl ester samples at $70 \% \mathrm{RH}$ and are given in Appendix $\mathrm{C}$ in Figure 170, Figure 171 and Figure 172. The graphs showed that the average moisture content for neat, $2 \mathrm{wt} \%$ and $5 \mathrm{wt} \%$ clay loaded samples was $0.8 \%$ at $70 \% \mathrm{RH}$.

Graphs of $\mathrm{M}_{\mathrm{t}} / \mathrm{M}_{\infty}$ versus $\mathrm{t}^{1 / 2}$ for neat vinyl ester samples and those containing 2 $\mathrm{wt} \%$ and $5 \mathrm{wt} \%$ Cloisite $10 \mathrm{~A}^{\circledR}$ were plotted and are given in Appendix C in Figure 173, Figure 174 and Figure 175 respectively. The graphs showed a linear initial uptake indicating Fickian diffusion and the diffusion coefficients were found to be $4.18 \times 10^{-9}$ $\mathrm{cm}^{2} / \mathrm{s}$ for neat vinyl ester samples, $2.99 \times 10^{-9} \mathrm{~cm}^{2} / \mathrm{s}$ for $2 \mathrm{wt} \%$ clay loaded samples and $2.72 \times 10^{-9} \mathrm{~cm}^{2} / \mathrm{s}$ for $5 \mathrm{wt} \%$ clay loaded samples. The raw data for sorption experiments with neat vinyl ester samples and those containing $2 \mathrm{wt} \%$ and $5 \mathrm{wt} \%$ Cloisite $10 \mathrm{~A}^{\circledR}$ exposed to $70 \% \mathrm{RH}$ at $25^{\circ} \mathrm{C}$ is given in Appendix D in Table 36, Table 37 and Table 38 respectively.

\subsubsection{EMC at $80 \%$ Relative Humidity}

Similar graphs of moisture content versus time at $80 \% \mathrm{RH}$ were drawn for neat vinyl ester samples and clay loaded vinyl ester samples and are given in Appendix C in 
Figure 176, Figure 177 and Figure 178 respectively. The graphs showed that the average moisture content for neat, $2 \mathrm{wt} \%$ and $5 \mathrm{wt} \%$ clay loaded samples was $0.9 \%$ at $80 \% \mathrm{RH}$.

Graphs of $\mathrm{M}_{\mathrm{t}} / \mathrm{M}_{\infty}$ versus $\mathrm{t}^{1 / 2}$ for neat vinyl ester samples and those containing 2 $\mathrm{wt} \%$ and $5 \mathrm{wt} \%$ Cloisite $10 \mathrm{~A}^{\circledR}$ were plotted and are given in Appendix C in Figure 179, Figure 180 and Figure 181 respectively. The graphs showed a linear initial uptake indicating Fickian diffusion and the diffusion coefficients were found to be $4.18 \times 10^{-9}$ $\mathrm{cm}^{2} / \mathrm{s}$ for neat vinyl ester samples, $2.92 \times 10^{-9} \mathrm{~cm}^{2} / \mathrm{s}$ for $2 \mathrm{wt} \%$ clay loaded samples and $2.43 \times 10^{-9} \mathrm{~cm}^{2} / \mathrm{s}$ for $5 \mathrm{wt} \%$ clay loaded samples. The raw data for sorption experiments with neat vinyl ester samples and those containing $2 \mathrm{wt} \%$ and $5 \mathrm{wt} \%$ Cloisite $10 \mathrm{~A}^{\circledR}$ exposed to $80 \% \mathrm{RH}$ at $25^{\circ} \mathrm{C}$ is given in Appendix D in Table 39, Table 40 and Table 41 respectively.

Equilibrium moisture content (EMC) and the diffusivity values calculated using $M_{t} / M_{\infty}$ versus $t^{1 / 2}$ curves for respective vinyl ester samples at various humidities are summarized in Table 6. The equilibrium moisture content (\%) and Diffusivity as a function of relative humidity (\%RH) for vinyl ester samples containing different amounts of clay are given in Figure 77 and Figure 78 respectively. For a given $w t \%$ clay, the diffusivity remained constant with increase in relative humidity and the equilibrium moisture content increased with increasing level of RH. Reduction in diffusivity value with increase in wt $\%$ clay was also observed at all RH levels, while equilibrium moisture content almost remained constant with increasing clay loading. Hoppel et al. (2000) investigated the moisture absorption characteristics of different composite materials. It was shown that moisture absorption in composites is a strong function of environmental conditions as well as material parameters (void volume fraction) and that the equilibrium moisture content is a linear function of the exposed relative humidity. Alfred and George (1979) observed similar phenomenon in moisture absorption of graphite-epoxy composite and maximum moisture content depended on the relative humidity but was insensitive to temperature. 
Table 6. Variation of Equilibrium Moisture Content and Diffusivity with Relative Humidity if Exposed Environment

\begin{tabular}{|c|c|c|c|c|c|c|c|c|}
\hline $\mathrm{Wt} \%$ & \multicolumn{2}{|c|}{$40 \% \mathrm{RH}$} & \multicolumn{2}{|r|}{$60 \%$ RH } & \multicolumn{2}{|c|}{$70 \% \mathrm{RH}$} & \multicolumn{2}{|c|}{$80 \% \mathrm{RH}$} \\
\hline $\begin{array}{l}\text { Cloisite } \\
10 \mathrm{~A}^{\circledR}\end{array}$ & EMC & $\begin{array}{l}\mathrm{Dx} 10^{9} \\
\left(\mathrm{~cm}^{2} / \mathrm{s}\right)\end{array}$ & EMC & $\mathrm{Dx} 10^{9}(\mathrm{c}$ & EMC & $\begin{array}{l}\text { Dx109 } \\
\left(\mathrm{cm}^{2} / \mathrm{s}\right)\end{array}$ & EMC & $\begin{array}{l}\text { Dx10 } \\
\left(\mathrm{cm}^{2} / \mathrm{s}\right)\end{array}$ \\
\hline 0 & $0.43 \pm 0.02$ & $4.17 \pm$ & $0.59 \pm$ & 3.9 & $0.8 \pm 0.01$ & $4.18 \pm 0.26$ & .17 & $4.18 \pm 0.62$ \\
\hline 2 & $0.44 \pm 0.02$ & $2.73 \pm 0.5$ & $0.61 \pm 0.01$ & $2.66 \pm 0.19$ & $0.87 \pm 0.02$ & $2.99 \pm 0.02$ & $0.91 \pm 0.07$ & $2.92 \pm 0.27$ \\
\hline 5 & $0.46 \pm 0.02$ & $2.52 \pm 0.8$ & $0.61 \pm 0.01$ & $2.31 \pm 0.12$ & $0.9 \pm 0.01$ & $2.72 \pm 0.72$ & $0.91 \pm 0.1$ & $2.43 \pm 0.41$ \\
\hline
\end{tabular}

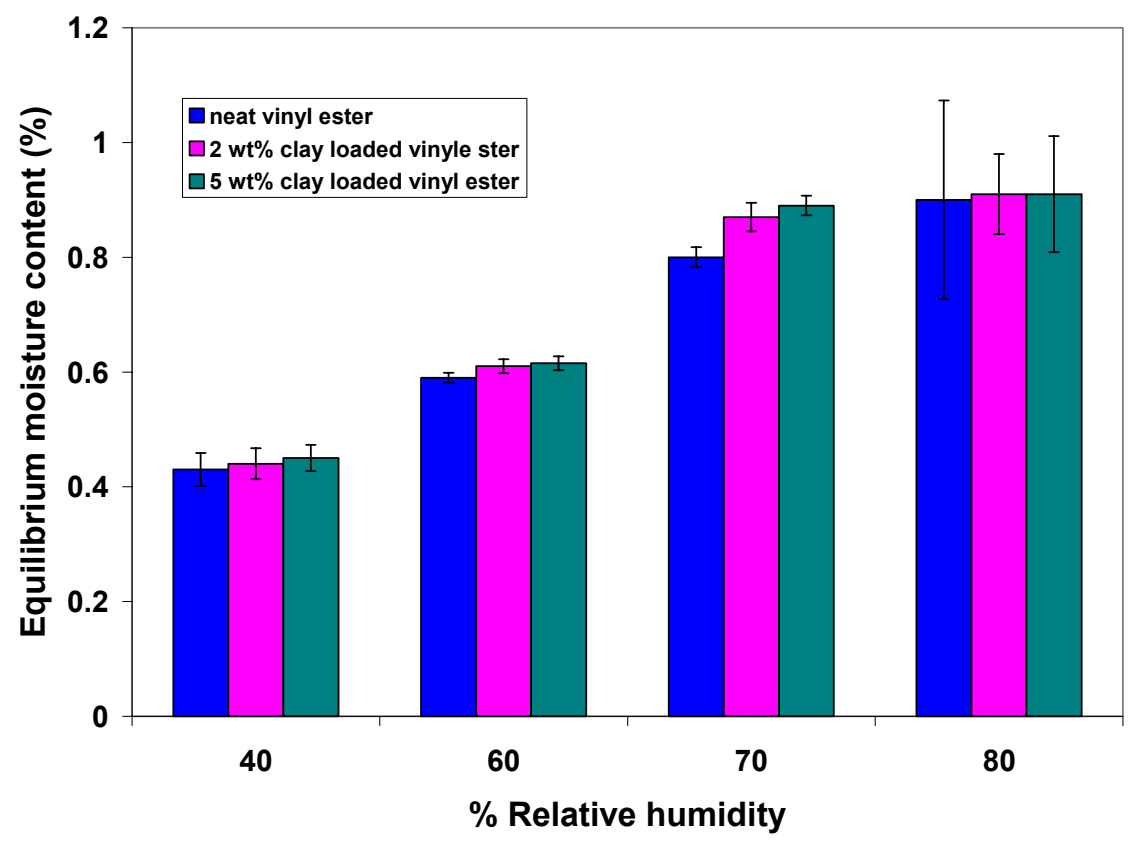

Figure 77 Variation of equilibrium moisture content with variation in relative humidity (\%) for vinyl ester samples containing different wt percentages of Cloisite $10 A^{\circledR}$ at $25{ }^{\circ} \mathrm{C}$ 


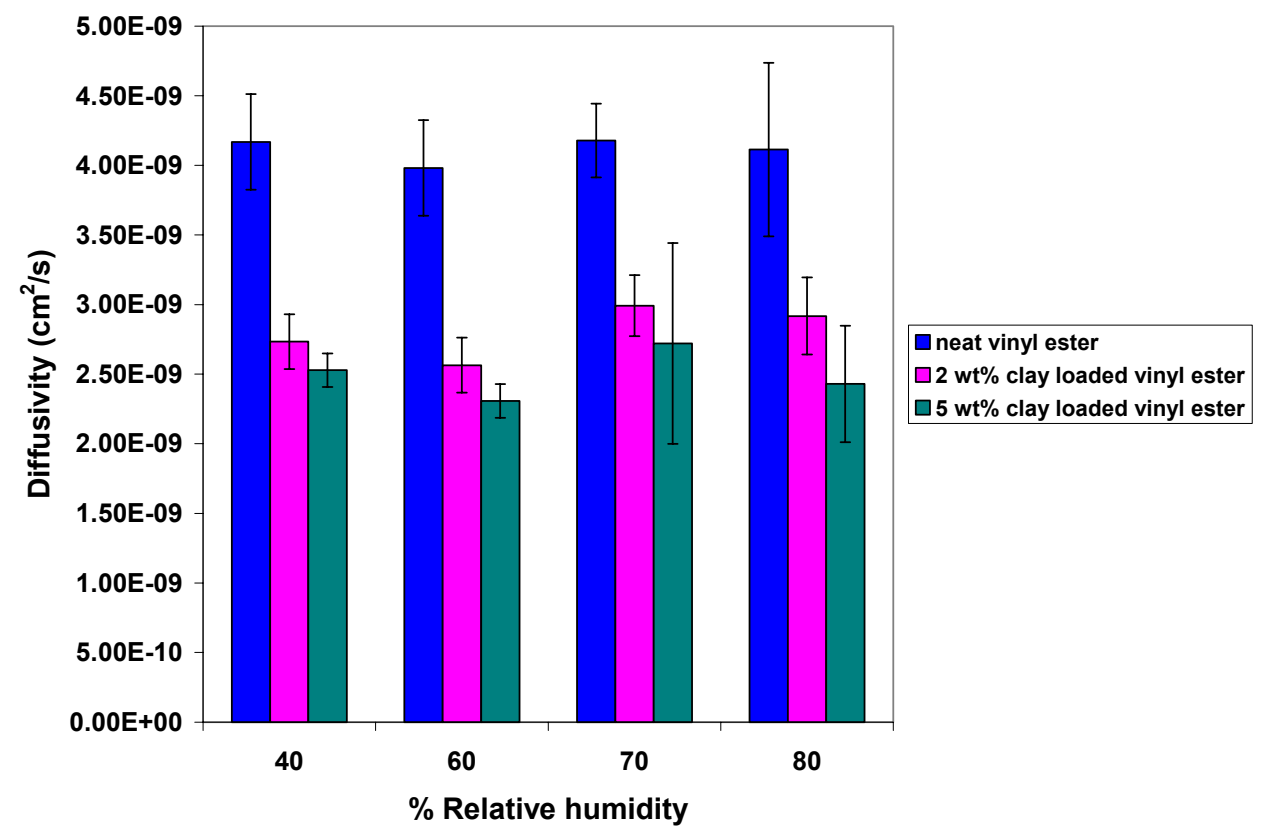

Figure 78 Variation of Diffusivity with variation in relative humidity (\%) for vinyl ester samples containing different wt percentages of Cloisite $10 \mathrm{~A}^{\circledR}$ at $25^{\circ} \mathrm{C}$

\subsection{Sorption Experiments with Vinyl ester under Stress}

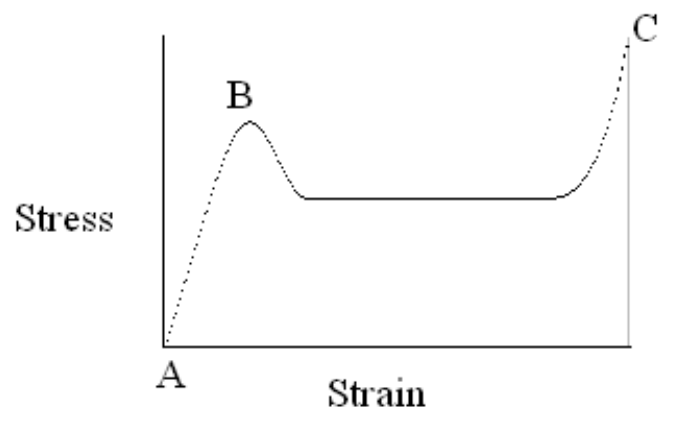

Figure 79 Typical stress strain curve in a polymer

Figure 79 shows typical stress-strain curve of a polymer. The initial linear part AB represents elastic deformation, and any changes in material dimensions in this region are reversed to the original dimensions upon the removal of applied stresses. This linear relationship is given by Hooke's law. The slope of the initial curve for elastic deformation gives Young's Modulus. The part BC represents plastic deformation where the material does not revert to its original dimensions when the applied stress is removed. Point $\mathrm{C}$ represents the failure of the material and the stress corresponding to $\mathrm{C}$ is called Ultimate Tensile Strength (UTS). Figure 80 shows stress-strain curve of neat vinyl ester (Rana, 
2003). The slope of the straight line part of the curve gives Young's Modulus and the average value of which was found to be $4162 \mathrm{psi}(28.7 \mathrm{GPa})$ and the average Ultimate tensile strength was found to be $2712 \mathrm{psi}(18.7 \mathrm{MPa})$.

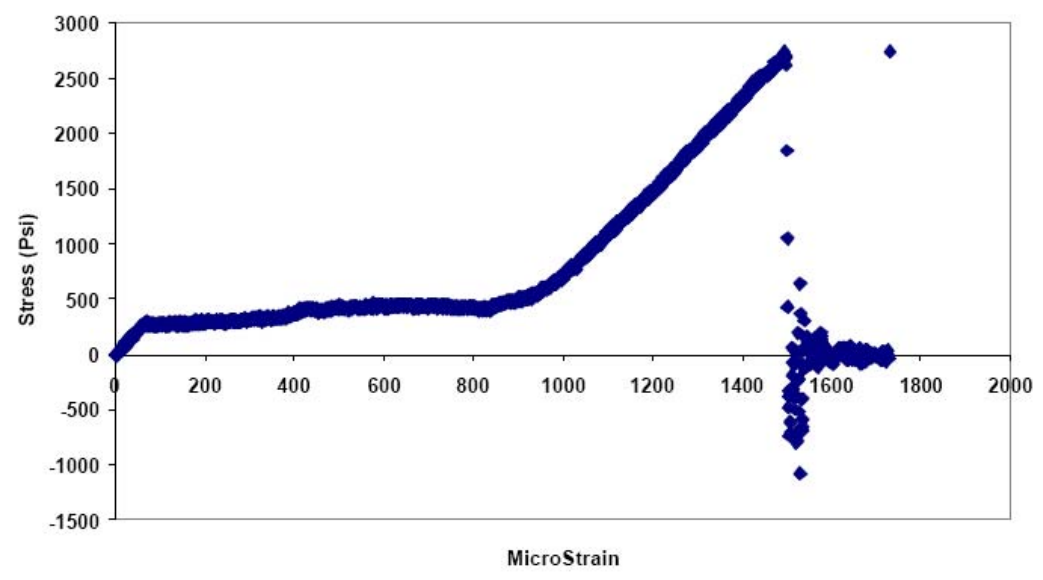

Figure 80 Stress Strain Curve for a Representative Neat Vinyl ester (Rana, 2003)

Sorption experiments under two different load levels, a load of $8 \mathrm{lb}_{\mathrm{f}}$ corresponding to a stress of $3.3 \mathrm{MPa}$ (approximately 17\% Ultimate tensile stress, UTS) and $14 \mathrm{lb}_{\mathrm{f}}$ corresponding to a stress of $5.78 \mathrm{MPa}$ (approximately 30\% UTS), were done with neat vinyl ester samples and those containing $5 \mathrm{wt} \%$ clay. The experiments were conducted in two different environments, in water and at $60 \% \mathrm{RH}$. Two different stresses were applied by applying a load on the samples with the help of die springs. Twelve specimens parallel to each other were loaded to the same stress level and each specimen had an independent nut-bolt-and-spring arrangement for stress application, such that application or removal of stress on one specimen did not affect the stress acting on the other. The stress was applied on 12 parallel specimens attached to the load frame, each specimen consisting of 3 samples in series. Graphs of moisture uptake versus time and moisture content (\%) versus time were plotted for vinyl ester samples with and without clay. The data for all the samples were plotted to demonstrate the effect of stress and clay addition on the equilibrium moisture content and diffusivity. During the initial stages of absorption (until $\mathrm{M}_{\mathrm{t}} / \mathrm{M}_{\infty}=0.6$, approximately 2 days), moisture uptake of the samples was monitored by unloading three different samples at regular intervals of time and measuring the weight gain of the samples. Removal of samples did not affect the stress acting on the other samples. After the weight-gain measurement, these samples were not reloaded onto the 
load frame but kept aside for any further characterization. At later stages, the moisture uptake was monitored by unloading the samples to measure weight gain and reloading the samples. The masses uptake after initial period of absorption (approximately after 100 hrs), were the average masses uptake for ten different samples taken until equilibrium.

\subsubsection{Sorption Experiments under Stress in Water}

Figure 81 shows moisture uptake versus time for neat vinyl ester samples immersed in water and subjected to $17 \%$ UTS at $25{ }^{\circ} \mathrm{C}$. Using the moisture uptake data, moisture content versus time was plotted as shown in Figure 82. The equilibrium moisture content of the neat vinyl ester samples under a stress of $17 \%$ UTS is about $1.15 \%$. This is less than the equilibrium moisture content of the neat resin samples without any stress (1.24\%). The raw sorption data of vinyl ester samples containing $0 \mathrm{wt} \%$ Cloisite $10 \mathrm{~A}$ immersed in distilled water subjected to $17 \%$ UTS at $25{ }^{\circ} \mathrm{C}$ is given in Appendix D in Table 42 .

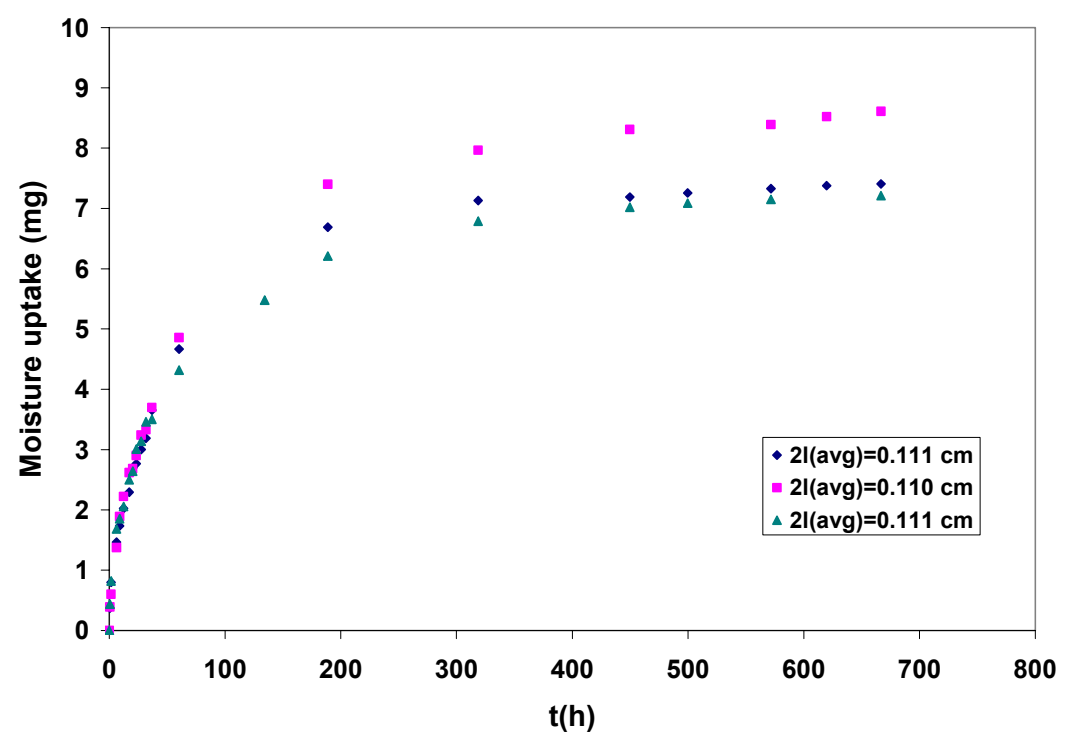

Figure 81 Moisture uptake (mg) versus t (h) for neat vinyl ester samples immersed in water and subjected to $17 \%$ UTS at $25^{\circ} \mathrm{C}$ 


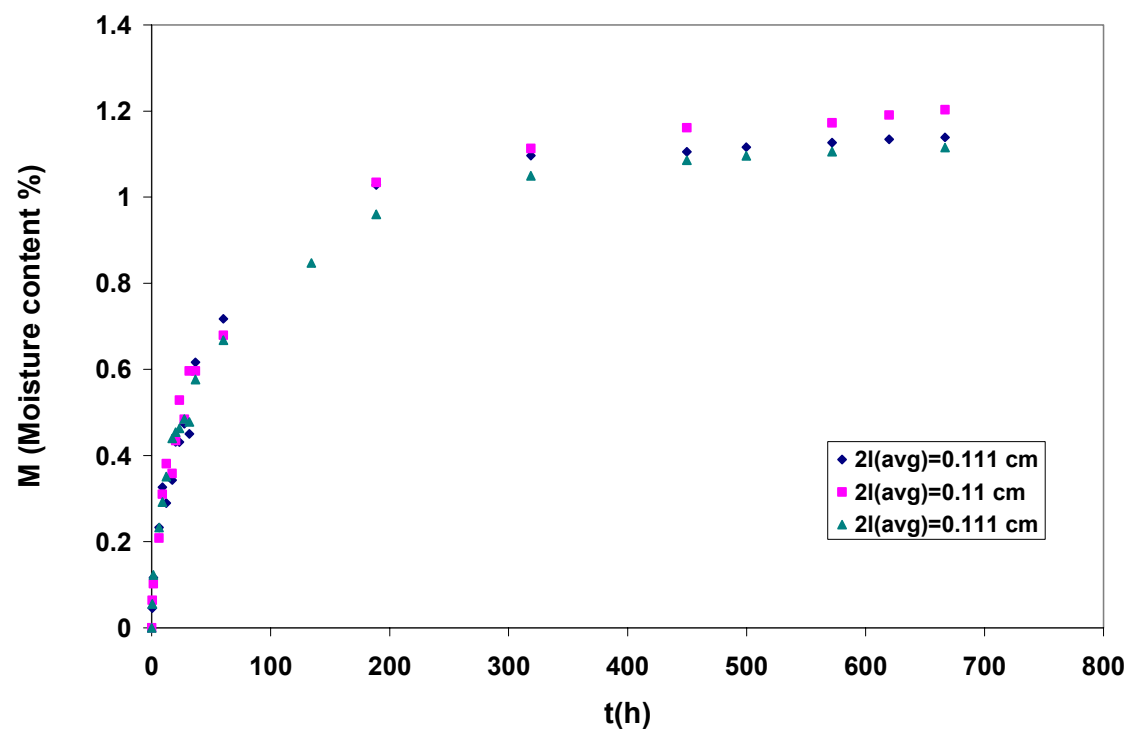

Figure 82 Moisture content versus $t$ for neat vinyl ester samples immersed in water and subjected to $17 \%$ UTS at $25^{\circ} \mathrm{C}$

Figure 83 shows $M_{t} / M_{\infty}$ versus $t^{1 / 2}$ for the samples plotted using the moisture content data. The linear initial uptake clearly shows that the diffusion under 17\% UTS followed Fickian process. The average diffusivity calculated from the slope of the initial uptake curve was found to be $4.06 \times 10^{-9} \mathrm{~cm}^{2} / \mathrm{s}$, which is comparable to the diffusivity without stress $\left(4.15 \times 10^{-9} \mathrm{~cm}^{2} / \mathrm{s}\right)$.

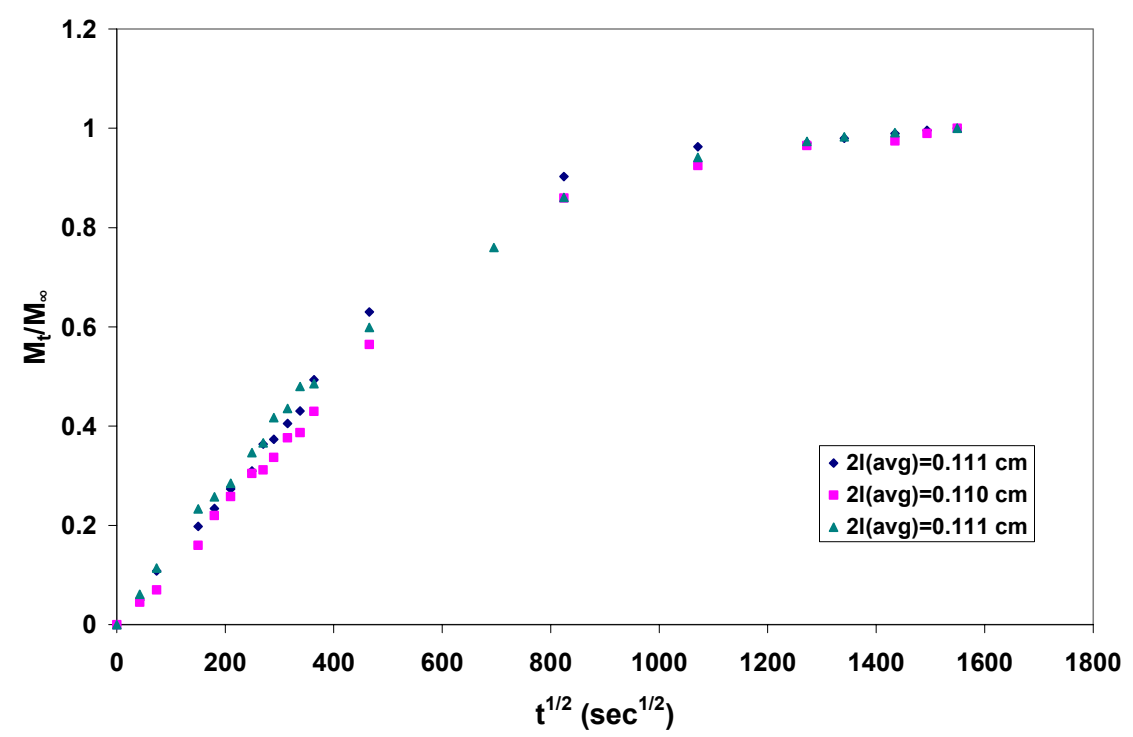

Figure $83 M_{t} / M_{\infty}$ versus $t^{1 / 2}$ for neat vinyl ester samples immersed in water and subjected to $17 \%$ UTS at $25^{\circ} \mathrm{C}$

Figure 84, Figure 85 and Figure 86 show plots of corresponding moisture uptake versus time, moisture content (\%) versus time and $\mathrm{M}_{\mathrm{t}} / \mathrm{M}_{\infty}$ versus $\mathrm{t}^{1 / 2}$ for neat vinyl ester 
samples immersed in water and subjected to $30 \%$ UTS.

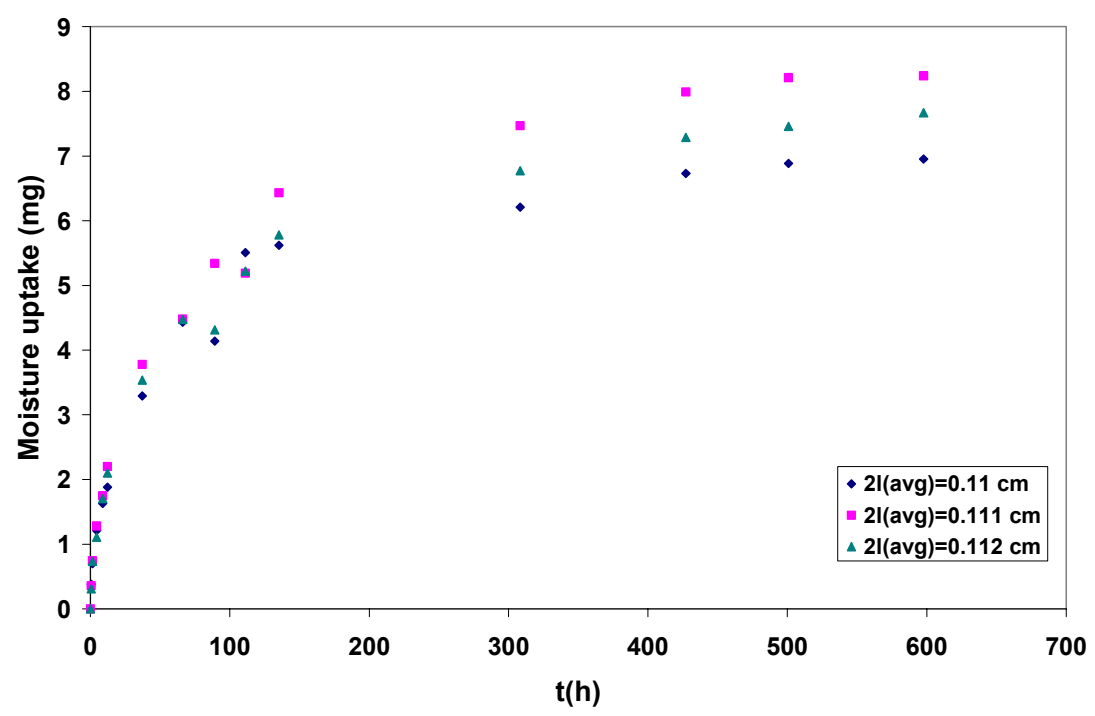

Figure 84 Moisture uptake (mg) versus t (h) for neat vinyl ester samples immersed in water and subjected to $30 \%$ UTS at $25^{\circ} \mathrm{C}$

The average equilibrium moisture content of the samples is about $1.15 \%$, which is same as that of the samples subjected to $17 \%$ UTS. This indicates that the increase in stress level did not affect the equilibrium moisture content of neat vinyl ester samples immersed in water. The raw sorption data of vinyl ester samples containing $0 \mathrm{wt} \%$ Cloisite 10A immersed in distilled water subjected to $30 \%$ UTS at $25^{\circ} \mathrm{C}$ is given in Appendix D in Table 44.

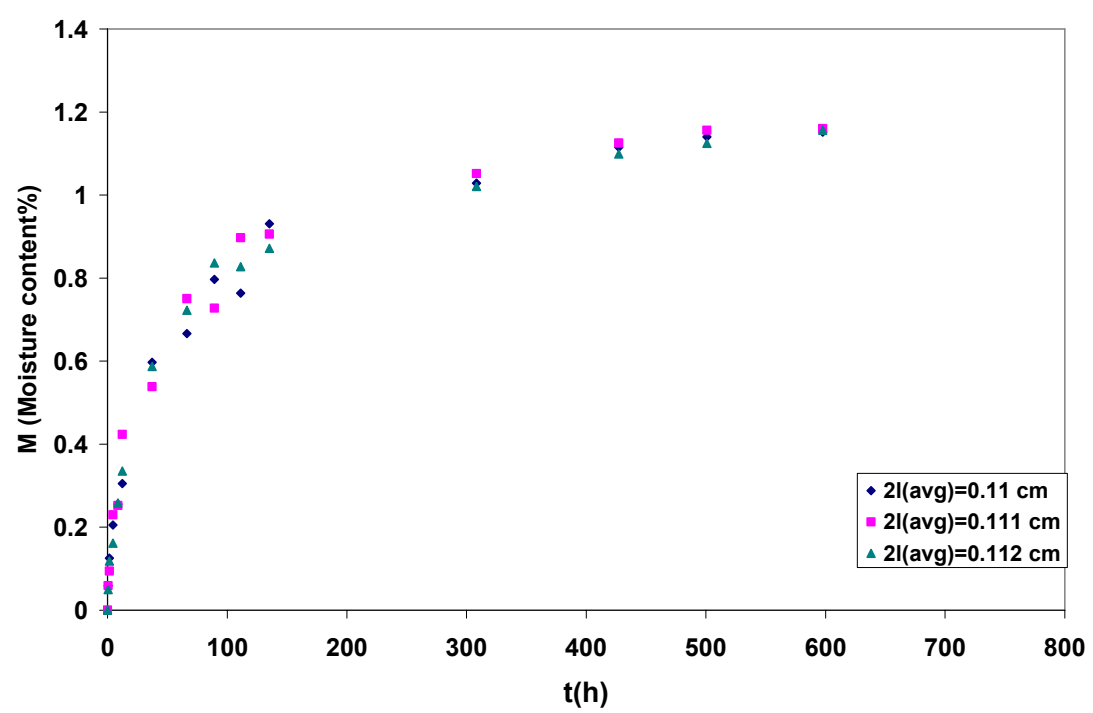

Figure 85 Moisture content versus $t$ for neat vinyl ester samples immersed in water and subjected to $30 \% \mathrm{UTS}$ at $25^{\circ} \mathrm{C}$ 
The linear initial uptake curve of $\mathrm{M}_{t} / \mathrm{M}_{\infty}$ versus $\mathrm{t}^{1 / 2}$ plot in Figure 86 shows that the diffusion under $30 \%$ UTS followed Fickian diffusion. The diffusivity was found to be $4.12 \times 10^{-9} \mathrm{~cm}^{2} / \mathrm{s}$.

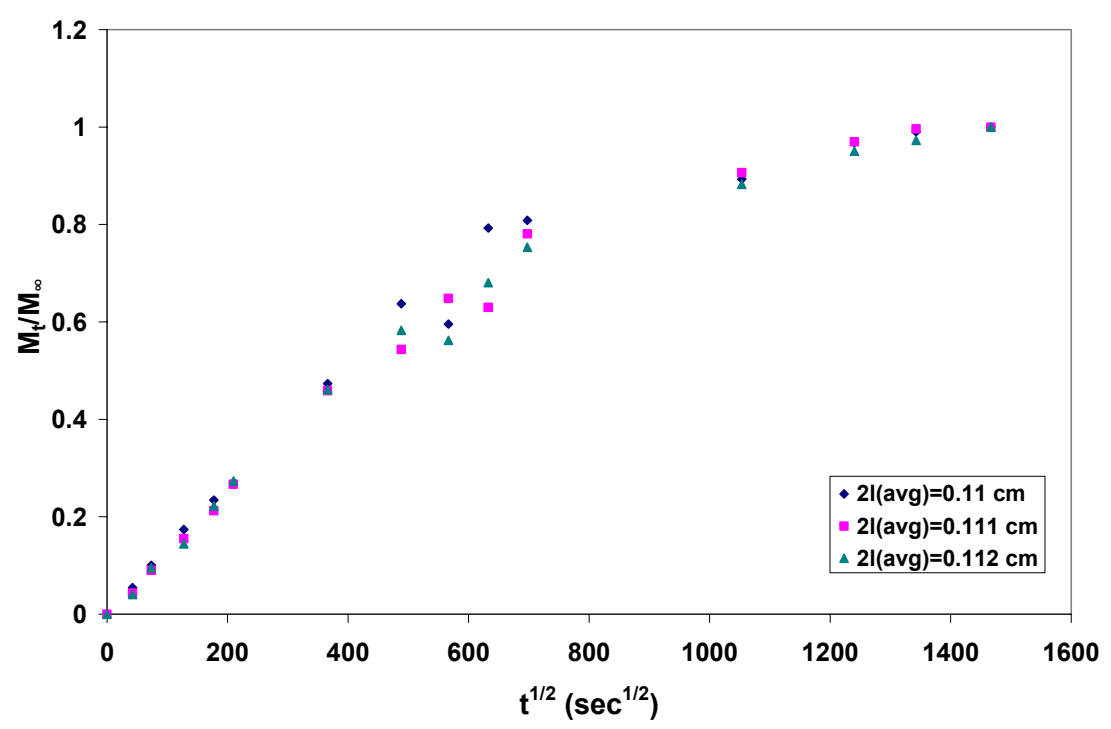

Figure $86 M_{t} / M_{\infty}$ versus $t^{1 / 2}$ for neat vinyl ester samples immersed in water and subjected to $30 \%$ UTS at $25^{\circ} \mathrm{C}$

The diffusivities of neat vinyl ester were found to be $4.15 \times 10^{-9} \mathrm{~cm}^{2} / \mathrm{s}$ without any stress, $4.06 \times 10^{-9} \mathrm{~cm}^{2} / \mathrm{s}$ under $17 \%$ UTS and $4.12 \times 10^{-9} \mathrm{~cm}^{2} / \mathrm{s}$ under $30 \%$ UTS. The diffusivity of water in neat vinyl ester samples seemed to remain constant with the increase in the stress level.

Figure 87, Figure 88 and Figure 89 show corresponding plots of moisture uptake versus time, moisture content (\%) versus time and $\mathrm{M}_{\mathrm{t}} / \mathrm{M}_{\infty}$ versus $\mathrm{t}^{1 / 2}$ for $5 \mathrm{wt} \%$ clay loaded vinyl ester samples immersed in water and subjected to $17 \%$ UTS. The average equilibrium moisture content of vinyl ester samples containing $5 \mathrm{wt} \%$ clay and subjected to $17 \%$ UTS was about $1.22 \%$. The raw sorption data of vinyl ester samples containing 5 wt $\%$ Cloisite $10 \mathrm{~A}$ immersed in distilled water subjected to $17 \%$ UTS at $25{ }^{\circ} \mathrm{C}$ is given in Appendix D in Table 43. 


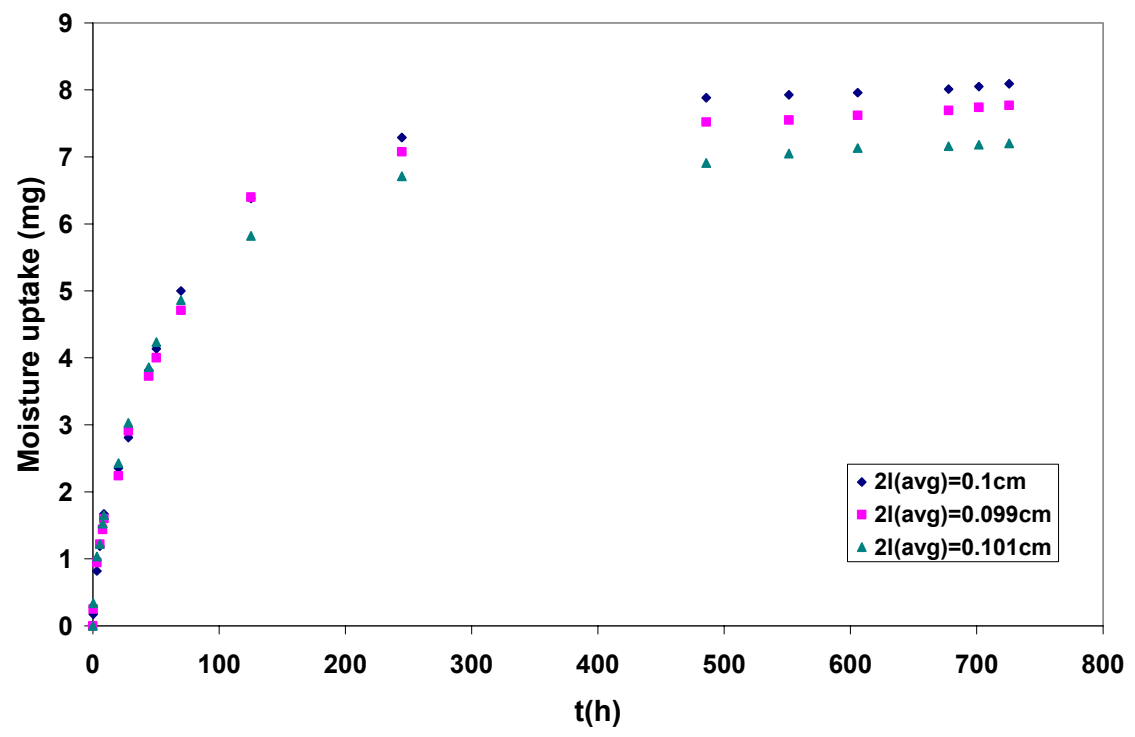

Figure 87 Moisture uptake (mg) versus t (h) for vinyl ester samples containing 5 wt $\%$ clay immersed in water and subjected to $17 \%$ UTS at $25^{\circ} \mathrm{C}$

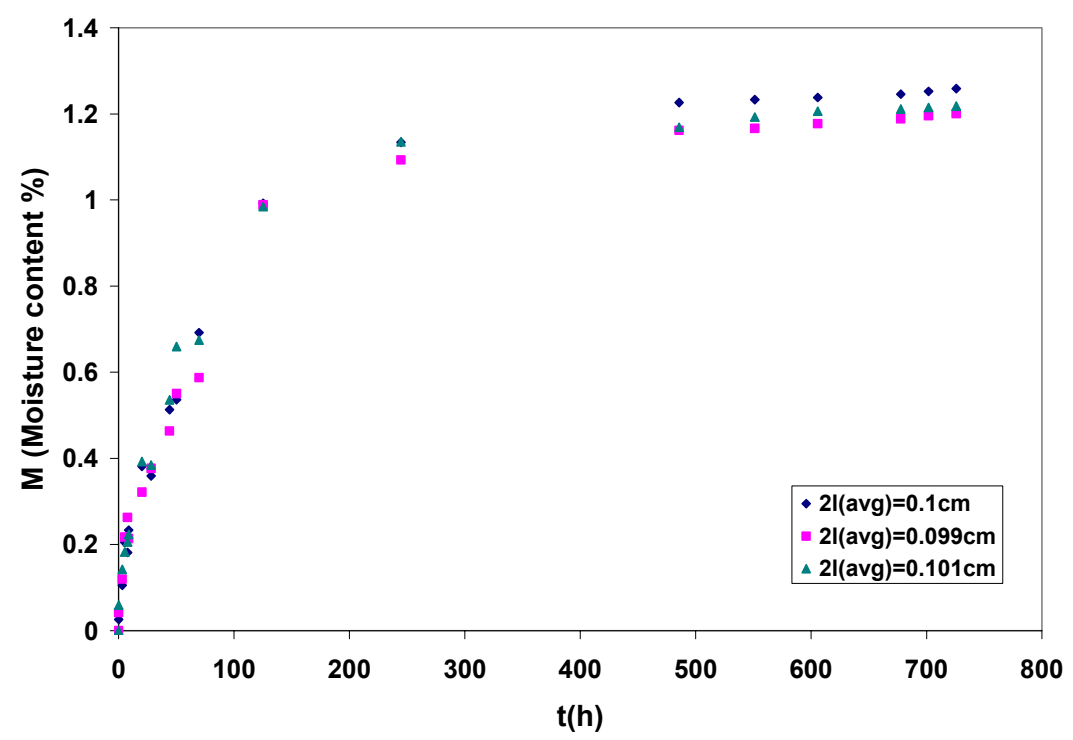

Figure 88 Moisture content versus t for vinyl ester samples containing $5 \mathrm{wt} \%$ clay immersed in water and subjected to $17 \%$ UTS at $25^{\circ} \mathrm{C}$

A graph of $\mathrm{M}_{\mathrm{t}} / \mathrm{M}_{\infty}$ versus $\mathrm{t}^{1 / 2}$ in Figure 89 shows linear initial uptake curve indicating that the diffusion in $5 \mathrm{wt} \%$ clay loaded vinyl ester samples under $17 \%$ UTS followed Fickian diffusion. The diffusivity was found to be $2.96 \times 10^{-9} \mathrm{~cm}^{2} / \mathrm{s}$. 


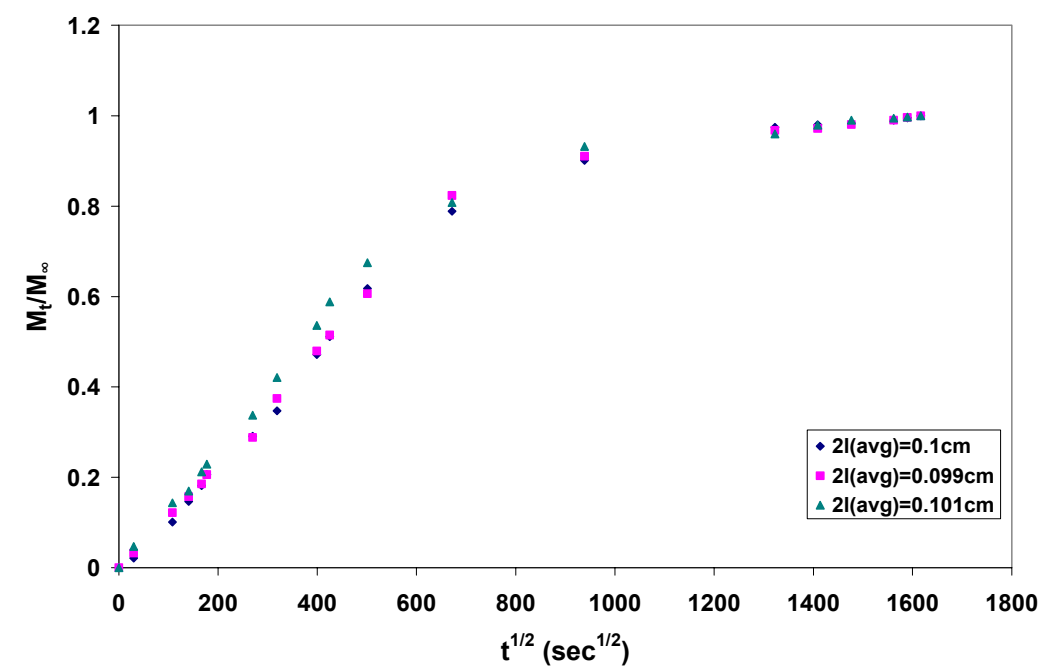

Figure $89 M_{t} / M_{\infty}$ versus $t^{1 / 2}$ for vinyl ester samples containing $5 \mathrm{wt} \%$ clay immersed in water and subjected to $17 \%$ UTS at $25^{\circ} \mathrm{C}$

Figure 90, Figure 91 and Figure 92 show corresponding plots of moisture uptake versus time, moisture content (\%) versus time and $M_{t} / M_{\infty}$ versus $t^{1 / 2}$ for $5 w t \%$ clay loaded vinyl ester samples immersed in water and subjected to $30 \%$ UTS. The average equilibrium moisture content of vinyl ester samples containing $5 \mathrm{wt} \%$ clay and subjected to $30 \%$ UTS was about $1.22 \%$, which is same as that of the samples subjected to $17 \%$ UTS. This indicates that the increase in stress level did not affect the equilibrium moisture content of $5 \mathrm{wt} \%$ clay loaded vinyl ester samples immersed in water. The raw sorption data of vinyl ester samples containing $5 \mathrm{wt} \%$ Cloisite 10A immersed in distilled water subjected to $30 \%$ UTS at $25^{\circ} \mathrm{C}$ is given in Appendix D in Table 45 .

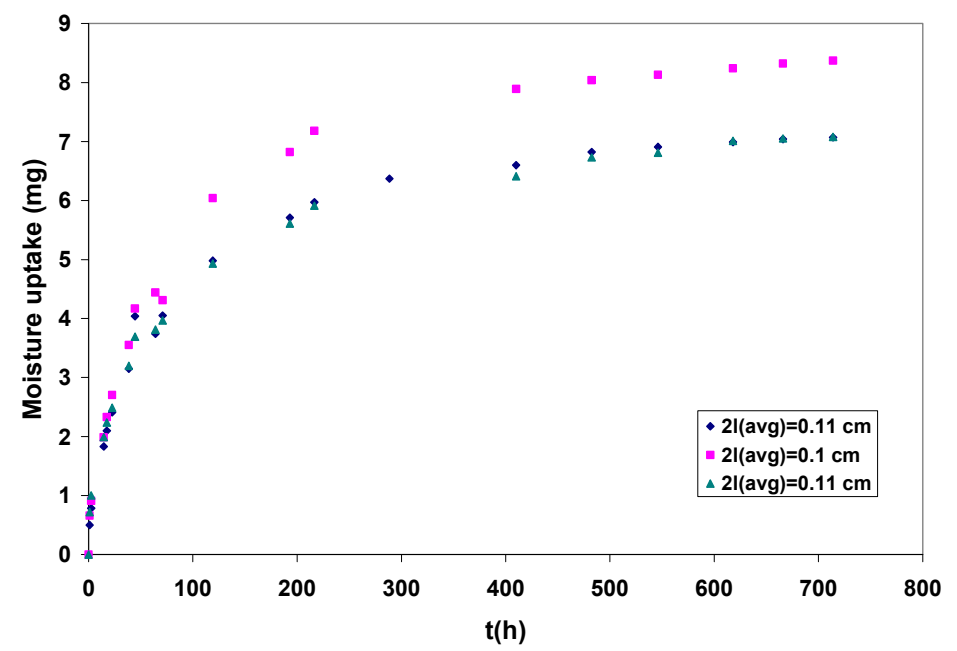

Figure 90 Moisture uptake (mg) versus $\mathrm{t}(\mathrm{h})$ for vinyl ester samples containing $5 \mathrm{wt} \%$ clay immersed in water and subjected to $30 \% \mathrm{UTS}$ at $25^{\circ} \mathrm{C}$ 


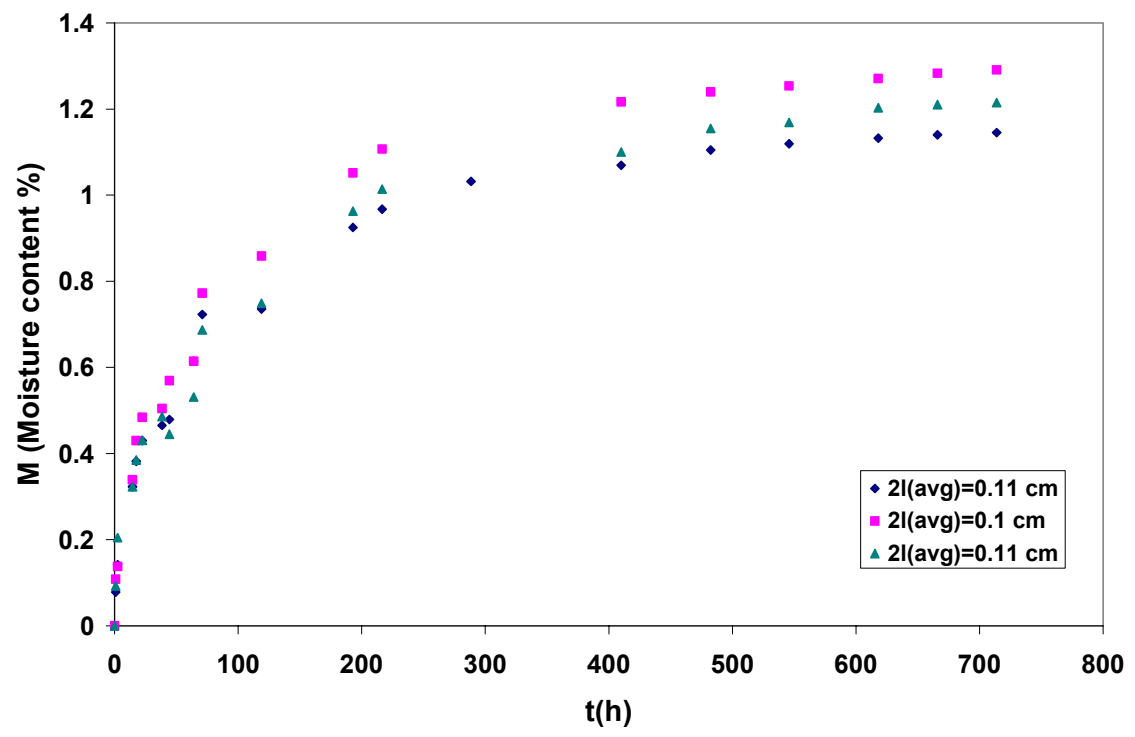

Figure 91 Moisture content versus $t$ for vinyl ester samples containing 5 wt\% clay immersed in water and subjected to $30 \% \mathrm{UTS}$ at $25^{\circ} \mathrm{C}$

The linear initial uptake curve of $\mathrm{M}_{\mathrm{t}} / \mathrm{M}_{\infty}$ versus $\mathrm{t}^{1 / 2}$ plot in Figure 92 shows that the diffusion under $30 \%$ UTS followed Fickian diffusion. The diffusivity was found to be $3.06 \times 10^{-9} \mathrm{~cm}^{2} / \mathrm{s}$.

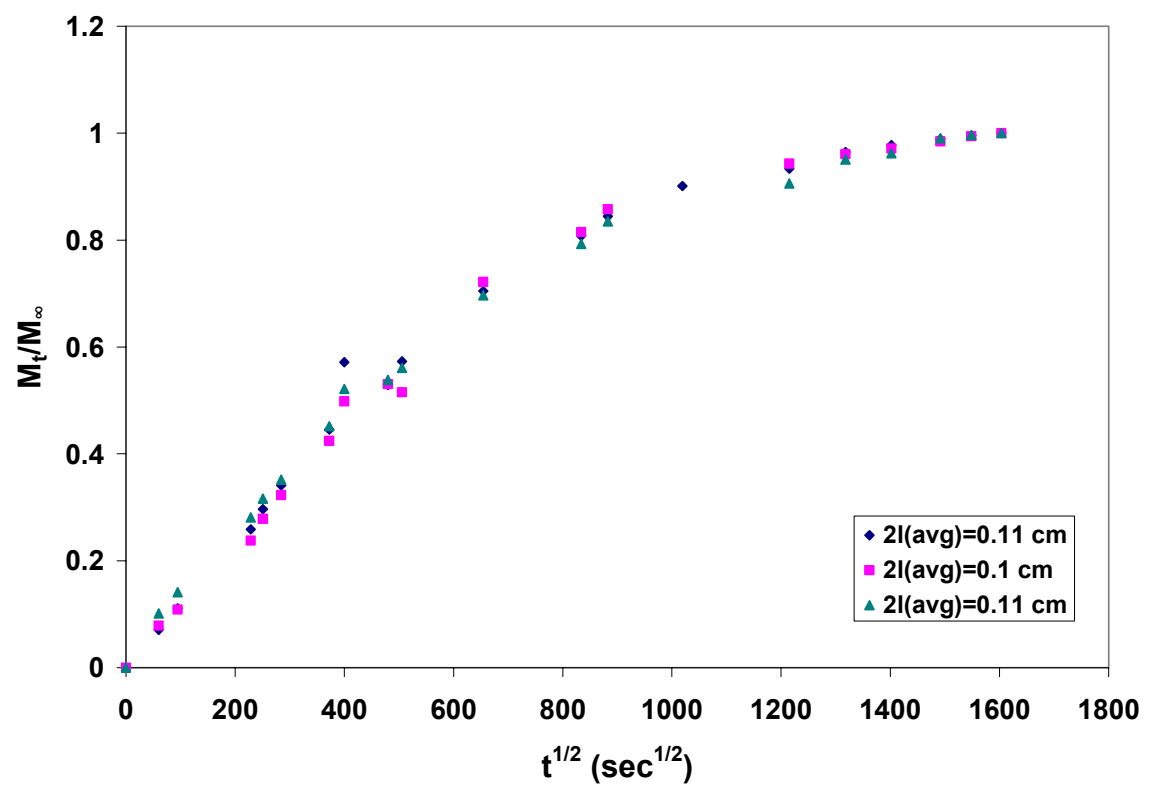

Figure $92 M_{t} / M_{\infty}$ versus $t^{1 / 2}$ for vinyl ester samples containing 5 wt $\%$ clay immersed in water and subjected to $30 \%$ UTS at $25{ }^{\circ} \mathrm{C}$

For neat vinyl ester samples immersed in water, the diffusivity values and equilibrium moisture content were found to remain constant with stress level. The 
diffusivity of water in neat vinyl ester samples subjected to $17 \%$ UTS was found to be $4 \mathrm{x}$ $10^{-9} \mathrm{~cm}^{2} / \mathrm{s}$ and at $30 \%$ UTS the value of diffusivity was found to be $4.12 \times 10^{-9} \mathrm{~cm}^{2} / \mathrm{s}$. The diffusivity of neat vinyl ester without any stress was found to be $4.15 \times 10^{-9} \mathrm{~cm}^{2} / \mathrm{s}$.

$5 \mathrm{wt} \%$ clay loaded vinyl ester samples exhibited a marked increase in diffusivity values with the application of stress. With the application of stress on $5 \mathrm{wt} \%$ clay loaded samples, the diffusivity increased from $2.04 \times 10^{-9} \mathrm{~cm}^{2} / \mathrm{s}$ (without stress) to $2.96 \times 10^{-9}$ $\mathrm{cm}^{2} / \mathrm{s}$ at $17 \%$ UTS and $3.06 \times 10^{-9} \mathrm{~cm}^{2} / \mathrm{s}$ at $30 \%$ UTS respectively. The increase in diffusivity was observed in the samples immersed in water and those exposed to $60 \% \mathrm{RH}$ environment. The equilibrium moisture content of the samples seemed to decrease, though not very significantly, with the application of stress.

\subsubsection{Sorption Experiments under Stress at $60 \%$ RH}

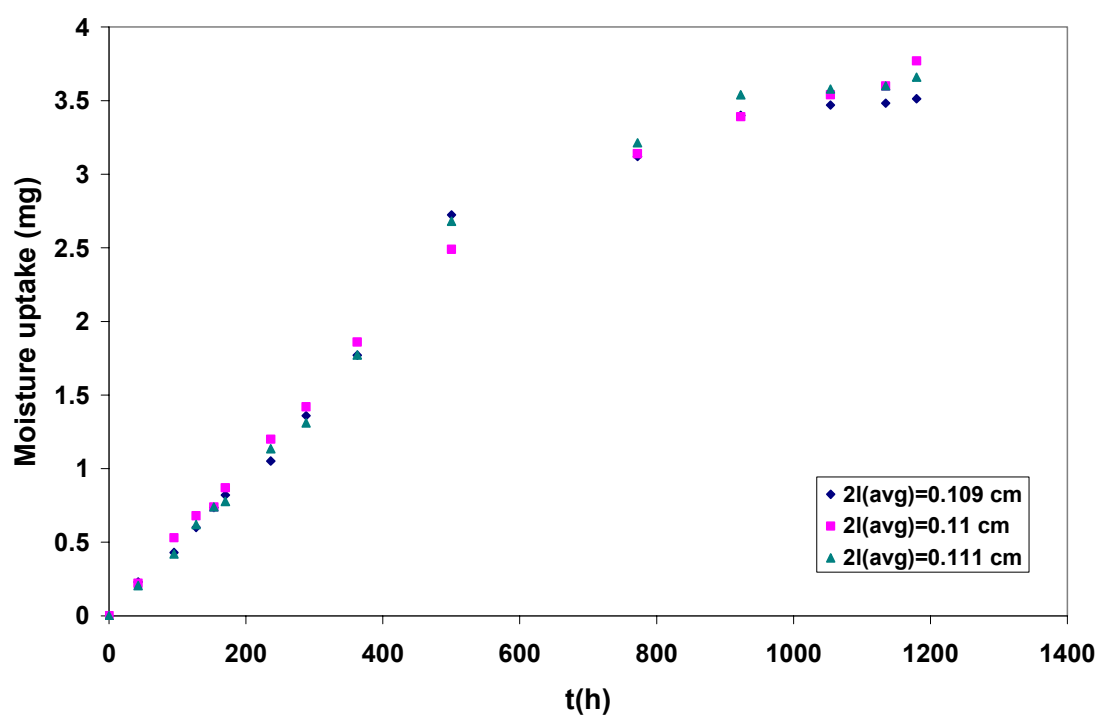

Figure 93 Moisture uptake (mg) versus $t(h)$ for neat vinyl ester samples at $60 \%$ RH and subjected to $30 \%$ UTS at $25^{\circ} \mathrm{C}$

Figure 93, Figure 94 and Figure 95 show plots of corresponding moisture uptake versus time, moisture content $(\%)$ versus time and $M_{t} / M_{\infty}$ versus $t^{1 / 2}$ for neat vinyl ester samples at $60 \%$ relative humidity and subjected to $30 \%$ UTS at $25{ }^{\circ} \mathrm{C}$. The raw sorption data of vinyl ester samples containing $0 \mathrm{wt} \%$ Cloisite $10 \mathrm{~A}$ exposed to $60 \% \mathrm{RH}$ at $25^{\circ} \mathrm{C}$ subjected to $17 \% \mathrm{UTS}$ at $25^{\circ} \mathrm{C}$ is given in Appendix D in Table 46. 


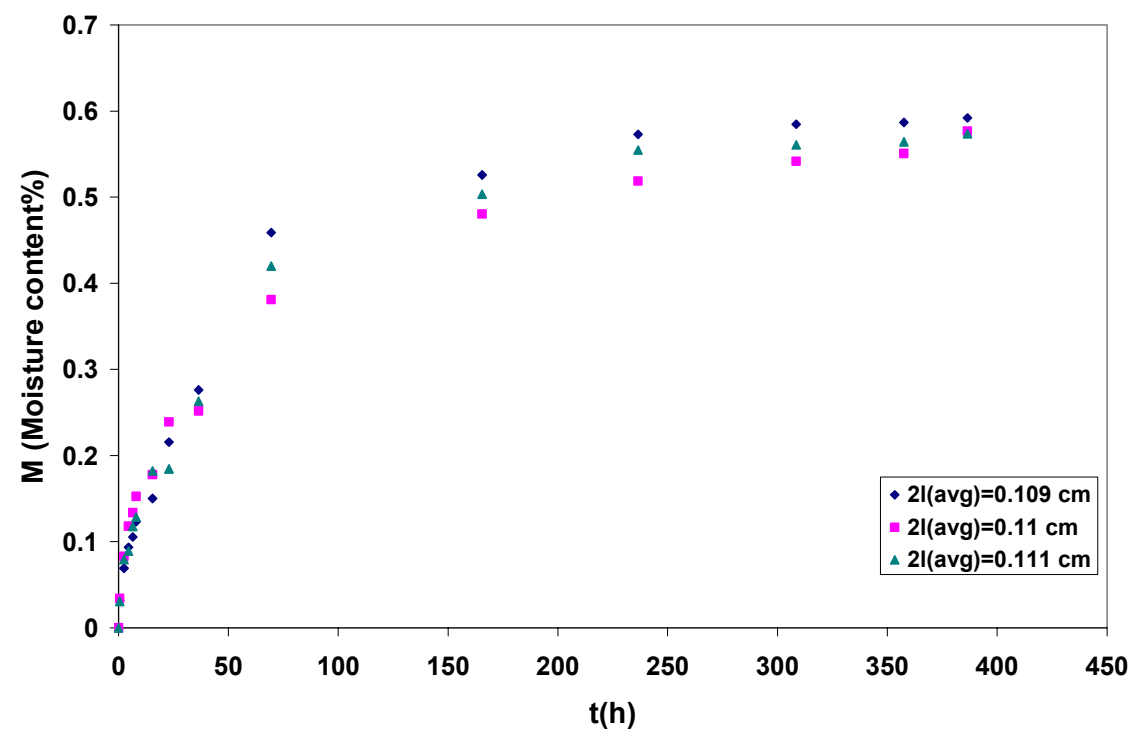

Figure 94 Moisture content versus t for neat vinyl ester samples at $60 \%$ RH and subjected to $30 \%$ UTS at $25^{\circ} \mathrm{C}$

The average equilibrium moisture content of the samples is about $0.6 \%$, which is same as that of the samples exposed at $60 \% \mathrm{RH}$ without any stress. This indicates that the increase in stress level did not affect the equilibrium moisture content of neat vinyl ester samples exposed at $60 \% \mathrm{RH}$.

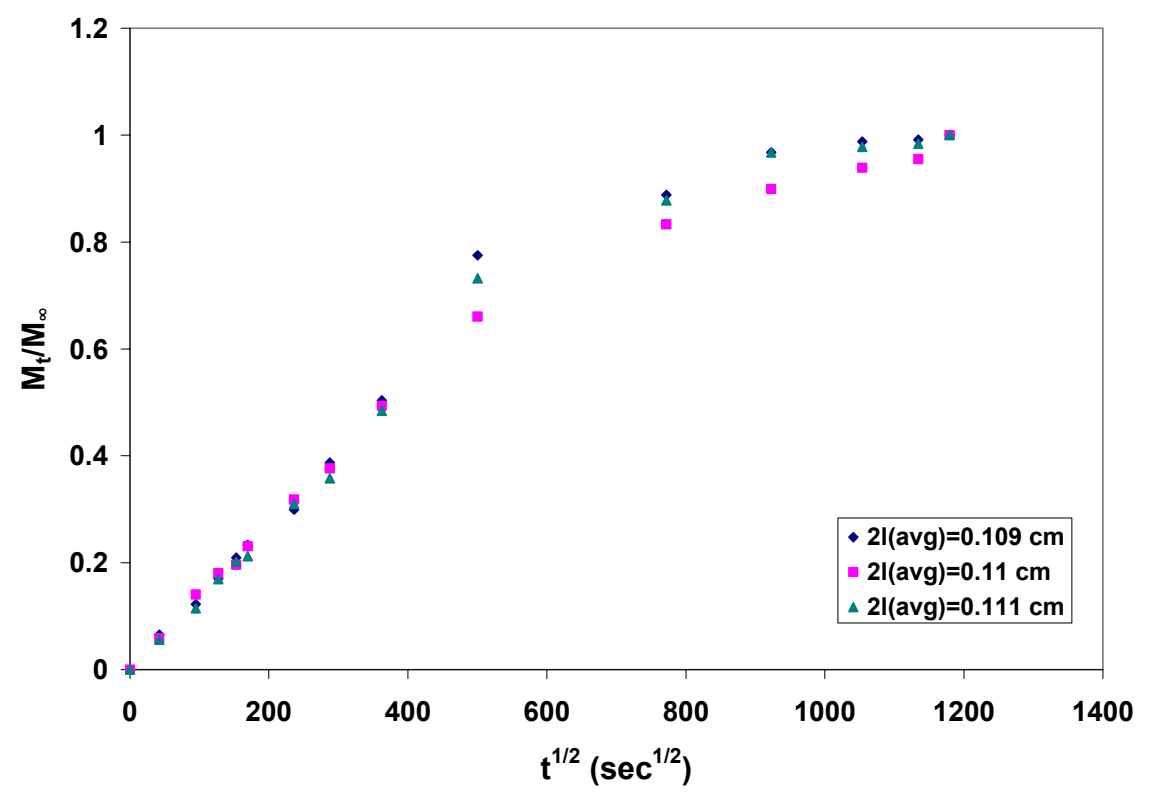

Figure $95 M_{t} / M_{\infty}$ versus $t^{1 / 2}$ for neat vinyl ester samples at $60 \%$ RH and subjected to $30 \%$ UTS at 25 ${ }^{\circ} \mathbf{C}$

The linear initial uptake curve of $\mathrm{M}_{\mathrm{t}} / \mathrm{M}_{\infty}$ versus $\mathrm{t}^{1 / 2}$ plot in Figure 95 shows that the diffusion at $60 \%$ RH under $30 \%$ UTS followed Fickian diffusion. The diffusivity was 
found to be $4.17 \times 10^{-9} \mathrm{~cm}^{2} / \mathrm{s}$, same as that of moisture in neat vinyl ester without any stress $\left(4.15 \times 10^{-9} \mathrm{~cm}^{2} / \mathrm{s}\right)$.

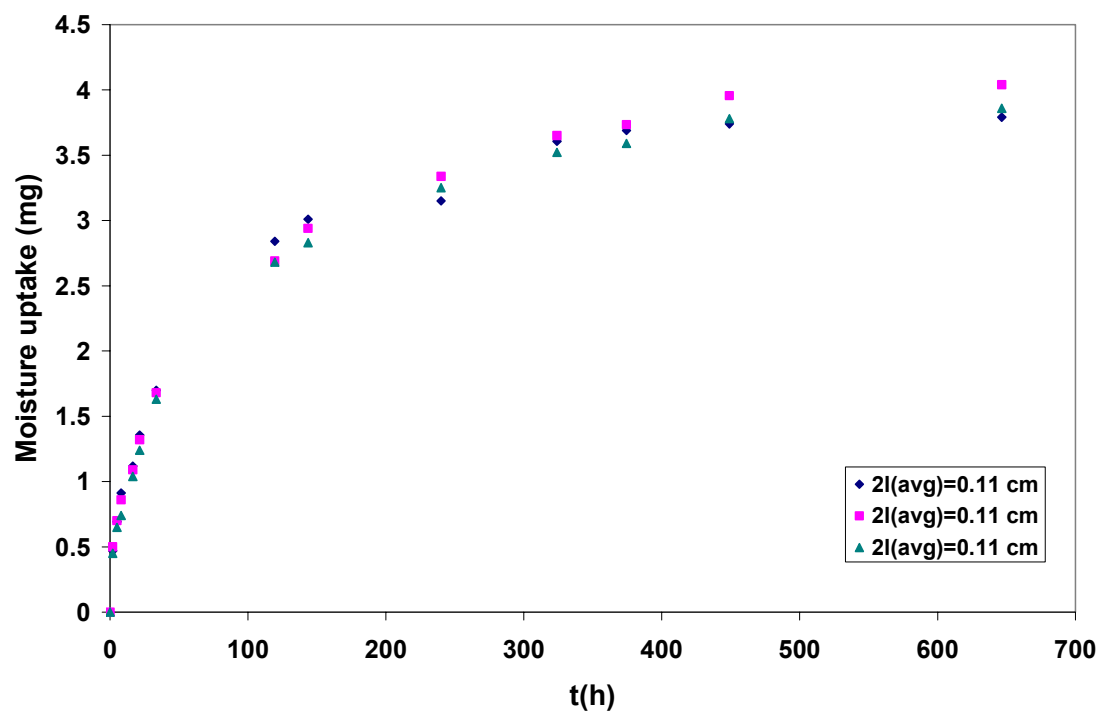

Figure 96 Moisture uptake $(\mathrm{mg})$ versus $\mathrm{t}(\mathrm{h})$ for vinyl ester samples containing $5 \mathrm{wt} \%$ clay at $60 \%$ $\mathrm{RH}$ and subjected to $30 \% \mathrm{UTS}$ at $25^{\circ} \mathrm{C}$

Figure 96, Figure 97 and Figure 98 show corresponding plots of moisture uptake versus time, moisture content (\%) versus time and $M_{t} / M_{\infty}$ versus $t^{1 / 2}$ for $5 \mathrm{wt} \%$ clay loaded vinyl ester samples exposed at 60\% RH and subjected to 30\% UTS. Figure 97 shows that the average equilibrium moisture content of vinyl ester samples containing 5 wt $\%$ clay and subjected to $30 \%$ UTS was about $0.6 \%$, which is same as that of the samples under no stress and exposed at $60 \% \mathrm{RH}$. This indicates that the increase in stress level did not affect the equilibrium moisture content of $5 \mathrm{wt} \%$ clay loaded vinyl ester samples exposed at $60 \% \mathrm{RH}$. The raw sorption data of vinyl ester samples containing 5 wt $\%$ Cloisite $10 \mathrm{~A}$ exposed to $60 \% \mathrm{RH}$ at $25^{\circ} \mathrm{C}$ subjected to $17 \%$ UTS at $25^{\circ} \mathrm{C}$ is given in Appendix D in Table 47. 


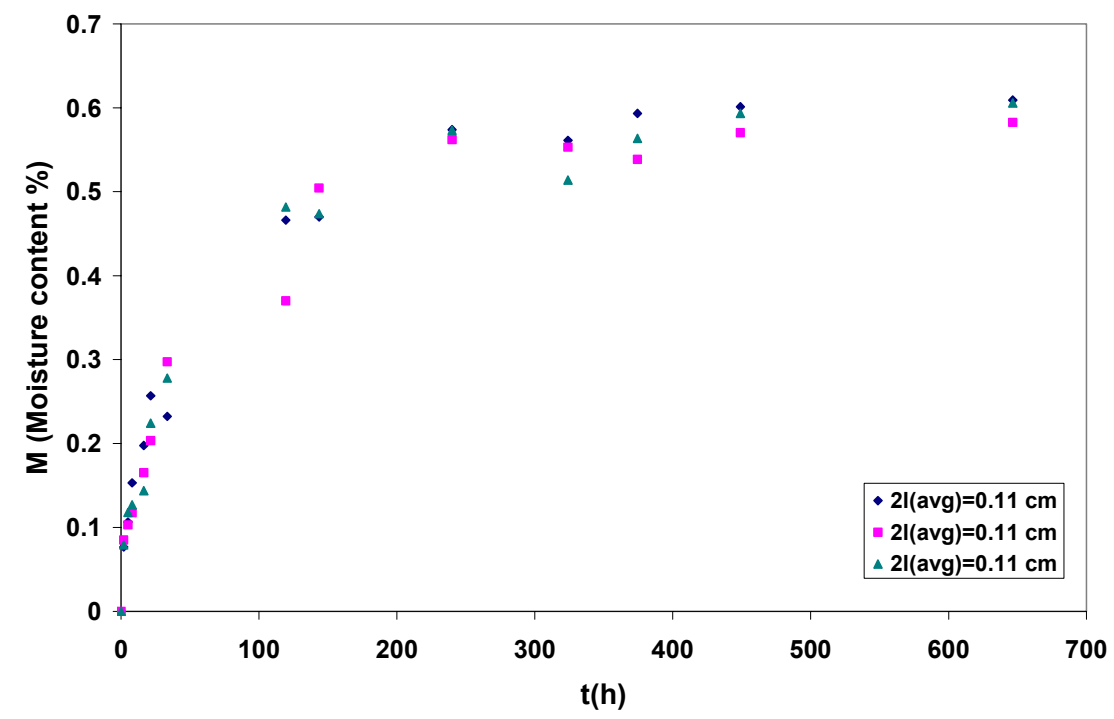

Figure 97 Moisture content versus t (h) for vinyl ester samples containing 5 wt $\%$ clay at $60 \%$ RH and subjected to $30 \% \mathrm{UTS}$ at $25^{\circ} \mathrm{C}$

The linear initial uptake curve of $\mathrm{M}_{\mathrm{t}} / \mathrm{M}_{\infty}$ versus $\mathrm{t}^{1 / 2}$ plot in Figure 98 shows that the diffusion at $60 \%$ RH and at 30\% UTS followed Fickian diffusion. The diffusivity was found to be $3.3 \times 10^{-9} \mathrm{~cm}^{2} / \mathrm{s}$. Similar to the stress coupled sorption experiments in water, $5 \mathrm{wt} \%$ clay loaded vinyl ester samples exposed to $60 \% \mathrm{RH}$ environment exhibited a marked increase in diffusivity values with the application of stress.

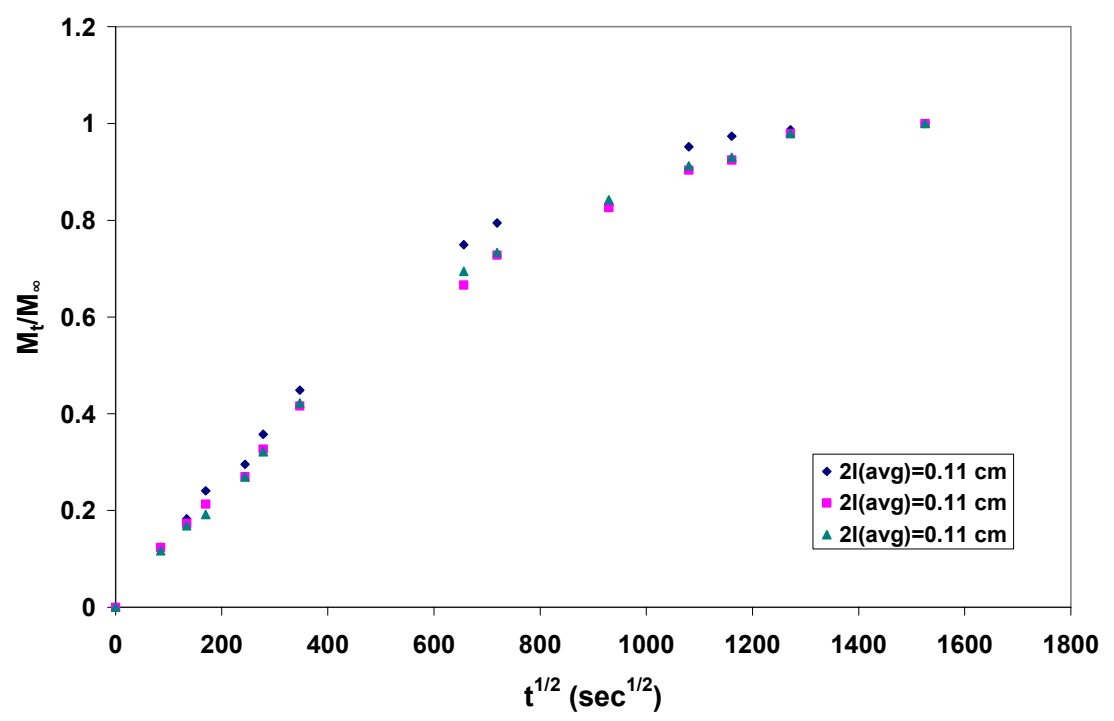

Figure $98 M_{t} / M_{\infty}$ versus $t^{1 / 2}$ for vinyl ester samples containing 5 wt $\%$ clay at $60 \%$ RH and subjected to $30 \%$ UTS at $25^{\circ} \mathrm{C}$

Similar to the results obtained in the stress coupled diffusion in water, for neat vinyl ester samples at $60 \% \mathrm{RH}$, the diffusivity seemed to remain constant with stress level. The 
diffusivity of water in neat vinyl ester samples subjected to $30 \%$ UTS was found to be $4.12 \times 10^{9} \mathrm{~cm}^{2} / \mathrm{s}$. The diffusivity of moisture in neat vinyl ester without any stress at $60 \%$ RH was found to be $4.0 \times 10^{-9} \mathrm{~cm}^{2} / \mathrm{s}$.

Table 7 and Table 8 show the variation in equilibrium moisture content (EMC) and diffusivity (D) of moisture with various stress levels and percentage clay loadings for samples immersed in water and those exposed at $60 \%$ relative humidity $(\mathrm{RH})$ respectively. $5 \mathrm{wt} \%$ clay loaded vinyl ester samples exhibited a marked increase in diffusivity values with the application of stress. With the application of stress on $5 \mathrm{wt} \%$ clay loaded samples, the diffusivity increased from $2.3 \times 10^{-9} \mathrm{~cm}^{2} / \mathrm{s}$ (without stress) to $3.3 \times 10^{-9}$ $\mathrm{cm}^{2} / \mathrm{s}$ at $30 \%$ UTS in samples exposed to $60 \%$ RH. No change in equilibrium moisture content was observed in the samples immersed in water and those exposed to $60 \% \mathrm{RH}$ environment with increase in stress level. The reason for the increase in the diffusivity of moisture in $5 \mathrm{wt} \%$ clay loaded samples could be due to the micro-structural damage occurred due to the application of stress. To verify this, SEM analysis on the $5 \mathrm{wt} \%$ clay loaded samples subjected to stress was done. The images obtained (Figure 107, Figure 108, Figure 109, Figure 110, Figure 111, Figure 112, Figure 113 and Figure 114) during the analysis showed formation of cracks in the samples.

Table 7. Variation of equilibrium moisture content and diffusivity with various stress levels and percentage clay loadings for samples immersed in water

\begin{tabular}{|r|c|c|c|c|c|c|}
\hline \multirow{2}{*}{$\begin{array}{c}\text { Clay } \\
\text { loading }\end{array}$} & \multicolumn{6}{|c|}{ Stress Level } \\
\cline { 2 - 7 } & $0 \%$ UTS & \multicolumn{2}{|c|}{$17 \%$ UTS } & \multicolumn{2}{c|}{$30 \%$ UTS } \\
\cline { 2 - 7 } & EMC (\%) & $\begin{array}{l}\text { Dx10 } \\
\left(\mathrm{cm}^{2} / \mathrm{s}\right)\end{array}$ & EMC (\%) & $\begin{array}{l}\text { Dx10 } \\
\left(\mathrm{cm}^{2} / \mathrm{s}\right)\end{array}$ & EMC (\%) & $\begin{array}{l}\text { Dx } 10^{9} \\
\left(\mathrm{~cm}^{2} / \mathrm{s}\right)\end{array}$ \\
\hline $0 \mathrm{wt} \%$ & $1.23 \pm 0.03$ & $4.15 \pm 0.7$ & $1.15 \pm 0.04$ & $4.06 \pm 0.58$ & $1.15 \pm 0.004$ & $4.12 \pm 0.45$ \\
\hline $5 \mathrm{wt} \%$ & $1.49 \pm 0.07$ & $2.04 \pm 0.14$ & $1.22 \pm 0.02$ & $2.96 \pm 0.22$ & $1.22 \pm 0.07$ & $3.06 \pm 0.26$ \\
\hline
\end{tabular}

Table 8. Variation of equilibrium moisture content and diffusivity with various stress levels and percentage clay loadings for samples exposed at $60 \% \mathrm{RH}$

\begin{tabular}{|c|r|r|r|r|}
\hline \multirow{2}{*}{$\begin{array}{c}\text { Clay } \\
\text { loading }\end{array}$} & \multicolumn{3}{|c|}{ Stress Level } \\
\cline { 2 - 5 } & EMC (\%) & Dx 10 $\left(\mathrm{cm}^{2} / \mathrm{s}\right)$ & EMC (\%) & Dx10 $\left(\mathrm{cm}^{2} / \mathrm{s}\right)$ \\
\cline { 2 - 5 } & $0.588 \pm 0.008$ & $4.0 \pm 0.34$ & $0.58 \pm 0.001$ & $4.17 \pm 0.17$ \\
\hline $0 \mathrm{wt} \%$ & $0.615 \pm 0.01$ & $2.3 \pm 0.12$ & $0.6 \pm 0.01$ & $3.3 \pm 0.36$ \\
\hline $5 \mathrm{wt} \%$ & & & & \\
\hline
\end{tabular}




\subsubsection{Mechanism of Diffusion through Polymer Nanocomposites under Stress}

The imposed external stress has important effect on the moisture diffusion through polymers. Liu (2004) studied the diffusion of dichloromethane through PDMS nanocomposites. The results showed that the extension of the membrane will not only decrease the thickness of the membrane, resulting in enhanced diffusion but also packs and reorients the polymer chains (decreasing the free volume), which can decrease the diffusion coefficient. The packing of the polymer chains reduces the free volume and increases the activation energy for diffusion, which leads to a decreased diffusion coefficient. For higher clay concentrations (due to reduced polymer chain mobility Shah, 2002), the packing of the polymer chains became more difficult, resulting in a smaller decrease. It was also reported in literature that application of tensile stress increases the space between the nano-particles which can increase the diffusivity. Also as reported by others, clay proved to be detrimental to the durability of the composites in terms of strength reduction. Ravindran (2005) reported a decrease in the tensile strength of the clay loaded fiber reinforced vinyl ester composites when subjected to a sustained load in alkaline solution. The phenomenon was thought to be due to the formation of microcracks. Wang et al. (2005) and Gam (2003) studied the formation and crack propagation in epoxy nanocomposites and their results indicated that the presence of nanoclay layers forced the crack to propagate along a very tortuous path. The results implied that the clay layers acted as stress concentrators and promoted the formation of a large number of microcracks when the sample was loaded.

\subsection{Scanning Electron Microscopy}

Scanning electron micrographs of freshly made neat and clay loaded samples were taken. Those were recognized as "Reference" samples. Figure 99, Figure 100, Figure 101 and Figure 102 show the SEM images of the "Reference" samples, neat vinyl ester, 5 $\mathrm{wt} \%$ clay loaded vinyl ester, $2 \mathrm{wt} \%$ clay loaded epoxy and $5 \mathrm{wt} \%$ clay loaded epoxy respectively. There were no cracks seen in the images taken. 


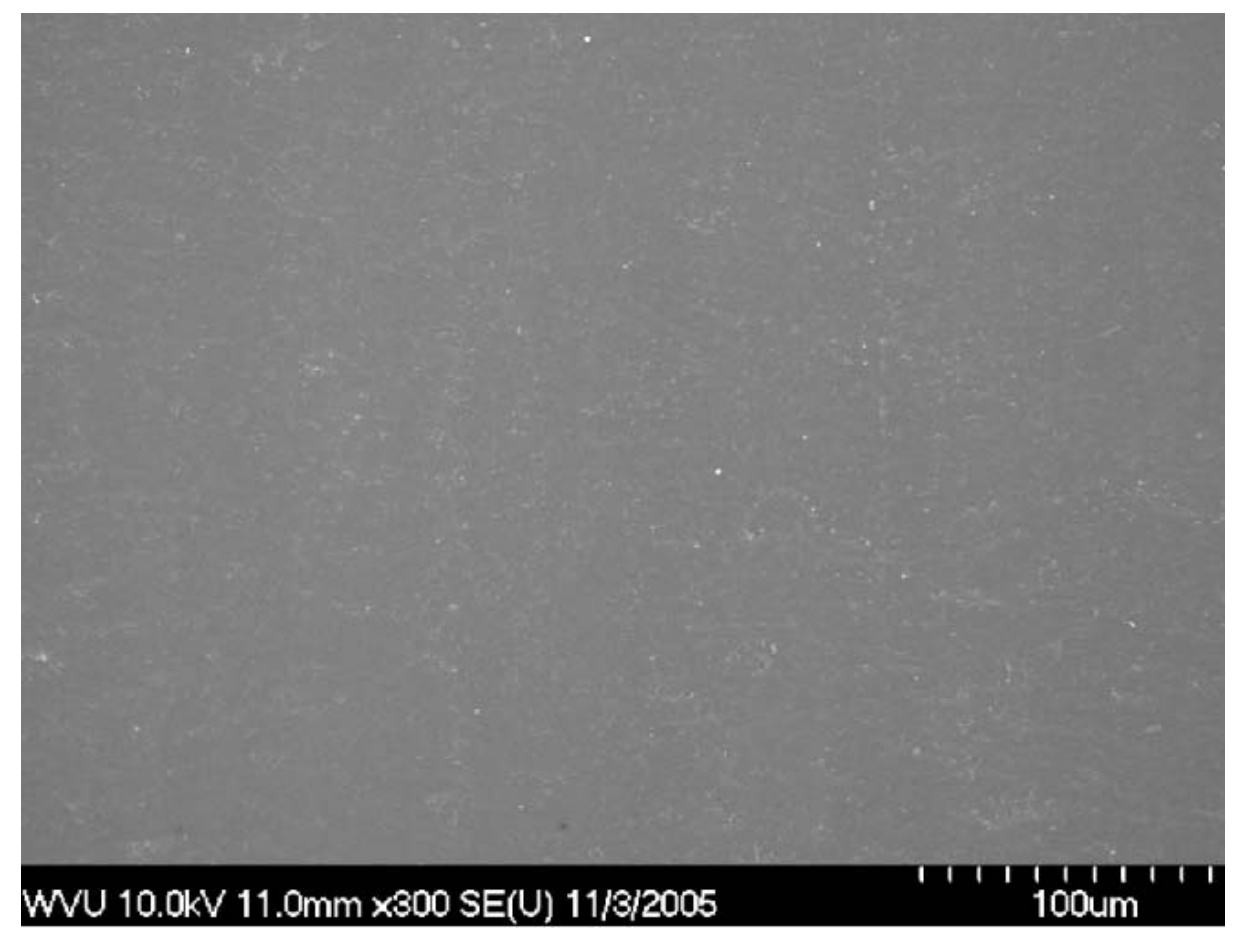

Figure 99 SEM image of freshly prepared neat vinyl ester sample (no cracks)

WV $10.0 \mathrm{kV} 10.7 \mathrm{~mm} \times 300 \mathrm{SE}(\mathrm{U}) 11 / 3 / 2005$

11111111111 100um

Figure 100 SEM image of freshly prepared 5 wt\% clay loaded vinyl ester sample (no cracks) 


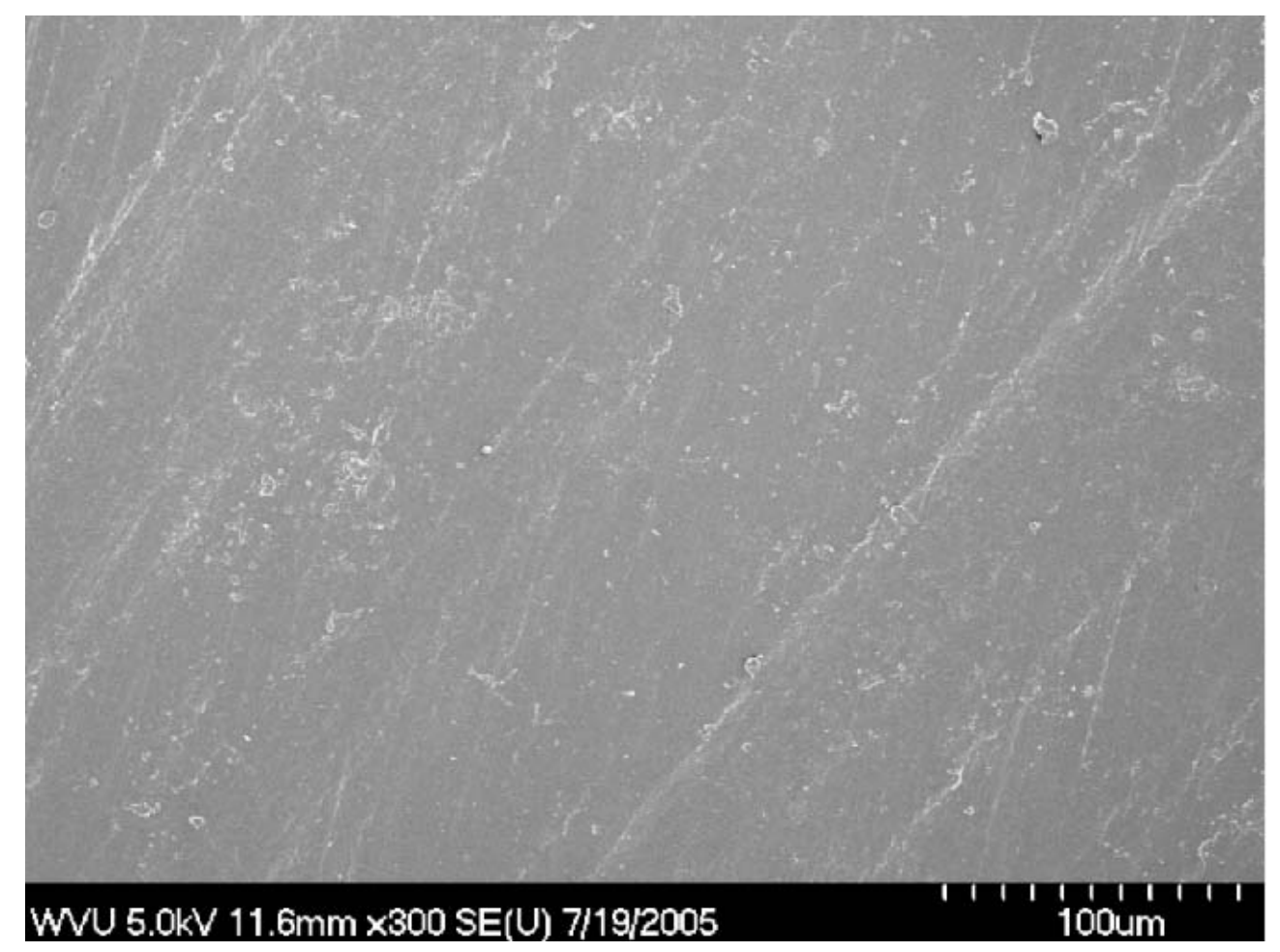

Figure 101 SEM image of freshly prepared 2 wt\% clay loaded epoxy sample (no cracks)

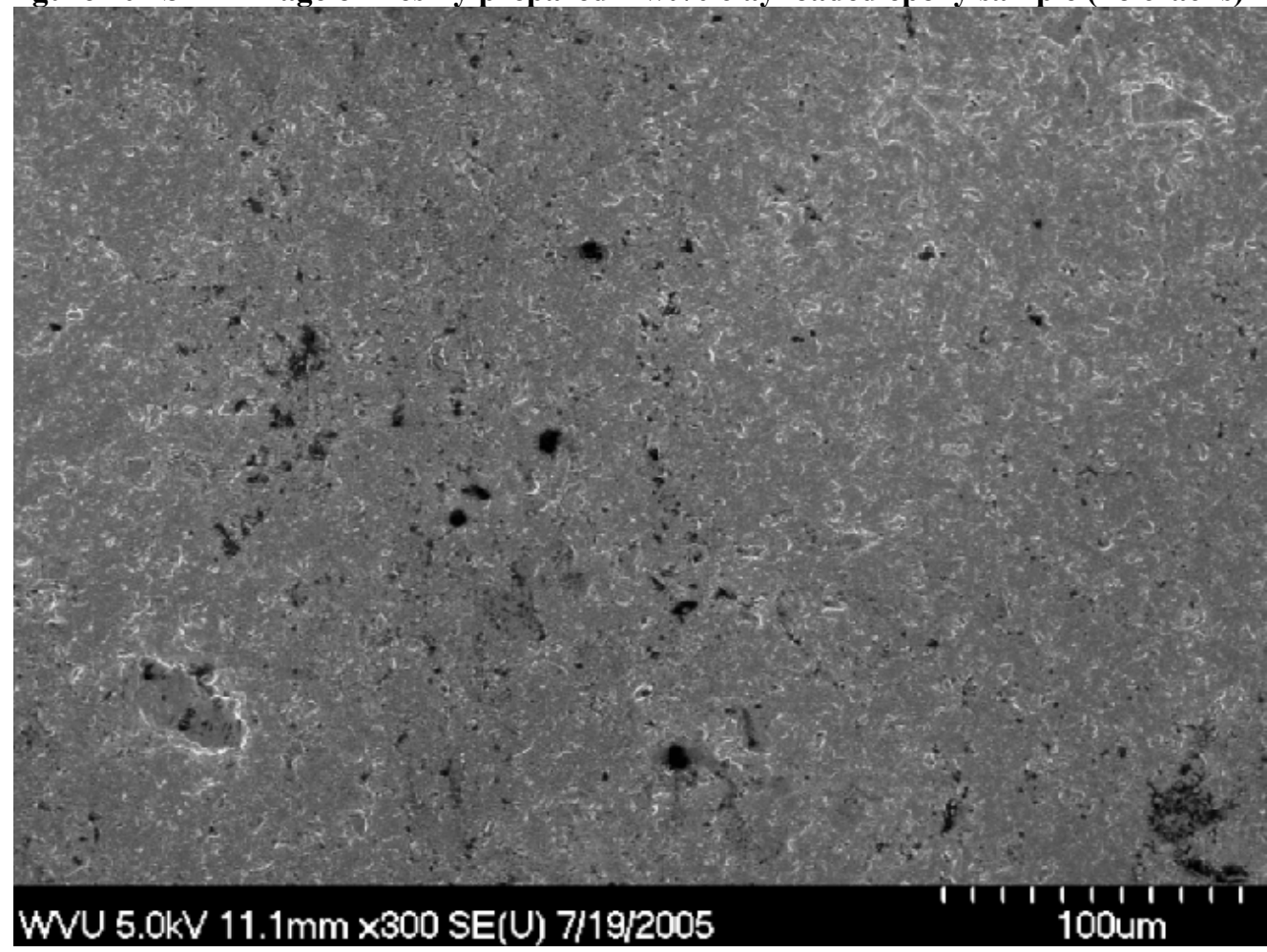

Figure 102 SEM image of freshly prepared $5 \mathrm{wt} \%$ clay loaded epoxy sample (no cracks)

The images taken for $2 \mathrm{wt} \%$ and $5 \mathrm{wt} \%$ clay loaded epoxy samples subjected to cyclic sorption-desorption and $5 \mathrm{wt} \%$ clay loaded vinyl ester samples subjected to 
sorption under stress showed the formation of cracks. Figure 103 and Figure 104 show the images of $2 \mathrm{wt} \%$ clay loaded epoxy subjected to cyclic moisture sorption-desorption. Figure 103 shows the presence of microcracks throughout the surface and under higher magnification as shown in Figure 104 the size of the cracks was found to be approximately $0.2 \mu \mathrm{m}$.

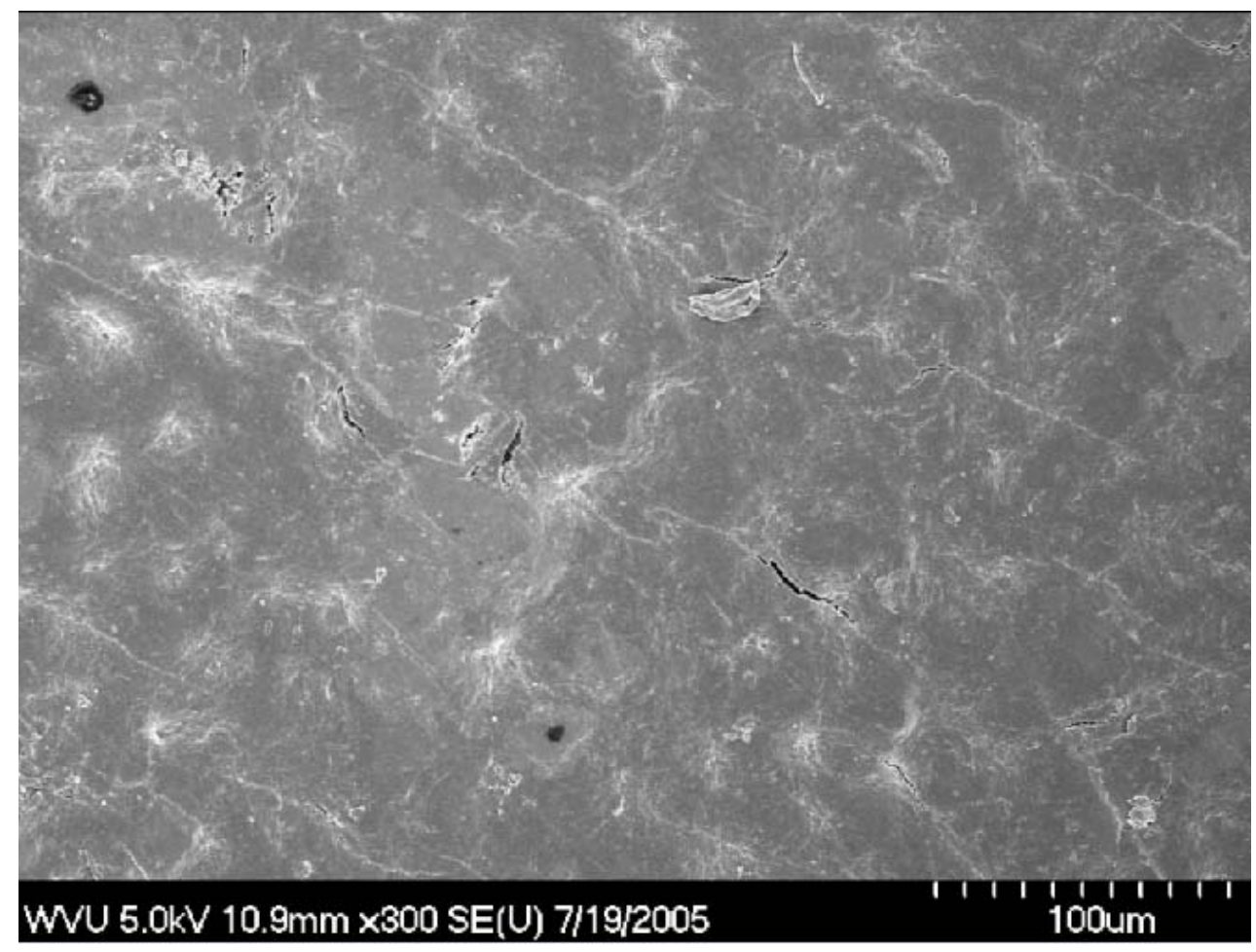

Figure 103 SEM image of 2 wt\% clay loaded epoxy subjected to cyclic sorption-desorption 


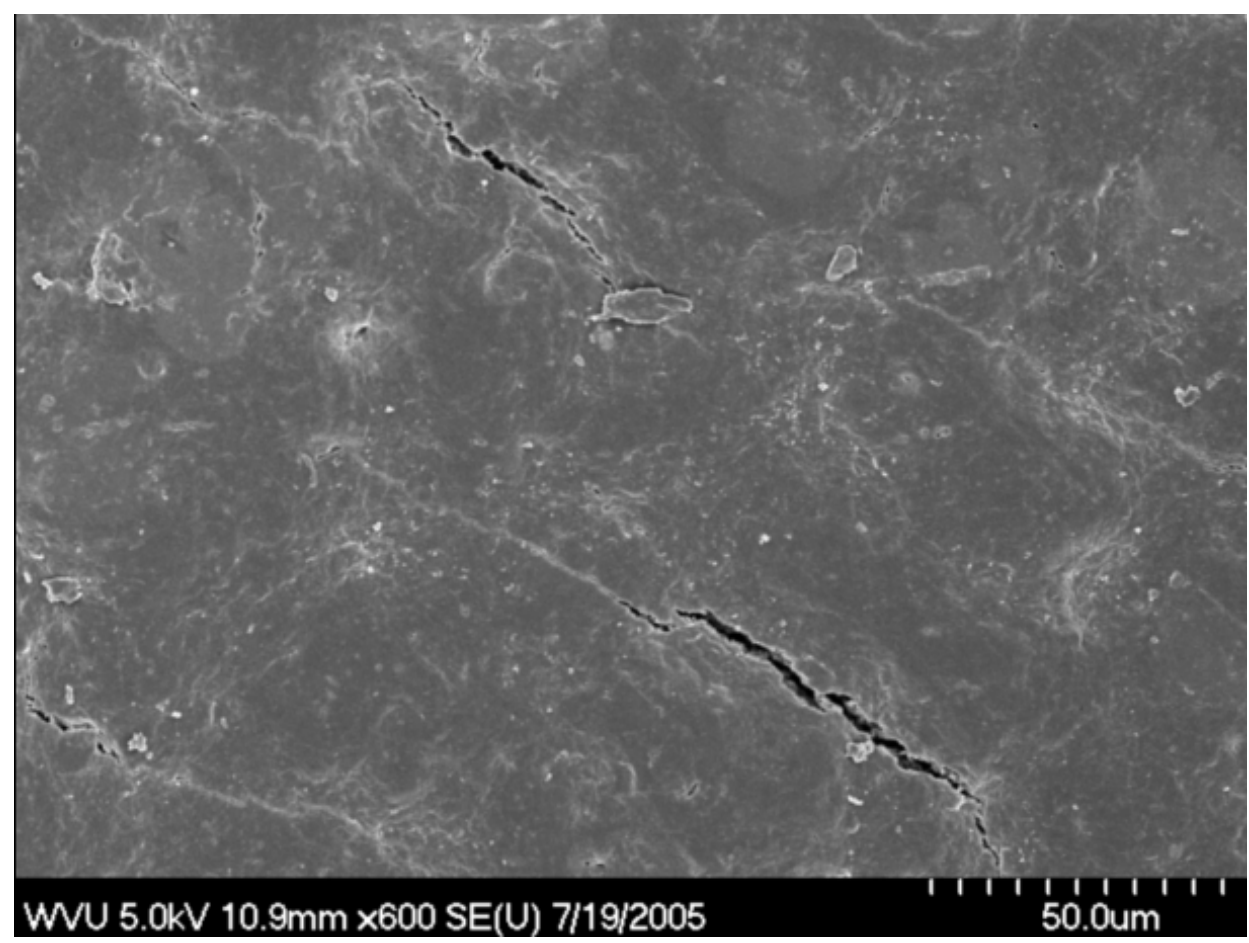

Figure 104 SEM image of $2 \mathrm{wt} \%$ clay loaded epoxy subjected to cyclic sorption-desorption (closer view)

Figure 105 and Figure 106 show the images of 5wt\% clay loaded epoxy subjected to cyclic moisture sorption-desorption.

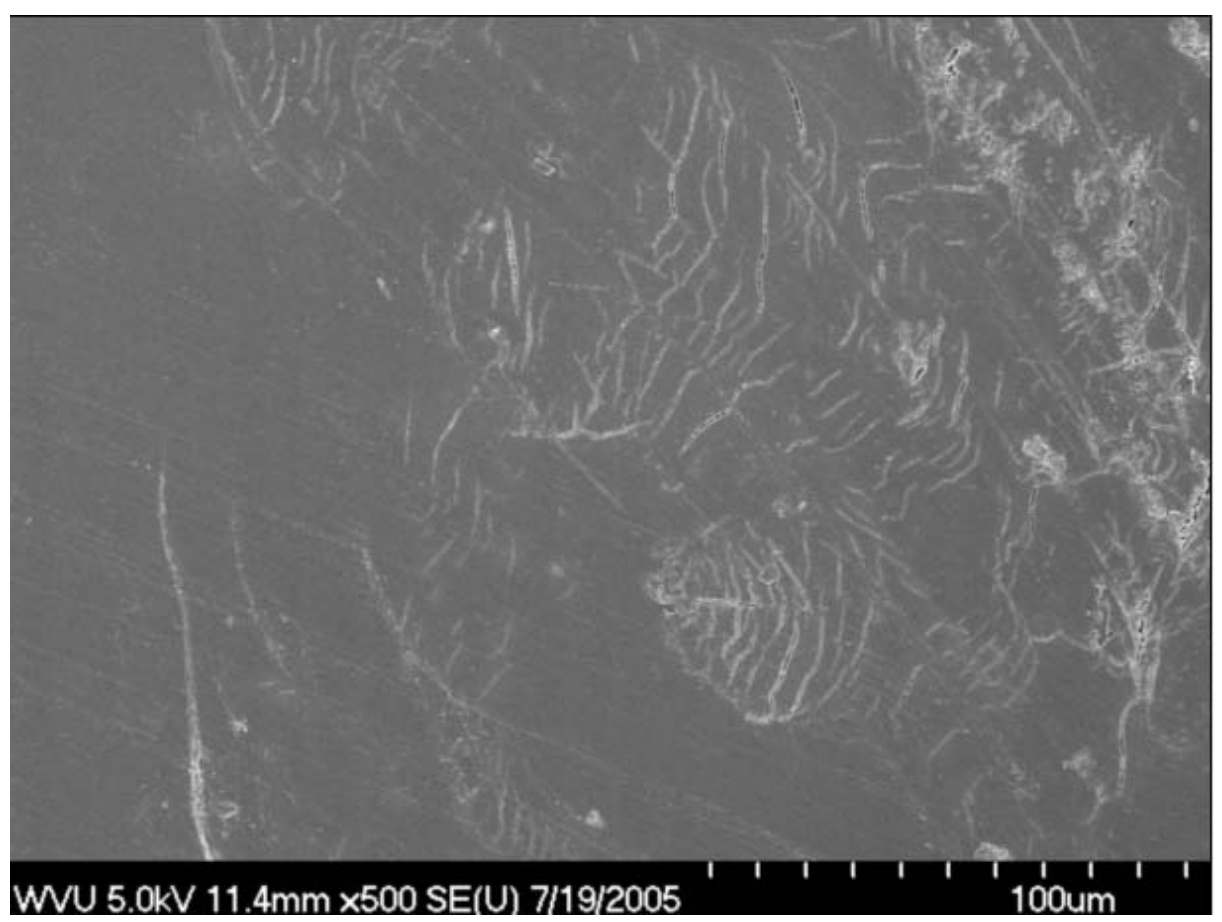

Figure 105 SEM image of $5 \mathrm{wt} \%$ clay loaded epoxy subjected to cyclic sorption-desorption Figure 105 and Figure 106 show the formation of large number of microcracks with 
increase in clay loading. Some clusters are also observed which indicate the presence of high concentration of clay in the neighboring regions. The path of the cracks was found to be tortuous due to the presence of nanoclay layers which force the crack to propagate along a very tortuous path. Thus it can be concluded that crack density increased with clay loading.

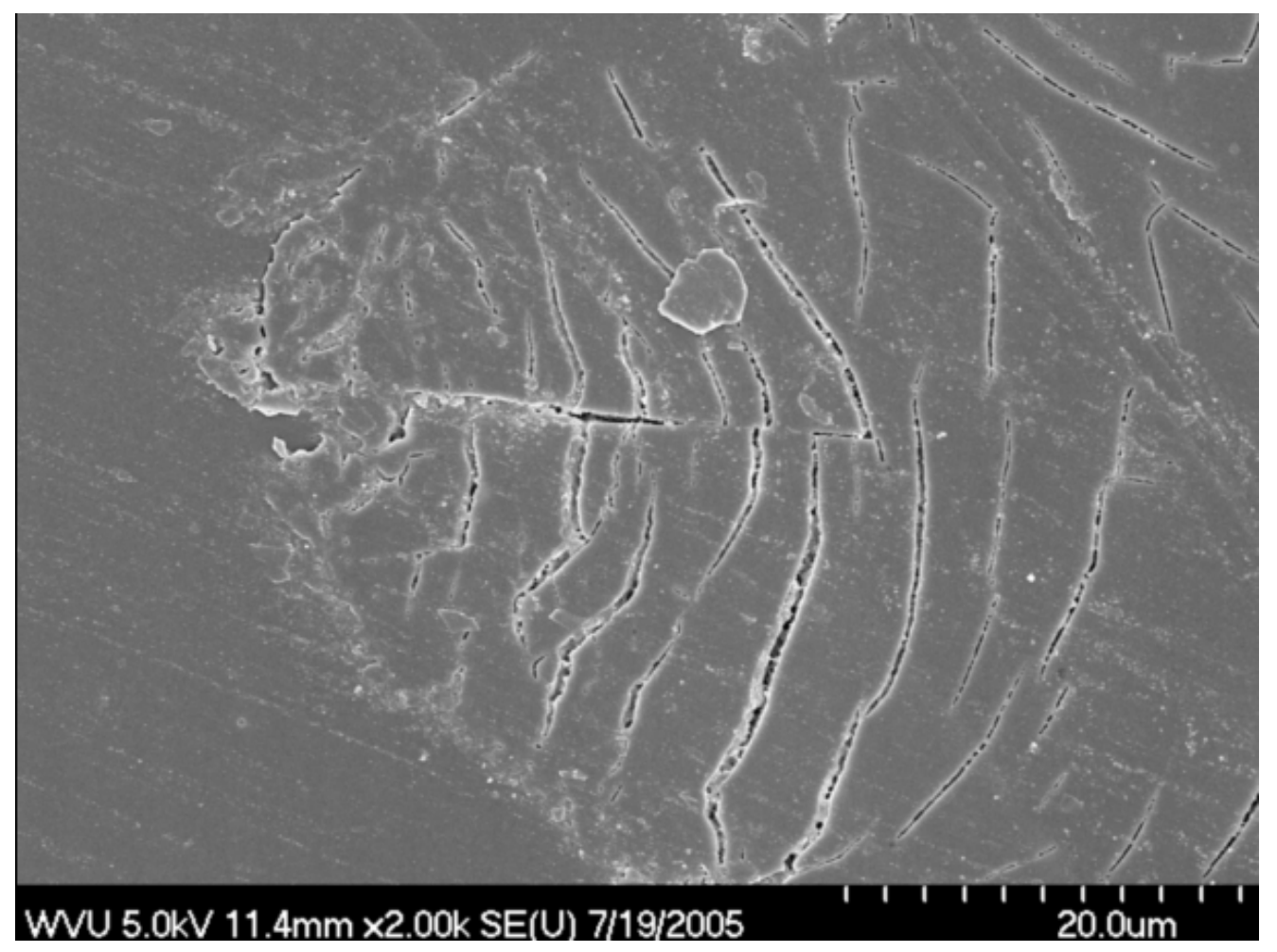

Figure $106 \mathrm{SEM}$ image of $5 \mathrm{wt} \%$ clay loaded epoxy subjected to cyclic sorption-desorption (closer view) 


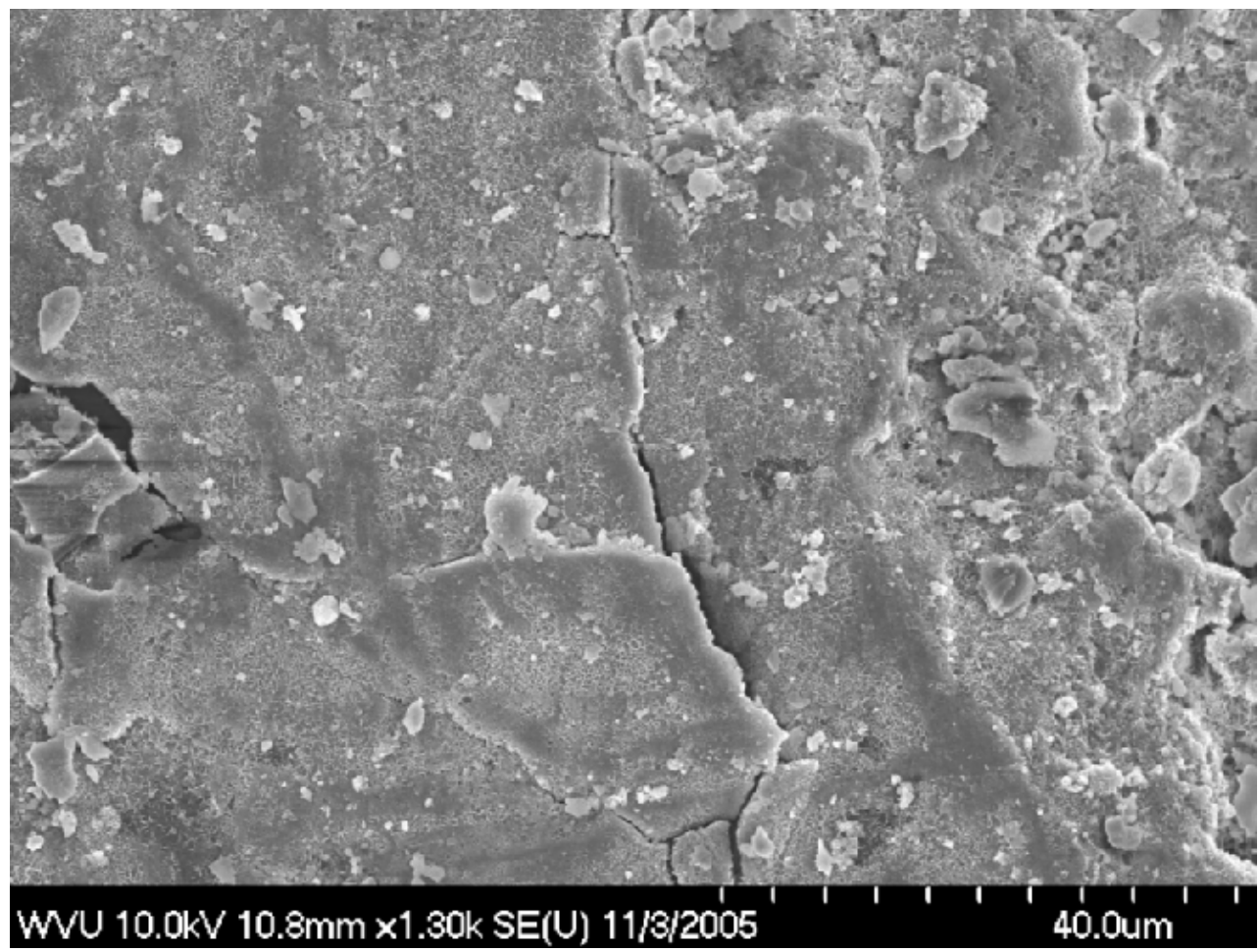

Figure 107 SEM image of $5 \mathrm{wt} \%$ clay loaded vinyl ester sample immersed in water and subjected to

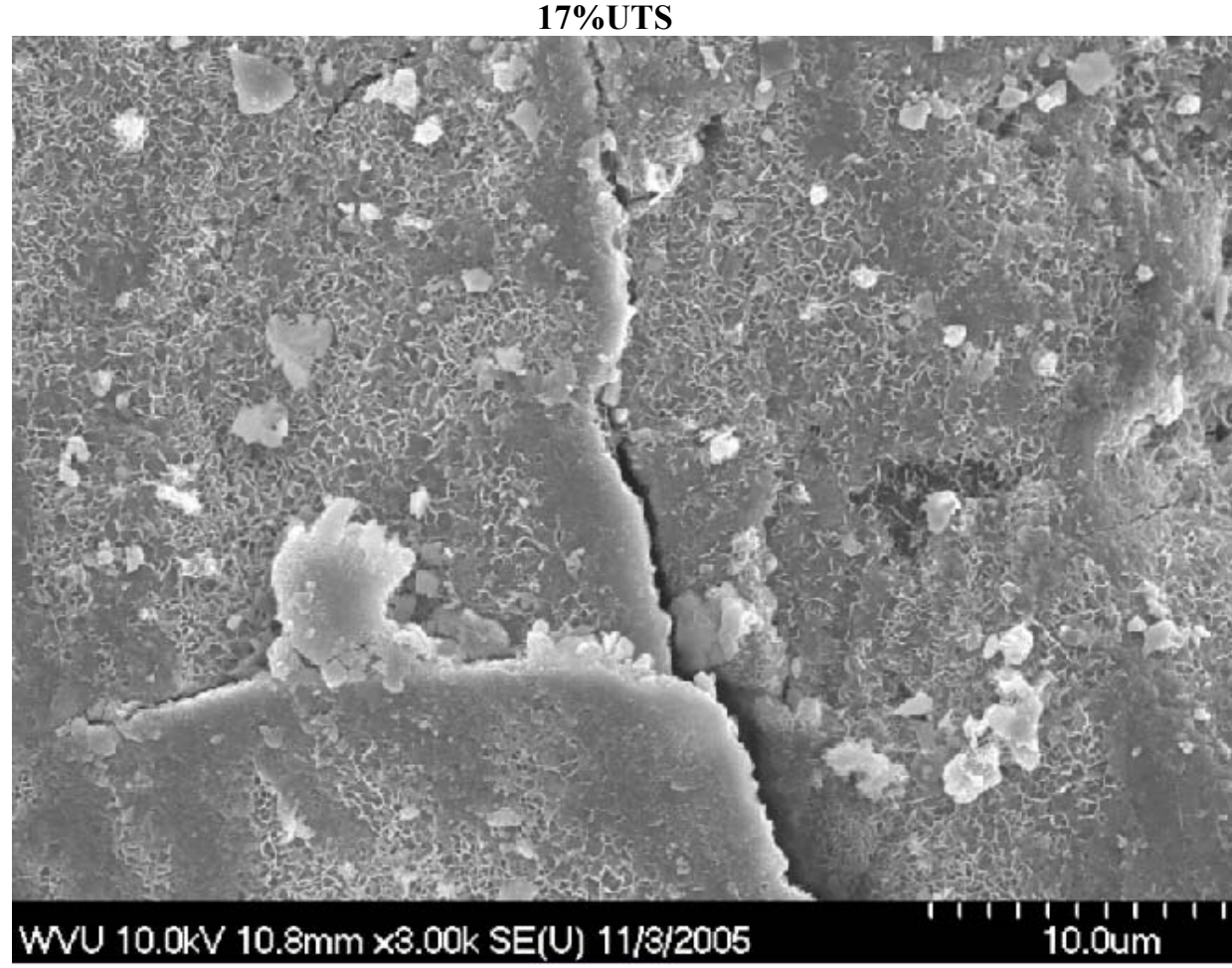

Figure 108 SEM image of 5 wt\% clay loaded vinyl ester sample immersed in water and subjected to 17\%UTS (closer view)

Figure 107 and Figure 108 show SEM images of $5 \mathrm{wt} \%$ clay loaded vinyl ester samples subjected to a load corresponding to $17 \%$ UTS. The figures show formation of 
micrcocracks and also scaling of the surface indicating that the presence of nanoclay layers forced the crack to propagate along a very tortuous path. The clay layers could have acted as stress concentrators and promoted the formation of a large number of microcracks when the sample was loaded. This is clearly seen in Figure 109 and Figure 110 , which show the increase in the number of cracks per unit area with the increase in the loading. Figure 109, Figure 110, Figure 111 and Figure 112 show the images of 5 wt $\%$ clay loaded samples immersed in water and subjected to $30 \%$ UTS. The size of the cracks formed in samples subjected to $30 \%$ UTS was found to be $0.2 \mu \mathrm{m}$.

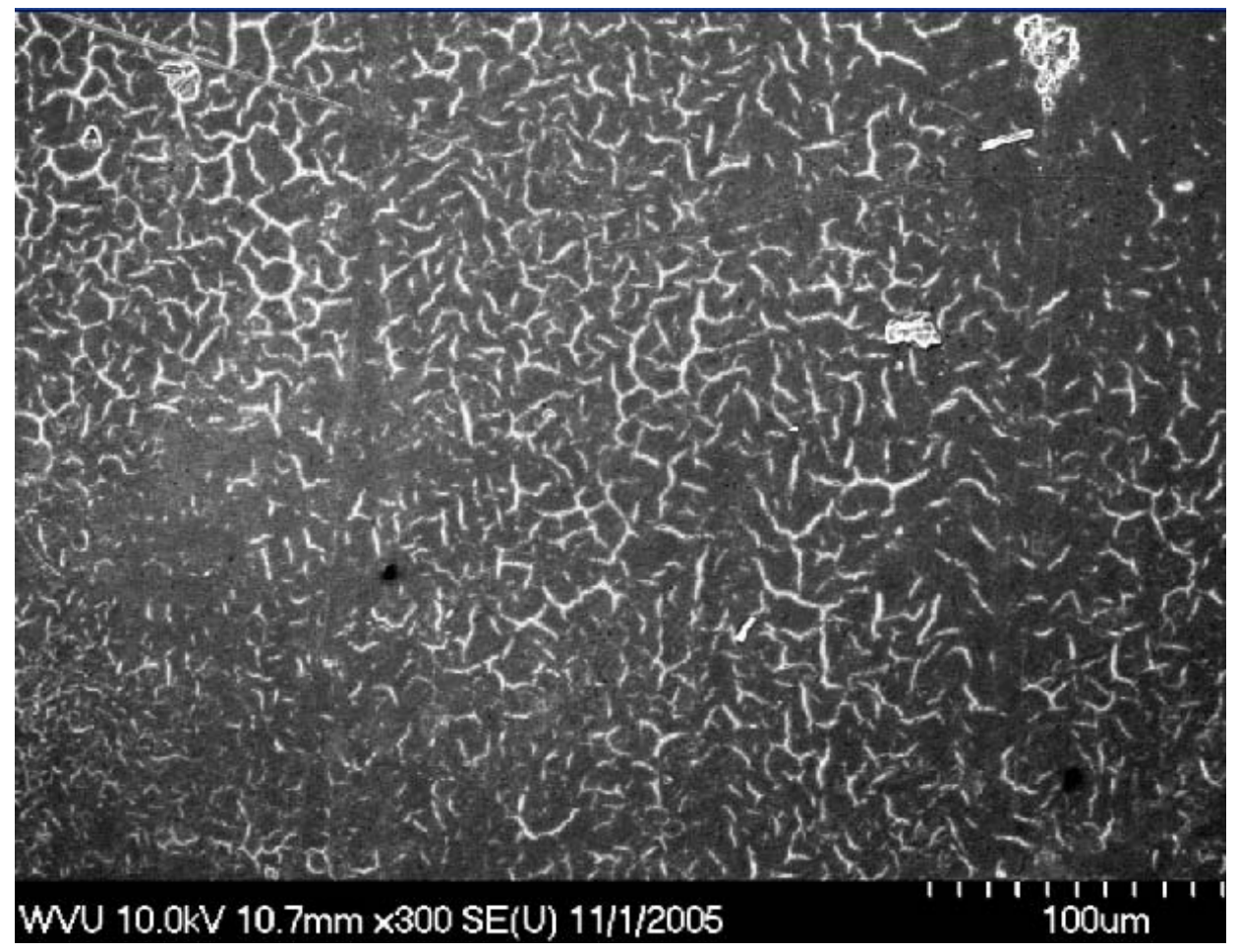

Figure 109 SEM image of $5 \mathrm{wt} \%$ clay loaded vinyl ester sample immersed in water and subjected to $30 \%$ UTS 


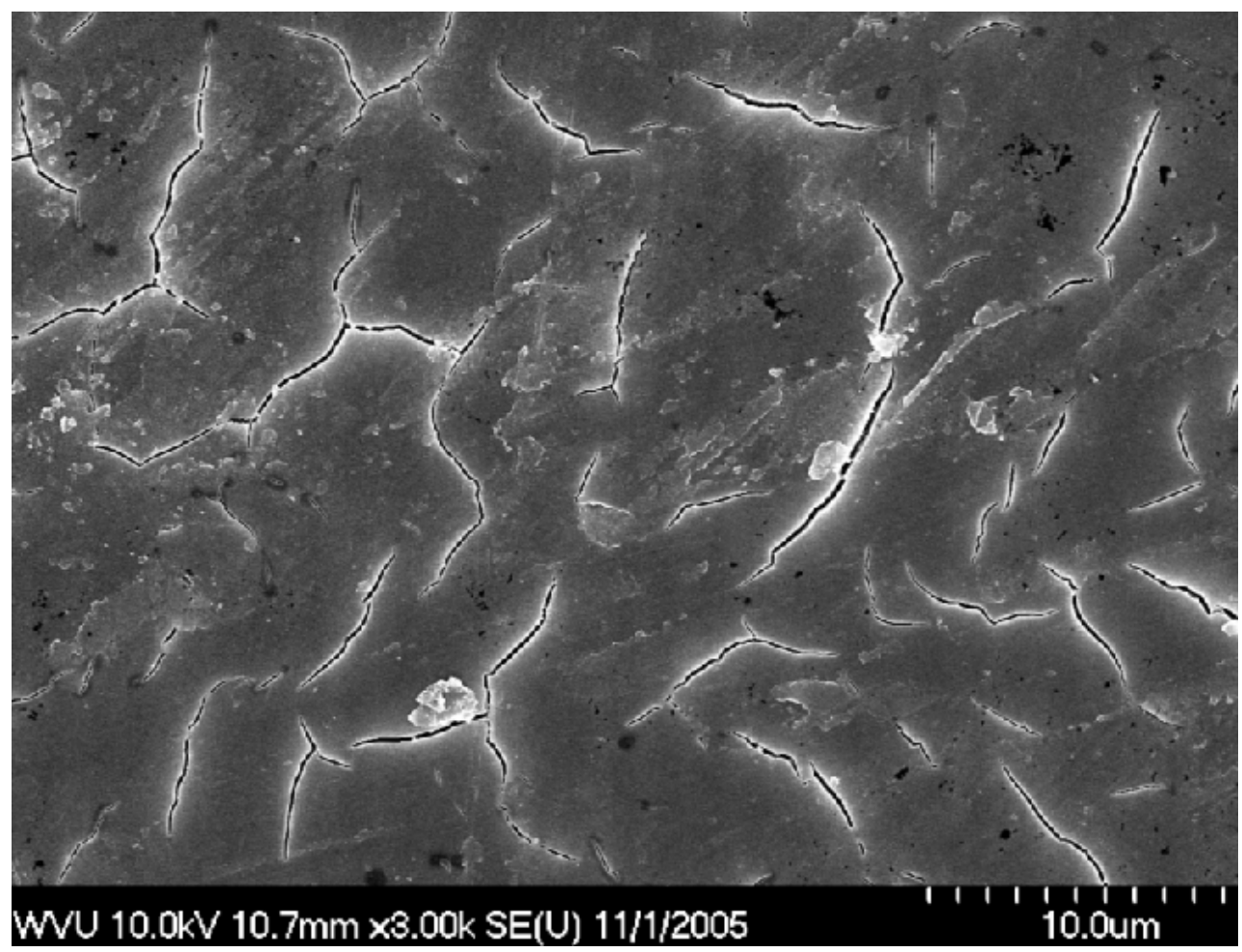

Figure 110 SEM image of $5 \mathrm{wt} \%$ clay loaded vinyl ester sample immersed in water and subjected to $30 \%$ UTS (closer view)

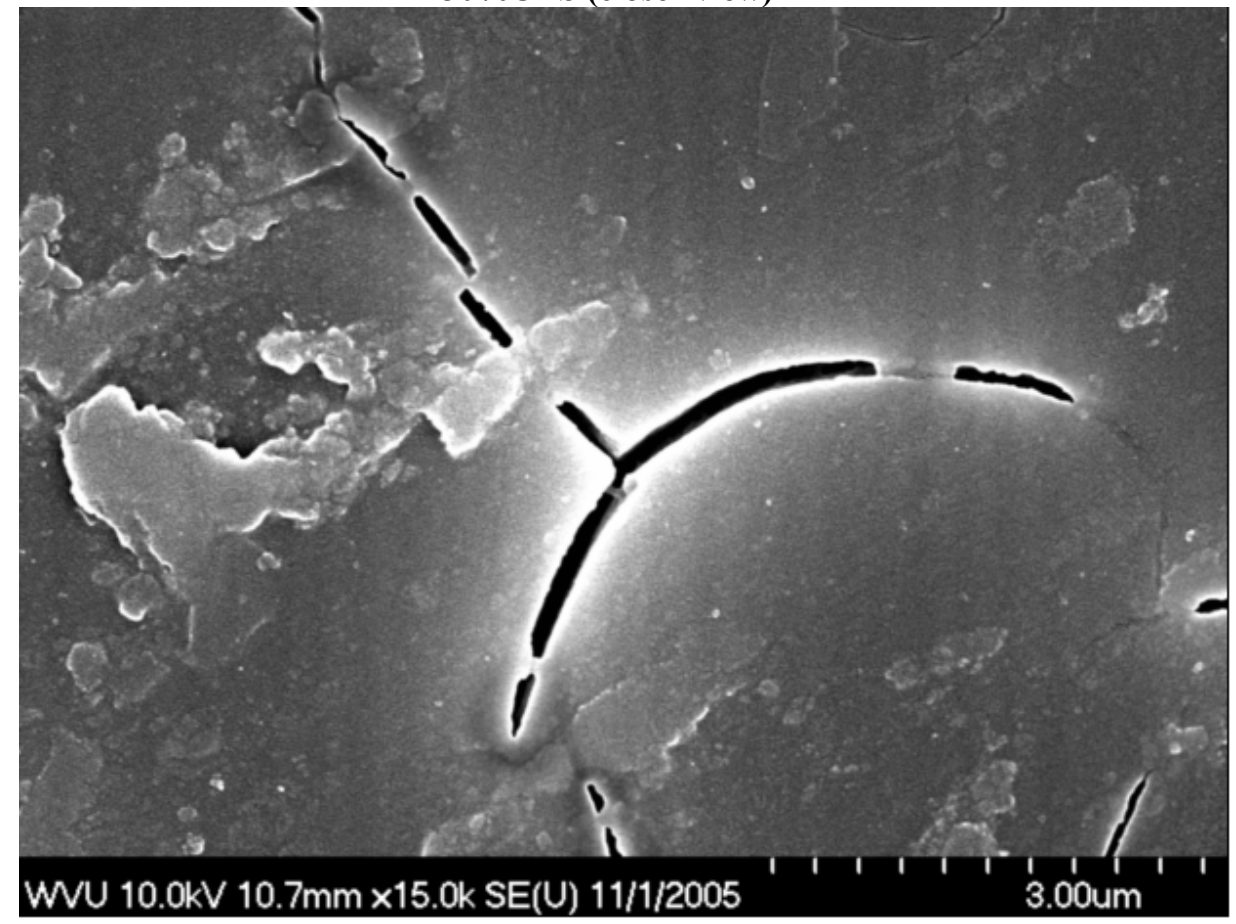

Figure 111 SEM image of $5 \mathrm{wt} \%$ clay loaded vinyl ester sample immersed in water and subjected to $30 \%$ UTS (closer view) 


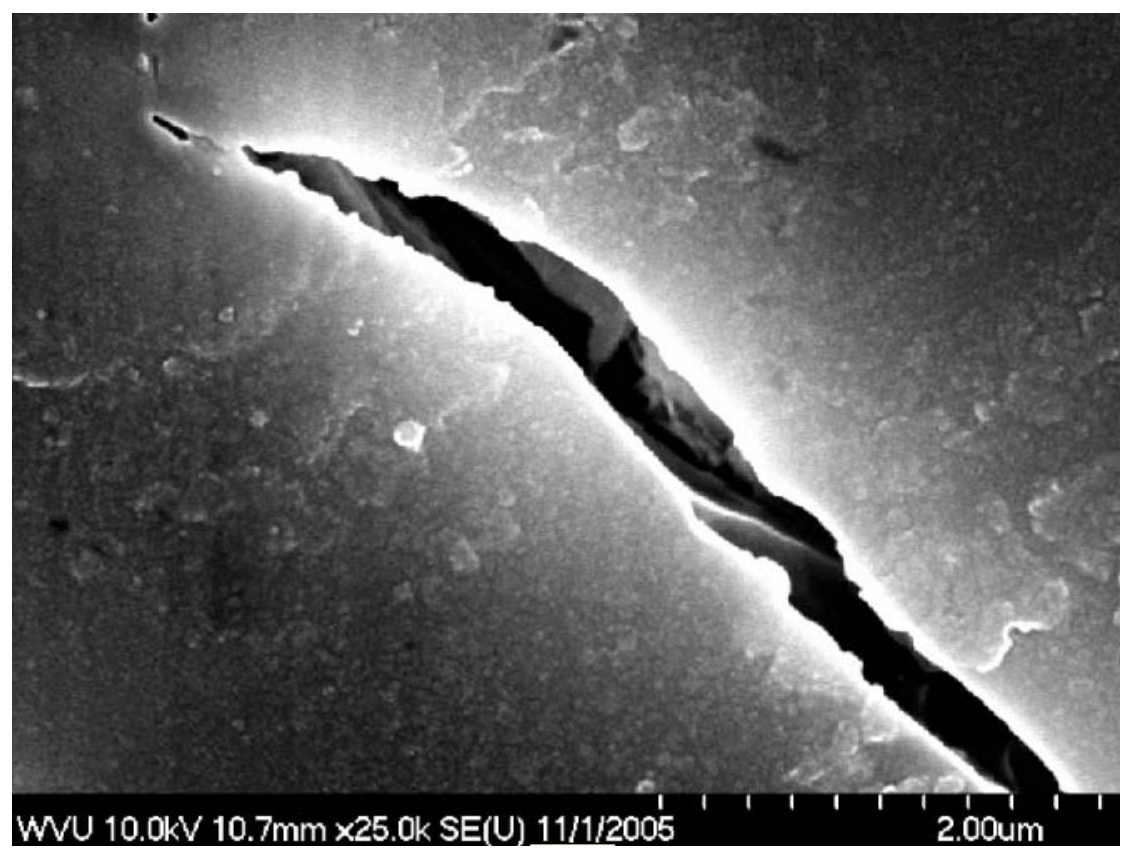

Figure 112 SEM image of $5 \mathrm{wt} \%$ clay loaded vinyl ester sample immersed in water and subjected to $30 \%$ UTS (closer view, showing the size of crack $(0.2 \mu \mathrm{m})$

Figure 111 and Figure 112 clearly show a closer view of crack propagation and the crack dimensions.

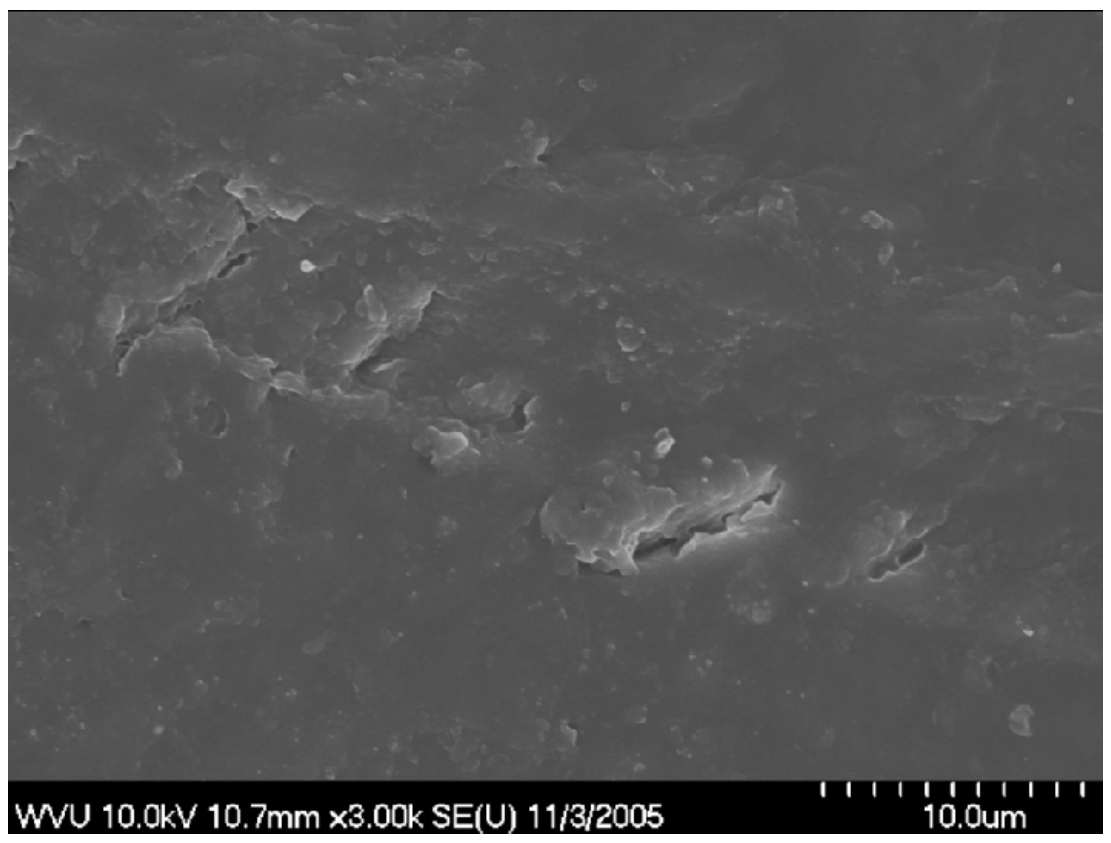

Figure 113 SEM image of $5 \mathrm{wt} \%$ clay loaded vinyl ester sample exposed to $60 \%$ RH and subjected to $30 \%$ UTS 


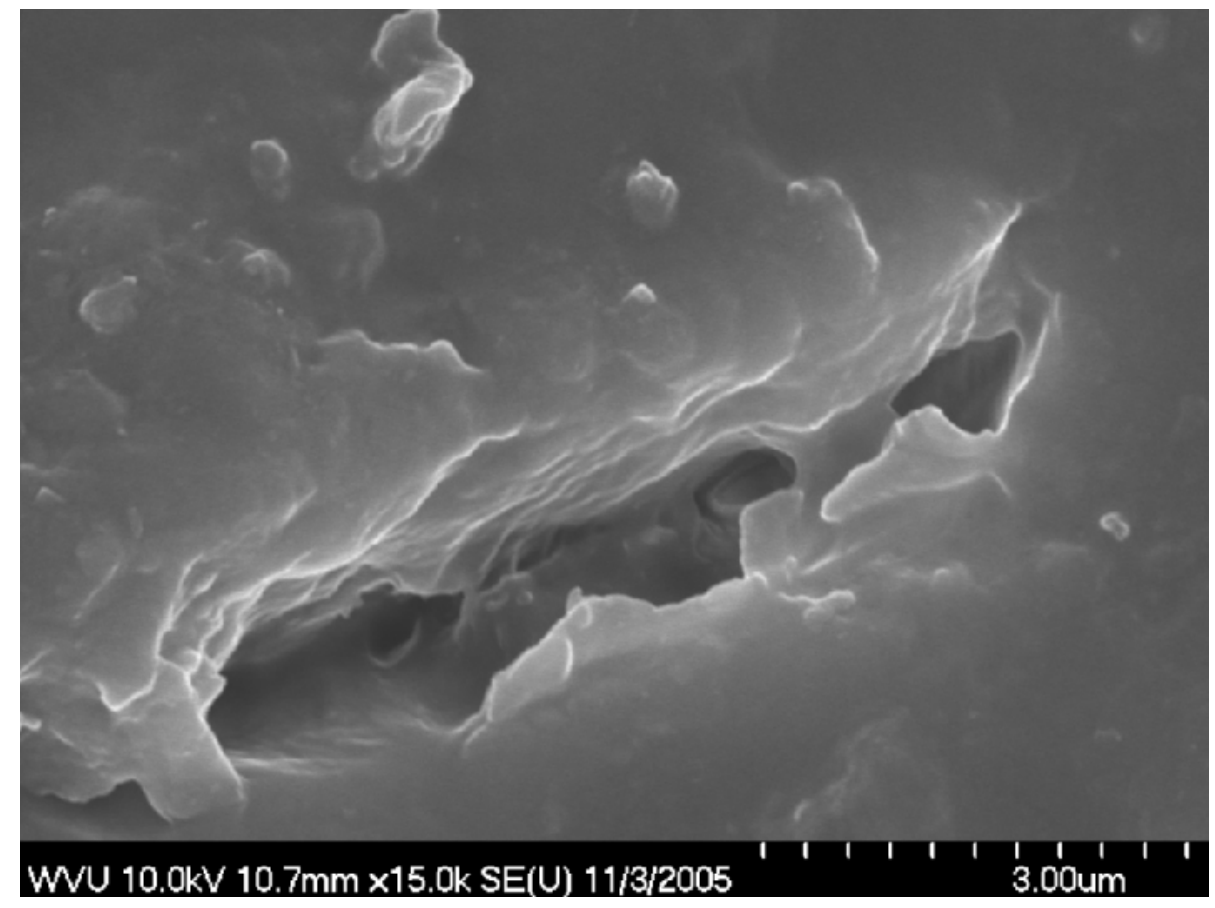

Figure 114 SEM image of $5 \mathrm{wt} \%$ clay loaded vinyl ester sample exposed to $60 \%$ RH and subjected to 30\%UTS (Closer view)

Figure 113 and Figure 114 show SEM images of $5 \mathrm{wt} \%$ clay loaded vinyl ester samples exposed to $60 \% \mathrm{RH}$ and subjected to a load corresponding to $30 \%$ UTS. The figures show formation of micrcocracks and also scaling of the surface indicating that the presence of nanoclay layers forced the crack to propagate along a very tortuous path. When moisture is being absorbed into a dry laminate, the outer regions tend to swell isotropically, but, the inner moisture-free core will restrain swelling. This non-uniform swelling through the thickness of the laminate would yield high stresses at the surface of the laminate that can result in crack formation (Shirrell, 1978). Wang et al. (2005) and Liu (2004) studied mechanical properties and fracture mechanisms in epoxy nanocomposites with highly exfoliated and intercalated clay. They observed several discontinuous cavities in the cracks, which are associated with clay platelets. These cavities were also observed in the present study in the vinyl ester nanocomposites subjected to moisture sorption under stress. Most microcracks were assumed to have formed either along the matrix-clay interface or inside the clay platelets via delamination. Similar results on the crack initiation were observed in the work done by Kim et al. (2001). When observed under high magnification with TEM, their work revealed that they were initiated within the intergallery of clay layers rather than at the interface. 


\subsubsection{Mechanism of Crack Initiation and Propagation}

When the sample is subjected to a load, stress concentration around the clay tactoids due to the difference of Young's modulus and Poisson's ratio of clay and matrix occurs (Wang et al., 2005). Due to the weaker interlayer strength of clay than the matrixclay interfacial bonding strength and epoxy cohesive strength, interlaminar debonding occurs. As a result, microcracks form and on further loading, the neighboring microcracks will extend in length, penetrate into the matrix ligaments between them and finally develop into a macroscopic crack. 


\section{CHAPTER 5}

\section{CONCLUSIONS}

The nanocomposites of various polymers used in the study with montmorillonite clay exhibited a morphology which is a combination of exfoliation and intercalation. XRD scans and TEM pictures reveal the fact that the clay existed as individual platelets and aggregates and total breakdown of such aggregates could be achieved by vigorous mixing techniques.

Cyclic sorption-desorption experiments with vinyl ester and its nanocomposites showed that the montmorillonite clay was effective in reducing the diffusivity of water through the polymer and also retained its effectiveness with subsequent sorptiondesorption cycles. The diffusivity of water in neat vinyl ester and its nanocomposites decreased after the first absorption cycle and seemed to level off and remain constant with subsequent cycles. This could be due to the catalytic effect of water in further curing and greater cross linking of the polymer chains with time and further reabsorption.

Cyclic sorption-desorption experiments with polyester and its nanocomposites also showed results similar to that shown by vinyl ester. The diffusivity of water in polyester was reduced with the addition of clay and the clay retained its effect throughout the cycling process. The diffusivity of water in polyester resin and its nanocomposites decreased after the first absorption cycle and remained constant with subsequent cycling. This could be again due to the catalytic effect of water in improving curing and greater crosslinking of polymer chains.

Cyclic sorption-desorption experiments with epoxy and its nanocomposites showed an opposite trend to vinyl ester and polyester resins in that the diffusivity of water increased with subsequent cycling. Although, reduction in diffusivity with the addition of clay was observed, the increased diffusivity with further cycling could be due to the micostructural damage done due to cyclical aging in water. The SEM images proved the presence of cracks in $2 \mathrm{wt} \%$ and $5 \mathrm{wt} \%$ clay loaded epoxy nanocomposites. Number of cracks per unit area increased with increased clay loading and size of the cracks remained the same in both the clay loaded samples. It was found to be around 0.2 
$\mu \mathrm{m}$.

The cyclical aging in water showed no effect on the equilibrium moisture content of all the polymers and their polymer based nanocomposites used in the study. However, it increased with increased clay loading for a given cycle.

The diffusivities of moisture in vinyl ester and its nanocomposites at various relative humidities, $40 \% \mathrm{RH}, 60 \% \mathrm{RH}, 70 \% \mathrm{RH}, 80 \% \mathrm{RH}$ (all at $25^{\circ} \mathrm{C}$ ) showed that the diffusivity remained constant with varying relative humidities indicating that diffusivity of moisture in vinyl ester is concentration-independent. However, the equilibrium moisture content of the neat vinyl ester and its nanocomposites increased with increasing relative humidity and was found to be a non linear function of relative humidity. Also, the equilibrium moisture content of clay loaded samples was found to be same as neat vinyl ester samples at a given relative humidity.

Stress coupled sorption experiments with vinyl ester and $5 \mathrm{wt} \%$ clay loaded vinyl ester samples showed that the diffusivity of water in neat vinyl ester resin remained constant with the increasing tensile stress level, while increased with increasing tensile stress level in case of $5 \mathrm{wt} \%$ clay loaded nanocomposites. This shows detrimental effects of clay in moisture absorption under stress. Similar results were found when the stress coupled moisture experiments were carried out at a relative humidity of $60 \% \mathrm{RH}$.

SEM analysis on vinyl ester nanocomposites subjected to various stress levels revealed the presence of microcracks of about $0.2 \mu \mathrm{m}$ in size, which were responsible for the increase in diffusivity with increasing level of stress in vinyl ester nanocomposites. The number of cracks seemed to increase with the increasing stress levels while the size of the cracks remained the same. 


\section{REFERENCES}

Ajit, R., D’Souza, N., Bruce, G. and Ann, R.J., "Permeability measurement of polymers and layered silicate nanocomposites", Annual Technical Conference - Society of Plastics Engineers, 62, 2405-2409 (2004).

Alamgir, K., Koray, Y., Carson, M., Eric, A. and Ramanan, K., "Combinatorial methods for polymer materials science: Phase behaviour of nanocomposite blend films", Polym. Eng. Sci., 42, 1836-1840 (2002).

Alfrey, T., Gurnee, E.F. and Lloyd, W.G., "Diffusion in Glassy Polymers", J. Polym. Sci., C, 12, 249-261 (1966).

Alfred, C.L. and George, S.S., "Moisture absorption of graphite-epoxy composites immersed in liquids and humid air", J. Comp. Mat., 13, 131-147, (1979).

Aminabhavi, T.M. and Naik, H.G., "Sorption/desorption studies on polypropylene geomembrane in the presence of hazardous organic liquids", J. Appl. Polym. Sci., 72, 1291-1298 (1999).

Aminabhavi, T.M. and Naik, H.G., "Sorption/desorption, diffusion, and swelling characteristics of geomembranes in the presence of halo-organic liquids", J. Appl. Polym. Sci., 72, 349-359 (1999).

Barrie, J.A. and Platt, B., "Sorption and diffusion in crystalline elastomers. I. Permeation of isomeric hydrocarbons in stretched rubber", J. Polym. Sci., 49, 479-493 (1961).

Becker, O., Varley, R.J. and Simon, G.P., "Thermal stability and water uptake of high performance epoxy layered silicate nanocomposites”, Eur. Polym. J., 40, 187-195, (2004).

Bharadwaj, R.K., "Modeling the barrier properties of polymer-layered silicate nanocomposites", Macromolecules, 36, 9189-9192 (2001).

Cai, X., Huang, W., Xu, B., Kaltenpoth, G. and Cheng, Z., "A study of moisture diffusion in plastic packaging”, J. Elec. Mat., 31, 449-455 (2002).

Carter, H.G. and Kibler, K.G., "Langmuir-Type model for Anomalous Moisture Diffusion in Composite Resins", J. Comp. Mat., 12, 118 - 131 (1978). 
Chen, C. and Curliss, D., "Morphological development and barrier properties of exfoliated aerospace epoxy-organoclay nanocomposites", $47^{\text {th }}$ Int. SAMPE Symp. May 12-16, 1074-1084 (2002).

Chin, J.W., Nguyen, T. and Aouadi, K., "Sorption and diffusion of water, salt water and concrete pore solution in composite matrices", J. Appl. Polym. Sci., 71, 483-492 (1999).

Chipalkatti, M.H., "Stress and deformation coupled moisture transport in polymers", $\mathrm{Ph} . \mathrm{D}$. Thesis, Department of Polymer Science and Engineering, University of Massachusetts, MA, (1989).

Chipalkatti, M.H., Farris, R.J. and Ottino, J.M., "History dependence of stress coupled transport in polymer fibers and ribbons", Proc. of the ACS division of Polymeric Materials, Science and Engineering., 55, 831-835 (1986).

Chung, T.S., Cao, C. and Wang, R., "Pressure and temperatrue dependence of the gas transport properties of dense poly[1,6-toluene-2,2-bis(3,4-dicarboxylphenyl) hexafluoropropane diimide] membranes", J. Polym. Sci. Part B: Polym. Phys., 42, 354364 (2003).

Crank, J. and Park, G.S., "Diffusion in polymers", Academic Press, London, (1968).

Crank, J., Mathematics of Diffusion, $2^{\text {nd }}$ Ed., Oxford University Press, London, (1975).

Cussler, E.L., Hughes, S.E., Ward, W.J. and Aris, R., "Barrier Membranes", J Mem. Sci., 38, 161-174 (1988).

De Kee, D., Chan Man Fong, C. F., Pintauro, P., Hinestroza, J., Yuan, G. and Burczyk, A., "Effect of Temperature and Elongation on the Liquid Diffusion and Permeation Characteristics of Natural Rubber, Nitrile Rubber, and Bromobutyl Rubber”, J. Appl. Polym. Sci., 78, 1250-1255 (2000).

Drozdov, A.D., Christiansen, J.dec., Gupta, R.K. and Shah, A.P., 'Model for Anomalous Moisture Diffusion through a Polymer-Clay Nanocomposite", AIChE J., 41, 476-492 (2003). 
Eitzman, D.M., Melkote, R.R. and Cussler, E.L., 'Barrier membranes with tipped impermeable flakes", AIChE J., 42, 2-9 (1996).

Fahmy, A.A. and Hurt, J.C., "Stress dependence of water diffusion in epoxy resin", Polym. Comp., 1, 77-80 (1980).

Folkman, J., Long, D.M. and Rosenbaum, R., "Silicone rubber: A new diffusion property useful for general anesthesia", Science, 154, 148 (1966).

Frisch, H.L., "Sorption and Transport in Glassy Polymers-A review", Polym. Eng. Sci., 20(2), (1980).

Gam, T., Miyamoto, M., Nishimura, R. and Sue, H.J., "Fracture behavior of Core-shell rubber-modified clay-epoxy nanocomposites”, Polym. Eng. Sci., 43, 1635-1645 (2003).

Garcia, K., Hayes, M.D., Verghese, N. and Lesko, J.J., "The effects of cyclic moisture aging on a glass/vinyl ester composite system", Progress in Durability Analysis of Composite Systems, Proceedings of the International Conference on Progress in Durability Analysis of Composite Systems, 173-179, (1998).

Giuliana, G., Loredana, T., Mariarosaria, T., Vittoria, V., Dirk, K., Peter, R. and Rolf, M., "Transport properties of organic vapors in nanocomposites of isotactic polypropylene", J. Polym. Sci., Part B: Polym. Phys., 41(15), (2003).

Gopalan, R., Somashekar, B.R. and Dattaguru, B., "Environmental effects on fiberpolymer composites", Polym. Degradation and Stability, 24, 361-371 (1989).

Hedenqvist, M., Angelstok, A., Edsberg, L., Larsson, P.T. and Gedde, U.W., "Diffusion of small-molecule penetrants in polyethylene: free volume and morphology" Polymer, 37, 2887-2902 (1996).

Hedenqvist, M.S., Yousefi, H., Malmstrom, E., Johansson, M., Hult, A., Gedde, U.W. and Trollas, M., "Transport properties of hyperbranched and dendrimer-like start polymers", Polymer, 41, 1827-1840 (2000).

Henson, M.C., "Effect of external stress on moisture diffusion in an epoxy resin and its composite material", Master's Thesis, Department of Civil Engineering, Texas A\&M University, TX, (1986). 
Hoppel, C., Bogetti, T. and Newill, J.F, "Effects of voids on moisture diffusion in composite materials", Proceedings of the American Society for Composites, Technical Conference, 1094-1102, (2000).

Junya, T., Tohru, K., Jun-ichi, H. and Masayayoshi, K., "Gas permeability modification of polyolefin films induced by D-limonene swelling”, J. Mem. Sci., 188, 39-48 (2001).

Khinnavar, R.S. and Aminabhavi, T.M., "Diffusion and sorption of organic liquids through polymer membranes. VI. Polyurethane, neoprene, natural rubber, nitrile butadiene rubber, styrene butadiene rubber, and ethylene propylene diene terpolymer versus organic esters”, J. of Appl. Polym. Sci., 46, 909-920 (1992).

Koros, W.J., "Barrier Polymers and Structures", ACS Symposium Series 423:

Developed From a Symposium at the 197th National Meeting of the American Chemical Society, Dallas, Texas, April, (1990).

Lee, S.B., Hoffman, R.D. and Rockett T.J., "Interactions of water with unsaturated polyester, vinyl ester, and acrylic resins, Polymer, 33 (17), (1992).

Liu, Q., "Mass transport through polymeric materials with complex interfaces" $\mathrm{Ph} . \mathrm{D}$. Thesis, Dept. of Chem. and Biomol. Engg., Tulane University. LA, (2004).

Liu, T., Tjiu, W.C., Tong, Y., He, C., Goh, S.S. and Chung, T., "Morphology and fracture behavior of intercalated epoxy/clay nanocomposites”, J. Appl. Polym. Sci., 94, 12361244 (2004).

Malwitz, M.M., Lin-Gibson, S., Hobbie, E.K., Butter, P.D. and Schmidt G., "Orientation of platelets in multilayered nanocomposite polymer films", J. Polym. Sci. :Part B: Polym. Phys., 41, 1-12 (2003).

Marais, S., Metayer, M., Nguyen, T.Q., Labbe, M. and Saiter, J.M., "Diffusion and permeation of water through unsaturated polyester resins-influence of resin curing", Eur. Polym. J, 36, 453-462, (2000).

Marais, S., Metayer, M. and Labbe, M., "Water diffusion in unsaturated polyester films. Effect of plasticization on the glass transition", Polym. Engg. Sci., 39, 1508-1516, (1999). 
Marom, G. and Broutman, L.J., "Moisture penetration into composites under external stress", Polym. Comp., 2, 132-136 (1981).

Martin, Y.M., Chiang and Marta Fernandez-Garcia, "Effect of water exposure cycles on physical properties of a particle-filled, epoxy-based adhesive", Int. SAMPE Symp. and Exhibition, 1172-1180, (2000).

Mauri, R.E., Crossman, F.W. and Warren, W.J., "Assessment of moisture altered dimensional stability of structural composites", National SAMPE Symp. and exhibition, 1202-1217, (1978).

Nishide, H., Ohyanagi, M., Okada, O. and Tsuchida, E., "Highly selective transport of molecular oxygen in a polymer containing a cobalt porphyrin complex as a fixed carrier", Macromolecules, 19, 494-496 (1986).

Petrovicova, E., Knight, R. and Schadler, L.S. and Twardowski T.E., "Nylon 11/Silica nanocomposite coatings applied by the HVOF process. II. Mechanical and barrier properties”, J. Appl. Polym. Sci., 78, 2272-2289 (2000).

Rana, H.T., "Moisture diffusion through neat and glass-fiber reinforced vinyl ester resin containing nanoclay", Master's Thesis, Dept of Chem. Engg., West Virginia University. WV, (2003).

Ravindran, N., "Durability of E-glass fiber reinforced vinyl ester composites with nanoclay in an alkaline environment", Master's Thesis, Dept. of Chem. Engg., West Virginia University. WV, (2005).

Roseman, T.J., "Release of steroids from a silicone polymer", “J. Pharm. Sci.”, 61, 46-50 (1972).

Shah, A.P., "Moisture diffusion through Vinyl ester/clay nanocomposites", Master's Thesis, Department of Chemical Engineering, West Virginia University. WV, (2001)

Sok.R.M., "Permeation of Small Molecules across Polymer Membranes", Ph.D.Thesis, (1994). 
Shah, A.P., Gupta, R.K., GangaRao, H.V.S. and Powell, C.E. "Moisture diffusion through vinyl ester nanocomposites made with montmorillonite clay". Polym. Engg. and Sci., 42, 1852-1863 (2002).

Shijian, L., Johannes, L. and Wong, C.P., "Study on mobility of water and polymer chain in epoxy and its influence on adhesion”, J. Appl. Polym. Sci., 85, 1-8 (2002).

Shirrell, D.C., "Moisture sorption and desorption in epoxy resin matrix composites", Int. SAMPE Symp. and Exhibition, 175-191 (1978).

Startsev, O.V.., Krotov, A.S., Perov, B.V. and Vapirov, Yu.M., "Interaction of water with polymers under their climatic ageing", (1985).

Stastna, J. and De Kee, D., "Transport Properties in Polymers", Technomic Publishing company, Inc., Lancaster (1995).

Tsuchida, E., Nishide, H. and Ohyanagi, M., "Reversible coordination of molecular nitrogen to polymeric benzenecarbonylchromium complexes", J. of Macromol. Sci. and Chemistry, A25 (10\&11), 1339-1348 (1988).

Verghese, K.N.E., Hayes, M.D., Garcia, K., Carrier, C., Wood, J., Riffle, J.R. and Lesko, J.J., "Influence of matrix chemistry on the short term, hygrothermal aging of vinyl ester matrix composites under both isothermal and thermal spiking conditions", J. Comp. Mat., 33, $1918-1938$ (1999).

Wang, K., Chen, L., Wu, J., Toh, M.L., He, C. and Yee, A.F., "Epoxy Nanocomposites with highly exfoliated clay: Mechanical Properties and Fracture Mechanisms", Macromolecules, 38, 788-800 (2005).

Weitsman, Y. and Henson, M.C., "Stress effect on moisture transport in an epoxy resin and its composite", Composites 1986; Recent Advances in Japan and the United States; Proc. of the Third Japan-U.S. Conference on Comp. Mat., June 23-25, 1, 775-784 (1986).

Yang, C., Smyrl, W.H. and Cussler, E.L., "Flake alignment in composite coatings", J. Mem. Sci., 231, 1-12 (2004). 


\section{Appendix A}

\section{A.1.Chemistry of Resins used in the Study}

\section{A.1.1.Vinyl ester}

Vinyl ester resins are produced by addition of various epoxide resins and unsaturated monocarboxylic acids, most commonly methacrylic acid, resulting in a molecule with unsaturated polymeric reaction end groups (double bonds) and ester groups. Figure 115 shows idealized chemical structure of a typical epoxy based vinyl ester. In many industrial products, vinyl ester resins are comprised of 40-50 wt \% styrene.

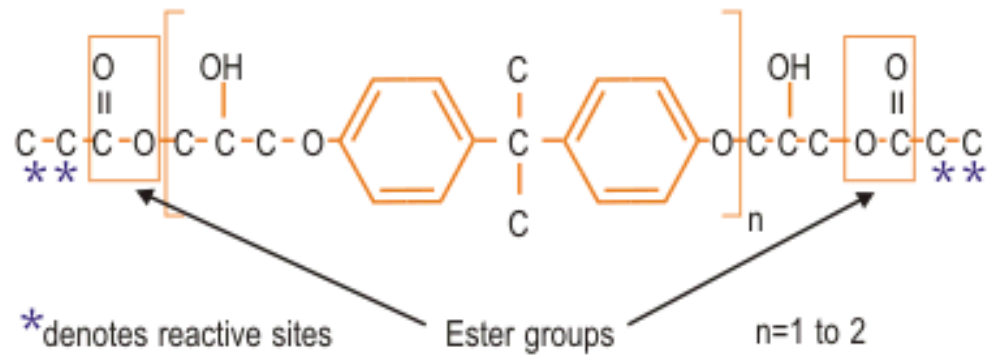

Figure 115 Idealized chemical structure of a typical epoxy based vinyl ester Vinyl ester resins cure by chemical cross-linking reactions between the vinyl ester oligomers and styrene with initiator/promoter systems. Figure 116 shows schematic of a cross linked vinyl ester resin. The most common sources of free radicals, which are needed to initiate the curing reaction, are peroxides such as methyl ethyl ketone peroxide (MEKP) and benzoyl peroxide; these are called initiators. The function of the promoter, usually cobalt naphthenate, is to decompose the initiator rapidly at room temperature. The promoter is mixed in thoroughly before adding the initiator. The initiator then reacts with the promoter to cause the resin to gel.

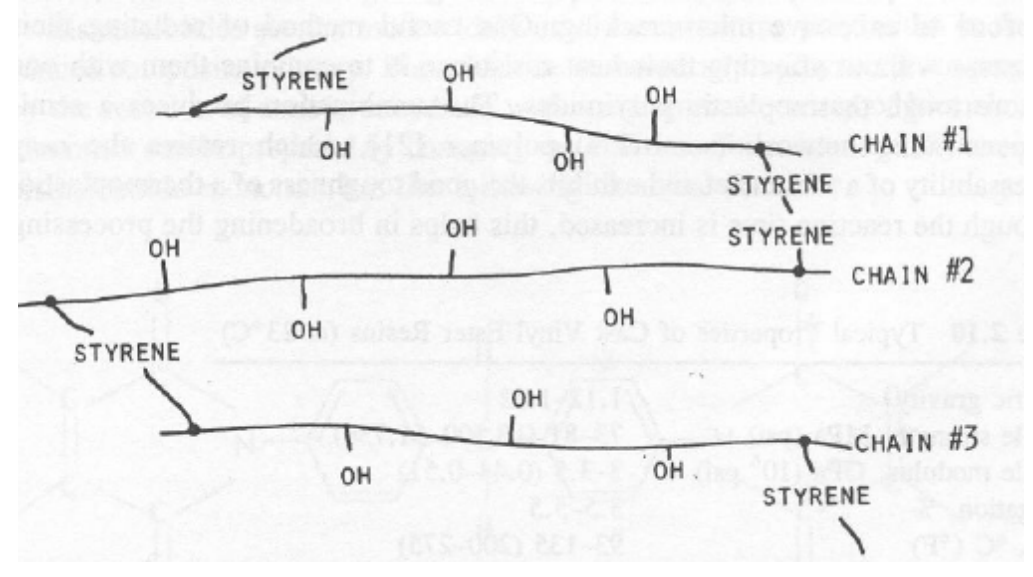


Figure 116 Schematic of a cross linked vinyl ester resin (Mallick, 1993)

\section{A.1.2.Polyester}

Polyester is formed when special alcohols such as glycol react with di-basic acids. This reaction, together with the addition of compounds such as saturated di-basic acids and cross-linking monomers, forms the basic process of polyester manufacture. Figure 117 shows idealized chemical structure of a typical epoxy based polyester.

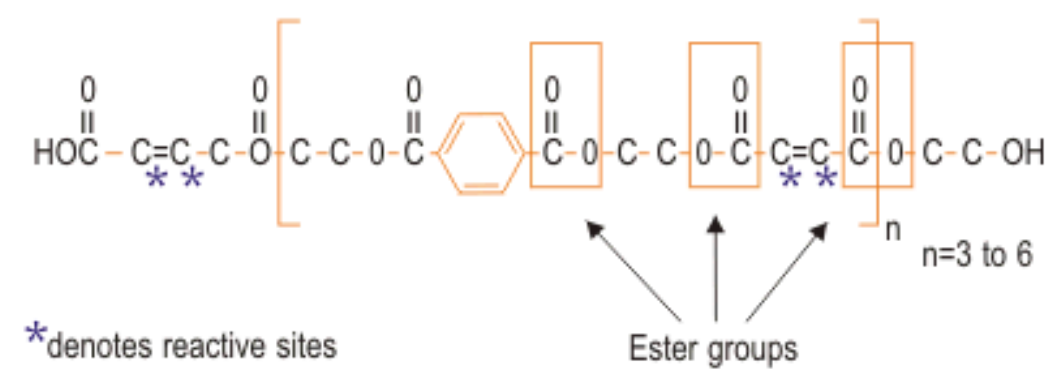

Figure 117 Idealized chemical structure of a typical epoxy based polyester

The reaction of styrene and unsaturated polyester resin is a free radical chain growth crosslinking copolymerization. It includes three major reactions: styrene-polyester vinyl, styrene-styrene and polyester vinyl-polyester vinyl. The styrene in which resin is dissolved performs the vital function of enabling the resin to cure from a liquid to a solid by 'cross-linking' the molecular chains of the polyester in the presence of an initiator and catalyst. Small quantities of inhibitor are added to the resin as polyester resins have limited storage life and will set or gel on their own over a long period of time.

\section{A.1.3.Epoxy}

Epoxy resins are formed from a long chain molecular structure similar to vinyl ester with reactive sites at either end. In the epoxy resin, however, epoxy groups instead of ester groups form these reactive sites. The absence of ester groups means that the epoxy resin has particularly good water resistance. The epoxy molecule also contains two ring groups at its centre which are able to absorb both mechanical and thermal stresses better than linear groups and therefore give the epoxy resin very good stiffness, toughness and heat resistant properties. Figure 118 shows the idealized chemical structure of a typical epoxy 


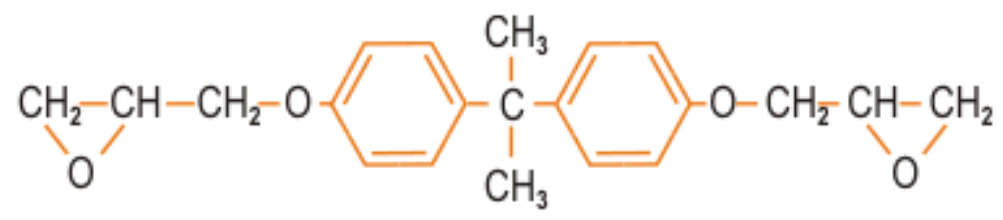

Figure 118 Idealized chemical structure of a typical epoxy (diglycidyl ether of bisphenol-A) Epoxies differ from polyester resins in that a 'hardener' rather than a catalyst cures them. The hardener, often an amine, is used to cure the epoxy by an addition reaction where both materials take part in the chemical reaction. The chemistry of this reaction means that there are usually two epoxy sites binding to each amine site. This forms a complex three-dimensional molecular structure, which is illustrated in the following Figure 119

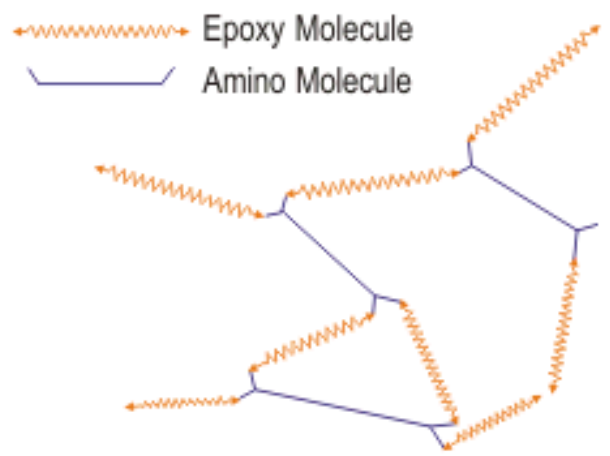

Figure 119 Schematic representation of epoxy resin 


\section{Appendix B}

\section{B.1.Sample Calculations}

\section{B.1.1.Sample Calculation for Absorption Diffusion Coefficient $\left(D_{a}\right)$}

Sample thickness $2 l=0.0488 \mathrm{~cm}$

Initial dry weight of the sample $\mathrm{W}_{0}=342.01 \mathrm{mg}$

Weight of the sample at time $\mathrm{t}=\mathrm{W}_{\mathrm{t}} \mathrm{mg}$

Table 9. Sorption Data of Vinyl ester Samples containing 0 wt\% Cloisite 10A at $2^{\circ} \mathrm{C}$ During First Cycle of Absorption

\begin{tabular}{|c|c|c|c|c|c|}
\hline Time, $\mathrm{h}$ & $ل_{\mathrm{t}}, \mathrm{sec}^{1 / 2}$ & $\mathrm{~W}_{\mathrm{t}}, \mathrm{mg}$ & $\mathrm{M}_{\mathrm{t}}, \mathrm{mg}$ & Moisture uptake, $\%$ & $\mathrm{M}_{\mathrm{t}} / \mathrm{M}_{\infty}$ \\
\hline 0 & 0 & $\mathrm{~W}_{0}=342.01$ & 0 & 0 & 0.0000 \\
\hline 0.5 & 42.4264 & 342.14 & 0.13 & 0.0380 & 0.0313 \\
\hline 1.5 & 73.4847 & 342.36 & 0.35 & 0.1023 & 0.0844 \\
\hline 4 & 120 & 342.967 & 0.957 & 0.2798 & 0.2307 \\
\hline 5.5 & 140.712 & 343.387 & 1.377 & 0.4026 & 0.3319 \\
\hline 7 & 158.745 & 343.55 & 1.54 & 0.4503 & 0.3712 \\
\hline 8 & 169.706 & 343.711 & 1.701 & 0.4974 & 0.4100 \\
\hline 10.75 & 196.723 & 344.011 & 2.001 & 0.5851 & 0.4823 \\
\hline 11.75 & 205.67 & 344.11 & 2.1 & 0.6140 & 0.5061 \\
\hline 25.75 & 304.467 & 344.57 & 2.56 & 0.7485 & 0.6170 \\
\hline 32.75 & 343.366 & 344.768 & 2.758 & 0.8064 & 0.6647 \\
\hline 49.75 & 423.202 & 345.184 & 3.174 & 0.9280 & 0.7650 \\
\hline 75.25 & 520.481 & 345.354 & 3.344 & 0.9777 & 0.8060 \\
\hline 95.25 & 585.577 & 345.456 & 3.446 & 1.0076 & 0.8306 \\
\hline 122.75 & 664.756 & 345.587 & 3.577 & 1.0459 & 0.8621 \\
\hline 149.25 & 733.008 & 345.738 & 3.728 & 1.0900 & 0.8985 \\
\hline 166.25 & 773.628 & 345.8 & 3.79 & 1.1082 & 0.9135 \\
\hline 192 & 831.384 & 345.87 & 3.86 & 1.1286 & 0.9303 \\
\hline 218.25 & 886.397 & 345.923 & 3.913 & 1.1441 & 0.9431 \\
\hline 244.75 & 938.669 & 346.002 & 3.992 & 1.1672 & 0.9622 \\
\hline 271.25 & 988.18 & 346.054 & 4.044 & 1.1824 & 0.9747 \\
\hline 291.25 & 1023.96 & 346.098 & 4.088 & 1.1953 & 0.9853 \\
\hline 313.5 & 1062.36 & 346.112 & 4.102 & 1.1994 & 0.9887 \\
\hline 337 & 1101.45 & 346.132 & 4.122 & 1.2052 & 0.9935 \\
\hline 365 & 1146.3 & 346.144 & 4.134 & 1.2087 & 0.9964 \\
\hline 387 & 1180.34 & 346.151 & 4.141 & 1.2108 & 0.9981 \\
\hline 409 & 1213.42 & 346.159 & $M_{\infty}=4.149$ & 1.2131 & 1.0000 \\
\hline & & & & & \\
\hline
\end{tabular}

Moisture uptake $=\frac{W_{t}-W_{0}}{W_{0}} \times 100$

$$
=\frac{342.14-342.01}{342.01} \times 100=0.03801
$$


$\mathrm{M}_{\mathrm{t}} / \mathrm{M}_{\infty}=\frac{W_{t}-W_{0}}{W_{\infty}-W_{0}}=\frac{342.14-342.01}{346.159-342.01}=0.0313$

The absorption diffusion coefficient was then calculated using equation

$$
\begin{aligned}
& \frac{\mathrm{M}_{t}}{\mathrm{M}_{\infty}}=4\left(\frac{D t}{\pi(2 l)^{2}}\right)^{1 / 2} \\
& D=\frac{\pi \times(2 l)^{2}}{16}\left(\frac{\mathrm{M}_{t} / \mathrm{M}_{\infty}}{\sqrt{t}}\right)^{2}
\end{aligned}
$$

Where $\frac{M_{t} / M_{\infty}}{\sqrt{t}}$ is the slope of the straight line from the plot of $M t / M_{\infty}$ versus $V_{t}$ drawn up to $\mathrm{M}_{\mathrm{t}} / \mathrm{M}_{\infty}<0.5$ and the units of $\mathrm{D}$ are $\mathrm{cm}^{2} / \mathrm{sec}$

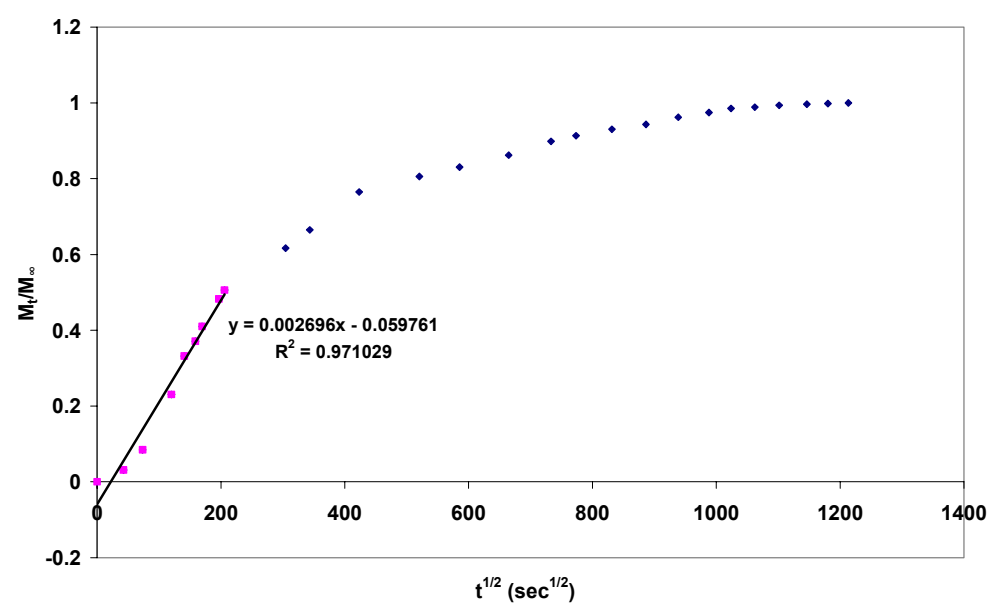

Figure $120 \mathrm{M}_{\mathrm{t}} / \mathrm{M}_{\infty}$ versus $\mathrm{t}^{1 / 2}$ for vinyl ester sample containing $0 \mathrm{wt}^{\circ} \mathrm{Cloisite} 10 \mathrm{~A}^{\circledR}$ at $25{ }^{\circ} \mathrm{C}$ during first cycle of absorption

$$
\therefore D_{a}=\frac{\pi \times(0.0488)^{2}}{16}(0.002696)^{2}=3.4 \times 10^{-9} \mathrm{~cm}^{2} / \mathrm{s}
$$

\section{B.1.2.Sample Calculation for Desortpion Diffusion Coefficient $\left(D_{d}\right)$}

Initial weight of the sample $=346.167 \mathrm{mg}$

$\mathrm{M}_{\mathrm{t}}=346.167-342.14=4.157 \mathrm{mg}$

The desorption diffusion coefficient was then calculated using equation

$$
\frac{d}{d t}\left\{\ln \left[\mathrm{M}_{t}-\mathrm{M}_{\infty}\right]\right\}=-\frac{\pi^{2} D}{(2 l)^{2}}
$$




$$
D=\left(\frac{\ln \left[\mathrm{M}_{t}-\mathrm{M}_{\infty}\right]}{t}\right) \frac{(2 l)^{2}}{\pi^{2}}
$$

Where $\left(\frac{\ln \left[\mathrm{M}_{t}-\mathrm{M}_{\infty}\right]}{t}\right)$ is the negative slope of the straight line from the plot of $\ln \left[\mathrm{M}_{t}-\mathrm{M}_{\infty}\right]$ versus $t$ drawn during the last stages of desorption and the units of $D$ are $\mathrm{cm}^{2} / \mathrm{sec}$

Table 10. Desorption Data of Vinyl ester Samples containing 0 wt\% Cloisite 10A at $25^{\circ} \mathrm{C}$ During First Cycle of Absorption

\begin{tabular}{|r|r|r|r|}
\hline Time,sec & $\mathrm{W}_{\mathrm{t}}, \mathrm{mg}$ & $\mathrm{M}_{\mathrm{t}}, \mathrm{mg}$ & $\ln \left(\mathrm{M}_{\mathrm{t}}-\mathrm{M}_{\infty}\right)$ \\
\hline 0 & 346.167 & 4.157 & 1.3928 \\
\hline 3600 & 345.989 & 3.979 & 1.3476 \\
\hline 5400 & 345.698 & 3.688 & 1.2689 \\
\hline 7200.005 & 345.356 & 3.346 & 1.1678 \\
\hline 9000.01 & 345.054 & 3.044 & 1.0692 \\
\hline 12600 & 344.8 & 2.79 & 0.9780 \\
\hline 16199.99 & 344.587 & 2.577 & 0.8945 \\
\hline 19799.98 & 344.329 & 2.319 & 0.7830 \\
\hline 23399.97 & 344.147 & 2.137 & 0.6961 \\
\hline 30599.95 & 343.775 & 1.765 & 0.4910 \\
\hline 41399.92 & 343.48 & 1.47 & 0.2919 \\
\hline 92700 & 342.692 & 0.682 & -0.5960 \\
\hline 182700 & 342.522 & 0.512 & -0.9650 \\
\hline 261900 & 342.309 & 0.299 & -1.7838 \\
\hline 353100 & 342.223 & 0.213 & -2.5010 \\
\hline 452700 & 342.196 & 0.186 & -2.9004 \\
\hline 504300 & 342.178 & 0.168 & -3.2968 \\
\hline 521400 & 342.165 & 0.155 & -3.7297 \\
\hline 609600 & 342.156 & 0.146 & -4.1997 \\
\hline 695100 & 342.148 & 0.138 & -4.9618 \\
\hline
\end{tabular}

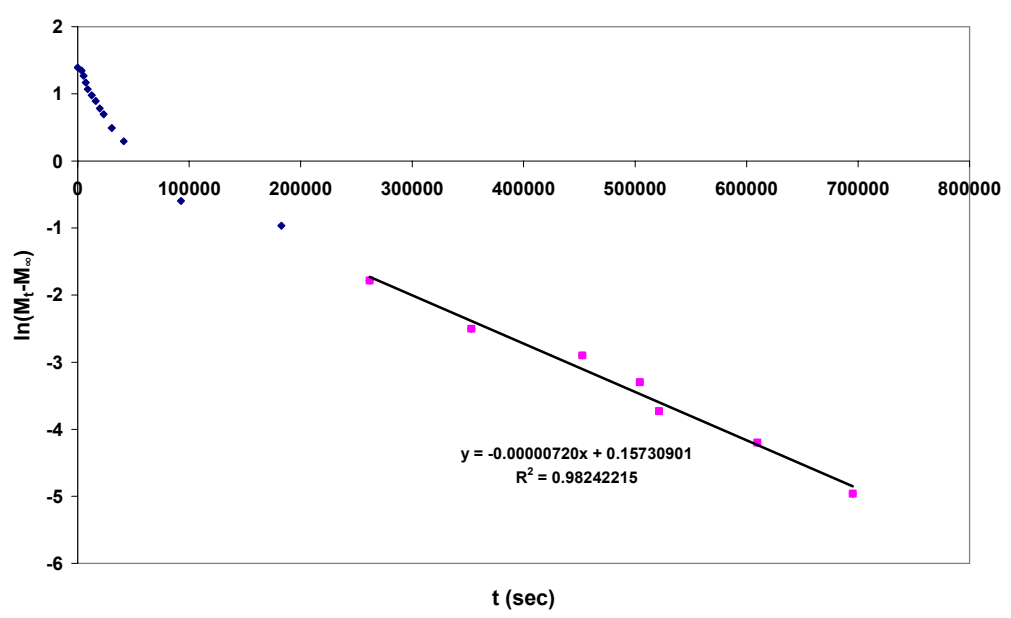

Figure 121 In $\left(M_{t}-M_{\infty}\right)$ versus $t$ for vinyl ester sample containing 0 wt $\%$ Cloisite $10 A^{\circledR}$ at $25^{\circ} \mathrm{C}$ during first cycle of desorption

$\therefore D_{d}=(0.0000072) \frac{(0.0488)^{2}}{\pi^{2}}=1.736 \times 10^{-9} \mathrm{~cm}^{2} / \mathrm{s}$ 


\section{B.1.3.Sample Calculation for Sorption Experiments under Stress}

Sample average thickness $2 l=0.111 \mathrm{~cm}$

Table 11. Sorption data of vinyl ester samples containing 0 wt\% Cloisite $10 \mathrm{~A}$ immersed in distilled water subjected to $17 \%$ UTS at $25{ }^{\circ} \mathrm{C}$

\begin{tabular}{|c|c|c|c|c|c|}
\hline Time,h & $\sqrt{ } \mathrm{t}, \sec ^{1 / 2}$ & $\mathrm{~W}_{\mathrm{t}}, \mathrm{mg}$ & $\mathrm{M}_{\mathrm{t}}, \mathrm{mg}$ & Moisture uptake, \% & $M_{t} / M_{\infty}$ \\
\hline 0 & 0 & 804.631 & 0 & 0.0000 & 0.0000 \\
\hline \multirow[t]{2}{*}{0.5} & 42.42641 & 805 & 0.369 & 0.0459 & 0.0498 \\
\hline & sample-2 & 688.14 & & & \\
\hline \multirow[t]{2}{*}{1.5} & 73.48469 & 688.94 & 0.8 & 0.1163 & 0.1080 \\
\hline & sample-3 & 629.167 & & & \\
\hline \multirow[t]{2}{*}{6.25} & 150 & 630.632 & 1.465 & 0.2328 & 0.1978 \\
\hline & sample-4 & 530.92 & & & \\
\hline \multirow[t]{2}{*}{9} & 180 & 532.654 & 1.734 & 0.3266 & 0.2341 \\
\hline & sample-5 & 698.485 & & & \\
\hline \multirow[t]{2}{*}{12.25} & 210 & 700.51 & 2.025 & 0.2899 & 0.2734 \\
\hline & sample-6 & 668.596 & & & \\
\hline \multirow[t]{2}{*}{17.25} & 249.1987 & 670.89 & 2.294 & 0.3431 & 0.3097 \\
\hline & sample-7 & 624.16 & & & \\
\hline \multirow[t]{2}{*}{20.25} & 270 & 626.854 & 2.694 & 0.4316 & 0.3637 \\
\hline & sample-8 & 638.521 & & & \\
\hline \multirow[t]{2}{*}{23.25} & 289.3095 & 641.287 & 2.766 & 0.4313 & 0.3734 \\
\hline & sample-9 & 630.21 & & & \\
\hline \multirow[t]{2}{*}{27.5} & 314.6427 & 633.213 & 3.003 & 0.4742 & 0.4054 \\
\hline & sample-10 & 704.7 & & & \\
\hline \multirow[t]{2}{*}{31.75} & 338.0828 & 707.889 & 3.189 & 0.4505 & 0.4305 \\
\hline & sample-11 & 589.414 & & & \\
\hline \multirow[t]{2}{*}{36.75} & 363.7307 & 593.07 & 3.656 & 0.6165 & 0.4935 \\
\hline & sample-12 & 650.412 & & & \\
\hline 60.25 & 465.7252 & 655.08 & 4.668 & 0.7177 & 0.6301 \\
\hline 188.75 & 824.3179 & 657.1 & 6.688 & 1.0283 & 0.9028 \\
\hline 318.75 & 1071.214 & 657.543 & 7.131 & 1.0964 & 0.9626 \\
\hline 449.75 & 1272.439 & 657.6 & 7.188 & 1.1051 & 0.9703 \\
\hline 499.75 & 1341.305 & 657.67 & 7.258 & 1.1159 & 0.9798 \\
\hline 571.75 & 1434.678 & 657.74 & 7.328 & 1.1267 & 0.9892 \\
\hline 619.75 & 1493.687 & 657.79 & 7.378 & 1.1344 & 0.9960 \\
\hline
\end{tabular}

Moisture uptake $=\frac{W_{t}-W_{0}}{W_{0}} \times 100$

$$
=\frac{657.6-650.412}{650.412} \times 100=1.1051
$$

$\mathrm{M}_{\mathrm{t}} / \mathrm{M}_{\infty}=\frac{W_{t}-W_{0}}{W_{\infty}-W_{0}}=\frac{657.6-650.412}{657.82-650.412}=0.9703$

The absorption diffusion coefficient was then calculated using equation 


$$
\begin{aligned}
& \frac{\mathrm{M}_{t}}{\mathrm{M}_{\infty}}=4\left(\frac{D t}{\pi(2 l)^{2}}\right)^{1 / 2} \\
& D=\frac{\pi \times(2 l)^{2}}{16}\left(\frac{\mathrm{M}_{t} / \mathrm{M}_{\infty}}{\sqrt{t}}\right)^{2}
\end{aligned}
$$

Where $\frac{M_{t} / M_{\infty}}{\sqrt{t}}$ is the slope of the straight line from the plot of $M_{t} / M_{\infty}$ versus $V_{t}$ drawn up to $M_{t} / M_{\infty}<0.5$ and the units of $D$ are $\mathrm{cm}^{2} / \mathrm{sec}$

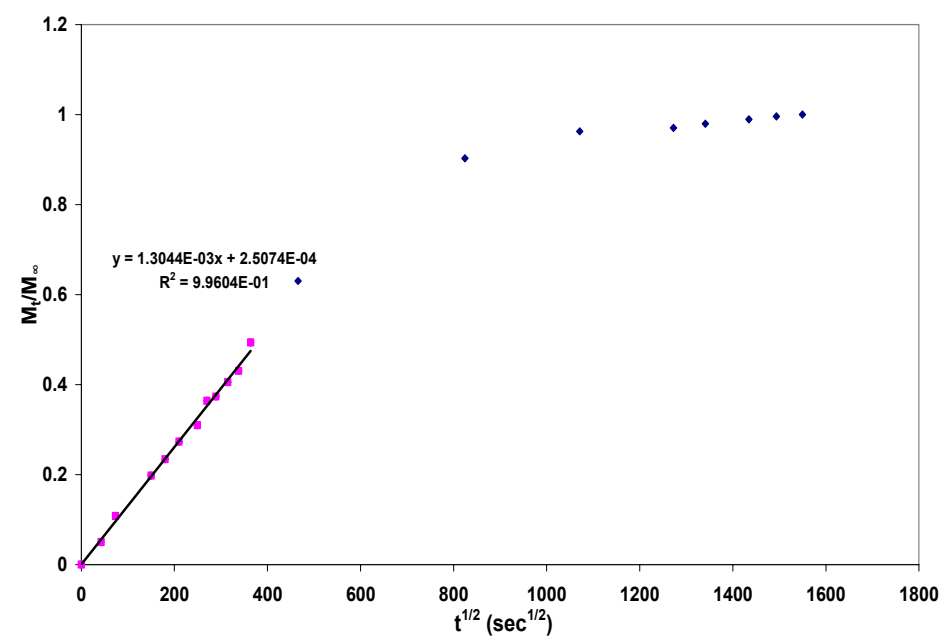

Figure $122 M_{t} / M_{\infty}$ versus t1/2 for vinyl ester sample containing 0 wt $\%$ Cloisite $10 A^{\circledR}$ immersed in distilled water and subjected to $17 \%$ UTS at $25^{\circ} \mathrm{C}$

$$
\therefore D=\frac{\pi \times(0.111)^{2}}{16}(0.001304)^{2}=4.12 \times 10^{-9} \mathrm{~cm}^{2} / \mathrm{s}
$$




\section{Appendix C}

\section{C.1.Results of Cyclic Sorption-Desorption Experiments with Distilled Water at}

\section{Room Temperature}

\section{C.1.1.Experiments with Vinyl ester}

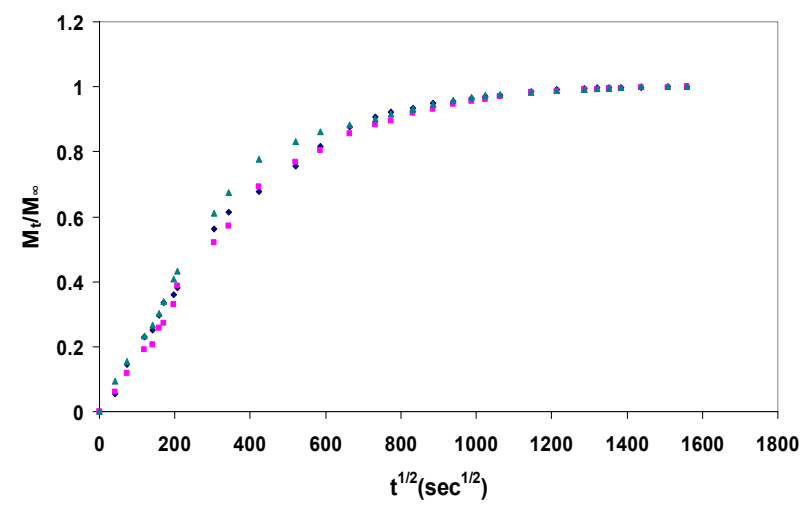

Figure $123 M_{t} / M_{\infty}$ versus $t^{1 / 2}$ for vinyl ester samples containing $5 w^{\%} \%$ Cloisite $10 A^{\circledR}$ at $25{ }^{\circ} \mathrm{C}$ during first cycle of absorption

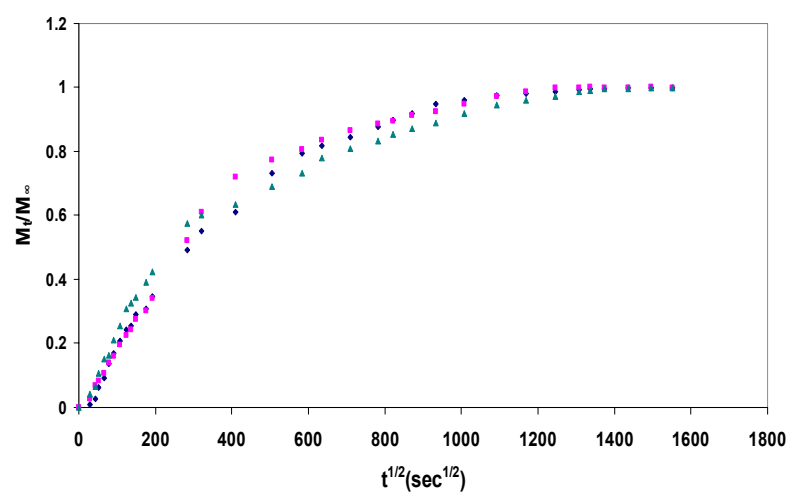

Figure $124 M_{t} / M_{\infty}$ versus $t^{1 / 2}$ for vinyl ester samples containing $5 w_{t} \%$ Cloisite $10 A^{\circledR}$ at $25{ }^{\circ} \mathrm{C}$ during second cycle of absorption

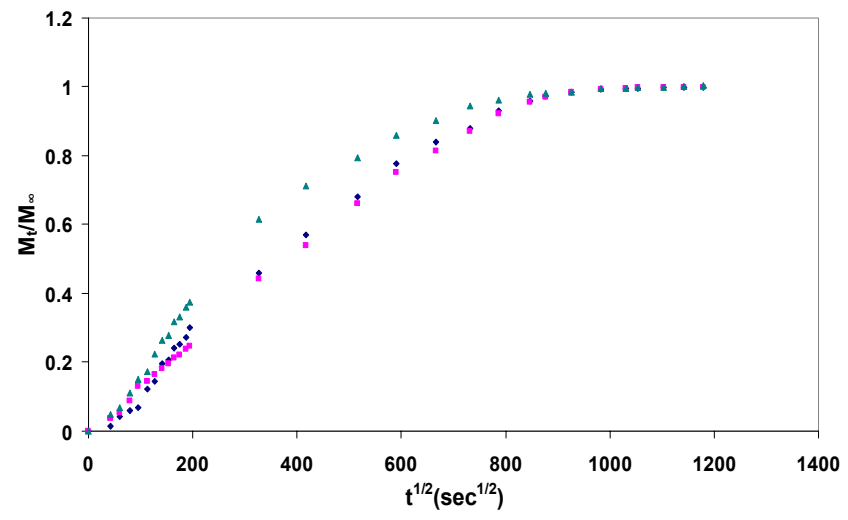


Figure $125 M_{t} / M_{\infty}$ versus $t^{1 / 2}$ for vinyl ester samples containing 5 wt $\%$ Cloisite $10 A{ }^{\circledR}$ at $25{ }^{\circ} \mathrm{C}$ during third cycle of absorption

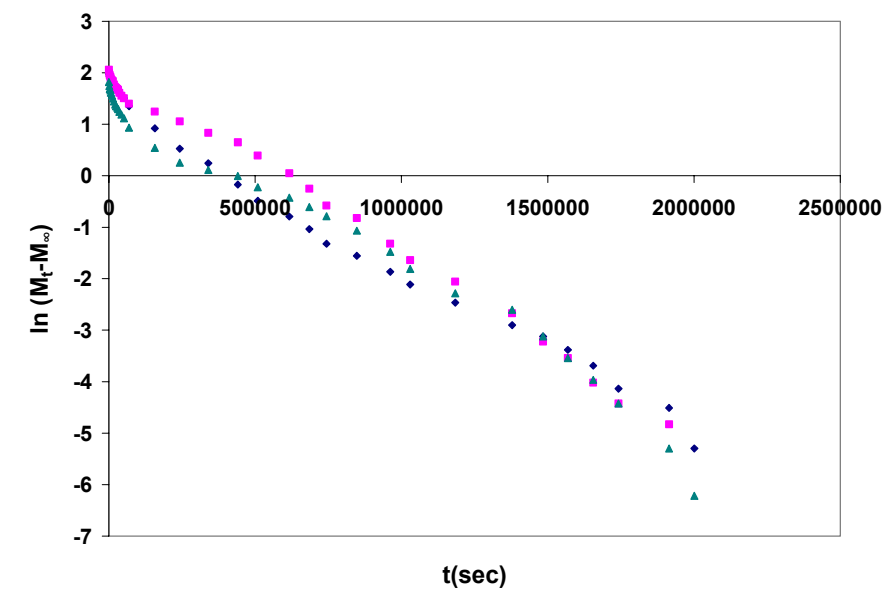

Figure $126 \ln \left(M_{t}-M_{\infty}\right)$ versus $t$ for vinyl ester samples containing $5 \mathrm{wt} \%$ Cloisite $10 \mathrm{~A} 囚$ at $25^{\circ} \mathrm{C}$ during first cycle of desorption

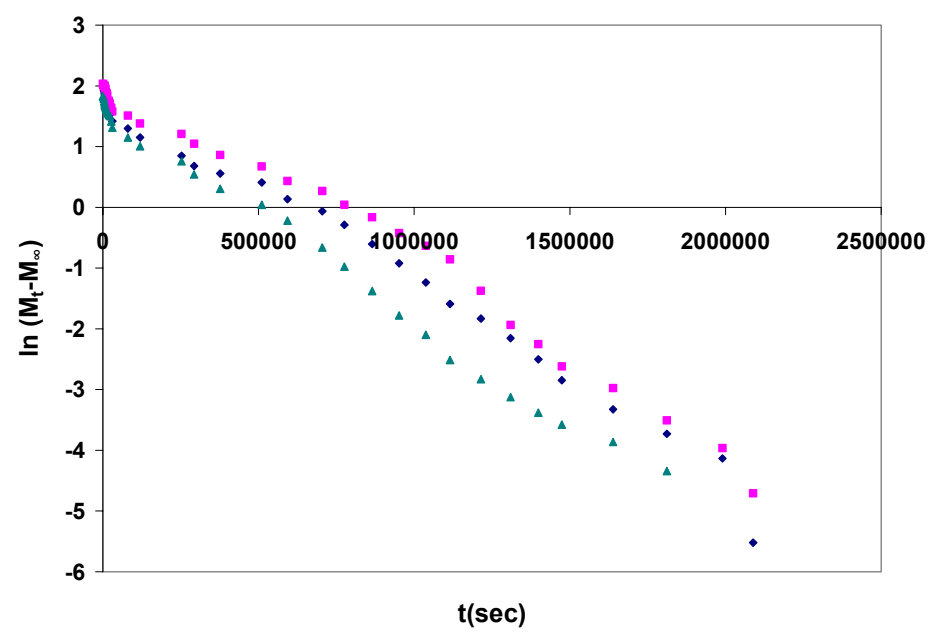

Figure $127 \ln \left(M_{t}-M_{\infty}\right)$ versus $t$ for vinyl ester samples containing $5 \mathrm{wt} \%$ Cloisite $10 \mathrm{~A}{ }^{\circledR}$ at $25{ }^{\circ} \mathrm{C}$ during second cycle of desorption

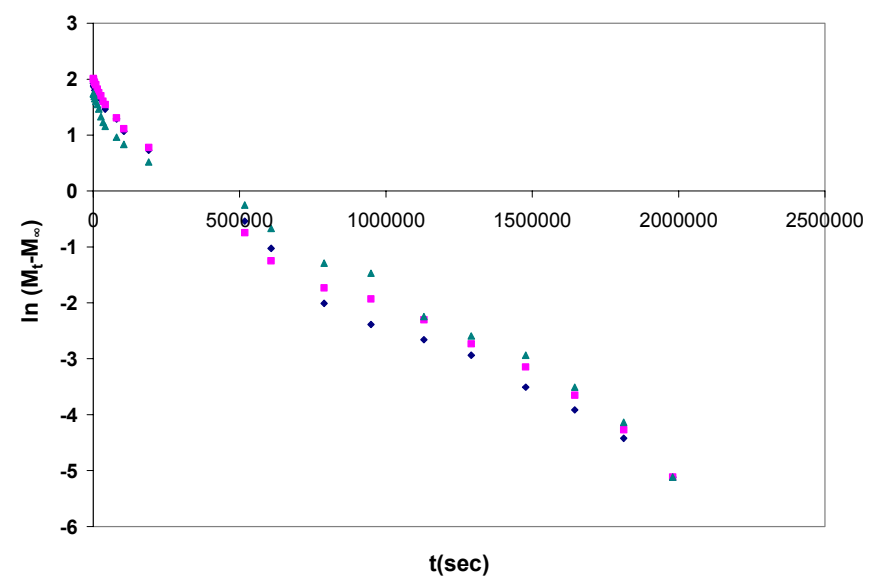


Figure $128 \ln \left(M_{t}-M_{\infty}\right)$ versus $t$ for vinyl ester samples containing $5 \mathrm{wt} \%$ Cloisite $10 A^{\circledR}$ at $25{ }^{\circ} \mathrm{C}$ during third cycle of desorption

\section{C.1.2.Experiments with Polyester}

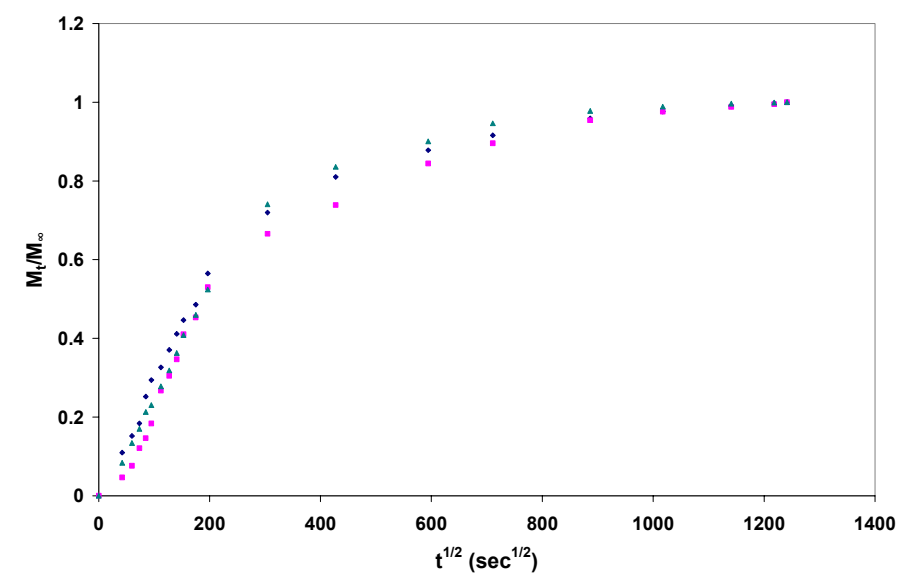

Figure $129 M_{t} / M_{\infty}$ versus $t^{1 / 2}$ for polyester samples containing $0 \mathrm{wt} \%$ Cloisite $10 \mathrm{~A} 囚$ at $25{ }^{\circ} \mathrm{C}$ during first cycle of absorption

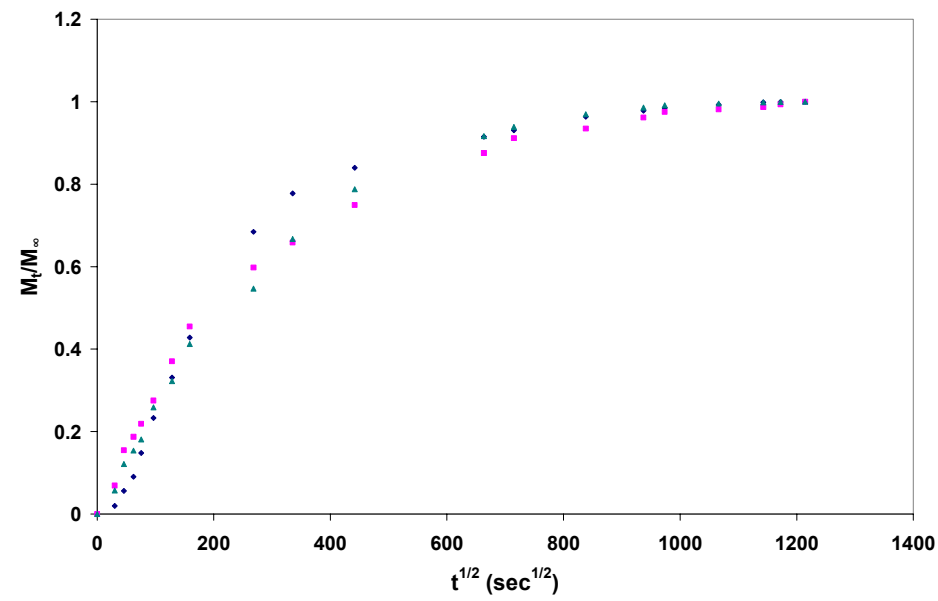

Figure $130 \mathrm{M}_{\mathrm{t}} / \mathrm{M}_{\infty}$ versus $^{1 / 2}$ for polyester samples containing $0 \mathrm{wt} \%$ Cloisite $10 \mathrm{~A}^{\circledR}$ at $25{ }^{\circ} \mathrm{C}$ during second cycle of absorption

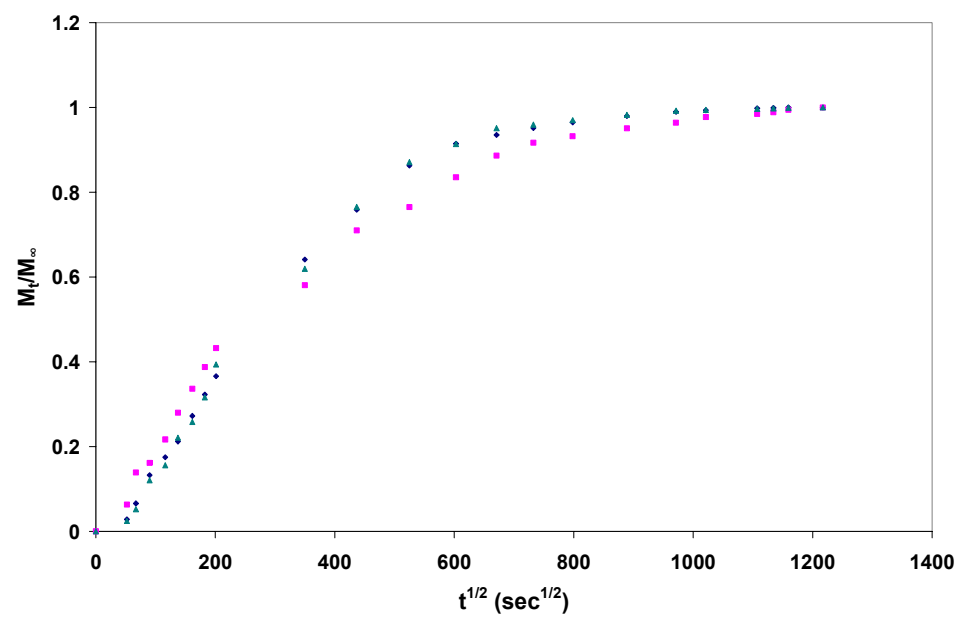


Figure $131 M_{t} / M_{\infty}$ versus $t^{1 / 2}$ for polyester samples containing $0 \mathrm{wt}^{\circ} \mathrm{Cloisite} 10 \mathrm{~A}^{\circledR}$ at $25{ }^{\circ} \mathrm{C}$ during third cycle of absorption

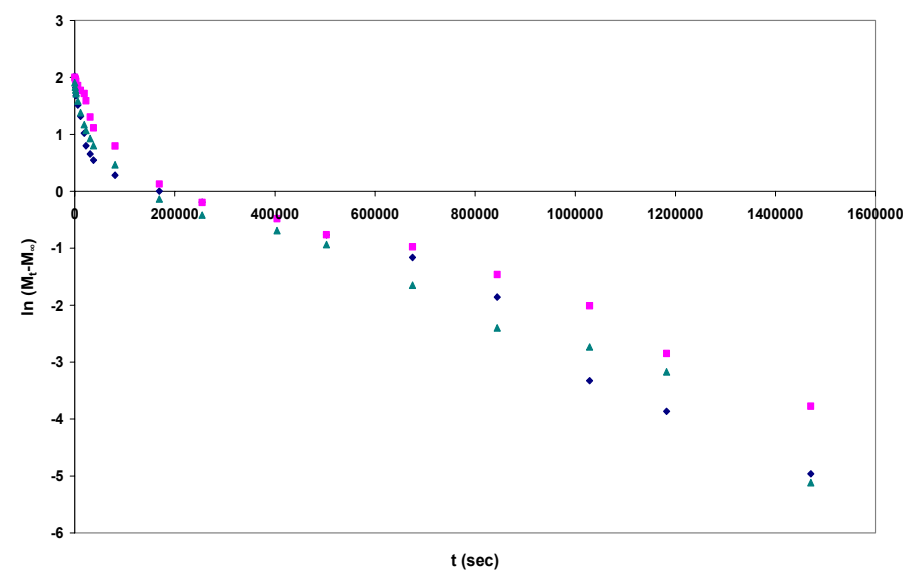

Figure $132 \ln \left(M_{t}-M_{\infty}\right)$ versus $t$ for polyester samples containing $0 \mathrm{wt} \%$ Cloisite $10 A^{\circledR}$ at $25{ }^{\circ} \mathrm{C}$ during first cycle of desorption

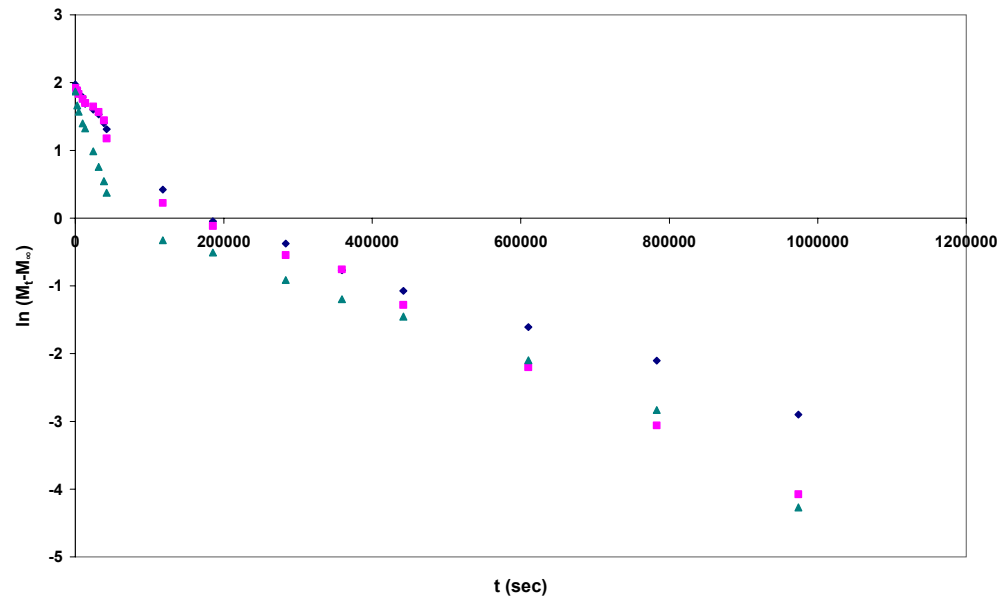

Figure $133 \ln \left(\mathrm{M}_{\mathrm{t}}-\mathrm{M}_{\infty}\right)$ versus t for polyester samples containing 0 wt $\%$ Cloisite $10 \mathrm{~A}^{\circledR}$ at $25{ }^{\circ} \mathrm{C}$ during second cycle of desorption

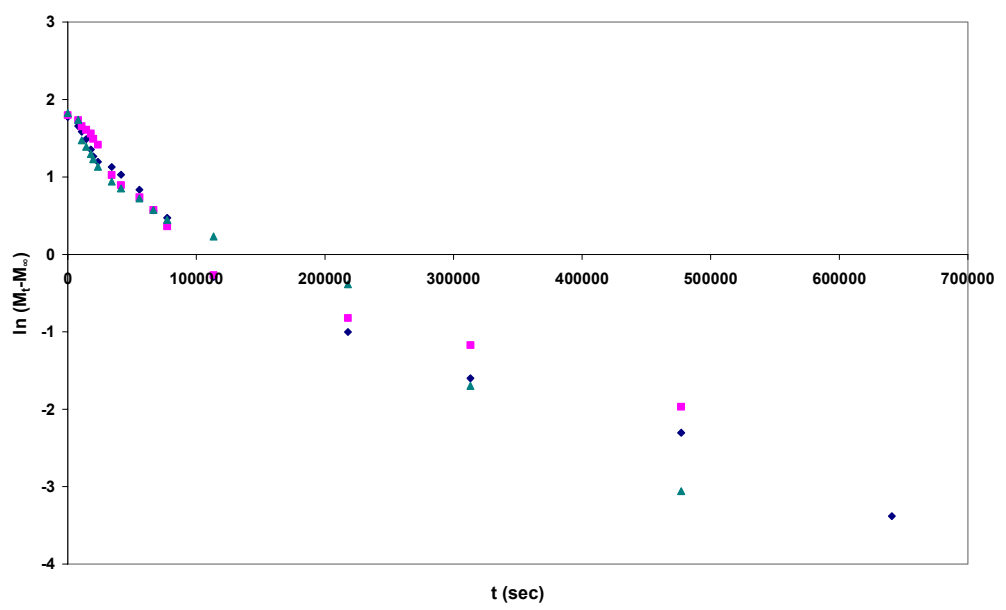


Figure 134 In $(\mathrm{Mt}-\mathrm{M} \infty)$ versus t for samples containing 0 wt\% Cloisite $10 \mathrm{~A} ®$ at $25^{\circ} \mathrm{C}$ during third cycle of desorption

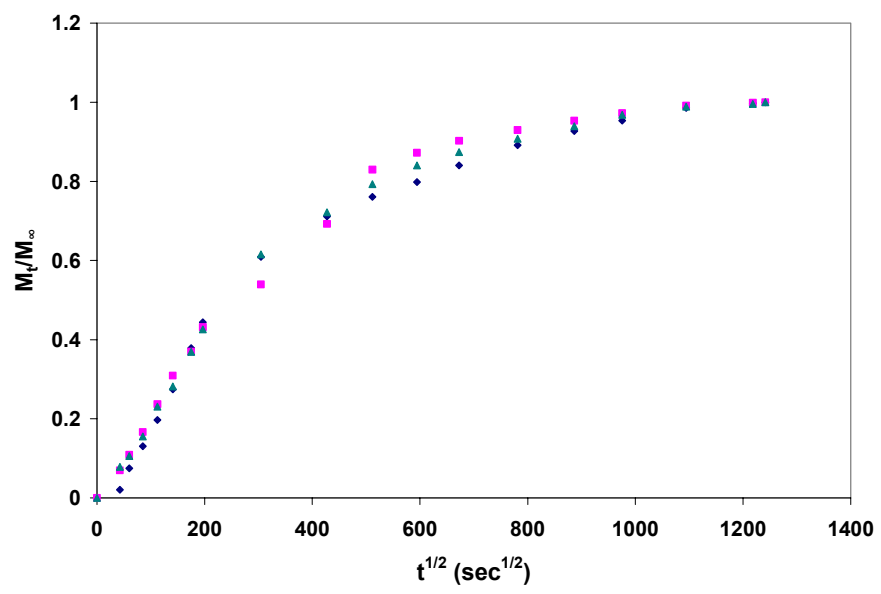

Figure $135 \mathrm{M}_{t} / \mathrm{M}_{\infty}$ versus $\mathrm{t}^{1 / 2}$ for polyester samples containing $2 \mathrm{wt}^{\mathrm{o}} \mathrm{Cloisite} 10 \mathrm{~A}^{\circledR}$ at $25{ }^{\circ} \mathrm{C}$ during first cycle of absorption

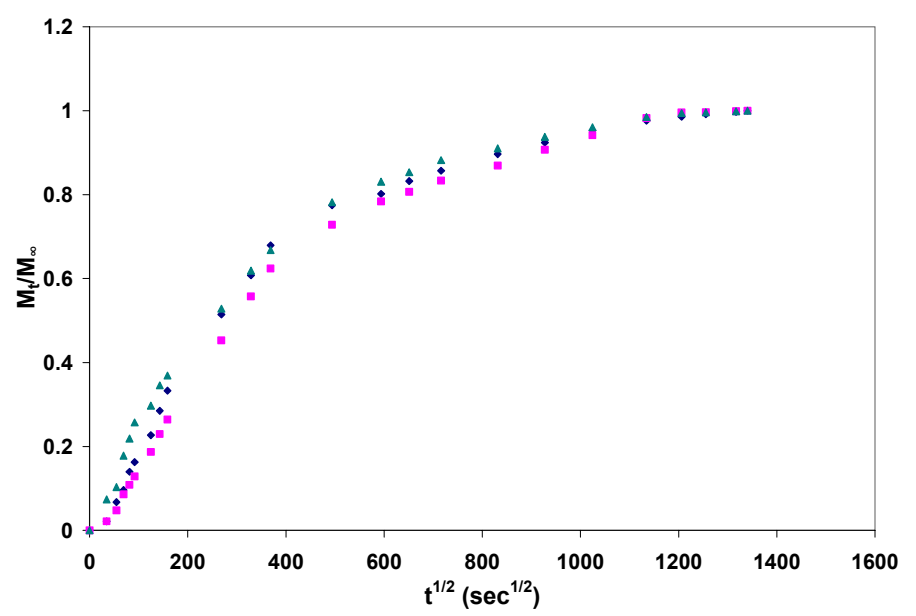

Figure $136 \mathrm{M}_{\mathrm{t}} / \mathrm{M}_{\infty}$ versus $\mathrm{t}^{1 / 2}$ for polyester samples containing $2 \mathrm{wt}^{\circ} \mathrm{Cloisite} 10 \mathrm{~A}^{\circledR}$ at $25{ }^{\circ} \mathrm{C}$ during second cycle of absorption

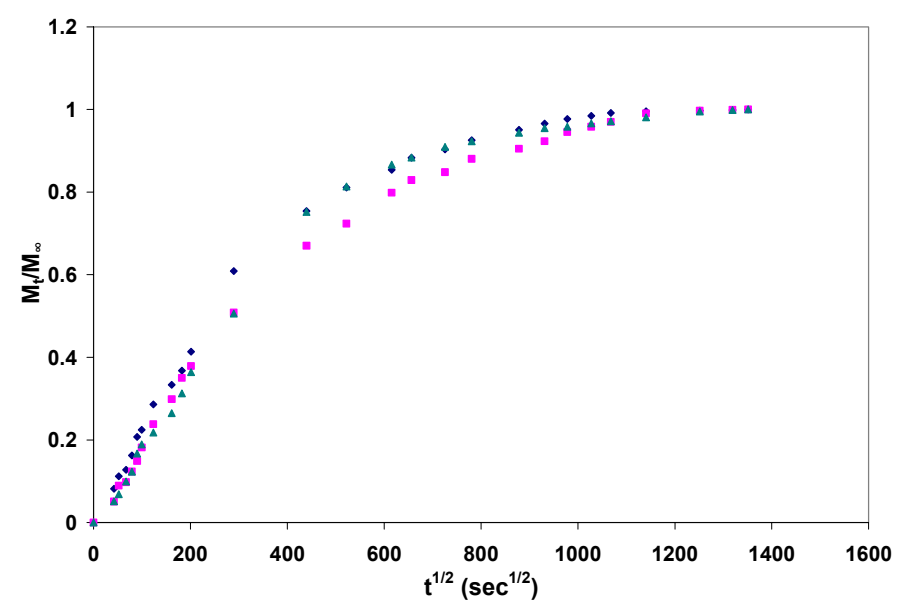


Figure $137 M_{t} / M_{\infty}$ versus $t^{1 / 2}$ for polyester samples containing $2 \mathrm{wt}^{\circ}$ Cloisite $10 \mathrm{~A}^{\circledR}$ at $25{ }^{\circ} \mathrm{C}$ during third cycle of absorption

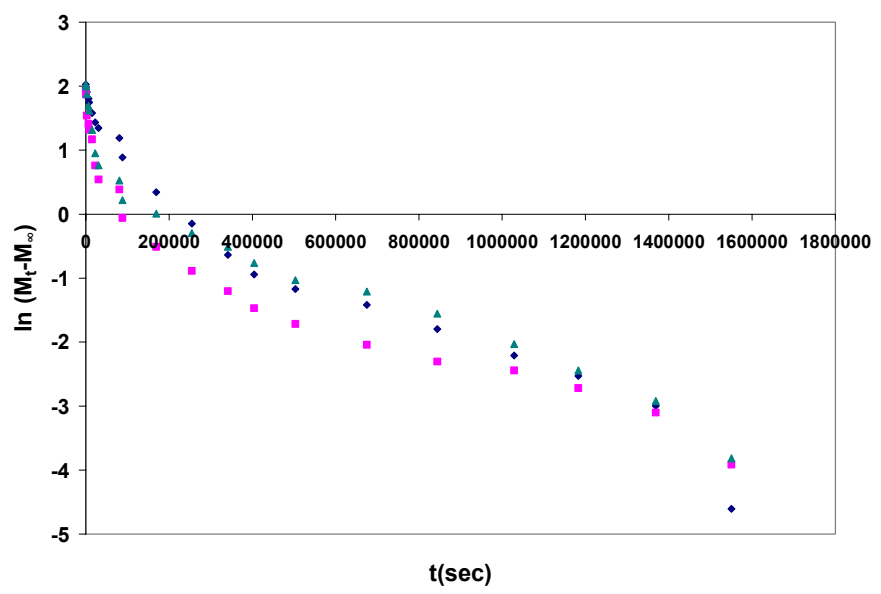

Figure $138 \ln \left(M_{t}-M_{\infty}\right)$ versus $t$ for polyester samples containing $2 w_{t} \%$ Cloisite $10 A^{\circledR}$ at $25{ }^{\circ} \mathrm{C}$ during first cycle of desorption

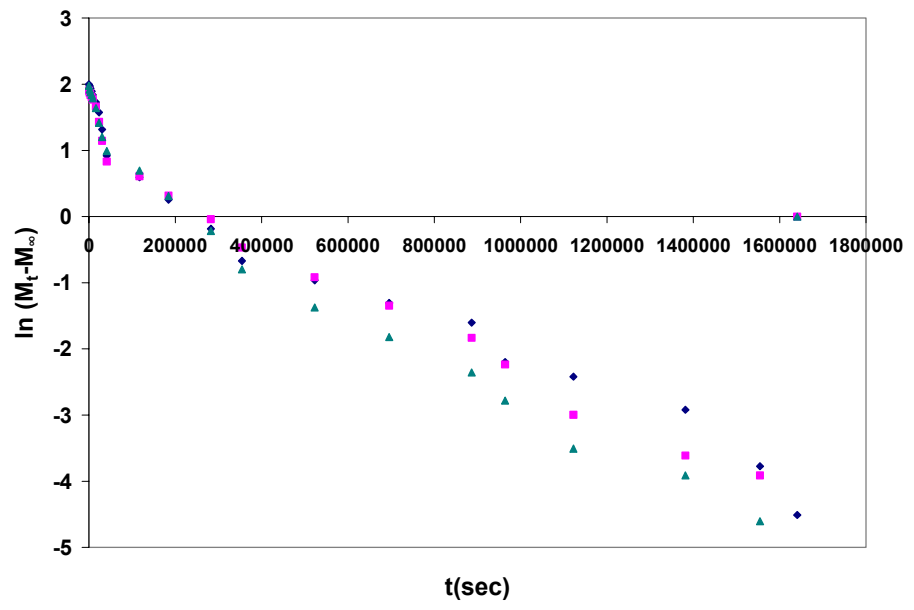

Figure $139 \ln \left(M_{t}-M_{\infty}\right)$ versus $t$ for polyester samples containing $2 \mathrm{wt}^{\circ}$ Cloisite $10 A^{\circledR}$ at $25{ }^{\circ} \mathrm{C}$ during second cycle of desorption

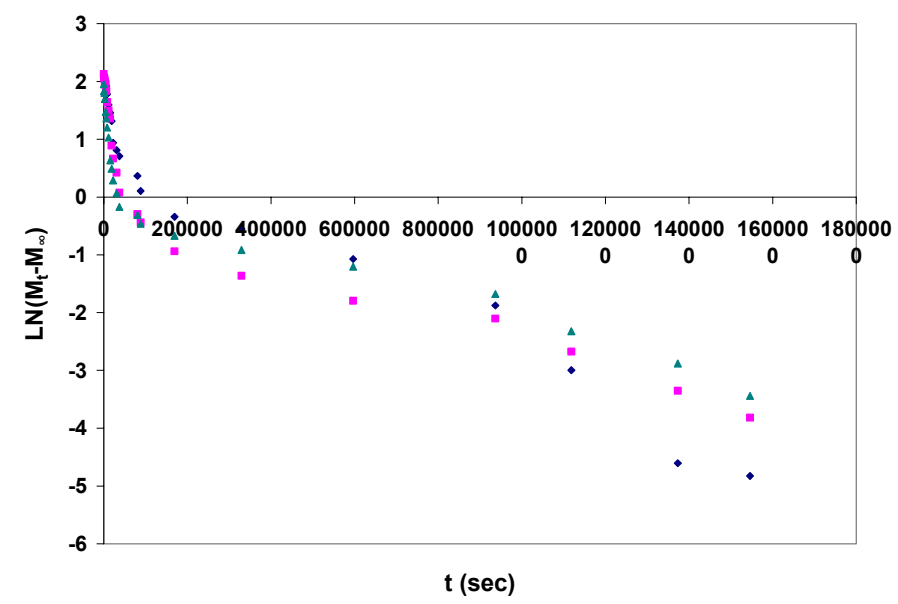




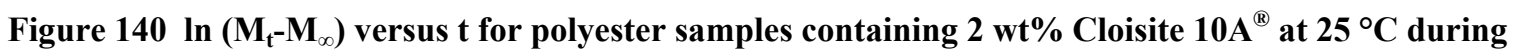
third cycle of desorption

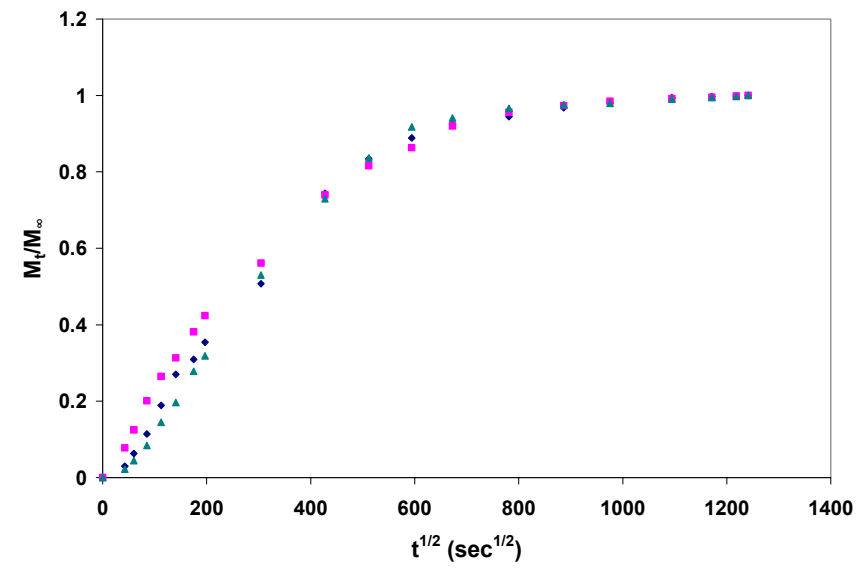

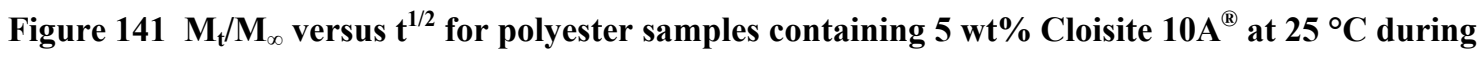
first cycle of absorption

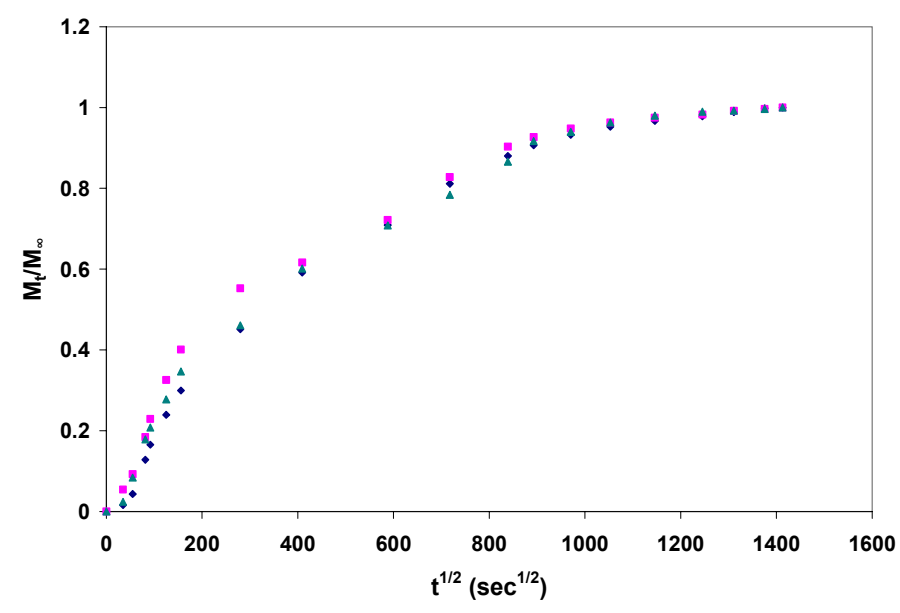

Figure $142 \mathrm{M}_{\mathrm{t}} / \mathrm{M}_{\infty}$ versus $\mathrm{t}^{1 / 2}$ for polyester samples containing $5 \mathrm{wt}^{\circ} \mathrm{Cloisite} 10 \mathrm{~A}^{\circledR}$ at $25{ }^{\circ} \mathrm{C}$ during second cycle of absorption

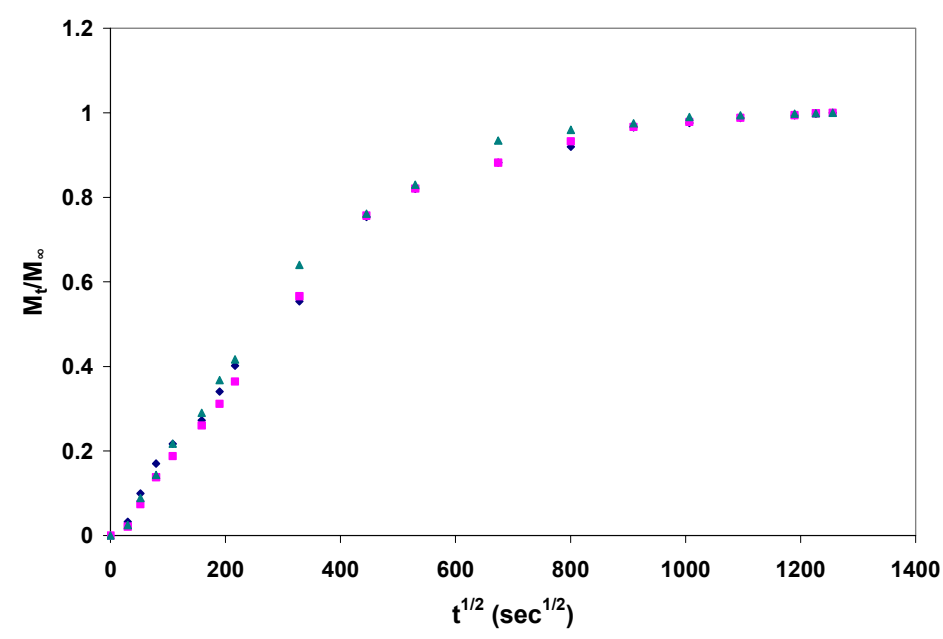


Figure $143 \mathrm{M}_{\mathrm{t}} / \mathrm{M}_{\infty}$ versus $\mathrm{t}^{1 / 2}$ for polyester samples containing $5 \mathrm{wt}^{\circ}$ Cloisite $10 \mathrm{~A}^{\circledR}$ at $25{ }^{\circ} \mathrm{C}$ during third cycle of absorption

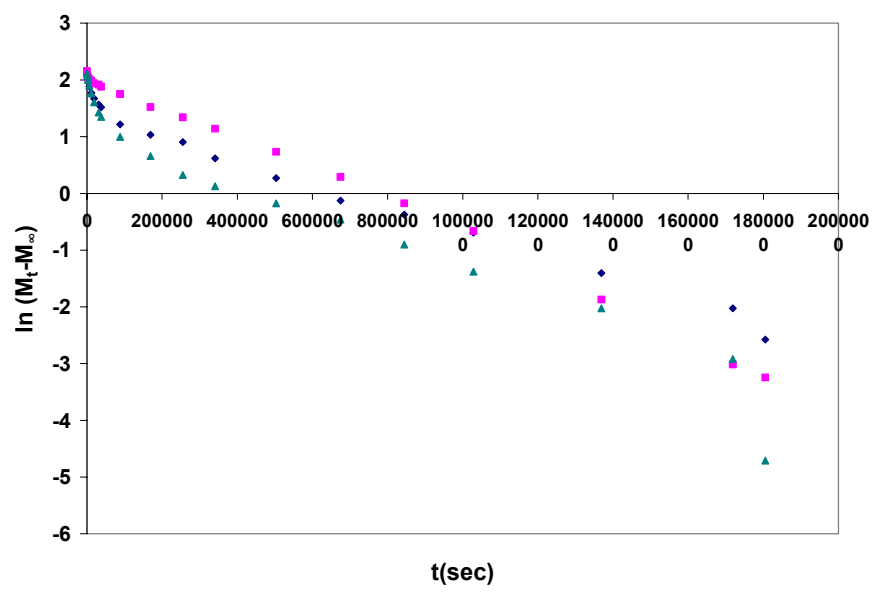

Figure $144 \ln \left(\mathrm{M}_{\mathrm{t}}-\mathrm{M}_{\infty}\right)$ versus t for polyester samples containing $5 \mathrm{wt}^{\circ} \mathrm{Cloisite} 10 \mathrm{~A}^{\circledR}$ at $25^{\circ} \mathrm{C}$ during first cycle of desorption

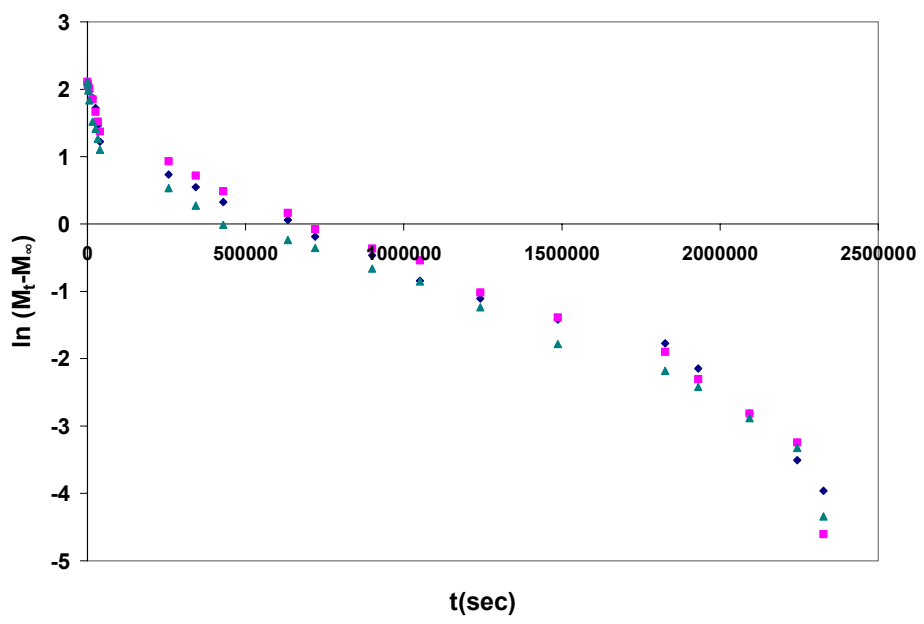

Figure $145 \ln \left(\mathrm{M}_{\mathrm{t}}-\mathrm{M}_{\infty}\right)$ versus t for polyester samples containing $5 \mathrm{wt} \%$ Cloisite $10 \mathrm{~A}^{\circledR}$ at $25^{\circ} \mathrm{C}$ during second cycle of desorption

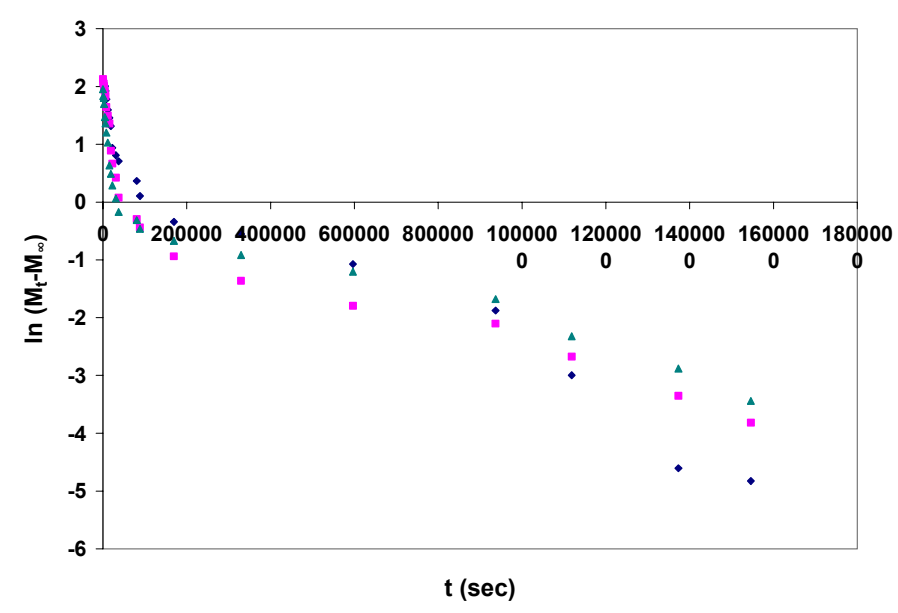


Figure 146 In $\left(M_{t}-M_{\infty}\right)$ versus t for polyester samples containing $5 w t \%$ Cloisite $10 A^{\circledR}$ at $25{ }^{\circ} \mathrm{C}$ during third cycle of desorption

\section{C.1.3.Experiments with Epoxy}

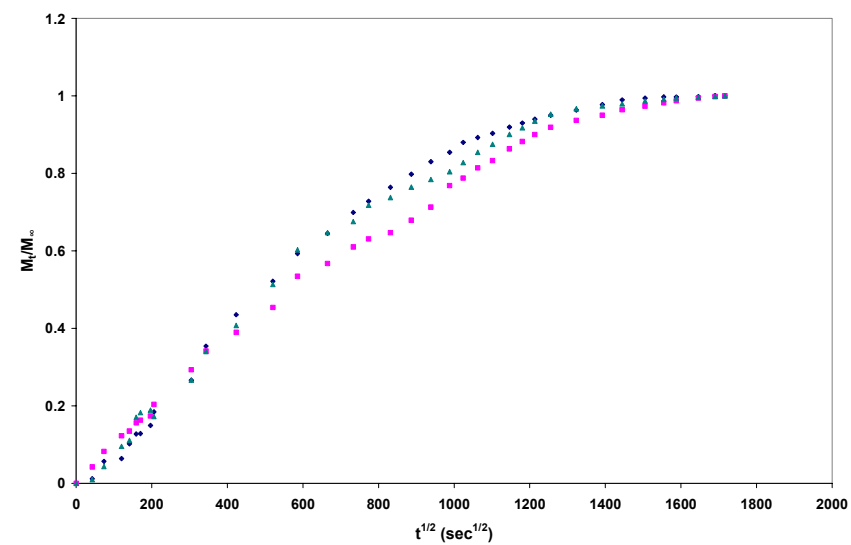

Figure $147 M_{t} / M_{\infty}$ versus $t^{1 / 2}$ for epoxy samples containing 0 wt $\%$ Cloisite $10 A^{\circledR}$ at $25{ }^{\circ} \mathrm{C}$ during first cycle of absorption

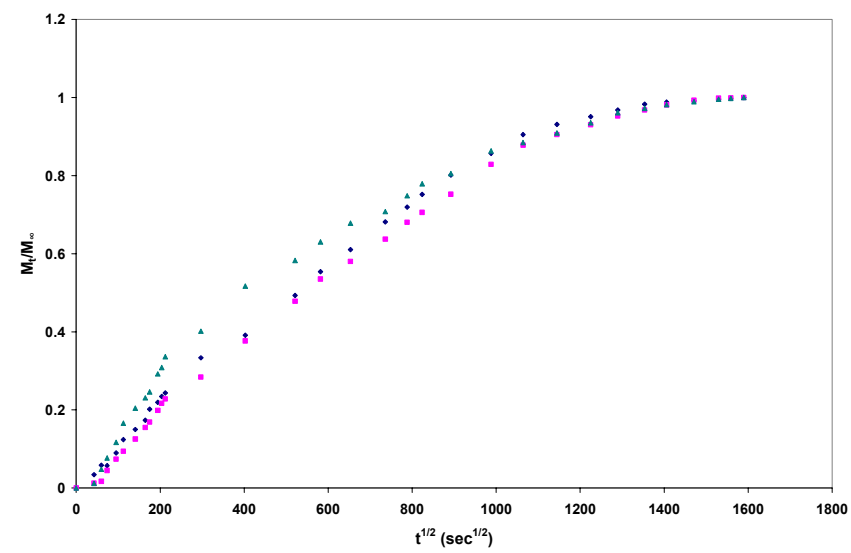

Figure $148 M_{t} / M_{\infty}$ versus $t^{1 / 2}$ for epoxy samples containing 0 wt $\%$ Cloisite $10 A^{\circledR}$ at $25{ }^{\circ} \mathrm{C}$ during second cycle of absorption

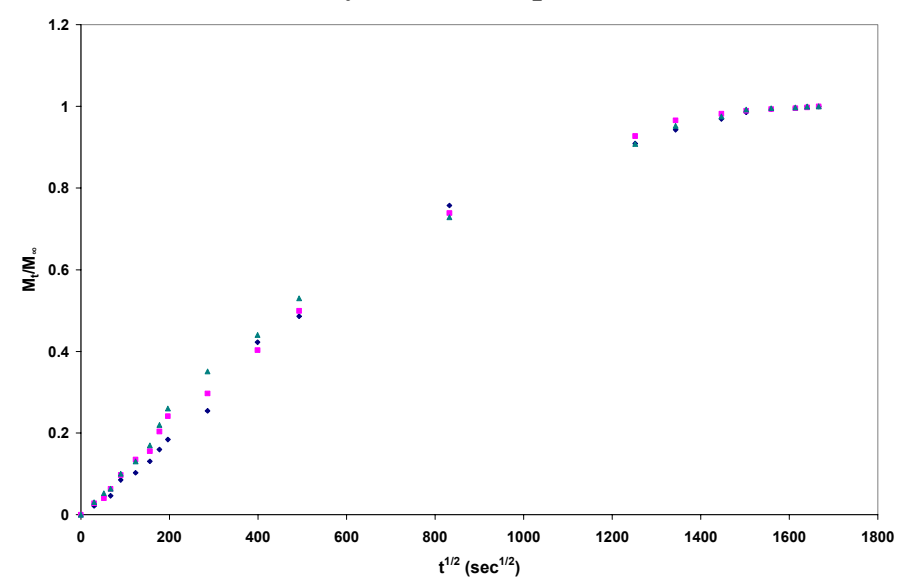

Figure $149 M_{t} / M_{\infty}$ versus $^{1 / 2}$ for epoxy samples containing 0 wt $\%$ Cloisite $10 A^{\circledR}$ at $25{ }^{\circ} \mathrm{C}$ during third cycle of absorption 


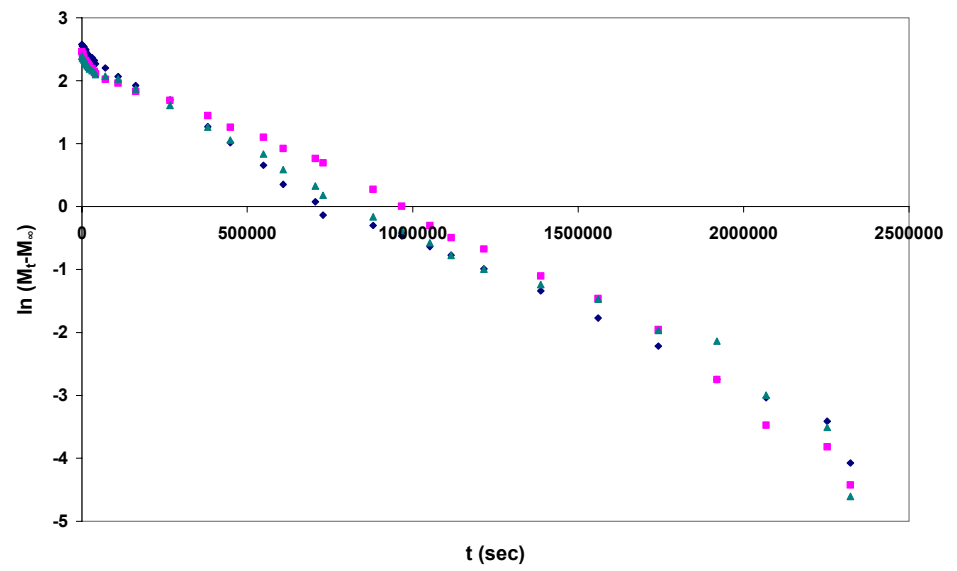

Figure 150 ln $\left(M_{t}-M_{\infty}\right)$ versus $t$ for epoxy samples containing 0 wt $\%$ Cloisite $10 A^{\circledR}$ at $25{ }^{\circ} \mathrm{C}$ during first cycle of desorption

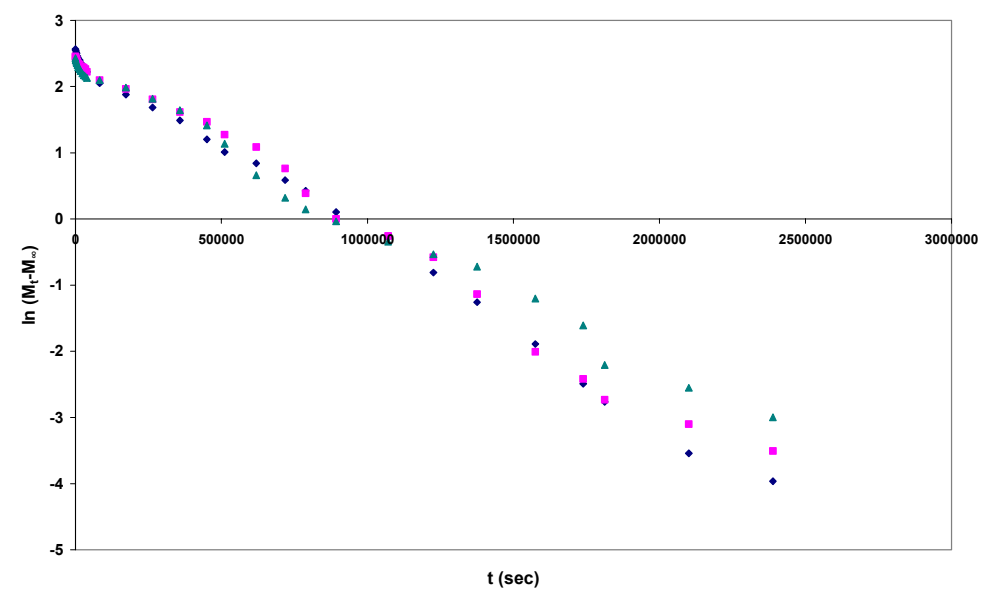

Figure $151 \ln \left(M_{t}-M_{\infty}\right)$ versus $t$ for epoxy samples containing 0 wt $\%$ Cloisite $10 A^{\circledR}$ at $25^{\circ} \mathrm{C}$ during second cycle of desorption

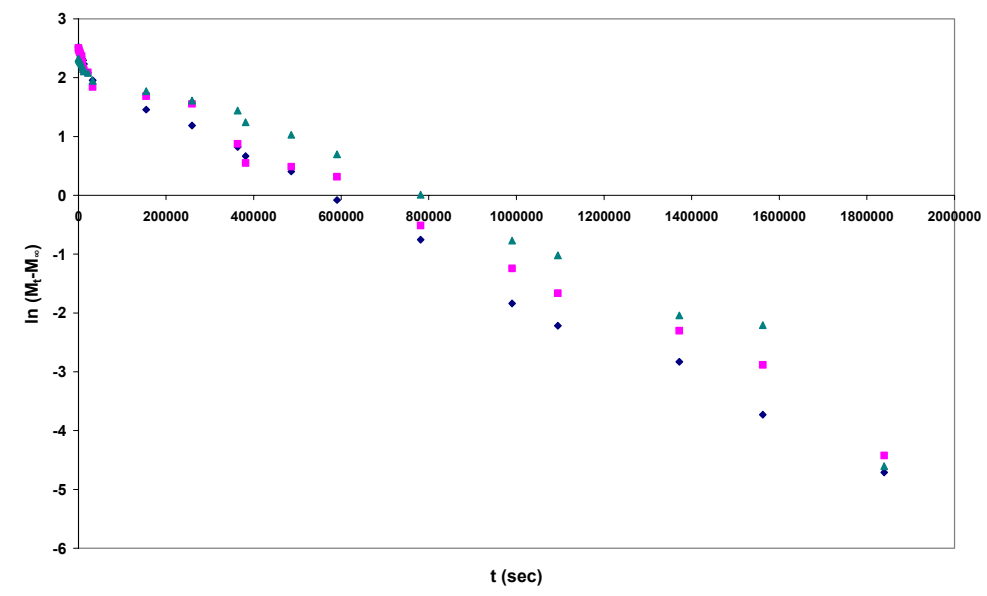

Figure $152 \ln \left(M_{t}-M_{\infty}\right)$ versus $t$ for epoxy samples containing 0 wt\% Cloisite $10 A^{\circledR}$ at $25{ }^{\circ} \mathrm{C}$ during third cycle of desorption 


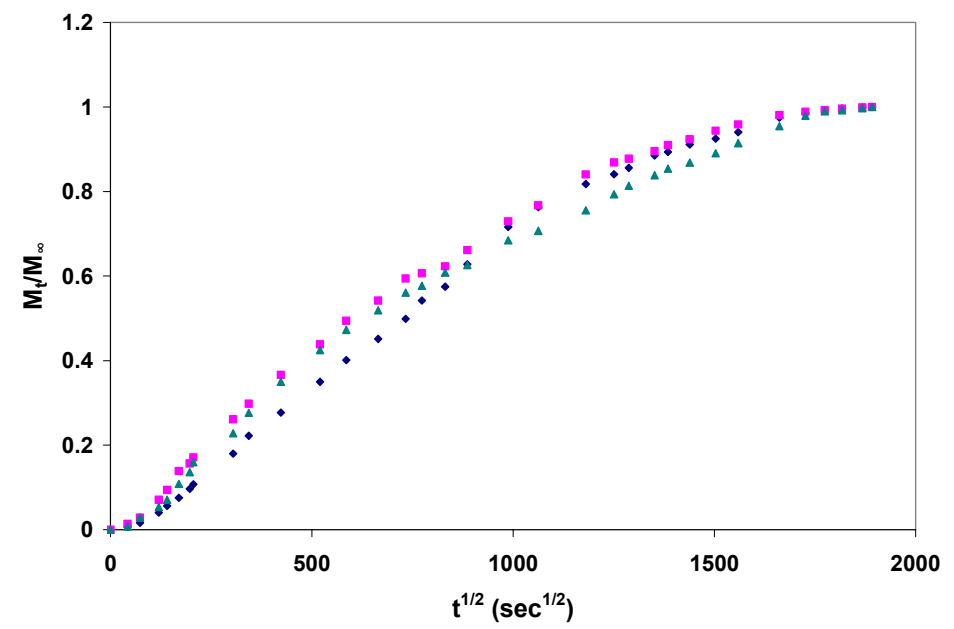

Figure $153 M_{t} / M_{\infty}$ versus $t^{1 / 2}$ for epoxy samples containing 2 wt $\%$ Cloisite $10 A^{\circledR}$ at $25{ }^{\circ} \mathrm{C}$ during first cycle of absorption

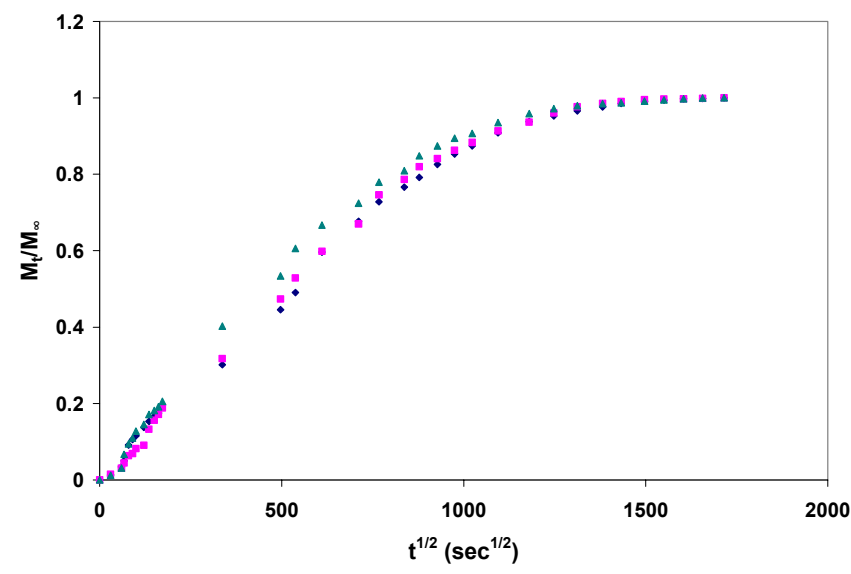

Figure $154 M_{t} / M_{\infty}$ versus $t^{1 / 2}$ for epoxy samples containing $2 w^{\circ} \%$ Cloisite $10 A^{\circledR}$ at $25{ }^{\circ} \mathrm{C}$ during second cycle of absorption

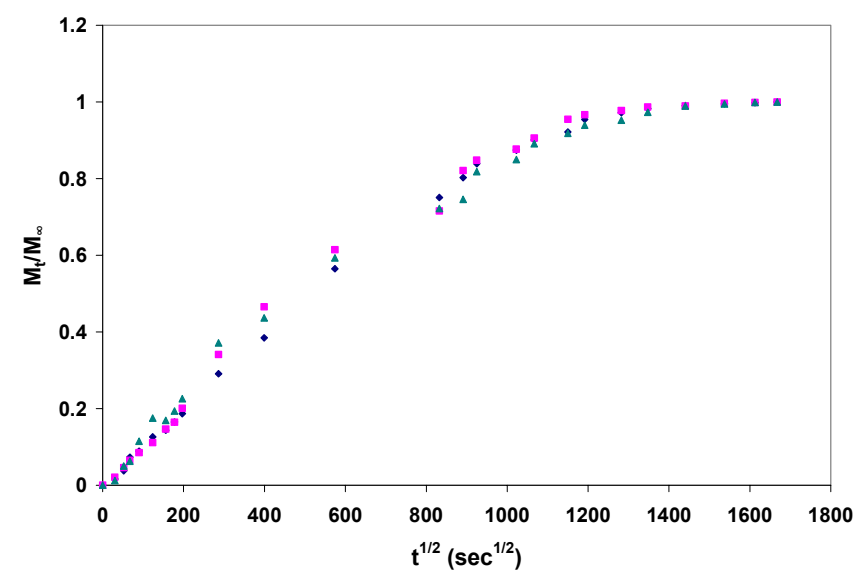

Figure $155 M_{t} / M_{\infty}$ versus $t^{1 / 2}$ for epoxy samples containing $2 w^{t} \%$ Cloisite $10 A^{\circledR}$ at $25{ }^{\circ} \mathrm{C}$ during third cycle of absorption 


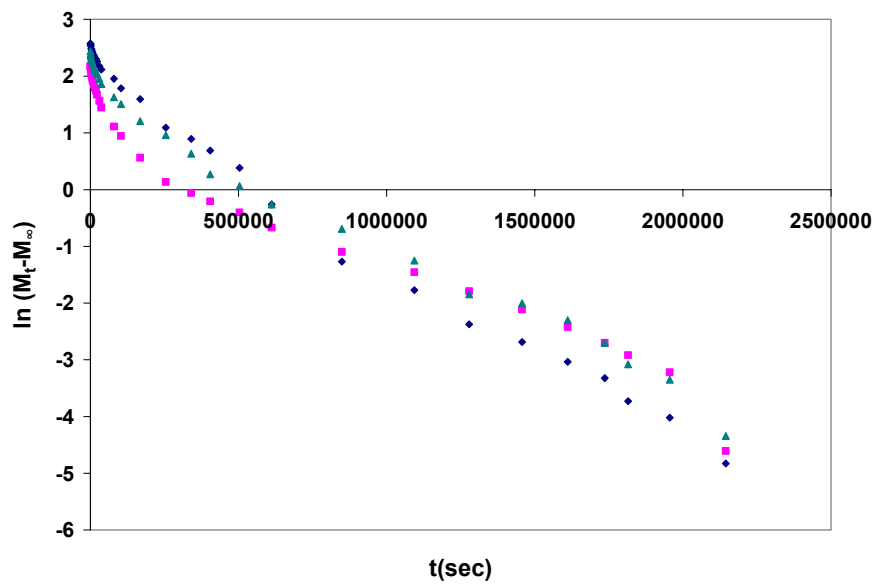

Figure $156 \ln \left(M_{t}-M_{\infty}\right)$ versus $t$ for epoxy samples containing $2 w^{\circ} \%$ Cloisite $10 A^{\circledR}$ at $25{ }^{\circ} \mathrm{C}$ during first cycle of desorption

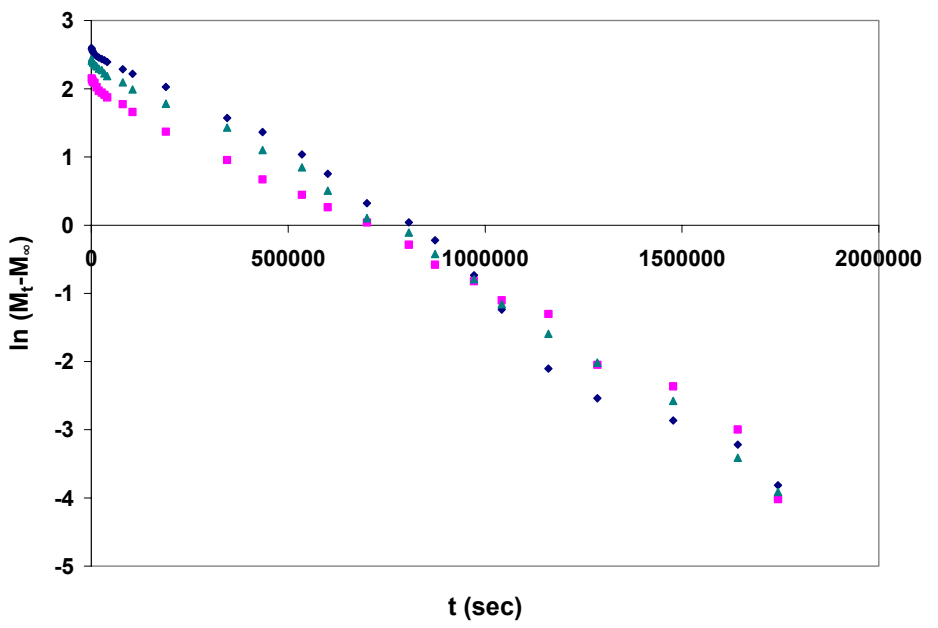

Figure $157 \ln \left(M_{t}-M_{\infty}\right)$ versus t for epoxy samples containing $2 w^{\circ} \%$ Cloisite $10 A^{\circledR}$ at $25^{\circ} \mathrm{C}$ during second cycle of desorption

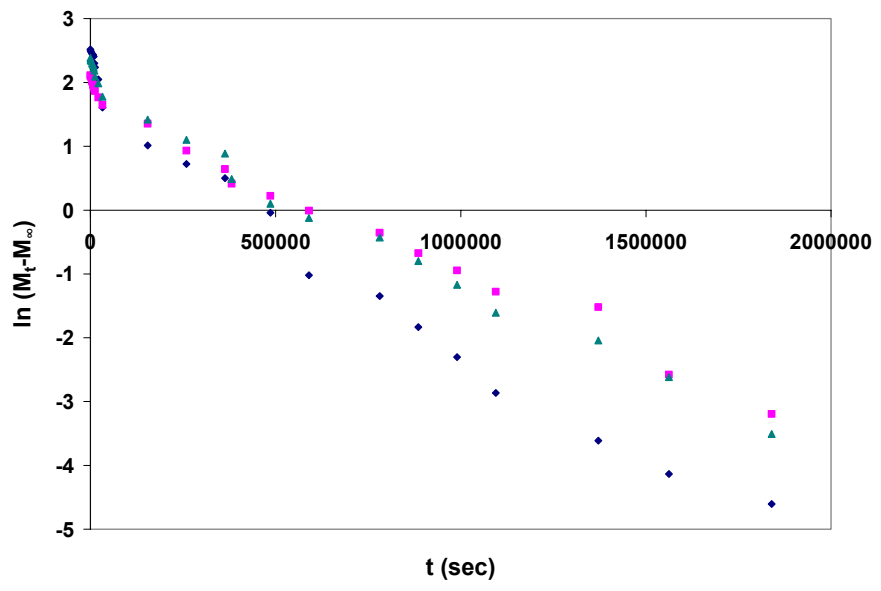

Figure $158 \ln \left(M_{t}-M_{\infty}\right)$ versus $t$ for epoxy samples containing $2 w^{\circ} \%$ Cloisite $10 A^{\circledR}$ at $25^{\circ} \mathrm{C}$ during third cycle of desorption 


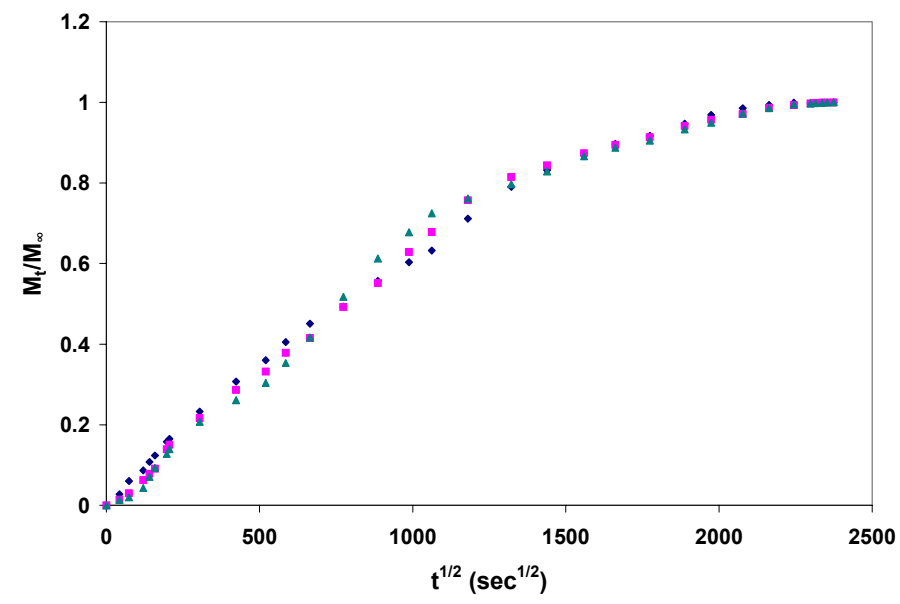

Figure $159 M_{t} / M_{\infty}$ versus $t^{1 / 2}$ for epoxy samples containing 5 wt $\%$ Cloisite $10 A^{\circledR}$ at $25{ }^{\circ} \mathrm{C}$ during first cycle of absorption

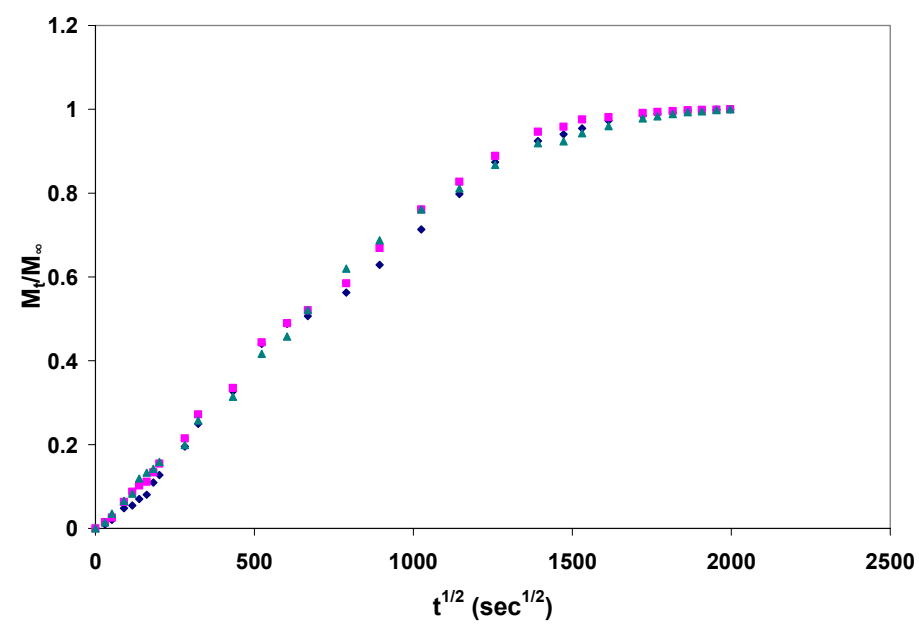

Figure $160 \mathrm{M}_{\mathrm{t}} / \mathrm{M}_{\infty}$ versus $\mathrm{t}^{1 / 2}$ for epoxy samples containing $5 \mathrm{wt}^{\%}$ Cloisite $10 \mathrm{~A}^{\circledR}$ at $25{ }^{\circ} \mathrm{C}$ during second cycle of absorption

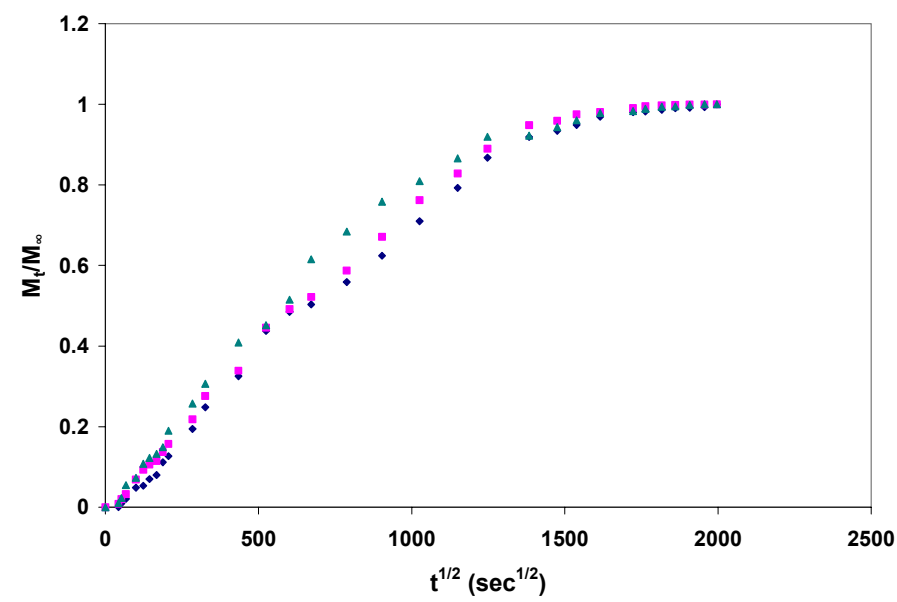

Figure $161 \mathrm{M}_{t} / \mathrm{M}_{\infty}$ versus $\mathrm{t}^{1 / 2}$ for epoxy samples containing $5 \mathrm{wt} \%$ Cloisite $10 \mathrm{~A}^{\circledR}$ at $25^{\circ} \mathrm{C}$ during third cycle of absorption 


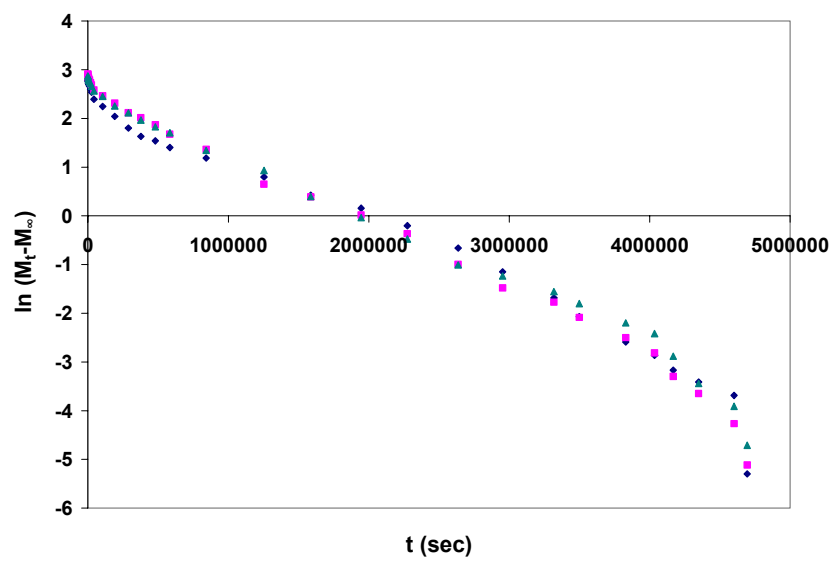

Figure $162 \ln \left(M_{t}-M_{\infty}\right)$ versus t for epoxy samples containing 5 wt\% Cloisite $10 A^{\circledR}$ at $25^{\circ} \mathrm{C}$ during first cycle of desorption

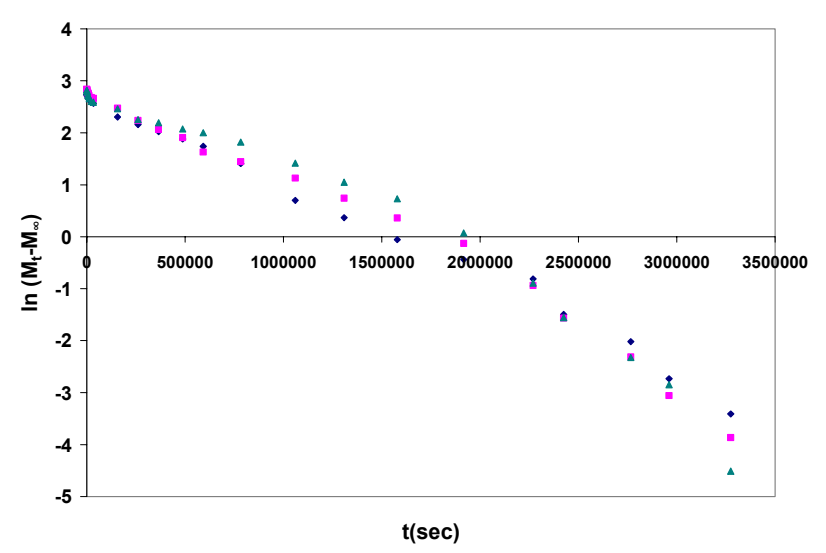

Figure $163 \ln \left(M_{t}-M_{\infty}\right)$ versus t for epoxy samples containing $5 w^{\circ} \%$ Cloisite $10 A^{\circledR}$ at $25^{\circ} \mathrm{C}$ during second cycle of desorption 


\section{C.2.Results of Sorption Experiments with Neat and Clay loaded Vinyl ester}

Samples at Different Relative Humidities (\%RH)

\section{C.2.1.Experiments at $60 \% \mathrm{RH}$}

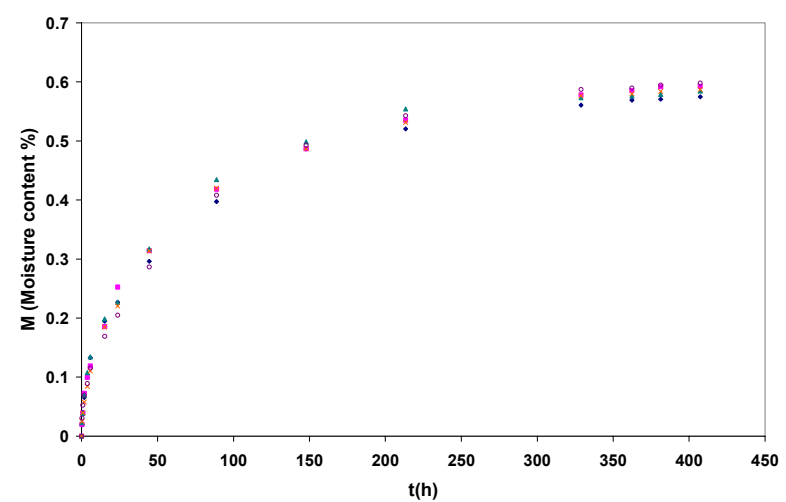

Figure 164 Moisture content versus t for neat vinyl ester samples exposed to $60 \% \mathrm{RH}$ at $25^{\circ} \mathrm{C}$

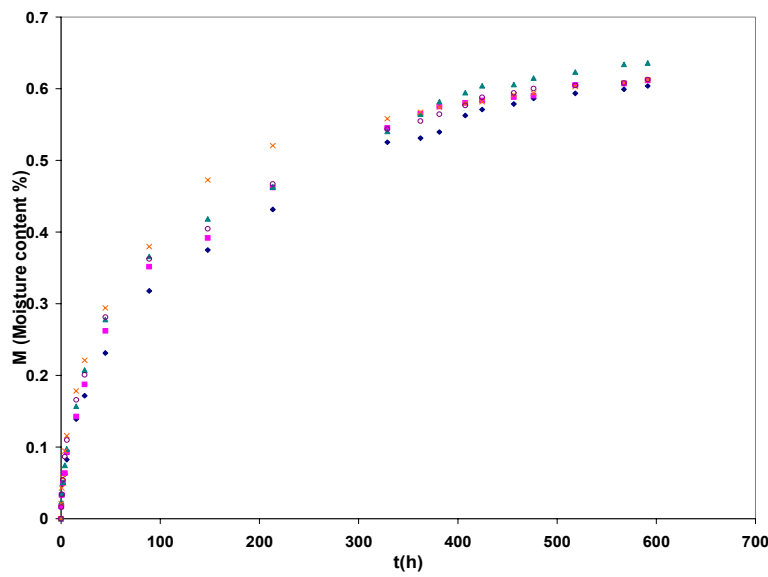

Figure 165 Moisture content versus t for $2 \mathrm{wt} \%$ clay loaded vinyl ester samples exposed to $60 \% \mathrm{RH}$ at $25^{\circ} \mathrm{C}$

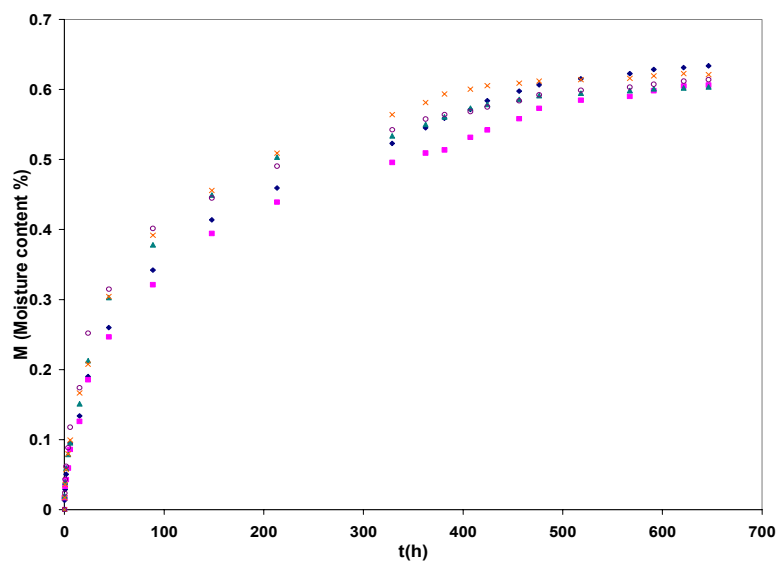


Figure 166 Moisture content versus t for 5 wt\% clay loaded vinyl ester samples exposed to $60 \%$ RH at $25^{\circ} \mathrm{C}$

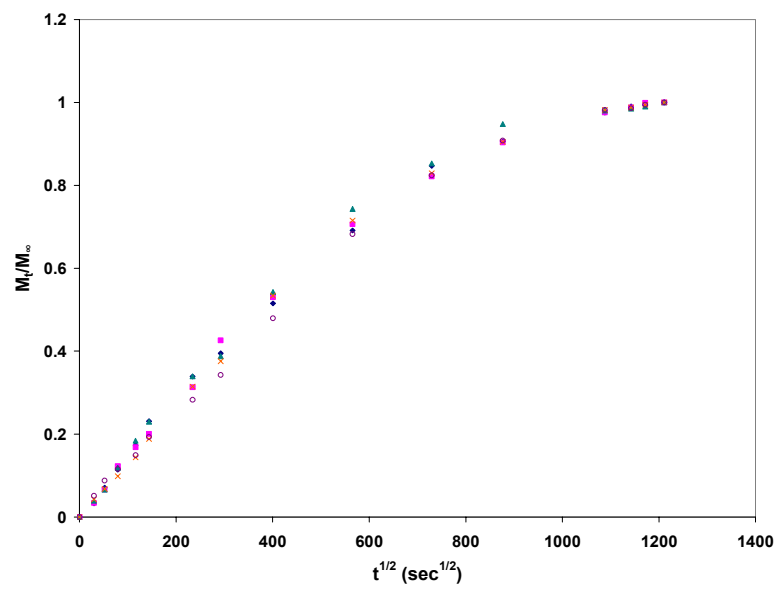

Figure $167 \mathrm{M}_{\mathrm{t}} / \mathrm{M}_{\infty}$ versus $\mathrm{t}^{1 / 2}$ for vinyl ester samples containing 0 wt\% Cloisite $10 \mathrm{~A}^{\circledR}$ exposed to $60 \%$ RH

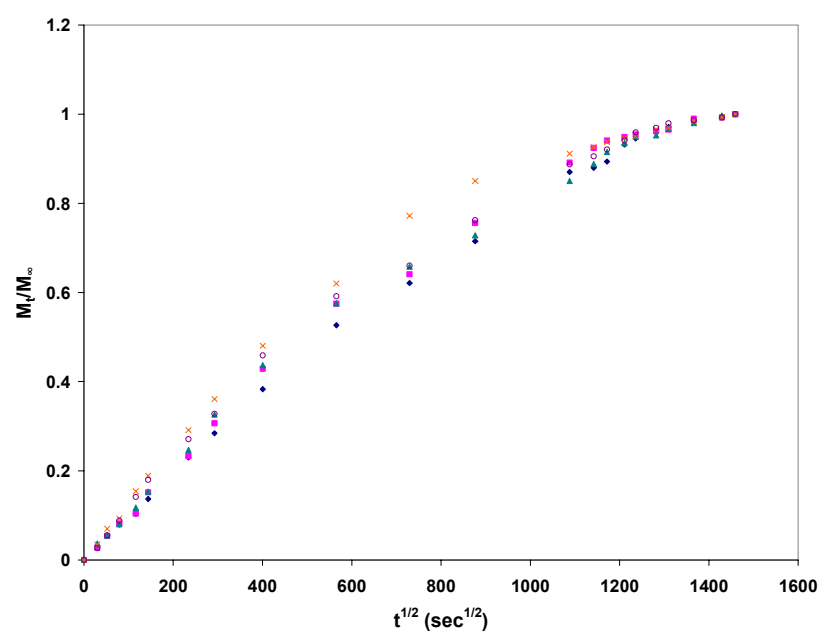

Figure $168 M_{t} / M_{\infty}$ versus $t^{1 / 2}$ for vinyl ester samples containing $2 w^{\circ} \%$ Cloisite $10 A^{\circledR}$ exposed to $60 \%$ RH

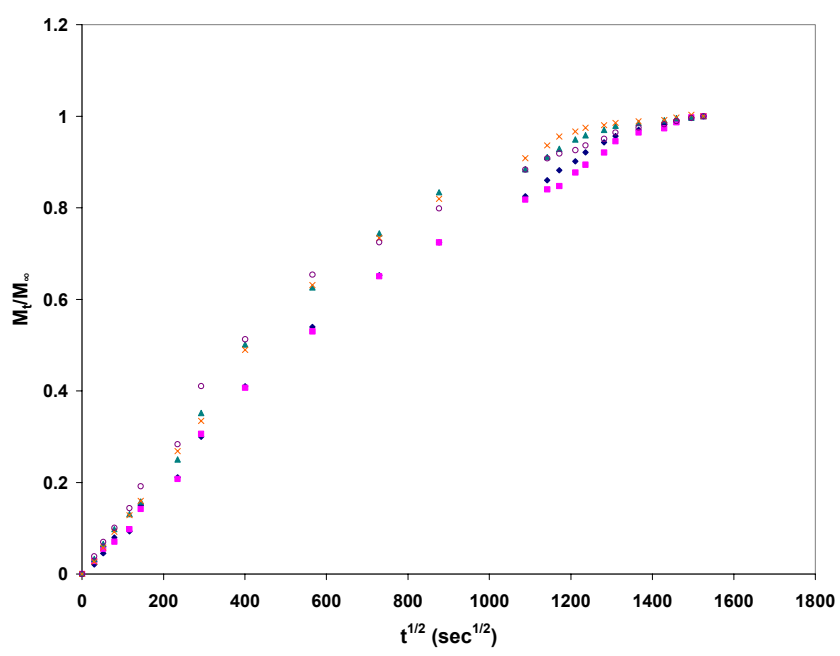


Figure $169 M_{t} / M_{\infty}$ versus $t^{1 / 2}$ for vinyl ester samples containing $5 w^{\circ} \%$ Cloisite $10 A^{\circledR}$ exposed to $60 \%$ RH

\section{C.2.2.Experiments at $70 \% \mathrm{RH}$}

Figure 170 Moisture content versus t for neat vinyl ester samples exposed to $70 \% \mathrm{RH}$ at $25{ }^{\circ} \mathrm{C}$

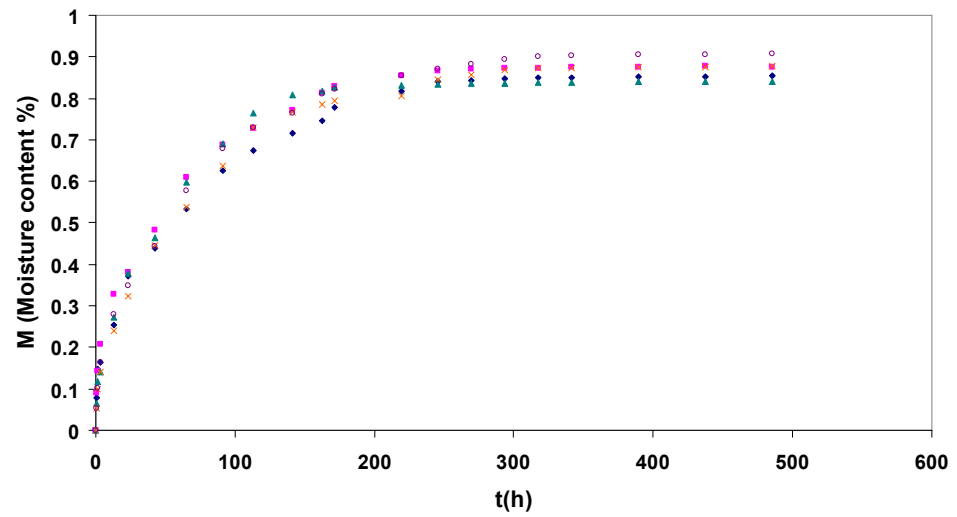

Figure 171 Moisture content versus t for 2 wt \% clay loaded vinyl ester samples exposed to $70 \% \mathrm{RH}$ at $25^{\circ} \mathrm{C}$

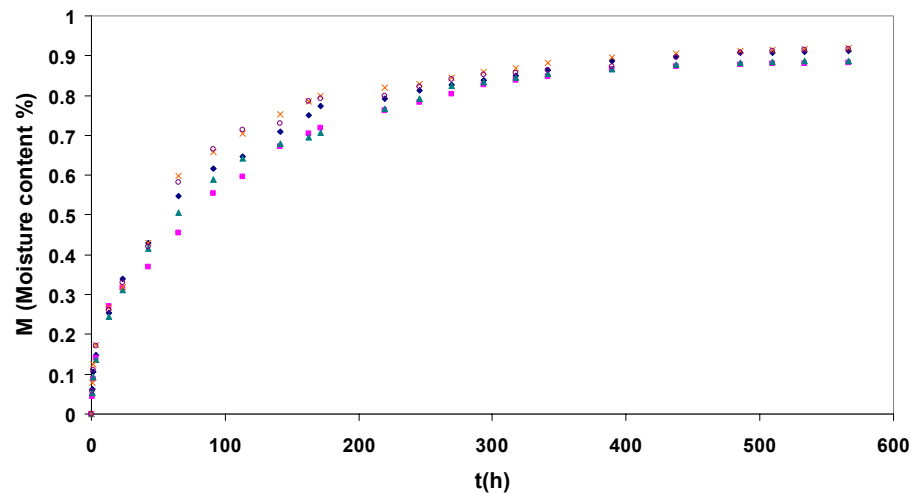

Figure 172 Moisture content versus t for $5 \mathrm{wt} \%$ clay loaded vinyl ester samples exposed to $70 \% \mathrm{RH}$ at $25^{\circ} \mathrm{C}$

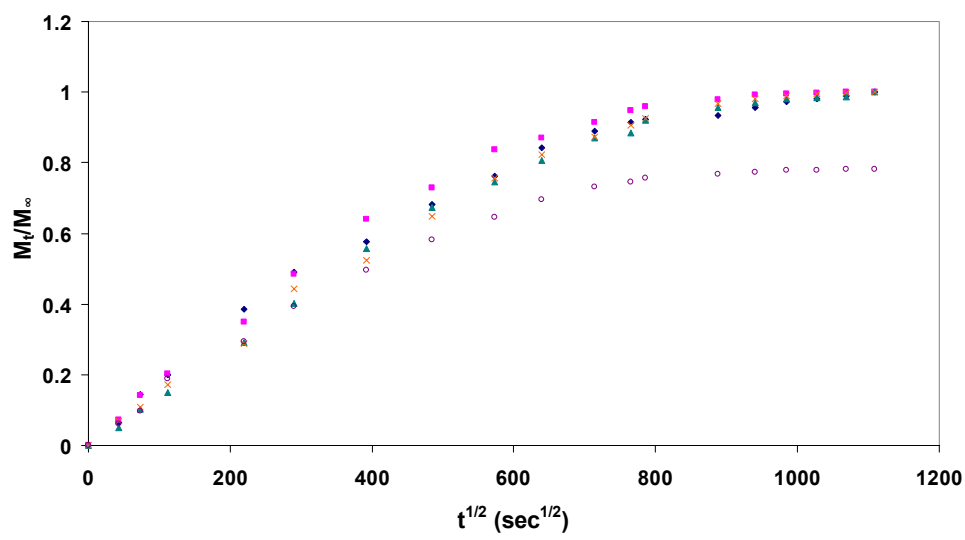

Figure $173 M_{t} / M_{\infty}$ versus $t^{1 / 2}$ for vinyl ester samples containing $0 \mathrm{wt}^{\%}$ Cloisite $10 A^{\circledR}$ exposed to $70 \%$ RH 


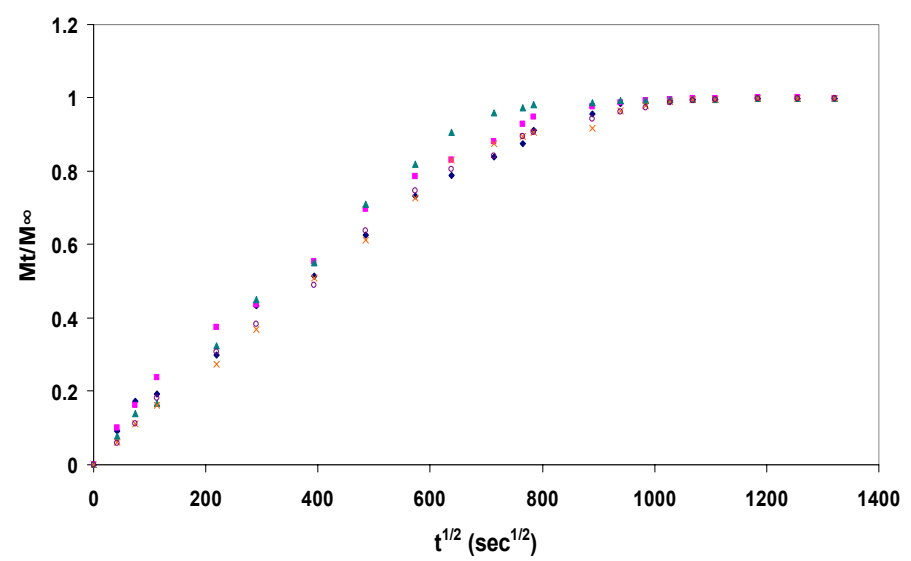

Figure $174 M_{t} / M_{\infty}$ versus $t^{1 / 2}$ for vinyl ester samples containing 2 wt $\%$ Cloisite $10 A^{\circledR}$ exposed to $70 \%$ RH

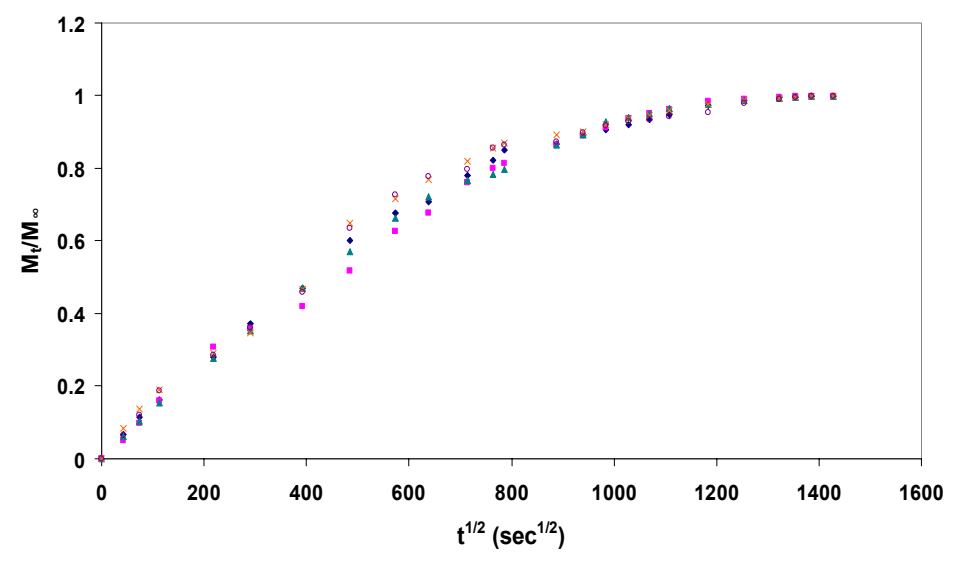

Figure $175 M_{t} / M_{\infty}$ versus $t^{1 / 2}$ for vinyl ester samples containing $5 w^{\%} \%$ Cloisite $10 A^{\circledR}$ exposed to $70 \%$ RH

\section{C.2.3.Experiments at $80 \% \mathrm{RH}$}

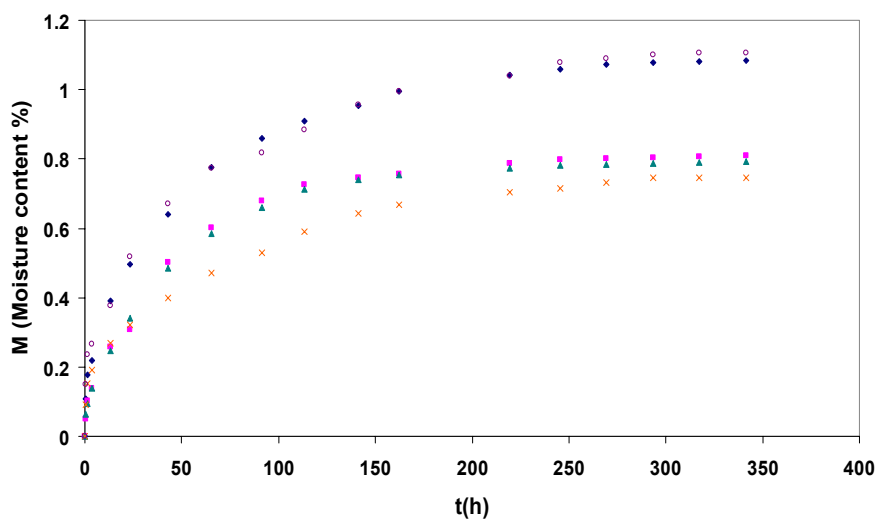

Figure 176 Moisture content versus t for neat vinyl ester samples exposed to $80 \% \mathrm{RH}$ at $25{ }^{\circ} \mathrm{C}$ 


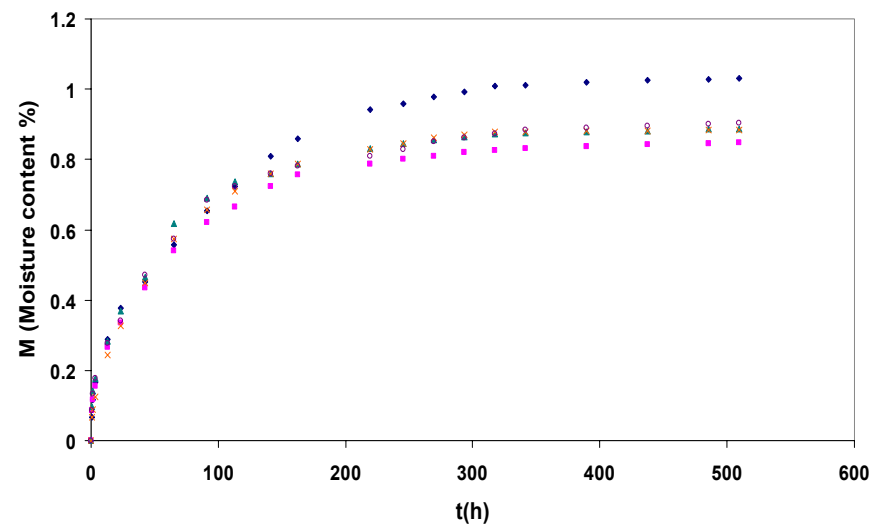

Figure 177 Moisture content versus t for 2 wt \% clay loaded vinyl ester samples exposed to $80 \% \mathrm{RH}$ at $25^{\circ} \mathrm{C}$

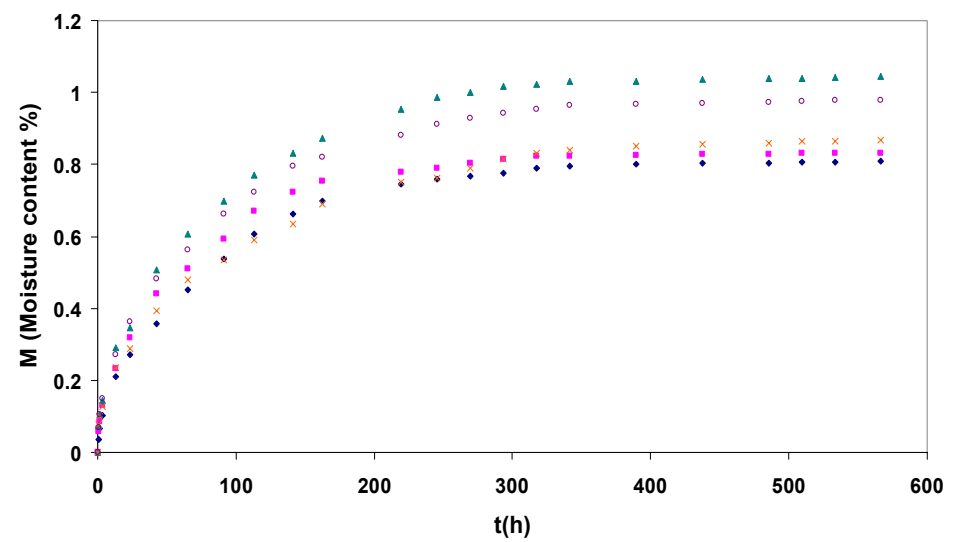

Figure 178 Moisture content versus t for $5 \mathrm{wt} \%$ clay loaded vinyl ester samples exposed to $80 \% \mathrm{RH}$ at $25^{\circ} \mathrm{C}$

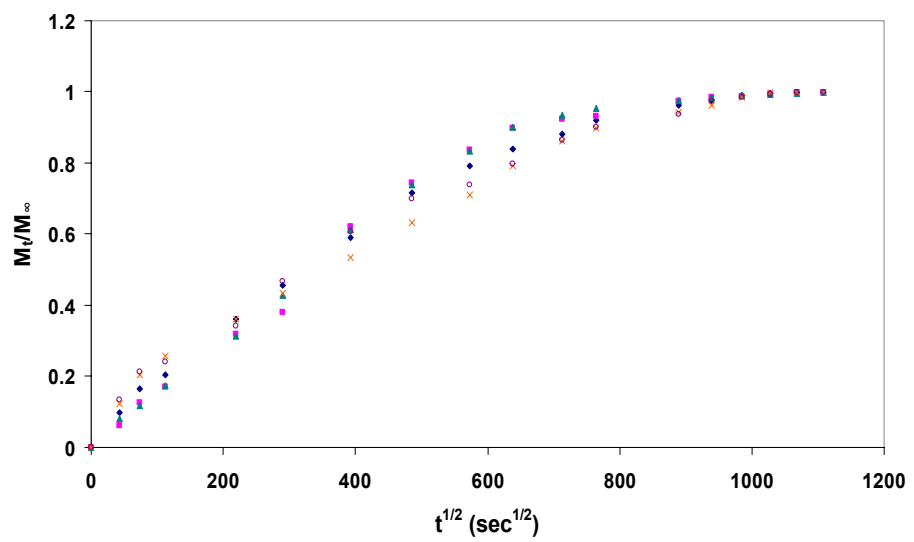

Figure $179 M_{t} / M_{\infty}$ versus $t^{1 / 2}$ for vinyl ester samples containing 0 wt $\%$ Cloisite $10 A^{\circledR}$ exposed to $80 \%$ RH 


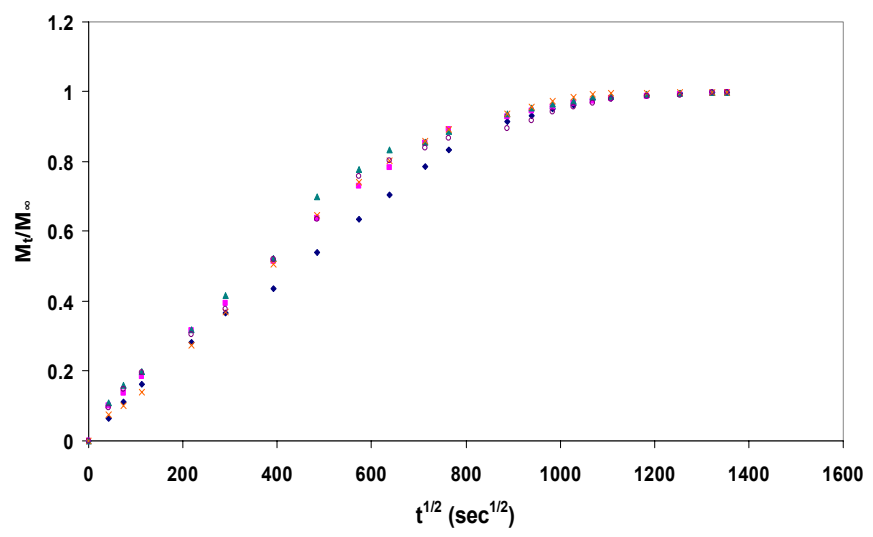

Figure $180 M_{t} / M_{\infty}$ versus $t^{1 / 2}$ for vinyl ester samples containing $2 w^{2} \%$ Cloisite $10 A^{\circledR}$ exposed to $80 \%$ RH

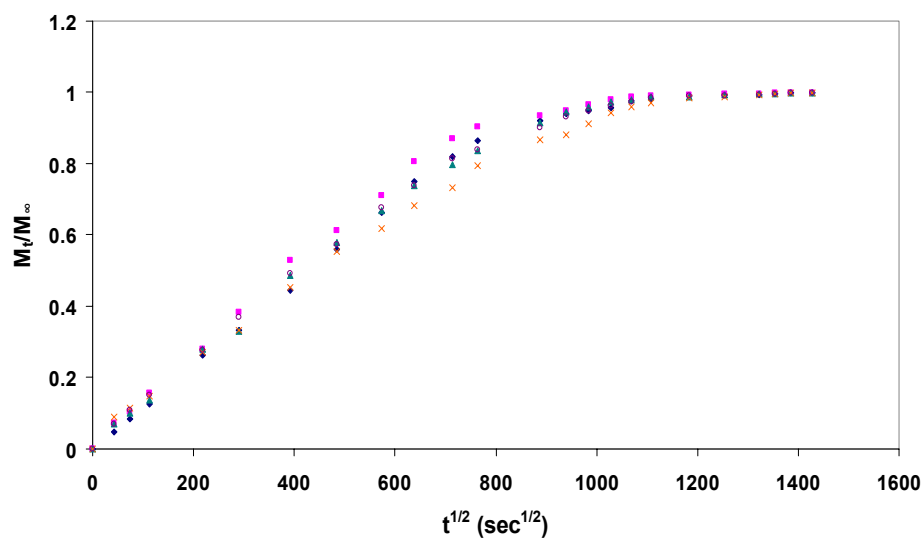

Figure $181 M_{t} / M_{\infty}$ versus $t^{1 / 2}$ for vinyl ester samples containing $5 w^{2} \%$ Cloisite $10 A^{\circledR}$ exposed to $80 \%$ RH 


\section{Appendix D}

\section{Raw Data}

Table 12. Sorption Data of Vinyl ester Samples containing 0 wt\% Cloisite 10A at $2^{\circ} \mathrm{C}$ During Three Cycles of Absorption

\begin{tabular}{|c|c|c|c|c|c|c|c|c|c|c|c|}
\hline & & & & sample-1 & & $2 I=0.0488 \mathrm{~cm}$ & & & & & \\
\hline & & Cycle-1 & & & & Cycle-2 & & & & Cycle-3 & \\
\hline Time, $\mathrm{h}$ & Weight, mg & Water Content, wt \% & $\mathrm{M}_{\mathrm{t}} / \mathrm{M}_{\infty}$ & Time, $\mathrm{h}$ & Weight, mg & Water Content, wt $\%$ & $\mathrm{M}_{\mathrm{t}} / \mathrm{M}_{\infty}$ & Time, $\mathrm{h}$ & Weight, mg & Water Content, wt \% & $\mathrm{M}_{\mathrm{t}} / \mathrm{M}_{\infty}$ \\
\hline 0.5 & 342.14 & 0.0380 & 0.0313 & 0.5 & 342.298 & 0.084208064 & 0.04 & 0.25 & 342.352 & 0.099997076 & 0.0287 \\
\hline 1.5 & 342.36 & 0.1023 & 0.0844 & 1 & 342.411 & 0.117248034 & 0.068 & 0.5 & 342.461 & 0.131867489 & 0.0567 \\
\hline 4 & 342.967 & 0.2798 & 0.2307 & 1.5 & 342.551 & 0.158182509 & 0.103 & 1.25 & 342.765 & 0.220753779 & 0.1347 \\
\hline 5.5 & 343.387 & 0.4026 & 0.3319 & 2 & 342.685 & 0.19736265 & 0.137 & 1.5 & 342.911 & 0.263442589 & 0.1721 \\
\hline 7 & 343.55 & 0.4503 & 0.3712 & 2.5 & 342.756 & 0.218122277 & 0.155 & 2 & 343.065 & 0.308470513 & 0.2116 \\
\hline 8 & 343.711 & 0.4974 & 0.4100 & 3 & 342.843 & 0.24356013 & 0.176 & 2.5 & 343.248 & 0.36197772 & 0.2586 \\
\hline 10.75 & 344.011 & 0.5851 & 0.4823 & 4 & 343.012 & 0.29297389 & 0.219 & 3 & 343.349 & 0.39150902 & 0.2845 \\
\hline 11.75 & 344.11 & 0.6140 & 0.5061 & 5 & 343.138 & 0.329814918 & 0.25 & 4.333 & 343.581 & 0.459343294 & 0.344 \\
\hline 25.75 & 344.57 & 0.7485 & 0.6170 & 7 & 343.342 & 0.389462296 & 0.301 & 5.333 & 343.764 & 0.512850501 & 0.391 \\
\hline 49.75 & 345.184 & 0.9280 & 0.7650 & 43 & 344.632 & 0.76664425 & 0.624 & 7.5 & 343.951 & 0.567527265 & 0.4389 \\
\hline 75.25 & 345.354 & 0.9777 & 0.8060 & 54.8333 & 344.843 & 0.828338353 & 0.677 & 25.25 & 344.511 & 0.731265168 & 0.5826 \\
\hline 95.25 & 345.456 & 1.0076 & 0.8306 & 57.8333 & 345.037 & 0.88506184 & 0.726 & 42.75 & 344.943 & 0.857577264 & 0.6934 \\
\hline 122.75 & 345.587 & 1.0459 & 0.8621 & 66.0833 & 345.123 & 0.910207304 & 0.747 & 70 & 345.332 & 0.971316628 & 0.7932 \\
\hline 149.25 & 345.738 & 1.0900 & 0.8985 & 76.8333 & 345.218 & 0.937984269 & 0.771 & 91.75 & 345.552 & 1.035642233 & 0.8497 \\
\hline 166.25 & 345.8 & 1. 1082 & 0.9135 & 91.5833 & 345.417 & 0.996169703 & 0.821 & 119.7 & 345.774 & 1. 100552615 & 0.9066 \\
\hline 192 & 345.87 & 1. 1286 & 0.9303 & 120.333 & 345.698 & 1.078331043 & 0.891 & 143 & 345.921 & 1. 143533815 & 0.9443 \\
\hline 218.25 & 345.923 & 1. 1441 & 0.9431 & 152.083 & 345.921 & 1.143533815 & 0.947 & 162.5 & 346.039 & 1.17803573 & 0.9746 \\
\hline 244.75 & 346.002 & 1.1672 & 0.9622 & 171.083 & 346.021 & 1.172772726 & 0.972 & 197.3 & 346.098 & 1. 195286688 & 0.9897 \\
\hline 271.25 & 346.054 & 1. 1824 & 0.9747 & 198.833 & 346.068 & 1. 186515014 & 0.984 & 219.2 & 346.111 & 1. 199087746 & 0.9931 \\
\hline 291.25 & 346.098 & 1.1953 & 0.9853 & 217.833 & 346.112 & 1. 199380135 & 0.995 & 237.2 & 346.132 & 1.205227917 & 0.9985 \\
\hline 313.5 & 346.112 & 1. 1994 & 0.9887 & 238.833 & 346.121 & 1.202011637 & 0.997 & 264.2 & 346.138 & 1.206982252 & 1 \\
\hline 365 & 346.144 & 1.2087 & 0.9964 & 287.333 & 346.133 & 1.205520306 & 1 & & & & \\
\hline 387 & 346.151 & 1.2108 & 0.9981 & & & & & & & & \\
\hline
\end{tabular}




\begin{tabular}{|c|c|c|c|c|c|c|c|c|c|c|c|}
\hline & & & & sample-2 & & $2 I=0.0588 \mathrm{~cm}$ & & & & & \\
\hline & & Cycle-1 & & & & Cycle-2 & & & & Cycle-3 & \\
\hline Time, $\mathrm{h}$ & Weight, mg & Water Content, wt \% & $M_{t} / M_{\infty}$ & Time, $\mathrm{h}$ & Weight, mg & Water Content, wt $\%$ & $M_{t} / M_{\infty}$ & Time, $\mathrm{h}$ & Weight, mg & Water Content, wt $\%$ & $\mathrm{M}_{\mathrm{t}} / \mathrm{M}_{\infty}$ \\
\hline 0 & 394.85 & 0.0000 & 0.0000 & 0 & 395.154 & 0.076991263 & 0 & 0 & 395.324 & 0.120045587 & 0 \\
\hline 0.5 & 395.17 & 0.0810 & 0.0666 & 0.5 & 395.215 & 0.092440167 & 0.013 & 0.25 & 395.483 & 0.160314043 & 0.0362 \\
\hline 1.5 & 395.789 & 0.2378 & 0.1954 & 1 & 395.279 & 0.108648854 & 0.028 & 0.5 & 395.673 & 0.208433582 & 0.0795 \\
\hline 5.5 & 396.532 & 0.4260 & 0.3500 & 2 & 395.468 & 0.156515132 & 0.069 & 1.5 & 396.112 & 0.319615044 & 0.1795 \\
\hline 7 & 396.723 & 0.4744 & 0.3897 & 2.5 & 395.564 & 0.180828163 & 0.091 & 2 & 396.342 & 0.377865012 & 0.2318 \\
\hline 8 & 396.886 & 0.5156 & 0.4236 & 3 & 395.638 & 0.199569457 & 0.107 & 2.5 & 396.564 & 0.434088895 & 0.2824 \\
\hline 10.75 & 397.15 & 0.5825 & 0.4786 & 4 & 395.802 & 0.241104217 & 0.143 & 3 & 396.687 & 0.465239965 & 0.3104 \\
\hline 11.75 & 397.243 & 0.6061 & 0.4979 & 5 & 395.961 & 0.281372673 & 0.178 & 4.333 & 396.765 & 0.484994302 & 0.3282 \\
\hline 25.75 & 398.126 & 0.8297 & 0.6816 & 7 & 396.131 & 0.324426998 & 0.216 & 5.333 & 396.856 & 0.508041028 & 0.3489 \\
\hline 49.75 & 398.611 & 0.9525 & 0.7826 & 43 & 397.689 & 0.719007218 & 0.56 & 7.5 & 397.033 & 0.552868178 & 0.3892 \\
\hline 75.25 & 398.812 & 1.0034 & 0.8244 & 54.8333 & 397.9 & 0.772445232 & 0.607 & 25.25 & 397.711 & 0.724578954 & 0.5436 \\
\hline 95.25 & 398.967 & 1.0427 & 0.8566 & 57.8333 & 398 & 0.797771306 & 0.629 & 42.75 & 398.209 & 0.850702799 & 0.657 \\
\hline 122.75 & 399.213 & 1.1050 & 0.9078 & 66.0833 & 398.331 & 0.881600608 & 0.702 & 70 & 398.684 & 0.971001646 & 0.7652 \\
\hline 149.25 & 399.268 & 1.1189 & 0.9193 & 76.8333 & 398.615 & 0.953526656 & 0.765 & 91.75 & 398.995 & 1.049765734 & 0.836 \\
\hline 166.25 & 399.301 & 1.1273 & 0.9261 & 91.5833 & 398.829 & 1.007724452 & 0.812 & 119.7 & 399.269 & 1.119159174 & 0.8984 \\
\hline 192 & 399.358 & 1.1417 & 0.9380 & 120.333 & 399.349 & 1. 139420033 & 0.927 & 143 & 399.44 & 1.16246676 & 0.9374 \\
\hline 218.25 & 399.467 & 1.1693 & 0.9607 & 152.083 & 399.499 & 1.177409143 & 0.96 & 162.5 & 399.571 & 1. 195643915 & 0.9672 \\
\hline 244.75 & 399.513 & 1.1810 & 0.9702 & 171.083 & 399.618 & 1.20754717 & 0.986 & 197.3 & 399.679 & 1.222996074 & 0.9918 \\
\hline 271.25 & 399.567 & 1.1946 & 0.9815 & 198.833 & 399.645 & 1.21438521 & 0.992 & 219.2 & 399.687 & 1.22502216 & 0.9936 \\
\hline 291.25 & 399.589 & 1.2002 & 0.9861 & 217.833 & 399.656 & 1.217171078 & 0.994 & 237.2 & 399.699 & 1.228061289 & 0.9964 \\
\hline 365 & 399.634 & 1.2116 & 0.9954 & 287.333 & 399.681 & 1.223502596 & 1 & & & & \\
\hline 387 & 399.639 & 1.2129 & 0.9965 & & & & & & & & \\
\hline 409 & 399.656 & 1.2172 & 1.0000 & & & & & & & & \\
\hline
\end{tabular}




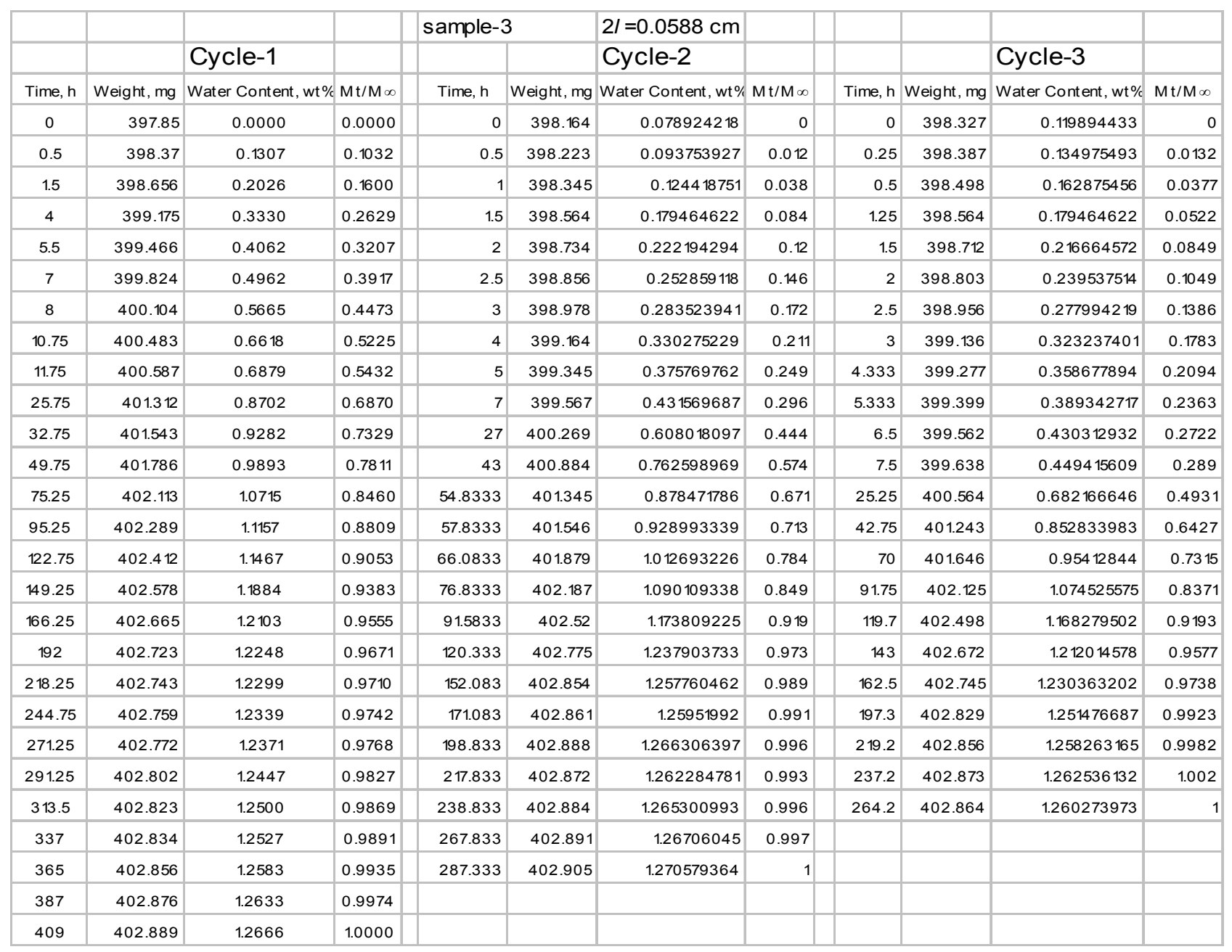


Table 13. Desorption Data of Vinyl ester Samples containing 0 wt\% Cloisite 10A at $2^{\circ} \mathrm{C}$ During Three Cycles of Absorption

\begin{tabular}{|c|c|c|c|c|c|c|c|c|c|c|c|}
\hline & & & & sample- & & $2 I=0.0488 \mathrm{~cm}$ & & & & & \\
\hline & & Cycle-1 & & & & Cycle-2 & & & & Cycle-3 & \\
\hline Time, $\mathrm{h}$ & Weight, mg & Water Content, wt & $\ln (\mathrm{M} t-\mathrm{M} \infty)$ & Time, $\mathrm{h}$ & Weight, mg & Water Content, wt $\%$ & $\ln (M t-M \infty)$ & Time, $\mathrm{h}$ & Weight, mg & Water Content, wt & $n(M t-M \infty)$ \\
\hline 0 & 346.167 & 1.2155 & 1.3928 & 0 & 346.138 & 1.2070 & 1.36046 & 0 & 346.144 & 1.2087 & 1.3271 \\
\hline 1 & 345.989 & 1.1634 & 1.3476 & 0.25 & 345.92 & 1.1432 & 1.30291 & 0.25 & 345.958 & 1.1544 & 1.2765 \\
\hline 1.5 & 345.698 & 1.0783 & 1.2689 & 0.5 & 345.659 & 1.0669 & 1.22935 & 0.75 & 345.653 & 1.0652 & 1. 1875 \\
\hline 2 & 345.356 & 0.9783 & 1.1678 & 1 & 345.264 & 0.9514 & 1.10658 & 1.25 & 345.375 & 0.9839 & 1.0989 \\
\hline 2.5 & 345.054 & 0.8900 & 1.0692 & 1.5 & 344.869 & 0.8359 & 0.9666 & 2 & 345.16 & 0.9210 & 1.0246 \\
\hline 3.5 & 344.8 & 0.8158 & 0.9780 & 2 & 344.536 & 0.7386 & 0.83117 & 2.75 & 344.831 & 0.8248 & 0.8989 \\
\hline 4.5 & 344.587 & 0.7535 & 0.8945 & 3 & 344.212 & 0.6438 & 0.67905 & 4 & 344.626 & 0.7649 & 0.8118 \\
\hline 5.5 & 344.329 & 0.6781 & 0.7830 & 4 & 344.02 & 0.5877 & 0.57661 & 5 & 344.492 & 0.7257 & 0.7505 \\
\hline 6.5 & 344.147 & 0.6248 & 0.6961 & 5 & 343.824 & 0.5304 & 0.45995 & 6.5 & 344.351 & 0.6845 & 0.6816 \\
\hline 8.5 & 343.775 & 0.5161 & 0.4910 & 6 & 343.571 & 0.4564 & 0.28593 & 8 & 344.209 & 0.6430 & 0.607 \\
\hline 11.5 & 343.48 & 0.4298 & 0.2919 & 8.25 & 343.188 & 0.3444 & -0.0534 & 9.5 & 343.905 & 0.5541 & 0.4259 \\
\hline 25.75 & 342.692 & 0.1994 & -0.5960 & 10 & 343.012 & 0.2930 & -0.2588 & 11 & 343.983 & 0.5769 & 0.4756 \\
\hline 50.75 & 342.522 & 0.1497 & -0.9650 & 22 & 342.765 & 0.2208 & -0.6444 & 25 & 343.304 & 0.3784 & -0.0726 \\
\hline 72.75 & 342.309 & 0.0874 & -1.7838 & 28.5 & 342.632 & 0.1819 & -0.9365 & 58 & 342.834 & 0.2409 & -0.7765 \\
\hline 98.083 & 342.223 & 0.0623 & -2.5010 & 46.5 & 342.489 & 0.1401 & -1.3903 & 72.75 & 342.657 & 0.1892 & -1.2623 \\
\hline 125.75 & 342.196 & 0.0544 & -2.9004 & 70.5 & 342.385 & 0.1096 & -1.931 & 100.5 & 342.567 & 0.1629 & -1.6451 \\
\hline 140.08 & 342.178 & 0.0491 & -3.2968 & 94.25 & 342.324 & 0.0918 & -2.4769 & 127.7 & 342.487 & 0.1395 & -2.1804 \\
\hline 144.83 & 342.165 & 0.0453 & -3.7297 & 112 & 342.3 & 0.0848 & -2.8134 & 148.7 & 342.454 & 0.1298 & -2.5257 \\
\hline 169.33 & 342.156 & 0.0427 & -4.1997 & 139.5 & 342.275 & 0.0775 & -3.3524 & 171.8 & 342.421 & 0.1202 & -3.0576 \\
\hline 193.08 & 342.148 & 0.0403 & -4.9618 & 169.75 & 342.265 & 0.0746 & -3.6889 & 194.5 & 342.4 & 0.1140 & -3.6497 \\
\hline \multirow[t]{4}{*}{218.08} & 342.141 & 0.0383 & 0.9768 & 187.25 & 342.258 & 0.0725 & -4.0174 & 224 & 342.387 & 0.1102 & -4.3428 \\
\hline & & & & 210.25 & 342.25 & 0.0702 & -4.6052 & 248 & 342.38 & 0.1082 & -5.116 \\
\hline & & & & 235.5 & 342.248 & 0.0696 & -4.8283 & 272 & 342.377 & 0.1073 & -5.8091 \\
\hline & & & & 254.5 & 342.24 & 0.0672 & & 296 & 342.374 & 0.1064 & \\
\hline
\end{tabular}




\begin{tabular}{|c|c|c|c|c|c|c|c|c|c|c|c|}
\hline & & & & \multicolumn{2}{|c|}{ sample-2 } & \multirow{2}{*}{$\begin{array}{l}2 I=0.0588 \mathrm{~cm} \\
\text { Cycle-2 }\end{array}$} & & & & \multirow[b]{2}{*}{ Cycle-3 } & \multirow[b]{3}{*}{$\ln (\mathrm{Mt}-\mathrm{M} \infty)$} \\
\hline & & Cycle-1 & & \multirow[b]{2}{*}{ Time, $\mathrm{h}$} & \multirow[b]{2}{*}{ Weight, mg } & & & \multirow[b]{2}{*}{ Time, $\mathrm{h}$} & \multirow[b]{2}{*}{ Weight, mg } & & \\
\hline Time, $\mathrm{h}$ & Weight, mg & Water Content, wt \% & $(\mathrm{M} \mathrm{t}-\mathrm{M} \infty)$ & & & Water Content, wt $\%$ ? & $(\mathrm{Mt}-\mathrm{M} \infty)$ & & & Water Content, wt $\%$ & \\
\hline 0 & 399.661 & 1.2184 & 1.5047 & 0 & 399.675 & 1.2220 & 1.469 & 0 & 399.702 & 1.2288 & 1.4495 \\
\hline 1 & 399.402 & 1.1528 & 1.4455 & 0.25 & 399.425 & 1. 1587 & 1.41 & 0.25 & 399.472 & 1.1706 & 1.394 \\
\hline 1.5 & 399.406 & 1. 1539 & 1.4464 & 0.5 & 399.155 & 1.0903 & 1.342 & 0.75 & 399.337 & 1. 1364 & 1.36 \\
\hline 2.5 & 399.018 & 1.0556 & 1.3507 & 1.5 & 398.697 & 0.9743 & 1.215 & 2 & 398.918 & 1.0303 & 1.2462 \\
\hline 3.5 & 398.732 & 0.9832 & 1.2737 & 2 & 398.466 & 0.9158 & 1.144 & 2.75 & 398.776 & 0.9943 & 1.2045 \\
\hline 4.5 & 398.513 & 0.9277 & 1.2105 & 3 & 398.133 & 0.8315 & 1.031 & 4 & 398.552 & 0.9376 & 1.1349 \\
\hline 5.5 & 398.407 & 0.9008 & 1.1783 & 4 & 397.869 & 0.7646 & 0.933 & 5 & 398.407 & 0.9008 & 1.0872 \\
\hline 6.5 & 398.089 & 0.8203 & 1.0753 & 5 & 397.711 & 0.7246 & 0.868 & 6.5 & 398.121 & 0.8284 & 0.9858 \\
\hline 8.5 & 397.716 & 0.7258 & 0.9392 & 6 & 397.397 & 0.6451 & 0.727 & 8 & 397.896 & 0.7714 & 0.8981 \\
\hline 11.5 & 397.297 & 0.6197 & 0.7603 & 8.25 & 397.272 & 0.6134 & 0.665 & 9.5 & 397.511 & 0.6739 & 0.7275 \\
\hline 25.75 & 396.369 & 0.3847 & 0.1914 & 10 & 396.827 & 0.5007 & 0.405 & 11 & 397.123 & 0.5757 & 0.52 \\
\hline 50.75 & 395.445 & 0.1507 & -1.2483 & 22 & 396.131 & 0.3244 & -0.219 & 25 & 396.456 & 0.4067 & 0.0149 \\
\hline 72.75 & 395.311 & 0.1168 & -1.8773 & 28.5 & 395.956 & 0.2801 & -0.465 & 58 & 396.032 & 0.2994 & -0.5259 \\
\hline 98.083 & 395.21 & 0.0912 & -2.9565 & 46.5 & 395.511 & 0.1674 & -1.698 & 72.75 & 395.896 & 0.2649 & -0.7875 \\
\hline 125.75 & 395.192 & 0.0866 & -3.3814 & 70.5 & 395.443 & 0.1502 & -2.163 & 100.5 & 395.668 & 0.2072 & -1.4828 \\
\hline 140.08 & 395.18 & 0.0836 & -3.8167 & 94.25 & 395.412 & 0.1423 & -2.477 & 127.7 & 395.6 & 0.1899 & -1.8389 \\
\hline 144.83 & 395.178 & 0.0831 & -3.9120 & 112 & 395.386 & 0.1357 & -2.847 & 148.7 & 395.556 & 0.1788 & -2.1628 \\
\hline 169.33 & 395.171 & 0.0813 & \#\#\#\# & 139.5 & 395.36 & 0.1292 & -3.442 & 171.8 & 395.511 & 0.1674 & -2.6593 \\
\hline 193.08 & 395.17 & 0.0810 & \#\#\#\# & 169.75 & 395.35 & 0.1266 & -3.817 & 194.5 & 395.489 & 0.1618 & -3.0366 \\
\hline 218.08 & 395.158 & 0.0780 & & 187.25 & 395.342 & 0.1246 & -4.269 & 224 & 395.467 & 0.1563 & -3.6497 \\
\hline & & & & 210.25 & 395.335 & 0.1228 & -4.962 & 248 & 395.456 & 0.1535 & -4.1997 \\
\hline
\end{tabular}




\begin{tabular}{|c|c|c|c|c|c|c|c|c|c|c|c|}
\hline & & & & sample-3 & & $2 I=0.0588 \mathrm{~cm}$ & & & & & \\
\hline & & Cycle-1 & & & & Cycle-2 & & & & Cycle-3 & \\
\hline Time, $\mathrm{h}$ & Weight, mg & Water Content, wt $\%$ & $n(M t-M \infty)$ & Time, $\mathrm{h}$ & Weight, mg & Water Content, wt $\%$ & $\ln (\mathrm{Mt}-\mathrm{M} \infty)$ & Time, $\mathrm{h}$ & Weight, mg & Water Content, wt $\%$ & $\ln (\mathrm{Mt}-\mathrm{M} \infty)$ \\
\hline 0 & 402.902 & 1.2698 & 1.5548 & 0 & 402.865 & 1.2605 & 1.5116 & 0 & 402.882 & 1.2648 & 1.51447 \\
\hline 1 & 402.793 & 1.2424 & 1.5315 & 0.25 & 402.789 & 1.2414 & 1.4947 & 0.25 & 402.691 & 1.2168 & 1.47155 \\
\hline 1.5 & 402.563 & 1. 1846 & 1.4805 & 0.5 & 402.518 & 1.1733 & 1.432 & 0.75 & 402.633 & 1.2022 & 1.45815 \\
\hline 2 & 402.276 & 1.1125 & 1.4129 & 1 & 402.269 & 1.1107 & 1.3707 & 1.25 & 402.408 & 1. 1457 & 1.40438 \\
\hline 2.5 & 402.185 & 1.0896 & 1.3905 & 1.5 & 402.026 & 1.0496 & 1.307 & 2 & 402.245 & 1. 1047 & 1.36354 \\
\hline 3.5 & 402.014 & 1.0466 & 1.3470 & 2 & 401.766 & 0.9843 & 1.234 & 2.75 & 402.073 & 1.0615 & 1.31855 \\
\hline 4.5 & 401.805 & 0.9941 & 1.2912 & 3 & 401.986 & 1.0396 & 1.2961 & 4 & 401.864 & 1.0089 & 1.26101 \\
\hline 5.49999 & 401.625 & 0.9489 & 1.2404 & 4 & 401.21 & 0.8445 & 1.0574 & 5 & 401.699 & 0.9675 & 1.21313 \\
\hline 6.49999 & 401.498 & 0.9169 & 1.2030 & 5 & 401.037 & 0.8011 & 0.9955 & 6.5 & 401.515 & 0.9212 & 1. 15688 \\
\hline 8.49999 & 401.114 & 0.8204 & 1.0804 & 6 & 400.733 & 0.7246 & 0.8763 & 8 & 401.342 & 0.8777 & 1. 10094 \\
\hline 11.5 & 400.611 & 0.6940 & 0.8932 & 8.25 & 400.345 & 0.6271 & 0.7001 & 9.5 & 401.249 & 0.8543 & 1.06953 \\
\hline 25.75 & 399.612 & 0.4429 & 0.3674 & 10 & 400.028 & 0.5474 & 0.5289 & 11 & 401.095 & 0.8156 & 1.01523 \\
\hline 50.75 & 398.878 & 0.2584 & \#\#\#\#\#\# & 22 & 399.287 & 0.3612 & -0.045 & 25 & 400.157 & 0.5799 & 0.59993 \\
\hline 72.75 & 398.617 & 0.1928 & \#\#\#\#\#\# & 28.5 & 399.138 & 0.3237 & -0.214 & 58 & 398.896 & 0.2629 & -0.578 \\
\hline 98.0833 & 398.376 & 0.1322 & -1.5702 & 46.5 & 398.799 & 0.2385 & -0.759 & 72.75 & 398.687 & 0.2104 & -1.0441 \\
\hline 125.75 & 398.211 & 0.0907 & -3.1466 & 70.5 & 398.512 & 0.1664 & -1.709 & 100.5 & 398.523 & 0.1692 & -1.6713 \\
\hline 140.083 & 398.201 & 0.0882 & -3.4112 & 94.25 & 398.451 & 0.1511 & -2.12 & 127.75 & 398.416 & 0.1423 & -2.5133 \\
\hline 144.833 & 398.189 & 0.0852 & \#\#\#\#\#\# & 112 & 398.432 & 0.1463 & -2.293 & 148.75 & 398.38 & 0.1332 & -3.1011 \\
\hline 169.333 & 398.18 & 0.0829 & \#\#\#\#\#\# & 139.5 & 398.4 & 0.1382 & -2.674 & 171.75 & 398.365 & 0.1294 & -3.5066 \\
\hline 193.083 & 398.175 & 0.0817 & -4.9618 & 169.75 & 398.376 & 0.1322 & -3.101 & 194.5 & 398.352 & 0.1262 & -4.0745 \\
\hline \multirow[t]{4}{*}{218.083} & 398.168 & 0.0799 & & 187.25 & 398.359 & 0.1279 & -3.576 & 224 & 398.343 & 0.1239 & -4.8283 \\
\hline & & & & 210.25 & 398.349 & 0.1254 & -4.017 & 248 & 398.339 & 0.1229 & -5.5215 \\
\hline & & & & 235.5 & 398.34 & 0.1232 & -4.711 & 272 & 398.333 & 0.1214 & \\
\hline & & & & 254.5 & 398.331 & 0.1209 & & 296 & 398.335 & 0.1219 & \\
\hline
\end{tabular}


Table 14. Sorption Data of Vinyl ester Samples containing 2 wt\% Cloisite 10A at $25^{\circ} \mathrm{C}$ During Three Cycles of Absorption

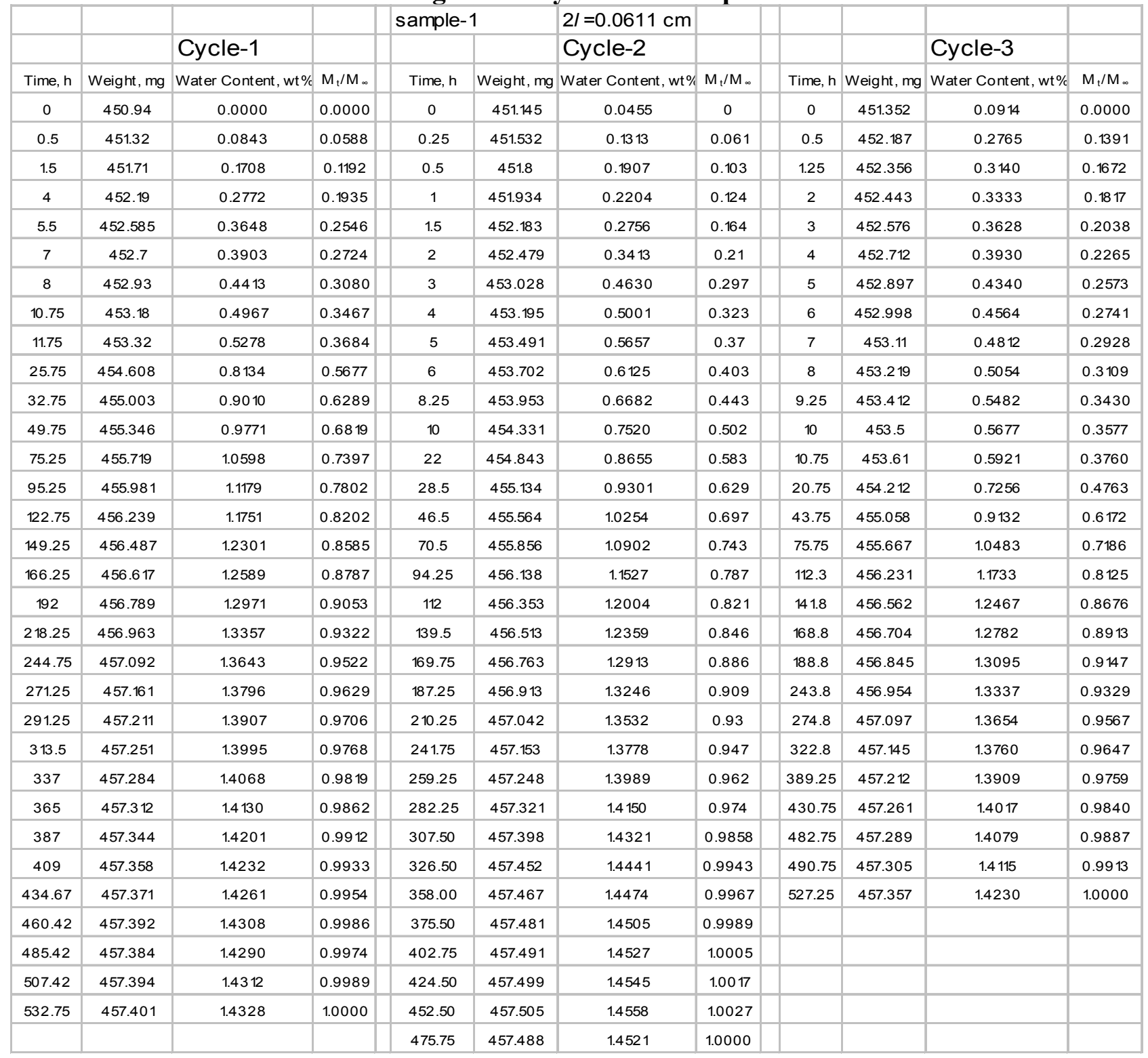




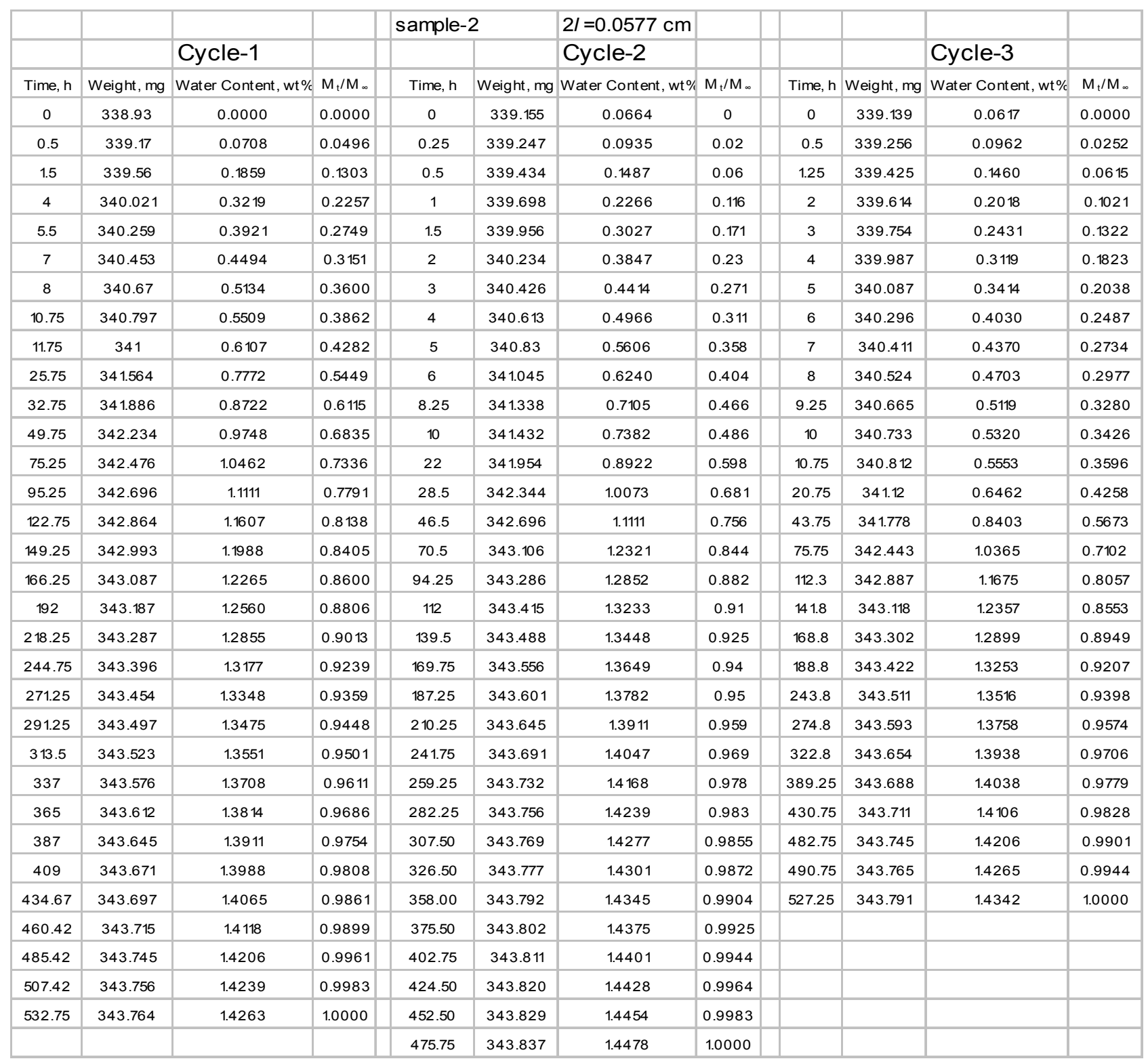




\begin{tabular}{|c|c|c|c|c|c|c|c|c|c|c|c|}
\hline & & & & sample- & & $2 I=0.0833 \mathrm{~cm}$ & & & & & \\
\hline & & Cycle-1 & & & & Cycle-2 & & & & Cycle-3 & \\
\hline Time, $\mathrm{h}$ & Weight, mg & Water Content, wt $\%$ & $\mathrm{M}_{\mathrm{t}} / \mathrm{M}_{\infty}$ & Time, h & Weight, mg & Water Content, wt $\%$ & $\mathrm{M}_{\mathrm{t}} / \mathrm{M}_{\infty}$ & Time, $\mathrm{h}$ & Weight, mg & Water Content, wt $\%$ & $M_{t} / M_{\infty}$ \\
\hline 0 & 550.18 & 0.0000 & 0.0000 & 0 & 550.365 & 0.0336 & 0 & 0 & 550.36 & 0.0327 & 0 \\
\hline 0.5 & 550.312 & 0.0240 & 0.0180 & 0.25 & 550.564 & 0.0698 & 0.027 & 0.5 & 550.546 & 0.0665 & 0.026 \\
\hline 1.5 & 550.566 & 0.0702 & 0.0527 & 0.5 & 550.846 & 0.1211 & 0.065 & 1.25 & 550.785 & 0.1100 & 0.0593 \\
\hline 4 & 551.231 & 0.1910 & 0.1435 & 1 & 551.111 & 0.1692 & 0.101 & 2 & 551.065 & 0.1609 & 0.0984 \\
\hline 5.5 & 551.432 & 0.2276 & 0.1709 & 1.5 & 551.354 & 0.2134 & 0.133 & 3 & 551.231 & 0.1910 & 0.1215 \\
\hline 7 & 551.673 & 0.2714 & 0.2038 & 2 & 551.633 & 0.2641 & 0.171 & 4 & 551.364 & 0.2152 & 0.1401 \\
\hline 8 & 551.872 & 0.3075 & 0.2310 & 3 & 551.812 & 0.2966 & 0.195 & 5 & 551.488 & 0.2377 & 0.1574 \\
\hline 10.75 & 551.999 & 0.3306 & 0.2483 & 4 & 552.187 & 0.3648 & 0.246 & 6 & 551.623 & 0.2623 & 0.1762 \\
\hline 11.75 & 552.345 & 0.3935 & 0.2955 & 5 & 552.387 & 0.4011 & 0.273 & 7 & 551.732 & 0.2821 & 0.1915 \\
\hline 25.75 & 553.373 & 0.5804 & 0.4358 & 6 & 552.485 & 0.4190 & 0.286 & 8 & 551.854 & 0.3043 & 0.2085 \\
\hline 32.75 & 553.756 & 0.6500 & 0.4881 & 8.25 & 552.673 & 0.4531 & 0.311 & 9.25 & 551.933 & 0.3186 & 0.2195 \\
\hline 49.75 & 554.677 & 0.8174 & 0.6138 & 10 & 552.947 & 0.5029 & 0.348 & 10 & 552.098 & 0.3486 & 0.2425 \\
\hline 75.25 & 555.234 & 0.9186 & 0.6899 & 22 & 553.978 & 0.6903 & 0.487 & 10.75 & 552.114 & 0.3515 & 0.2448 \\
\hline 95.25 & 555.568 & 0.9793 & 0.7355 & 28.5 & 554.221 & 0.7345 & 0.52 & 20.75 & 552.967 & 0.5066 & 0.3638 \\
\hline 122.75 & 556.131 & 1.0816 & 0.8123 & 46.5 & 554.877 & 0.8537 & 0.608 & 43.75 & 553.989 & 0.6923 & 0.5064 \\
\hline 149.25 & 556.362 & 1.1236 & 0.8438 & 70.5 & 555.555 & 0.9770 & 0.7 & 75.75 & 555.342 & 0.9382 & 0.6952 \\
\hline 166.25 & 556.587 & 1.1645 & 0.8746 & 94.25 & 555.996 & 1.0571 & 0.759 & 112.3 & 555.788 & 1.0193 & 0.7575 \\
\hline 192 & 556.859 & 1.2140 & 0.9117 & 112 & 556.312 & 1.1145 & 0.802 & 141.8 & 556.321 & 1.1162 & 0.8318 \\
\hline 218.25 & 557.068 & 1.2520 & 0.9402 & 139.5 & 556.656 & 1.1771 & 0.848 & 168.8 & 556.754 & 1.1949 & 0.8923 \\
\hline 244.75 & 557.186 & 1.2734 & 0.9563 & 169.75 & 556.856 & 1.2134 & 0.875 & 188.8 & 556.998 & 1.2392 & 0.9263 \\
\hline 271.25 & 557.248 & 1.2847 & 0.9648 & 187.25 & 557.1 & 1.2578 & 0.908 & 243.8 & 557.212 & 1.2781 & 0.9562 \\
\hline 291.25 & 557.312 & 1.2963 & 0.9735 & 210.25 & 557.3 & 1.2941 & 0.935 & 274.8 & 557.335 & 1.3005 & 0.9733 \\
\hline 313.5 & 557.348 & 1.3028 & 0.9784 & 241.75 & 557.412 & 1.3145 & 0.95 & 322.8 & 557.412 & 1.3145 & 0.9841 \\
\hline 337 & 557.396 & 1.3116 & 0.9850 & 259.25 & 557.5 & 1.3305 & 0.962 & 389.25 & 557.489 & 1.3285 & 0.9948 \\
\hline 365 & 557.421 & 1.3161 & 0.9884 & 282.25 & 557.589 & 1.3467 & 0.974 & 430.75 & 557.500 & 1.3305 & 0.9964 \\
\hline 387 & 557.44 & 1.3196 & 0.9910 & 307.50 & 557.654 & 1.3585 & 0.9826 & 482.75 & 557.512 & 1.3327 & 0.9980 \\
\hline 409 & 557.456 & 1.3225 & 0.9932 & 326.50 & 557.700 & 1.3668 & 0.9888 & 490.75 & 557.521 & 1.3343 & 0.9993 \\
\hline 434.67 & 557.466 & 1.3243 & 0.9945 & 358.00 & 557.723 & 1.3710 & 0.9919 & 527.25 & 557.526 & 1.3352 & 1.0000 \\
\hline 460.42 & 557.472 & 1.3254 & 0.9954 & 375.50 & 557.740 & 1.3741 & 0.9942 & & & & \\
\hline 485.42 & 557.490 & 1.3287 & 0.9978 & 402.75 & 557.760 & 1.3777 & 0.9969 & & & & \\
\hline 507.42 & 557.500 & 1.3305 & 0.9992 & 424.50 & 557.770 & 1.3795 & 0.9982 & & & & \\
\hline \multirow[t]{2}{*}{532.75} & 557.506 & 1.3316 & 1.0000 & 452.50 & 557.778 & 1.3810 & 0.9993 & & & & \\
\hline & & & & 475.75 & 557.783 & 1.3819 & 1.0000 & & & & \\
\hline
\end{tabular}


Table 15. Desorption Data of Vinyl ester Samples containing 2 wt\% Cloisite 10A at $\mathbf{2 5}^{\circ} \mathrm{C}$ During Three Cycles of Absorption

\begin{tabular}{|c|c|c|c|c|c|c|c|c|c|c|c|}
\hline & & & & sample-1 & & $2 I=0.0611 \mathrm{~cm}$ & & & & & \\
\hline & & Cycle-1 & & & & Cycle-2 & & & & Cycle-3 & \\
\hline Time, $\mathrm{h}$ & Weight, mg & Water Content, wt $\%$ & $\ln (M t-M \infty)$ & Time, $\mathrm{h}$ & Weight, mg & Water Content, wt $\%$ & $\ln (\mathrm{Mt}-\mathrm{M} \infty)$ & Time, $\mathrm{h}$ & Weight, mg & Water Content, wt $\%$ & $\ln (\mathrm{Mt}-\mathrm{M} \infty)$ \\
\hline 0.00 & 457.408 & 1.4343 & 1.8339 & 0.00 & 457.501 & 1.4550 & 1.8166 & 0 & 457.362 & 1.4241 & 1.7954 \\
\hline 0.33 & 457.129 & 1.3725 & 1.7883 & 0.25 & 457.421 & 1.4372 & 1.8035 & 0.5 & 457.117 & 1.3698 & 1.7539 \\
\hline 0.83 & 456.889 & 1.3192 & 1.7473 & 0.75 & 457.354 & 1.4224 & 1.7924 & 1 & 456.918 & 1.3257 & 1.7188 \\
\hline 1.33 & 456.396 & 1.2099 & 1.6575 & 1.00 & 457.223 & 1.3933 & 1.7704 & 2 & 456.676 & 1.2720 & 1.6745 \\
\hline 1.83 & 456.209 & 1.1684 & 1.6212 & 1.25 & 457.132 & 1.3731 & 1.7547 & 3.5 & 456.545 & 1.2430 & 1.6496 \\
\hline 2.83 & 455.936 & 1.1079 & 1.5657 & 1.50 & 457.023 & 1.3490 & 1.7357 & 5 & 456.275 & 1. 1831 & 1.5964 \\
\hline 3.83 & 455.716 & 1.0591 & 1.5186 & 2.00 & 457.011 & 1.3463 & 1.7336 & 7 & 456.011 & 1.1245 & 1.5414 \\
\hline 4.83 & 455.645 & 1.0434 & 1.5030 & 2.50 & 456.912 & 1.3243 & 1.7160 & 9 & 455.735 & 1.0633 & 1.4805 \\
\hline 5.83 & 455.523 & 1.0163 & 1.4754 & 3.00 & 456.832 & 1.3066 & 1.7015 & 11 & 455.711 & 1.0580 & 1.4750 \\
\hline 6.83 & 455.389 & 0.9866 & 1.4443 & 3.50 & 456.682 & 1.2733 & 1.6737 & 21.75 & 454.836 & 0.8640 & 1.2516 \\
\hline 7.83 & 455.296 & 0.9660 & 1.4221 & 4.83 & 456.557 & 1.2456 & 1.6500 & 28.75 & 454.379 & 0.7626 & 1.1115 \\
\hline 8.83 & 454.879 & 0.8735 & 1.3161 & 5.83 & 456.427 & 1.2168 & 1.6247 & 50.75 & 453.473 & 0.5617 & 0.7575 \\
\hline 9.83 & 454.416 & 0.7708 & 1.1836 & 7.00 & 456.3 & 1.1886 & 1.5994 & 80.75 & 452.389 & 0.3213 & 0.0478 \\
\hline 11.83 & 454.284 & 0.7416 & 1.1423 & 8.00 & 455.987 & 1.1192 & 1.5341 & 94.75 & 451.9 & 0.2129 & -0.5798 \\
\hline 14.33 & 454.183 & 0.7192 & 1.1096 & 21.75 & 455.676 & 1.0503 & 1.4646 & 122.25 & 451.677 & 0.1634 & -1.0877 \\
\hline 19.08 & 453.821 & 0.6389 & 0.9825 & 32.75 & 455.123 & 0.9276 & 1.3279 & 148.75 & 451.523 & 0.1293 & -1.6983 \\
\hline 43.58 & 452.82 & 0.4169 & 0.5128 & 45.75 & 454.666 & 0.8263 & 1. 1988 & 171.25 & 451.449 & 0.1129 & -2.2164 \\
\hline 67.33 & 452.37 & 0.3171 & 0.1989 & 57.00 & 454.06 & 0.6919 & 0.9969 & 190.75 & 451.398 & 0.1016 & -2.8473 \\
\hline 94.33 & 452.121 & 0.2619 & -0.0294 & 80.25 & 453.533 & 0.5750 & 0.7807 & 216.75 & 451.367 & 0.0947 & -3.6119 \\
\hline 122.33 & 451.881 & 0.2087 & -0.3133 & 117.25 & 453.132 & 0.4861 & 0.5777 & 245.25 & 451.352 & 0.0914 & -4.4228 \\
\hline 141.33 & 451.674 & 0.1628 & -0.6463 & 140.25 & 452.612 & 0.3708 & 0.2327 & 269.25 & 451.347 & 0.0903 & -4.9618 \\
\hline 171.33 & 451.562 & 0.1379 & -0.8867 & 171.25 & 452.134 & 0.2648 & -0.2433 & 293.25 & 451.34 & 0.0887 & \#NUM! \\
\hline 190.33 & 451.443 & 0.1115 & -1.2276 & 191.00 & 451.92 & 0.2173 & -0.5621 & & & & \\
\hline 206.58 & 451.343 & 0.0894 & -1.6451 & 215.75 & 451.779 & 0.1861 & -0.8463 & & & & \\
\hline 235.33 & 451.277 & 0.0747 & -2.0636 & 239.75 & 451.679 & 0.1639 & -1.1117 & & & & \\
\hline 267.08 & 451.231 & 0.0645 & -2.5133 & 263.75 & 451.598 & 0.1459 & -1.3943 & & & & \\
\hline 286.08 & 451.2 & 0.0577 & -2.9957 & 285.25 & 451.532 & 0.1313 & -1.7037 & & & & \\
\hline 313.83 & 451.176 & 0.0523 & -3.6497 & 309.25 & 451.476 & 0.1189 & -2.0715 & & & & \\
\hline 328.83 & 451.166 & 0.0501 & -4.1352 & 336.75 & 451.443 & 0.1115 & -2.3752 & & & & \\
\hline 355.83 & 451.157 & 0.0481 & -4.9618 & 363.25 & 451.412 & 0.1047 & -2.7806 & & & & \\
\hline \multirow[t]{7}{*}{382.83} & 451. 15 & 0.0466 & \#NUM! & 388.00 & 451.39 & 0.0998 & -3.2189 & & & & \\
\hline & & & & 409.00 & 451.38 & 0.0976 & -3.5066 & & & & \\
\hline & & & & 432.00 & 451.371 & 0.0956 & -3.8632 & & & & \\
\hline & & & & 454.75 & 451.367 & 0.0947 & -4.0745 & & & & \\
\hline & & & & 478.75 & 451.36 & 0.0931 & -4.6052 & & & & \\
\hline & & & & 502.75 & 451.355 & 0.0920 & -5.2983 & & & & \\
\hline & & & & 525.5 & 451.35 & 0.0909 & \#NUM! & & & & \\
\hline
\end{tabular}




\begin{tabular}{|c|c|c|c|c|c|c|c|c|c|c|c|}
\hline & & & & sample-2 & & $2 I=0.0577 \mathrm{~cm}$ & & & & & \\
\hline & & Cycle-1 & & & & Cycle-2 & & & & Cycle-3 & \\
\hline Time, $\mathrm{h}$ & Weight, mg & Water Content, wt $\%$ & $\ln (\mathrm{Mt}-\mathrm{M} \infty)$ & Time, $\mathrm{h}$ & Weight, mg & Water Content, wt $\%$ & $\ln (\mathrm{Mt}-\mathrm{M} \infty)$ & Time, $\mathrm{h}$ & Weight, mg & Water Content, wt $\%$ & $\ln (\mathrm{Mt}-\mathrm{M} \infty)$ \\
\hline 0.00 & 343.771 & 1.4283 & 1.5297 & 0.00 & 343.827 & 1.4448 & 1.5442 & 0 & 343.784 & 1.4322 & 1.5399 \\
\hline 0.33 & 343.386 & 1.3147 & 1.4427 & 0.25 & 343.711 & 1.4106 & 1.5191 & 0.5 & 343.47 & 1.3395 & 1.4702 \\
\hline 0.83 & 343.056 & 1.2174 & 1.3615 & 0.75 & 343.516 & 1.3531 & 1.4754 & 1 & 343.312 & 1.2929 & 1.4332 \\
\hline 1.33 & 342.905 & 1.1728 & 1.3220 & 1.00 & 343.427 & 1.3268 & 1.4549 & 2 & 343.084 & 1.2256 & 1.3773 \\
\hline 1.83 & 342.665 & 1.1020 & 1.2559 & 1.25 & 343.128 & 1.2386 & 1.3825 & 3.5 & 342.81 & 1.1448 & 1.3056 \\
\hline 2.83 & 342.37 & 1.0150 & 1.1681 & 1.50 & 343.021 & 1.2070 & 1.3553 & 5 & 342.633 & 1.0926 & 1.2565 \\
\hline 3.83 & 342.148 & 0.9495 & 1.0966 & 2.00 & 342.849 & 1.1563 & 1.3100 & 7 & 342.406 & 1.0256 & 1. 1897 \\
\hline 4.83 & 342.008 & 0.9082 & 1.0487 & 2.50 & 342.651 & 1.0979 & 1.2550 & 9 & 342.182 & 0.9595 & 1.1191 \\
\hline 5.83 & 341.717 & 0.8223 & 0.9412 & 3.00 & 342.412 & 1.0274 & 1. 1845 & 11 & 341.967 & 0.8961 & 1.0463 \\
\hline 6.83 & 341.623 & 0.7946 & 0.9038 & 3.50 & 342.298 & 0.9937 & 1.1490 & 21.75 & 341.311 & 0.7025 & 0.7844 \\
\hline 7.83 & 341.521 & 0.7645 & 0.8616 & 4.83 & 342.056 & 0.9223 & 1.0692 & 28.75 & 341.15 & 0.6550 & 0.7080 \\
\hline 8.83 & 341.402 & 0.7294 & 0.8100 & 5.83 & 341.986 & 0.9017 & 1.0449 & 50.75 & 340.586 & 0.4886 & 0.3825 \\
\hline 9.83 & 341.326 & 0.7069 & 0.7756 & 7.00 & 341.712 & 0.8208 & 0.9435 & 80.75 & 340.012 & 0.3192 & -0.1143 \\
\hline 11.83 & 340.911 & 0.5845 & 0.5636 & 8.00 & 341.553 & 0.7739 & 0.8796 & 94.75 & 339.786 & 0.2526 & -0.4065 \\
\hline 14.33 & 340.784 & 0.5470 & 0.4886 & 21.75 & 341.318 & 0.7046 & 0.7770 & 122.25 & 339.414 & 0.1428 & -1.2242 \\
\hline 19.08 & 340.478 & 0.4567 & 0.2807 & 32.75 & 341.036 & 0.6214 & 0.6382 & 148.75 & 339.204 & 0.0808 & -2.4769 \\
\hline 43.58 & 339.98 & 0.3098 & -0.1912 & 45.75 & 340.889 & 0.5780 & 0.5573 & 171.25 & 339.178 & 0.0732 & -2.8473 \\
\hline 67.33 & 339.778 & 0.2502 & -0.4716 & 57.00 & 340.762 & 0.5405 & 0.4818 & 190.75 & 339.156 & 0.0667 & -3.3242 \\
\hline 94.33 & 339.632 & 0.2071 & -0.7381 & 80.25 & 340.563 & 0.4818 & 0.3507 & 216.75 & 339.143 & 0.0628 & -3.7723 \\
\hline 122.33 & 339.487 & 0.1643 & -1.0996 & 117.25 & 340.267 & 0.3945 & 0.1169 & 245.25 & 339.133 & 0.0599 & -4.3428 \\
\hline 141.33 & 339.399 & 0.1384 & -1.4065 & 140.25 & 339.989 & 0.3125 & -0.1672 & 269.25 & 339.126 & 0.0578 & -5.1160 \\
\hline 171.33 & 339.321 & 0.1154 & -1.7898 & 171.25 & 339.842 & 0.2691 & -0.3581 & 293.25 & 339.12 & 0.0561 & \#NUM! \\
\hline 190.33 & 339.27 & 0.1003 & -2.1542 & 191.00 & 339.708 & 0.2295 & -0.5709 & & & & \\
\hline 206.58 & 339.24 & 0.0915 & -2.4534 & 215.75 & 339.576 & 0.1906 & -0.8370 & & & & \\
\hline 235.33 & 339.2 & 0.0797 & -3.0791 & 239.75 & 339.439 & 0.1502 & -1.2174 & & & & \\
\hline 267.08 & 339.19 & 0.0767 & -3.3242 & 263.75 & 339.325 & 0.1165 & -1.7037 & & & & \\
\hline 286.08 & 339.181 & 0.0741 & -3.6119 & 285.25 & 339.286 & 0.1050 & -1.9449 & & & & \\
\hline 313.83 & 339.173 & 0.0717 & -3.9633 & 309.25 & 339.256 & 0.0962 & -2.1804 & & & & \\
\hline 328.83 & 339.168 & 0.0702 & -4.2687 & 336.75 & 339.235 & 0.0900 & -2.3860 & & & & \\
\hline 355.83 & 339.16 & 0.0679 & -5.1160 & 363.25 & 339.212 & 0.0832 & -2.6736 & & & & \\
\hline \multirow[t]{7}{*}{382.83} & 339.154 & 0.0661 & \#NUM! & 388.00 & 339.189 & 0.0764 & -3.0791 & & & & \\
\hline & & & & 409.00 & 339.175 & 0.0723 & -3.4420 & & & & \\
\hline & & & & 432.00 & 339.165 & 0.0693 & -3.8167 & & & & \\
\hline & & & & 454.75 & 339.157 & 0.0670 & -4.2687 & & & & \\
\hline & & & & 478.75 & 339.15 & 0.0649 & -4.9618 & & & & \\
\hline & & & & 502.75 & 339.147 & 0.0640 & -5.5215 & & & & \\
\hline & & & & 525.5 & 339.143 & 0.0628 & \#NUM! & & & & \\
\hline
\end{tabular}




\begin{tabular}{|c|c|c|c|c|c|c|c|c|c|c|c|}
\hline & & & & sample-3 & & $2 I=0.0833 \mathrm{~cm}$ & & & & & \\
\hline & & Cycle-1 & & & & Cycle-2 & & & & Cycle-3 & \\
\hline Time, $\mathrm{h}$ & Weight, mg & Water Content, wt $\%$ & $\ln (\mathrm{Mt}-\mathrm{M} \infty)$ & Time, $\mathrm{h}$ & Weight, mg & Water Content, wt $\%$ & $\ln (\mathrm{Mt}-\mathrm{M} \infty)$ & Time, $\mathrm{h}$ & Weight, mg & Water Content, wt $\%$ & $\ln (\mathrm{Mt}-\mathrm{M} \infty)$ \\
\hline 0.00 & 557.509 & 1.3321 & 1.9654 & 0.00 & 557.786 & 1.3825 & 2.0042 & 0 & 557.53 & 1.3359 & 1.9455 \\
\hline 0.33 & 557.308 & 1.2956 & 1.9369 & 0.25 & 557.299 & 1.2939 & 1.9363 & 0.5 & 556.95 & 1.2305 & 1.8590 \\
\hline 0.83 & 556.944 & 1.2294 & 1.8830 & 0.75 & 557.012 & 1.2418 & 1.8940 & 1 & 556.411 & 1.1325 & 1.7712 \\
\hline 1.33 & 556.755 & 1. 1951 & 1.8538 & 1.00 & 556.785 & 1.2005 & 1.8593 & 2 & 556.56 & 1. 1596 & 1.7962 \\
\hline 1.83 & 556.641 & 1.1743 & 1.8358 & 1.25 & 556.499 & 1.1485 & 1.8137 & 3.5 & 556.154 & 1.0858 & 1.7265 \\
\hline 2.83 & 556.271 & 1. 1071 & 1.7750 & 1.50 & 556.347 & 1. 1209 & 1.7886 & 5 & 555.869 & 1.0340 & 1.6745 \\
\hline 3.83 & 556.017 & 1.0609 & 1.7309 & 2.00 & 556.084 & 1.0731 & 1.7436 & 7 & 555.411 & 0.9508 & 1.5847 \\
\hline 4.83 & 555.81 & 1.0233 & 1.6936 & 2.50 & 554.947 & 0.8664 & 1.5219 & 9 & 554.803 & 0.8403 & 1.4516 \\
\hline 5.83 & 555.583 & 0.9820 & 1.6510 & 3.00 & 554.123 & 0.7167 & 1.3236 & 11 & 554.556 & 0.7954 & 1.3920 \\
\hline 6.83 & 555.422 & 0.9528 & 1.6196 & 3.50 & 553.864 & 0.6696 & 1.2522 & 21.75 & 553.769 & 0.6523 & 1.1743 \\
\hline 7.83 & 555.376 & 0.9444 & 1.6104 & 4.83 & 553.555 & 0.6134 & 1. 1597 & 28.75 & 553.264 & 0.5605 & 1.0047 \\
\hline 8.83 & 555.214 & 0.9150 & 1.5775 & 5.83 & 553.213 & 0.5513 & 1.0463 & 50.75 & 552.043 & 0.3386 & 0.4121 \\
\hline 9.83 & 555.123 & 0.8984 & 1.5586 & 7.00 & 553.089 & 0.5287 & 1.0017 & 80.75 & 551.045 & 0.1572 & -0.6694 \\
\hline 11.83 & 554.789 & 0.8377 & 1.4857 & 8.00 & 552.989 & 0.5106 & 0.9643 & 94.75 & 550.873 & 0.1260 & -1.0788 \\
\hline 14.33 & 554.354 & 0.7587 & 1.3820 & 21.75 & 552.687 & 0.4557 & 0.8420 & 122.25 & 550.77 & 0.1072 & -1.4397 \\
\hline 19.08 & 553.987 & 0.6920 & 1.2854 & 32.75 & 552.333 & 0.3913 & 0.6765 & 148.75 & 550.7 & 0.0945 & -1.7898 \\
\hline 43.58 & 552.598 & 0.4395 & 0.8007 & 45.75 & 552.012 & 0.3330 & 0.4983 & 171.25 & 550.612 & 0.0785 & -2.5383 \\
\hline 67.33 & 551.786 & 0.2919 & 0.3471 & 57.00 & 551.664 & 0.2697 & 0.2608 & 190.75 & 550.587 & 0.0740 & -2.9188 \\
\hline 94.33 & 551.387 & 0.2194 & 0.0159 & 80.25 & 551.423 & 0.2259 & 0.0554 & 216.75 & 550.564 & 0.0698 & -3.4738 \\
\hline 122.33 & 551.111 & 0.1692 & -0.3011 & 117.25 & 551.265 & 0.1972 & -0.1065 & 245.25 & 550.55 & 0.0673 & -4.0745 \\
\hline 141.33 & 550.887 & 0.1285 & -0.6616 & 140.25 & 551.032 & 0.1549 & -0.4065 & 269.25 & 550.54 & 0.0654 & -4.9618 \\
\hline 171.33 & 550.711 & 0.0965 & -1.0788 & 171.25 & 550.888 & 0.1287 & -0.6501 & 293.25 & 550.533 & 0.0642 & \#NUM! \\
\hline 190.33 & 550.612 & 0.0785 & -1.4230 & 191.00 & 550.788 & 0.1105 & -0.8627 & & & & \\
\hline 206.58 & 550.523 & 0.0623 & -1.8839 & 215.75 & 550.721 & 0.0983 & -1.0356 & & & & \\
\hline 235.33 & 550.476 & 0.0538 & -2.2538 & 239.75 & 550.643 & 0.0842 & -1.2837 & & & & \\
\hline 267.08 & 550.443 & 0.0478 & -2.6311 & 263.75 & 550.589 & 0.0743 & -1.5006 & & & & \\
\hline 286.08 & 550.421 & 0.0438 & -2.9957 & 285.25 & 550.543 & 0.0660 & -1.7316 & & & & \\
\hline 313.83 & 550.4 & 0.0400 & -3.5405 & 309.25 & 550.5 & 0.0582 & -2.0099 & & & & \\
\hline 328.83 & 550.389 & 0.0380 & -4.0174 & 336.75 & 550.47 & 0.0527 & -2.2634 & & & & \\
\hline 355.83 & 550.38 & 0.0364 & -4.7105 & 363.25 & 550.443 & 0.0478 & -2.5639 & & & & \\
\hline \multirow[t]{7}{*}{382.83} & 550.371 & 0.0347 & \#NUM! & 388.00 & 550.421 & 0.0438 & -2.9004 & & & & \\
\hline & & & & 409.00 & 550.41 & 0.0418 & -3.1236 & & & & \\
\hline & & & & 432.00 & 550.398 & 0.0396 & -3.4420 & & & & \\
\hline & & & & 454.75 & 550.388 & 0.0378 & -3.8167 & & & & \\
\hline & & & & 478.75 & 550.38 & 0.0364 & -4.2687 & & & & \\
\hline & & & & 502.75 & 550.372 & 0.0349 & -5.1160 & & & & \\
\hline & & & & 525.5 & 550.366 & 0.0338 & \#NUM! & & & & \\
\hline
\end{tabular}


Table 16. Sorption Data of Vinyl ester Samples containing 5 wt\% Cloisite 10A at $25^{\circ} \mathrm{C}$ During Three Cycles of Absorption

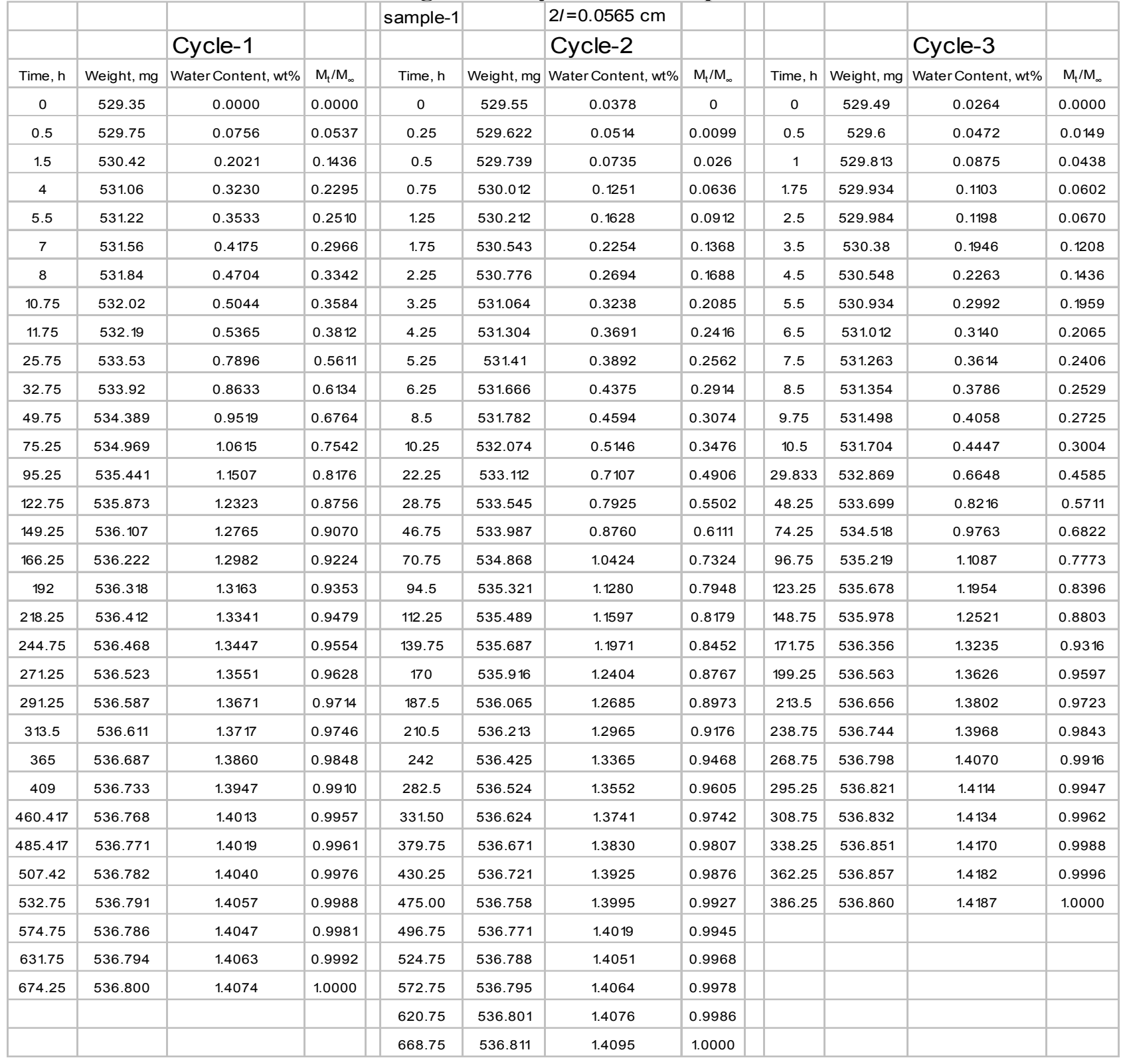




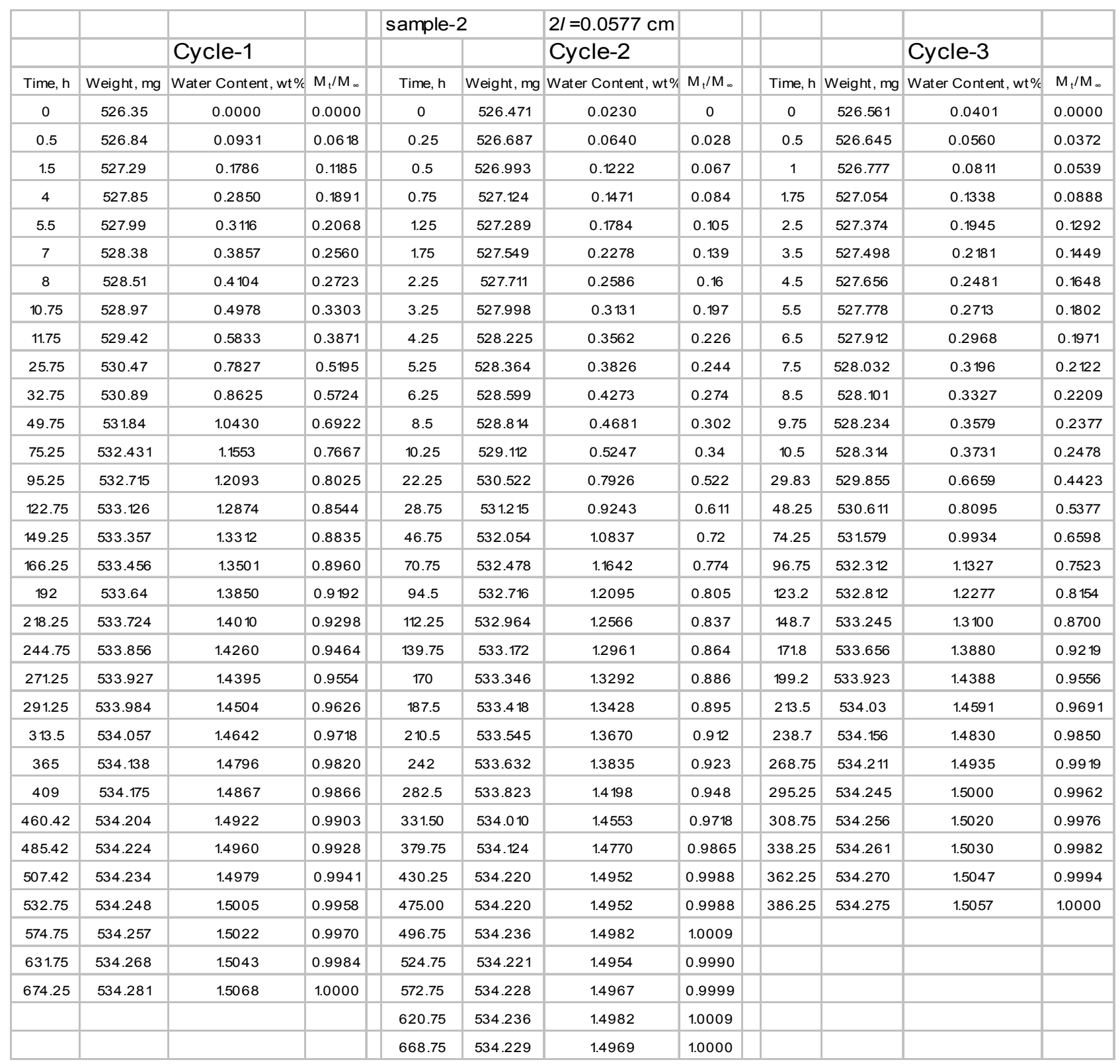




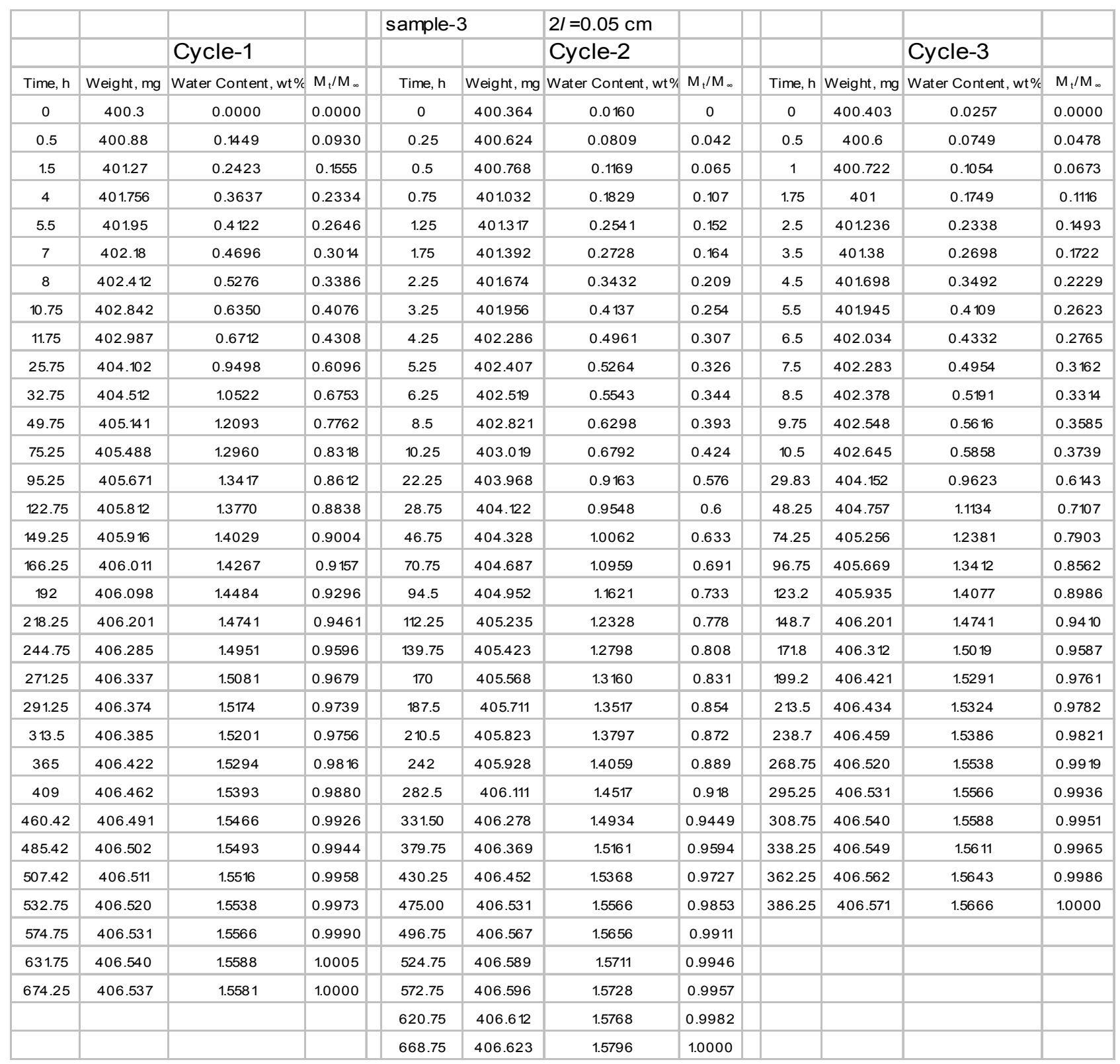


Table 17. Desorption Data of Vinyl ester Samples containing 5 wt\% Cloisite 10A at $2^{\circ} \mathrm{C}$ During Three Cycles of Absorption

\begin{tabular}{|c|c|c|c|c|c|c|c|c|c|c|c|}
\hline & & & & sample-1 & & $2 I=0.0565 \mathrm{~cm}$ & & & & & \\
\hline & & Cycle-1 & & & & Cycle-2 & & & & Cycle-3 & \\
\hline Time, $\mathrm{h}$ & Weight, mg & Water Content, wt $\%$ & $\ln (M t-M \infty)$ & Time, $\mathrm{h}$ & Weight, mg & Water Content, wt\% & $\ln (\mathrm{Mt}-\mathrm{M} \infty)$ & Time, $\mathrm{h}$ & Weight, mg & Water Content, wt $\%$ & $\ln (\mathrm{Mt}-\mathrm{M} \infty)$ \\
\hline 0.00 & 536.802 & 1.4078 & 1.9820 & 0.00 & 536.798 & 1.4070 & 1.9881 & 0 & 536.411 & 1.3339 & 1.9273 \\
\hline 0.33 & 536.671 & 1.3830 & 1.9638 & 0.50 & 536.645 & 1.3781 & 1.9670 & 0.25 & 536.077 & 1.2708 & 1.8775 \\
\hline 0.83 & 536.45 & 1.3413 & 1.9322 & 0.75 & 536.421 & 1.3358 & 1.9351 & 0.75 & 535.93 & 1.2430 & 1.8547 \\
\hline 1.33 & 536.23 & 1.2997 & 1.8999 & 1.25 & 536.243 & 1.3022 & 1.9091 & 1.25 & 535.598 & 1.1803 & 1.8014 \\
\hline 1.83 & 536.073 & 1.2700 & 1.8761 & 1.50 & 536.011 & 1.2583 & 1.8741 & 2.25 & 535.388 & 1.1406 & 1.7661 \\
\hline 2.83 & 535.786 & 1.2158 & 1.8311 & 1.75 & 535.874 & 1.2325 & 1.8529 & 3.75 & 535.199 & 1.1049 & 1.7332 \\
\hline 3.83 & 535.562 & 1.1735 & 1.7946 & 2.00 & 535.661 & 1. 1922 & 1.8189 & 5.25 & 534.945 & 1.0570 & 1.6873 \\
\hline 4.83 & 535.29 & 1. 1221 & 1.7483 & 2.50 & 535.421 & 1.1469 & 1.7792 & 7.25 & 534.685 & 1.0078 & 1.6380 \\
\hline 5.83 & 535.036 & 1.0741 & 1.7031 & 3.00 & 535.284 & 1.1210 & 1.7558 & 9.25 & 534.416 & 0.9570 & 1.5843 \\
\hline 6.83 & 534.935 & 1.0551 & 1.6845 & 3.50 & 535.084 & 1.0832 & 1.7206 & 11.25 & 533.863 & 0.8526 & 1.4639 \\
\hline 7.83 & 534.853 & 1.0396 & 1.6692 & 4.00 & 534.911 & 1.0505 & 1.6892 & 22 & 533.165 & 0.7207 & 1.2879 \\
\hline 8.83 & 534.765 & 1.0230 & 1.6525 & 5.33 & 534.672 & 1.0054 & 1.6440 & 29 & 532.443 & 0.5843 & 1.0657 \\
\hline 9.83 & 534.631 & 0.9976 & 1.6265 & 6.33 & 534.546 & 0.9816 & 1.6194 & 52.5 & 531.61 & 0.4269 & 0.7275 \\
\hline 11.83 & 534.311 & 0.9372 & 1.5615 & 7.50 & 534.212 & 0.9185 & 1.5510 & 143.75 & 530.123 & 0.1460 & -0.5396 \\
\hline 14.33 & 534.058 & 0.8894 & 1.5070 & 8.50 & 533.644 & 0.8112 & 1.4226 & 168.75 & 529.898 & 0.1035 & -1.0272 \\
\hline 19.08 & 533.408 & 0.7666 & 1.3514 & 22.25 & 533.164 & 0.7205 & 1.2996 & 219 & 529.674 & 0.0612 & -2.0099 \\
\hline 43.58 & 532.054 & 0.5108 & 0.9199 & 33.25 & 532.655 & 0.6244 & 1. 1503 & 263.5 & 529.632 & 0.0533 & -2.3860 \\
\hline 67.33 & 531.234 & 0.3559 & 0.5241 & 70.25 & 531.833 & 0.4691 & 0.8489 & 313.75 & 529.61 & 0.0491 & -2.6593 \\
\hline 94.33 & 530.819 & 0.2775 & 0.2422 & 81.50 & 531.474 & 0.4012 & 0.6821 & 358.75 & 529.593 & 0.0459 & -2.9375 \\
\hline 122.33 & 530.387 & 0.1959 & -0.1720 & 104.75 & 531.245 & 0.3580 & 0.5590 & 410.5 & 529.57 & 0.0416 & -3.5066 \\
\hline 141.33 & 530.158 & 0.1526 & -0.4894 & 141.75 & 531.002 & 0.3121 & 0.4095 & 457 & 529.56 & 0.0397 & -3.9120 \\
\hline 171.33 & 529.998 & 0.1224 & -0.7919 & 164.75 & 530.642 & 0.2441 & 0.1363 & 503.5 & 529.552 & 0.0382 & -4.4228 \\
\hline 190.33 & 529.9 & 0.1039 & -1.0356 & 195.75 & 530.435 & 0.2050 & -0.0629 & 550 & 529.546 & 0.0370 & -5.1160 \\
\hline 206.58 & 529.812 & 0.0873 & -1.3205 & 215.50 & 530.246 & 0.1693 & -0.2877 & 596.5 & 529.54 & 0.0359 & \\
\hline 235.33 & 529.756 & 0.0767 & -1.5559 & 240.25 & 530.042 & 0.1307 & -0.6051 & & & & \\
\hline 267.08 & 529.7 & 0.0661 & -1.8643 & 264.25 & 529.894 & 0.1028 & -0.9213 & & & & \\
\hline 286.08 & 529.666 & 0.0597 & -2.1120 & 288.25 & 529.786 & 0.0824 & -1.2379 & & & & \\
\hline 328.83 & 529.63 & 0.0529 & -2.4651 & 309.75 & 529.7 & 0.0661 & -1.5896 & & & & \\
\hline 382.83 & 529.6 & 0.0472 & -2.9004 & 337.25 & 529.656 & 0.0578 & -1.8326 & & & & \\
\hline 412.33 & 529.589 & 0.0451 & -3.1236 & 363.75 & 529.612 & 0.0495 & -2.1542 & & & & \\
\hline 435.83 & 529.579 & 0.0433 & -3.3814 & 388.50 & 529.578 & 0.0431 & -2.5010 & & & & \\
\hline 459.83 & 529.570 & 0.0416 & -3.6889 & 409.50 & 529.554 & 0.0385 & -2.8473 & & & & \\
\hline 483.83 & 529.561 & 0.0399 & -4.1352 & 455.25 & 529.532 & 0.0344 & -3.3242 & & & & \\
\hline 531.83 & 529.556 & 0.0389 & -4.5099 & 503.25 & 529.52 & 0.0321 & -3.7297 & & & & \\
\hline 555.83 & 529.550 & 0.0378 & -5.2983 & 552.75 & 529.512 & 0.0306 & -4.1352 & & & & \\
\hline \multirow[t]{2}{*}{579.83} & 529.545 & 0.0368 & \#NUM! & 580.25 & 529.5 & 0.0283 & -5.5215 & & & & \\
\hline & & & & 595 & 529.496 & 0.0276 & \#NUM! & & & & \\
\hline & & & & & & & & & & & \\
\hline
\end{tabular}




\begin{tabular}{|c|c|c|c|c|c|c|c|c|c|c|c|}
\hline & & & & sample-2 & & $2 I=0.0577 \mathrm{~cm}$ & & & & & \\
\hline & & Cycle-1 & & & & Cycle-2 & & & & Cycle-3 & \\
\hline Time, $\mathrm{h}$ & Weight, mg & Water Content, wt $\%$ & $\ln (M t-M \infty)$ & Time, $\mathrm{h}$ & Weight, mg & Water Content, wt\% & $\ln (M t-M \infty)$ & Time, $\mathrm{h}$ & Weight, mg & Water Content, wt $\%$ & $\ln (\mathrm{Mt}-\mathrm{M} \infty)$ \\
\hline 0.00 & 534.292 & 1.5089 & 2.0567 & 0.00 & 534.241 & 1.4992 & 2.0374 & 0 & 534.014 & 1.4561 & 2.0136 \\
\hline 0.33 & 533.796 & 1.4146 & 1.9912 & 0.50 & 534.138 & 1.4796 & 2.0239 & 0.25 & 533.893 & 1.4331 & 1.9973 \\
\hline 0.83 & 533.523 & 1.3628 & 1.9532 & 0.75 & 534.011 & 1.4555 & 2.0070 & 0.75 & 533.596 & 1.3767 & 1.9561 \\
\hline 1.33 & 533.297 & 1.3198 & 1.9206 & 1.25 & 533.986 & 1.4507 & 2.0036 & 1.25 & 533.415 & 1.3423 & 1.9302 \\
\hline 1.83 & 533.093 & 1.2811 & 1.8902 & 1.50 & 533.999 & 1.4532 & 2.0054 & 2.25 & 533.2 & 1.3014 & 1.8985 \\
\hline 2.83 & 532.875 & 1.2397 & 1.8568 & 1.75 & 533.865 & 1.4278 & 1.9872 & 3.75 & 532.715 & 1.2093 & 1.8231 \\
\hline 3.83 & 532.733 & 1.2127 & 1.8343 & 2.00 & 533.725 & 1.4012 & 1.9678 & 5.25 & 532.312 & 1.1327 & 1.7558 \\
\hline 4.83 & 532.338 & 1.1376 & 1.7692 & 2.50 & 533.564 & 1.3706 & 1.9451 & 7.25 & 532.003 & 1.0740 & 1.7009 \\
\hline 5.83 & 532.097 & 1.0919 & 1.7272 & 3.00 & 533.235 & 1.3081 & 1.8969 & 9.25 & 531.493 & 0.9771 & 1.6032 \\
\hline 6.83 & 531.978 & 1.0693 & 1.7058 & 3.50 & 533.111 & 1.2845 & 1.8781 & 11.25 & 531.204 & 0.9222 & 1.5433 \\
\hline 7.83 & 531.878 & 1.0503 & 1.6875 & 4.00 & 532.876 & 1.2399 & 1.8415 & 22 & 530.212 & 0.7337 & 1.3051 \\
\hline 8.83 & 531.763 & 1.0284 & 1.6660 & 5.33 & 532.356 & 1.1411 & 1.7554 & 29 & 529.572 & 0.6121 & 1.1145 \\
\hline 9.83 & 531.453 & 0.9695 & 1.6056 & 6.33 & 532.112 & 1.0947 & 1.7124 & 52.5 & 528.698 & 0.4461 & 0.7766 \\
\hline 11.83 & 531.198 & 0.9211 & 1.5531 & 7.50 & 531.724 & 1.0210 & 1.6398 & 143.75 & 526.998 & 0.1231 & -0.7465 \\
\hline 14.33 & 530.971 & 0.8779 & 1.5039 & 8.50 & 531.426 & 0.9644 & 1.5802 & 168.75 & 526.811 & 0.0876 & -1.2483 \\
\hline 19.08 & 530.519 & 0.7921 & 1.3980 & 22.25 & 531.103 & 0.9030 & 1.5114 & 219 & 526.701 & 0.0667 & -1.7316 \\
\hline 43.58 & 529.946 & 0.6832 & 1.2453 & 33.25 & 530.556 & 0.7991 & 1.3828 & 263.5 & 526.669 & 0.0606 & -1.9310 \\
\hline 67.33 & 529.338 & 0.5677 & 1.0529 & 70.25 & 529.916 & 0.6775 & 1.2078 & 313.75 & 526.624 & 0.0521 & -2.3026 \\
\hline 94.33 & 528.768 & 0.4594 & 0.8312 & 81.50 & 529.425 & 0.5842 & 1.0491 & 358.75 & 526.589 & 0.0454 & -2.7334 \\
\hline 122.33 & 528.381 & 0.3859 & 0.6466 & 104.75 & 528.938 & 0.4917 & 0.8620 & 410.5 & 526.567 & 0.0412 & -3.1466 \\
\hline 141.33 & 527.949 & 0.3038 & 0.3900 & 141.75 & 528.533 & 0.4147 & 0.6745 & 457 & 526.55 & 0.0380 & -3.6497 \\
\hline 171.33 & 527.518 & 0.2219 & 0.0450 & 164.75 & 528.112 & 0.3348 & 0.4331 & 503.5 & 526.538 & 0.0357 & -4.2687 \\
\hline 190.33 & 527.251 & 0.1712 & -0.2497 & 195.75 & 527.876 & 0.2899 & 0.2670 & 550 & 526.53 & 0.0342 & -5.1160 \\
\hline 206.58 & 527.032 & 0.1296 & -0.5798 & 215.50 & 527.614 & 0.2401 & 0.0431 & 596.5 & 526.524 & 0.0331 & \\
\hline 235.33 & 526.912 & 0.1068 & -0.8210 & 240.25 & 527.421 & 0.2035 & -0.1613 & & & & \\
\hline 267.08 & 526.739 & 0.0739 & -1.3205 & 264.25 & 527.225 & 0.1662 & -0.4231 & & & & \\
\hline 286.08 & 526.666 & 0.0600 & -1.6399 & 288.25 & 527.101 & 0.1427 & -0.6330 & & & & \\
\hline 328.83 & 526.6 & 0.0475 & -2.0557 & 309.75 & 526.996 & 0.1227 & -0.8533 & & & & \\
\hline 382.83 & 526.541 & 0.0363 & -2.6736 & 337.25 & 526.823 & 0.0899 & -1.3744 & & & & \\
\hline 412.33 & 526.512 & 0.0308 & -3.2189 & 363.75 & 526.714 & 0.0692 & -1.9379 & & & & \\
\hline 435.83 & 526.501 & 0.0287 & -3.5405 & 388.50 & 526.675 & 0.0617 & -2.2538 & & & & \\
\hline 459.83 & 526.490 & 0.0266 & -4.0174 & 409.50 & 526.643 & 0.0557 & -2.6173 & & & & \\
\hline 483.83 & 526.484 & 0.0255 & -4.4228 & 455.25 & 526.621 & 0.0515 & -2.9759 & & & & \\
\hline 531.83 & 526.480 & 0.0247 & -4.8283 & 503.25 & 526.6 & 0.0475 & -3.5066 & & & & \\
\hline 555.83 & 526.476 & 0.0239 & -5.5215 & 552.75 & 526.589 & 0.0454 & -3.9633 & & & & \\
\hline \multirow[t]{3}{*}{579.83} & 526.472 & 0.0232 & \#NUM! & 580.25 & 526.579 & 0.0435 & -4.7105 & & & & \\
\hline & & & & 595.00 & 526.57 & 0.0418 & \#NUM! & & & & \\
\hline & & & & & & & & & & & \\
\hline
\end{tabular}




\begin{tabular}{|c|c|c|c|c|c|c|c|c|c|c|c|}
\hline & & & & sample-3 & & $2 I=0.05 \mathrm{~cm}$ & & & & & \\
\hline & & Cycle-1 & & & & Cycle-2 & & & & Cycle-3 & \\
\hline Time, $\mathrm{h}$ & Weight, mg & Water Content, wt $\%$ & $\ln (M t-M \infty)$ & Time, $\mathrm{h}$ & Weight, mg & Water Content, wt \% & $\ln (\mathrm{Mt}-\mathrm{M} \infty)$ & Time, $\mathrm{h}$ & Weight, mg & Water Content, wt \% & $\ln (\mathrm{Mt}-\mathrm{M} \infty)$ \\
\hline 0.00 & 406.542 & 1.5593 & 1.8203 & 0.00 & 406.629 & 1.5811 & 1.8278 & 0 & 406.164 & 1.4649 & 1.7417 \\
\hline 0.33 & 406.06 & 1.4389 & 1.7391 & 0.50 & 406.542 & 1.5593 & 1.8137 & 0.25 & 406.091 & 1.4467 & 1.7288 \\
\hline 0.83 & 405.761 & 1.3642 & 1.6851 & 0.75 & 406.356 & 1.5129 & 1.7829 & 0.75 & 405.885 & 1.3952 & 1.6916 \\
\hline 1.33 & 405.619 & 1.3288 & 1.6584 & 1.25 & 406.123 & 1.4547 & 1.7429 & 1.25 & 405.673 & 1.3422 & 1.6517 \\
\hline 1.83 & 405.388 & 1.2710 & 1.6134 & 1.50 & 405.945 & 1.4102 & 1.7113 & 2.25 & 405.414 & 1.2775 & 1.6008 \\
\hline 2.83 & 405.124 & 1.2051 & 1.5594 & 1.75 & 405.823 & 1.3797 & 1.6890 & 3.75 & 405.161 & 1.2143 & 1.5484 \\
\hline 3.83 & 404.851 & 1. 1369 & 1.5003 & 2.00 & 405.711 & 1.3517 & 1.6681 & 5.25 & 404.789 & 1. 1214 & 1.4660 \\
\hline 4.83 & 404.604 & 1.0752 & 1.4436 & 2.50 & 405.588 & 1.3210 & 1.6446 & 7.25 & 404.235 & 0.9830 & 1.3292 \\
\hline 5.83 & 404.357 & 1.0135 & 1.3835 & 3.00 & 405.423 & 1.2798 & 1.6122 & 9.25 & 403.876 & 0.8933 & 1.2293 \\
\hline 6.83 & 404.211 & 0.9770 & 1.3463 & 3.50 & 405.332 & 1.2571 & 1.5939 & 11.25 & 403.644 & 0.8354 & 1. 1591 \\
\hline 7.83 & 404.123 & 0.9550 & 1.3231 & 4.00 & 405.112 & 1.2021 & 1.5482 & 22 & 403.074 & 0.6930 & 0.9620 \\
\hline 8.83 & 404.011 & 0.9271 & 1.2928 & 5.33 & 405.001 & 1.1744 & 1.5243 & 29 & 402.759 & 0.6143 & 0.8338 \\
\hline 9.83 & 403.825 & 0.8806 & 1.2404 & 6.33 & 404.912 & 1. 1521 & 1.5047 & 52.5 & 402.135 & 0.4584 & 0.5176 \\
\hline 11.83 & 403.656 & 0.8384 & 1. 1903 & 7.50 & 404.534 & 1.0577 & 1.4171 & 143.75 & 401.235 & 0.2336 & -0.2510 \\
\hline 14.33 & 403.415 & 0.7782 & 1. 1142 & 8.50 & 404.112 & 0.9523 & 1.3091 & 168.75 & 400.968 & 0.1669 & -0.6714 \\
\hline 19.08 & 402.911 & 0.6523 & 0.9333 & 22.25 & 403.571 & 0.8171 & 1. 1512 & 219 & 400.732 & 0.1079 & -1.2910 \\
\hline 43.58 & 402.082 & 0.4452 & 0.5388 & 33.25 & 403.142 & 0.7100 & 1.0054 & 263.5 & 400.687 & 0.0967 & -1.4697 \\
\hline 67.33 & 401.657 & 0.3390 & 0.2539 & 70.25 & 402.542 & 0.5601 & 0.7575 & 313.75 & 400.563 & 0.0657 & -2.2443 \\
\hline 94.33 & 401.486 & 0.2963 & 0.1115 & 81.50 & 402.134 & 0.4582 & 0.5452 & 358.75 & 400.532 & 0.0580 & -2.5903 \\
\hline 122.33 & 401.365 & 0.2661 & -0.0030 & 104.75 & 401.768 & 0.3667 & 0.3067 & 410.5 & 400.51 & 0.0525 & -2.9375 \\
\hline 141.33 & 401.165 & 0.2161 & -0.2269 & 141.75 & 401.453 & 0.2880 & 0.0431 & 457 & 400.487 & 0.0467 & -3.5066 \\
\hline 171.33 & 401.021 & 0.1801 & -0.4262 & 164.75 & 401.213 & 0.2281 & -0.2182 & 503.5 & 400.473 & 0.0432 & -4.1352 \\
\hline 190.33 & 400.912 & 0.1529 & -0.6088 & 195.75 & 400.925 & 0.1561 & -0.6616 & 550 & 400.463 & 0.0407 & -5.1160 \\
\hline 206.58 & 400.823 & 0.1307 & -0.7875 & 215.50 & 400.785 & 0.1212 & -0.9782 & 596.5 & 400.457 & 0.0392 & \#NUM! \\
\hline 235.33 & 400.712 & 0.1029 & -1.0671 & 240.25 & 400.661 & 0.0902 & -1.3783 & & & & \\
\hline 267.08 & 400.596 & 0.0739 & -1.4784 & 264.25 & 400.578 & 0.0694 & -1.7779 & & & & \\
\hline 286.08 & 400.532 & 0.0580 & -1.8079 & 288.25 & 400.532 & 0.0580 & -2.0956 & & & & \\
\hline 328.83 & 400.47 & 0.0425 & -2.2828 & 309.75 & 400.49 & 0.0475 & -2.5133 & & & & \\
\hline 382.83 & 400.442 & 0.0355 & -2.6037 & 337.25 & 400.468 & 0.0420 & -2.8302 & & & & \\
\hline 412.33 & 400.412 & 0.0280 & -3.1236 & 363.75 & 400.453 & 0.0382 & -3.1236 & & & & \\
\hline 435.83 & 400.397 & 0.0242 & -3.5405 & 388.50 & 400.443 & 0.0357 & -3.3814 & & & & \\
\hline 459.83 & 400.387 & 0.0217 & -3.9633 & 409.50 & 400.437 & 0.0342 & -3.5756 & & & & \\
\hline 483.83 & 400.380 & 0.0200 & -4.4228 & 455.25 & 400.43 & 0.0325 & -3.8632 & & & & \\
\hline 531.83 & 400.373 & 0.0182 & -5.2983 & 503.25 & 400.422 & 0.0305 & -4.3428 & & & & \\
\hline 555.83 & 400.370 & 0.0175 & -6.2146 & 552.75 & 400.416 & 0.0290 & -4.9618 & & & & \\
\hline \multirow[t]{2}{*}{579.83} & 400.368 & 0.0170 & \#NUM! & 580.25 & 400.411 & 0.0277 & -6.2146 & & & & \\
\hline & & & & 595 & 400.409 & 0.0272 & \#NUM! & & & & \\
\hline
\end{tabular}


Table 18. Sorption Data of Polyester Samples containing 0 wt $\%$ Cloisite $10 \mathrm{~A}$ at $25^{\circ} \mathrm{C}$

During Three Cycles of Absorption

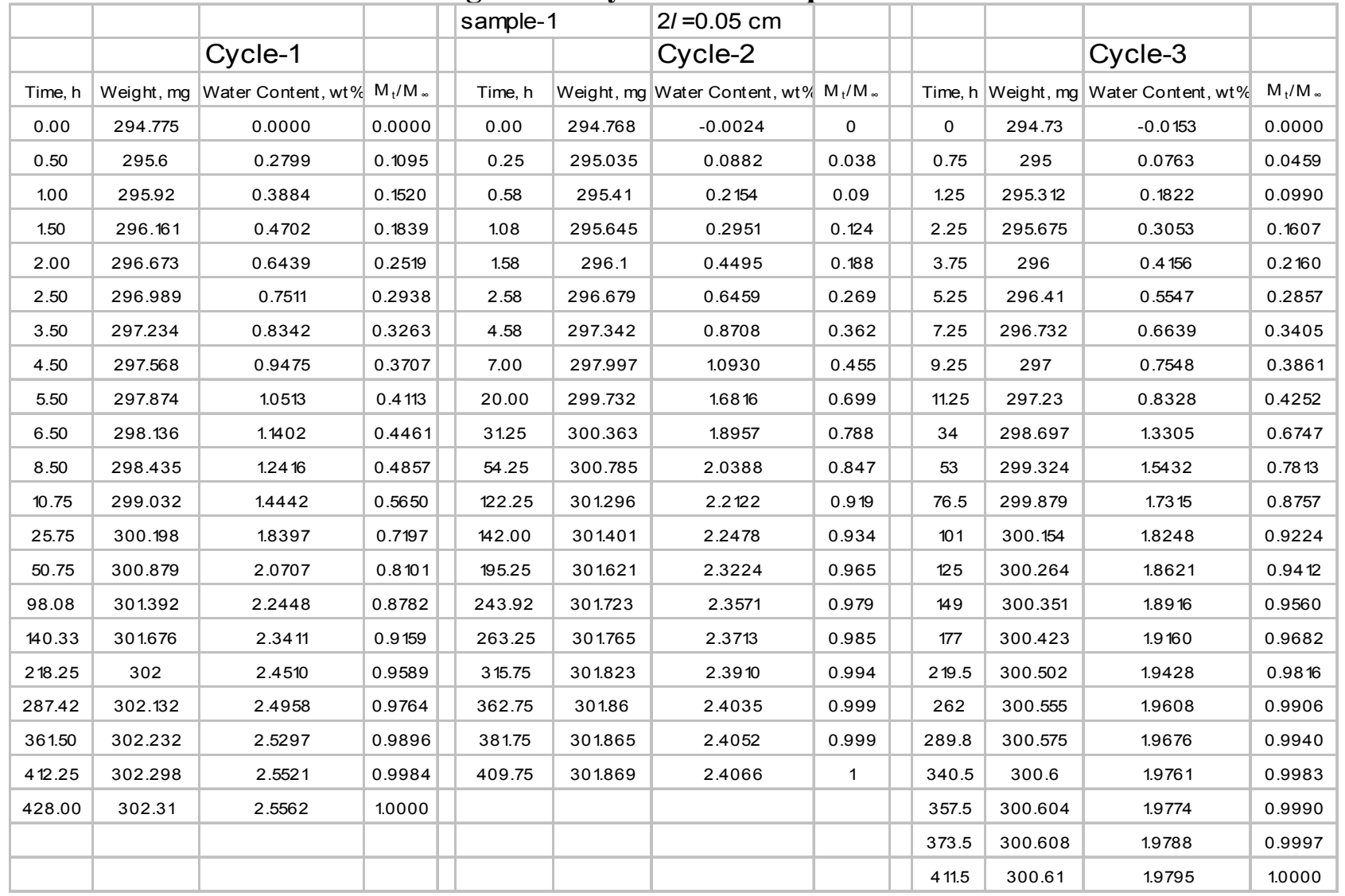




\begin{tabular}{|c|c|c|c|c|c|c|c|c|c|c|c|}
\hline & & & & sample- & & $2 I=0.055 \mathrm{~cm}$ & & & & & \\
\hline & & Cycle-1 & & & & Cycle-2 & & & & Cycle-3 & \\
\hline Time, $\mathrm{h}$ & Weight, mg & Water Content, wt \% & $M_{t} / M_{\infty}$ & Time, $\mathrm{h}$ & Weight, mg & Water Content, wt $\%$ & $\mathrm{M}_{\mathrm{t}} / \mathrm{M}_{\infty}$ & Time, $\mathrm{h}$ & Weight, mg & Water Content, wt \% & $M_{t} / M_{\infty}$ \\
\hline 0.00 & 348.436 & 0.0000 & 0.0000 & 0.00 & 348.43 & -0.0017 & 0.0000 & 0 & 348.44 & 0.0011 & 0.0000 \\
\hline 0.50 & 348.778 & 0.0980 & 0.0465 & 0.25 & 348.612 & 0.0504 & 0.0267 & 0.75 & 348.87 & 0.1244 & 0.0700 \\
\hline 1.00 & 348.996 & 0.1605 & 0.0762 & 0.58 & 349 & 0.1616 & 0.0835 & 1.25 & 349.34 & 0.2590 & 0.1464 \\
\hline 2.00 & 349.513 & 0.3086 & 0.1465 & 1.58 & 350.1 & 0.4768 & 0.2448 & 3.75 & 350 & 0.4481 & 0.2538 \\
\hline 2.50 & 349.785 & 0.3865 & 0.1835 & 2.58 & 350.47 & 0.5828 & 0.2990 & 5.25 & 350.37 & 0.5542 & 0.3140 \\
\hline 3.50 & 350.4 & 0.5628 & 0.2671 & 4.58 & 351.1 & 0.7633 & 0.3913 & 7.25 & 350.7 & 0.6487 & 0.3677 \\
\hline 4.50 & 350.678 & 0.6424 & 0.3049 & 7.00 & 351.657 & 0.9229 & 0.4730 & 9.25 & 351 & 0.7347 & 0.4165 \\
\hline 5.50 & 350.986 & 0.7307 & 0.3468 & 20.00 & 352.6 & 1.1931 & 0.6112 & 11.25 & 351.26 & 0.8092 & 0.4588 \\
\hline 6.50 & 351.453 & 0.8645 & 0.4103 & 31.25 & 353 & 1.3078 & 0.6698 & 34 & 352.13 & 1.0585 & 0.6003 \\
\hline 10.75 & 352.332 & 1.1163 & 0.5299 & 122.25 & 354.432 & 1.7181 & 0.8797 & 76.5 & 353.21 & 1.3679 & 0.7760 \\
\hline 25.75 & 353.331 & 1.4026 & 0.6657 & 142.00 & 354.672 & 1.7868 & 0.9148 & 101 & 353.621 & 1.4857 & 0.8429 \\
\hline 50.75 & 353.868 & 1.5565 & 0.7387 & 195.25 & 354.823 & 1.8301 & 0.9370 & 125 & 353.921 & 1.5717 & 0.8917 \\
\hline 98.08 & 354.645 & 1.7791 & 0.8444 & 243.92 & 355 & 1.8808 & 0.9629 & 149 & 354.1 & 1.6229 & 0.9208 \\
\hline 140.33 & 355.021 & 1.8868 & 0.8956 & 263.25 & 355.089 & 1.9063 & 0.9760 & 177 & 354.188 & 1.6482 & 0.9351 \\
\hline 218.25 & 355.453 & 2.0106 & 0.9543 & 315.75 & 355.132 & 1.9186 & 0.9823 & 219.5 & 354.298 & 1.6797 & 0.9530 \\
\hline 287.42 & 355.61 & 2.0556 & 0.9757 & 362.75 & 355.167 & 1.9287 & 0.9874 & 262 & 354.376 & 1.7020 & 0.9657 \\
\hline 361.50 & 355.7 & 2.0814 & 0.9879 & 381.75 & 355.211 & 1.9413 & 0.9938 & 289.8 & 354.453 & 1.7241 & 0.9782 \\
\hline 412.25 & 355.754 & 2.0969 & 0.9952 & 409.75 & 355.253 & 1.9533 & 1.0000 & 340.5 & 354.498 & 1.7370 & 0.9855 \\
\hline \multirow[t]{2}{*}{428.00} & 355.789 & 2.1069 & 1.0000 & & & & & 357.5 & 354.522 & 1.7439 & 0.9894 \\
\hline & & & & & & & & 373.5 & 354.555 & 1.7533 & 0.9948 \\
\hline
\end{tabular}




\begin{tabular}{|c|c|c|c|c|c|c|c|c|c|c|c|}
\hline & & & & sample & & $2 I=0.045 \mathrm{~cm}$ & & & & & \\
\hline & & Cycle-1 & & & & Cycle-2 & & & & Cycle-3 & \\
\hline Time, $\mathrm{h}$ & Weight, mg & Water Content, wt \% & $M_{t} / M_{\infty}$ & Time, $\mathrm{h}$ & Weight, mg & Water Content, wt $\%$ & $\mathrm{M}_{\mathrm{t}} / \mathrm{M}_{\infty}$ & Time, $\mathrm{h}$ & Weight, mg & Water Content, wt \% & $M_{t} / M_{\infty}$ \\
\hline 0.00 & 246.429 & 0.0000 & 0.0000 & 0.00 & 246.502 & 0.0295 & 0.0000 & 0 & 246.38 & -0.0198 & 0.0000 \\
\hline 0.50 & 246.998 & 0.2300 & 0.0835 & 0.25 & 246.869 & 0.1779 & 0.0574 & 0.75 & 246.71 & 0.1136 & 0.0527 \\
\hline 1.00 & 247.342 & 0.3691 & 0.1339 & 0.58 & 247.277 & 0.3428 & 0.1213 & 1.25 & 246.89 & 0.1864 & 0.0814 \\
\hline 2.00 & 247.879 & 0.5862 & 0.2127 & 1.58 & 247.656 & 0.4961 & 0.1806 & 3.75 & 247.568 & 0.4605 & 0.1896 \\
\hline 2.50 & 248 & 0.6352 & 0.2305 & 2.58 & 248.154 & 0.6974 & 0.2586 & 5.25 & 247.96 & 0.6190 & 0.2522 \\
\hline 3.50 & 248.323 & 0.7657 & 0.2779 & 4.58 & 248.563 & 0.8628 & 0.3226 & 7.25 & 248.184 & 0.7095 & 0.2879 \\
\hline 4.50 & 248.6 & 0.8777 & 0.3185 & 7.00 & 249.137 & 1.0948 & 0.4124 & 9.25 & 248.531 & 0.8498 & 0.3433 \\
\hline 5.50 & 248.9 & 0.9990 & 0.3625 & 20.00 & 249.995 & 1.4417 & 0.5467 & 11.25 & 248.998 & 1.0386 & 0.4179 \\
\hline 6.50 & 249.21 & 1. 1244 & 0.4080 & 31.25 & 250.764 & 1.7526 & 0.6671 & 34 & 250.356 & 1.5877 & 0.6346 \\
\hline 8.50 & 249.56 & 1.2659 & 0.4594 & 54.25 & 251.536 & 2.0648 & 0.7879 & 53 & 251.234 & 1.9427 & 0.7748 \\
\hline 10.75 & 250 & 1.4437 & 0.5239 & 122.25 & 252.359 & 2.3975 & 0.9167 & 76.5 & 251.868 & 2.1990 & 0.8760 \\
\hline 25.75 & 251.479 & 2.0417 & 0.7409 & 142.00 & 252.498 & 2.4537 & 0.9385 & 101 & 252.126 & 2.3033 & 0.9172 \\
\hline 50.75 & 252.125 & 2.3029 & 0.8357 & 195.25 & 252.698 & 2.5345 & 0.9698 & 125 & 252.35 & 2.3939 & 0.9529 \\
\hline 98.08 & 252.568 & 2.4820 & 0.9007 & 243.92 & 252.801 & 2.5762 & 0.9859 & 149 & 252.4 & 2.4141 & 0.9609 \\
\hline 140.33 & 252.879 & 2.6077 & 0.9463 & 263.25 & 252.835 & 2.5899 & 0.9912 & 177 & 252.465 & 2.4403 & 0.9713 \\
\hline 218.25 & 253.096 & 2.6955 & 0.9781 & 315.75 & 252.863 & 2.6013 & 0.9956 & 219.5 & 252.54 & 2.4707 & 0.9832 \\
\hline 287.42 & 253.168 & 2.7246 & 0.9887 & 362.75 & 252.881 & 2.6085 & 0.9984 & 262 & 252.598 & 2.4941 & 0.9925 \\
\hline 361.50 & 253.22 & 2.7456 & 0.9963 & 381.75 & 252.889 & 2.6118 & 0.9997 & 289.8 & 252.611 & 2.4994 & 0.9946 \\
\hline 412.25 & 253.24 & 2.7537 & 0.9993 & 409.75 & 252.891 & 2.6126 & 1.0000 & 340.5 & 252.624 & 2.5046 & 0.9966 \\
\hline \multirow[t]{2}{*}{428.00} & 253.245 & 2.7557 & 1.0000 & & & & & 357.5 & 252.631 & 2.5075 & 0.9978 \\
\hline & & & & & & & & 373.5 & 252.639 & 2.5107 & 0.9990 \\
\hline
\end{tabular}


Table 19. Desorption Data of Polyester Samples containing 0 wt\% Cloisite $10 \mathrm{~A}$ at $25^{\circ} \mathrm{C}$ During Three Cycles of Absorption

\begin{tabular}{|c|c|c|c|c|c|c|c|c|c|c|c|}
\hline & & & & sample-1 & & $2 I=0.05 \mathrm{~cm}$ & & & & & \\
\hline & & Cycle-1 & & & & Cycle-2 & & & & Cycle-3 & \\
\hline Time, $\mathrm{h}$ & Weight, mg & Water Content, wt $\%$ & $\ln (\mathrm{Mt}-\mathrm{M} \infty)$ & Time, $\mathrm{h}$ & Weight, mg & Water Content, wt \% & $\ln (\mathrm{Mt}-\mathrm{M} \infty)$ & Time, $\mathrm{h}$ & Weight, mg & Water Content, wt $\%$ & $\ln (\mathrm{Mt}-\mathrm{M} \infty)$ \\
\hline 0.00 & 302.32 & 2.5596 & 2.0210 & 0 & 301.901 & 2.4174 & 1.9726 & 0 & 300.699 & 2.0097 & 1.7751 \\
\hline 0.25 & 301.78 & 2.3764 & 1.9468 & 0.75 & 301.453 & 2.2655 & 1.9082 & 2.25 & 300.043 & 1.7871 & 1.6573 \\
\hline 0.50 & 300.944 & 2.0928 & 1.8197 & 1.25 & 301 & 2.1118 & 1.8386 & 3 & 299.675 & 1.6623 & 1.5845 \\
\hline 0.75 & 300.153 & 1.8244 & 1.6825 & 2.75 & 300.675 & 2.0015 & 1.7856 & 4 & 299.231 & 1.5117 & 1.4891 \\
\hline 1.75 & 299.317 & 1.5408 & 1.5136 & 3.75 & 300.123 & 1.8143 & 1.6884 & 5 & 298.675 & 1.3230 & 1.3551 \\
\hline 3.25 & 298.5 & 1.2637 & 1.3153 & 6.75 & 299.675 & 1.6623 & 1.6020 & 5.5 & 298.345 & 1.2111 & 1.2661 \\
\hline 5.25 & 297.546 & 0.9400 & 1.0196 & 8.75 & 299.333 & 1.5463 & 1.5306 & 6.5 & 298.1 & 1. 1280 & 1. 1945 \\
\hline 6.25 & 297 & 0.7548 & 0.8002 & 10.75 & 298.787 & 1.3610 & 1.4049 & 9.5 & 297.89 & 1.0567 & 1. 1288 \\
\hline 8.58 & 296.698 & 0.6524 & 0.6544 & 11.75 & 298.433 & 1.2409 & 1.3140 & 11.5 & 297.6 & 0.9584 & 1.0303 \\
\hline 10.42 & 296.5 & 0.5852 & 0.5458 & 32.75 & 296.234 & 0.4950 & 0.4200 & 15.5 & 297.1 & 0.7887 & 0.8338 \\
\hline 22.42 & 296.1 & 0.4495 & 0.2822 & 51.5 & 295.667 & 0.3026 & -0.0460 & 18.5 & 296.564 & 0.6069 & 0.5687 \\
\hline 47.00 & 295.778 & 0.3403 & 0.0040 & 78.75 & 295.399 & 0.2117 & -0.3754 & 21.5 & 296.4 & 0.5513 & 0.4713 \\
\hline 70.75 & 295.6 & 0.2799 & -0.1912 & 99.75 & 295.176 & 0.1360 & -0.7679 & 31.5 & 295.546 & 0.2616 & -0.2904 \\
\hline 112.25 & 295.4 & 0.2120 & -0.4684 & 122.75 & 295.054 & 0.0946 & -1.0729 & 60.5 & 295.165 & 0.1323 & -1.0024 \\
\hline 139.75 & 295.24 & 0.1577 & -0.7636 & 169.5 & 294.912 & 0.0465 & -1.6094 & 87 & 295 & 0.0763 & -1.5995 \\
\hline 187.50 & 295.087 & 0.1058 & -1.1616 & 217.5 & 294.834 & 0.0200 & -2.1037 & 132.5 & 294.898 & 0.0417 & -2.3026 \\
\hline 234.50 & 294.93 & 0.0526 & -1.8579 & 270.5 & 294.767 & -0.0027 & -2.9004 & 178 & 294.832 & 0.0193 & -3.3814 \\
\hline 285.75 & 294.81 & 0.0119 & -3.3242 & 292 & 294.712 & -0.0214 & \#NUM! & 223.5 & 294.798 & 0.0078 & \#NUM! \\
\hline 328.50 & 294.795 & 0.0068 & -3.8632 & & & & & 269 & 294.745 & -0.0102 & \#NUM! \\
\hline 408.50 & 294.781 & 0.0020 & -4.9618 & & & & & & & & \\
\hline 430.75 & 294.774 & -0.0003 & \#NUM! & & & & & & & & \\
\hline
\end{tabular}

\begin{tabular}{|c|c|c|c|c|c|c|c|c|c|c|c|}
\hline & & & & sample-2 & & $2 I=0.055 \mathrm{~cm}$ & & & & & \\
\hline & & Cycle-1 & & & & Cycle-2 & & & & Cycle-3 & \\
\hline Time, $\mathrm{h}$ & Weight, mg & Water Content, wt $\%$ & $\ln (\mathrm{Mt}-\mathrm{M} \infty)$ & Time, $\mathrm{h}$ & Weight, mg & Water Content, wt $\%$ & $\ln (\mathrm{Mt}-\mathrm{M} \infty)$ & Time, $\mathrm{h}$ & Weight, mg & Water Content, wt \% & $\ln (\mathrm{Mt}-\mathrm{M} \infty)$ \\
\hline 0.00 & 355.82 & 2.1158 & 1.9997 & 0 & 355.26 & 1.9553 & 1.9226 & 0 & 354.594 & 1.7645 & 1.7974 \\
\hline 0.25 & 355.64 & 2.0642 & 1.9751 & 0.75 & 355.01 & 1.8837 & 1.8854 & 2.25 & 354.222 & 1.6579 & 1.7338 \\
\hline 0.50 & 355.543 & 2.0364 & 1.9615 & 1.25 & 354.674 & 1.7874 & 1.8331 & 3 & 353.789 & 1.5338 & 1.6542 \\
\hline 0.75 & 355.332 & 1.9760 & 1.9314 & 2.75 & 354.231 & 1.6605 & 1.7596 & 4 & 353.564 & 1.4694 & 1.6102 \\
\hline 1.75 & 354.84 & 1.8350 & 1.8574 & 3.75 & 353.897 & 1.5648 & 1.7004 & 5 & 353.32 & 1.3994 & 1.5602 \\
\hline 3.25 & 354.311 & 1.6834 & 1.7712 & 6.75 & 353.61 & 1.4825 & 1.6465 & 5.5 & 353 & 1.3078 & 1.4907 \\
\hline 5.25 & 354.007 & 1.5963 & 1.7181 & 8.75 & 353.21 & 1.3679 & 1.5663 & 6.5 & 352.684 & 1.2172 & 1.4168 \\
\hline 6.25 & 353.33 & 1.4023 & 1.5886 & 10.75 & 352.661 & 1.2106 & 1.4446 & 9.5 & 351.349 & 0.8347 & 1.0257 \\
\hline 8.58 & 352.108 & 1.0522 & 1.3016 & 11.75 & 351.661 & 0.9241 & 1.1756 & 11.5 & 351.006 & 0.7364 & 0.8945 \\
\hline 10.42 & 351.48 & 0.8722 & 1.1142 & 32.75 & 349.674 & 0.3547 & 0.2255 & 15.5 & 350.649 & 0.6341 & 0.7367 \\
\hline 22.42 & 350.648 & 0.6338 & 0.7953 & 51.5 & 349.312 & 0.2510 & -0.1154 & 18.5 & 350.333 & 0.5436 & 0.5727 \\
\hline 47.00 & 349.568 & 0.3244 & 0.1266 & 78.75 & 349 & 0.1616 & -0.5465 & 21.5 & 350 & 0.4481 & 0.3646 \\
\hline 70.75 & 349.256 & 0.2350 & -0.1948 & 99.75 & 348.89 & 0.1301 & -0.7572 & 31.5 & 349.325 & 0.2547 & -0.2679 \\
\hline 112.25 & 349.05 & 0.1759 & -0.4829 & 122.75 & 348.699 & 0.0754 & -1.2801 & 60.5 & 349 & 0.1616 & -0.8210 \\
\hline 139.75 & 348.9 & 0.1330 & -0.7614 & 169.5 & 348.532 & 0.0275 & -2.1982 & 87 & 348.87 & 0.1244 & -1.1712 \\
\hline 187.50 & 348.81 & 0.1072 & -0.9755 & 217.5 & 348.468 & 0.0092 & -3.0576 & 132.5 & 348.7 & 0.0756 & -1.9661 \\
\hline 234.50 & 348.665 & 0.0656 & -1.4610 & 270.5 & 348.438 & 0.0006 & -4.0745 & 178 & 348.6 & 0.0470 & -3.2189 \\
\hline 285.75 & 348.567 & 0.0375 & -2.0099 & 292 & 348.421 & -0.0043 & \#NUM! & 223.5 & 348.56 & 0.0355 & \#NUM! \\
\hline 328.50 & 348.491 & 0.0158 & -2.8473 & & & & & 269 & 348.521 & 0.0244 & \#NUM! \\
\hline 408.50 & 348.456 & 0.0057 & -3.7723 & & & & & & & & \\
\hline 430.75 & 348.433 & -0.0009 & \#NUM! & & & & & & & & \\
\hline
\end{tabular}




\begin{tabular}{|c|c|c|c|c|c|c|c|c|c|c|c|}
\hline & & & & sample-3 & & $2 I=0.045 \mathrm{~cm}$ & & & & & \\
\hline & & Cycle-1 & & & & Cycle-2 & & & & Cycle-3 & \\
\hline Time, $\mathrm{h}$ & Weight, mg & Water Content, wt $\%$ & $\ln (\mathrm{Mt}-\mathrm{M} \infty)$ & Time, $\mathrm{h}$ & Weight, mg & Water Content, wt $\%$ & $\ln (\mathrm{Mt}-\mathrm{M} \infty)$ & Time, $\mathrm{h}$ & Weight, mg & Water Content, wt $\%$ & $\ln (\mathrm{Mt}-\mathrm{M} \infty)$ \\
\hline 0.00 & 253.248 & 2.7569 & 1.9078 & 0 & 252.894 & 2.6138 & 1.8712 & 0 & 252.649 & 2.5147 & 1.8260 \\
\hline 0.25 & 252.739 & 2.5511 & 1.8292 & 0.75 & 251.678 & 2.1222 & 1.6639 & 2.25 & 252.123 & 2.3021 & 1.7375 \\
\hline 0.50 & 252.426 & 2.4246 & 1.7777 & 1.25 & 251.215 & 1.9350 & 1.5722 & 3 & 250.799 & 1.7668 & 1.4722 \\
\hline 0.75 & 252.038 & 2.2677 & 1.7098 & 2.75 & 250.454 & 1.6273 & 1.4002 & 4 & 250.453 & 1.6269 & 1.3895 \\
\hline 1.75 & 251.379 & 2.0013 & 1.5829 & 3.75 & 250.164 & 1.5101 & 1.3260 & 5 & 250.1 & 1.4842 & 1.2975 \\
\hline 3.25 & 250.485 & 1.6398 & 1.3800 & 6.75 & 249.08 & 1.0718 & 0.9866 & 5.5 & 249.856 & 1.3855 & 1.2285 \\
\hline 5.25 & 249.735 & 1.3366 & 1.1709 & 8.75 & 248.531 & 0.8498 & 0.7575 & 6.5 & 249.543 & 1.2590 & 1. 1324 \\
\hline 6.25 & 249.418 & 1.2084 & 1.0675 & 10.75 & 248.125 & 0.6857 & 0.5464 & 9.5 & 249 & 1.0395 & 0.9400 \\
\hline 8.58 & 249.037 & 1.0544 & 0.9270 & 11.75 & 247.854 & 0.5761 & 0.3757 & 11.5 & 248.78 & 0.9505 & 0.8502 \\
\hline 10.42 & 248.737 & 0.9331 & 0.8007 & 32.75 & 247.12 & 0.2794 & -0.3257 & 15.5 & 248.5 & 0.8373 & 0.7227 \\
\hline 22.42 & 248.103 & 0.6768 & 0.4656 & 51.5 & 247 & 0.2309 & -0.5075 & 18.5 & 248.213 & 0.7213 & 0.5727 \\
\hline 47.00 & 247.384 & 0.3861 & -0.1347 & 78.75 & 246.8 & 0.1500 & -0.9113 & 21.5 & 248 & 0.6352 & 0.4447 \\
\hline 70.75 & 247.168 & 0.2988 & -0.4186 & 99.75 & 246.7 & 0.1096 & -1.1973 & 31.5 & 247.7 & 0.5139 & 0.2311 \\
\hline 112.25 & 247.012 & 0.2357 & -0.6892 & 122.75 & 246.632 & 0.0821 & -1.4524 & 60.5 & 247.12 & 0.2794 & -0.3857 \\
\hline 139.75 & 246.902 & 0.1912 & -0.9365 & 169.5 & 246.521 & 0.0372 & -2.0956 & 87 & 246.623 & 0.0784 & -1.6983 \\
\hline 187.50 & 246.702 & 0.1104 & -1.6503 & 217.5 & 246.457 & 0.0113 & -2.8302 & 132.5 & 246.487 & 0.0234 & -3.0576 \\
\hline 234.50 & 246.601 & 0.0695 & -2.3969 & 270.5 & 246.412 & -0.0069 & -4.2687 & 178 & 246.46 & 0.0125 & -3.9120 \\
\hline 285.75 & 246.575 & 0.0590 & -2.7334 & 292 & 246.398 & -0.0125 & \#NUM! & 223.5 & 246.44 & 0.0044 & \#NUM! \\
\hline 328.50 & 246.552 & 0.0497 & -3.1701 & & & & & 269 & 246.425 & -0.0016 & \#NUM! \\
\hline 408.50 & 246.516 & 0.0352 & -5.1160 & & & & & & & & \\
\hline 430.75 & 246.51 & 0.0327 & \#NUM! & & & & & & & & \\
\hline
\end{tabular}


Table 20. Sorption Data of Polyester Samples containing 2 wt\% Cloisite 10A at $25^{\circ} \mathrm{C}$ During Three Cycles of Absorption

\begin{tabular}{|c|c|c|c|c|c|c|c|c|c|c|c|}
\hline & & & & sample- & & $2 I=0.0577 \mathrm{~cm}$ & & & & & \\
\hline & & Cycle-1 & & & & Cycle-2 & & & & Cycle-3 & \\
\hline Time, h & Weight, mg & Water Content, wt $\%$ & $M_{t} / M_{\infty}$ & Time, $\mathrm{h}$ & Weight, mg & Water Content, wt $\%$ & $M_{t} / M_{\infty}$ & Time, $\mathrm{h}$ & Weight, mg & Water Content, wt \% & $M_{t} / M_{\infty}$ \\
\hline 0.00 & 453.358 & 0.0000 & 0.0000 & 0.00 & 453.581 & 0.0492 & 0 & 0 & 453.43 & 0.0159 & 0.0000 \\
\hline 0.50 & 453.519 & 0.0355 & 0.0206 & 0.33 & 453.738 & 0.0838 & 0.022 & 0.5 & 454 & 0.1416 & 0.0815 \\
\hline 1.00 & 453.941 & 0.1286 & 0.0745 & 0.83 & 454.071 & 0.1573 & 0.067 & 0.75 & 454.211 & 0.1882 & 0.1117 \\
\hline 3.50 & 454.895 & 0.3390 & 0.1965 & 1.83 & 454.595 & 0.2729 & 0.139 & 1.75 & 454.566 & 0.2665 & 0.1625 \\
\hline 5.50 & 455.506 & 0.4738 & 0.2746 & 2.33 & 454.762 & 0.3097 & 0.162 & 2.25 & 454.879 & 0.3355 & 0.2073 \\
\hline 8.50 & 456.32 & 0.6533 & 0.3787 & 4.33 & 455.231 & 0.4131 & 0.227 & 2.75 & 455 & 0.3622 & 0.2246 \\
\hline 10.75 & 456.832 & 0.7663 & 0.4442 & 5.67 & 455.653 & 0.5062 & 0.285 & 4.25 & 455.43 & 0.4570 & 0.2861 \\
\hline 25.75 & 458.123 & 1.0510 & 0.6093 & 7.00 & 456 & 0.5828 & 0.333 & 7.25 & 455.76 & 0.5298 & 0.3333 \\
\hline 50.75 & 458.921 & 1.2271 & 0.7113 & 20.00 & 457.32 & 0.8739 & 0.514 & 9.25 & 456 & 0.5828 & 0.3677 \\
\hline 98.08 & 459.6 & 1.3768 & 0.7981 & 37.75 & 458.52 & 1.1386 & 0.679 & 23.25 & 457.687 & 0.9549 & 0.6090 \\
\hline 125.75 & 459.932 & 1.4501 & 0.8406 & 67.75 & 459.213 & 1.2915 & 0.775 & 53.75 & 458.7 & 1.1783 & 0.7539 \\
\hline 169.50 & 460.333 & 1.5385 & 0.8918 & 98.00 & 459.411 & 1.3351 & 0.802 & 75.75 & 459.1 & 1.2665 & 0.8112 \\
\hline 218.25 & 460.611 & 1.5998 & 0.9274 & 117.75 & 459.632 & 1.3839 & 0.832 & 105.3 & 459.4 & 1.3327 & 0.8541 \\
\hline 264.42 & 460.82 & 1.6459 & 0.9541 & 142.50 & 459.81 & 1.4232 & 0.857 & 119.8 & 459.603 & 1.3775 & 0.8831 \\
\hline 332.75 & 461.065 & 1.7000 & 0.9854 & 192.00 & 460.1 & 1.4871 & 0.897 & 146.3 & 459.743 & 1.4084 & 0.9031 \\
\hline 412.25 & 461.165 & 1.7220 & 0.9982 & 239.00 & 460.3 & 1.5312 & 0.924 & 169.3 & 459.9 & 1.4430 & 0.9256 \\
\hline \multirow[t]{7}{*}{428.00} & 461.179 & 1.7251 & 1.0000 & 291.50 & 460.51 & 1.5776 & 0.953 & 214.3 & 460.076 & 1.4818 & 0.9508 \\
\hline & & & & 357.50 & 460.676 & 1.6142 & 0.976 & 240.8 & 460.181 & 1.5050 & 0.9658 \\
\hline & & & & 404.00 & 460.748 & 1.6301 & 0.986 & 265.8 & 460.26 & 1.5224 & 0.9771 \\
\hline & & & & 438.00 & 460.788 & 1.6389 & 0.991 & 293.3 & 460.31 & 1.5334 & 0.9843 \\
\hline & & & & & & & & 435.25 & 460.400 & 1.5533 & 0.9971 \\
\hline & & & & & & & & 483.25 & 460.410 & 1.5555 & 0.9986 \\
\hline & & & & & & & & 507.25 & 460.420 & 1.5577 & 1.0000 \\
\hline
\end{tabular}




\begin{tabular}{|c|c|c|c|c|c|c|c|c|c|c|c|}
\hline & & & & sample- & & $2 I=0.0655 \mathrm{~cm}$ & & & & & \\
\hline & & Cycle-1 & & & & Cycle-2 & & & & Cycle-3 & \\
\hline Time, $\mathrm{h}$ & Weight, mg & Water Content, wt \% & $M_{t} / M_{\infty}$ & Time, $\mathrm{h}$ & Weight, mg & Water Content, wt $\%$ & $M_{t} / M_{\infty}$ & Time, $\mathrm{h}$ & Weight, mg & Water Content, wt \% & $\mathrm{M}_{\mathrm{t}} / \mathrm{M}_{\infty}$ \\
\hline 0.00 & 350.069 & 0.0000 & 0.0000 & 0.00 & 350.39 & 0.0917 & 0 & 0 & 350.15 & 0.0231 & 0.0000 \\
\hline 0.50 & 350.575 & 0.1445 & 0.0695 & 0.33 & 350.53 & 0.1317 & 0.022 & 0.5 & 350.499 & 0.1228 & 0.0506 \\
\hline 1.00 & 350.865 & 0.2274 & 0.1093 & 0.83 & 350.698 & 0.1797 & 0.048 & 0.75 & 350.764 & 0.1985 & 0.0891 \\
\hline 3.50 & 351.794 & 0.4928 & 0.2369 & 1.83 & 351.093 & 0.2925 & 0.109 & 1.75 & 351 & 0.2659 & 0.1233 \\
\hline 5.50 & 352.321 & 0.6433 & 0.3093 & 2.33 & 351.221 & 0.3291 & 0.128 & 2.25 & 351.175 & 0.3159 & 0.1487 \\
\hline 8.50 & 352.763 & 0.7696 & 0.3700 & 4.33 & 351.6 & 0.4373 & 0.187 & 2.75 & 351.4 & 0.3802 & 0.1814 \\
\hline 10.75 & 353.212 & 0.8978 & 0.4316 & 5.67 & 351.876 & 0.5162 & 0.229 & 4.25 & 351.789 & 0.4913 & 0.2378 \\
\hline 25.75 & 353.998 & 1. 1224 & 0.5395 & 7.00 & 352.1 & 0.5802 & 0.264 & 7.25 & 352.21 & 0.6116 & 0.2989 \\
\hline 50.75 & 355.111 & 1.4403 & 0.6924 & 20.00 & 353.32 & 0.9287 & 0.452 & 9.25 & 352.564 & 0.7127 & 0.3503 \\
\hline 98.08 & 356.423 & 1.8151 & 0.8726 & 37.75 & 354.43 & 1.2458 & 0.624 & 23.25 & 353.654 & 1.0241 & 0.5084 \\
\hline 125.75 & 356.644 & 1.8782 & 0.9029 & 67.75 & 355.106 & 1.4389 & 0.728 & 53.75 & 354.769 & 1.3426 & 0.6702 \\
\hline 169.50 & 356.839 & 1.9339 & 0.9297 & 98.00 & 355.466 & 1.5417 & 0.784 & 75.75 & 355.138 & 1.4480 & 0.7237 \\
\hline 218.25 & 357.011 & 1.9830 & 0.9533 & 117.75 & 355.614 & 1.5840 & 0.807 & 105.3 & 355.655 & 1.5957 & 0.7988 \\
\hline 264.42 & 357.153 & 2.0236 & 0.9728 & 142.50 & 355.788 & 1.6337 & 0.834 & 119.8 & 355.862 & 1.6548 & 0.8288 \\
\hline 332.75 & 357.289 & 2.0625 & 0.9915 & 192.00 & 356.021 & 1.7002 & 0.87 & 146.3 & 355.997 & 1.6934 & 0.8484 \\
\hline 412.25 & 357.343 & 2.0779 & 0.9989 & 239.00 & 356.265 & 1.7699 & 0.907 & 169.3 & 356.219 & 1.7568 & 0.8806 \\
\hline \multirow[t]{7}{*}{428.00} & 357.351 & 2.0802 & 1.0000 & 291.50 & 356.488 & 1.8336 & 0.942 & 214.3 & 356.387 & 1.8048 & 0.9050 \\
\hline & & & & 357.50 & 356.753 & 1.9093 & 0.983 & 240.8 & 356.512 & 1.8405 & 0.9231 \\
\hline & & & & 404.00 & 356.838 & 1.9336 & 0.996 & 265.8 & 356.667 & 1.8848 & 0.9456 \\
\hline & & & & 438.00 & 356.843 & 1.9350 & 0.996 & 293.3 & 356.754 & 1.9096 & 0.9582 \\
\hline & & & & & & & & 435.25 & 357.025 & 1.9870 & 0.9975 \\
\hline & & & & & & & & 483.25 & 357.037 & 1.9905 & 0.9993 \\
\hline & & & & & & & & 507.25 & 357.042 & 1.9919 & 1.0000 \\
\hline
\end{tabular}




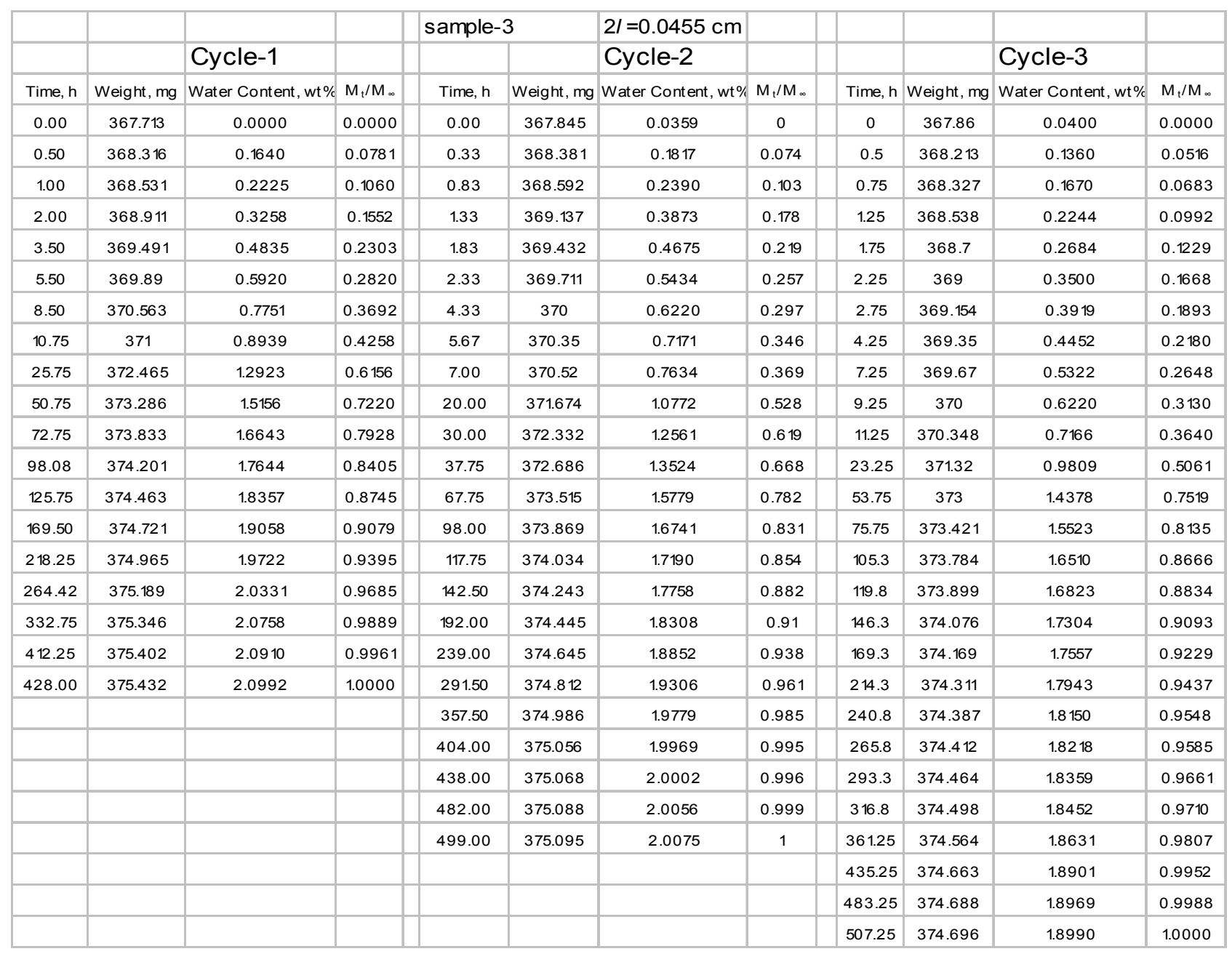


Table 21. Desorption Data of Polyester Samples containing 2 wt\% Cloisite $10 \mathrm{~A}$ at $25^{\circ} \mathrm{C}$ During Three Cycles of Absorption

\begin{tabular}{|c|c|c|c|c|c|c|c|c|c|c|c|}
\hline & & & & sample-1 & & $2 I=0.0577 \mathrm{~cm}$ & & & & & \\
\hline & & Cycle-1 & & & & Cycle-2 & & & & Cycle-3 & \\
\hline Time, $\mathrm{h}$ & Weight, mg & Water Content, wt $\%$ & $\ln (\mathrm{Mt}-\mathrm{M} \infty)$ & Time, h & Weight, mg & Water Content, wt $\%$ & $\ln (\mathrm{Mt}-\mathrm{M} \infty)$ & Time, $\mathrm{h}$ & Weight, mg & Water Content, wt $\%$ & $\ln (\mathrm{Mt}-\mathrm{M} \infty)$ \\
\hline 0.00 & 461.187 & 1.7269 & 2.0278 & 0 & 460.866 & 1.6561 & 1.9984 & 0 & 460.43 & 1.5599 & 1.8825 \\
\hline 0.25 & 460.89 & 1.6614 & 1.9879 & 0.5 & 460.677 & 1.6144 & 1.9724 & 0.25 & 460.21 & 1.5114 & 1.8485 \\
\hline 0.75 & 460.321 & 1.5359 & 1.9067 & 1 & 460.432 & 1.5604 & 1.9377 & 0.75 & 460 & 1.4651 & 1.8148 \\
\hline 1.75 & 459.675 & 1.3934 & 1.8058 & 1.75 & 460.123 & 1.4922 & 1.8922 & 1.25 & 459.679 & 1.3943 & 1.7611 \\
\hline 2.25 & 459.321 & 1.3153 & 1.7459 & 2.5 & 459.765 & 1.4132 & 1.8367 & 2.25 & 459 & 1.2445 & 1.6371 \\
\hline 4.25 & 458.444 & 1.1219 & 1.5798 & 4.5 & 459.122 & 1.2714 & 1.7286 & 3.25 & 458.237 & 1.0762 & 1.4764 \\
\hline 6.25 & 457.78 & 0.9754 & 1.4327 & 6.5 & 458.32 & 1.0945 & 1.5751 & 7 & 457.235 & 0.8552 & 1.2164 \\
\hline 8.58 & 457.43 & 0.8982 & 1.3455 & 8.5 & 457.213 & 0.8503 & 1.3148 & 10 & 456.531 & 0.6999 & 0.9825 \\
\hline 22.42 & 456.87 & 0.7747 & 1.1878 & 11.5 & 456 & 0.5828 & 0.9207 & 29.75 & 455.432 & 0.4575 & 0.4523 \\
\hline 24.50 & 456.021 & 0.5874 & 0.8883 & 32.5 & 455.3 & 0.4284 & 0.5939 & 54.75 & 454.897 & 0.3395 & 0.0363 \\
\hline 47.00 & 455 & 0.3622 & 0.3436 & 51.25 & 454.78 & 0.3137 & 0.2554 & 84.75 & 454.643 & 0.2834 & -0.2446 \\
\hline 70.75 & 454.453 & 0.2415 & -0.1473 & 78.5 & 454.321 & 0.2124 & -0.1839 & 111.25 & 454.397 & 0.2292 & -0.6218 \\
\hline 94.75 & 454.12 & 0.1681 & -0.6349 & 98.5 & 454 & 0.1416 & -0.6714 & 154.75 & 454.3 & 0.2078 & -0.8210 \\
\hline 112.25 & 453.98 & 0.1372 & -0.9416 & 145.25 & 453.87 & 0.1129 & -0.9650 & 198.75 & 454.1 & 0.1637 & -1.4271 \\
\hline 139.75 & 453.9 & 0.1196 & -1.1712 & 193.25 & 453.76 & 0.0887 & -1.3056 & 248.75 & 453.98 & 0.1372 & -2.1203 \\
\hline 187.50 & 453.832 & 0.1046 & -1.4188 & 246.25 & 453.69 & 0.0732 & -1.6045 & 292.75 & 453.94 & 0.1284 & -2.5257 \\
\hline 234.50 & 453.756 & 0.0878 & -1.7958 & 267.75 & 453.6 & 0.0534 & -2.1982 & 350.25 & 453.9 & 0.1196 & -3.2189 \\
\hline 285.75 & 453.7 & 0.0754 & -2.2073 & 311.75 & 453.578 & 0.0485 & -2.4191 & 395.75 & 453.89 & 0.1173 & -3.5066 \\
\hline 328.50 & 453.67 & 0.0688 & -2.5257 & 383.75 & 453.543 & 0.0408 & -2.9188 & 441.25 & 453.87 & 0.1129 & -4.6052 \\
\hline 380.25 & 453.64 & 0.0622 & -2.9957 & 431.75 & 453.512 & 0.0340 & -3.7723 & 486.75 & 453.86 & 0.1107 & \#NUM! \\
\hline 430.75 & 453.6 & 0.0534 & -4.6052 & 455.75 & 453.5 & 0.0313 & -4.5099 & & & & \\
\hline 453.50 & 453.590 & 0.0512 & \#NUM! & 479.5 & 453.489 & 0.0289 & \#NUM! & & & & \\
\hline
\end{tabular}




\begin{tabular}{|c|c|c|c|c|c|c|c|c|c|c|c|}
\hline & & & & sample-2 & & $2 I=0.0655 \mathrm{~cm}$ & & & & & \\
\hline & & Cycle-1 & & & & Cycle-2 & & & & Cycle-3 & \\
\hline Time, $\mathrm{h}$ & Weight, mg & Water Content, wt $\%$ & $\ln (\mathrm{Mt}-\mathrm{M} \infty)$ & Time, $\mathrm{h}$ & Weight, mg & Water Content, wt $\%$ & $\ln (\mathrm{Mt}-\mathrm{M} \infty)$ & Time, $\mathrm{h}$ & Weight, mg & Water Content, wt\% & $\ln (\mathrm{Mt}-\mathrm{M} \infty)$ \\
\hline 0.00 & 357.364 & 2.0839 & 1.9408 & 0 & 356.864 & 1.9410 & 1.9027 & 0 & 357.048 & 1.9936 & 1.93442 \\
\hline 0.25 & 356.896 & 1.9502 & 1.8712 & 0.5 & 356.651 & 1.8802 & 1.8704 & 0.25 & 356.394 & 1.8068 & 1.83514 \\
\hline 0.75 & 355.059 & 1.4254 & 1.5388 & 1 & 356.421 & 1.8145 & 1.8343 & 0.75 & 355.849 & 1.6511 & 1.74414 \\
\hline 1.75 & 354.496 & 1.2646 & 1.4100 & 1.75 & 356.235 & 1.7614 & 1.8042 & 1.25 & 355.463 & 1.5408 & 1.67429 \\
\hline 2.25 & 354.131 & 1.1603 & 1.3167 & 2.5 & 356.012 & 1.6977 & 1.7668 & 2.25 & 354.687 & 1.3192 & 1.5171 \\
\hline 4.25 & 353.615 & 1.0129 & 1. 1678 & 4.5 & 355.423 & 1.5294 & 1.6607 & 3.25 & 353.976 & 1.1161 & 1.34755 \\
\hline 6.25 & 352.542 & 0.7064 & 0.7617 & 6.5 & 354.334 & 1.2183 & 1.4289 & 7 & 352.687 & 0.7479 & 0.93962 \\
\hline 8.58 & 352.12 & 0.5859 & 0.5423 & 8.5 & 353.295 & 0.9215 & 1. 1426 & 10 & 351.627 & 0.4451 & 0.4048 \\
\hline 22.42 & 351.869 & 0.5142 & 0.3846 & 11.5 & 352.456 & 0.6819 & 0.8312 & 29.75 & 350.943 & 0.2497 & -0.2046 \\
\hline 24.50 & 351.343 & 0.3639 & -0.0587 & 32.5 & 352 & 0.5516 & 0.6098 & 54.75 & 350.591 & 0.1491 & -0.77 \\
\hline 47.00 & 351 & 0.2659 & -0.5108 & 51.25 & 351.532 & 0.4179 & 0.3163 & 84.75 & 350.542 & 0.1351 & -0.8819 \\
\hline 70.75 & 350.812 & 0.2122 & -0.8867 & 78.5 & 351.121 & 0.3005 & -0.0398 & 111.25 & 350.421 & 0.1006 & -1.2276 \\
\hline 94.75 & 350.7 & 0.1803 & -1.2040 & 98.5 & 350.786 & 0.2048 & -0.4684 & 154.75 & 350.312 & 0.0694 & -1.6928 \\
\hline 112.25 & 350.63 & 0.1603 & -1.4697 & 145.25 & 350.56 & 0.1403 & -0.9163 & 198.75 & 350.287 & 0.0623 & -1.8389 \\
\hline 139.75 & 350.58 & 0.1460 & -1.7148 & 193.25 & 350.42 & 0.1003 & -1.3471 & 248.75 & 350.234 & 0.0471 & -2.2443 \\
\hline 187.50 & 350.53 & 0.1317 & -2.0402 & 246.25 & 350.32 & 0.0717 & -1.8326 & 292.75 & 350.189 & 0.0343 & -2.7969 \\
\hline 234.50 & 350.5 & 0.1231 & -2.3026 & 267.75 & 350.267 & 0.0566 & -2.2349 & 350.25 & 350.167 & 0.0280 & -3.2442 \\
\hline 285.75 & 350.487 & 0.1194 & -2.4418 & 311.75 & 350.21 & 0.0403 & -2.9957 & 395.75 & 350.145 & 0.0217 & -4.0745 \\
\hline 328.50 & 350.466 & 0.1134 & -2.7181 & 383.75 & 350.187 & 0.0337 & -3.6119 & 441.25 & 350.132 & 0.0180 & -5.5215 \\
\hline 380.25 & 350.445 & 0.1074 & -3.1011 & 431.75 & 350.18 & 0.0317 & -3.9120 & 486.75 & 350.128 & 0.0169 & \#NUM! \\
\hline 430.75 & 350.42 & 0.1003 & -3.9120 & 455.75 & 350.16 & 0.0260 & \#NUM! & & & & \\
\hline 453.50 & 350.400 & 0.0946 & \#NUM! & 479.5 & 350.16 & 0.0260 & \#NUM! & & & & \\
\hline
\end{tabular}

\begin{tabular}{|c|c|c|c|c|c|c|c|c|c|c|c|}
\hline & & & & sample-3 & & $2 I=0.0455 \mathrm{~cm}$ & & & & & \\
\hline & & Cycle-1 & & & & Cycle-2 & & & & Cycle-3 & \\
\hline Time, $\mathrm{h}$ & Weight, mg & Water Content, wt $\%$ & $\ln (\mathrm{Mt}-\mathrm{M} \infty)$ & Time, $\mathrm{h}$ & Weight, mg & Water Content, wt $\%$ & $\ln (\mathrm{Mt}-\mathrm{M} \infty)$ & Time, $\mathrm{h}$ & Weight, mg & Water Content, wt $\%$ & $\ln (\mathrm{Mt}-\mathrm{M} \infty)$ \\
\hline 0.00 & 375.451 & 2.1044 & 2.0275 & 0 & 375.099 & 2.0086 & 1.9781 & 0 & 374.711 & 1.9031 & 1.9330 \\
\hline 0.25 & 375.211 & 2.0391 & 1.9954 & 0.5 & 374.685 & 1.8960 & 1.9191 & 0.25 & 374.156 & 1.7522 & 1.8492 \\
\hline 0.75 & 374.387 & 1.8150 & 1.8766 & 1 & 374.421 & 1.8242 & 1.8796 & 0.75 & 373.289 & 1.5164 & 1.7026 \\
\hline 1.75 & 373.279 & 1.5137 & 1.6906 & 1.75 & 374.156 & 1.7522 & 1.8383 & 1.25 & 372.905 & 1.4120 & 1.6300 \\
\hline 2.25 & 372.886 & 1.4068 & 1.6154 & 2.5 & 373.843 & 1.6671 & 1.7872 & 2.25 & 372.126 & 1.2001 & 1.4644 \\
\hline 4.25 & 371.579 & 1.0514 & 1.3145 & 4.5 & 373.021 & 1.4435 & 1.6392 & 3.25 & 371.421 & 1.0084 & 1.2865 \\
\hline 6.25 & 370.448 & 0.7438 & 0.9524 & 6.5 & 372 & 1. 1659 & 1.4183 & 7 & 370.784 & 0.8352 & 1.0929 \\
\hline 8.58 & 370.002 & 0.6225 & 0.7636 & 8.5 & 371.198 & 0.9478 & 1.2024 & 10 & 369.913 & 0.5983 & 0.7476 \\
\hline 22.42 & 369.546 & 0.4985 & 0.5247 & 11.5 & 370.564 & 0.7753 & 0.9910 & 29.75 & 369.337 & 0.4416 & 0.4292 \\
\hline 24.50 & 369.1 & 0.3772 & 0.2183 & 32.5 & 369.876 & 0.5882 & 0.6961 & 54.75 & 368.777 & 0.2894 & -0.0243 \\
\hline 47.00 & 368.864 & 0.3130 & 0.0080 & 51.25 & 369.234 & 0.4136 & 0.3104 & 84.75 & 368.564 & 0.2314 & -0.2705 \\
\hline 70.75 & 368.6 & 0.2412 & -0.2957 & 78.5 & 368.675 & 0.2616 & -0.2169 & 111.25 & 368.453 & 0.2012 & -0.4277 \\
\hline 94.75 & 368.457 & 0.2023 & -0.5092 & 98.5 & 368.321 & 0.1653 & -0.7963 & 154.75 & 368.323 & 0.1659 & -0.6501 \\
\hline 112.25 & 368.323 & 0.1659 & -0.7614 & 145.25 & 368.123 & 0.1115 & -1.3744 & 198.75 & 368.121 & 0.1110 & -1.1394 \\
\hline 139.75 & 368.213 & 0.1360 & -1.0300 & 193.25 & 368.032 & 0.0868 & -1.8202 & 248.75 & 368.002 & 0.0786 & -1.6045 \\
\hline 187.50 & 368.154 & 0.1199 & -1.2107 & 246.25 & 367.965 & 0.0685 & -2.3539 & 292.75 & 367.898 & 0.0503 & -2.3330 \\
\hline 234.50 & 368.067 & 0.0963 & -1.5559 & 267.75 & 367.932 & 0.0596 & -2.7806 & 350.25 & 367.856 & 0.0389 & -2.9004 \\
\hline 285.75 & 367.987 & 0.0745 & -2.0326 & 311.75 & 367.9 & 0.0509 & -3.5066 & 395.75 & 367.832 & 0.0324 & -3.4738 \\
\hline 328.50 & 367.943 & 0.0625 & -2.4418 & 383.75 & 367.89 & 0.0481 & -3.9120 & 441.25 & 367.811 & 0.0267 & -4.6052 \\
\hline 380.25 & 367.91 & 0.0536 & -2.9188 & 431.75 & 367.88 & 0.0454 & -4.6052 & 486.75 & 367.801 & 0.0239 & \#NUM! \\
\hline 430.75 & 367.878 & 0.0449 & -3.8167 & 455.75 & 367.87 & 0.0427 & \#NUM! & & & & \\
\hline 453.50 & 367.856 & 0.0389 & \#NUM! & 479.5 & 367.87 & 0.0427 & \#NUM! & & & & \\
\hline
\end{tabular}


Table 22. Sorption Data of Polyester Samples containing 5 wt\% Cloisite 10A at $25^{\circ} \mathrm{C}$ During Three Cycles of Absorption

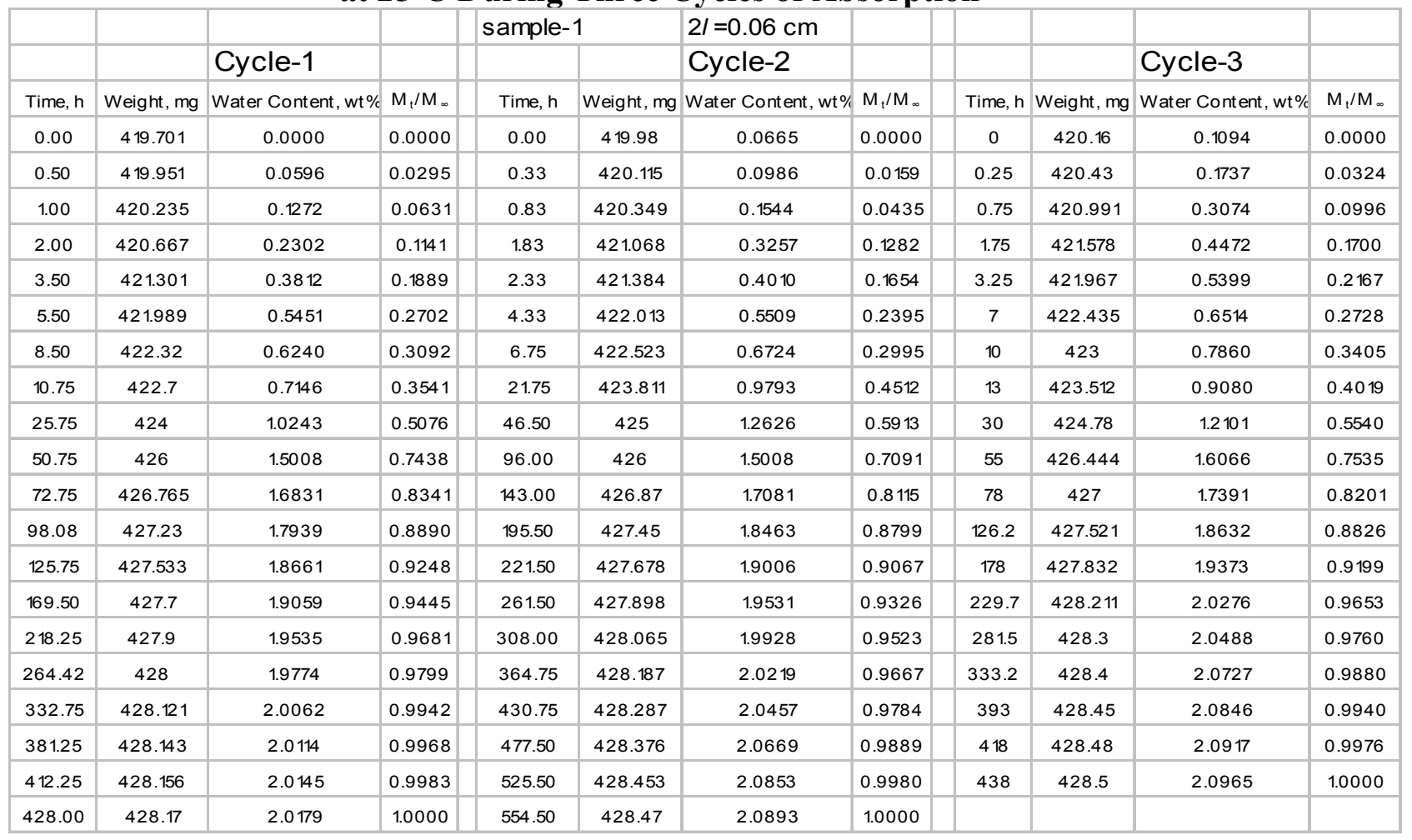

\begin{tabular}{|c|c|c|c|c|c|c|c|c|c|c|c|}
\hline & & & & sample- & & $2 I=0.06 \mathrm{~cm}$ & & & & & \\
\hline & & Cycle-1 & & & & Cycle-2 & & & & Cycle-3 & \\
\hline Time, $\mathrm{h}$ & Weight, mg & Water Content, wt \% & $M_{t} / M_{\infty}$ & Time, $\mathrm{h}$ & Weight, mg & Water Content, wt $\%$ & $M_{t} / M_{\infty}$ & Time, $\mathrm{h}$ & Weight, mg & Water Content, wt $\%$ & $M_{t} / M_{\infty}$ \\
\hline 0.00 & 341.934 & 0.0000 & 0.0000 & 0.00 & 341.941 & 0.0020 & 0.0000 & 0 & 342.04 & 0.0310 & 0.0000 \\
\hline 0.50 & 342.608 & 0.1971 & 0.0780 & 0.33 & 342.396 & 0.1351 & 0.0544 & 0.25 & 342.223 & 0.0845 & 0.0209 \\
\hline 1.00 & 343.012 & 0.3153 & 0.1247 & 0.83 & 342.715 & 0.2284 & 0.0925 & 0.75 & 342.687 & 0.2202 & 0.0739 \\
\hline 3.50 & 344.22 & 0.6686 & 0.2644 & 2.33 & 343.859 & 0.5630 & 0.2292 & 3.25 & 343.687 & 0.5127 & 0.1880 \\
\hline 5.50 & 344.641 & 0.7917 & 0.3131 & 4.33 & 344.665 & 0.7987 & 0.3255 & 7 & 344.32 & 0.6978 & 0.2603 \\
\hline 8.50 & 345.231 & 0.9642 & 0.3813 & 6.75 & 345.298 & 0.9838 & 0.4011 & 10 & 344.77 & 0.8294 & 0.3116 \\
\hline 10.75 & 345.6 & 1.0721 & 0.4240 & 21.75 & 346.564 & 1.3541 & 0.5524 & 13 & 345.231 & 0.9642 & 0.3643 \\
\hline 25.75 & 346.786 & 1.4190 & 0.5612 & 46.50 & 347.1 & 1.5108 & 0.6164 & 30 & 347 & 1.4816 & 0.5662 \\
\hline 50.75 & 348.33 & 1.8705 & 0.7398 & 96.00 & 347.98 & 1.7682 & 0.7216 & 55 & 348.67 & 1.9700 & 0.7568 \\
\hline 72.75 & 348.987 & 2.0627 & 0.8158 & 143.00 & 348.87 & 2.0285 & 0.8279 & 78 & 349.23 & 2.1337 & 0.8208 \\
\hline 98.08 & 349.4 & 2.1835 & 0.8635 & 195.50 & 349.5 & 2.2127 & 0.9032 & 126.2 & 349.765 & 2.2902 & 0.8818 \\
\hline 125.75 & 349.89 & 2.3268 & 0.9202 & 221.50 & 349.7 & 2.2712 & 0.9271 & 178 & 350.21 & 2.4204 & 0.9326 \\
\hline 169.50 & 350.2 & 2.4174 & 0.9560 & 261.50 & 349.876 & 2.3227 & 0.9481 & 229.7 & 350.51 & 2.5081 & 0.9669 \\
\hline 218.25 & 350.35 & 2.4613 & 0.9734 & 308.00 & 350 & 2.3589 & 0.9630 & 281.5 & 350.61 & 2.5373 & 0.9783 \\
\hline 264.42 & 350.45 & 2.4905 & 0.9850 & 364.75 & 350.098 & 2.3876 & 0.9747 & 333.2 & 350.7 & 2.5637 & 0.9886 \\
\hline 332.75 & 350.51 & 2.5081 & 0.9919 & 430.75 & 350.165 & 2.4072 & 0.9827 & 393 & 350.75 & 2.5783 & 0.9943 \\
\hline 381.25 & 350.54 & 2.5169 & 0.9954 & 477.50 & 350.243 & 2.4300 & 0.9920 & 418 & 350.789 & 2.5897 & 0.9987 \\
\hline 412.25 & 350.568 & 2.5250 & 0.9986 & 525.50 & 350.28 & 2.4408 & 0.9964 & 438 & 350.8 & 2.5929 & 1.0000 \\
\hline 428.00 & 350.58 & 2.5286 & 1.0000 & 554.50 & 350.31 & 2.4496 & 1.0000 & & & & \\
\hline
\end{tabular}




\begin{tabular}{|c|c|c|c|c|c|c|c|c|c|c|c|}
\hline & & & & sample- & & $2 I=0.04 \mathrm{~cm}$ & & & & & \\
\hline & & Cycle-1 & & & & Cycle-2 & & & & Cycle-3 & \\
\hline Time, $\mathrm{h}$ & Weight, mg & Water Content, wt $\%$ & $M_{t} / M_{\infty}$ & Time, $\mathrm{h}$ & Weight, mg & Water Content, wt $\%$ & $M_{t} / M_{\infty}$ & Time, $\mathrm{h}$ & Weight, mg & Water Content, wt $\%$ & $M_{t} / M_{\infty}$ \\
\hline 0.00 & 287.561 & 0.0000 & 0.0000 & 0.00 & 287.674 & 0.0393 & 0.0000 & 0 & 287.678 & 0.0407 & 0.0000 \\
\hline 0.50 & 287.745 & 0.0640 & 0.0220 & 0.33 & 287.875 & 0.1092 & 0.0243 & 0.25 & 287.887 & 0.1134 & 0.0247 \\
\hline 1.00 & 287.932 & 0.1290 & 0.0443 & 0.83 & 288.369 & 0.2810 & 0.0840 & 0.75 & 288.429 & 0.3018 & 0.0889 \\
\hline 3.50 & 288.77 & 0.4204 & 0.1444 & 2.33 & 289.397 & 0.6385 & 0.2081 & 3.25 & 289.512 & 0.6785 & 0.2171 \\
\hline 5.50 & 289.21 & 0.5734 & 0.1969 & 4.33 & 289.969 & 0.8374 & 0.2772 & 7 & 290.13 & 0.8934 & 0.2902 \\
\hline 8.50 & 289.89 & 0.8099 & 0.2781 & 6.75 & 290.545 & 1.0377 & 0.3468 & 10 & 290.786 & 1.1215 & 0.3679 \\
\hline 10.75 & 290.23 & 0.9282 & 0.3187 & 21.75 & 291.489 & 1.3660 & 0.4609 & 13 & 291.2 & 1.2655 & 0.4169 \\
\hline 25.75 & 292 & 1.5437 & 0.5301 & 46.50 & 292.654 & 1.7711 & 0.6016 & 30 & 293.089 & 1.9224 & 0.6404 \\
\hline 50.75 & 293.67 & 2.1244 & 0.7295 & 96.00 & 293.536 & 2.0778 & 0.7081 & 55 & 294.112 & 2.2781 & 0.7615 \\
\hline 98.08 & 295.245 & 2.6721 & 0.9176 & 195.50 & 294.841 & 2.5316 & 0.8658 & 126.2 & 295.574 & 2.7865 & 0.9345 \\
\hline 125.75 & 295.443 & 2.7410 & 0.9412 & 221.50 & 295.264 & 2.6787 & 0.9169 & 178 & 295.788 & 2.8610 & 0.9599 \\
\hline 169.50 & 295.654 & 2.8144 & 0.9664 & 261.50 & 295.454 & 2.7448 & 0.9398 & 229.7 & 295.922 & 2.9076 & 0.9757 \\
\hline 218.25 & 295.732 & 2.8415 & 0.9758 & 308.00 & 295.646 & 2.8116 & 0.9630 & 281.5 & 296.043 & 2.9496 & 0.9901 \\
\hline 264.42 & 295.765 & 2.8530 & 0.9797 & 364.75 & 295.785 & 2.8599 & 0.9798 & 333.2 & 296.076 & 2.9611 & 0.9940 \\
\hline 332.75 & 295.854 & 2.8839 & 0.9903 & 430.75 & 295.865 & 2.8877 & 0.9895 & 393 & 296.109 & 2.9726 & 0.9979 \\
\hline 381.25 & 295.889 & 2.8961 & 0.9945 & 477.50 & 295.889 & 2.8961 & 0.9924 & 418 & 296.121 & 2.9768 & 0.9993 \\
\hline 412.25 & 295.912 & 2.9041 & 0.9973 & 525.50 & 295.922 & 2.9076 & 0.9964 & 438 & 296.127 & 2.9788 & 1.0000 \\
\hline 428.00 & 295.935 & 2.9121 & 1.0000 & 554.50 & 295.952 & 2.9180 & 1.0000 & & & & \\
\hline
\end{tabular}


Table 23. Desorption Data of Polyester Samples containing 5 wt\% Cloisite $10 \mathrm{~A}$ at $25^{\circ} \mathrm{C}$ During Three Cycles of Absorption

\begin{tabular}{|c|c|c|c|c|c|c|c|c|c|c|c|}
\hline & & & & sample-1 & & $2 I=0.06 \mathrm{~cm}$ & & & & & \\
\hline & & Cycle-1 & & & & Cycle-2 & & & & Cycle-3 & \\
\hline Time, h & Weight, mg & Water Content, wt\% & $\ln (\mathrm{Mt}-\mathrm{M} \infty)$ & Time, h & Weight, mg & Water Content, wt\% & $\ln (\mathrm{Mt}-\mathrm{M} \infty)$ & Time, $\mathrm{h}$ & Weight, mg & Water Content, wt $\%$ & $\ln (\mathrm{Mt}-\mathrm{M} \infty)$ \\
\hline 0.00 & 428.18 & 2.0202 & 2.1017 & 0 & 428.48 & 2.0917 & 2.11746 & 0 & 428.51 & 2.0989 & 2.11866 \\
\hline 0.25 & 427.98 & 1.9726 & 2.0769 & 0.5 & 428.12 & 2.0060 & 2.07317 & 0.25 & 428.321 & 2.0538 & 2.09568 \\
\hline 0.75 & 427.32 & 1.8153 & 1.9906 & 0.75 & 427.878 & 1.9483 & 2.04226 & 0.5 & 428 & 1.9774 & 2.0554 \\
\hline 1.75 & 426.569 & 1.6364 & 1.8824 & 1.75 & 427.342 & 1.8206 & 1.97018 & 0.75 & 427.769 & 1.9223 & 2.02538 \\
\hline 3.25 & 425.879 & 1.4720 & 1.7714 & 4.75 & 426.654 & 1.6567 & 1.86934 & 1.25 & 427.624 & 1.8878 & 2.00606 \\
\hline 5.25 & 425.312 & 1.3369 & 1.6700 & 7.25 & 425.765 & 1.4448 & 1.72187 & 1.75 & 427.031 & 1.7465 & 1.92293 \\
\hline 8.58 & 424.786 & 1.2116 & 1.5657 & 9.25 & 424.482 & 1. 1391 & 1.4614 & 2.25 & 426.113 & 1.5278 & 1.77884 \\
\hline 10.42 & 424.564 & 1.1587 & 1.5182 & 11 & 423.563 & 0.9202 & 1.22171 & 3.25 & 425.114 & 1.2897 & 1.59412 \\
\hline 24.50 & 423.372 & 0.8747 & 1.2155 & 71.25 & 422.252 & 0.6078 & 0.73333 & 4.25 & 424.482 & 1.1391 & 1.45675 \\
\hline 47.00 & 422.811 & 0.7410 & 1.0335 & 95.25 & 421.897 & 0.5232 & 0.54639 & 5.25 & 423.913 & 1.0036 & 1.31453 \\
\hline 70.75 & 422.478 & 0.6617 & 0.9075 & 119.25 & 421.554 & 0.4415 & 0.32498 & 6.25 & 422.752 & 0.7269 & 0.94079 \\
\hline 94.75 & 421.854 & 0.5130 & 0.6173 & 176 & 421.231 & 0.3645 & 0.05921 & 8.5833 & 422.439 & 0.6524 & 0.81049 \\
\hline 139.75 & 421.312 & 0.3838 & 0.2716 & 200 & 421 & 0.3095 & -0.1863 & 10.417 & 422.216 & 0.5992 & 0.70606 \\
\hline 187.50 & 420.88 & 0.2809 & -0.1278 & 250 & 420.797 & 0.2611 & -0.4668 & 22.417 & 421.632 & 0.4601 & 0.36603 \\
\hline 234.50 & 420.688 & 0.2352 & -0.3740 & 292 & 420.6 & 0.2142 & -0.844 & 24.5 & 421.3 & 0.3810 & 0.10436 \\
\hline 285.75 & 420.5 & 0.1904 & -0.6931 & 345 & 420.5 & 0.1904 & -1.1087 & 47 & 420.9 & 0.2857 & -0.3425 \\
\hline 380.25 & 420.245 & 0.1296 & -1.4065 & 413 & 420.412 & 0.1694 & -1.4188 & 91.5 & 420.765 & 0.2535 & -0.5534 \\
\hline 477.50 & 420.132 & 0.1027 & -2.0250 & 507.25 & 420.34 & 0.1523 & -1.772 & 165.75 & 420.532 & 0.1980 & -1.0729 \\
\hline 501.50 & 420.076 & 0.0893 & -2.5770 & 536.25 & 420.287 & 0.1396 & -2.1456 & 260.25 & 420.343 & 0.1530 & -1.8773 \\
\hline \multirow[t]{4}{*}{549.50} & 420 & 0.0712 & \#NUM! & 581.25 & 420.23 & 0.1260 & -2.8134 & 310.75 & 420.24 & 0.1284 & -2.9957 \\
\hline & & & & 623.25 & 420.2 & 0.1189 & -3.5066 & 381.5 & 420.2 & 0.1189 & -4.6052 \\
\hline & & & & 646.25 & 420.189 & 0.1163 & -3.9633 & 429.5 & 420.198 & 0.1184 & -4.8283 \\
\hline & & & & 671.25 & 420.17 & 0.1117 & \#NUM! & 453.75 & 420.19 & 0.1165 & \#NUM! \\
\hline
\end{tabular}




\begin{tabular}{|c|c|c|c|c|c|c|c|c|c|c|c|}
\hline & & & & sample-2 & & $2 I=0.06 \mathrm{~cm}$ & & & & & \\
\hline & & Cycle-1 & & & & Cycle-2 & & & & Cycle-3 & \\
\hline Time, $\mathrm{h}$ & Weight, mg & Water Content, wt $\%$ & $\ln (\mathrm{Mt}-\mathrm{M} \infty)$ & Time, $\mathrm{h}$ & Weight, mg & Water Content, wt \% & $\ln (\mathrm{Mt}-\mathrm{M} \infty)$ & Time, $\mathrm{h}$ & Weight, mg & Water Content, wt $\%$ & $\ln (\mathrm{Mt}-\mathrm{M} \infty)$ \\
\hline 0.00 & 350.59 & 2.5315 & 2.1567 & 0.00 & 350.32 & 2.4525 & 2.1126 & 0.00 & 350.564 & 2.5239 & 2.1294 \\
\hline 0.25 & 350 & 2.3589 & 2.0860 & 0.50 & 350 & 2.3589 & 2.0732 & 0.25 & 350.1122 & 2.3917 & 2.0742 \\
\hline 0.75 & 349.675 & 2.2639 & 2.0449 & 0.75 & 349.786 & 2.2963 & 2.0459 & 0.50 & 349.876 & 2.3227 & 2.0441 \\
\hline 1.75 & 349.43 & 2.1922 & 2.0126 & 1.75 & 349.521 & 2.2188 & 2.0110 & 0.75 & 349.54 & 2.2244 & 1.9996 \\
\hline 3.25 & 349.21 & 2.1279 & 1.9828 & 4.75 & 348.418 & 1.8963 & 1.8513 & 1.25 & 349 & 2.0665 & 1.9237 \\
\hline 5.25 & 348.898 & 2.0367 & 1.9389 & 7.25 & 347.342 & 1.5816 & 1.6662 & 1.75 & 348.418 & 1.8963 & 1.8348 \\
\hline 8.58 & 348.745 & 1.9919 & 1.9166 & 9.25 & 346.624 & 1.3716 & 1.5204 & 2.25 & 347.342 & 1.5816 & 1.6463 \\
\hline 10.42 & 348.496 & 1.9191 & 1.8793 & 11.00 & 346 & 1.1891 & 1.3737 & 3.25 & 346.624 & 1.3716 & 1.4974 \\
\hline 24.50 & 347.706 & 1.6880 & 1.7508 & 71.25 & 344.589 & 0.7765 & 0.9318 & 4.25 & 346.047 & 1.2029 & 1.3592 \\
\hline 47.00 & 346.534 & 1.3453 & 1.5232 & 95.25 & 344.101 & 0.6337 & 0.7183 & 5.25 & 344.589 & 0.7765 & 0.8899 \\
\hline 70.75 & 345.764 & 1. 1201 & 1.3395 & 119.25 & 343.679 & 0.5103 & 0.4880 & 6.25 & 344.101 & 0.6337 & 0.6663 \\
\hline 94.75 & 345.081 & 0.9204 & 1. 1423 & 176.00 & 343.23 & 0.3790 & 0.1655 & 8.58 & 343.679 & 0.5103 & 0.4220 \\
\hline 139.75 & 344.026 & 0.6118 & 0.7319 & 200.00 & 342.978 & 0.3053 & -0.0747 & 10.42 & 343.23 & 0.3790 & 0.0733 \\
\hline 187.50 & 343.283 & 0.3945 & 0.2897 & 250.00 & 342.745 & 0.2372 & -0.3638 & 22.42 & 342.899 & 0.2822 & -0.2944 \\
\hline 234.50 & 342.787 & 0.2495 & -0.1744 & 292.00 & 342.632 & 0.2041 & -0.5413 & 24.50 & 342.8 & 0.2533 & -0.4370 \\
\hline 285.75 & 342.461 & 0.1541 & -0.6655 & 345.00 & 342.412 & 0.1398 & -1.0161 & 47.00 & 342.545 & 0.1787 & -0.9390 \\
\hline 380.25 & 342.101 & 0.0488 & -1.8708 & 413.00 & 342.3 & 0.1070 & -1.3863 & 91.50 & 342.41 & 0.1392 & -1.3626 \\
\hline 477.50 & 341.996 & 0.0181 & -3.0159 & 507.25 & 342.2 & 0.0778 & -1.8971 & 165.75 & 342.32 & 0.1129 & -1.7958 \\
\hline 501.50 & 341.986 & 0.0152 & -3.2442 & 536.25 & 342.15 & 0.0632 & -2.3026 & 260.25 & 342.276 & 0.1000 & -2.1037 \\
\hline \multirow[t]{4}{*}{549.50} & 341.947 & 0.0038 & \#NUM! & 581.25 & 342.11 & 0.0515 & -2.8134 & 310.75 & 342.223 & 0.0845 & -2.6736 \\
\hline & & & & 623.25 & 342.089 & 0.0453 & -3.2442 & 381.50 & 342.189 & 0.0746 & -3.3524 \\
\hline & & & & 646.25 & 342.06 & 0.0368 & -4.6052 & 429.50 & 342.176 & 0.0708 & -3.8167 \\
\hline & & & & 671.25 & 342.05 & 0.0339 & \#NUM! & 453.75 & 342.154 & 0.0643 & \#NUM! \\
\hline
\end{tabular}




\begin{tabular}{|c|c|c|c|c|c|c|c|c|c|c|c|}
\hline & & & & sample-3 & & $2 I=0.04 \mathrm{~cm}$ & & & & & \\
\hline & & Cycle-1 & & & & Cycle-2 & & & & Cycle-3 & \\
\hline Time, $\mathrm{h}$ & Weight, mg & Water Content, wt $\%$ & $\ln (\mathrm{Mt}-\mathrm{M} \infty)$ & Time, $\mathrm{h}$ & Weight, mg & Water Content, wt $\%$ & $\ln (\mathrm{Mt}-\mathrm{M} \infty)$ & Time, $\mathrm{h}$ & Weight, mg & Water Content, wt $\%$ & $\ln (\mathrm{Mt}-\mathrm{M} \infty)$ \\
\hline 0.00 & 295.951 & 2.9176 & 2.1128 & 0 & 295.944 & 2.9152 & 2.11106 & 0 & 294.947 & 2.5685 & 1.9526 \\
\hline 0.25 & 295.612 & 2.7998 & 2.0709 & 0.5 & 295.63 & 2.8060 & 2.07229 & 0.25 & 294.155 & 2.2931 & 1.83338 \\
\hline 0.75 & 295.043 & 2.6019 & 1.9965 & 0.75 & 294.947 & 2.5685 & 1.98238 & 0.5 & 293.953 & 2.2228 & 1.80055 \\
\hline 1.75 & 294.364 & 2.3658 & 1.8997 & 1.75 & 293.953 & 2.2228 & 1.83514 & 0.75 & 293.372 & 2.0208 & 1.69964 \\
\hline 3.25 & 293.532 & 2.0764 & 1.7668 & 4.75 & 292.255 & 1.6323 & 1.51908 & 1.25 & 292.255 & 1.6323 & 1.47132 \\
\hline 5.25 & 292.664 & 1.7746 & 1.6062 & 7.25 & 291.8 & 1.4741 & 1.41415 & 1.75 & 291.8 & 1.4741 & 1.36098 \\
\hline 8.58 & 291.845 & 1.4898 & 1.4267 & 9.25 & 291.231 & 1.2763 & 1.26526 & 2.25 & 291.231 & 1.2763 & 1.20327 \\
\hline 10.42 & 291.533 & 1.3813 & 1.3489 & 11 & 290.698 & 1.0909 & 1. 10227 & 3.25 & 290.698 & 1.0909 & 1.0289 \\
\hline 24.50 & 290.387 & 0.9827 & 0.9958 & 71.25 & 289.388 & 0.6353 & 0.53122 & 4.25 & 289.788 & 0.7744 & 0.63552 \\
\hline 47.00 & 289.612 & 0.7132 & 0.6586 & 95.25 & 288.999 & 0.5001 & 0.27155 & 5.25 & 289.53 & 0.6847 & 0.48858 \\
\hline 70.75 & 289.064 & 0.5227 & 0.3250 & 119.25 & 288.673 & 0.3867 & -0.0141 & 6.25 & 289.232 & 0.5811 & 0.28668 \\
\hline 94.75 & 288.815 & 0.4361 & 0.1266 & 176 & 288.476 & 0.3182 & -0.237 & 8.5833 & 288.967 & 0.4889 & 0.06485 \\
\hline 139.75 & 288.521 & 0.3338 & -0.1732 & 200 & 288.387 & 0.2872 & -0.3567 & 10.417 & 288.743 & 0.4110 & -0.1708 \\
\hline 187.50 & 288.311 & 0.2608 & -0.4604 & 250 & 288.203 & 0.2233 & -0.6616 & 22.417 & 288.632 & 0.3724 & -0.312 \\
\hline 234.50 & 288.086 & 0.1826 & -0.9014 & 292 & 288.112 & 0.1916 & -0.8557 & 24.5 & 288.53 & 0.3370 & -0.462 \\
\hline 285.75 & 287.932 & 0.1290 & -1.3783 & 345 & 287.977 & 0.1447 & -1.2379 & 47 & 288.412 & 0.2959 & -0.6694 \\
\hline 380.25 & 287.812 & 0.0873 & -2.0250 & 413 & 287.855 & 0.1022 & -1.7838 & 91.5 & 288.3 & 0.2570 & -0.9163 \\
\hline 477.50 & 287.734 & 0.0602 & -2.9188 & 507.25 & 287.8 & 0.0831 & -2.1804 & 165.75 & 288.2 & 0.2222 & -1.204 \\
\hline 501.50 & 287.689 & 0.0445 & -4.7105 & 536.25 & 287.776 & 0.0748 & -2.4191 & 260.25 & 288.087 & 0.1829 & -1.6766 \\
\hline \multirow[t]{4}{*}{549.50} & 287.68 & 0.0414 & \#NUM! & 581.25 & 287.743 & 0.0633 & -2.8824 & 310.75 & 287.998 & 0.1520 & -2.3228 \\
\hline & & & & 623.25 & 287.723 & 0.0563 & -3.3242 & 381.5 & 287.956 & 0.1374 & -2.8824 \\
\hline & & & & 646.25 & 287.7 & 0.0483 & -4.3428 & 429.5 & 287.932 & 0.1290 & -3.442 \\
\hline & & & & 671.25 & 287.687 & 0.0438 & \#NUM! & 453.75 & 287.9 & 0.1179 & \#NUM! \\
\hline
\end{tabular}


Table 24. Sorption Data of Epoxy Samples containing $0 \mathrm{wt} \%$ Cloisite $10 \mathrm{~A}$ at $25^{\circ} \mathrm{C}$ During Three Cycles of Absorption

\begin{tabular}{|c|c|c|c|c|c|c|c|c|c|c|c|}
\hline & & & & sample-1 & & $2 I=0.104 \mathrm{~cm}$ & & & & & \\
\hline & & Cycle-1 & & & & Cycle-2 & & & & Cycle-3 & \\
\hline Time, $\mathrm{h}$ & Weight, mg & Water Content, wt $\%$ & $\mathrm{Mt} / \mathrm{M} \infty$ & Time, $\mathrm{h}$ & Weight, mg & Water Content, wt $\%$ & $\mathrm{Mt} / \mathrm{M} \infty$ & Time, $\mathrm{h}$ & Weight, mg & Water Content, wt $\%$ & $\mathrm{Mt} / \mathrm{M} \infty$ \\
\hline 0 & 791.108 & 0.0000 & 0.0000 & 0.00 & 791.251 & 0.0181 & 0.0000 & 0 & 791.336 & 0.0288 & 0.0000 \\
\hline 0.5 & 791.262 & 0.0194 & 0.0116 & 0.50 & 791.693 & 0.0739 & 0.0338 & 0.25 & 791.618 & 0.0644 & 0.0216 \\
\hline 1.5 & 791.859 & 0.0948 & 0.0566 & 1.00 & 792.015 & 0.1145 & 0.0583 & 0.75 & 791.915 & 0.1019 & 0.0443 \\
\hline 4 & 791.954 & 0.1068 & 0.0638 & 1.50 & 792 & 0.1126 & 0.0572 & 1.25 & 791.942 & 0.1053 & 0.0464 \\
\hline 5.5 & 792.459 & 0.1706 & 0.1019 & 2.50 & 792.426 & 0.1664 & 0.0897 & 2.25 & 792.45 & 0.1695 & 0.0853 \\
\hline 7 & 792.795 & 0.2130 & 0.1272 & 3.50 & 792.87 & 0.2225 & 0.1236 & 4.25 & 792.679 & 0.1984 & 0.1028 \\
\hline 8 & 792.81 & 0.2149 & 0.1283 & 5.50 & 793.21 & 0.2655 & 0.1496 & 6.75 & 793.043 & 0.2444 & 0.1307 \\
\hline 10.75 & 793.089 & 0.2502 & 0.1494 & 7.50 & 793.52 & 0.3046 & 0.1733 & 8.75 & 793.423 & 0.2924 & 0.1598 \\
\hline 11.75 & 793.553 & 0.3088 & 0.1843 & 8.50 & 793.89 & 0.3513 & 0.2015 & 10.75 & 793.743 & 0.3328 & 0.1842 \\
\hline 25.75 & 794.64 & 0.4460 & 0.2663 & 10.50 & 794.123 & 0.3807 & 0.2193 & 22.75 & 794.659 & 0.4484 & 0.2544 \\
\hline 32.75 & 795.803 & 0.5929 & 0.3540 & 11.50 & 794.316 & 0.4051 & 0.2341 & 44.25 & 796.856 & 0.7259 & 0.4225 \\
\hline 49.75 & 796.88 & 0.7289 & 0.4352 & 12.50 & 794.437 & 0.4204 & 0.2433 & 67.5 & 797.684 & 0.8305 & 0.4859 \\
\hline 75.25 & 798.026 & 0.8736 & 0.5216 & 24.50 & 795.613 & 0.5689 & 0.3331 & 192.5 & 801.231 & 1.2784 & 0.7574 \\
\hline 95.25 & 798.972 & 0.9931 & 0.5929 & 45.00 & 796.372 & 0.6648 & 0.3911 & 435.25 & 803.21 & 1.5283 & 0.9089 \\
\hline 122.75 & 799.667 & 1.0809 & 0.6453 & 75.50 & 797.707 & 0.8334 & 0.4931 & 501.25 & 803.654 & 1.5844 & 0.9429 \\
\hline 149.25 & 800.383 & 1.1713 & 0.6993 & 94.00 & 798.502 & 0.9338 & 0.5538 & 581.25 & 804 & 1.6281 & 0.9694 \\
\hline 166.25 & 800.764 & 1.2194 & 0.7280 & 118.50 & 799.245 & 1.0276 & 0.6105 & 627.25 & 804.213 & 1.6550 & 0.9857 \\
\hline 192 & 801.246 & 1.2803 & 0.7643 & 150.50 & 800.173 & 1.1448 & 0.6814 & 675.25 & 804.31 & 1.6672 & 0.9931 \\
\hline 218.25 & 801.696 & 1.3371 & 0.7983 & 172.50 & 800.672 & 1.2078 & 0.7195 & 723.25 & 804.35 & 1.6723 & 0.9962 \\
\hline 244.75 & 802.122 & 1.3909 & 0.8304 & 188.50 & 801.095 & 1.2612 & 0.7518 & 747.25 & 804.39 & 1.6773 & 0.9992 \\
\hline 271.25 & 802.441 & 1.4312 & 0.8544 & 221.00 & 801.745 & 1.3433 & 0.8014 & 771.25 & 804.4 & 1.6786 & 1.0000 \\
\hline 291.25 & 802.782 & 1.4743 & 0.8801 & 271.00 & 802.472 & 1.4351 & 0.8570 & & & & \\
\hline 313.5 & 802.946 & 1.4950 & 0.8925 & 314.50 & 803.102 & 1.5147 & 0.9051 & & & & \\
\hline 337 & 803.091 & 1.5133 & 0.9034 & 364.00 & 803.445 & 1.5580 & 0.9313 & & & & \\
\hline 365 & 803.304 & 1.5402 & 0.9195 & 417.00 & 803.702 & 1.5904 & 0.9509 & & & & \\
\hline 387 & 803.445 & 1.5580 & 0.9301 & 462.00 & 803.926 & 1.6187 & 0.9680 & & & & \\
\hline 409 & 803.572 & 1.5740 & 0.9397 & 509.00 & 804.122 & 1.6435 & 0.9830 & & & & \\
\hline 437.75 & 803.713 & 1.5918 & 0.9503 & 549.00 & 804.193 & 1.6524 & 0.9884 & & & & \\
\hline 486.25 & 803.890 & 1.6142 & 0.9637 & 601.00 & 804.232 & 1.6574 & 0.9914 & & & & \\
\hline 538.25 & 804.075 & 1.6375 & 0.9776 & 650.00 & 804.292 & 1.6649 & 0.9960 & & & & \\
\hline 579.75 & 804.237 & 1.6580 & 0.9898 & 675.00 & 804.315 & 1.6678 & 0.9977 & & & & \\
\hline 629.25 & 804.299 & 1.6658 & 0.9945 & 702.00 & 804.345 & 1.6716 & 1.0000 & & & & \\
\hline 671.25 & 804.339 & 1.6709 & 0.9975 & & & & & & & & \\
\hline 700.25 & 804.335 & 1.6704 & 0.9972 & & & & & & & & \\
\hline 752.67 & 804.350 & 1.6723 & 0.9983 & & & & & & & & \\
\hline 793.75 & 804.381 & 1.6762 & 1.0007 & & & & & & & & \\
\hline 818.25 & 804.372 & 1.6750 & 1.0000 & & & & & & & & \\
\hline
\end{tabular}




\begin{tabular}{|c|c|c|c|c|c|c|c|c|c|c|c|}
\hline & & & & sample-2 & & $2 I=0.104 \mathrm{~cm}$ & & & & & \\
\hline & & Cycle-1 & & & & Cycle-2 & & & & Cycle-3 & \\
\hline Time, $\mathrm{h}$ & Weight, mg & Water Content, wt $\%$ & $\mathrm{Mt} / \mathrm{M} \infty$ & Time, $\mathrm{h}$ & Weight, mg & Water Content, wt $\%$ & $\mathrm{Mt} / \mathrm{M} \infty$ & Time, $\mathrm{h}$ & Weight, mg & Water Content, wt $\%$ & $\mathrm{Mt} / \mathrm{M} \infty$ \\
\hline 0 & 691.349 & 0.0000 & 0.0000 & 0.00 & 692.059 & 0.1025 & 0 & 0 & 692.192 & 0.1218 & 0 \\
\hline 0.5 & 691.875 & 0.0760 & 0.0423 & 0.50 & 692.21 & 0.1244 & 0.0126 & 0.25 & 692.518 & 0.1688 & 0.02803 \\
\hline 1.5 & 692.371 & 0.1476 & 0.0821 & 1.00 & 692.261 & 0.1317 & 0.0168 & 0.75 & 692.661 & 0.1895 & 0.04033 \\
\hline 5.5 & 693.026 & 0.2422 & 0.1347 & 2.50 & 692.942 & 0.2301 & 0.0736 & 2.25 & 693.321 & 0.2848 & 0.09708 \\
\hline 7 & 693.289 & 0.2802 & 0.1558 & 3.50 & 693.185 & 0.2652 & 0.0939 & 4.25 & 693.765 & 0.3489 & 0.13527 \\
\hline 8 & 693.376 & 0.2928 & 0.1628 & 5.50 & 693.562 & 0.3196 & 0.1253 & 6.75 & 694 & 0.3829 & 0.15547 \\
\hline 10.75 & 693.511 & 0.3123 & 0.1737 & 7.50 & 693.917 & 0.3709 & 0.1549 & 8.75 & 694.564 & 0.4643 & 0.20397 \\
\hline 11.75 & 693.883 & 0.3660 & 0.2036 & 8.50 & 694.083 & 0.3949 & 0.1688 & 10.75 & 695 & 0.5273 & 0.24147 \\
\hline 25.75 & 695 & 0.5273 & 0.2933 & 10.50 & 694.441 & 0.4466 & 0.1986 & 22.75 & 695.643 & 0.6202 & 0.29676 \\
\hline 49.75 & 696.2 & 0.7006 & 0.3897 & 12.50 & 694.793 & 0.4974 & 0.228 & 67.5 & 698 & 0.9606 & 0.49944 \\
\hline 75.25 & 697 & 0.8162 & 0.4540 & 24.50 & 695.465 & 0.5945 & 0.284 & 192.5 & 700.786 & 1.3630 & 0.73901 \\
\hline 95.25 & 698 & 0.9606 & 0.5343 & 45.00 & 696.574 & 0.7547 & 0.3765 & 435.25 & 702.976 & 1.6793 & 0.92734 \\
\hline 122.75 & 698.41 & 1.0198 & 0.5672 & 75.50 & 697.793 & 0.9307 & 0.4781 & 501.25 & 703.423 & 1.7439 & 0.96578 \\
\hline 149.25 & 698.943 & 1.0968 & 0.6101 & 94.00 & 698.476 & 1.0294 & 0.5351 & 581.25 & 703.611 & 1.7710 & 0.98194 \\
\hline 166.25 & 699.2 & 1.1339 & 0.6307 & 118.50 & 699.018 & 1.1076 & 0.5803 & 627.25 & 703.7 & 1.7839 & 0.98959 \\
\hline 192 & 699.4 & 1.1628 & 0.6468 & 150.50 & 699.702 & 1.2064 & 0.6373 & 675.25 & 703.743 & 1.7901 & 0.99329 \\
\hline 218.25 & 699.8 & 1.2206 & 0.6789 & 172.50 & 700.221 & 1.2814 & 0.6806 & 723.25 & 703.768 & 1.7937 & 0.99544 \\
\hline 244.75 & 700.222 & 1.2815 & 0.7128 & 188.50 & 700.527 & 1.3256 & 0.7061 & 747.25 & 703.791 & 1.7970 & 0.99742 \\
\hline 271.25 & 700.918 & 1.3821 & 0.7687 & 221.00 & 701.083 & 1.4059 & 0.7524 & 771.25 & 703.821 & 1.8013 & 1 \\
\hline 291.25 & 701.155 & 1.4163 & 0.7878 & 271.00 & 702.002 & 1.5386 & 0.8291 & & & & \\
\hline 365 & 702.097 & 1.5523 & 0.8634 & 417.00 & 703.216 & 1.7140 & 0.9303 & & & & \\
\hline 387 & 702.331 & 1.5861 & 0.8822 & 462.00 & 703.482 & 1.7524 & 0.9525 & & & & \\
\hline 409 & 702.554 & 1.6184 & 0.9001 & 509.00 & 703.671 & 1.7797 & 0.9682 & & & & \\
\hline 437.75 & 702.793 & 1.6529 & 0.9193 & 549.00 & 703.827 & 1.8022 & 0.9812 & & & & \\
\hline 486.25 & 703.013 & 1.6846 & 0.9370 & 601.00 & 703.972 & 1.8232 & 0.9933 & & & & \\
\hline 538.25 & 703.174 & 1.7079 & 0.9500 & 650.00 & 704.032 & 1.8318 & 0.9983 & & & & \\
\hline 579.75 & 703.355 & 1.7340 & 0.9645 & 675.00 & 704.043 & 1.8334 & 0.9992 & & & & \\
\hline 629.25 & 703.464 & 1.7498 & 0.9732 & 702.00 & 704.052 & 1.8347 & 1.0000 & & & & \\
\hline 671.25 & 703.575 & 1.7658 & 0.9822 & & & & & & & & \\
\hline 700.25 & 703.641 & 1.7753 & 0.9875 & & & & & & & & \\
\hline 752.67 & 703.730 & 1.7882 & 0.9946 & & & & & & & & \\
\hline 793.75 & 703.780 & 1.7954 & 0.9986 & & & & & & & & \\
\hline 818.25 & 703.797 & 1.7979 & 1.0000 & & & & & & & & \\
\hline
\end{tabular}




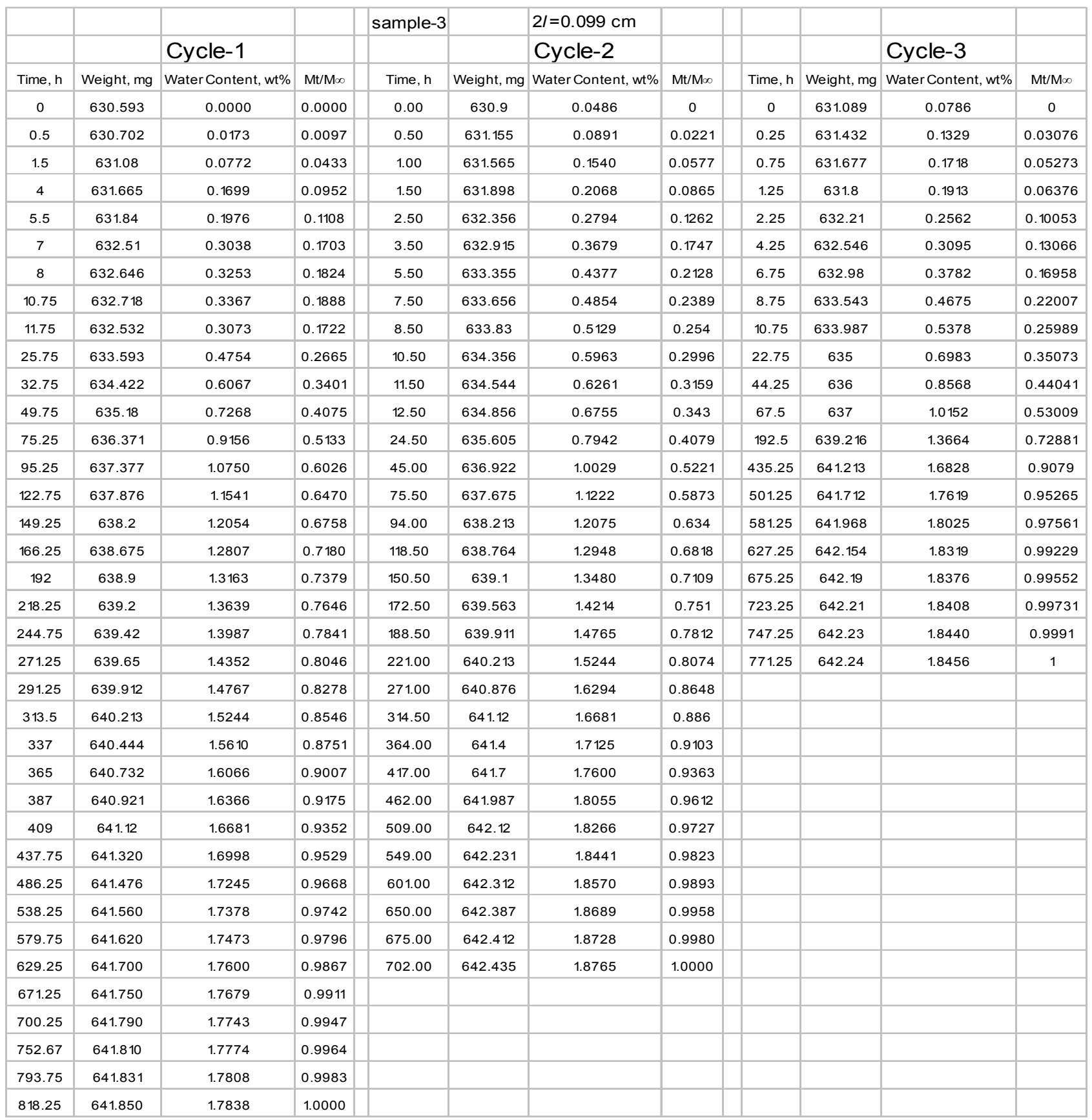


Table 25. Desorption Data of Epoxy Samples containing 0 wt\% Cloisite 10A at $25^{\circ} \mathrm{C}$ During Three Cycles of Absorption

\begin{tabular}{|c|c|c|c|c|c|c|c|c|c|c|c|}
\hline & & & & sample-1 & & $2 I=0.104 \mathrm{~cm}$ & & & & & \\
\hline & & Cycle-1 & & & & Cycle-2 & & & & Cycle-3 & \\
\hline Time, $\mathrm{h}$ & Weight, mg & Water Content, wt $\%$ & $\ln (\mathrm{Mt}-\mathrm{M} \infty)$ & Time, $\mathrm{h}$ & Weight, mg & Water Content, wt \% & $\ln (\mathrm{Mt}-\mathrm{M} \infty)$ & Time, $\mathrm{h}$ & Weight, mg & Water Content, wt $\%$ & $\ln (\mathrm{Mt}-\mathrm{M} \infty)$ \\
\hline 0 & 804.383 & 1.6764 & 2.5751 & 0 & 804.36 & 1.6735 & 2.56649 & 0 & 804.423 & 1.6815 & 2.52429 \\
\hline 0.5 & 804.055 & 1.6350 & 2.5498 & 0.25 & 804.101 & 1.6408 & 2.54639 & 0.25 & 804 & 1.6281 & 2.48981 \\
\hline 1 & 803.971 & 1.6244 & 2.5432 & 0.75 & 803.769 & 1.5989 & 2.52003 & 0.75 & 803.561 & 1.5726 & 2.45273 \\
\hline 1.75 & 803.935 & 1.6199 & 2.5403 & 1.25 & 803.55 & 1.5712 & 2.50226 & 1.25 & 803 & 1.5018 & 2.40324 \\
\hline 2.75 & 803.416 & 1.5543 & 2.4986 & 2 & 803.012 & 1.5033 & 2.45719 & 2 & 802.567 & 1.4471 & 2.3633 \\
\hline 3.25 & 803.302 & 1.5399 & 2.4891 & 2.75 & 802.669 & 1.4600 & 2.42737 & 2.5 & 802.121 & 1.3908 & 2.32043 \\
\hline 3.5 & 802.905 & 1.4898 & 2.4556 & 4 & 802.337 & 1.4181 & 2.39762 & 3 & 801.87 & 1.3591 & 2.29546 \\
\hline 4.5 & 802.572 & 1.4477 & 2.4267 & 5 & 801.906 & 1.3636 & 2.35764 & 3.5 & 801.234 & 1.2788 & 2.22926 \\
\hline 5.5 & 802.366 & 1.4217 & 2.4083 & 6.5 & 801.57 & 1.3212 & 2.32532 & 6 & 800 & 1. 1229 & 2.08679 \\
\hline 6.5 & 802.115 & 1.3900 & 2.3855 & 8 & 801.234 & 1.2788 & 2.29193 & 9 & 799 & 0.9966 & 1.9543 \\
\hline 8.5 & 801.905 & 1.3635 & 2.3659 & 9.5 & 800.891 & 1.2354 & 2.25665 & 43 & 796.23 & 0.6468 & 1.45605 \\
\hline 10.5 & 801.424 & 1.3028 & 2.3197 & 11 & 800.553 & 1.1928 & 2.22062 & 72 & 795.213 & 0.5184 & 1. 1854 \\
\hline 11.5 & 800.907 & 1.2375 & 2.2676 & 23 & 799.112 & 1.0108 & 2.05053 & 101 & 794.215 & 0.3924 & 0.82154 \\
\hline 19.75 & 800.297 & 1. 1604 & 2.2023 & 48 & 797.885 & 0.8558 & 1.8787 & 106 & 793.89 & 0.3513 & 0.66732 \\
\hline 30.5 & 799.137 & 1.0139 & 2.0651 & 73.5 & 796.725 & 0.7093 & 1.68362 & 135 & 793.44 & 0.2945 & 0.4048 \\
\hline 45.25 & 798.095 & 0.8824 & 1.9234 & 99.5 & 795.778 & 0.5898 & 1.4902 & 164 & 792.864 & 0.2218 & -0.0801 \\
\hline 74 & 796.696 & 0.7057 & 1.6947 & 125 & 794.67 & 0.4498 & 1.20297 & 217 & 792.412 & 0.1647 & -0.7529 \\
\hline 105.75 & 794.804 & 0.4667 & 1.2678 & 142 & 794.086 & 0.3761 & 1.01015 & 275 & 792.1 & 0.1253 & -1.8389 \\
\hline 124.75 & 794.012 & 0.3667 & 1.0156 & 172 & 793.659 & 0.3222 & 0.84114 & 304 & 792.05 & 0.1190 & -2.2164 \\
\hline 152.5 & 793.18 & 0.2617 & 0.6570 & 199.5 & 793.14 & 0.2566 & 0.58779 & 381 & 792 & 0.1126 & -2.8302 \\
\hline 169 & 792.674 & 0.1978 & 0.3528 & 219 & 792.869 & 0.2224 & 0.42461 & 434 & 791.965 & 0.1082 & -3.7297 \\
\hline 196 & 792.329 & 0.1542 & 0.0751 & 248 & 792.45 & 0.1695 & 0.10436 & 511 & 791.95 & 0.1063 & -4.7105 \\
\hline 202.5 & 792.124 & 0.1283 & -0.1358 & 297.5 & 792.095 & 0.1246 & -0.281 & 564 & 791.941 & 0.1052 & \#NUM! \\
\hline 244.5 & 791.991 & 0.1115 & -0.3011 & 340.5 & 791.785 & 0.0855 & -0.8097 & & & & \\
\hline 268.5 & 791.879 & 0.0974 & -0.4652 & 382 & 791.624 & 0.0652 & -1.2588 & & & & \\
\hline 292.25 & 791.78 & 0.0849 & -0.6368 & 437.5 & 791.491 & 0.0484 & -1.8905 & & & & \\
\hline 310 & 791.712 & 0.0763 & -0.7744 & 483 & 791.423 & 0.0398 & -2.4889 & & & & \\
\hline 337.5 & 791.622 & 0.0649 & -0.9916 & 503.5 & 791.403 & 0.0373 & -2.7646 & & & & \\
\hline 385.25 & 791.513 & 0.0511 & -1.3394 & 583.5 & 791.369 & 0.0330 & -3.5405 & & & & \\
\hline 433.5 & 791.421 & 0.0395 & -1.772 & 663.5 & 791.359 & 0.0317 & -3.9633 & & & & \\
\hline 484 & 791.36 & 0.0318 & -2.2164 & 743.5 & 791.34 & 0.0293 & \#NUM! & & & & \\
\hline 533.25 & 791.315 & 0.0261 & -2.7489 & & & & & & & & \\
\hline 574.5 & 791.299 & 0.0241 & -3.0366 & & & & & & & & \\
\hline 625.75 & 791.284 & 0.0222 & -3.4112 & & & & & & & & \\
\hline 645.25 & 791.268 & 0.0202 & -4.0745 & & & & & & & & \\
\hline 680 & 791.251 & 0.0181 & \#NUM! & & & & & & & & \\
\hline
\end{tabular}




\begin{tabular}{|c|c|c|c|c|c|c|c|c|c|c|c|}
\hline & & & & sample-2 & & $2 I=0.104 \mathrm{~cm}$ & & & & & \\
\hline & & Cycle-1 & & & & Cycle-2 & & & & Cycle-3 & \\
\hline Time, $\mathrm{h}$ & Weight, mg & Water Content, wt $\%$ & $\ln (\mathrm{Mt}-\mathrm{M} \infty)$ & Time, $\mathrm{h}$ & Weight, mg & Water Content, wt $\%$ & $\ln (\mathrm{Mt}-\mathrm{M} \infty)$ & Time, $\mathrm{h}$ & Weight, mg & Water Content, wt $\%$ & $\ln (\mathrm{Mt}-\mathrm{M} \infty)$ \\
\hline 0 & 703.804 & 1.7989 & 2.4627 & 0 & 703.84 & 1.8041 & 2.4544 & 0 & 703.84 & 1.8041 & 2.5047 \\
\hline 0.5 & 703.443 & 1.7468 & 2.4314 & 0.25 & 703.712 & 1.7856 & 2.4434 & 0.25 & 703.423 & 1.7439 & 2.4700 \\
\hline 1 & 703.341 & 1.7320 & 2.4224 & 0.75 & 703.423 & 1.7439 & 2.4180 & 0.75 & 702.952 & 1.6758 & 2.4294 \\
\hline 1.75 & 702.701 & 1.6396 & 2.3640 & 1.25 & 703.331 & 1.7306 & 2.4097 & 1.25 & 702.671 & 1.6353 & 2.4043 \\
\hline 2.75 & 702.274 & 1.5779 & 2.3230 & 2 & 702.952 & 1.6758 & 2.3751 & 2 & 702.24 & 1.5730 & 2.3646 \\
\hline 3.25 & 702.177 & 1.5639 & 2.3134 & 2.75 & 702.671 & 1.6353 & 2.3486 & 2.5 & 701. 184 & 1.4205 & 2.2601 \\
\hline 3.5 & 702.014 & 1.5404 & 2.2972 & 4 & 702.502 & 1.6108 & 2.3323 & 3 & 700.32 & 1.2957 & 2.1656 \\
\hline 4.5 & 701.84 & 1.5152 & 2.2795 & 5 & 702.24 & 1.5730 & 2.3066 & 3.5 & 700 & 1.2495 & 2.1282 \\
\hline 5.5 & 701.626 & 1.4843 & 2.2574 & 6.5 & 702.132 & 1.5574 & 2.2958 & 6 & 699.675 & 1.2025 & 2.0888 \\
\hline 6.5 & 701.332 & 1.4419 & 2.2261 & 8 & 702.02 & 1.5412 & 2.2844 & 9 & 697.9 & 0.9462 & 1.8405 \\
\hline 8.5 & 701.028 & 1.3979 & 2.1928 & 9.5 & 701.814 & 1.5115 & 2.2632 & 43 & 697 & 0.8162 & 1.6864 \\
\hline 10.5 & 700.635 & 1.3412 & 2.1479 & 11 & 701.44 & 1.4575 & 2.2235 & 72 & 696.321 & 0.7181 & 1.5520 \\
\hline 11.5 & 700.335 & 1.2979 & 2.1123 & 23 & 700.34 & 1.2986 & 2.0968 & 101 & 694 & 0.3829 & 0.8755 \\
\hline 19.75 & 699.614 & 1. 1937 & 2.0210 & 48 & 699.33 & 1.1527 & 1.9643 & 106 & 693.333 & 0.2866 & 0.5499 \\
\hline 30.5 & 699.197 & 1.1335 & 1.9642 & 73.5 & 698.285 & 1.0018 & 1.8058 & 135 & 693.228 & 0.2714 & 0.4874 \\
\hline 45.25 & 698.311 & 1.0055 & 1.8315 & 99.5 & 697.231 & 0.8495 & 1.6156 & 164 & 692.972 & 0.2344 & 0.3163 \\
\hline 74 & 697.485 & 0.8862 & 1.6895 & 125 & 696.54 & 0.7497 & 1.4679 & 217 & 692.2 & 0.1229 & -0.5108 \\
\hline 105.75 & 696.311 & 0.7167 & 1.4453 & 142 & 695.776 & 0.6394 & 1.2742 & 275 & 691.889 & 0.0780 & -1.2413 \\
\hline 124.75 & 695.597 & 0.6135 & 1.2610 & 172 & 695.161 & 0.5506 & 1.0855 & 304 & 691.789 & 0.0635 & -1.6660 \\
\hline 152.5 & 695.074 & 0.5380 & 1.1006 & 199.5 & 694.34 & 0.4320 & 0.7608 & 381 & 691.7 & 0.0507 & -2.3026 \\
\hline 169 & 694.584 & 0.4672 & 0.9227 & 219 & 693.672 & 0.3355 & 0.3866 & 434 & 691.656 & 0.0443 & -2.8824 \\
\hline 196 & 694.210 & 0.4132 & 0.7617 & 248 & 693.2 & 0.2673 & 0.0000 & 511 & 691.612 & 0.0380 & -4.4228 \\
\hline 202.5 & 694.074 & 0.3936 & 0.69614 & 297.5 & 692.972 & 0.2344 & -0.2588 & 564 & 691.6 & 0.0363 & \#NUM! \\
\hline 244.5 & 693.383 & 0.2938 & 0.27384 & 340.5 & 692.761 & 0.2039 & -0.5780 & & & & \\
\hline 268.5 & 693.074 & 0.2491 & 0.00598 & 382 & 692.521 & 0.1693 & -1.1363 & & & & \\
\hline 292.25 & 692.807 & 0.2106 & -0.3025 & 437.5 & 692.334 & 0.1423 & -2.0099 & & & & \\
\hline 310 & 692.678 & 0.1919 & -0.4943 & 483 & 692.289 & 0.1358 & -2.4191 & & & & \\
\hline 337.5 & 692.578 & 0.1775 & -0.6733 & 503.5 & 692.265 & 0.1323 & -2.7334 & & & & \\
\hline 385.25 & 692.4 & 0.1518 & -1.1026 & 583.5 & 692.245 & 0.1294 & -3.1011 & & & & \\
\hline 433.5 & 692.3 & 0.1374 & -1.461 & 663.5 & 692.23 & 0.1272 & -3.5066 & & & & \\
\hline 484 & 692.21 & 0.1244 & -1.9519 & 743.5 & 692.2 & 0.1229 & \#NUM! & & & & \\
\hline 533.25 & 692.132 & 0.1131 & -2.7489 & & & & & & & & \\
\hline 574.5 & 692.099 & 0.1083 & -3.4738 & & & & & & & & \\
\hline 625.75 & 692.09 & 0.1070 & -3.8167 & & & & & & & & \\
\hline 645.25 & 692.08 & 0.1056 & -4.4228 & & & & & & & & \\
\hline 680 & 692.068 & 0.1038 & \#NUM! & & & & & & & & \\
\hline
\end{tabular}




\begin{tabular}{|c|c|c|c|c|c|c|c|c|c|c|c|}
\hline & & & & sample-3 & & $2 I=0.099 \mathrm{~cm}$ & & & & & \\
\hline & & Cycle-1 & & & & Cycle-2 & & & & Cycle-3 & \\
\hline Time, $\mathrm{h}$ & Weight, mg & Water Content, wt $\%$ & $\ln (\mathrm{Mt}-\mathrm{M} \infty)$ & Time, $\mathrm{h}$ & Weight, mg & Water Content, wt\% & $\ln (\mathrm{Mt}-\mathrm{M} \infty)$ & Time, $\mathrm{h}$ & Weight, mg & Water Content, wt $\%$ & $\ln (\mathrm{Mt}-\mathrm{M} \infty)$ \\
\hline 0 & 641.86 & 1.7854 & 2.3878 & 0 & 642.441 & 1.8774 & 2.42842 & 0 & 642.241 & 1.8457 & 2.3274 \\
\hline 0.5 & 641.56 & 1.7378 & 2.3599 & 0.25 & 642.123 & 1.8270 & 2.39998 & 0.25 & 642 & 1.8075 & 2.3036 \\
\hline 1 & 641.432 & 1.7175 & 2.3477 & 0.75 & 641.875 & 1.7877 & 2.37723 & 0.75 & 641.78 & 1.7727 & 2.2814 \\
\hline 1.75 & 641.213 & 1.6828 & 2.3266 & 1.25 & 641.611 & 1.7459 & 2.35242 & 1.25 & 641.512 & 1.7302 & 2.2536 \\
\hline 2.75 & 641 & 1.6491 & 2.3056 & 2 & 641.321 & 1.6999 & 2.32444 & 2 & 641.231 & 1.6857 & 2.2237 \\
\hline 3.25 & 640.732 & 1.6066 & 2.2785 & 2.75 & 641 & 1.6491 & 2.29253 & 2.5 & 640.889 & 1.6315 & 2.1859 \\
\hline 3.5 & 640.543 & 1.5767 & 2.2589 & 4 & 640.732 & 1.6066 & 2.26509 & 3 & 640.53 & 1.5746 & 2.1448 \\
\hline 4.5 & 640.312 & 1.5401 & 2.2345 & 5 & 640.432 & 1.5591 & 2.23345 & 3.5 & 640.213 & 1.5244 & 2.1069 \\
\hline 5.5 & 640.1 & 1.5065 & 2.2116 & 6.5 & 640.12 & 1.5096 & 2.19944 & 6 & 640 & 1.4906 & 2.0807 \\
\hline 6.5 & 639.87 & 1.4700 & 2.1861 & 8 & 639.867 & 1.4695 & 2.17099 & 9 & 639 & 1.3322 & 1.9473 \\
\hline 8.5 & 639.621 & 1.4306 & 2.1577 & 9.5 & 639.711 & 1.4448 & 2.15304 & 43 & 637.865 & 1.1523 & 1.7707 \\
\hline 10.5 & 639.4 & 1.3955 & 2.1318 & 11 & 639.521 & 1.4147 & 2.13073 & 72 & 637 & 1.0152 & 1.6114 \\
\hline 11.5 & 639.1 & 1.3480 & 2.0956 & 23 & 639.241 & 1.3703 & 2.09691 & 101 & 636.211 & 0.8902 & 1.4401 \\
\hline 19.75 & 638.9 & 1.3163 & 2.0707 & 48 & 638.365 & 1.2315 & 1.98307 & 106 & 635.456 & 0.7706 & 1.2430 \\
\hline 30.5 & 638.567 & 1.2635 & 2.0278 & 73.5 & 637.245 & 1.0541 & 1.81564 & 135 & 634.787 & 0.6646 & 1.0285 \\
\hline 45.25 & 637.459 & 1.0880 & 1.8701 & 99.5 & 636.266 & 0.8989 & 1.6421 & 164 & 633.999 & 0.5397 & 0.6976 \\
\hline 74 & 635.956 & 0.8498 & 1.6066 & 125 & 635.208 & 0.7313 & 1.41294 & 217 & 633 & 0.3814 & 0.0100 \\
\hline 105.75 & 634.497 & 0.6186 & 1.2604 & 142 & 634.213 & 0.5736 & 1. 13559 & 275 & 632.453 & 0.2947 & -0.7700 \\
\hline 124.75 & 633.845 & 0.5153 & 1.0561 & 172 & 633.034 & 0.3868 & 0.65959 & 304 & 632.35 & 0.2784 & -1.0217 \\
\hline 152.5 & 633.275 & 0.4250 & 0.8351 & 199.5 & 632.476 & 0.2984 & 0.31918 & 381 & 632.12 & 0.2420 & -2.0402 \\
\hline 169 & 632.767 & 0.3445 & 0.5861 & 219 & 632.256 & 0.2635 & 0.14497 & 434 & 632.1 & 0.2388 & -2.2073 \\
\hline 196 & 632.356 & 0.2794 & 0.3264 & 248 & 632.065 & 0.2333 & -0.0356 & 511 & 632 & 0.2230 & -4.6052 \\
\hline 202.5 & 632.167 & 0.2494 & 0.17982 & 297.5 & 631.809 & 0.1927 & -0.3439 & 564 & 631.99 & 0.2214 & \#NUM! \\
\hline 244.5 & 631.82 & 0.1944 & -0.1625 & 340.5 & 631.687 & 0.1734 & -0.5327 & & & & \\
\hline 268.5 & 631.656 & 0.1684 & -0.3769 & 382 & 631.587 & 0.1575 & -0.7195 & & & & \\
\hline 292.25 & 631.532 & 0.1488 & -0.5763 & 437.5 & 631.4 & 0.1279 & -1.204 & & & & \\
\hline 310 & 631.43 & 0.1326 & -0.7765 & 483 & 631.3 & 0.1120 & -1.6094 & & & & \\
\hline 337.5 & 631.34 & 0.1184 & -0.9943 & 503.5 & 631.21 & 0.0978 & -2.2073 & & & & \\
\hline 385.25 & 631.26 & 0.1057 & -1.2379 & 583.5 & 631.178 & 0.0927 & -2.551 & & & & \\
\hline 433.5 & 631.2 & 0.0962 & -1.4697 & 663.5 & 631.15 & 0.0883 & -2.9957 & & & & \\
\hline 484 & 631.11 & 0.0819 & -1.9661 & 743.5 & 631.1 & 0.0803 & \#NUM! & & & & \\
\hline 533.25 & 631.088 & 0.0784 & -2.1371 & & & & & & & & \\
\hline 574.5 & 631.02 & 0.0677 & -2.9957 & & & & & & & & \\
\hline 625.75 & 631 & 0.0645 & -3.5066 & & & & & & & & \\
\hline 645.25 & 630.98 & 0.0613 & -4.6052 & & & & & & & & \\
\hline 680 & 630.97 & 0.0597 & \#NUM! & & & & & & & & \\
\hline
\end{tabular}


Table 26. Sorption Data of Epoxy Samples containing $2 \mathrm{wt} \%$ Cloisite $10 \mathrm{~A}$ at $25^{\circ} \mathrm{C}$ During Three Cycles of Absorption

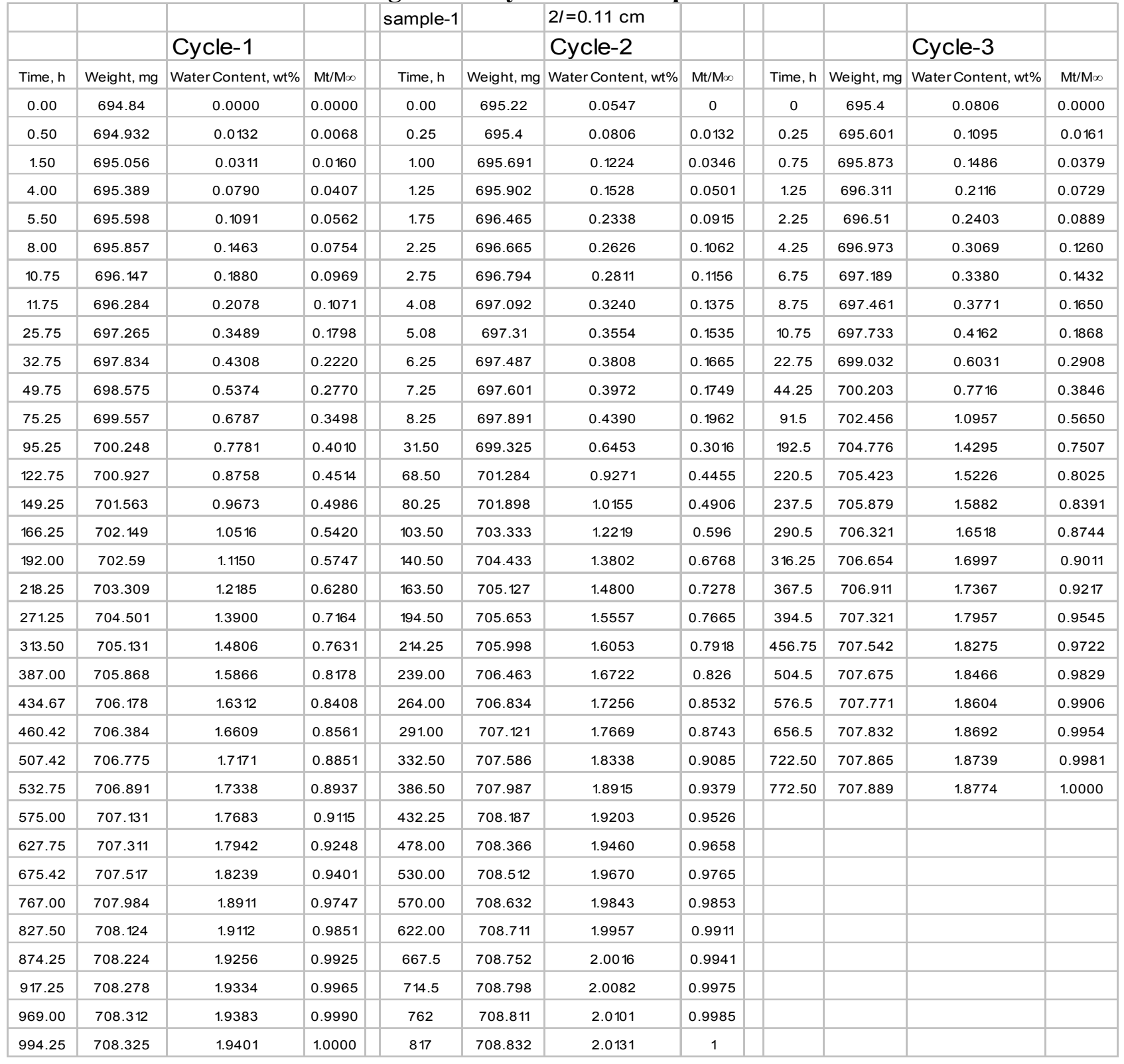




\begin{tabular}{|c|c|c|c|c|c|c|c|c|c|c|c|}
\hline & & & & sample-2 & & $2 I=0.0877 \mathrm{~cm}$ & & & & & \\
\hline & & Cycle-1 & & & & Cycle-2 & & & & Cycle-3 & \\
\hline Time, h & Weight, mg & Water Content, wt $\%$ & $\mathrm{Mt} / \mathrm{M} \infty$ & Time, $\mathrm{h}$ & Weight, mg & Water Content, wt $\%$ & $\mathrm{Mt} / \mathrm{M} \infty$ & Time, $\mathrm{h}$ & Weight, mg & Water Content, wt $\%$ & $\mathrm{Mt} / \mathrm{M} \infty$ \\
\hline 0 & 521.93 & 0.0000 & 0.0000 & 0.00 & 522 & 0.0134 & 0 & 0 & 522.365 & 0.0833 & 0.0000 \\
\hline 0.5 & 522.053 & 0.0236 & 0.0136 & 0.25 & 522.134 & 0.0391 & 0.015 & 0.25 & 522.54 & 0.1168 & 0.0210 \\
\hline 1.5 & 522.189 & 0.0496 & 0.0286 & 1.00 & 522.278 & 0.0666 & 0.0311 & 0.75 & 522.748 & 0.1566 & 0.0460 \\
\hline 4 & 522.568 & 0.1222 & 0.0706 & 1.25 & 522.398 & 0.0896 & 0.0445 & 1.25 & 522.904 & 0.1865 & 0.0647 \\
\hline 5.5 & 522.781 & 0.1630 & 0.0941 & 1.75 & 522.567 & 0.1220 & 0.0634 & 2.25 & 523.07 & 0.2183 & 0.0846 \\
\hline 8 & 523.184 & 0.2401 & 0.1387 & 2.25 & 522.616 & 0.1314 & 0.0689 & 4.25 & 523.288 & 0.2601 & 0.1108 \\
\hline 10.75 & 523.345 & 0.2710 & 0.1565 & 2.75 & 522.734 & 0.1540 & 0.0821 & 6.75 & 523.586 & 0.3171 & 0.1465 \\
\hline 11.75 & 523.478 & 0.2964 & 0.1712 & 4.08 & 522.812 & 0.1689 & 0.0908 & 8.75 & 523.734 & 0.3455 & 0.1643 \\
\hline 25.75 & 524.289 & 0.4518 & 0.2609 & 5.08 & 523.187 & 0.2407 & 0.1328 & 10.75 & 524.037 & 0.4035 & 0.2006 \\
\hline 32.75 & 524.624 & 0.5159 & 0.2980 & 6.25 & 523.395 & 0.2805 & 0.156 & 22.75 & 525.206 & 0.6274 & 0.3409 \\
\hline 49.75 & 525.241 & 0.6341 & 0.3662 & 7.25 & 523.538 & 0.3079 & 0.172 & 44.25 & 526.244 & 0.8261 & 0.4655 \\
\hline 75.25 & 525.892 & 0.7587 & 0.4382 & 8.25 & 523.687 & 0.3365 & 0.1887 & 91.5 & 527.482 & 1.0632 & 0.6141 \\
\hline 95.25 & 526.398 & 0.8556 & 0.4942 & 31.50 & 524.838 & 0.5569 & 0.3174 & 192.5 & 528.325 & 1.2247 & 0.7152 \\
\hline 122.75 & 526.831 & 0.9385 & 0.5421 & 68.50 & 526.231 & 0.8236 & 0.4732 & 220.5 & 529.205 & 1.3932 & 0.8208 \\
\hline 149.25 & 527.301 & 1.0286 & 0.5941 & 80.25 & 526.726 & 0.9184 & 0.5286 & 237.5 & 529.432 & 1.4366 & 0.8481 \\
\hline 166.25 & 527.414 & 1.0502 & 0.6066 & 103.50 & 527.348 & 1.0376 & 0.5981 & 290.5 & 529.673 & 1.4828 & 0.8770 \\
\hline 192 & 527.562 & 1.0785 & 0.6229 & 140.50 & 527.991 & 1. 1607 & 0.6701 & 316.25 & 529.911 & 1.5284 & 0.9056 \\
\hline 218.25 & 527.912 & 1. 1456 & 0.6617 & 163.50 & 528.669 & 1.2905 & 0.7459 & 367.5 & 530.321 & 1.6069 & 0.9548 \\
\hline 271.25 & 528.524 & 1.2628 & 0.7293 & 194.50 & 529.032 & 1.3600 & 0.7865 & 394.5 & 530.421 & 1.6260 & 0.9668 \\
\hline 313.5 & 528.867 & 1.3284 & 0.7673 & 214.25 & 529.331 & 1.4173 & 0.8199 & 456.75 & 530.511 & 1.6433 & 0.9776 \\
\hline 387 & 529.526 & 1.4546 & 0.8402 & 239.00 & 529.521 & 1.4537 & 0.8412 & 504.5 & 530.589 & 1.6582 & 0.9869 \\
\hline 434.667 & 529.786 & 1.5044 & 0.8689 & 264.00 & 529.713 & 1.4905 & 0.8627 & 576.5 & 530.612 & 1.6626 & 0.9897 \\
\hline 460.417 & 529.865 & 1.5196 & 0.8777 & 291.00 & 529.898 & 1.5259 & 0.8833 & 656.5 & 530.667 & 1.6731 & 0.9963 \\
\hline 507.417 & 530.025 & 1.5502 & 0.8954 & 332.50 & 530.165 & 1.5770 & 0.9132 & 722.50 & 530.687 & 1.6770 & 0.9987 \\
\hline 532.75 & 530.154 & 1.5749 & 0.9096 & 386.50 & 530.376 & 1.6174 & 0.9368 & 772.50 & 530.698 & 1.6791 & 1.0000 \\
\hline 575 & 530.281 & 1.5992 & 0.9237 & 432.25 & 530.586 & 1.6576 & 0.9603 & & & & \\
\hline 627.75 & 530.462 & 1.6339 & 0.9437 & 478.00 & 530.732 & 1.6856 & 0.9766 & & & & \\
\hline 675.42 & 530.596 & 1.6596 & 0.9585 & 530.00 & 530.811 & 1.7007 & 0.9855 & & & & \\
\hline 767.00 & 530.798 & 1.6982 & 0.9809 & 570.00 & 530.854 & 1.7090 & 0.9903 & & & & \\
\hline 827.50 & 530.869 & 1.7118 & 0.9887 & 622.00 & 530.897 & 1.7172 & 0.9951 & & & & \\
\hline 874.25 & 530.908 & 1.7193 & 0.9930 & 667.50 & 530.912 & 1.7201 & 0.9968 & & & & \\
\hline 917.25 & 530.934 & 1.7243 & 0.9959 & 714.5 & 530.921 & 1.7218 & 0.9978 & & & & \\
\hline 969.00 & 530.959 & 1.7291 & 0.9987 & 762 & 530.929 & 1.7233 & 0.9987 & & & & \\
\hline 994.25 & 530.971 & 1.7314 & 1.0000 & 817 & 530.941 & 1.7256 & 1 & & & & \\
\hline
\end{tabular}




\begin{tabular}{|c|c|c|c|c|c|c|c|c|c|c|c|}
\hline & & & & sample-3 & & $2 I=0.0889 \mathrm{~cm}$ & & & & & \\
\hline & & Cycle-1 & & & & Cycle-2 & & & & Cycle-3 & \\
\hline Time, $\mathrm{h}$ & Weight, mg & Water Content, wt $\%$ & $\mathrm{Mt} / \mathrm{M} \infty$ & Time, $\mathrm{h}$ & Weight, mg & Water Content, wt $\%$ & $\mathrm{Mt} / \mathrm{M} \infty$ & Time, $\mathrm{h}$ & Weight, mg & Water Content, wt $\%$ & $\mathrm{Mt} / \mathrm{M} \infty$ \\
\hline 0.00 & 685.34 & 0.0000 & 0.0000 & 0.00 & 685.644 & 0.0443 & 0 & 0 & 685.67 & 0.0481 & 0.0000 \\
\hline 0.50 & 685.43 & 0.0131 & 0.0077 & 0.25 & 685.781 & 0.0643 & 0.012 & 0.25 & 685.8 & 0.0671 & 0.0120 \\
\hline 1.50 & 685.677 & 0.0491 & 0.0288 & 1.00 & 686.003 & 0.0967 & 0.0315 & 0.75 & 686.209 & 0.1267 & 0.0497 \\
\hline 5.50 & 686.167 & 0.1206 & 0.0706 & 1.75 & 686.722 & 0.2016 & 0.0944 & 2.25 & 686.916 & 0.2298 & 0.1149 \\
\hline 8.00 & 686.611 & 0.1854 & 0.1085 & 2.25 & 686.9 & 0.2275 & 0.11 & 4.25 & 687.567 & 0.3248 & 0.1750 \\
\hline 10.75 & 686.934 & 0.2325 & 0.1361 & 2.75 & 687.1 & 0.2567 & 0.1276 & 6.75 & 687.502 & 0.3153 & 0.1690 \\
\hline 11.75 & 687.212 & 0.2730 & 0.1598 & 4.08 & 687.305 & 0.2866 & 0.1455 & 8.75 & 687.769 & 0.3542 & 0.1936 \\
\hline 25.75 & 688.011 & 0.3895 & 0.2280 & 5.08 & 687.6 & 0.3296 & 0.1714 & 10.75 & 688.116 & 0.4049 & 0.2256 \\
\hline 32.75 & 688.578 & 0.4722 & 0.2764 & 6.25 & 687.72 & 0.3471 & 0.1819 & 22.75 & 689.694 & 0.6350 & 0.3712 \\
\hline 75.25 & 690.317 & 0.7259 & 0.4249 & 8.25 & 687.989 & 0.3863 & 0.2054 & 91.5 & 692.101 & 0.9860 & 0.5933 \\
\hline 95.25 & 690.879 & 0.8078 & 0.4729 & 31.50 & 690.24 & 0.7146 & 0.4027 & 192.5 & 693.495 & 1. 1893 & 0.7219 \\
\hline 122.75 & 691.423 & 0.8872 & 0.5193 & 68.50 & 691.739 & 0.9332 & 0.534 & 220.5 & 693.757 & 1.2275 & 0.7460 \\
\hline 149.25 & 691.912 & 0.9585 & 0.5610 & 80.25 & 692.558 & 1.0527 & 0.6057 & 237.5 & 694.538 & 1.3414 & 0.8181 \\
\hline 166.25 & 692.105 & 0.9866 & 0.5775 & 103.50 & 693.259 & 1.1549 & 0.6672 & 290.5 & 694.884 & 1.3919 & 0.8500 \\
\hline 192.00 & 692.467 & 1.0394 & 0.6084 & 140.50 & 693.911 & 1.2500 & 0.7243 & 316.25 & 695.327 & 1.4565 & 0.8909 \\
\hline 218.25 & 692.674 & 1.0696 & 0.6261 & 163.50 & 694.538 & 1.3414 & 0.7792 & 367.5 & 695.621 & 1.4994 & 0.9180 \\
\hline 271.25 & 693.357 & 1. 1692 & 0.6844 & 194.50 & 694.884 & 1.3919 & 0.8095 & 394.5 & 695.854 & 1.5334 & 0.9395 \\
\hline 313.50 & 693.621 & 1.2077 & 0.7069 & 214.25 & 695.327 & 1.4565 & 0.8483 & 456.75 & 695.994 & 1.5538 & 0.9524 \\
\hline 387.00 & 694.192 & 1.2910 & 0.7557 & 239.00 & 695.621 & 1.4994 & 0.8741 & 504.5 & 696.221 & 1.5869 & 0.9733 \\
\hline 434.67 & 694.636 & 1.3557 & 0.7936 & 264.00 & 695.854 & 1.5334 & 0.8945 & 576.5 & 696.396 & 1.6124 & 0.9895 \\
\hline 532.75 & 695.347 & 1.4594 & 0.8543 & 386.50 & 696.585 & 1.6400 & 0.9586 & 772.50 & 696.510 & 1.6290 & 1.0000 \\
\hline 575.00 & 695.512 & 1.4835 & 0.8684 & 432.25 & 696.734 & 1.6617 & 0.9716 & & & & \\
\hline 627.75 & 695.772 & 1.5214 & 0.8906 & 478.00 & 696.823 & 1.6747 & 0.9794 & & & & \\
\hline 675.42 & 696.054 & 1.5625 & 0.9146 & 530.00 & 696.884 & 1.6836 & 0.9848 & & & & \\
\hline 767.00 & 696.523 & 1.6309 & 0.9547 & 570.00 & 696.912 & 1.6877 & 0.9872 & & & & \\
\hline 827.50 & 696.812 & 1.6731 & 0.9793 & 622.00 & 696.956 & 1.6941 & 0.9911 & & & & \\
\hline 874.25 & 696.932 & 1.6906 & 0.9896 & 667.50 & 696.997 & 1.7001 & 0.9947 & & & & \\
\hline 917.25 & 696.965 & 1.6954 & 0.9924 & 714.50 & 697.032 & 1.7052 & 0.9977 & & & & \\
\hline 969.00 & 697.020 & 1.7034 & 0.9971 & 762.00 & 697.054 & 1.7084 & 0.9996 & & & & \\
\hline 994.25 & 697.054 & 1.7084 & 1.0000 & 817.00 & 697.058 & 1.7090 & 1 & & & & \\
\hline
\end{tabular}


Table 27. Desorption Data of Epoxy Samples containing 2 wt\% Cloisite 10A at $25^{\circ} \mathrm{C}$ During Three Cycles of Absorption

\begin{tabular}{|c|c|c|c|c|c|c|c|c|c|c|c|}
\hline & & & & sample-1 & & $2 I=0.11 \mathrm{~cm}$ & & & & & \\
\hline & & Cycle-1 & & & & Cycle-2 & & & & Cycle-3 & \\
\hline Time, $\mathrm{h}$ & Weight, mg & Water Content, wt $\%$ & $\ln (\mathrm{Mt}-\mathrm{M} \infty)$ & Time, h & Weight, mg & Water Content, wt $\%$ & $\ln (\mathrm{Mt}-\mathrm{M} \infty)$ & Time, $\mathrm{h}$ & Weight, mg & Water Content, wt $\%$ & $\ln (\mathrm{Mt}-\mathrm{M} \infty)$ \\
\hline 0 & 708.341 & 1.9424 & 2.5735 & 0.00 & 708.842 & 2.0145 & 2.59764 & 0 & 707.678 & 1.8470 & 2.51915 \\
\hline 0.25 & 708.081 & 1.9050 & 2.5534 & 0.25 & 708.686 & 1.9921 & 2.58596 & 0.25 & 707.364 & 1.8019 & 2.49354 \\
\hline 0.5 & 707.791 & 1.8633 & 2.5306 & 0.75 & 708.304 & 1.9371 & 2.55676 & 0.75 & 707.089 & 1.7623 & 2.47055 \\
\hline 0.75 & 707.207 & 1.7793 & 2.4830 & 1.25 & 708.048 & 1.9003 & 2.53671 & 1.25 & 706.821 & 1.7237 & 2.44764 \\
\hline 1.25 & 706.955 & 1.7430 & 2.4617 & 2.25 & 707.678 & 1.8470 & 2.50699 & 2 & 706.629 & 1.6961 & 2.43089 \\
\hline 1.75 & 706.549 & 1.6846 & 2.4265 & 3.75 & 707.364 & 1.8019 & 2.48107 & 2.5 & 706.355 & 1.6567 & 2.40649 \\
\hline 2.25 & 706.233 & 1.6391 & 2.3982 & 5.25 & 707.089 & 1.7623 & 2.45779 & 3 & 705.232 & 1.4951 & 2.29978 \\
\hline 3.25 & 705.826 & 1.5806 & 2.3605 & 7.25 & 706.821 & 1.7237 & 2.43458 & 3.5 & 704.604 & 1.4048 & 2.23473 \\
\hline 4.25 & 705.371 & 1.5151 & 2.3166 & 9.25 & 706.629 & 1.6961 & 2.41761 & 6 & 703 & 1.1740 & 2.0464 \\
\hline 5.25 & 705.2 & 1.4905 & 2.2996 & 11.25 & 706.355 & 1.6567 & 2.39288 & 9 & 700.222 & 0.7743 & 1.60181 \\
\hline 6.25 & 704.781 & 1.4302 & 2.2566 & 22.17 & 705.232 & 1.4951 & 2.28462 & 43 & 698 & 0.4546 & 1.00796 \\
\hline 8.5 & 704.062 & 1.3268 & 2.1784 & 29.00 & 704.604 & 1.4048 & 2.21855 & 72 & 697.3 & 0.3539 & 0.71295 \\
\hline 10.25 & 703.532 & 1.2505 & 2.1165 & 52.50 & 703 & 1.1740 & 2.02683 & 101 & 696.89 & 0.2949 & 0.48858 \\
\hline 22.25 & 702.273 & 1.0694 & 1.9520 & 95.75 & 700.222 & 0.7743 & 1.57111 & 106 & 696.789 & 0.2804 & 0.42461 \\
\hline 28.75 & 701.182 & 0.9124 & 1.7837 & 120.75 & 699.323 & 0.6450 & 1.3643 & 135 & 696.2 & 0.1957 & -0.0619 \\
\hline 46.75 & 700.151 & 0.7641 & 1.5935 & 148.50 & 698.23 & 0.4877 & 1.03674 & 164 & 695.6 & 0.1093 & -1.0788 \\
\hline 70.75 & 698.213 & 0.4853 & 1.0929 & 166.75 & 697.532 & 0.3873 & 0.75236 & 217 & 695.47 & 0.0906 & -1.5606 \\
\hline 94.5 & 697.674 & 0.4077 & 0.8936 & 194.50 & 696.789 & 0.2804 & 0.32136 & 246 & 695.38 & 0.0777 & -2.1203 \\
\hline 112.25 & 697.217 & 0.3420 & 0.6866 & 224.00 & 696.453 & 0.2321 & 0.0421 & 275 & 695.34 & 0.0719 & -2.5257 \\
\hline 139.75 & 696.697 & 0.2672 & 0.3832 & 242.50 & 696.211 & 0.1973 & -0.2219 & 304 & 695.31 & 0.0676 & -2.9957 \\
\hline 170 & 696 & 0.1669 & -0.2614 & 270.00 & 695.889 & 0.1509 & -0.7361 & 381 & 695.287 & 0.0643 & -3.6119 \\
\hline 235.75 & 695.511 & 0.0965 & -1.2694 & 289.50 & 695.7 & 0.1237 & -1.2379 & 434 & 695.274 & 0.0624 & -4.2687 \\
\hline 303.75 & 695.4 & 0.0806 & -1.772 & 322.50 & 695.532 & 0.0996 & -2.1037 & 511 & 695.268 & 0.0616 & -4.8283 \\
\hline 355 & 695.323 & 0.0695 & -2.3752 & 357.00 & 695.489 & 0.0934 & -2.5383 & 564 & 695.26 & 0.0604 & \\
\hline 404.75 & 695.298 & 0.0659 & -2.6882 & 410.50 & 695.467 & 0.0902 & -2.8647 & & & & \\
\hline 447.5 & 695.278 & 0.0630 & -3.0366 & 456.00 & 695.45 & 0.0878 & -3.2189 & & & & \\
\hline 482.25 & 695.266 & 0.0613 & -3.3242 & 484.50 & 695.432 & 0.0852 & -3.8167 & & & & \\
\hline 504.25 & 695.254 & 0.0596 & -3.7297 & 509.00 & 695.41 & 0.0820 & \#NUM! & & & & \\
\hline 543.25 & 695.248 & 0.0587 & -4.0174 & & & & & & & & \\
\hline 595.75 & 695.238 & 0.0573 & -4.8283 & & & & & & & & \\
\hline 617.25 & 695.23 & 0.0561 & \#NUM! & & & & & & & & \\
\hline
\end{tabular}




\begin{tabular}{|c|c|c|c|c|c|c|c|c|c|c|c|}
\hline & & & & sample-2 & & $2 I=0.0877 \mathrm{~cm}$ & & & & & \\
\hline & & Cycle-1 & & & & Cycle-2 & & & & Cycle-3 & \\
\hline Time, $\mathrm{h}$ & Weight, mg & Water Content, wt $\%$ & $\ln (\mathrm{Mt}-\mathrm{M} \infty)$ & Time, $\mathrm{h}$ & Weight, mg & Water Content, wt \% & $\ln (\mathrm{Mt}-\mathrm{M} \infty)$ & Time, $\mathrm{h}$ & Weight, mg & Water Content, wt \% & $\ln (\mathrm{Mt}-\mathrm{M} \infty)$ \\
\hline 0 & 530.985 & 1.7340 & 2.1730 & 0 & 530.948 & 1.7270 & 2.14908 & 0 & 530.703 & 1.6800 & 2.11372 \\
\hline 0.25 & 530.949 & 1.7272 & 2.1689 & 0.25 & 530.956 & 1.7285 & 2.15002 & 0.25 & 530.557 & 1.6521 & 2.09593 \\
\hline 0.5 & 530.543 & 1.6494 & 2.1214 & 0.75 & 530.754 & 1.6898 & 2.12621 & 0.75 & 530.418 & 1.6255 & 2.07869 \\
\hline 0.75 & 530.015 & 1.5483 & 2.0560 & 1.25 & 530.557 & 1.6521 & 2.10243 & 1.25 & 529.926 & 1.5312 & 2.01517 \\
\hline 1.25 & 529.646 & 1.4776 & 2.0077 & 2.25 & 530.418 & 1.6255 & 2.0853 & 2 & 529.54 & 1.4573 & 1.96235 \\
\hline 1.75 & 529.348 & 1.4206 & 1.9668 & 3.75 & 529.926 & 1.5312 & 2.02221 & 2.5 & 529.35 & 1.4209 & 1.93528 \\
\hline 2.25 & 529.009 & 1.3556 & 1.9182 & 5.25 & 529.54 & 1.4573 & 1.96977 & 3 & 529.123 & 1.3775 & 1.90196 \\
\hline 3.25 & 528.554 & 1.2685 & 1.8491 & 7.25 & 529.35 & 1.4209 & 1.94291 & 3.5 & 528.879 & 1.3307 & 1.86486 \\
\hline 4.25 & 528.187 & 1. 1982 & 1.7896 & 9.25 & 529.123 & 1.3775 & 1.90984 & 6 & 528.263 & 1.2128 & 1.76456 \\
\hline 5.25 & 527.912 & 1. 1456 & 1.7426 & 11.25 & 528.879 & 1.3307 & 1.87303 & 9 & 527.626 & 1.0908 & 1.64904 \\
\hline 6.25 & 527.534 & 1.0732 & 1.6741 & 22.16667 & 528.263 & 1.2128 & 1.7736 & 43 & 526.306 & 0.8380 & 1.35635 \\
\hline 8.5 & 526.975 & 0.9661 & 1.5634 & 29 & 527.626 & 1.0908 & 1.65918 & 72 & 524.966 & 0.5814 & 0.93295 \\
\hline 10.25 & 526.446 & 0.8648 & 1.4460 & 52.5 & 526.306 & 0.8380 & 1.36991 & 101 & 524.328 & 0.4592 & 0.64396 \\
\hline 22.25 & 525.233 & 0.6325 & 1. 1096 & 95.75 & 524.966 & 0.5814 & 0.95359 & 106 & 523.937 & 0.3843 & 0.41409 \\
\hline 28.75 & 524.771 & 0.5441 & 0.9443 & 120.75 & 524.328 & 0.4592 & 0.67141 & 135 & 523.675 & 0.3342 & 0.22394 \\
\hline 46.75 & 523.956 & 0.3880 & 0.5630 & 148.5 & 523.932 & 0.3834 & 0.44533 & 164 & 523.415 & 0.2844 & -0.009 \\
\hline 70.75 & 523.343 & 0.2706 & 0.1337 & 166.75 & 523.673 & 0.3338 & 0.2639 & 217 & 523.126 & 0.2290 & -0.3538 \\
\hline 94.5 & 523.143 & 0.2323 & -0.0587 & 194.5 & 523.411 & 0.2836 & 0.03922 & 246 & 522.934 & 0.1923 & -0.6733 \\
\hline 112.25 & 523.012 & 0.2072 & -0.2083 & 224 & 523.122 & 0.2283 & -0.2863 & 275 & 522.813 & 0.1691 & -0.9442 \\
\hline 139.75 & 522.869 & 0.1798 & -0.4020 & 242.5 & 522.93 & 0.1915 & -0.5816 & 304 & 522.703 & 0.1480 & -1.2765 \\
\hline 170 & 522.712 & 0.1498 & -0.6694 & 270 & 522.81 & 0.1685 & -0.8233 & 381 & 522.643 & 0.1365 & -1.5187 \\
\hline 235.75 & 522.533 & 0.1155 & -1.0996 & 289.5 & 522.703 & 0.1480 & -1.1026 & 434 & 522.5 & 0.1092 & -2.577 \\
\hline 303.75 & 522.433 & 0.0963 & -1.4567 & 322.5 & 522.643 & 0.1365 & -1.302 & 511 & 522.465 & 0.1025 & -3.1942 \\
\hline 355 & 522.367 & 0.0837 & -1.7898 & 357 & 522.5 & 0.1092 & -2.0479 & 564 & 522.424 & 0.0946 & \\
\hline 404.75 & 522.321 & 0.0749 & -2.112 & 410.5 & 522.465 & 0.1025 & -2.3645 & & & & \\
\hline 447.5 & 522.289 & 0.0687 & -2.4191 & 456 & 522.421 & 0.0940 & -2.9957 & & & & \\
\hline 482.25 & 522.267 & 0.0645 & -2.7031 & 484.5 & 522.389 & 0.0879 & -4.0174 & & & & \\
\hline 504.25 & 522.254 & 0.0620 & -2.9188 & 509 & 522.371 & 0.0845 & \#NUM! & & & & \\
\hline 543.25 & 522.24 & 0.0594 & -3.2189 & & & & & & & & \\
\hline 595.75 & 522.21 & 0.0536 & -4.6052 & & & & & & & & \\
\hline 617.25 & 522.2 & 0.0517 & \#NUM! & & & & & & & & \\
\hline
\end{tabular}




\begin{tabular}{|c|c|c|c|c|c|c|c|c|c|c|c|}
\hline & & & & sample-3 & & $2 I=0.0889 \mathrm{~cm}$ & & & & & \\
\hline & & Cycle-1 & & & & Cycle-2 & & & & Cycle-3 & \\
\hline Time, $\mathrm{h}$ & Weight, mg & Water Content, wt $\%$ & $\ln (\mathrm{Mt}-\mathrm{M} \infty)$ & Time, $\mathrm{h}$ & Weight, mg & Water Content, wt \% & $\ln (\mathrm{Mt}-\mathrm{M} \infty)$ & Time, $\mathrm{h}$ & Weight, mg & Water Content, wt \% & $\ln (\mathrm{Mt}-\mathrm{M} \infty)$ \\
\hline 0 & 697.071 & 1.7109 & 2.4351 & 0 & 697.06 & 1.7093 & 2.433 & 0 & 696.52 & 1.6305 & 2.38417 \\
\hline 0.25 & 696.568 & 1.6375 & 2.3900 & 0.25 & 696.843 & 1.6776 & 2.41377 & 0.25 & 696.188 & 1.5821 & 2.35309 \\
\hline 0.5 & 696.187 & 1.5819 & 2.3545 & 0.75 & 696.761 & 1.6657 & 2.4064 & 0.75 & 695.961 & 1.5490 & 2.33127 \\
\hline 0.75 & 695.781 & 1.5227 & 2.3152 & 1.25 & 696.536 & 1.6328 & 2.38591 & 1.25 & 695.604 & 1.4969 & 2.29596 \\
\hline 1.25 & 695.464 & 1.4765 & 2.2834 & 2.25 & 696.188 & 1.5821 & 2.35337 & 2 & 695.379 & 1.4641 & 2.27305 \\
\hline 1.75 & 695.106 & 1.4243 & 2.2462 & 3.75 & 695.961 & 1.5490 & 2.33156 & 2.5 & 694.929 & 1.3985 & 2.2256 \\
\hline 2.25 & 694.785 & 1.3775 & 2.2117 & 5.25 & 695.604 & 1.4969 & 2.29627 & 3 & 694.544 & 1.3423 & 2.18313 \\
\hline 3.25 & 694.333 & 1.3116 & 2.1609 & 7.25 & 695.379 & 1.4641 & 2.27336 & 3.5 & 693.753 & 1.2270 & 2.08976 \\
\hline 4.25 & 693.935 & 1.2535 & 2.1140 & 9.25 & 694.929 & 1.3985 & 2.22592 & 6 & 692.966 & 1.1122 & 1.98733 \\
\hline 5.25 & 693.675 & 1.2156 & 2.0821 & 11.25 & 694.562 & 1.3449 & 2.18549 & 9 & 691.589 & 0.9114 & 1.77817 \\
\hline 6.25 & 693.284 & 1. 1586 & 2.0321 & 22.16667 & 693.786 & 1.2318 & 2.09421 & 43 & 689.8 & 0.6505 & 1.41828 \\
\hline 8.5 & 692.704 & 1.0740 & 1.9530 & 29 & 692.985 & 1.1150 & 1.99034 & 72 & 688.677 & 0.4867 & 1.10094 \\
\hline 10.25 & 692.083 & 0.9834 & 1.8608 & 52.5 & 691.608 & 0.9141 & 1.78188 & 101 & 688.1 & 0.4025 & 0.88789 \\
\hline 22.25 & 690.752 & 0.7893 & 1.6288 & 95.75 & 689.844 & 0.6569 & 1.42959 & 106 & 687.3 & 0.2858 & 0.48858 \\
\hline 28.75 & 690.164 & 0.7035 & 1.5063 & 120.75 & 688.672 & 0.4859 & 1. 10028 & 135 & 686.777 & 0.2096 & 0.10165 \\
\hline 46.75 & 688.996 & 0.5332 & 1.2066 & 148.5 & 688 & 0.3879 & 0.84715 & 164 & 686.554 & 0.1771 & -0.1233 \\
\hline 70.75 & 688.265 & 0.4266 & 0.9597 & 166.75 & 687.321 & 0.2889 & 0.5032 & 217 & 686.321 & 0.1431 & -0.4292 \\
\hline 94.5 & 687.534 & 0.3200 & 0.6313 & 194.5 & 686.777 & 0.2096 & 0.10436 & 246 & 686.12 & 0.1138 & -0.7985 \\
\hline 112.25 & 686.965 & 0.2370 & 0.2708 & 224 & 686.564 & 0.1785 & -0.1087 & 275 & 685.98 & 0.0933 & -1.1712 \\
\hline 139.75 & 686.721 & 0.2014 & 0.0649 & 242.5 & 686.321 & 0.1431 & -0.4246 & 304 & 685.87 & 0.0773 & -1.6094 \\
\hline 170 & 686.423 & 0.1579 & -0.2627 & 270 & 686.12 & 0.1138 & -0.7919 & 381 & 685.8 & 0.0671 & -2.0402 \\
\hline 235.75 & 686.154 & 0.1187 & -0.6931 & 289.5 & 685.98 & 0.0933 & -1.1616 & 434 & 685.743 & 0.0588 & -2.6173 \\
\hline 303.75 & 685.941 & 0.0877 & -1.2483 & 322.5 & 685.87 & 0.0773 & -1.5945 & 511 & 685.7 & 0.0525 & -3.5066 \\
\hline 355 & 685.812 & 0.0688 & -1.8452 & 357 & 685.8 & 0.0671 & -2.0174 & & & & \\
\hline 404.75 & 685.789 & 0.0655 & -2.0025 & 410.5 & 685.743 & 0.0588 & -2.5770 & & & & \\
\hline 447.5 & 685.754 & 0.0604 & -2.3026 & 456 & 685.7 & 0.0525 & -3.4112 & & & & \\
\hline 482.25 & 685.721 & 0.0556 & -2.7031 & 484.5 & 685.687 & 0.0506 & -3.9120 & & & & \\
\hline 504.25 & 685.7 & 0.0525 & -3.0791 & 509 & 685.667 & 0.0477 & \#NUM! & & & & \\
\hline 543.25 & 685.689 & 0.0509 & -3.3524 & & & & & & & & \\
\hline 595.75 & 685.667 & 0.0477 & -4.3428 & & & & & & & & \\
\hline 617.25 & 685.654 & 0.0458 & \#NUM! & & & & & & & & \\
\hline
\end{tabular}


Table 28. Sorption Data of Epoxy Samples containing $5 \mathrm{wt} \%$ Cloisite $10 \mathrm{~A}$ at $25^{\circ} \mathrm{C}$ During Three Cycles of Absorption

\begin{tabular}{|c|c|c|c|c|c|c|c|c|c|c|c|}
\hline & & & & sample-1 & & $2 I=0.115 \mathrm{~cm}$ & & & & & \\
\hline & & Cycle-1 & & & & Cycle-2 & & & & Cycle-3 & \\
\hline Time, $\mathrm{h}$ & Weight, mg & Water Content, wt $\%$ & $\mathrm{Mt} / \mathrm{M} \infty$ & Time, $\mathrm{h}$ & Weight, mg & Water Content, wt\% & $\mathrm{Mt} / \mathrm{M} \infty$ & Time, $\mathrm{h}$ & Weight, mg & Water Content, wt $\%$ & $\mathrm{Mt} / \mathrm{M} \infty$ \\
\hline 0 & 630.815 & 0.0000 & 0.0000 & 0 & 631.587 & 0.1222 & 0 & 0 & 631.48 & 0.1052 & 0.0000 \\
\hline 0.5 & 631.279 & 0.0734 & 0.0275 & 0.25 & 631.732 & 0.1451 & 0.0092 & 0.5 & 631.487 & 0.1064 & 0.0004 \\
\hline 1.5 & 631.83 & 0.1606 & 0.0601 & 0.75 & 631.9 & 0.1717 & 0.0199 & 0.75 & 631.632 & 0.1293 & 0.0096 \\
\hline 4 & 632.276 & 0.2312 & 0.0866 & 2.25 & 632.342 & 0.2417 & 0.0479 & 1.25 & 631.81 & 0.1575 & 0.0208 \\
\hline 5.5 & 632.63 & 0.2873 & 0.1075 & 3.75 & 632.45 & 0.2588 & 0.0548 & 2.75 & 632.252 & 0.2274 & 0.0487 \\
\hline 7 & 632.905 & 0.3308 & 0.1238 & 5.25 & 632.688 & 0.2964 & 0.0699 & 4.25 & 632.325 & 0.2390 & 0.0533 \\
\hline 10.75 & 633.476 & 0.4212 & 0.1577 & 7.25 & 632.849 & 0.3219 & 0.0801 & 5.75 & 632.588 & 0.2806 & 0.0699 \\
\hline 11.75 & 633.6 & 0.4408 & 0.1650 & 9.25 & 633.308 & 0.3946 & 0.1093 & 7.75 & 632.749 & 0.3061 & 0.0800 \\
\hline 25.75 & 634.743 & 0.6217 & 0.2328 & 11.25 & 633.593 & 0.4397 & 0.1274 & 9.75 & 633.248 & 0.3851 & 0.1115 \\
\hline 49.75 & 636 & 0.8206 & 0.3072 & 22 & 634.659 & 0.6084 & 0.195 & 11.75 & 633.493 & 0.4238 & 0.1269 \\
\hline 75.25 & 636.89 & 0.9615 & 0.3600 & 29 & 635.514 & 0.7437 & 0.2493 & 22.5 & 634.559 & 0.5926 & 0.1942 \\
\hline 95.25 & 637.654 & 1.0824 & 0.4053 & 52 & 636.739 & 0.9376 & 0.3271 & 29.5 & 635.414 & 0.7279 & 0.2481 \\
\hline 122.75 & 638.423 & 1.2041 & 0.4508 & 76 & 638.518 & 1.2192 & 0.44 & 52.5 & 636.639 & 0.9218 & 0.3253 \\
\hline 166.25 & 639.132 & 1.3163 & 0.4928 & 101 & 639.272 & 1.3385 & 0.4879 & 76.5 & 638.418 & 1.2033 & 0.4375 \\
\hline 218.25 & 640.213 & 1.4874 & 0.5569 & 124 & 639.564 & 1.3847 & 0.5064 & 100.5 & 639.172 & 1.3227 & 0.4851 \\
\hline 271.25 & 641 & 1.6120 & 0.6035 & 173 & 640.445 & 1.5241 & 0.5624 & 125.5 & 639.464 & 1.3689 & 0.5035 \\
\hline 313.5 & 641.488 & 1.6892 & 0.6324 & 222 & 641.488 & 1.6892 & 0.6286 & 172.5 & 640.345 & 1.5083 & 0.5590 \\
\hline 387 & 642.823 & 1.9005 & 0.7115 & 292 & 642.823 & 1.9005 & 0.7134 & 226.5 & 641.378 & 1.6718 & 0.6242 \\
\hline 485.417 & 644.157 & 2.1116 & 0.7906 & 364 & 644.157 & 2.1116 & 0.798 & 292.5 & 642.733 & 1.8863 & 0.7096 \\
\hline 575 & 644.856 & 2.2223 & 0.8320 & 439 & 645.356 & 2.3014 & 0.8742 & 367.5 & 644.047 & 2.0942 & 0.7925 \\
\hline 675.417 & 645.548 & 2.3318 & 0.8730 & 538 & 646.145 & 2.4263 & 0.9243 & 432.5 & 645.236 & 2.2824 & 0.8674 \\
\hline 767 & 645.951 & 2.3956 & 0.8969 & 602 & 646.399 & 2.4665 & 0.9404 & 531.5 & 646.055 & 2.4120 & 0.9191 \\
\hline 874.25 & 646.287 & 2.4488 & 0.9168 & 651 & 646.623 & 2.5019 & 0.9546 & 604.5 & 646.296 & 2.4502 & 0.9343 \\
\hline 990 & 646.798 & 2.5296 & 0.9471 & 724 & 646.91 & 2.5474 & 0.9728 & 657.50 & 646.521 & 2.4858 & 0.9485 \\
\hline 1083 & 647.169 & 2.5884 & 0.9691 & 823 & 647.1 & 2.5774 & 0.9849 & 724.50 & 646.850 & 2.5379 & 0.9692 \\
\hline 1199.25 & 647.451 & 2.6330 & 0.9858 & 868 & 647.17 & 2.5885 & 0.9893 & 824.50 & 647.030 & 2.5664 & 0.9806 \\
\hline 1300.25 & 647.586 & 2.6544 & 0.9938 & 916 & 647.23 & 2.5980 & 0.9931 & 863.50 & 647.056 & 2.5705 & 0.9822 \\
\hline 1399.75 & 647.678 & 2.6689 & 0.9992 & 964 & 647.29 & 2.6075 & 0.9970 & 916.5 & 647.121 & 2.5808 & 0.9863 \\
\hline 1468.25 & 647.666 & 2.6670 & 0.9985 & 1011 & 647.31 & 2.6107 & 0.9982 & 961.5 & 647.187 & 2.5912 & 0.9905 \\
\hline 1489.25 & 647.672 & 2.6680 & 0.9989 & 1060 & 647.33 & 2.6138 & 0.9995 & 1010.5 & 647.204 & 2.5939 & 0.9916 \\
\hline 1516.25 & 647.680 & 2.6692 & 0.9993 & 1108 & 647.338 & 2.6151 & 1.0000 & 1062.5 & 647.223 & 2.5969 & 0.9927 \\
\hline 1537.75 & 647.685 & 2.6700 & 0.9996 & & & & & 1107.5 & 647.338 & 2.6151 & 1.0000 \\
\hline 1565.75 & 647.691 & 2.6710 & 1.0000 & & & & & & & & \\
\hline
\end{tabular}




\begin{tabular}{|c|c|c|c|c|c|c|c|c|c|c|c|}
\hline & & & & sample-2 & & $2 I=0.11 \mathrm{~cm}$ & & & & & \\
\hline & & Cycle-1 & & & & Cycle-2 & & & & Cycle-3 & \\
\hline Time, $\mathrm{h}$ & Weight, mg & Water Content, wt $\%$ & $\mathrm{Mt} / \mathrm{M} \infty$ & Time, $\mathrm{h}$ & Weight, mg & Water Content, wt \% & $\mathrm{Mt} / \mathrm{M} \infty$ & Time, $\mathrm{h}$ & Weight, mg & Water Content, wt \% & $\mathrm{Mt} / \mathrm{M} \infty$ \\
\hline 0 & 702.79 & 0.0000 & 0.0000 & 0 & 703.08 & 0.0412 & 0 & 0 & 702.996 & 0.0293 & 0.0000 \\
\hline 0.5 & 703.056 & 0.0378 & 0.0142 & 0.25 & 703.333 & 0.0772 & 0.0148 & 0.5 & 703.139 & 0.0496 & 0.0083 \\
\hline 1.5 & 703.351 & 0.0798 & 0.0300 & 0.75 & 703.521 & 0.1039 & 0.0257 & 0.75 & 703.342 & 0.0785 & 0.0201 \\
\hline 4 & 703.958 & 0.1661 & 0.0625 & 2.25 & 704.158 & 0.1945 & 0.0629 & 1.25 & 703.554 & 0.1086 & 0.0324 \\
\hline 5.5 & 704.254 & 0.2081 & 0.0783 & 3.75 & 704.576 & 0.2539 & 0.0873 & 2.75 & 704.178 & 0.1973 & 0.0686 \\
\hline 7 & 704.489 & 0.2416 & 0.0909 & 5.25 & 704.834 & 0.2906 & 0.1024 & 4.25 & 704.591 & 0.2561 & 0.0926 \\
\hline 10.75 & 705.384 & 0.3688 & 0.1388 & 7.25 & 704.989 & 0.3126 & 0.1114 & 5.75 & 704.823 & 0.2890 & 0.1061 \\
\hline 11.75 & 705.604 & 0.4001 & 0.1506 & 9.25 & 705.369 & 0.3667 & 0.1336 & 7.75 & 704.976 & 0.3108 & 0.1150 \\
\hline 25.75 & 706.832 & 0.5747 & 0.2163 & 11.25 & 705.727 & 0.4176 & 0.1545 & 9.75 & 705.354 & 0.3645 & 0.1369 \\
\hline 49.75 & 708.137 & 0.7602 & 0.2861 & 22 & 706.76 & 0.5644 & 0.2148 & 11.75 & 705.703 & 0.4142 & 0.1572 \\
\hline 75.25 & 708.996 & 0.8823 & 0.3320 & 29 & 707.744 & 0.7043 & 0.2722 & 22.5 & 706.75 & 0.5630 & 0.2180 \\
\hline 95.25 & 709.865 & 1.0059 & 0.3785 & 52 & 708.822 & 0.8576 & 0.3351 & 29.5 & 707.751 & 0.7053 & 0.2761 \\
\hline 122.75 & 710.546 & 1. 1027 & 0.4150 & 76 & 710.686 & 1. 1226 & 0.4439 & 52.5 & 708.831 & 0.8589 & 0.3388 \\
\hline 166.25 & 711.993 & 1.3085 & 0.4924 & 101 & 711.469 & 1.2340 & 0.4896 & 76.5 & 710.671 & 1. 1205 & 0.4456 \\
\hline 218.25 & 713.102 & 1.4661 & 0.5517 & 124 & 711.993 & 1.3085 & 0.5202 & 100.5 & 711.4695 & 1.2340 & 0.4920 \\
\hline 271.25 & 714.543 & 1.6710 & 0.6288 & 173 & 713.102 & 1.4661 & 0.5849 & 125.5 & 711.986 & 1.3075 & 0.5219 \\
\hline 313.5 & 715.464 & 1.8019 & 0.6781 & 222 & 714.543 & 1.6710 & 0.669 & 172.5 & 713.11 & 1.4673 & 0.5872 \\
\hline 387 & 716.943 & 2.0122 & 0.7572 & 292 & 716.123 & 1.8956 & 0.7612 & 226.5 & 714.551 & 1.6721 & 0.6709 \\
\hline 485.417 & 718.024 & 2.1659 & 0.8151 & 364 & 717.247 & 2.0554 & 0.8268 & 292.5 & 716.118 & 1.8949 & 0.7618 \\
\hline 575 & 718.564 & 2.2427 & 0.8440 & 439 & 718.308 & 2.2063 & 0.8888 & 367.5 & 717.262 & 2.0576 & 0.8283 \\
\hline 675.417 & 719.123 & 2.3222 & 0.8739 & 538 & 719.3 & 2.3473 & 0.9467 & 432.5 & 718.318 & 2.2077 & 0.8896 \\
\hline 767 & 719.507 & 2.3768 & 0.8944 & 602 & 719.507 & 2.3768 & 0.9587 & 531.5 & 719.332 & 2.3519 & 0.9484 \\
\hline 874.25 & 719.857 & 2.4265 & 0.9132 & 651 & 719.796 & 2.4179 & 0.9756 & 604.5 & 719.518 & 2.3783 & 0.9592 \\
\hline 990 & 720.382 & 2.5012 & 0.9413 & 724 & 719.897 & 2.4322 & 0.9815 & 657.50 & 719.791 & 2.4171 & 0.9751 \\
\hline 1083 & 720.673 & 2.5425 & 0.9568 & 823 & 720.067 & 2.4564 & 0.9914 & 724.50 & 719.889 & 2.4311 & 0.9808 \\
\hline 1199.25 & 720.934 & 2.5797 & 0.9708 & 868 & 720.11 & 2.4625 & 0.9939 & 824.50 & 720.053 & 2.4544 & 0.9903 \\
\hline 1300.25 & 721.223 & 2.6207 & 0.9862 & 916 & 720.14 & 2.4668 & 0.9957 & 863.50 & 720.140 & 2.4668 & 0.9954 \\
\hline 1399.75 & 721.354 & 2.6394 & 0.9933 & 964 & 720.176 & 2.4719 & 0.9978 & 916.5 & 720.17 & 2.4710 & 0.9971 \\
\hline 1468.25 & 721.432 & 2.6505 & 0.9974 & 1011 & 720.19 & 2.4739 & 0.9986 & 961.5 & 720.191 & 2.4740 & 0.9983 \\
\hline 1489.25 & 721.451 & 2.6532 & 0.9984 & 1060 & 720.204 & 2.4759 & 0.9994 & 1010.5 & 720.21 & 2.4767 & 0.9994 \\
\hline 1516.25 & 721.463 & 2.6549 & 0.9991 & 1108 & 720.214 & 2.4773 & 1.0000 & 1062.5 & 720.2041 & 2.4759 & 0.9991 \\
\hline 1537.75 & 721.470 & 2.6559 & 0.9995 & & & & & 1107.5 & 720.22 & 2.4781 & 1.0000 \\
\hline 1565.75 & 721.480 & 2.6573 & 1.0000 & & & & & & & & \\
\hline
\end{tabular}




\begin{tabular}{|c|c|c|c|c|c|c|c|c|c|c|c|}
\hline & & & & sample-3 & & $2 I=0.115 \mathrm{~cm}$ & & & & & \\
\hline & & Cycle-1 & & & & Cycle-2 & & & & Cycle-3 & \\
\hline Time, h & Weight, mg & Water Content, wt $\%$ & $\mathrm{Mt} / \mathrm{M} \infty$ & Time, $\mathrm{h}$ & Weight, mg & Water Content, wt \% & $\mathrm{Mt} / \mathrm{M} \infty$ & Time, h & Weight, mg & Water Content, wt $\%$ & $\mathrm{Mt} / \mathrm{M} \infty$ \\
\hline 0 & 667.1 & 0.0000 & 0.0000 & 0 & 667.37 & 0.0405 & 0 & 0 & 667.47 & 0.0554 & 0.0000 \\
\hline 0.5 & 667.341 & 0.0361 & 0.0134 & 0.25 & 667.612 & 0.0767 & 0.014 & 0.5 & 667.6512 & 0.0826 & 0.0106 \\
\hline 1.5 & 667.45 & 0.0524 & 0.0195 & 0.75 & 667.975 & 0.1311 & 0.0349 & 0.75 & 667.865 & 0.1146 & 0.0231 \\
\hline 4 & 667.874 & 0.1160 & 0.0431 & 2.25 & 668.503 & 0.2102 & 0.0654 & 1.25 & 668.413 & 0.1967 & 0.0551 \\
\hline 5.5 & 668.367 & 0.1898 & 0.0705 & 3.75 & 668.801 & 0.2549 & 0.0826 & 2.75 & 668.721 & 0.2429 & 0.0731 \\
\hline 7 & 668.771 & 0.2504 & 0.0930 & 5.25 & 669.432 & 0.3494 & 0.119 & 4.25 & 669.322 & 0.3329 & 0.1082 \\
\hline 10.75 & 669.389 & 0.3429 & 0.1274 & 7.25 & 669.673 & 0.3855 & 0.1329 & 5.75 & 669.563 & 0.3690 & 0.1223 \\
\hline 11.75 & 669.602 & 0.3749 & 0.1392 & 9.25 & 669.829 & 0.4089 & 0.1419 & 7.75 & 669.739 & 0.3954 & 0.1325 \\
\hline 25.75 & 670.823 & 0.5578 & 0.2071 & 11.25 & 670.112 & 0.4513 & 0.1582 & 9.75 & 670.022 & 0.4378 & 0.1491 \\
\hline 49.75 & 671.789 & 0.7025 & 0.2609 & 22 & 670.814 & 0.5564 & 0.1987 & 11.75 & 670.724 & 0.5430 & 0.1901 \\
\hline 75.25 & 672.563 & 0.8185 & 0.3039 & 29 & 671.83 & 0.7087 & 0.2574 & 22.5 & 671.873 & 0.7151 & 0.2572 \\
\hline 95.25 & 673.451 & 0.9515 & 0.3533 & 52 & 672.811 & 0.8556 & 0.314 & 29.5 & 672.711 & 0.8407 & 0.3061 \\
\hline 122.75 & 674.589 & 1. 1220 & 0.4167 & 76 & 674.586 & 1.1216 & 0.4164 & 52.5 & 674.466 & 1. 1036 & 0.4086 \\
\hline 166.25 & 676.398 & 1.3931 & 0.5173 & 101 & 675.299 & 1.2284 & 0.4576 & 76.5 & 675.199 & 1.2134 & 0.4515 \\
\hline 218.25 & 678.11 & 1.6496 & 0.6126 & 124 & 676.398 & 1.3931 & 0.521 & 100.5 & 676.288 & 1.3766 & 0.5151 \\
\hline 271.25 & 679.282 & 1.8252 & 0.6778 & 173 & 678.11 & 1.6496 & 0.6198 & 125.5 & 678.01 & 1.6346 & 0.6157 \\
\hline 313.5 & 680.123 & 1.9512 & 0.7245 & 222 & 679.282 & 1.8252 & 0.6874 & 172.5 & 679.182 & 1.8102 & 0.6841 \\
\hline 387 & 680.787 & 2.0506 & 0.7615 & 292 & 680.556 & 2.0160 & 0.7609 & 226.5 & 680.456 & 2.0010 & 0.7585 \\
\hline 485.417 & 681.423 & 2.1459 & 0.7969 & 364 & 681.423 & 2.1459 & 0.811 & 292.5 & 681.323 & 2.1309 & 0.8092 \\
\hline 575 & 681.993 & 2.2313 & 0.8286 & 439 & 682.397 & 2.2919 & 0.8672 & 367.5 & 682.297 & 2.2769 & 0.8661 \\
\hline 675.417 & 682.673 & 2.3332 & 0.8664 & 538 & 683.3 & 2.4271 & 0.9193 & 432.5 & 683.213 & 2.4141 & 0.9196 \\
\hline 767 & 683.058 & 2.3909 & 0.8878 & 602 & 683.371 & 2.4378 & 0.9234 & 531.5 & 683.261 & 2.4213 & 0.9224 \\
\hline 874.25 & 683.371 & 2.4378 & 0.9053 & 651 & 683.711 & 2.4887 & 0.943 & 604.5 & 683.621 & 2.4752 & 0.9434 \\
\hline 990 & 683.872 & 2.5128 & 0.9331 & 724 & 684 & 2.5320 & 0.9597 & 657.50 & 683.910 & 2.5185 & 0.9603 \\
\hline 1083 & 684.164 & 2.5566 & 0.9494 & 823 & 684.321 & 2.5801 & 0.9782 & 724.50 & 684.221 & 2.5651 & 0.9784 \\
\hline 1199.25 & 684.576 & 2.6183 & 0.9723 & 868 & 684.412 & 2.5938 & 0.9834 & 824.50 & 684.302 & 2.5773 & 0.9832 \\
\hline 1300.25 & 684.816 & 2.6543 & 0.9856 & 916 & 684.5 & 2.6069 & 0.9885 & 863.50 & 684.400 & 2.5920 & 0.9889 \\
\hline 1399.75 & 684.987 & 2.6799 & 0.9952 & 964 & 684.587 & 2.6200 & 0.9935 & 916.5 & 684.487 & 2.6050 & 0.9940 \\
\hline 1468.25 & 685.023 & 2.6853 & 0.9972 & 1011 & 684.612 & 2.6237 & 0.9950 & 961.5 & 684.502 & 2.6072 & 0.9949 \\
\hline 1489.25 & 685.040 & 2.6878 & 0.9981 & 1060 & 684.667 & 2.6320 & 0.9982 & 1010.5 & 684.567 & 2.6170 & 0.9987 \\
\hline 1516.25 & 685.055 & 2.6901 & 0.9989 & 1108 & 684.699 & 2.6368 & 1.0000 & 1062.5 & 684.599 & 2.6218 & 1.0005 \\
\hline 1537.75 & 685.065 & 2.6916 & 0.9995 & & & & & 1107.5 & 684.59 & 2.6204 & 1.0000 \\
\hline 1565.75 & 685.074 & 2.6929 & 1.0000 & & & & & & & & \\
\hline
\end{tabular}


Table 29. Desorption Data of Epoxy Samples containing 5 wt\% Cloisite 10A at $25^{\circ} \mathrm{C}$ During Three Cycles of Absorption

\begin{tabular}{|c|c|c|c|c|c|c|c|}
\hline & & sample-1 & & $2 I=0.11$ & $\mathrm{~cm}$ & & \\
\hline & & Cycle-1 & & & & Cycle-2 & \\
\hline Time, $\mathrm{h}$ & Weight, mg & Water Content, wt $\%$ & $\ln (\mathrm{Mt}-\mathrm{M} \infty)$ & Time, $\mathrm{h}$ & Weight, mg & Water Content, wt\% & $\ln (\mathrm{Mt}-\mathrm{M} \infty)$ \\
\hline 0 & 647.691 & 2.6710 & 2.7786 & 0 & 647 & 2.5616 & 2.73722 \\
\hline 0.25 & 647.398 & 2.6246 & 2.7602 & 0.5 & 646.78 & 2.5268 & 2.72287 \\
\hline 0.75 & 646.872 & 2.5413 & 2.7263 & 0.75 & 646.54 & 2.4888 & 2.70698 \\
\hline 1.5 & 646.403 & 2.4671 & 2.6952 & 1.75 & 646 & 2.4033 & 2.67028 \\
\hline 3.25 & 645.891 & 2.3861 & 2.6600 & 2.5 & 645.89 & 2.3859 & 2.66263 \\
\hline 5.25 & 645.056 & 2.2539 & 2.5998 & 3.5 & 645.53 & 2.3289 & 2.6372 \\
\hline 7.25 & 644.224 & 2.1222 & 2.5360 & 6.5 & 645.484 & 2.3217 & 2.6339 \\
\hline 12 & 642.574 & 1.8611 & 2.3960 & 9.5 & 644.593 & 2.1806 & 2.56779 \\
\hline 29.25 & 641.056 & 1.6208 & 2.2472 & 43.5 & 641.561 & 1.7008 & 2.30308 \\
\hline 53.25 & 639.308 & 1.3442 & 2.0429 & 72.5 & 640.21 & 1.4870 & 2.15802 \\
\hline 80 & 637.664 & 1.0840 & 1.8032 & 101.5 & 639.112 & 1.3132 & 2.02234 \\
\hline 104.75 & 636.71 & 0.9330 & 1.6322 & 135.5 & 638.12 & 1.1562 & 1.8816 \\
\hline 133.25 & 636.263 & 0.8623 & 1.5407 & 164.5 & 637.235 & 1.0161 & 1.73678 \\
\hline 162 & 635.662 & 0.7671 & 1.4029 & 217.5 & 635.641 & 0.7638 & 1.40732 \\
\hline 234 & 634.867 & 0.6413 & 1. 1854 & 294.5 & 633.568 & 0.4357 & 0.69913 \\
\hline 348.25 & 633.821 & 0.4758 & 0.8002 & 363.5 & 633 & 0.3458 & 0.36742 \\
\hline 440.75 & 633.121 & 0.3650 & 0.4226 & 438.5 & 632.5 & 0.2667 & -0.0576 \\
\hline 540.25 & 632.765 & 0.3086 & 0.1570 & 532.5 & 632.2 & 0.2192 & -0.4401 \\
\hline 631.75 & 632.412 & 0.2528 & -0.2021 & 630.5 & 632 & 0.1876 & -0.8119 \\
\hline 732.25 & 632.112 & 0.2053 & -0.6597 & 673.5 & 631.78 & 0.1527 & -1.4961 \\
\hline 820.25 & 631.912 & 0.1736 & -1.1489 & 768.5 & 631.689 & 0.1383 & -2.0174 \\
\hline 921.75 & 631.780 & 0.1527 & -1.6874 & 822.5 & 631.621 & 0.1276 & -2.7334 \\
\hline 971.75 & 631.721 & 0.1434 & -2.0715 & 909.5 & 631.589 & 0.1225 & -3.4112 \\
\hline 1063.75 & 631.67 & 0.1353 & -2.5903 & 966.5 & 631.556 & 0.1173 & \#NUM! \\
\hline 1120.75 & 631.652 & 0.1325 & -2.8647 & 1016.5 & 631.512 & 0.110314483 & \#NUM! \\
\hline 1157.75 & 631.637 & 0.1301 & -3.1701 & 1062.5 & 631.498 & 0.108098697 & \#NUM! \\
\hline 1207.75 & 631.628 & 0.1287 & -3.4112 & & & & \\
\hline 1277.75 & 631.62 & 0.1274 & -3.6889 & & & & \\
\hline 1303.75 & 631.6 & 0.1242 & -5.2983 & & & & \\
\hline 1327.75 & 631.595 & 0.1235 & \#NUM! & & & & \\
\hline & & & & & & & \\
\hline
\end{tabular}




\begin{tabular}{|c|c|c|c|c|c|c|c|}
\hline & & sample-2 & & $2 I=0.11$ & $\mathrm{~cm}$ & & \\
\hline & & Cycle-1 & & & & Cycle-2 & \\
\hline Time, $\mathrm{h}$ & Weight, mg & Water Content, wt $\%$ & $\ln (\mathrm{Mt}-\mathrm{M} \infty)$ & Time, $\mathrm{h}$ & Weight, mg & Water Content, wt $\%$ & $\ln (\mathrm{Mt}-\mathrm{M} \infty)$ \\
\hline 0 & 721.48 & 2.6573 & 2.9120 & 0 & 720.224 & 2.4787 & 2.83925 \\
\hline 0.25 & 721.223 & 2.6207 & 2.8980 & 0.5 & 720 & 2.4469 & 2.82607 \\
\hline 0.75 & 720.401 & 2.5039 & 2.8516 & 0.75 & 719.678 & 2.4011 & 2.80681 \\
\hline 1.5 & 720.003 & 2.4473 & 2.8283 & 1.75 & 719 & 2.3047 & 2.765 \\
\hline 3.25 & 719.38 & 2.3587 & 2.7908 & 2.5 & 718.789 & 2.2747 & 2.75162 \\
\hline 5.25 & 718.474 & 2.2299 & 2.7336 & 3.5 & 718.232 & 2.1955 & 2.71542 \\
\hline 7.25 & 717.824 & 2.1375 & 2.6904 & 6.5 & 717.677 & 2.1166 & 2.678 \\
\hline 12 & 716.352 & 1.9282 & 2.5852 & 9.5 & 717.453 & 2.0847 & 2.66249 \\
\hline 29.25 & 714.864 & 1.7166 & 2.4662 & 43.5 & 714.986 & 1.7340 & 2.47359 \\
\hline 53.25 & 713.189 & 1.4785 & 2.3128 & 72.5 & 712.468 & 1.3760 & 2.23506 \\
\hline 80 & 711.415 & 1.2263 & 2.1197 & 101.5 & 711 & 1. 1673 & 2.0642 \\
\hline 104.75 & 710.568 & 1. 1058 & 2.0125 & 135.5 & 709.867 & 1.0062 & 1.90895 \\
\hline 133.25 & 709.587 & 0.9664 & 1.8720 & 164.5 & 708.216 & 0.7714 & 1.62826 \\
\hline 162 & 708.425 & 0.8012 & 1.6750 & 217.5 & 707.356 & 0.6492 & 1.44338 \\
\hline 234 & 707 & 0.5986 & 1.3646 & 294.5 & 706.213 & 0.4867 & 1. 12882 \\
\hline 348.25 & 705 & 0.3142 & 0.6492 & 363.5 & 705.222 & 0.3458 & 0.74241 \\
\hline 440.75 & 704.561 & 0.2518 & 0.3887 & 438.5 & 704.556 & 0.2511 & 0.36116 \\
\hline 540.25 & 704.103 & 0.1867 & 0.0169 & 532.5 & 704 & 0.1720 & -0.129 \\
\hline 631.75 & 703.779 & 0.1406 & -0.3667 & 630.5 & 703.512 & 0.1027 & -0.939 \\
\hline 732.25 & 703.456 & 0.0947 & -0.9943 & 673.5 & 703.33 & 0.0768 & -1.5654 \\
\hline 820.25 & 703.313 & 0.0744 & -1.4828 & 768.5 & 703.22 & 0.0611 & -2.3126 \\
\hline 921.75 & 703.256 & 0.0663 & -1.7720 & 822.5 & 703.168 & 0.0537 & -3.0576 \\
\hline 971.75 & 703.21 & 0.0597 & -2.0875 & 909.5 & 703.142 & 0.0500 & -3.8632 \\
\hline 1063.75 & 703.168 & 0.0537 & -2.501 & 966.5 & 703.121 & 0.0471 & \#NUM! \\
\hline 1120.75 & 703.146 & 0.0506 & -2.8134 & 1016.5 & 703.11 & 0.045496488 & \#NUM! \\
\hline 1157.75 & 703.123 & 0.0473 & -3.2968 & 1062.5 & 703.1 & 0.044074722 & \#NUM! \\
\hline 1207.75 & 703.112 & 0.0458 & -3.6497 & & & & \\
\hline 1277.75 & 703.1 & 0.0441 & -4.2687 & & & & \\
\hline 1303.75 & 703.092 & 0.0429 & -5.116 & & & & \\
\hline 1327.75 & 703.086 & 0.0421 & \#NUM! & & & & \\
\hline
\end{tabular}




\begin{tabular}{|c|c|c|c|c|c|c|c|}
\hline & & sample-3 & & $2 I=0.11$ & $\mathrm{~cm}$ & & \\
\hline & & Cycle-1 & & & & Cycle-2 & \\
\hline Time, $\mathrm{h}$ & Weight, mg & Water Content, wt $\%$ & $\ln (\mathrm{Mt}-\mathrm{M} \infty)$ & Time, $\mathrm{h}$ & Weight, mg & Water Content, wt \% & $\ln (\mathrm{Mt}-\mathrm{M} \infty)$ \\
\hline 0 & 667.1 & 0.0000 & 0.0000 & 0 & 684.345 & 2.5837 & 2.82471 \\
\hline 0.25 & 667.341 & 0.0361 & 0.0134 & 0.5 & 684 & 2.5320 & 2.80403 \\
\hline 0.75 & 667.45 & 0.0524 & 0.0195 & 0.75 & 683.657 & 2.4806 & 2.78303 \\
\hline 1.5 & 667.874 & 0.1160 & 0.0431 & 1.75 & 682.786 & 2.3501 & 2.72766 \\
\hline 3.25 & 668.367 & 0.1898 & 0.0705 & 2.5 & 682.342 & 2.2836 & 2.6982 \\
\hline 5.25 & 668.771 & 0.2504 & 0.0930 & 3.5 & 681.675 & 2.1837 & 2.65226 \\
\hline 7.25 & 669.389 & 0.3429 & 0.1274 & 6.5 & 681 & 2.0826 & 2.6035 \\
\hline 12 & 669.602 & 0.3749 & 0.1392 & 9.5 & 680.789 & 2.0509 & 2.58776 \\
\hline 29.25 & 670.823 & 0.5578 & 0.2071 & 43.5 & 679.232 & 1.8177 & 2.46326 \\
\hline 53.25 & 671.789 & 0.7025 & 0.2609 & 72.5 & 677 & 1.4833 & 2.25245 \\
\hline 80 & 672.563 & 0.8185 & 0.3039 & 101.5 & 676.453 & 1.4013 & 2.19322 \\
\hline 104.75 & 673.451 & 0.9515 & 0.3533 & 135.5 & 675.437 & 1.2491 & 2.07292 \\
\hline 133.25 & 674.589 & 1. 1220 & 0.4167 & 164.5 & 674.897 & 1. 1682 & 2.00256 \\
\hline 162 & 676.398 & 1.3931 & 0.5173 & 217.5 & 673.677 & 0.9854 & 1.82261 \\
\hline 234 & 678.11 & 1.6496 & 0.6126 & 294.5 & 671.612 & 0.6760 & 1.41658 \\
\hline 348.25 & 679.282 & 1.8252 & 0.6778 & 363.5 & 670.344 & 0.4860 & 1.04907 \\
\hline 440.75 & 680.123 & 1.9512 & 0.7245 & 438.5 & 669.564 & 0.3692 & 0.72996 \\
\hline 540.25 & 680.787 & 2.0506 & 0.7615 & 532.5 & 668.564 & 0.2193 & 0.07232 \\
\hline 631.75 & 681.423 & 2.1459 & 0.7969 & 630.5 & 667.898 & 0.1196 & -0.894 \\
\hline 732.25 & 681.993 & 2.2313 & 0.8286 & 673.5 & 667.7 & 0.0899 & -1.5559 \\
\hline 820.25 & 682.673 & 2.3332 & 0.8664 & 768.5 & 667.587 & 0.0730 & -2.3228 \\
\hline 921.75 & 683.058 & 2.3909 & 0.8878 & 822.5 & 667.547 & 0.0670 & -2.8473 \\
\hline 971.75 & 683.371 & 2.4378 & 0.90525 & 909.5 & 667.5 & 0.0599 & -4.5099 \\
\hline 1063.75 & 683.872 & 2.5128 & 0.93313 & 966.5 & 667.489 & 0.0583 & \#NUM! \\
\hline 1120.75 & 684.164 & 2.5566 & 0.94937 & 1016.5 & 667.476 & 0.056333808 & \#NUM! \\
\hline 1157.75 & 684.576 & 2.6183 & 0.97229 & 1062.5 & 667.466 & 0.054835568 & \#NUM! \\
\hline 1207.75 & 684.816 & 2.6543 & 0.98565 & & & & \\
\hline 1277.75 & 684.987 & 2.6799 & 0.99516 & & & & \\
\hline 1303.75 & 685.023 & 2.6853 & 0.99716 & & & & \\
\hline \multirow[t]{2}{*}{1327.75} & 685.04 & 2.6878 & 0.99811 & & & & \\
\hline & 685.055 & 2.6901 & 0.99894 & & & & \\
\hline
\end{tabular}


Table 30. Sorption Data of neat vinyl ester Samples exposed to $40 \% \mathrm{RH}$ at $25^{\circ} \mathrm{C}$

\begin{tabular}{|c|c|c|c|c|c|c|c|c|c|}
\hline & sample-1 & $2 I=0.07 \mathrm{~cm}$ & & sample-2 & $2 I=0.07 \mathrm{~cm}$ & & sample-3 & $2 I=0.072 \mathrm{~cm}$ & \\
\hline Time, $\mathrm{h}$ & Weight, mg & Water Content, wt \% & $\mathrm{Mt} / \mathrm{M} \infty$ & Weight, mg & Water Content, wt \% & $\mathrm{Mt} / \mathrm{M} \infty$ & Weight, mg & Water Content, wt $\%$ & $\mathrm{Mt} / \mathrm{M} \infty$ \\
\hline 0 & 510.656 & 0.0000 & 0.0000 & 624.88 & 0.0000 & 0 & 661.596 & 0.0000 & 0.0000 \\
\hline 0.25 & 510.942 & 0.0560 & 0.1197 & 624.909 & 0.0046 & 0.0117 & 661.786 & 0.0287 & 0.0641 \\
\hline 0.75 & 511.056 & 0.0783 & 0.1674 & 624.974 & 0.0150 & 0.0378 & 661.898 & 0.0456 & 0.1019 \\
\hline 1.25 & 511.262 & 0.1187 & 0.2537 & 625.067 & 0.0299 & 0.0753 & 662.054 & 0.0692 & 0.1545 \\
\hline 2.25 & 511.34 & 0.1339 & 0.2863 & 625.15 & 0.0432 & 0.1087 & 662.155 & 0.0845 & 0.1886 \\
\hline 4.25 & 511.503 & 0.1659 & 0.3545 & 625.39 & 0.0816 & 0.2053 & 662.371 & 0.1171 & 0.2615 \\
\hline 6.25 & 511.63 & 0.1907 & 0.4077 & 625.515 & 0.1016 & 0.2556 & 662.499 & 0.1365 & 0.3047 \\
\hline 15.75 & 512.016 & 0.2663 & 0.5693 & 625.968 & 0.1741 & 0.438 & 662.963 & 0.2066 & 0.4612 \\
\hline 24.25 & 512.331 & 0.3280 & 0.7011 & 626.227 & 0.2156 & 0.5423 & 663.333 & 0.2625 & 0.5860 \\
\hline 45 & 512.561 & 0.3730 & 0.7974 & 626.586 & 0.2730 & 0.6868 & 663.706 & 0.3189 & 0.7119 \\
\hline 89.25 & 512.932 & 0.4457 & 0.9527 & 627.133 & 0.3605 & 0.907 & 664.222 & 0.3969 & 0.8860 \\
\hline 148 & 513.012 & 0.4614 & 0.9862 & 627.29 & 0.3857 & 0.9702 & 664.518 & 0.4417 & 0.9858 \\
\hline 213.5 & 513.023 & 0.4635 & 0.9908 & 627.311 & 0.3890 & 0.9787 & 664.523 & 0.4424 & 0.9875 \\
\hline 237.5 & 513.036 & 0.4661 & 0.9962 & 627.323 & 0.3910 & 0.9835 & 664.53 & 0.4435 & 0.9899 \\
\hline 285.5 & 513.04 & 0.4669 & 0.9979 & 627.338 & 0.3934 & 0.9895 & 664.536 & 0.4444 & 0.9919 \\
\hline 329 & 513.035 & 0.4659 & 0.9958 & 627.345 & 0.3945 & 0.9924 & 664.549 & 0.4463 & 0.9963 \\
\hline 363 & 513.045 & 0.4678 & 1.0000 & 627.364 & 0.3975 & 1 & 664.56 & 0.4480 & 1.0000 \\
\hline
\end{tabular}

\begin{tabular}{|c|c|c|c|c|c|c|}
\hline & sample-4 & $2 I=0.08 \mathrm{~cm}$ & & sample-5 & $2 I=0.085 \mathrm{~cm}$ & \\
\hline Time, $\mathrm{h}$ & Weight, mg & Water Content, wt $\%$ & $\mathrm{Mt} / \mathrm{M} \infty$ & Weight, mg & Water Content, wt $\%$ & $\mathrm{Mt} / \mathrm{M} \infty$ \\
\hline 0 & 703.823 & 0.0000 & 0.0000 & 788.249 & 0.0000 & 0 \\
\hline 0.25 & 703.853 & 0.0043 & 0.0104 & 788.48 & 0.0293 & 0.0678 \\
\hline 0.75 & 703.981 & 0.0224 & 0.0550 & 788.591 & 0.0434 & 0.1004 \\
\hline 1.25 & 704.16 & 0.0479 & 0.1172 & 788.714 & 0.0590 & 0.1365 \\
\hline 2.25 & 704.266 & 0.0629 & 0.1541 & 788.818 & 0.0722 & 0.167 \\
\hline 4.25 & 704.462 & 0.0908 & 0.2223 & 789.133 & 0.1121 & 0.2595 \\
\hline 6.25 & 704.589 & 0.1088 & 0.2664 & 789.157 & 0.1152 & 0.2665 \\
\hline 15.75 & 705.061 & 0.1759 & 0.4306 & 789.626 & 0.1747 & 0.4042 \\
\hline 24.25 & 705.382 & 0.2215 & 0.5423 & 789.982 & 0.2199 & 0.5087 \\
\hline 45 & 705.763 & 0.2756 & 0.6748 & 790.386 & 0.2711 & 0.6272 \\
\hline 89.25 & 706.358 & 0.3602 & 0.8817 & 791.11 & 0.3630 & 0.8397 \\
\hline 148 & 706.602 & 0.3948 & 0.9666 & 791.485 & 0.4105 & 0.9498 \\
\hline 213.5 & 706.635 & 0.3995 & 0.9781 & 791.562 & 0.4203 & 0.9724 \\
\hline 237.5 & 706.645 & 0.4010 & 0.9816 & 791.586 & 0.4233 & 0.9795 \\
\hline 285.5 & 706.659 & 0.4029 & 0.9864 & 791.602 & 0.4254 & 0.9842 \\
\hline 329 & 706.687 & 0.4069 & 0.9962 & 791.632 & 0.4292 & 0.993 \\
\hline 363 & 706.698 & 0.4085 & 1.0000 & 791.656 & 0.4322 & 1 \\
\hline
\end{tabular}


Table 31. Sorption Data of vinyl ester samples containing $2 \mathrm{wt}^{\%} \mathrm{Cloisite}_{10 \mathrm{~A}^{\circledR}}$ exposed to $40 \% \mathrm{RH}$ at $25^{\circ} \mathrm{C}$

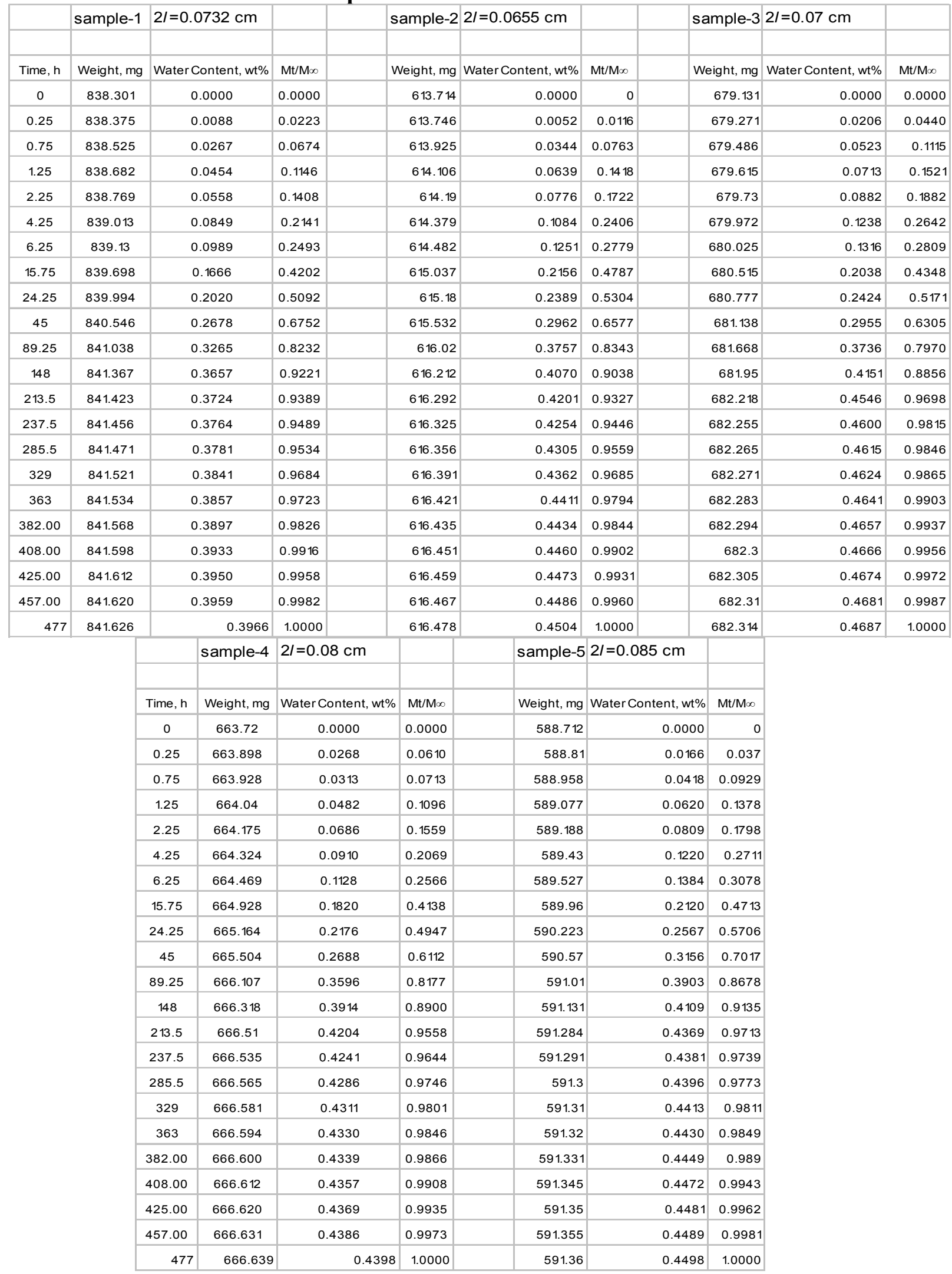




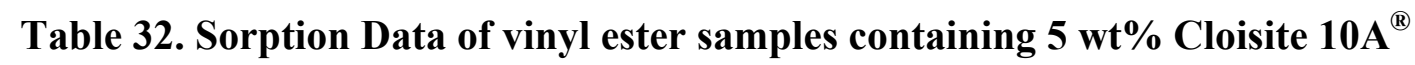

exposed to $40 \%$ RH at $25^{\circ} \mathrm{C}$

\begin{tabular}{|c|c|c|c|c|c|c|c|c|c|}
\hline & sample-1 & $2 I=0.062 \mathrm{~cm}$ & & sample-2 & $2 I=0.067 \mathrm{~cm}$ & & sample-3 & $2 I=0.0585 \mathrm{~cm}$ & \\
\hline Time, $\mathrm{h}$ & Weight, mg & Water Content, wt $\%$ & $\mathrm{Mt} / \mathrm{M} \infty$ & Weight, mg & Water Content, wt\% & $\mathrm{Mt} / \mathrm{M} \infty$ & Weight, mg & Water Content, wt $\%$ & $\mathrm{Mt} / \mathrm{M} \infty$ \\
\hline 0 & 650.515 & 0.0000 & 0.0000 & 705.438 & 0.0000 & 0 & 616.742 & 0.0000 & 0.0000 \\
\hline 0.25 & 650.573 & 0.0089 & 0.0190 & 705.513 & 0.0106 & 0.0241 & 616.801 & 0.0096 & 0.0219 \\
\hline 0.75 & 650.778 & 0.0404 & 0.0863 & 705.658 & 0.0312 & 0.0707 & 616.971 & 0.0371 & 0.0850 \\
\hline 1.25 & 650.847 & 0.0510 & 0.1090 & 705.505 & 0.0095 & 0.0215 & 617.084 & 0.0555 & 0.1270 \\
\hline 2.25 & 650.938 & 0.0650 & 0.1388 & 705.835 & 0.0563 & 0.1276 & 617.21 & 0.0759 & 0.1738 \\
\hline 4.25 & 651.093 & 0.0889 & 0.1897 & 706.089 & 0.0923 & 0.2093 & 617.368 & 0.1015 & 0.2325 \\
\hline 6.25 & 651.248 & 0.1127 & 0.2406 & 706.141 & 0.0997 & 0.226 & 617.513 & 0.1250 & 0.2863 \\
\hline 15.75 & 651.605 & 0.1676 & 0.3577 & 706.588 & 0.1630 & 0.3697 & 617.854 & 0.1803 & 0.4129 \\
\hline 24.25 & 652.04 & 0.2344 & 0.5005 & 706.881 & 0.2046 & 0.4638 & 618.187 & 0.2343 & 0.5366 \\
\hline 45 & 652.271 & 0.2699 & 0.5763 & 707.337 & 0.2692 & 0.6104 & 618.417 & 0.2716 & 0.6220 \\
\hline 89.25 & 652.76 & 0.3451 & 0.7368 & 707.793 & 0.3338 & 0.757 & 618.899 & 0.3497 & 0.8010 \\
\hline 148 & 653.165 & 0.4074 & 0.8697 & 708.05 & 0.3703 & 0.8396 & 619.191 & 0.3971 & 0.9094 \\
\hline 213.5 & 653.295 & 0.4274 & 0.9124 & 708.302 & 0.4060 & 0.9206 & 619.296 & 0.4141 & 0.9484 \\
\hline 237.5 & 653.366 & 0.4383 & 0.9357 & 708.35 & 0.4128 & 0.936 & 619.323 & 0.4185 & 0.9584 \\
\hline 285.5 & 653.435 & 0.4489 & 0.9583 & 708.398 & 0.4196 & 0.9515 & 619.356 & 0.4238 & 0.9707 \\
\hline 329 & 653.456 & 0.4521 & 0.9652 & 708.425 & 0.4234 & 0.9601 & 619.372 & 0.4264 & 0.9766 \\
\hline 363 & 653.485 & 0.4566 & 0.9747 & 708.468 & 0.4295 & 0.974 & 619.388 & 0.4290 & 0.9825 \\
\hline 382.00 & 653.500 & 0.4589 & 0.9797 & 708.498 & 0.4338 & 0.9836 & 619.402 & 0.4313 & 0.9877 \\
\hline 408.00 & 653.510 & 0.4604 & 0.9829 & 708.51 & 0.4355 & 0.9875 & 619.41 & 0.4326 & 0.9907 \\
\hline 425.00 & 653.521 & 0.4621 & 0.9865 & 708.521 & 0.4370 & 0.9910 & 619.415 & 0.4334 & 0.9926 \\
\hline 457.00 & 653.536 & 0.4644 & 0.9915 & 708.528 & 0.4380 & 0.9932 & 619.421 & 0.4344 & 0.9948 \\
\hline 477 & 653.546 & 0.4659 & 0.9947 & 708.533 & 0.4387 & 0.9949 & 619.421 & 0.4344 & 0.9948 \\
\hline 519.00 & 653.56 & 0.4675 & 0.9980 & 708.54 & 0.4399 & 0.9974 & 619.43 & 0.4362 & 0.9989 \\
\hline 568.00 & 653.56 & 0.4684 & 1.0000 & 708.55 & 0.4410 & 1.0000 & 619.44 & 0.4366 & 1.0000 \\
\hline
\end{tabular}




\begin{tabular}{|c|c|c|c|c|c|c|}
\hline & sample-4 & $2 I=0.0575 \mathrm{~cm}$ & & sample-5 & $2 /=0.08 \mathrm{~cm}$ & \\
\hline Time, $\mathrm{h}$ & Weight, mg & Water Content, wt $\%$ & $\mathrm{Mt} / \mathrm{M} \infty$ & Weight, mg & Water Content, wt $\%$ & $\mathrm{Mt} / \mathrm{M} \infty$ \\
\hline 0 & 546.687 & 0.0000 & 0.0000 & 534.02 & 0.0000 & 0 \\
\hline 0.25 & 546.759 & 0.0132 & 0.0268 & 534.115 & 0.0178 & 0.0396 \\
\hline 0.75 & 546.912 & 0.0412 & 0.0836 & 534.223 & 0.0380 & 0.0846 \\
\hline 1.25 & 547.051 & 0.0666 & 0.1353 & 534.264 & 0.0457 & 0.1017 \\
\hline 2.25 & 547.144 & 0.0836 & 0.1698 & 534.575 & 0.1039 & 0.2313 \\
\hline 4.25 & 547.358 & 0.1227 & 0.2493 & 534.596 & 0.1079 & 0.2401 \\
\hline 6.25 & 547.468 & 0.1429 & 0.2902 & 534.732 & 0.1333 & 0.2968 \\
\hline 15.75 & 547.728 & 0.1904 & 0.3868 & 534.968 & 0.1775 & 0.3952 \\
\hline 24.25 & 548.017 & 0.2433 & 0.4942 & 535.165 & 0.2144 & 0.4773 \\
\hline 45 & 548.405 & 0.3143 & 0.6384 & 535.496 & 0.2764 & 0.6153 \\
\hline 89.25 & 548.87 & 0.3993 & 0.8112 & 535.894 & 0.3509 & 0.7812 \\
\hline 148 & 549.065 & 0.4350 & 0.8837 & 536.11 & 0.3914 & 0.8712 \\
\hline 213.5 & 549.154 & 0.4513 & 0.9168 & 536.27 & 0.4213 & 0.9379 \\
\hline 237.5 & 549.198 & 0.4593 & 0.9331 & 536.298 & 0.4266 & 0.9496 \\
\hline 285.5 & 549.235 & 0.4661 & 0.9469 & 536.312 & 0.4292 & 0.9554 \\
\hline 329 & 549.265 & 0.4716 & 0.9580 & 536.325 & 0.4316 & 0.9608 \\
\hline 363 & 549.284 & 0.4750 & 0.9651 & 536.352 & 0.4367 & 0.9721 \\
\hline 382.00 & 549.299 & 0.4778 & 0.9706 & 536.368 & 0.4397 & 0.9787 \\
\hline 408.00 & 549.312 & 0.4802 & 0.9755 & 536.381 & 0.4421 & 0.9842 \\
\hline 425.00 & 549.335 & 0.4844 & 0.9840 & 536.398 & 0.4453 & 0.9912 \\
\hline 457.00 & 549.351 & 0.4873 & 0.9900 & 536.405 & 0.4466 & 0.9942 \\
\hline 477 & 549.365 & 0.4899 & 0.9952 & 536.41 & 0.4475 & 0.9962 \\
\hline 519.00 & 549.37 & 0.4910 & 0.9974 & 536.42 & 0.4487 & 0.9987 \\
\hline 568.00 & 549.38 & 0.4922 & 1.0000 & 536.42 & 0.4492 & 1.0000 \\
\hline
\end{tabular}

Table 33. Sorption Data of neat vinyl ester Samples exposed to $60 \% \mathrm{RH}$ at $25^{\circ} \mathrm{C}$

\begin{tabular}{|c|c|c|c|c|c|c|c|c|c|}
\hline & sample-1 & $2 I=0.11 \mathrm{~cm}$ & & sample-2 & $2 I=0.1043 \mathrm{~cm}$ & & sample-3 & $2 I=0.1 \mathrm{~cm}$ & \\
\hline Time, $\mathrm{h}$ & Weight, mg & Water Content, wt $\%$ & $\mathrm{Mt} / \mathrm{M} \infty$ & Weight, mg & Water Content, wt $\%$ & $\mathrm{Mt} / \mathrm{M} \infty$ & Weight, mg & Water Content, wt $\%$ & $\mathrm{Mt} / \mathrm{M} \infty$ \\
\hline 0 & 594.208 & 0.0000 & 0.0000 & 597.801 & 0.0000 & 0 & 577.489 & 0.0000 & 0.0000 \\
\hline 0.25 & 594.32 & 0.0188 & 0.0328 & 597.921 & 0.0201 & 0.0339 & 577.621 & 0.0229 & 0.0391 \\
\hline 0.75 & 594.45 & 0.0407 & 0.0709 & 598.035 & 0.0391 & 0.0661 & 577.712 & 0.0386 & 0.0661 \\
\hline 1.75 & 594.598 & 0.0656 & 0.1142 & 598.235 & 0.0726 & 0.1226 & 577.889 & 0.0693 & 0.1185 \\
\hline 3.75 & 594.8 & 0.0996 & 0.1734 & 598.397 & 0.0997 & 0.1683 & 578.11 & 0.1075 & 0.1839 \\
\hline 5.75 & 594.998 & 0.1330 & 0.2313 & 598.511 & 0.1188 & 0.2005 & 578.265 & 0.1344 & 0.2299 \\
\hline 15.25 & 595.365 & 0.1947 & 0.3388 & 598.91 & 0.1855 & 0.3132 & 578.635 & 0.1984 & 0.3395 \\
\hline 23.75 & 595.556 & 0.2269 & 0.3947 & 599.31 & 0.2524 & 0.4262 & 578.798 & 0.2267 & 0.3877 \\
\hline 44.5833 & 595.968 & 0.2962 & 0.5154 & 599.678 & 0.3140 & 0.5301 & 579.321 & 0.3172 & 0.5427 \\
\hline 88.8333 & 596.568 & 0.3972 & 0.6911 & 600.302 & 0.4184 & 0.7063 & 579.998 & 0.4345 & 0.7432 \\
\hline 147.833 & 597.1 & 0.4867 & 0.8469 & 600.711 & 0.4868 & 0.8218 & 580.368 & 0.4985 & 0.8528 \\
\hline 213.333 & 597.3 & 0.5204 & 0.9054 & 601 & 0.5351 & 0.9034 & 580.689 & 0.5541 & 0.9479 \\
\hline 328.833 & 597.54 & 0.5607 & 0.9757 & 601.256 & 0.5780 & 0.9757 & 580.8 & 0.5733 & 0.9807 \\
\hline 362.333 & 597.59 & 0.5692 & 0.9903 & 601.299 & 0.5851 & 0.9879 & 580.815 & 0.5759 & 0.9852 \\
\hline 381.333 & 597.599 & 0.5707 & 0.9930 & 601.339 & 0.5918 & 0.9992 & 580.832 & 0.5789 & 0.9902 \\
\hline 407.333 & 597.623 & 0.5747 & 1.0000 & 601.342 & 0.5923 & 1 & 580.865 & 0.5846 & 1.0000 \\
\hline
\end{tabular}




\begin{tabular}{|c|c|c|c|c|c|c|}
\hline & sample-4 & $2 I=0.114 \mathrm{~cm}$ & & sample-5 & $2 I=0.121 \mathrm{~cm}$ & \\
\hline Time, $\mathrm{h}$ & Weight, mg & Water Content, wt $\%$ & $\mathrm{Mt} / \mathrm{M} \infty$ & Weight, mg & Water Content, wt \% & $\mathrm{Mt} / \mathrm{M} \infty$ \\
\hline 0 & 718.105 & 0.0000 & 0.0000 & 597.775 & 0.0000 & 0 \\
\hline 0.25 & 718.284 & 0.0249 & 0.0425 & 597.958 & 0.0306 & 0.0512 \\
\hline 0.75 & 718.39 & 0.0397 & 0.0676 & 598.089 & 0.0525 & 0.0878 \\
\hline 1.75 & 718.52 & 0.0578 & 0.0984 & 598.189 & 0.0693 & 0.1158 \\
\hline 3.75 & 718.711 & 0.0844 & 0.1437 & 598.308 & 0.0892 & 0.1491 \\
\hline 5.75 & 718.898 & 0.1104 & 0.1881 & 598.465 & 0.1154 & 0.193 \\
\hline 15.25 & 719.432 & 0.1848 & 0.3148 & 598.786 & 0.1691 & 0.2828 \\
\hline 23.75 & 719.689 & 0.2206 & 0.3757 & 598.999 & 0.2048 & 0.3424 \\
\hline 44.5833 & 720.356 & 0.3135 & 0.5339 & 599.489 & 0.2867 & 0.4794 \\
\hline 88.8333 & 721.12 & 0.4199 & 0.7151 & 600.215 & 0.4082 & 0.6825 \\
\hline 147.833 & 721.601 & 0.4868 & 0.8292 & 600.721 & 0.4928 & 0.8241 \\
\hline 213.333 & 721.921 & 0.5314 & 0.9051 & 601.02 & 0.5428 & 0.9077 \\
\hline 328.833 & 722.245 & 0.5765 & 0.9820 & 601.285 & 0.5872 & 0.9818 \\
\hline 362.333 & 722.27 & 0.5800 & 0.9879 & 601.3 & 0.5897 & 0.986 \\
\hline 381.333 & 722.298 & 0.5839 & 0.9945 & 601.33 & 0.5947 & 0.9944 \\
\hline 407.333 & 722.321 & 0.5871 & 1.0000 & 601.35 & 0.5981 & 1 \\
\hline
\end{tabular}

Table 34. Sorption Data of vinyl ester samples containing $2 \mathrm{wt}^{\%} \mathrm{Cloisite}_{10 \mathrm{~A}^{\circledR}}$ exposed to $60 \% \mathrm{RH}$ at $25^{\circ} \mathrm{C}$

\begin{tabular}{|c|c|c|c|c|c|c|c|c|c|}
\hline & sample-1 & $2 I=0.124 \mathrm{~cm}$ & & sample-2 & $2 I=0.1051 \mathrm{~cm}$ & & sample-3 & $2 I=0.1063 \mathrm{~cm}$ & \\
\hline Time, $\mathrm{h}$ & Weight, mg & Water Content, wt \% & $\mathrm{Mt} / \mathrm{M} \infty$ & Weight, mg & Water Content, wt\% & $\mathrm{Mt} / \mathrm{M}_{\infty}$ & Weight, mg & Water Content, wt $\%$ & $\mathrm{Mt} / \mathrm{M} \infty$ \\
\hline 0 & 704.082 & 0.0000 & 0.0000 & 670.244 & 0.0000 & 0 & 700.756 & 0.0000 & 0.0000 \\
\hline 0.25 & 704.211 & 0.0183 & 0.0304 & 670.356 & 0.0167 & 0.0273 & 700.921 & 0.0235 & 0.0370 \\
\hline 0.75 & 704.312 & 0.0327 & 0.0541 & 670.465 & 0.0330 & 0.0539 & 701 & 0.0348 & 0.0548 \\
\hline 1.75 & 704.421 & 0.0481 & 0.0798 & 670.578 & 0.0498 & 0.0815 & 701.112 & 0.0508 & 0.0799 \\
\hline 3.75 & 704.521 & 0.0624 & 0.1033 & 670.67 & 0.0636 & 0.104 & 701.278 & 0.0745 & 0.1172 \\
\hline 5.75 & 704.663 & 0.0825 & 0.1367 & 670.865 & 0.0927 & 0.1515 & 701.44 & 0.0976 & 0.1535 \\
\hline 15.25 & 705.06 & 0.1389 & 0.2301 & 671.2 & 0.1426 & 0.2333 & 701.856 & 0.1570 & 0.2469 \\
\hline 23.75 & 705.29 & 0.1716 & 0.2842 & 671.5 & 0.1874 & 0.3065 & 702.21 & 0.2075 & 0.3264 \\
\hline 44.5833 & 705.71 & 0.2312 & 0.3831 & 672 & 0.2620 & 0.4285 & 702.703 & 0.2778 & 0.4370 \\
\hline 88.8333 & 706.32 & 0.3179 & 0.5266 & 672.6 & 0.3515 & 0.5749 & 703.321 & 0.3660 & 0.5758 \\
\hline 147.833 & 706.721 & 0.3748 & 0.6209 & 672.87 & 0.3918 & 0.6408 & 703.687 & 0.4183 & 0.6579 \\
\hline 213.333 & 707.12 & 0.4315 & 0.7148 & 673.342 & 0.4622 & 0.756 & 704 & 0.4629 & 0.7282 \\
\hline 328.833 & 707.78 & 0.5252 & 0.8701 & 673.897 & 0.5450 & 0.8914 & 704.543 & 0.5404 & 0.8501 \\
\hline 362.333 & 707.82 & 0.5309 & 0.8795 & 674.032 & 0.5652 & 0.9244 & 704.712 & 0.5645 & 0.8880 \\
\hline 381.333 & 707.88 & 0.5394 & 0.8936 & 674.098 & 0.5750 & 0.9405 & 704.833 & 0.5818 & 0.9152 \\
\hline 407.333 & 708.043 & 0.5626 & 0.9320 & 674.132 & 0.5801 & 0.9488 & 704.921 & 0.5944 & 0.9349 \\
\hline 424.333 & 708.101 & 0.5708 & 0.9456 & 674.154 & 0.5834 & 0.9541 & 704.988 & 0.6039 & 0.9499 \\
\hline 456.33 & 708.156 & 0.5786 & 0.9586 & 674.187 & 0.5883 & 0.9622 & 705 & 0.6056 & 0.9526 \\
\hline 476.33 & 708.210 & 0.5863 & 0.9713 & 674.2 & 0.5902 & 0.9653 & 705.064 & 0.6148 & 0.9670 \\
\hline 518.33 & 708.260 & 0.5934 & 0.9831 & 674.3 & 0.6052 & 0.9898 & 705.123 & 0.6232 & 0.9802 \\
\hline 567.33 & 708.300 & 0.5991 & 0.9925 & 674.312 & 0.6069 & 0.9927 & 705.198 & 0.6339 & 0.9971 \\
\hline 591.333 & 708.332 & 0.6036 & 1.0000 & 674.342 & 0.6114 & 1.0000 & 705.211 & 0.6357 & 1.0000 \\
\hline
\end{tabular}




\begin{tabular}{|c|c|c|c|c|c|c|}
\hline & sample-4 & $2 I=0.1 \mathrm{~cm}$ & & sample-5 & $2 I=0.0965 \mathrm{~cm}$ & \\
\hline Time, $\mathrm{h}$ & Weight, mg & Water Content, wt \% & $\mathrm{Mt} / \mathrm{M} \infty$ & Weight, mg & Water Content, wt $\%$ & $\mathrm{Mt} / \mathrm{M} \infty$ \\
\hline 0 & 560.671 & 0.0000 & 0.0000 & 638.418 & 0.0000 & 0 \\
\hline 0.25 & 560.789 & 0.0210 & 0.0344 & 638.521 & 0.0161 & 0.0263 \\
\hline 0.75 & 560.911 & 0.0428 & 0.0699 & 638.634 & 0.0338 & 0.0552 \\
\hline 1.75 & 560.99 & 0.0569 & 0.0929 & 638.764 & 0.0542 & 0.0884 \\
\hline 3.75 & 561.2 & 0.0944 & 0.1541 & 638.97 & 0.0865 & 0.1411 \\
\hline 5.75 & 561.32 & 0.1158 & 0.1890 & 639.12 & 0.1100 & 0.1794 \\
\hline 15.25 & 561.67 & 0.1782 & 0.2910 & 639.478 & 0.1660 & 0.271 \\
\hline 23.75 & 561.91 & 0.2210 & 0.3609 & 639.7 & 0.2008 & 0.3277 \\
\hline 44.5833 & 562.32 & 0.2941 & 0.4803 & 640.213 & 0.2812 & 0.4588 \\
\hline 88.8333 & 562.8 & 0.3797 & 0.6202 & 640.732 & 0.3625 & 0.5915 \\
\hline 147.833 & 563.321 & 0.4726 & 0.7719 & 641 & 0.4044 & 0.66 \\
\hline 213.333 & 563.59 & 0.5206 & 0.8503 & 641.4 & 0.4671 & 0.7623 \\
\hline 328.833 & 563.8 & 0.5581 & 0.9114 & 641.89 & 0.5438 & 0.8875 \\
\hline 362.333 & 563.85 & 0.5670 & 0.9260 & 641.96 & 0.5548 & 0.9054 \\
\hline 381.333 & 563.89 & 0.5741 & 0.9377 & 642.02 & 0.5642 & 0.9208 \\
\hline 407.333 & 563.92 & 0.5795 & 0.9464 & 642.1 & 0.5767 & 0.9412 \\
\hline 424.333 & 563.932 & 0.5816 & 0.9499 & 642.17 & 0.5877 & 0.9591 \\
\hline 456.33 & 563.987 & 0.5914 & 0.9659 & 642.21 & 0.5940 & 0.9693 \\
\hline 476.33 & 564.000 & 0.5938 & 0.9697 & 642.25 & 0.6002 & 0.9796 \\
\hline 518.33 & 564.050 & 0.6027 & 0.9843 & 642.278 & 0.6046 & 0.9867 \\
\hline 567.33 & 564.080 & 0.6080 & 0.9930 & 642.3 & 0.6081 & 0.9923 \\
\hline 591.333 & 564.104 & 0.6123 & 1.0000 & 642.33 & 0.6128 & 1.0000 \\
\hline
\end{tabular}




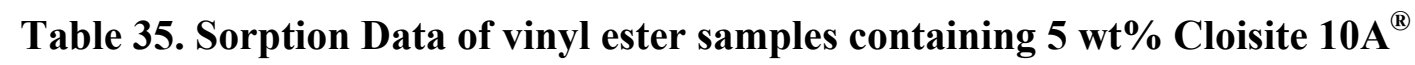

exposed to $60 \%$ RH at $25^{\circ} \mathrm{C}$

\begin{tabular}{|c|c|c|c|c|c|c|c|c|c|}
\hline & sample-1 & $2 I=0.124 \mathrm{~cm}$ & & sample-2 & $2 I=0.1051 \mathrm{~cm}$ & & sample-3 & $2 I=0.1063 \mathrm{~cm}$ & \\
\hline Time, $\mathrm{h}$ & Weight, mg & Water Content, wt $\%$ & $\mathrm{Mt} / \mathrm{M} \infty$ & Weight, mg & Water Content, wt\% & $\mathrm{Mt} / \mathrm{M} \infty$ & Weight, mg & Water Content, wt\% & $\mathrm{Mt} / \mathrm{M} \infty$ \\
\hline 0 & 802.125 & 0.0000 & 0.0000 & 670.555 & 0.0000 & 0 & 558.289 & 0.0000 & 0.0000 \\
\hline 0.25 & 802.231 & 0.0132 & 0.0208 & 670.67 & 0.0171 & 0.0283 & 558.399 & 0.0197 & 0.0326 \\
\hline 0.75 & 802.355 & 0.0287 & 0.0452 & 670.78 & 0.0336 & 0.0554 & 558.51 & 0.0396 & 0.0656 \\
\hline 1.75 & 802.53 & 0.0505 & 0.0796 & 670.843 & 0.0429 & 0.0708 & 558.62 & 0.0593 & 0.0982 \\
\hline 3.75 & 802.6 & 0.0592 & 0.0934 & 670.954 & 0.0595 & 0.0982 & 558.73 & 0.0790 & 0.1308 \\
\hline 5.75 & 802.89 & 0.0954 & 0.1504 & 671.132 & 0.0860 & 0.1419 & 558.823 & 0.0956 & 0.1584 \\
\hline 15.25 & 803.2 & 0.1340 & 0.2114 & 671.4 & 0.1260 & 0.2079 & 559.133 & 0.1512 & 0.2504 \\
\hline 23.75 & 803.65 & 0.1901 & 0.2999 & 671.8 & 0.1857 & 0.3063 & 559.476 & 0.2126 & 0.3521 \\
\hline 44.5833 & 804.21 & 0.2599 & 0.4100 & 672.21 & 0.2468 & 0.4071 & 559.98 & 0.3029 & 0.5016 \\
\hline 88.8333 & 804.87 & 0.3422 & 0.5398 & 672.71 & 0.3214 & 0.5301 & 560.4 & 0.3781 & 0.6262 \\
\hline 147.833 & 805.444 & 0.4138 & 0.6527 & 673.2 & 0.3944 & 0.6507 & 560.798 & 0.4494 & 0.7443 \\
\hline 213.333 & 805.81 & 0.4594 & 0.7247 & 673.5 & 0.4392 & 0.7245 & 561.1 & 0.5035 & 0.8339 \\
\hline 328.833 & 806.321 & 0.5231 & 0.8252 & 673.88 & 0.4959 & 0.818 & 561.27 & 0.5340 & 0.8843 \\
\hline 362.333 & 806.5 & 0.5454 & 0.8604 & 673.97 & 0.5093 & 0.8401 & 561.36 & 0.5501 & 0.9110 \\
\hline 381.333 & 806.61 & 0.5591 & 0.8820 & 674 & 0.5138 & 0.8475 & 561.42 & 0.5608 & 0.9288 \\
\hline 407.333 & 806.71 & 0.5716 & 0.9017 & 674.12 & 0.5316 & 0.877 & 561.49 & 0.5734 & 0.9496 \\
\hline 424.333 & 806.81 & 0.5841 & 0.9213 & 674.19 & 0.5421 & 0.8942 & 561.52 & 0.5787 & 0.9585 \\
\hline 456.33 & 806.920 & 0.5978 & 0.9430 & 674.298 & 0.5582 & 0.9208 & 561.56 & 0.5859 & 0.9703 \\
\hline 476.33 & 806.990 & 0.6065 & 0.9567 & 674.398 & 0.5731 & 0.9454 & 561.59 & 0.5913 & 0.9792 \\
\hline 518.33 & 807.060 & 0.6152 & 0.9705 & 674.476 & 0.5847 & 0.9646 & 561.61 & 0.5949 & 0.9852 \\
\hline 567.33 & 807.120 & 0.6227 & 0.9823 & 674.512 & 0.5901 & 0.9734 & 561.63 & 0.5984 & 0.9911 \\
\hline 591.333 & 807.167 & 0.6286 & 0.9915 & 674.567 & 0.5983 & 0.9870 & 561.645 & 0.6011 & 0.9956 \\
\hline 621.333 & 807.19 & 0.6314 & 0.9961 & 674.611 & 0.6049 & 0.9978 & 561.65 & 0.6020 & 0.9970 \\
\hline 646.333 & 807.21 & 0.6339 & 1.0000 & 674.62 & 0.6062 & 1.0000 & 561.66 & 0.6038 & 1.0000 \\
\hline
\end{tabular}




\begin{tabular}{|c|c|c|c|c|c|c|}
\hline & sample-4 & $2 I=0.0886 \mathrm{~cm}$ & & sample-5 & $2 I=0.088 \mathrm{~cm}$ & \\
\hline Time, $\mathrm{h}$ & Weight, mg & Water Content, wt $\%$ & $\mathrm{Mt} / \mathrm{M} \infty$ & Weight, mg & Water Content, wt $\%$ & $\mathrm{Mt} / \mathrm{M} \infty$ \\
\hline 0 & 580.823 & 0.0000 & 0.0000 & 461.347 & 0.0000 & 0 \\
\hline 0.25 & 580.921 & 0.0169 & 0.0272 & 461.456 & 0.0236 & 0.0385 \\
\hline 0.75 & 581.032 & 0.0360 & 0.0579 & 461.546 & 0.0431 & 0.0702 \\
\hline 1.75 & 581.156 & 0.0573 & 0.0923 & 461.633 & 0.0620 & 0.101 \\
\hline 3.75 & 581.287 & 0.0799 & 0.1286 & 461.755 & 0.0884 & 0.144 \\
\hline 5.75 & 581.4 & 0.0993 & 0.1600 & 461.89 & 0.1177 & 0.1917 \\
\hline 15.25 & 581.791 & 0.1667 & 0.2684 & 462.15 & 0.1741 & 0.2834 \\
\hline 23.75 & 582.03 & 0.2078 & 0.3346 & 462.51 & 0.2521 & 0.4105 \\
\hline 44.5833 & 582.59 & 0.3042 & 0.4899 & 462.8 & 0.3149 & 0.5129 \\
\hline 88.8333 & 583.1 & 0.3920 & 0.6313 & 463.2 & 0.4016 & 0.6541 \\
\hline 147.833 & 583.47 & 0.4557 & 0.7339 & 463.4 & 0.4450 & 0.7247 \\
\hline 213.333 & 583.78 & 0.5091 & 0.8198 & 463.61 & 0.4905 & 0.7988 \\
\hline 328.833 & 584.1 & 0.5642 & 0.9085 & 463.85 & 0.5425 & 0.8835 \\
\hline 362.333 & 584.2 & 0.5814 & 0.9362 & 463.92 & 0.5577 & 0.9082 \\
\hline 381.333 & 584.27 & 0.5935 & 0.9556 & 463.95 & 0.5642 & 0.9188 \\
\hline 407.333 & 584.31 & 0.6004 & 0.9667 & 463.97 & 0.5686 & 0.9259 \\
\hline 424.333 & 584.34 & 0.6055 & 0.9750 & 464 & 0.5751 & 0.9365 \\
\hline 456.33 & 584.360 & 0.6090 & 0.9806 & 464.04 & 0.5837 & 0.9506 \\
\hline 476.33 & 584.378 & 0.6121 & 0.9856 & 464.08 & 0.5924 & 0.9647 \\
\hline 518.33 & 584.390 & 0.6141 & 0.9889 & 464.11 & 0.5989 & 0.9753 \\
\hline 567.33 & 584.400 & 0.6159 & 0.9917 & 464.13 & 0.6032 & 0.9824 \\
\hline 591.333 & 584.42 & 0.6193 & 0.9972 & 464.15 & 0.6076 & 0.9894 \\
\hline 621.333 & 584.44 & 0.6227 & 1.0028 & 464.17 & 0.6119 & 0.9965 \\
\hline 646.333 & 584.43 & 0.6210 & 1.0000 & 464.18 & 0.6141 & 1.0000 \\
\hline
\end{tabular}

Table 36. Sorption Data of neat vinyl ester Samples exposed to $70 \% \mathrm{RH}$ at $25^{\circ} \mathrm{C}$

\begin{tabular}{|c|c|c|c|c|c|c|c|c|c|}
\hline & sample-1 & $2 I=0.11 \mathrm{~cm}$ & & sample-2 & $2 I=0.1043 \mathrm{~cm}$ & & sample-3 & $2 I=0.1 \mathrm{~cm}$ & \\
\hline Time, $\mathrm{h}$ & Weight, mg & Water Content, wt $\%$ & $\mathrm{Mt} / \mathrm{M} \infty$ & Weight, mg & Water Content, wt $\%$ & $\mathrm{Mt} / \mathrm{M} \infty$ & Weight, mg & Water Content, wt $\%$ & $\mathrm{Mt} / \mathrm{M} \infty$ \\
\hline 0 & 644.87 & 0.0000 & 0.0000 & 597.29 & 0.0000 & 0 & 730.07 & 0.0000 & 0.0000 \\
\hline 0.5 & 645.21 & 0.0527 & 0.0644 & 597.64 & 0.0586 & 0.0713 & 730.359 & 0.0396 & 0.0498 \\
\hline 1.5 & 645.63 & 0.1179 & 0.1439 & 597.98 & 0.1155 & 0.1405 & 730.66 & 0.0808 & 0.1017 \\
\hline 3.5 & 645.92 & 0.1628 & 0.1989 & 598.28 & 0.1657 & 0.2016 & 730.943 & 0.1196 & 0.1505 \\
\hline 13.3333 & 646.9 & 0.3148 & 0.3845 & 599 & 0.2863 & 0.3483 & 731.764 & 0.2320 & 0.2921 \\
\hline 23.3333 & 647.456 & 0.4010 & 0.4898 & 599.675 & 0.3993 & 0.4857 & 732.4 & 0.3191 & 0.4017 \\
\hline 42.8333 & 647.91 & 0.4714 & 0.5758 & 600.43 & 0.5257 & 0.6395 & 733.305 & 0.4431 & 0.5578 \\
\hline 65.3333 & 648.465 & 0.5575 & 0.6809 & 600.87 & 0.5994 & 0.7291 & 733.98 & 0.5356 & 0.6741 \\
\hline 91.3333 & 648.9 & 0.6249 & 0.7633 & 601.4 & 0.6881 & 0.8371 & 734.4 & 0.5931 & 0.7466 \\
\hline 113.333 & 649.32 & 0.6901 & 0.8428 & 601.56 & 0.7149 & 0.8697 & 734.747 & 0.6406 & 0.8064 \\
\hline 141.333 & 649.56 & 0.7273 & 0.8883 & 601.78 & 0.7517 & 0.9145 & 735.11 & 0.6903 & 0.8690 \\
\hline 162.333 & 649.7 & 0.7490 & 0.9148 & 601.94 & 0.7785 & 0.947 & 735.2 & 0.7027 & 0.8845 \\
\hline 171.333 & 649.74 & 0.7552 & 0.9223 & 602 & 0.7886 & 0.9593 & 735.4 & 0.7301 & 0.9190 \\
\hline 219.333 & 649.8 & 0.7645 & 0.9337 & 602.1 & 0.8053 & 0.9796 & 735.621 & 0.7603 & 0.9571 \\
\hline 245.333 & 649.92 & 0.7831 & 0.9564 & 602.16 & 0.8153 & 0.9919 & 735.7 & 0.7712 & 0.9707 \\
\hline 269.333 & 650 & 0.7955 & 0.9716 & 602.18 & 0.8187 & 0.9959 & 735.765 & 0.7801 & 0.9819 \\
\hline 293.33 & 650.050 & 0.8033 & 0.9811 & 602.19 & 0.8204 & 0.998 & 735.78 & 0.7821 & 0.9845 \\
\hline 317.33 & 650.100 & 0.8110 & 0.9905 & 602.196 & 0.8214 & 0.9992 & 735.8 & 0.7849 & 0.9879 \\
\hline 341.33 & 650.150 & 0.8188 & 1.0000 & 602.2 & 0.8220 & 1.0000 & 735.87 & 0.7944 & 1.0000 \\
\hline
\end{tabular}




\begin{tabular}{|c|c|c|c|c|c|c|}
\hline & sample-4 & $2 I=0.102 \mathrm{~cm}$ & & sample-5 & $2 I=0.089 \mathrm{~cm}$ & \\
\hline Time, $\mathrm{h}$ & Weight, mg & Water Content, wt \% & $\mathrm{Mt} / \mathrm{M} \infty$ & Weight, mg & Water Content, wt $\%$ & $\mathrm{Mt} / \mathrm{M} \infty$ \\
\hline 0 & 782.21 & 0.0000 & 0.0000 & 553.25 & 0.0000 & 0 \\
\hline 0.5 & 782.64 & 0.0550 & 0.0692 & 553.59 & 0.0615 & 0.0786 \\
\hline 1.5 & 782.879 & 0.0855 & 0.1077 & 553.78 & 0.0958 & 0.1225 \\
\hline 3.5 & 783.28 & 0.1368 & 0.1723 & 554.3 & 0.1898 & 0.2428 \\
\hline 13.3333 & 784 & 0.2288 & 0.2882 & 554.88 & 0.2946 & 0.3769 \\
\hline 23.3333 & 784.96 & 0.3516 & 0.4428 & 555.432 & 0.3944 & 0.5045 \\
\hline 42.8333 & 785.47 & 0.4168 & 0.5250 & 556 & 0.4971 & 0.6358 \\
\hline 65.3333 & 786.231 & 0.5141 & 0.6475 & 556.476 & 0.5831 & 0.7459 \\
\hline 91.3333 & 786.91 & 0.6009 & 0.7568 & 556.821 & 0.6455 & 0.8257 \\
\hline 113.333 & 787.321 & 0.6534 & 0.8230 & 557.1 & 0.6959 & 0.8902 \\
\hline 141.333 & 787.633 & 0.6933 & 0.8733 & 557.3 & 0.7320 & 0.9364 \\
\hline 162.333 & 787.832 & 0.7187 & 0.9053 & 557.38 & 0.7465 & 0.9549 \\
\hline 171.333 & 787.956 & 0.7346 & 0.9253 & 557.44 & 0.7573 & 0.9688 \\
\hline 219.333 & 788.21 & 0.7671 & 0.9662 & 557.5 & 0.7682 & 0.9827 \\
\hline 245.333 & 788.3 & 0.7786 & 0.9807 & 557.53 & 0.7736 & 0.9896 \\
\hline 269.333 & 788.36 & 0.7862 & 0.9903 & 557.552 & 0.7776 & 0.9947 \\
\hline 293.33 & 788.390 & 0.7901 & 0.9952 & 557.563 & 0.7796 & 0.9972 \\
\hline 317.33 & 788.410 & 0.7926 & 0.9984 & 557.57 & 0.7808 & 0.9988 \\
\hline 341.33 & 788.420 & 0.7939 & 1.0000 & 557.575 & 0.7817 & 1.0000 \\
\hline
\end{tabular}

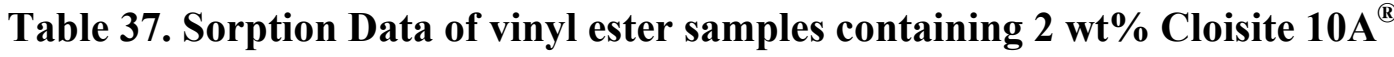 exposed to $70 \% \mathrm{RH}$ at $25^{\circ} \mathrm{C}$}

\begin{tabular}{|c|c|c|c|c|c|c|c|c|c|}
\hline & sample-1 & $2 I=0.102 \mathrm{~cm}$ & & sample-2 & $2 I=0.101 \mathrm{~cm}$ & & sample-3 & $2 I=0.1019 \mathrm{~cm}$ & \\
\hline Time, $\mathrm{h}$ & Weight, mg & Water Content, wt $\%$ & $\mathrm{Mt} / \mathrm{M} \infty$ & Weight, mg & Water Content, wt \% & $\mathrm{Mt} / \mathrm{M} \infty$ & Weight, mg & Water Content, wt $\%$ & $\mathrm{Mt} / \mathrm{M} \infty$ \\
\hline 0 & 720.817 & 0.0000 & 0.0000 & 709.768 & 0.0000 & 0 & 749.951 & 0.0000 & 0.0000 \\
\hline 0.5 & 721.38 & 0.0781 & 0.0915 & 710.4 & 0.0890 & 0.1017 & 750.44 & 0.0652 & 0.0775 \\
\hline 1.5 & 721.876 & 0.1469 & 0.1721 & 710.78 & 0.1426 & 0.1629 & 750.84 & 0.1185 & 0.1409 \\
\hline 3.5 & 722 & 0.1641 & 0.1923 & 711.24 & 0.2074 & 0.237 & 751.003 & 0.1403 & 0.1667 \\
\hline 13.3333 & 722.65 & 0.2543 & 0.2979 & 712.101 & 0.3287 & 0.3756 & 752 & 0.2732 & 0.3247 \\
\hline 23.3333 & 723.49 & 0.3708 & 0.4344 & 712.471 & 0.3808 & 0.4351 & 752.786 & 0.3780 & 0.4492 \\
\hline 42.8333 & 723.98 & 0.4388 & 0.5141 & 713.202 & 0.4838 & 0.5528 & 753.435 & 0.4646 & 0.5521 \\
\hline 65.3333 & 724.67 & 0.5345 & 0.6262 & 714.1 & 0.6103 & 0.6974 & 754.432 & 0.5975 & 0.7100 \\
\hline 91.3333 & 725.33 & 0.6261 & 0.7335 & 714.657 & 0.6888 & 0.787 & 755.121 & 0.6894 & 0.8192 \\
\hline 113.333 & 725.67 & 0.6733 & 0.7887 & 714.932 & 0.7276 & 0.8313 & 755.679 & 0.7638 & 0.9076 \\
\hline 141.333 & 725.98 & 0.7163 & 0.8391 & 715.243 & 0.7714 & 0.8814 & 756.01 & 0.8079 & 0.9601 \\
\hline 162.333 & 726.2 & 0.7468 & 0.8749 & 715.532 & 0.8121 & 0.9279 & 756.089 & 0.8185 & 0.9726 \\
\hline 171.333 & 726.43 & 0.7787 & 0.9122 & 715.66 & 0.8301 & 0.9485 & 756.154 & 0.8271 & 0.9829 \\
\hline 219.333 & 726.704 & 0.8167 & 0.9568 & 715.832 & 0.8544 & 0.9762 & 756.19 & 0.8319 & 0.9886 \\
\hline 245.333 & 726.87 & 0.8397 & 0.9837 & 715.91 & 0.8654 & 0.9887 & 756.21 & 0.8346 & 0.9918 \\
\hline 269.333 & 726.9 & 0.8439 & 0.9886 & 715.94 & 0.8696 & 0.9936 & 756.22 & 0.8359 & 0.9933 \\
\hline 293.333 & 726.92 & 0.8467 & 0.9919 & 715.956 & 0.8718 & 0.9961 & 756.228 & 0.8370 & 0.9946 \\
\hline 317.33 & 726.940 & 0.8495 & 0.9951 & 715.966 & 0.8732 & 0.9977 & 756.236 & 0.8381 & 0.9959 \\
\hline 341.33 & 726.950 & 0.8508 & 0.9967 & 715.973 & 0.8742 & 0.9989 & 756.241 & 0.8387 & 0.9967 \\
\hline 389.33 & 726.958 & 0.8519 & 0.9980 & 715.984 & 0.8758 & 1.0006 & 756.25 & 0.8399 & 0.9981 \\
\hline 437.33 & 726.966 & 0.8531 & 0.9993 & 715.99 & 0.8766 & 1.0016 & 756.257 & 0.8409 & 0.9992 \\
\hline 485.333 & 726.97 & 0.8536 & 1.0000 & 715.98 & 0.8752 & 1.0000 & 756.262 & 0.8415 & 1.0000 \\
\hline
\end{tabular}




\begin{tabular}{|c|c|c|c|c|c|c|}
\hline & sample-1 & $2 I=0.102 \mathrm{~cm}$ & & sample-2 & $2 I=0.101 \mathrm{~cm}$ & \\
\hline Time, $\mathrm{h}$ & Weight, mg & Water Content, wt $\%$ & $\mathrm{Mt} / \mathrm{M} \infty$ & Weight, mg & Water Content, wt $\%$ & $\mathrm{Mt} / \mathrm{M} \infty$ \\
\hline 0 & 757.599 & 0.0000 & 0.0000 & 672.78 & 0.0000 & 0 \\
\hline 0.5 & 758 & 0.0529 & 0.0604 & 673.132 & 0.0523 & 0.0577 \\
\hline 1.5 & 758.345 & 0.0985 & 0.1123 & 673.456 & 0.1005 & 0.1108 \\
\hline 3.5 & 758.675 & 0.1420 & 0.1620 & 673.889 & 0.1648 & 0.1818 \\
\hline 13.3333 & 759.421 & 0.2405 & 0.2744 & 674.665 & 0.2802 & 0.309 \\
\hline 23.3333 & 760.043 & 0.3226 & 0.3680 & 675.121 & 0.3480 & 0.3838 \\
\hline 42.8333 & 760.979 & 0.4461 & 0.5090 & 675.765 & 0.4437 & 0.4893 \\
\hline 65.3333 & 761.675 & 0.5380 & 0.6138 & 676.668 & 0.5779 & 0.6374 \\
\hline 91.3333 & 762.435 & 0.6383 & 0.7282 & 677.342 & 0.6781 & 0.7479 \\
\hline 113.333 & 763.12 & 0.7287 & 0.8314 & 677.692 & 0.7301 & 0.8052 \\
\hline 141.333 & 763.41 & 0.7670 & 0.8750 & 677.921 & 0.7641 & 0.8428 \\
\hline 162.333 & 763.543 & 0.7846 & 0.8950 & 678.232 & 0.8104 & 0.8938 \\
\hline 171.333 & 763.611 & 0.7936 & 0.9053 & 678.311 & 0.8221 & 0.9067 \\
\hline 219.333 & 763.7 & 0.8053 & 0.9187 & 678.532 & 0.8550 & 0.943 \\
\hline 245.333 & 764 & 0.8449 & 0.9639 & 678.645 & 0.8718 & 0.9615 \\
\hline 269.333 & 764.098 & 0.8578 & 0.9786 & 678.721 & 0.8831 & 0.9739 \\
\hline 293.333 & 764.177 & 0.8683 & 0.9905 & 678.798 & 0.8945 & 0.9866 \\
\hline 317.33 & 764.210 & 0.8726 & 0.9955 & 678.832 & 0.8996 & 0.9921 \\
\hline 341.33 & 764.220 & 0.8739 & 0.9970 & 678.854 & 0.9028 & 0.9957 \\
\hline 389.33 & 764.226 & 0.8747 & 0.9979 & 678.868 & 0.9049 & 0.9980 \\
\hline 437.33 & 764.234 & 0.8758 & 0.9991 & 678.878 & 0.9064 & 0.9997 \\
\hline 485.333 & 764.24 & 0.8766 & 1.0000 & 678.88 & 0.9067 & 1.0000 \\
\hline
\end{tabular}




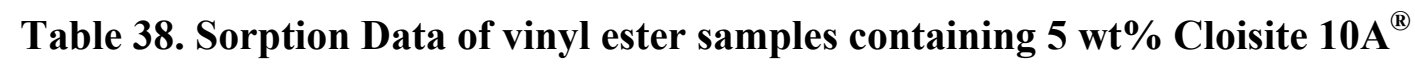
exposed to $70 \% \mathrm{RH}$ at $25^{\circ} \mathrm{C}$

\begin{tabular}{|c|c|c|c|c|c|c|c|c|c|}
\hline & sample-1 & $2 I=0.11 \mathrm{~cm}$ & & sample-2 & $2 I=0.112 \mathrm{~cm}$ & & sample-3 & $2 I=0.11 \mathrm{~cm}$ & \\
\hline Time, $\mathrm{h}$ & Weight, mg & Water Content, wt $\%$ & $\mathrm{Mt} / \mathrm{M} \infty$ & Weight, mg & Water Content, wt\% & $\mathrm{Mt} / \mathrm{M} \infty$ & Weight, mg & Water Content, wt\% & $\mathrm{Mt} / \mathrm{M} \infty$ \\
\hline 0 & 828.45 & 0.0000 & 0.0000 & 921.38 & 0.0000 & 0 & 935.497 & 0.0000 & 0.0000 \\
\hline 0.5 & 828.965 & 0.0622 & 0.0682 & 921.788 & 0.0443 & 0.0502 & 935.998 & 0.0536 & 0.0603 \\
\hline 1.5 & 829.321 & 0.1051 & 0.1154 & 922.181 & 0.0869 & 0.0986 & 936.367 & 0.0930 & 0.1048 \\
\hline 3.5 & 829.678 & 0.1482 & 0.1626 & 922.678 & 0.1409 & 0.1599 & 936.765 & 0.1355 & 0.1527 \\
\hline 13.3333 & 830.563 & 0.2551 & 0.2799 & 923.878 & 0.2711 & 0.3076 & 937.789 & 0.2450 & 0.2760 \\
\hline 23.3333 & 831.254 & 0.3385 & 0.3714 & 924.291 & 0.3159 & 0.3585 & 938.423 & 0.3128 & 0.3524 \\
\hline 42.8333 & 832.003 & 0.4289 & 0.4706 & 924.789 & 0.3700 & 0.4198 & 939.39 & 0.4161 & 0.4689 \\
\hline 65.3333 & 832.987 & 0.5476 & 0.6009 & 925.578 & 0.4556 & 0.517 & 940.234 & 0.5064 & 0.5705 \\
\hline 91.3333 & 833.564 & 0.6173 & 0.6774 & 926.477 & 0.5532 & 0.6277 & 941 & 0.5882 & 0.6628 \\
\hline 113.333 & 833.799 & 0.6457 & 0.7085 & 926.877 & 0.5966 & 0.677 & 941.5 & 0.6417 & 0.7230 \\
\hline 141.333 & 834.333 & 0.7101 & 0.7792 & 927.564 & 0.6712 & 0.7616 & 941.856 & 0.6797 & 0.7659 \\
\hline 162.333 & 834.666 & 0.7503 & 0.8233 & 927.878 & 0.7052 & 0.8002 & 941.999 & 0.6950 & 0.7831 \\
\hline 171.333 & 834.86 & 0.7737 & 0.8490 & 927.998 & 0.7183 & 0.815 & 942.111 & 0.7070 & 0.7966 \\
\hline 219.333 & 835.004 & 0.7911 & 0.8681 & 928.4 & 0.7619 & 0.8645 & 942.669 & 0.7667 & 0.8638 \\
\hline 245.333 & 835.178 & 0.8121 & 0.8911 & 928.6 & 0.7836 & 0.8892 & 942.897 & 0.7910 & 0.8912 \\
\hline 269.333 & 835.3 & 0.8268 & 0.9073 & 928.786 & 0.8038 & 0.9121 & 943.2 & 0.8234 & 0.9277 \\
\hline 293.333 & 835.4 & 0.8389 & 0.9205 & 929 & 0.8270 & 0.9384 & 943.3 & 0.8341 & 0.9398 \\
\hline 317.33 & 835.500 & 0.8510 & 0.9338 & 929.1 & 0.8379 & 0.9507 & 943.4 & 0.8448 & 0.9518 \\
\hline 341.33 & 835.600 & 0.8631 & 0.9470 & 929.2 & 0.8487 & 0.9631 & 943.5 & 0.8555 & 0.9639 \\
\hline 389.33 & 835.800 & 0.8872 & 0.9735 & 929.37 & 0.8672 & 0.9840 & 943.6 & 0.8662 & 0.9759 \\
\hline 437.33 & 835.900 & 0.8993 & 0.9868 & 929.43 & 0.8737 & 0.9914 & 943.7 & 0.8769 & 0.9880 \\
\hline 485.333 & 835.96 & 0.9065 & 0.9947 & 929.46 & 0.8769 & 0.9951 & 943.74 & 0.8811 & 0.9928 \\
\hline 509.33 & 835.98 & 0.9087 & 0.9971 & 929.48 & 0.8791 & 0.9975 & 943.77 & 0.8843 & 0.9964 \\
\hline 533.33 & 835.99 & 0.9100 & 0.9985 & 929.49 & 0.8802 & 0.9988 & 943.79 & 0.8865 & 0.9988 \\
\hline 566.33 & 836.00 & 0.9113 & 1.0000 & 929.50 & 0.8813 & 1.0000 & 943.80 & 0.8875 & 1.0000 \\
\hline
\end{tabular}




\begin{tabular}{|c|c|c|c|c|c|c|}
\hline & sample-4 & $2 I=0.089 \mathrm{~cm}$ & & sample-5 & $2 I=0.0845 \mathrm{~cm}$ & \\
\hline Time, $\mathrm{h}$ & Weight, mg & Water Content, wt $\%$ & $\mathrm{Mt} / \mathrm{M} \infty$ & Weight, mg & Water Content, wt $\%$ & $\mathrm{Mt} / \mathrm{M} \infty$ \\
\hline 0 & 687.04 & 0.0000 & 0.0000 & 664.144 & 0.0000 & 0 \\
\hline 0.5 & 687.575 & 0.0779 & 0.0848 & 664.532 & 0.0584 & 0.0638 \\
\hline 1.5 & 687.898 & 0.1249 & 0.1360 & 664.878 & 0.1105 & 0.1207 \\
\hline 3.5 & 688.232 & 0.1735 & 0.1889 & 665.276 & 0.1704 & 0.1861 \\
\hline 13.3333 & 688.876 & 0.2672 & 0.2910 & 665.878 & 0.2611 & 0.2851 \\
\hline 23.3333 & 689.232 & 0.3190 & 0.3474 & 666.342 & 0.3310 & 0.3614 \\
\hline 42.8333 & 689.987 & 0.4289 & 0.4670 & 666.934 & 0.4201 & 0.4587 \\
\hline 65.3333 & 691.143 & 0.5972 & 0.6502 & 668.003 & 0.5810 & 0.6345 \\
\hline 91.3333 & 691.563 & 0.6583 & 0.7168 & 668.564 & 0.6655 & 0.7267 \\
\hline 113.333 & 691.887 & 0.7055 & 0.7681 & 668.878 & 0.7128 & 0.7784 \\
\hline 141.333 & 692.212 & 0.7528 & 0.8197 & 668.998 & 0.7309 & 0.7981 \\
\hline 162.333 & 692.435 & 0.7853 & 0.8550 & 669.356 & 0.7848 & 0.857 \\
\hline 171.333 & 692.532 & 0.7994 & 0.8704 & 669.4 & 0.7914 & 0.8642 \\
\hline 219.333 & 692.678 & 0.8206 & 0.8935 & 669.453 & 0.7994 & 0.8729 \\
\hline 245.333 & 692.732 & 0.8285 & 0.9021 & 669.6 & 0.8215 & 0.8971 \\
\hline 269.333 & 692.854 & 0.8462 & 0.9214 & 669.721 & 0.8397 & 0.917 \\
\hline 293.333 & 692.949 & 0.8601 & 0.9365 & 669.798 & 0.8513 & 0.9296 \\
\hline 317.33 & 693.000 & 0.8675 & 0.9445 & 669.832 & 0.8564 & 0.9352 \\
\hline 341.33 & 693.100 & 0.8820 & 0.9604 & 669.876 & 0.8631 & 0.9425 \\
\hline 389.33 & 693.200 & 0.8966 & 0.9762 & 669.943 & 0.8732 & 0.9535 \\
\hline 437.33 & 693.265 & 0.9061 & 0.9865 & 670.1 & 0.8968 & 0.9793 \\
\hline 485.333 & 693.3 & 0.9112 & 0.9921 & 670.165 & 0.9066 & 0.9900 \\
\hline 509.33 & 693.33 & 0.9155 & 0.9968 & 670.20 & 0.9125 & 0.9964 \\
\hline 533.33 & 693.34 & 0.9170 & 0.9984 & 670.22 & 0.9143 & 0.9984 \\
\hline 566.33 & 693.35 & 0.9184 & 1.0000 & 670.23 & 0.9158 & 1.0000 \\
\hline
\end{tabular}

Table 39. Sorption Data of neat vinyl ester Samples exposed to $80 \% \mathrm{RH}$ at $25^{\circ} \mathrm{C}$

\begin{tabular}{|c|c|c|c|c|c|c|c|c|c|}
\hline & sample-1 & $2 I=0.0872 \mathrm{~cm}$ & & sample-2 & $2 I=0.11 \mathrm{~cm}$ & & sample-3 & $2 I=0.11 \mathrm{~cm}$ & \\
\hline Time, $\mathrm{h}$ & Weight, mg & Water Content, wt $\%$ & $\mathrm{Mt} / \mathrm{M} \infty$ & Weight, mg & Water Content, wt $\%$ & $\mathrm{Mt} / \mathrm{M} \infty$ & Weight, mg & Water Content, wt\% & $\mathrm{Mt} / \mathrm{M} \infty$ \\
\hline 0 & 492.98 & 0.0000 & 0.0000 & 659.33 & 0.0000 & 0 & 718.2 & 0.0000 & 0.0000 \\
\hline 0.5 & 493.51 & 0.1075 & 0.0993 & 659.654 & 0.0491 & 0.0607 & 718.66 & 0.0640 & 0.0808 \\
\hline 1.5 & 493.86 & 0.1785 & 0.1648 & 660 & 0.1016 & 0.1255 & 718.869 & 0.0931 & 0.1176 \\
\hline 3.5 & 494.063 & 0.2197 & 0.2028 & 660.235 & 0.1373 & 0.1695 & 719.186 & 0.1373 & 0.1733 \\
\hline 13.3333 & 494.9 & 0.3895 & 0.3596 & 661.03 & 0.2578 & 0.3184 & 719.98 & 0.2478 & 0.3128 \\
\hline 23.3333 & 495.42 & 0.4949 & 0.4569 & 661.356 & 0.3073 & 0.3794 & 720.64 & 0.3397 & 0.4288 \\
\hline 42.8333 & 496.13 & 0.6390 & 0.5899 & 662.64 & 0.5020 & 0.6199 & 721.68 & 0.4845 & 0.6116 \\
\hline 65.3333 & 496.8 & 0.7749 & 0.7154 & 663.3 & 0.6021 & 0.7434 & 722.4 & 0.5848 & 0.7381 \\
\hline 91.3333 & 497.21 & 0.8580 & 0.7921 & 663.8 & 0.6780 & 0.8371 & 722.94 & 0.6600 & 0.8330 \\
\hline 113.333 & 497.46 & 0.9088 & 0.8390 & 664.12 & 0.7265 & 0.897 & 723.32 & 0.7129 & 0.8998 \\
\hline 141.333 & 497.68 & 0.9534 & 0.8801 & 664.253 & 0.7467 & 0.9219 & 723.51 & 0.7393 & 0.9332 \\
\hline 162.333 & 497.89 & 0.9960 & 0.9195 & 664.311 & 0.7555 & 0.9328 & 723.62 & 0.7547 & 0.9525 \\
\hline 219.333 & 498.12 & 1.0426 & 0.9625 & 664.521 & 0.7873 & 0.9721 & 723.76 & 0.7742 & 0.9772 \\
\hline 245.333 & 498.2 & 1.0589 & 0.9775 & 664.587 & 0.7973 & 0.9845 & 723.81 & 0.7811 & 0.9859 \\
\hline 269.333 & 498.27 & 1.0731 & 0.9906 & 664.61 & 0.8008 & 0.9888 & 723.83 & 0.7839 & 0.9895 \\
\hline 293.333 & 498.3 & 1.0792 & 0.9963 & 664.634 & 0.8045 & 0.9933 & 723.85 & 0.7867 & 0.9930 \\
\hline 317.33 & 498.310 & 1.0812 & 0.9981 & 664.656 & 0.8078 & 0.9974 & 723.87 & 0.7895 & 0.9965 \\
\hline 341.33 & 498.320 & 1.0832 & 1.0000 & 664.67 & 0.8099 & 1.0000 & 723.89 & 0.7923 & 1.0000 \\
\hline
\end{tabular}




\begin{tabular}{|c|c|c|c|c|c|c|}
\hline & sample-4 & $2 I=0.102 \mathrm{~cm}$ & & sample-5 & $2 I=0.089 \mathrm{~cm}$ & \\
\hline Time, $\mathrm{h}$ & Weight, mg & Water Content, wt $\%$ & $\mathrm{Mt} / \mathrm{M} \infty$ & Weight, mg & Water Content, wt $\%$ & $\mathrm{Mt} / \mathrm{M} \infty$ \\
\hline 0 & 659.09 & 0.0000 & 0.0000 & 478.09 & 0.0000 & 0 \\
\hline 0.5 & 659.7 & 0.0926 & 0.1242 & 478.8 & 0.1485 & 0.1342 \\
\hline 1.5 & 660.09 & 0.1517 & 0.2037 & 479.21 & 0.2343 & 0.2117 \\
\hline 3.5 & 660.352 & 0.1915 & 0.2570 & 479.36 & 0.2656 & 0.2401 \\
\hline 13.3333 & 660.867 & 0.2696 & 0.3619 & 479.89 & 0.3765 & 0.3403 \\
\hline 23.3333 & 661.213 & 0.3221 & 0.4324 & 480.564 & 0.5175 & 0.4677 \\
\hline 42.8333 & 661.72 & 0.3990 & 0.5356 & 481.3 & 0.6714 & 0.6068 \\
\hline 65.3333 & 662.19 & 0.4703 & 0.6314 & 481.786 & 0.7731 & 0.6987 \\
\hline 91.3333 & 662.578 & 0.5292 & 0.7104 & 482 & 0.8178 & 0.7391 \\
\hline 113.333 & 662.98 & 0.5902 & 0.7923 & 482.31 & 0.8827 & 0.7977 \\
\hline 141.333 & 663.32 & 0.6418 & 0.8615 & 482.66 & 0.9559 & 0.8639 \\
\hline 162.333 & 663.5 & 0.6691 & 0.8982 & 482.85 & 0.9956 & 0.8998 \\
\hline 219.333 & 663.721 & 0.7026 & 0.9432 & 483.054 & 1.0383 & 0.9384 \\
\hline 245.333 & 663.811 & 0.7163 & 0.9615 & 483.24 & 1.0772 & 0.9735 \\
\hline 269.333 & 663.921 & 0.7330 & 0.9839 & 483.3 & 1.0898 & 0.9849 \\
\hline 293.333 & 663.997 & 0.7445 & 0.9994 & 483.35 & 1.1002 & 0.9943 \\
\hline 317.33 & 663.997 & 0.7445 & 0.9994 & 483.37 & 1. 1044 & 0.9981 \\
\hline 341.33 & 664.000 & 0.7450 & 1.0000 & 483.38 & 1.1065 & 1.0000 \\
\hline
\end{tabular}

\section{Table 40. Sorption Data of vinyl ester samples containing $2 \mathrm{wt}^{\%}$ Cloisite $10 \mathrm{~A}^{\circledR}$ exposed to $80 \% \mathrm{RH}$ at $25^{\circ} \mathrm{C}$}

\begin{tabular}{|c|c|c|c|c|c|c|c|c|c|}
\hline & sample-1 & $2 I=0.10895 \mathrm{~cm}$ & & sample-2 & $2 I=0.1 \mathrm{~cm}$ & & sample-3 & $2 I=0.1 \mathrm{~cm}$ & \\
\hline Time, $\mathrm{h}$ & Weight, mg & Water Content, wt \% & $\mathrm{Mt} / \mathrm{M} \infty$ & Weight, mg & Water Content, wt $\%$ & $\mathrm{Mt} / \mathrm{M} \infty$ & Weight, mg & Water Content, wt $\%$ & $\mathrm{Mt} / \mathrm{M} \infty$ \\
\hline 0 & 645.78 & 0.0000 & 0.0000 & 642.85 & 0.0000 & 0 & 694.332 & 0.0000 & 0.0000 \\
\hline 0.5 & 646.21 & 0.0666 & 0.0647 & 643.4 & 0.0856 & 0.1009 & 695 & 0.0962 & 0.1085 \\
\hline 1.5 & 646.53 & 0.1161 & 0.1128 & 643.6 & 0.1167 & 0.1376 & 695.31 & 0.1409 & 0.1588 \\
\hline 3.5 & 646.86 & 0.1672 & 0.1624 & 643.856 & 0.1565 & 0.1846 & 695.56 & 0.1769 & 0.1994 \\
\hline 13.3333 & 647.65 & 0.2896 & 0.2812 & 644.568 & 0.2672 & 0.3152 & 696.3 & 0.2834 & 0.3196 \\
\hline 23.3333 & 648.21 & 0.3763 & 0.3654 & 645 & 0.3344 & 0.3945 & 696.9 & 0.3699 & 0.4170 \\
\hline 42.8333 & 648.689 & 0.4505 & 0.4374 & 645.654 & 0.4362 & 0.5145 & 697.56 & 0.4649 & 0.5242 \\
\hline 65.3333 & 649.37 & 0.5559 & 0.5398 & 646.32 & 0.5398 & 0.6367 & 698.63 & 0.6190 & 0.6980 \\
\hline 91.3333 & 650 & 0.6535 & 0.6346 & 646.836 & 0.6201 & 0.7314 & 699.12 & 0.6896 & 0.7775 \\
\hline 113.333 & 650.46 & 0.7247 & 0.7038 & 647.12 & 0.6642 & 0.7835 & 699.457 & 0.7381 & 0.8323 \\
\hline 141.333 & 651 & 0.8083 & 0.7850 & 647.5 & 0.7233 & 0.8532 & 699.611 & 0.7603 & 0.8573 \\
\hline 162.333 & 651.32 & 0.8579 & 0.8331 & 647.72 & 0.7576 & 0.8936 & 699.797 & 0.7871 & 0.8875 \\
\hline 219.333 & 651.856 & 0.9409 & 0.9137 & 647.91 & 0.7871 & 0.9284 & 700.1 & 0.8307 & 0.9367 \\
\hline 245.333 & 651.978 & 0.9598 & 0.9320 & 648 & 0.8011 & 0.945 & 700.2 & 0.8451 & 0.9529 \\
\hline 269.333 & 652.1 & 0.9787 & 0.9504 & 648.06 & 0.8105 & 0.956 & 700.27 & 0.8552 & 0.9643 \\
\hline 293.333 & 652.187 & 0.9921 & 0.9635 & 648.12 & 0.8198 & 0.967 & 700.33 & 0.8639 & 0.9740 \\
\hline 317.333 & 652.287 & 1.0076 & 0.9785 & 648.16 & 0.8260 & 0.9743 & 700.39 & 0.8725 & 0.9838 \\
\hline 341.33 & 652.312 & 1.0115 & 0.9823 & 648.2 & 0.8322 & 0.9817 & 700.42 & 0.8768 & 0.9886 \\
\hline 389.33 & 652.367 & 1.0200 & 0.9905 & 648.23 & 0.8369 & 0.9872 & 700.44 & 0.8797 & 0.9919 \\
\hline 437.33 & 652.410 & 1.0267 & 0.9970 & 648.26 & 0.8416 & 0.9927 & 700.46 & 0.8826 & 0.9951 \\
\hline 485.33 & 652.420 & 1.0282 & 0.9985 & 648.28 & 0.8447 & 0.9963 & 700.48 & 0.8855 & 0.9984 \\
\hline 509.333 & 652.43 & 1.0298 & 1.0000 & 648.3 & 0.8478 & 1.0000 & 700.49 & 0.8869 & 1.0000 \\
\hline
\end{tabular}




\begin{tabular}{|c|c|c|c|c|c|c|}
\hline & sample-4 & $2 I=0.1 \mathrm{~cm}$ & & sample-5 & $2 I=0.0903 \mathrm{~cm}$ & \\
\hline Time, $\mathrm{h}$ & Weight, mg & Water Content, wt\% & $\mathrm{Mt} / \mathrm{M} \infty$ & Weight, mg & Water Content, wt $\%$ & $\mathrm{Mt} / \mathrm{M} \infty$ \\
\hline 0 & 644.43 & 0.0000 & 0.0000 & 593.81 & 0.0000 & 0 \\
\hline 0.5 & 644.86 & 0.0667 & 0.0754 & 594.32 & 0.0859 & 0.0951 \\
\hline 1.5 & 645 & 0.0885 & 0.1000 & 594.6 & 0.1330 & 0.1474 \\
\hline 3.5 & 645.23 & 0.1241 & 0.1404 & 594.86 & 0.1768 & 0.1959 \\
\hline 13.3333 & 646 & 0.2436 & 0.2754 & 595.45 & 0.2762 & 0.306 \\
\hline 23.3333 & 646.53 & 0.3259 & 0.3684 & 595.84 & 0.3419 & 0.3787 \\
\hline 42.8333 & 647.32 & 0.4485 & 0.5070 & 596.6 & 0.4698 & 0.5205 \\
\hline 65.3333 & 648.12 & 0.5726 & 0.6474 & 597.213 & 0.5731 & 0.6349 \\
\hline 91.3333 & 648.654 & 0.6555 & 0.7411 & 597.87 & 0.6837 & 0.7575 \\
\hline 113.333 & 648.998 & 0.7088 & 0.8014 & 598.112 & 0.7245 & 0.8026 \\
\hline 141.333 & 649.32 & 0.7588 & 0.8579 & 598.312 & 0.7582 & 0.8399 \\
\hline 162.333 & 649.51 & 0.7883 & 0.8912 & 598.453 & 0.7819 & 0.8662 \\
\hline 219.333 & 649.765 & 0.8279 & 0.9360 & 598.61 & 0.8083 & 0.8955 \\
\hline 245.333 & 649.883 & 0.8462 & 0.9567 & 598.732 & 0.8289 & 0.9183 \\
\hline 269.333 & 649.978 & 0.8609 & 0.9733 & 598.86 & 0.8504 & 0.9422 \\
\hline 293.333 & 650.045 & 0.8713 & 0.9851 & 598.932 & 0.8626 & 0.9556 \\
\hline 317.333 & 650.087 & 0.8778 & 0.9925 & 598.998 & 0.8737 & 0.9679 \\
\hline 341.33 & 650.099 & 0.8797 & 0.9946 & 599.054 & 0.8831 & 0.9784 \\
\hline 389.33 & 650.106 & 0.8808 & 0.9958 & 599.098 & 0.8905 & 0.9866 \\
\hline 437.33 & 650.115 & 0.8822 & 0.9974 & 599.123 & 0.8947 & 0.9912 \\
\hline 485.33 & 650.123 & 0.8834 & 0.9988 & 599.164 & 0.9016 & 0.9989 \\
\hline 509.333 & 650.13 & 0.8845 & 1.0000 & 599.17 & 0.9026 & 1.0000 \\
\hline
\end{tabular}




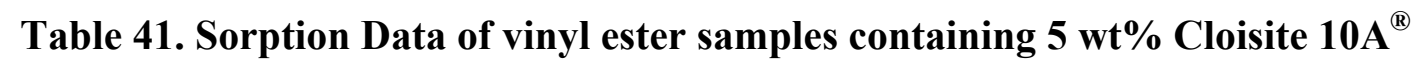

exposed to $80 \% \mathrm{RH}$ at $25^{\circ} \mathrm{C}$

\begin{tabular}{|c|c|c|c|c|c|c|c|c|c|}
\hline & sample-1 & $2 I=0.089 \mathrm{~cm}$ & & sample-2 & $2 I=0.0886 \mathrm{~cm}$ & & sample-3 & $2 I=0.09 \mathrm{~cm}$ & \\
\hline Time, $\mathrm{h}$ & Weight, mg & Water Content, wt $\%$ & $\mathrm{Mt} / \mathrm{M} \infty$ & Weight, mg & Water Content, wt\% & $\mathrm{Mt} / \mathrm{M} \infty$ & Weight, mg & Water Content, wt\% & $\mathrm{Mt} / \mathrm{M}_{\infty}$ \\
\hline 0 & 891.092 & 0.0000 & 0.0000 & 823.79 & 0.0000 & 0 & 619.21 & 0.0000 & 0.0000 \\
\hline 0.5 & 891.425 & 0.0374 & 0.0462 & 824.28 & 0.0595 & 0.0714 & 619.668 & 0.0740 & 0.0708 \\
\hline 1.5 & 891.687 & 0.0668 & 0.0825 & 824.5 & 0.0862 & 0.1035 & 619.869 & 0.1064 & 0.1019 \\
\hline 3.5 & 892 & 0.1019 & 0.1260 & 824.869 & 0.1310 & 0.1573 & 620.1 & 0.1437 & 0.1377 \\
\hline 13.3333 & 892.98 & 0.2119 & 0.2619 & 825.7 & 0.2319 & 0.2784 & 621.012 & 0.2910 & 0.2787 \\
\hline 23.3333 & 893.5 & 0.2702 & 0.3341 & 826.412 & 0.3183 & 0.3822 & 621.35 & 0.3456 & 0.3310 \\
\hline 42.8333 & 894.289 & 0.3588 & 0.4435 & 827.42 & 0.4406 & 0.5292 & 622.35 & 0.5071 & 0.4857 \\
\hline 65.3333 & 895.12 & 0.4520 & 0.5588 & 828 & 0.5111 & 0.6137 & 622.96 & 0.6056 & 0.5800 \\
\hline 91.3333 & 895.879 & 0.5372 & 0.6641 & 828.67 & 0.5924 & 0.7114 & 623.54 & 0.6993 & 0.6698 \\
\hline 113.333 & 896.5 & 0.6069 & 0.7503 & 829.32 & 0.6713 & 0.8061 & 623.98 & 0.7703 & 0.7378 \\
\hline 141.333 & 897 & 0.6630 & 0.8196 & 829.76 & 0.7247 & 0.8703 & 624.356 & 0.8311 & 0.7960 \\
\hline 162.333 & 897.32 & 0.6989 & 0.8640 & 829.99 & 0.7526 & 0.9038 & 624.621 & 0.8739 & 0.8370 \\
\hline 219.333 & 897.732 & 0.7452 & 0.9212 & 830.2 & 0.7781 & 0.9344 & 625.12 & 0.9544 & 0.9142 \\
\hline 245.333 & 897.86 & 0.7595 & 0.9390 & 830.3 & 0.7902 & 0.949 & 625.321 & 0.9869 & 0.9452 \\
\hline 269.333 & 897.921 & 0.7664 & 0.9474 & 830.41 & 0.8036 & 0.965 & 625.41 & 1.0013 & 0.9590 \\
\hline 293.333 & 897.996 & 0.7748 & 0.9578 & 830.5 & 0.8145 & 0.9781 & 625.51 & 1.0174 & 0.9745 \\
\hline 317.333 & 898.12 & 0.7887 & 0.9750 & 830.56 & 0.8218 & 0.9869 & 625.54 & 1.0223 & 0.9791 \\
\hline 341.33 & 898.168 & 0.7941 & 0.9817 & 830.58 & 0.8242 & 0.9898 & 625.589 & 1.0302 & 0.9867 \\
\hline 389.33 & 898.220 & 0.7999 & 0.9889 & 830.6 & 0.8267 & 0.9927 & 625.6 & 1.0320 & 0.9884 \\
\hline 437.33 & 898.245 & 0.8027 & 0.9924 & 830.612 & 0.8281 & 0.9945 & 625.621 & 1.0354 & 0.9916 \\
\hline 485.33 & 898.256 & 0.8040 & 0.9939 & 830.621 & 0.8292 & 0.9958 & 625.64 & 1.0384 & 0.9946 \\
\hline 509.333 & 898.271 & 0.8056 & 0.9960 & 830.632 & 0.8306 & 0.9974 & 625.651 & 1.0402 & 0.9963 \\
\hline 533.333 & 898.28 & 0.8067 & 0.9972 & 830.641 & 0.8316 & 0.9987 & 625.663 & 1.0421 & 0.9981 \\
\hline 566.333 & 898.3 & 0.8089 & 1.0000 & 830.65 & 0.8327 & 1.0000 & 625.675 & 1.0441 & 1.0000 \\
\hline
\end{tabular}




\begin{tabular}{|c|c|c|c|c|c|c|}
\hline & sample-4 & $2 I=0.09 \mathrm{~cm}$ & & sample-5 & $2 I=0.1 \mathrm{~cm}$ & \\
\hline Time, $\mathrm{h}$ & Weight, mg & Water Content, wt $\%$ & $\mathrm{Mt} / \mathrm{M} \infty$ & Weight, mg & Water Content, wt $\%$ & $\mathrm{Mt} / \mathrm{M} \infty$ \\
\hline 0 & 776.97 & 0.0000 & 0.0000 & 681.4 & 0.0000 & 0 \\
\hline 0.5 & 777.57 & 0.0772 & 0.0892 & 681.869 & 0.0688 & 0.0703 \\
\hline 1.5 & 777.74 & 0.0991 & 0.1144 & 682.12 & 0.1057 & 0.1079 \\
\hline 3.5 & 777.96 & 0.1274 & 0.1471 & 682.412 & 0.1485 & 0.1517 \\
\hline 13.3333 & 778.8 & 0.2355 & 0.2719 & 683.255 & 0.2722 & 0.2781 \\
\hline 23.3333 & 779.21 & 0.2883 & 0.3328 & 683.865 & 0.3618 & 0.3695 \\
\hline 42.8333 & 780.02 & 0.3926 & 0.4532 & 684.68 & 0.4814 & 0.4917 \\
\hline 65.3333 & 780.689 & 0.4787 & 0.5526 & 685.231 & 0.5622 & 0.5743 \\
\hline 91.3333 & 781.121 & 0.5343 & 0.6168 & 685.912 & 0.6622 & 0.6764 \\
\hline 113.333 & 781.564 & 0.5913 & 0.6826 & 686.321 & 0.7222 & 0.7377 \\
\hline 141.333 & 781.911 & 0.6359 & 0.7342 & 686.821 & 0.7956 & 0.8126 \\
\hline 162.333 & 782.325 & 0.6892 & 0.7957 & 686.99 & 0.8204 & 0.838 \\
\hline 219.333 & 782.798 & 0.7501 & 0.8660 & 687.412 & 0.8823 & 0.9012 \\
\hline 245.333 & 782.9 & 0.7632 & 0.8811 & 687.621 & 0.9130 & 0.9325 \\
\hline 269.333 & 783.1 & 0.7890 & 0.9108 & 687.732 & 0.9293 & 0.9492 \\
\hline 293.333 & 783.31 & 0.8160 & 0.9421 & 687.812 & 0.9410 & 0.9612 \\
\hline 317.333 & 783.421 & 0.8303 & 0.9585 & 687.889 & 0.9523 & 0.9727 \\
\hline 341.33 & 783.500 & 0.8404 & 0.9703 & 687.968 & 0.9639 & 0.9846 \\
\hline 389.33 & 783.589 & 0.8519 & 0.9835 & 687.998 & 0.9683 & 0.9891 \\
\hline 437.33 & 783.621 & 0.8560 & 0.9883 & 688.012 & 0.9704 & 0.9912 \\
\hline 485.33 & 783.654 & 0.8603 & 0.9932 & 688.032 & 0.9733 & 0.9942 \\
\hline 509.333 & 783.678 & 0.8634 & 0.9967 & 688.051 & 0.9761 & 0.9970 \\
\hline 533.333 & 783.69 & 0.8649 & 0.9985 & 688.06 & 0.9774 & 0.9984 \\
\hline 566.333 & 783.7 & 0.8662 & 1.0000 & 688.071 & 0.9790 & 1.0000 \\
\hline
\end{tabular}


Table 42. Sorption data of vinyl ester samples containing $0 \mathrm{wt} \%$ Cloisite $10 \mathrm{~A}$ immersed in distilled water subjected to $17 \%$ UTS at $25{ }^{\circ} \mathrm{C}$

\begin{tabular}{|c|c|c|c|c|}
\hline Time, h & Thickness, 2 l,cm & Weight mg & water content (\%) & $\mathrm{M}_{\mathrm{t}} / \mathrm{M}_{\infty}$ \\
\hline \multicolumn{5}{|l|}{ sample-1 } \\
\hline 0 & 0.12 & 804.631 & 0.0000 & 0.0000 \\
\hline 0.5 & & 805 & 0.0459 & 0.0498 \\
\hline sample-2 & 0.1 & 688.14 & & \\
\hline 1.5 & & 688.94 & 0.1163 & 0.1080 \\
\hline sample-3 & 0.09 & 629.167 & & \\
\hline 6.25 & & 630.632 & 0.2328 & 0.1978 \\
\hline sample-4 & 0.084 & 530.92 & & \\
\hline 9 & & 532.654 & 0.3266 & 0.2341 \\
\hline sample-5 & 0.11 & 698.485 & & \\
\hline 12.25 & & 700.51 & 0.2899 & 0.2734 \\
\hline sample-6 & 0.095 & 668.596 & & \\
\hline 17.25 & & 670.89 & 0.3431 & 0.3097 \\
\hline sample-7 & 0.089 & 624.16 & & \\
\hline 20.25 & & 626.854 & 0.4316 & 0.3637 \\
\hline sample-8 & 0.09 & 638.521 & & \\
\hline 23.25 & & 641.287 & 0.4313 & 0.3734 \\
\hline sample-9 & 0.089 & 630.21 & & \\
\hline 27.5 & & 633.213 & 0.4742 & 0.4054 \\
\hline sample-10 & 0.105 & 704.7 & & \\
\hline 31.75 & & 707.889 & 0.4505 & 0.4305 \\
\hline sample-11 & 0.088 & 589.414 & & \\
\hline 36.75 & & 593.07 & 0.6165 & 0.4935 \\
\hline sample-12 & 0.092 & & & \\
\hline 0 & & 650.412 & & \\
\hline 60.25 & & 655.08 & 0.7177 & 0.6301 \\
\hline 188.75 & & 657.1 & 1.0283 & 0.9028 \\
\hline 318.75 & & 657.543 & 1.0964 & 0.9626 \\
\hline 449.75 & & 657.6 & 1.1051 & 0.9703 \\
\hline 499.75 & & 657.67 & 1.1159 & 0.9798 \\
\hline 571.75 & & 657.74 & 1.1267 & 0.9892 \\
\hline 619.75 & & 657.79 & 1.1344 & 0.9960 \\
\hline 666.75 & & 657.82 & 1.1390 & 1.0000 \\
\hline
\end{tabular}




\begin{tabular}{|c|c|c|c|c|c|c|c|c|c|}
\hline & sample- 13 & $2 l=0.11 \mathrm{~cm}$ & & sample- 14 & $2 l=0.09 \mathrm{~cm}$ & & sample- 15 & $2 I=0.084 \mathrm{~cm}$ & \\
\hline Time,h & Weightmg & water content (\%) & $M_{t} / M_{\infty}$ & Weightmg & water content (\%) & $\mathrm{M}_{\mathrm{t}} / \mathrm{M}_{\infty}$ & Weightmg & water content $(\%)$ & $\mathrm{M}_{\mathrm{t}} / \mathrm{M}_{\infty}$ \\
\hline 0 & 715.6 & 0 & 0 & 646.711 & 0 & 0 & 504.63 & 0.0000 & 0.0000 \\
\hline 60.25 & 720.46 & 0.6792 & 0.5645 & 651.03 & 0.6678 & 0.5989 & 508.65 & 0.7966 & 0.7992 \\
\hline \multicolumn{10}{|l|}{89.25} \\
\hline 134.25 & & & & 652.19 & 0.8472 & 0.7597 & 509.64 & 0.9928 & 0.9960 \\
\hline \multicolumn{10}{|l|}{160.25} \\
\hline 188.75 & & & & 652.92 & 0.9601 & 0.8609 & 509.48 & 0.9611 & 0.9642 \\
\hline 225.75 & 723 & 1.0341 & 0.8595 & & & & & & \\
\hline 318.75 & & & & 653.5 & 1.0498 & 0.9413 & 509.54 & 0.9730 & 0.9761 \\
\hline 405.25 & 723.564 & 1.1129 & 0.9250 & & & & & & \\
\hline 449.75 & & & & 653.732 & 1.0856 & 0.9735 & 509.68 & 1.0007 & 1.0040 \\
\hline 499.75 & 723.91 & 1.1613 & 0.9652 & 653.8 & 1.0962 & 0.9829 & & & \\
\hline 571.75 & 723.99 & 1.1724 & 0.9744 & 653.86 & 1. 1054 & 0.9913 & & & \\
\hline 619.75 & 724.12 & 1. 1906 & 0.9895 & & & & & & \\
\hline 666.75 & & & & 653.923 & 1.1152 & 1.0000 & 509.66 & 0.9968 & 1.0000 \\
\hline 669.75 & 724.21 & 1.2032 & 1.0000 & & & & & & \\
\hline
\end{tabular}

\begin{tabular}{|c|c|c|c|c|c|c|c|c|c|}
\hline & sample- 16 & $2 I=0.084 \mathrm{~cm}$ & & sample-17 & $2 l=0.087 \mathrm{~cm}$ & & sample- 18 & $2 I=0.084 \mathrm{~cm}$ & \\
\hline Time,h & Weightmg & water content $(\%)$ & $M_{t} / M_{\infty}$ & Weight mg & water content (\%), & $\mathrm{M}_{\mathrm{t}} / \mathrm{M}_{\infty}$ & Weightmg & water content (\%) & $\mathrm{M}_{\mathrm{t}} / \mathrm{M}_{\infty}$ \\
\hline 0 & 503.378 & 0 & 0 & 584.5 & 0 & 0 & 530.08 & 0.0000 & 0.0000 \\
\hline 60.25 & 507.25 & 0.7692 & 0.7915 & & & & & & \\
\hline 89.25 & & & & 588.996 & 0.7692 & 0.7334 & 534.853 & 0.9004 & 0.7686 \\
\hline 134.25 & 508 & 0.9182 & 0.9448 & & & & & & \\
\hline 160.25 & & & & 589.54 & 0.8623 & 0.8222 & 535.18 & 0.9621 & 0.8213 \\
\hline 188.75 & 507.77 & 0.8725 & 0.8978 & & & & & & \\
\hline 225.75 & & & & 590.14 & 0.9649 & 0.9201 & 535.58 & 1.0376 & 0.8857 \\
\hline 318.75 & 508.07 & 0.9321 & 0.9591 & & & & & & \\
\hline 405.25 & & & & & & & 536.26 & 1.1659 & 0.9952 \\
\hline 449.75 & 508.12 & 0.9420 & 0.9693 & & & & 536.19 & 1. 1527 & 0.9839 \\
\hline \multicolumn{10}{|l|}{499.75} \\
\hline \multicolumn{10}{|l|}{571.75} \\
\hline \multicolumn{10}{|l|}{619.75} \\
\hline 666.75 & 508.27 & 0.9718 & 1.0000 & 590.63 & 1.0488 & 1.0000 & 536.29 & 1.1715 & 1.0000 \\
\hline 669.75 & & & & & & & & & \\
\hline
\end{tabular}


Table 43. Sorption data of vinyl ester samples containing $5 \mathrm{wt} \%$ Cloisite 10A immersed in distilled water subjected to $17 \%$ UTS at $25^{\circ} \mathrm{C}$

\begin{tabular}{|c|c|c|c|c|}
\hline Time,h & Thickness,2l,cm & $\mathrm{W}_{\mathrm{t}} \mathrm{mg}$ & $\mathrm{M}_{\mathrm{t}} \mathrm{mg}$ & Moisture uptake (\%) \\
\hline \multicolumn{5}{|l|}{ sample-1 } \\
\hline 0 & 0.095 & 665.04 & 0 & 0.0000 \\
\hline 0.25 & & 665.213 & 0.369 & 0.0459 \\
\hline sample-2 & 0.12 & 777.28 & & \\
\hline 3.25 & & 778.1 & 0.8 & 0.1163 \\
\hline sample-3 & 0.088 & 579.91 & & \\
\hline 5.5 & & 581.1 & 1.465 & 0.2328 \\
\hline sample-4 & 0.012 & 808.96 & & \\
\hline 7.75 & & 810.43 & 1.734 & 0.3266 \\
\hline sample-5 & 0.11 & 715.54 & & \\
\hline 8.75 & & 717.21 & 2.025 & 0.2899 \\
\hline sample-6 & 0.089 & 617.2 & & \\
\hline 20.25 & & 619.556 & 2.294 & 0.3431 \\
\hline sample-7 & 0.12 & 781.42 & & \\
\hline 28.25 & & 784.23 & 2.694 & 0.4316 \\
\hline sample-8 & 0.115 & 743.51 & & \\
\hline 44.25 & & 747.325 & 2.766 & 0.4313 \\
\hline sample-9 & 0.121 & 771.32 & & \\
\hline 50.25 & & 775.456 & 3.003 & 0.4742 \\
\hline sample-10 & 0.115 & 722.37 & & \\
\hline 69.75 & & 727.37 & 3.189 & 0.4505 \\
\hline sample-11 & 0.092 & 642.94 & & \\
\hline 125.25 & & 649.32 & 6.38 & 0.9923 \\
\hline \multicolumn{5}{|l|}{201.25} \\
\hline 244.75 & & 650.23 & 7.29 & 1.1339 \\
\hline \multicolumn{5}{|l|}{295.75} \\
\hline 485.75 & & 650.823 & 7.883 & 1.2261 \\
\hline 551.25 & & 650.867 & 7.927 & 1.2329 \\
\hline 605.75 & & 650.9 & 7.96 & 1.2381 \\
\hline 677.75 & & 650.95 & 8.01 & 1.2458 \\
\hline 701.75 & & 650.99 & 8.05 & 1.2521 \\
\hline 725.775 & & 651.03 & 8.09 & 1.2583 \\
\hline
\end{tabular}

\begin{tabular}{|c|c|c|c|c|c|c|c|c|c|}
\hline & sample- 12 & $2 l=0.095 \mathrm{~cm}$ & & sample- 13 & $2 I=0.088 \mathrm{~cm}$ & & sample- 14 & $2 l=0.1 \mathrm{~cm}$ & \\
\hline Time,h & Weightmg & water content (\%) & $\mathrm{M}_{\mathrm{t}} / \mathrm{M}_{\infty}$ & Weightmg & water content (\%) & $M_{t} / M_{\infty}$ & Weightmg & water content $(\%)$ & $M_{t} / M_{\infty}$ \\
\hline 0 & 647.36 & 0 & 0 & 591.07 & 0 & 0 & 700.05 & 0.0000 & 0.0000 \\
\hline 125.25 & 653.76 & 0.9886 & 0.8237 & 596.89 & 0.9847 & 0.8083 & 706.31 & 0.8942 & 0.7954 \\
\hline \multicolumn{10}{|l|}{201.25} \\
\hline 244.75 & 654.435 & 1.0929 & 0.9106 & 597.78 & 1. 1352 & 0.9319 & 707.02 & 0.9956 & 0.8856 \\
\hline \multicolumn{10}{|l|}{295.75} \\
\hline 485.75 & 654.88 & 1. 1616 & 0.9678 & 597.98 & 1. 1691 & 0.9597 & 707.52 & 1.0671 & 0.9492 \\
\hline 551.25 & 654.91 & 1. 1663 & 0.9717 & 598.12 & 1. 1928 & 0.9792 & 707.89 & 1.1199 & 0.9962 \\
\hline 605.75 & 654.98 & 1.1771 & 0.9807 & 598.2 & 1.2063 & 0.9903 & 707.91 & 1. 1228 & 0.9987 \\
\hline 677.75 & 655.054 & 1. 1885 & 0.9902 & 598.23 & 1.2114 & 0.9944 & 707.92 & 1. 1242 & 1.0000 \\
\hline 701.75 & 655.1 & 1. 195625309 & 0.996139 & 598.25 & 1.2147 & 0.9972 & & & \\
\hline 725.75 & 655.13 & 1.2003 & 1.0000 & 598.27 & 1.2181 & 1.0000 & & & \\
\hline
\end{tabular}




\begin{tabular}{|c|c|c|c|c|c|c|c|c|c|}
\hline & sample- 15 & $2 l=0.09 \mathrm{~cm}$ & & sample- 16 & $2 l=0.089 \mathrm{~cm}$ & & sample- 17 & $2 l=0.097 \mathrm{~cm}$ & \\
\hline Time,h & Weightmg & water content (\%) & $\mathrm{M}_{\mathrm{t}} / \mathrm{M}_{\infty}$ & Weightmg & water content $(\%)$ & $\mathrm{M}_{\mathrm{t}} / \mathrm{M}_{\infty}$ & Weightmg & water content (\%) & $\mathrm{M}_{\mathrm{t}} / \mathrm{M}_{\infty}$ \\
\hline 0 & 646.14 & 0 & 0 & 598.86 & 0 & 0 & 671.78 & 0.0000 & 0.0000 \\
\hline 125.25 & 652.09 & 0.9209 & 0.8263 & 604.43 & 0.9301 & 0.9042 & & & \\
\hline 201.25 & & & & & & & 677.56 & 0.8604 & 52.5455 \\
\hline 244.75 & 652.91 & 1.0478 & 0.9401 & 604.94 & 1.0153 & 0.9870 & & & \\
\hline 295.75 & & & & & & & 677.75 & 0.8887 & 54.2727 \\
\hline 485.75 & 653.29 & 1. 1066 & 0.9929 & 604.96 & 1.0186 & 0.9903 & 677.7 & 0.8812 & 53.8182 \\
\hline 551.25 & 653.31 & 1. 1097 & 0.9957 & 604.98 & 1.0219 & 0.9935 & 671.85 & 0.0104 & 0.6364 \\
\hline \multicolumn{10}{|l|}{605.75} \\
\hline \multicolumn{10}{|l|}{677.75} \\
\hline 701.75 & 653.33 & 1.1128 & 0.9985 & 605 & 1.0253 & 0.9968 & 671.87 & 0.0134 & 0.8182 \\
\hline 725.75 & 653.341 & 1.1145 & 1.0000 & 605.02 & 1.0286 & 1.0000 & 671.89 & 0.0164 & 1.0000 \\
\hline
\end{tabular}

Table 44. Sorption data of vinyl ester samples containing 0 wt\% Cloisite $10 \mathrm{~A}$ immersed in distilled water subjected to $30 \%$ UTS at $25^{\circ} \mathrm{C}$

\begin{tabular}{|c|c|c|c|c|}
\hline Time,h & Thickness, $21, \mathrm{~cm}$ & $\mathrm{~W}_{\mathrm{t}} \mathrm{mg}$ & $\mathrm{M}_{\mathrm{t}} \mathrm{mg}$ & Moisture uptake (\%) \\
\hline \multicolumn{5}{|l|}{ sample-10 } \\
\hline 0 & 0.094 & 647.41 & & \\
\hline 0.5 & & 647.79 & 0.38 & 0.0587 \\
\hline sample-2 & 0.086 & 559.62 & & \\
\hline 1.5 & & 560.32 & 0.7 & 0.1251 \\
\hline sample-3 & 0.088 & 589.41 & & \\
\hline 4.5 & & 590.62 & 1.21 & 0.2053 \\
\hline sample-4 & 0.09 & 638.8 & & \\
\hline 8.75 & & 640.43 & 1.63 & 0.2552 \\
\hline sample-5 & 0.089 & 616.63 & & \\
\hline 12.25 & & 618.51 & 1.88 & 0.3049 \\
\hline sample-6 & 0.087 & 551.27 & & \\
\hline 37.25 & & 554.562 & 0.60 & 0.4735 \\
\hline sample-7 & 0.095 & 664.98 & & \\
\hline 66.25 & & 669.41 & 0.67 & 0.6372 \\
\hline sample-8 & 0.084 & 519.69 & & \\
\hline 89.25 & & 523.83 & 0.80 & 0.5955 \\
\hline sample-9 & 0.11 & 721.491 & & \\
\hline 111.25 & & 727 & 0.76 & 0.7924 \\
\hline \multicolumn{5}{|l|}{ sample-10 } \\
\hline 135.25 & 0.088 & 609.41 & 5.62 & 0.9308 \\
\hline \multicolumn{5}{|l|}{165.25} \\
\hline \multicolumn{5}{|l|}{202.75} \\
\hline 308.25 & & 610 & 6.21 & 1.0285 \\
\hline \multicolumn{5}{|l|}{378.75} \\
\hline 427.25 & & 610.52 & 6.73 & 1.1146 \\
\hline \multicolumn{5}{|l|}{476.75} \\
\hline 500.75 & & 610.674 & 6.884 & 1.1401 \\
\hline 597.75 & & 610.742 & 6.952 & 1.1514 \\
\hline
\end{tabular}




\begin{tabular}{|c|c|c|c|c|c|c|c|c|c|}
\hline & sample-11 & $2 I=0.088 \mathrm{~cm}$ & & sample- 12 & $2 l=0.11 \mathrm{~cm}$ & & sample- 13 & $2 l=0.095 \mathrm{~cm}$ & \\
\hline Time,h & Weightmg & water content (\%) & $\mathrm{M}_{\mathrm{t}} / \mathrm{M}_{\infty}$ & Weightmg & water content (\%) & $\mathrm{M}_{\mathrm{t}} / \mathrm{M}_{\infty}$ & Weightmg & water content (\%) & $\mathrm{M}_{\mathrm{t}} / \mathrm{M}_{\infty}$ \\
\hline 0 & 603.79 & 0 & 0 & 710.21 & & & 663.43 & & \\
\hline 135.25 & 609.41 & 0.9308 & 0.8084 & 716.643 & 0.9058 & 0.7807 & 669.21 & 0.8712 & 0.7536 \\
\hline \multicolumn{10}{|l|}{165.25} \\
\hline \multicolumn{10}{|l|}{202.75} \\
\hline 308.25 & 610 & 1.0285 & 0.8933 & 717.678 & 1.0515 & 0.9063 & 670.2 & 1.0205 & 0.8827 \\
\hline \multicolumn{10}{|l|}{378.75} \\
\hline 427.25 & 610.52 & 1.1146 & 0.9681 & 718.2 & 1. 1250 & 0.9697 & 670.72 & 1.0988 & 0.9505 \\
\hline \multicolumn{10}{|l|}{476.75} \\
\hline 500.75 & 610.674 & 1. 1401 & 0.9902 & 718.42 & 1. 1560 & 0.9964 & 670.89 & 1. 1245 & 0.9726 \\
\hline 597.75 & 610.742 & 1. 151393696 & 1 & 718.45 & 1. 1602 & 1.0000 & 671.1 & 1. 1561 & 1.0000 \\
\hline
\end{tabular}

\begin{tabular}{|c|c|c|c|c|c|c|c|c|c|}
\hline & sample- 14 & $2 I=0.089 \mathrm{~cm}$ & & sample- 15 & $2 l=0.1 \mathrm{~cm}$ & & sample- 16 & $2 I=0.088 \mathrm{~cm}$ & \\
\hline Time,h & Weightmg & water content (\%) & $M_{t} / M_{\infty}$ & Weightmg & water content (\%) & $M_{t} / M_{\infty}$ & Weightmg & water content (\%) & $\mathrm{M}_{\mathrm{t}} / \mathrm{M}_{\infty}$ \\
\hline 0 & 625.4 & & & 697.53 & & & 575.5 & & \\
\hline 135.25 & 631.21 & 0.9290 & 0.8532 & 703.02 & 0.7871 & 0.7593 & 581.1 & 0.9731 & 0.8615 \\
\hline \multicolumn{10}{|l|}{165.25} \\
\hline \multicolumn{10}{|l|}{202.75} \\
\hline 308.25 & 631.6 & 0.9914 & 0.9104 & 703.76 & 0.8932 & 0.8617 & 581.657 & 1.0699 & 0.9472 \\
\hline \multicolumn{10}{|l|}{378.75} \\
\hline 427.25 & 631.73 & 1.0122 & 0.9295 & 704.1 & 0.9419 & 0.9087 & 581.865 & 1.1060 & 0.9792 \\
\hline \multicolumn{10}{|l|}{476.75} \\
\hline 500.75 & 631.98 & 1.0521 & 0.9662 & 704.54 & 1.0050 & 0.9696 & 581.9 & 1.1121 & 0.9846 \\
\hline 597.75 & 632.21 & 1.0889 & 1.0000 & 704.76 & 1.0365 & 1.0000 & 582 & 1. 1295 & 1.0000 \\
\hline
\end{tabular}


Table 45. Sorption data of vinyl ester samples containing 5 wt\% Cloisite 10A immersed in distilled water subjected to $30 \%$ UTS at $25^{\circ} \mathrm{C}$

\begin{tabular}{|c|c|c|c|c|c|}
\hline Time,h & Thickness,2I,cm & $\mathrm{W}_{\mathrm{t}} \mathrm{mg}$ & $\mathrm{M}_{\mathrm{t}} \mathrm{mg}$ & Moisture uptake (\%) & $\mathrm{M}_{\mathrm{t}} / \mathrm{M}_{\infty}$ \\
\hline \multicolumn{6}{|l|}{ sample-1 } \\
\hline 0 & 0.09 & 639.16 & 0 & 0.0000 & 0.0000 \\
\hline 1 & & 639.66 & 0.5 & 0.0782 & 0.0707 \\
\hline sample-2 & 0.086 & 551.59 & & & \\
\hline 2.5 & & 552.374 & 0.784 & 0.1421 & 0.1109 \\
\hline sample-3 & 0.086 & 566.78 & & & \\
\hline 14.5 & & 568.61 & 1.83 & 0.3229 & 0.2588 \\
\hline sample-4 & 0.085 & 549.08 & & & \\
\hline 17.5 & & 551.178 & 2.098 & 0.3821 & 0.2967 \\
\hline sample-5 & 0.086 & 560.29 & & & \\
\hline 22.5 & & 562.7 & 2.41 & 0.4301 & 0.3409 \\
\hline sample-6 & 0.097 & 676.76 & & & \\
\hline 38.5 & & 679.91 & 3.15 & 0.4655 & 0.4455 \\
\hline sample-7 & 0.12 & 842.85 & & & \\
\hline 44.5 & & 846.89 & 4.04 & 0.4793 & 0.5714 \\
\hline sample-8 & 0.088 & 608.74 & & & \\
\hline 64 & & 612.48 & 3.74 & 0.6144 & 0.5290 \\
\hline sample-9 & 0.096 & 667.75 & & & \\
\hline 71 & & 671.8 & 4.05 & 0.7228 & 0.5728 \\
\hline sample-10 & 0.115 & 729.45 & & & \\
\hline 119 & & 734.43 & 4.98 & 0.7359 & 0.7044 \\
\hline sample-11 & 0.087 & 611.61 & & & \\
\hline 193 & & 617.32 & 5.71 & 0.9250 & 0.8076 \\
\hline 216.5 & & 617.58 & 5.97 & 0.9671 & 0.8444 \\
\hline 288.5 & & 617.98 & 6.37 & 1.0319 & 0.9010 \\
\hline \multicolumn{6}{|l|}{313.5} \\
\hline 410 & & 618.21 & 6.6 & 1.0691 & 0.9335 \\
\hline 482.5 & & 618.43 & 6.82 & 1.1048 & 0.9646 \\
\hline 546 & & 618.52 & 6.91 & 1.1194 & 0.9774 \\
\hline 618 & & 618.6 & 6.99 & 1.1323 & 0.9887 \\
\hline 666 & & 618.65 & 7.04 & 1.1404 & 0.9958 \\
\hline 714 & & 618.68 & 7.07 & 1.1453 & 1.0000 \\
\hline
\end{tabular}

\begin{tabular}{|c|c|c|c|c|c|c|c|c|c|}
\hline & sample- 12 & $2 l=0.093 \mathrm{~cm}$ & & sample- 13 & $2 I=0.087 \mathrm{~cm}$ & & sample- 14 & $2 l=0.097 \mathrm{~cm}$ & \\
\hline Time,h & Weightmg & water content (\%) & $\mathrm{M}_{\mathrm{t}} / \mathrm{M}_{\infty}$ & Weightmg & water content (\%) & $M_{t} / M_{\infty}$ & Weightmg & water content (\%) & $M_{t} / M_{\infty}$ \\
\hline 0 & 648.49 & & & 582.69 & & & 687.26 & & \\
\hline 193 & 655.31 & 1.0517 & 0.8148 & 588.3 & 0.9628 & 0.7926 & 693.81 & 0.9531 & 0.8863 \\
\hline 216.5 & 655.67 & 1. 1072 & 0.8578 & 588.6 & 1.0143 & 0.8350 & 693.94 & 0.9720 & 0.9039 \\
\hline \multicolumn{10}{|l|}{288.5} \\
\hline \multicolumn{10}{|l|}{313.5} \\
\hline 410 & 656.38 & 1.2167 & 0.9427 & 589.1 & 1.1001 & 0.9056 & 694.48 & 1.0505 & 0.9770 \\
\hline 482.5 & 656.53 & 1.2398 & 0.9606 & 589.42 & 1.1550 & 0.9508 & 695.14 & 1.1466 & 1.0663 \\
\hline 546 & 656.62 & 1.2537 & 0.9713 & 589.5 & 1. 1687 & 0.9621 & 694.59 & 1.0666 & 0.9919 \\
\hline 618 & 656.73 & 1.2706 & 0.9845 & 589.7 & 1.2030 & 0.9904 & 694.61 & 1.0695 & 0.9946 \\
\hline 666 & 656.81 & 1.282980462 & 0.994026 & 589.743 & 1.2104 & 0.9965 & 694.635 & 1.0731 & 0.9980 \\
\hline 714 & 656.86 & 1.2907 & 1.0000 & 589.768 & 1.2147 & 1.0000 & 694.65 & 1.0753 & 1.0000 \\
\hline
\end{tabular}




\begin{tabular}{|c|c|c|c|c|c|c|c|c|c|}
\hline & sample- 15 & $2 l=0.089 \mathrm{~cm}$ & & sample- 16 & $2 l=0.086 \mathrm{~cm}$ & & sample- 17 & $2 l=0.088 \mathrm{~cm}$ & \\
\hline Time, $\mathrm{h}$ & Weightmg & water content $(\%)$ & $M_{t} / M_{\infty}$ & Weightmg & water content (\%) & $M_{t} / M_{\infty}$ & Weightmg & water content $(\%)$ & $M_{t} / M_{\infty}$ \\
\hline 0 & 624.9 & & & 543.88 & & & 585.52 & & \\
\hline 193 & 630.89 & 0.9586 & 0.8062 & 548.72 & 0.8899 & 0.8521 & 591.04 & 0.9428 & 0.8686 \\
\hline 216.5 & & & & & & & 591.01 & 0.9376 & 0.8639 \\
\hline 288.5 & 631.4 & 1.0402 & 0.8748 & 549.06 & 0.9524 & 0.9120 & 591.08 & 0.9496 & 0.8749 \\
\hline 313.5 & 631.54 & 1.0626 & 0.8937 & 549.02 & 0.9451 & 0.9049 & & & \\
\hline 410 & & & & 549.52 & 1.0370 & 0.9930 & 591.8 & 1.0726 & 0.9882 \\
\hline \multicolumn{10}{|l|}{482.5} \\
\hline \multicolumn{10}{|l|}{546} \\
\hline 618 & 632.29 & 1. 1826 & 0.9946 & & & & & & \\
\hline 666 & 632.31 & 1. 1858 & 0.9973 & 549.542 & 1.0410 & 0.9968 & 591.86 & 1.0828 & 0.9976 \\
\hline 714 & 632.33 & 1.1890 & 1.0000 & 549.56 & 1.0443 & 1.0000 & 591.875 & 1.0854 & 1.0000 \\
\hline
\end{tabular}

Table 46. Sorption data of vinyl ester samples containing 0 wt $\%$ Cloisite $10 \mathrm{~A}$ exposed to $60 \% \mathrm{RH}$ at $25{ }^{\circ} \mathrm{C}$ subjected to $30 \%$ UTS

\begin{tabular}{|c|c|c|c|c|c|}
\hline Time,h & Thickness, $21, \mathrm{~cm}$ & $\mathrm{~W}_{\mathrm{t}} \mathrm{mg}$ & $\mathrm{M}_{\mathrm{t}} \mathrm{mg}$ & Moisture uptake (\%) & $M_{t} / M_{\infty}$ \\
\hline \multicolumn{6}{|l|}{ sample-1 } \\
\hline 0 & 0.11 & 724.06 & 0 & 0.0000 & 0.0000 \\
\hline 0.5 & & 724.29 & 0.23 & 0.0318 & 0.0655 \\
\hline sample-2 & 0.089 & 621.08 & & & \\
\hline 2.5 & & 621.51 & 0.43 & 0.0692 & 0.1224 \\
\hline sample-3 & 0.09 & 642.25 & & & \\
\hline 4.5 & & 642.85 & 0.6 & 0.0934 & 0.1708 \\
\hline sample-4 & 0.1 & 697.12 & & & \\
\hline 6.5 & & 697.856 & 0.736 & 0.1056 & 0.2095 \\
\hline sample-5 & 0.095 & 665.03 & & & \\
\hline 8 & & 665.85 & 0.82 & 0.1233 & 0.2334 \\
\hline sample-6 & 0.1 & 700.628 & & & \\
\hline 15.5 & & 701.68 & 1.052 & 0.1502 & 0.2995 \\
\hline sample-7 & 0.09 & 630.76 & & & \\
\hline 23 & & 632.12 & 1.36 & 0.2156 & 0.3871 \\
\hline sample-8 & 0.09 & 640.83 & & & \\
\hline 36.5 & & 642.6 & 1.77 & 0.2762 & 0.5038 \\
\hline sample-9 & 0.088 & 593.53 & & & \\
\hline 69.5 & & 596.253 & 2.723 & 0.4588 & 0.7751 \\
\hline \multicolumn{6}{|l|}{165.5} \\
\hline 236.5 & & 596.98 & 3.45 & 0.5813 & 0.9821 \\
\hline \multicolumn{6}{|l|}{357.5} \\
\hline 386.5 & & 597.043 & 3.513 & 0.5919 & 1.0000 \\
\hline 458.5 & & 595.88 & 2.35 & 0.3959 & 0.6689 \\
\hline 543 & & 595.21 & 1.68 & 0.2831 & 0.4782 \\
\hline 595 & & 594.99 & 1.46 & 0.2460 & 0.4156 \\
\hline
\end{tabular}




\begin{tabular}{|c|c|c|c|c|c|c|c|c|c|}
\hline & sample- 10 & $2 I=0.088 \mathrm{~cm}$ & & sample-11 & $2 l=0.095 \mathrm{~cm}$ & & sample- 12 & $2 l=0.09 \mathrm{~cm}$ & \\
\hline Time,h & Weightmg & water content $(\%)$ & $\mathrm{M}_{\mathrm{t}} / \mathrm{M}_{\infty}$ & Weightmg & water content (\%) & $M_{t} / M_{\infty}$ & Weightmg & water content $(\%)$ & $M_{t} / M_{\infty}$ \\
\hline 0 & 593.53 & 0 & 0 & 653.61 & 0 & 0 & 638.21 & 0.0000 & 0.0000 \\
\hline 69.5 & 596.253 & 0.4588 & 0.7751 & 656.1 & 0.3810 & 0.6605 & 640.89 & 0.4199 & 0.7322 \\
\hline 165.5 & 596.65 & 0.5257 & 0.8881 & 656.75 & 0.4804 & 0.8329 & 641.423 & 0.5034 & 0.8779 \\
\hline 236.5 & 596.93 & 0.5728 & 0.9678 & 657 & 0.5187 & 0.8992 & 641.75 & 0.5547 & 0.9672 \\
\hline 308.5 & 597 & 0.5846 & 0.9878 & 657.15 & 0.5416 & 0.9390 & 641.789 & 0.5608 & 0.9779 \\
\hline 357.5 & 597.012 & 0.5867 & 0.9912 & 657.21 & 0.550787167 & 0.95491 & 641.81 & 0.564077655 & 0.98361 \\
\hline 386.5 & 597.043 & 0.591882466 & 1 & 657.38 & 0.576796561 & 1 & 641.87 & 0.573478949 & 1 \\
\hline & sample- 13 & $2 I=0.087 \mathrm{~cm}$ & & sample- 14 & $2 I=0.087 \mathrm{~cm}$ & & sample- 15 & $2 l=0.09 \mathrm{~cm}$ & \\
\hline Time, $\mathrm{h}$ & Weightmg & water content (\%) & $\mathrm{M}_{\mathrm{t}} / \mathrm{M}_{\infty}$ & Weightmg & water content (\%) & $M_{t} / M_{\infty}$ & Weightmg & water content (\%) & $\mathrm{M}_{\mathrm{t}} / \mathrm{M}_{\infty}$ \\
\hline 0 & 585.22 & 0 & 0 & 571.77 & 0 & 0 & 642.22 & 0.0000 & 0.0000 \\
\hline 69.5 & 586.83 & 0.2751 & 0.4777 & 573.36 & 0.2781 & 0.4923 & 643.62 & 0.2180 & 0.4192 \\
\hline 165.5 & 587.19 & 0.3366 & 0.5846 & 573.56 & 0.3131 & 0.5542 & 644.21 & 0.3099 & 0.5958 \\
\hline 236.5 & 587.453 & 0.3816 & 0.6626 & 573.89 & 0.3708 & 0.6563 & 644.86 & 0.4111 & 0.7904 \\
\hline 308.5 & 588 & 0.4750 & 0.8249 & 574.245 & 0.4329 & 0.7663 & 645.12 & 0.4516 & 0.8683 \\
\hline 357.5 & 588.45 & 0.5519 & 0.9585 & 574.78 & 0.526435455 & 0.93189 & 645.456 & 0.503877176 & 0.96886 \\
\hline 386.5 & 588.59 & 0.575851816 & 1 & 575 & 0.564912465 & 1 & 645.56 & 0.520071004 & 1 \\
\hline
\end{tabular}


Table 47. Sorption data of vinyl ester samples containing 5 wt\% Cloisite 10A exposed to $60 \%$ RH at $25{ }^{\circ} \mathrm{C}$ subjected to $30 \%$ UTS

\begin{tabular}{|c|c|c|c|c|c|}
\hline Time,h & Thickness,2l, cm & $\mathrm{W}_{\mathrm{t}} \mathrm{mg}$ & $\mathrm{M}_{\mathrm{t}} \mathrm{mg}$ & Moisture uptake (\%) & $M_{t} / M_{\infty}$ \\
\hline \multicolumn{6}{|l|}{ sample-1 } \\
\hline 0 & 0.088 & 612.87 & 0 & 0.0000 & 0.0000 \\
\hline 2 & & 613.34 & 0.47 & 0.0767 & 0.1240 \\
\hline sample-2 & 0.089 & 651.52 & & & \\
\hline 5 & & 652.213 & 0.693 & 0.1064 & 0.1828 \\
\hline sample-3 & 0.088 & 595.43 & & & \\
\hline 8 & & 596.342 & 0.912 & 0.1532 & 0.2406 \\
\hline sample-4 & 0.086 & 565.87 & & & \\
\hline 16.5 & & 566.989 & 1.119 & 0.1977 & 0.2953 \\
\hline sample-5 & 0.085 & 528.1 & & & \\
\hline 21.5 & & 529.456 & 1.356 & 0.2568 & 0.3578 \\
\hline sample-6 & 0.11 & 731.6 & & & \\
\hline 33.5 & & 733.3 & 1.7 & 0.2324 & 0.4485 \\
\hline sample-7 & 0.088 & 609.14 & & & \\
\hline 119.5 & & 611.98 & 2.84 & 0.4662 & 0.7493 \\
\hline sample-8 & 0.09 & 640.44 & & & \\
\hline 143.5 & & 643.45 & 3.01 & 0.4700 & 0.7942 \\
\hline sample-9 & 0.086 & 548.75 & & & \\
\hline 240 & & 551.9 & 3.15 & 0.5740 & 0.8311 \\
\hline sample-10 & 0.09 & 642.68 & & & \\
\hline 324 & & 646.287 & 3.607 & 0.5612 & 0.9517 \\
\hline sample-11 & 0.089 & 622.01 & & & \\
\hline 374.5 & & 625.7 & 3.69 & 0.5932 & 0.9736 \\
\hline 449 & & 625.75 & 3.74 & 0.6013 & 0.9868 \\
\hline 646.5 & & 625.8 & 3.79 & 0.6093 & 1.0000 \\
\hline
\end{tabular}

\begin{tabular}{|c|c|c|c|c|c|c|c|c|c|}
\hline & sample- 12 & $2 l=0.092 \mathrm{~cm}$ & & sample- 13 & $2 I=0.09 \mathrm{~cm}$ & & sample- 14 & $2 l=0.09 \mathrm{~cm}$ & \\
\hline Time, $\mathrm{h}$ & Weightmg & water content (\%) & $M_{t} / M_{\infty}$ & Weightmg & water content $(\%)$ & $M_{t} / M_{\infty}$ & Weightmg & water content (\%) & $\mathrm{M}_{\mathrm{t}} / \mathrm{M}_{\infty}$ \\
\hline 0 & 693.5 & & & 637.12 & & & 631.89 & & \\
\hline 374.5 & 697.234 & 0.5384 & 0.924257 & 640.71 & 0.5635 & 0.9301 & 633.94 & 0.3244 & 0.6949 \\
\hline 449 & 697.456 & 0.5704 & 0.979208 & 640.9 & 0.5933 & 0.9793 & 634.75 & 0.4526 & 0.9695 \\
\hline \multirow[t]{2}{*}{646.5} & 697.54 & 0.5826 & 1 & 640.98 & 0.6059 & 1.0000 & 634.84 & 0.4669 & 1.0000 \\
\hline & sample- 15 & $2 I=0.09 \mathrm{~cm}$ & & sample- 16 & $2 I=0.091 \mathrm{~cm}$ & & sample- 17 & $2 I=0.09 \mathrm{~cm}$ & \\
\hline Time,h & Weightmg & water content (\%) & $M_{t} / M_{\infty}$ & Weightmg & water content (\%) & $M_{t} / M_{\infty}$ & Weightmg & water content (\%) & $\mathrm{M}_{\mathrm{t}} / \mathrm{M}_{\infty}$ \\
\hline 0 & 658.96 & & & 667.2 & & & 631.89 & & \\
\hline 374.5 & 659.65 & 0.1047 & 0.401163 & 669.49 & 0.3432 & 0.8267 & 633.94 & 0.3244 & 0.6949 \\
\hline 449 & 660.23 & 0.1927 & 0.738372 & 669.45 & 0.3372 & 0.8123 & 634.75 & 0.4526 & 0.9695 \\
\hline 646.5 & 660.68 & 0.2610 & 1 & 669.97 & 0.4152 & 1.0000 & 634.84 & 0.4669 & 1.0000 \\
\hline
\end{tabular}

